\title{
WestVirginiaUniversity
}

THE RESEARCH REPOSITORY @ WVU

Graduate Theses, Dissertations, and Problem Reports

2001

\section{Effects of work stoppages at selected steel mills on production and safety systems}

Daniel Hartley

West Virginia University

Follow this and additional works at: https://researchrepository.wvu.edu/etd

\section{Recommended Citation}

Hartley, Daniel, "Effects of work stoppages at selected steel mills on production and safety systems" (2001). Graduate Theses, Dissertations, and Problem Reports. 2341.

https://researchrepository.wvu.edu/etd/2341

This Dissertation is protected by copyright and/or related rights. It has been brought to you by the The Research Repository @WVU with permission from the rights-holder(s). You are free to use this Dissertation in any way that is permitted by the copyright and related rights legislation that applies to your use. For other uses you must obtain permission from the rights-holder(s) directly, unless additional rights are indicated by a Creative Commons license in the record and/ or on the work itself. This Dissertation has been accepted for inclusion in WVU Graduate Theses, Dissertations, and Problem Reports collection by an authorized administrator of The Research Repository @ WVU.

For more information, please contact researchrepository@mail.wvu.edu. 
Effects of work stoppages at selected steel mills on production and safety systems

\author{
Daniel Hartley
}

\author{
Dissertation submitted to the \\ College of Human Resources and Education \\ at West Virginia University \\ in partial fulfillment of requirements \\ for the degree of
}

\author{
Doctor of Education \\ in \\ Technology Education
}

Edward C, Pytlik, Ph.D., Chair

David L. McCrory, Ph.D.

Daniel E. Della-Giustina, Ph.D.

Van O. Dempsey, III, Ph.D.

Gary Winn, Ph.D.

Department of Advanced Educational Studies

Morgantown, West Virginia

2001

Keywords: Work Stoppages, Occupational Injuries, Production Systems, Safety Systems 


\section{ABSTRACT \\ Effects of work stoppages at selected steel mills on production and safety systems}

\section{Daniel Hartley}

The purpose of this research was to identify if there was a significant difference between the OSHA recordable incidence rates at a selected steel manufacturer prior to a major work stoppage and subsequent to the work stoppage. Monthly and quarterly time periods were evaluated to determine the level of change that occurred between prior and post work stoppage periods. Raw steel production was also evaluated to determine the effects of the work stoppage on production totals. OSHA recordable incidence rates were generally lower after the work stoppage, while production totals were higher after the work stoppage. In many instances the lost work day and transitional incidence rates demonstrated a significant increase for the nine months immediately following the work stoppage, when compared to the nine months immediately preceding the work stoppage. When the time period used was non-inclusive of the nine month periods surrounding the work stoppage, the incidence rates generally demonstrated a decreasing trend for the period after the work stoppage. 


\section{DEDICATION}

To my parents 


\section{ACKNOWLEDGEMENTS}

I would like to start with a heartfelt THANK YOU to my Mother, Marie Hartley and my Father, Arthur Hartley. The support and inspiration that they have provided throughout my entire life and my educational experience is appreciated more than words can ever express.

I would like to acknowledge my doctoral committee chair, Dr. Edward C. Pytlik. His endless hours (many after his retirement) devoted to reading, proofing, and editing the numerous versions of this manuscript were extremely valuable. His availability and willingness to meet for discussions of subject and content matter were much appreciated. His final edit was incredibly thorough and improved the overall quality of this document immensely.

I would like to acknowledge the contributions of the rest of my committee, Dr. Daniel Della-Giustina, Dr. Gary Winn, Dr. David McCrory, and Dr. Van Dempsey. The cooperative approach that each of these committee members demonstrated throughout the course of my research lessened the stress of what can be an almost overwhelming process. The encouragement and support shown by Dr. Della-Giustina and Dr Winn prior to my entering the doctoral program was greatly appreciated. Their continued support and insight combined with that extended by Dr. Pytlik, Dr. McCrory and Dr. Dempsey was valued greatly during my research.

The remainder of my immediate family also provided their own unique methods of inspiration for me during this process. I would like to thank each of you for your contributions to my life. My brother Warren, his wife Donna, and their two children Rebecca and Melissa. My brother Bill, his wife Kim, and their two children Jacob and Matt. My brother Wayne, his wife Sheila, and their two children Emily and Jimmy. Additional thanks go to Bill and Kim, who graciously allowed me to use their computer when mine would no longer support the demands of this document.

Finally, I would like to thank a special group of people who helped in many different ways during the course of my research. Carol enthusiastically stepped me through the necessary paperwork throughout the research process. Lisa pushed me when I needed motivation and allowed me to use her computer to compile the fragments of this document into a whole. Elyce acted as my mentor at work and provided a sympathetic ear when I needed to talk about the peaks and valleys of this research. Others who provided help or encouragement along the way include: Pam, John, Lynn, Barb, Sarah, Mary, Clay, Al, my neighbors, all of my wonderful Tech Ed classmates, and many others. 


\section{TABLE OF CONTENTS}

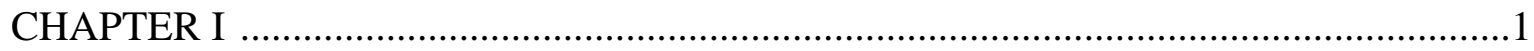

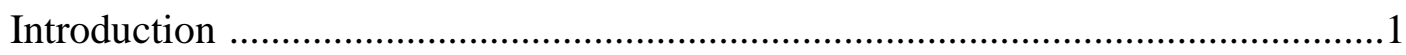

America's Transition to Organized Labor and Safety...............................1

A Changing Nation ............................................................

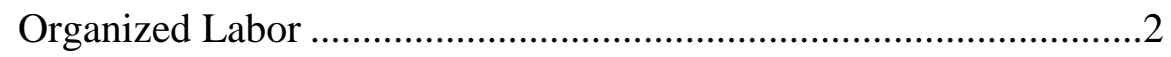

Early Safety Activity..........................................................4

Labor Strikes .................................................................6

Statement of the Problem....................................................................

Purposes of the Research ............................................................. 9

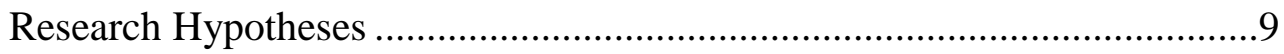

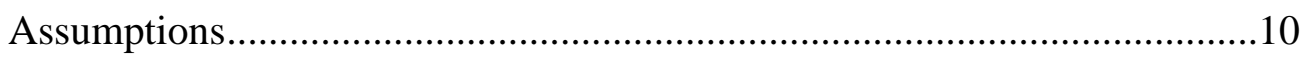

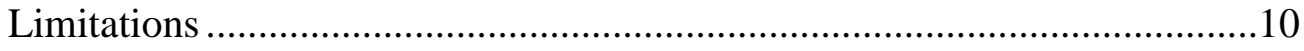

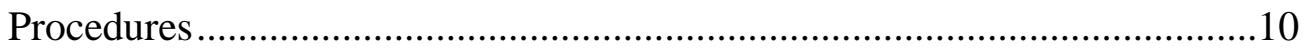

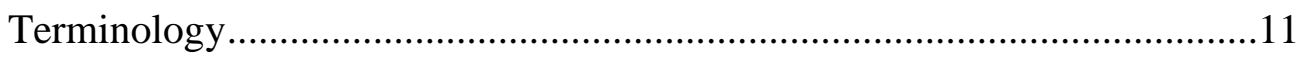

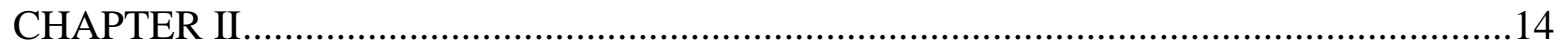

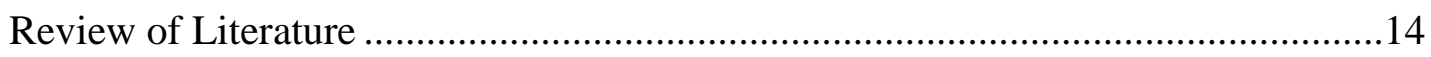

Measurements of Work Stoppage Effects on Safety and

Production Systems .................................................................. 14

Introduction .................................................................. 14

Occupational Safety and Health Act.............................................14

Occupational Safety and Health Administration ............................15

National Institute for Occupational Safety and Health ....................16 
OSHA Standards ............................................................................

OSHA Required Recordkeeping and Reporting ................................17

Injury and Illness Records ..........................................................18

Measuring Work Stoppage Effects on Safety Performance ……………......19

Safety Audits and Inspections..........................................................20

Note

Measuring Work Stoppage Effects on Production Systems ...........................23

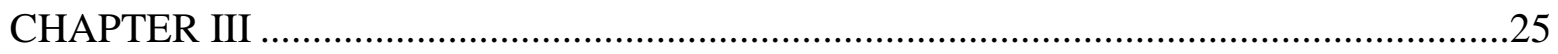

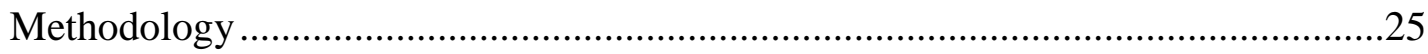

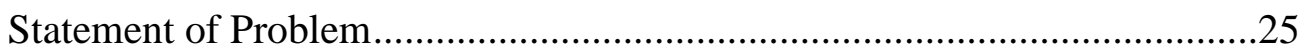

Research Hypotheses ...............................................................................25

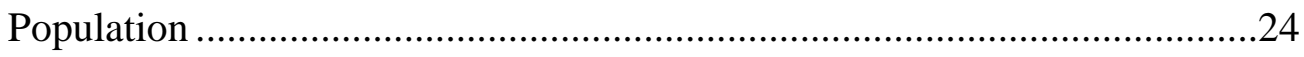

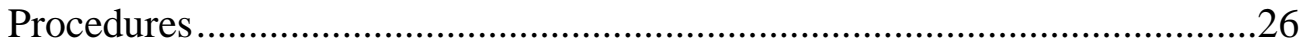

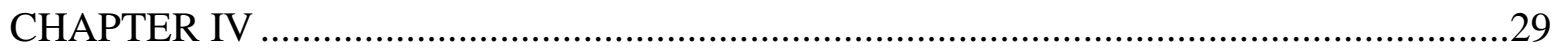

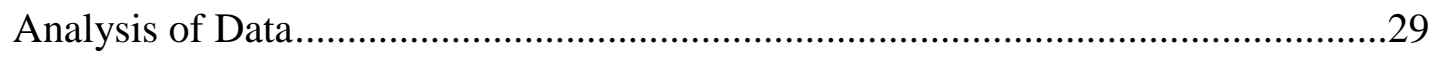

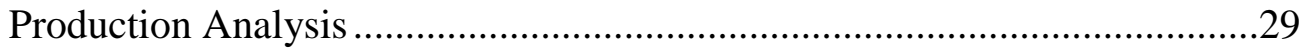

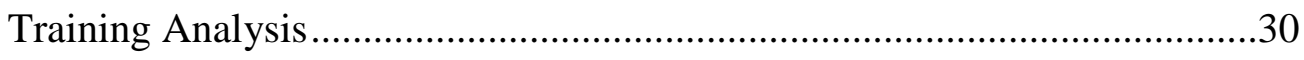

Audits and Inspections Analysis ...................................................................31

OSHA Recordable Analysis .......................................................................

Corporate Analysis of OSHA Recordable Incidents ............................31

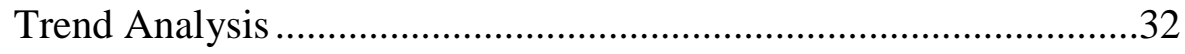

Corporate Analysis of OSHA Recordable Incidence Rates................33

Comparison of OSHA Recordable Incidence Rates to Control..........34 
Control Charts.

Quarterly Analysis of OSHA Recordable Data - Corporate 36

Seasonal Analysis of Quarterly OSHA Recordable Data -

Corporate. 39

Monthly Analysis of OSHA Recordable Data - Corporate.

Seasonal Analysis of Monthly OSHA Recordable Incidence

Rates - Corporate . .48

Testing the Periodic Statistical Relationship - Corporate .48

All 33 Months Prior to and Subsequent to the Work Stoppage . .48

First 24 Months and Last 24 Months of the Research Period

Nine Month Intervals Prior to and Subsequent to the Work

Stoppage.

Primary Plant Analysis .50

Quarterly Analysis of OSHA Recordable Data - Primary Plant 50

Seasonal Analysis of Quarterly OSHA Recordable Incidence Rates

Data - Primary Plant 53

Monthly Analysis of OSHA Recordable Data - Primary Plant.........54

Seasonal Analysis of Monthly OSHA Recordable Incidence Rates

Data - Primary Plant

Testing the Periodic Statistical Relationship - Primary Plant .62

All 33 Months Prior to and Subsequent to the Work Stoppage .62

First 24 Months and Last 24 Months of the Research Period .63

Nine Month Intervals Prior to and Subsequent to the Work 
Stoppage - Primary Plant.

Finishing Plant \#1 Analysis

Quarterly Analysis of OSHA Recordable Data - Finishing

Plant \#1 .63

Seasonal Analysis of Quarterly OSHA Recordable Incidence Rates

Data - Finishing Plant \#1.

Monthly Analysis of OSHA Recordable Data - Finishing

Plant \#1

Seasonal Analysis of Monthly OSHA Recordable Data - Finishing

Plant \#1 .76

Testing the Periodic Statistical Relationship - Finishing Plant \#1 .76

All 33 Months Prior to and Subsequent to the Work Stoppage.........76

First 24 Months and Last 24 Months of the Research Period .77

Nine Month Intervals Prior to and Subsequent to the Work

Stoppage.

Finishing Plant \#2 Analysis

Quarterly Analysis of OSHA Recordable Data - Finishing

Plant \#2 . .77

Seasonal Analysis of Quarterly OSHA Recordable Incidence Rates

Data - Finishing Plant \#2.

Monthly Analysis of OSHA Recordable Data - Finishing

Plant \#2

Seasonal Analysis of Monthly OSHA Recordable Data - Finishing 
Testing the Periodic Statistical Relationship - Finishing Plant \#2 ................90

All 33 Months Prior to and Subsequent to the Work Stoppage.........90

First 24 Months and Last 24 Months of the Research Period ...........91

Nine Month Intervals Prior to and Subsequent to the Work

Stoppage ........................................................................... 91

Finishing Plant \#3 Analysis

Quarterly Analysis of OSHA Recordable Data - Finishing

Plant \#3

Seasonal Analysis of Quarterly OSHA Recordable Incidence Rates

Data - Finishing Plant \#3 ..........................................................95

Monthly Analysis of OSHA Recordable Data - Finishing

Plant \#3 . .95

Seasonal Analysis of Monthly OSHA Recordable Data - Finishing

Plant \#3 .103

Testing the Periodic Statistical Relationship - Finishing Plant \#3 .

All 33 Months Prior to and Subsequent to the Work Stoppage .........103

First 24 Months and Last 24 Months of the Research Period 104

Nine Month Intervals Prior to and Subsequent to the Work

Stoppage. .104

Corporate Analysis of Lost Work Day Data 104

Quarterly Analysis of Lost Work Day Data - Corporate 104

Seasonal Analysis of Quarterly Lost Work Day Data - Corporate ...107 
Monthly Analysis of Lost Work Day Data - Corporate. 108

Seasonal Analysis of Monthly Lost Work Day Incidence

Rates - Corporate

Testing the Periodic Statistical Relationship of Lost Work Day

Data- Corporate

All 33 Months Prior to and Subsequent to the Work Stoppage

First 24 Months and Last 24 Months of the Research Period

Nine Month Intervals Prior to and Subsequent to the Work

Stoppage.

Primary Plant Analysis of Lost Work Day Data.

Quarterly Analysis of Lost Work Day Data - Primary Plant

Seasonal Analysis of Quarterly Lost Work Day Incidence Rates

Data - Primary Plant

Monthly Analysis of Lost Work Day Data - Primary Plant

Seasonal Analysis of Monthly Lost Work Day Incidence Rates

Data - Primary Plant 130

Testing the Periodic Statistical Relationship - Primary Plant

All 33 Months Prior to and Subsequent to the Work Stoppage

First 24 Months and Last 24 Months of the Research Period

Nine Month Intervals Prior to and Subsequent to the Work

Stoppage - Primary Plant.

Finishing Plant \#1 Analysis of Lost Work Day Data

Quarterly Analysis of Lost Work Day Data - Finishing Plant \#1 
Seasonal Analysis of Quarterly Lost Work Day Incidence Rates

Data - Finishing Plant \#1 ...........................................................136

Monthly Analysis of Lost Work Day Data - Finishing Plant \#1 .......136

Seasonal Analysis of Monthly Lost Work Day Incidence Rates

Data - Finishing Plant \#1

Testing the Periodic Statistical Relationship - Finishing Plant \#1

All 33 Months Prior to and Subsequent to the Work Stoppage

First 24 Months and Last 24 Months of the Research Period 145

Nine Month Intervals Prior to and Subsequent to the Work

Stoppage - Finishing Plant \#1

Finishing Plant \#2 Analysis of Lost Work Day Data 146

Quarterly Analysis of Lost Work Day Data - Finishing Plant \#2 .....146

Seasonal Analysis of Quarterly Lost Work Day Incidence Rates

Data - Finishing Plant \#2.

Monthly Analysis of Lost Work Day Data - Finishing Plant \#2 .......150

Seasonal Analysis of Monthly Lost Work Day Incidence Rates

Data - Finishing Plant \#2

Testing the Periodic Statistical Relationship - Finishing Plant \#2 158

All 33 Months Prior to and Subsequent to the Work Stoppage.........158

First 24 Months and Last 24 Months of the Research Period

Nine Month Intervals Prior to and Subsequent to the Work

Stoppage - Finishing Plant \#2

Finishing Plant \#3Analysis of Lost Work Day Data 160 
Quarterly Analysis of Lost Work Day Data - Finishing Plant \#3 .....160

Seasonal Analysis of Quarterly Lost Work Day Incidence Rates

Data - Finishing Plant \#3.

Monthly Analysis of Lost Work Day Data - Finishing Plant \#3 .......164

Seasonal Analysis of Monthly Lost Work Day Incidence Rates

Data - Finishing Plant \#3

Testing the Periodic Statistical Relationship - Finishing Plant \#3

All 33 Months Prior to and Subsequent to the Work Stoppage

First 24 Months and Last 24 Months of the Research Period

Nine Month Intervals Prior to and Subsequent to the Work

Stoppage - Finishing Plant \#3

Corporate Analysis of Transitional Incidence Rates

Quarterly Analysis of Transitional Data - Corporate

Seasonal Analysis of Quarterly Transitional Data - Corporate

Monthly Analysis of Transitional Data - Corporate

Seasonal Analysis of Monthly Transitional Incidence

Rates - Corporate

Testing the Periodic Statistical Relationship of Transitional

Data- Corporate

All 33 Months Prior to and Subsequent to the Work Stoppage 186

First 24 Months and Last 24 Months of the Research Period 186

Nine Month Intervals Prior to and Subsequent to the Work

Stoppage. 
Primary Plant Analysis of Transitional Incidence Rates

Quarterly Analysis of Transitional Data - Primary Plant

Seasonal Analysis of Quarterly Transitional Data - Primary Plant...191

Monthly Analysis of Transitional Data - Primary Plant

Seasonal Analysis of Monthly Transitional Incidence

Rates - Primary Plant

Testing the Periodic Statistical Relationship of Transitional

Data- Primary Plant

All 33 Months Prior to and Subsequent to the Work Stoppage.........200

First 24 Months and Last 24 Months of the Research Period............200

Nine Month Intervals Prior to and Subsequent to the Work

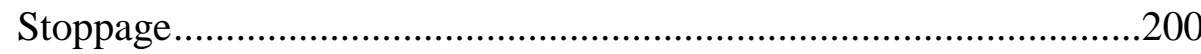

Finishing Plant \#1 Analysis of Transitional Incidence Rates ......................201

Quarterly Analysis of Transitional Data - Finishing Plant \#1 ..........201

Seasonal Analysis of Quarterly Transitional Data -

Finishing Plant \#1 .............................................................204

Monthly Analysis of Transitional Data - Finishing Plant \#1 ...........205

Seasonal Analysis of Monthly Transitional Incidence

Rates - Finishing Plant \#1

Testing the Periodic Statistical Relationship of Transitional

Data- Finishing Plant \#1

All 33 Months Prior to and Subsequent to the Work Stoppage

First 24 Months and Last 24 Months of the Research Period .213 
Nine Month Intervals Prior to and Subsequent to the Work

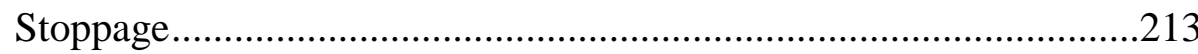

Finishing Plant \#2 Analysis of Transitional Incidence Rates .....................214

Quarterly Analysis of Transitional Data - Finishing Plant \#2 _.........214

Seasonal Analysis of Quarterly Transitional Data -

Finishing Plant \#2 …...............................................................218

Monthly Analysis of Transitional Data - Finishing Plant \#2 _..........218

Seasonal Analysis of Monthly Transitional Incidence

Rates - Finishing Plant \#2 _..................................................226

Testing the Periodic Statistical Relationship of Transitional

Data- Finishing Plant \#2 ......................................................................226

All 33 Months Prior to and Subsequent to the Work Stoppage .........226

First 24 Months and Last 24 Months of the Research Period............226

Nine Month Intervals Prior to and Subsequent to the Work

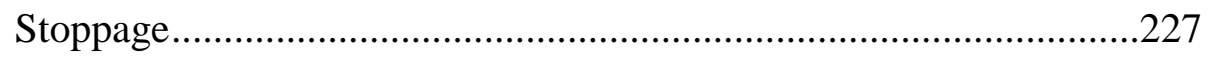

Finishing Plant \#3 Analysis of Transitional Incidence Rates ......................227

Quarterly Analysis of Transitional Data - Finishing Plant \#3..........227

Seasonal Analysis of Quarterly Transitional Data -

Finishing Plant \#3

Monthly Analysis of Transitional Data - Finishing Plant \#3

Seasonal Analysis of Monthly Transitional Incidence

Rates - Finishing Plant \#3

Testing the Periodic Statistical Relationship of Transitional 
Data- Finishing Plant \#3

All 33 Months Prior to and Subsequent to the Work Stoppage .........239

First 24 Months and Last 24 Months of the Research Period

Nine Month Intervals Prior to and Subsequent to the Work

Stoppage

Corporate Analysis of Medical Treatment Incidence Rates

Quarterly Analysis of Medical Treatment Data - Corporate

Seasonal Analysis of Quarterly Medical Treatment Data -

Corporate.

Monthly Analysis of Medical Treatment Data - Corporate

Seasonal Analysis of Monthly Medical Treatment Incidence

Rates - Corporate

Testing the Periodic Statistical Relationship of Medical Treatment

Data- Corporate .253

All 33 Months Prior to and Subsequent to the Work Stoppage .253

First 24 Months and Last 24 Months of the Research Period .254

Nine Month Intervals Prior to and Subsequent to the Work

Stoppage. .254

Primary Plant Analysis of Medical Treatment Incidence Rates 254

Quarterly Analysis of Medical Treatment Data - Primary Plant.......254

Seasonal Analysis of Quarterly Medical Treatment Data -

Primary Plant .258

Monthly Analysis of Medical Treatment Data - Primary Plant .258 
Seasonal Analysis of Monthly Medical Treatment Incidence

Rates - Primary Plant.

Testing the Periodic Statistical Relationship of Medical Treatment

Data- Primary Plant 267

All 33 Months Prior to and Subsequent to the Work Stoppage.........267

First 24 Months and Last 24 Months of the Research Period 268

Nine Month Intervals Prior to and Subsequent to the Work

Stoppage 268

Finishing Plant \#1 Analysis of Medical Treatment Incidence Rates

Quarterly Analysis of Medical Treatment Data-

Finishing Plant \#1

Seasonal Analysis of Quarterly Medical Treatment Data -

Finishing Plant \#1

Monthly Analysis of Medical Treatment Data -

Finishing Plant \#1

Seasonal Analysis of Monthly Medical Treatment Incidence

Rates - Finishing Plant \#1

Testing the Periodic Statistical Relationship of Medical Treatment

Data- Finishing Plant \#1

All 33 Months Prior to and Subsequent to the Work Stoppage .281

First 24 Months and Last 24 Months of the Research Period 281

Nine Month Intervals Prior to and Subsequent to the Work

Stoppage. .282 
Finishing Plant \#2 Analysis of Medical Treatment Incidence Rates

Quarterly Analysis of Medical Treatment Data -

Finishing Plant \#2

Seasonal Analysis of Quarterly Medical Treatment Data -

Finishing Plant \#2

Monthly Analysis of Medical Treatment Data -

Finishing Plant \#2

Seasonal Analysis of Monthly Medical Treatment Incidence

Rates - Finishing Plant \#2

Testing the Periodic Statistical Relationship of Medical Treatment

Data- Finishing Plant \#2

Nine Month Intervals Prior to and Subsequent to the Work

Stoppage

First 24 Months and Last 24 Months of the Research Period 295

All 33 Months Prior to and Subsequent to the Work Stoppage .........295

Finishing Plant \#3 Analysis of Medical Treatment Incidence Rates .296

Quarterly Analysis of Medical Treatment Data -

Finishing Plant \#3 .296

Seasonal Analysis of Quarterly Medical Treatment Data -

Finishing Plant \#3 .300

Monthly Analysis of Medical Treatment Data -

Finishing Plant \#3 .300

Seasonal Analysis of Monthly Medical Treatment Incidence 
Rates - Finishing Plant \#3 308

Testing the Periodic Statistical Relationship of Medical Treatment

Data- Finishing Plant \#3

Nine Month Intervals Prior to and Subsequent to the Work

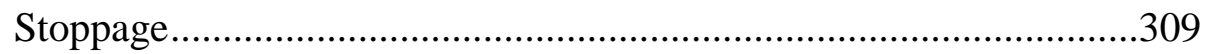

First 24 Months and Last 24 Months of the Research Period............309

All 33 Months Prior to and Subsequent to the Work Stoppage.........309

CHAPTER V

Findings, Conclusions, and Recommendations

Research Hypotheses

Findings and Conclusions

Production Levels

Number of OSHA Recordable Incidents and Number of

Employees

OSHA Recordable Incidence Rates

Quarterly OSHA Recordable Incidence Rates

Monthly OSHA Recordable Incidence Rates

OSHA Recordable Incidence Rates for Nine Months Prior and

Subsequent to the Work Stoppage

OSHA Recordable Incidence Rates for the First 24 Months and

Last 24 Months of the Research.

OSHA Recordable Incidence Rates for the entire 33 Months

Prior and Subsequent to the Work Stoppage .322 
Summary

Recommendations for Further Research .325

Bibliography 


\section{LIST OF FIGURES}

Figure $1 \quad$ OSHA Recordable Incidents - Annualized Numbers and Trend ...........................33

Figure 2 OSHA Recordable Incidence Rates - Annualized Numbers and Trend..................34

Figure 3 Corporate wide OSHA Recordable Incidence Rates ..........................................35

Figure 4 First Quarter 1994-2000 OSHA Recordable Incidence Rates - Corporate ...............36

Figure 5 Second Quarter 1994-2000 OSHA Recordable Incidence Rates - Corporate...........37

Figure 6 Third Quarter 1994-1999 OSHA Recordable Incidence Rates - Corporate..............38

Figure 7 Fourth Quarter 1994-1999 OSHA Recordable incidence Rates - Corporate ............38

Figure 8 Quarterly Seasonal Index for OSHA Recordable Incidence Rates - Corporate........40

Figure 9 January 1994-2000 OSHA Recordable Incidence Rates - Corporate ......................40

Figure 10 February 1994-2000 OSHA Recordable Incidence Rates - Corporate ...................41

Figure 11 March 1994-2000 OSHA Recordable Incidence Rates - Corporate .......................42

Figure 12 April 1994-2000 OSHA Recordable Incidence Rates - Corporate .........................42

Figure 13 May 1994-2000 OSHA Recordable Incidence Rates - Corporate .........................43

Figure 14 June 1994-2000 OSHA Recordable Incidence Rates - Corporate ..........................43

Figure 15 July 1994-1999 OSHA Recordable Incidence Rates - Corporate ..........................44

Figure 16 August 1994-1999 OSHA Recordable Incidence Rates - Corporate ......................44

Figure 17 September 1994-1999 OSHA Recordable Incidence Rates - Corporate..................45

Figure 18 October 1994-1999 OSHA Recordable Incidence Rates - Corporate......................46

Figure 19 November 1994-1999 OSHA Recordable Incidence Rates - Corporate..................46

Figure 20 December 1994-1999 OSHA Recordable Incidence Rates - Corporate ..................47

Figure 21 Monthly Seasonal Pattern of OSHA Recordable Incidence Rates. .........................48

Figure 22 First Quarter 1994-2000 OSHA Recordable Incidence Rates - Primary Plant..........50

Figure 23 Second Quarter 1994-2000 OSHA Recordable Incidence Rates - Primary Plant .....51

Figure 24 Third Quarter 1994-1999 OSHA Recordable Incidence Rates - Primary Plant ........52

Figure 25 Fourth Quarter 1994-1999 OSHA Recordable Incidence Rates - Primary Plant ......52

Figure 26 Quarterly Seasonal Index for OSHA Recordable Incidence Rates -

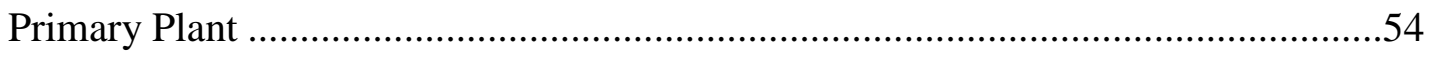

Figure 27 January 1994-2000 OSHA Recordable Incidence Rates - Primary Plant ................54

Figure 28 February 1994-2000 OSHA Recordable Incidence Rates - Primary Plant ...............55 
Figure 29 March 1994-2000 OSHA Recordable Incidence Rates - Primary Plant ..................56

Figure 30 April 1994-2000 OSHA Recordable Incidence Rates - Primary Plant ...................56

Figure 31 May 1994-2000 OSHA Recordable Incidence Rates - Primary Plant .....................57

Figure 32 June 1994-2000 OSHA Recordable Incidence Rates - Primary Plant .....................58

Figure 33 July 1994-1999 OSHA Recordable Incidence Rates - Primary Plant.....................58

Figure 34 August 1994-1999 OSHA Recordable Incidence Rates - Primary Plant .................59

Figure 35 September 1994-1999 OSHA Recordable Incidence Rates - Primary Plant ............59

Figure 36 October 1994-1999 OSHA Recordable Incidence Rates - Primary Plant................60

Figure 37 November 1994-1999 OSHA Recordable Incidence Rates - Primary Plant............60

Figure 38 December 1994-1999 OSHA Recordable Incidence Rates - Primary Plant ............61

Figure 39 Monthly Seasonal Pattern of OSHA Recordable Incidence Rates - Primary Plant ..62

Figure 40 First Quarter 1994-2000 OSHA Recordable Incidence Rates -

Finishing Plant \#1

Figure 41 Second Quarter 1994-2000 OSHA Recordable Incidence Rates -

Finishing Plant \#1

Figure 42 Third Quarter 1994-1999 OSHA Recordable Incidence Rates -

Finishing Plant \#1

Figure 43 Fourth Quarter 1994-1999 OSHA Recordable Incidence Rates -

Finishing Plant \#1

Figure 44 Quarterly Seasonal Index for OSHA Recordable Incidence Rates -

Finishing Plant \#1 .67

Figure 45 January 1994-2000 OSHA Recordable Incidence Rates - Finishing Plant \#1 ..........68

Figure 46 February 1994-2000 OSHA Recordable Incidence Rates - Finishing Plant \#1 ........68

Figure 47 March 1994-2000 OSHA Recordable Incidence Rates - Finishing Plant \#1 ...........69

Figure 48 April 1994-2000 OSHA Recordable Incidence Rates - Finishing Plant \#1 .............70

Figure 49 May 1994-2000 OSHA Recordable Incidence Rates - Finishing Plant \#1 ..............70

Figure 50 June 1994-2000 OSHA Recordable Incidence Rates - Finishing Plant \#1 _.............71

Figure 51 July 1994-1999 OSHA Recordable Incidence Rates - Finishing Plant \#1 ...............72

Figure 52 August 1994-1999 OSHA Recordable Incidence Rates - Finishing Plant \#1 ...........72

Figure 53 September 1994-1999 OSHA Recordable Incidence Rates - Finishing Plant \#1 .....73

Figure 54 October 1994-1999 OSHA Recordable Incidence Rates - Finishing Plant \#1 .........74 
Figure 55 November 1994-1999 OSHA Recordable Incidence Rates - Finishing Plant \#1 .....74

Figure 56 December 1994-1999 OSHA Recordable Incidence Rates - Finishing Plant \#1 ......75

Figure 57 Monthly Seasonal Pattern of OSHA Recordable Incidence Rates -

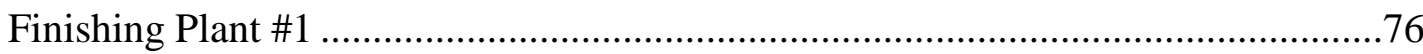

Figure 58 First Quarter 1994-2000 OSHA Recordable Incidence Rates -

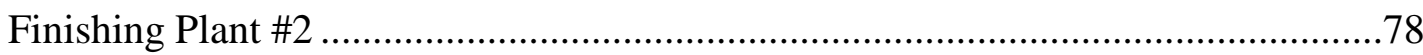

Figure 59 Second Quarter 1994-2000 OSHA Recordable Incidence Rates -

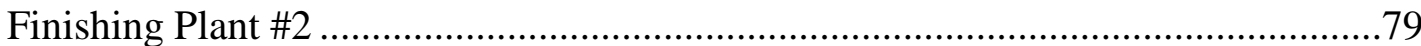

Figure 60 Third Quarter 1994-1999 OSHA Recordable Incidence Rates -

Finishing Plant \#2

Figure $61 \quad$ Fourth Quarter 1994-1999 OSHA Recordable Incidence Rates -

Finishing Plant \#2

Figure 62 Quarterly Seasonal Index for OSHA Recordable Incidence Rates -

Finishing Plant \#1

Figure 63 January 1994-2000 OSHA Recordable Incidence Rates -

Finishing Plant \#2

Figure 64 February 1994-2000 OSHA Recordable Incidence Rates -

Finishing Plant \#2

Figure 65 March 1994-2000 OSHA Recordable Incidence Rates -

Finishing Plant \#2 .83

Figure 66 April 1994-2000 OSHA Recordable Incidence Rates -

Finishing Plant \#2

Figure 67 May 1994-2000 OSHA Recordable Incidence Rates -

Finishing Plant \#2 .84

Figure 68 June 1994-2000 OSHA Recordable Incidence Rates -

Finishing Plant \#2

Figure 69 July 1994-1999 OSHA Recordable Incidence Rates -

Finishing Plant \#2 .86

Figure 70 August 1994-1999 OSHA Recordable Incidence Rates -

Finishing Plant \#2 .86

Figure 71 September 1994-1999 OSHA Recordable Incidence Rates - 
Finishing Plant \#2

Figure 72 October 1994-1999 OSHA Recordable Incidence Rates -

Finishing Plant \#2

Figure 73 November 1994-1999 OSHA Recordable Incidence Rates -

Finishing Plant \#2

Figure 74 December 1994-1999 OSHA Recordable Incidence Rates -

Finishing Plant \#2

Figure 75 Monthly Seasonal Pattern of OSHA Recordable Incidence Rates -

Finishing Plant \#2

Figure 76 First Quarter 1994-2000 OSHA Recordable Incidence Rates -

Finishing Plant \#3

Figure 77 Second Quarter 1994-2000 OSHA Recordable Incidence Rates -

Finishing Plant \#3

Figure 78 Third Quarter 1994-1999 OSHA Recordable Incidence Rates -

Finishing Plant \#3 ....

Figure 79 Fourth Quarter 1994-1999 OSHA Recordable Incidence Rates -

Finishing Plant \#3

Figure 80 Quarterly Seasonal Pattern of OSHA Recordable Incidence Rates -

Finishing Plant \#3

Figure 81 January 1994-2000 OSHA Recordable Incidence Rates -

Finishing Plant \#3 .96

Figure 82 February 1994-2000 OSHA Recordable Incidence Rates -

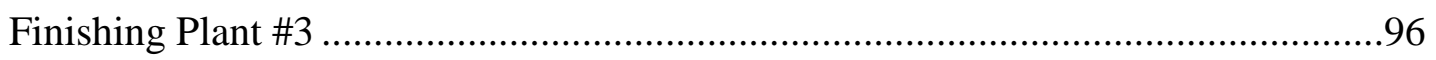

Figure 83 March 1994-2000 OSHA Recordable Incidence Rates -

Finishing Plant \#3

Figure 84 April 1994-2000 OSHA Recordable Incidence Rates -

Finishing Plant \#3 ...

Figure 85 May 1994-2000 OSHA Recordable Incidence Rates -

Finishing Plant \#3 . .98

Figure 86 June 1994-2000 OSHA Recordable Incidence Rates -

Finishing Plant \#3 
Figure 87 July 1994-1999 OSHA Recordable Incidence Rates -

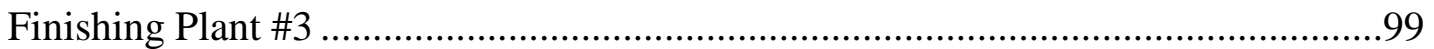

Figure 88 August 1994-1999 OSHA Recordable Incidence Rates -

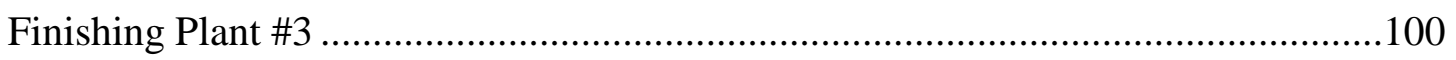

Figure 89 September 1994-1999 OSHA Recordable Incidence Rates -

Finishing Plant \#3

Figure 90 October 1994-1999 OSHA Recordable Incidence Rates -

Finishing Plant \#3

Figure $91 \quad$ November 1994-1999 OSHA Recordable Incidence Rates -

Finishing Plant \#3

Figure 92 December 1994-1999 OSHA Recordable Incidence Rates -

Finishing Plant \#3 .102

Figure 93 Monthly Seasonal Pattern of OSHA Recordable Incidence Rates -

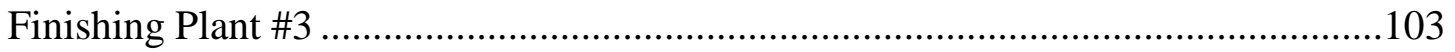

Figure 94 First Quarter 1994-2000 Lost Work Day Incidence Rates - Corporate ...................105

Figure 95 Second Quarter 1994-2000 Lost Work Day Incidence Rates - Corporate ................105

Figure 96 Third Quarter 1994-1999 Lost Work Day Incidence Rates - Corporate..................106

Figure 97 Fourth Quarter 1994-1999 Lost Work Day Incidence Rates - Corporate .................106

Figure 98 Quarterly Seasonal Pattern of Lost Work Day Incidence Rates - Corporate ............108

Figure 99 January 1994-2000 Lost Work Day Incidence Rates - Corporate ...........................108

Figure 100 February 1994-2000 Lost Work Day Incidence Rates - Corporate .........................109

Figure 101 March 1994-2000 Lost Work Day Incidence Rates - Corporate ............................110

Figure 102 April 1994-2000 Lost Work Day Incidence Rates - Corporate ..............................110

Figure 103 May 1994-2000 Lost Work Day Incidence Rates - Corporate...............................111

Figure 104 June 1994-2000 Lost Work Day Incidence rates - Corporate ................................112

Figure 105 July 1994-1999 Lost Work Day Incidence rates - Corporate.................................112

Figure 106 August 1994-1999 Lost Work Day Incidence rates - Corporate............................113

Figure 107 September 1994-1999 Lost Work Day Incidence Rates - Corporate.......................114

Figure 108 October 1994-1999 Lost Work Day Incidence Rates - Corporate ..........................114

Figure 109 November 1994-1999 Lost Work Day Incidence Rates - Corporate .......................115

Figure 110 December 1994-1999 Lost Work Day Incidence Rates - Corporate .......................116 
Figure 111 Monthly seasonal pattern of Lost Work day incidence rates -Corporate

Figure 112 First Quarter 1994-2000 Corporate Lost Work Day Incidence Rates -

Primary Plant

Figure 113 Second Quarter 1994-2000 Corporate Lost Work Day Incidence Rates -

Primary Plant

Figure 114 Third Quarter 1994-1999 Corporate Lost Work Day Incidence rates -

Primary Plant

Figure 115 Fourth Quarter 1994-1999 Corporate Lost Work Day Incidence Rates -

Primary Plant

Figure 116 Quarterly Seasonal Index of Lost Work Day Incidence Rates -

Primary plant.

Figure 117 January 1994-2000 Lost Work Day Incidence Rates - Primary Plant .....................123

Figure 118 February 1994-2000 Lost Work Day Incidence Rates - Primary Plant ...................123

Figure 119 March 1994-2000 Lost Work Day Incidence Rates - Primary Plant .......................124

Figure 120 April 1994-2000 Lost Work Day Incidence Rates - Primary Plant .........................125

Figure 121 May 1994-2000 Lost Work Day Incidence Rates - Primary Plant .........................125

Figure 122 June 1994-2000 Lost Work Day Incidence Rates - Primary Plant ..........................126

Figure 123 July 1994-1999 Lost Work Day Incidence Rates - Primary Plant..........................126

Figure 124 August 1994-1999 Lost Work Day Incidence Rates - Primary Plant ......................127

Figure 125 September 1994-1999 Lost Work Day Incidence Rates - Primary Plant .................127

Figure 126 October 1994-1999 Lost Work Day Incidence Rates - Primary Plant......................128

Figure 127 November 1994-1999 Lost Work Day Incidence Rates - Primary Plant..................129

Figure 128 December 1994-1999 Lost Work Day Incidence Rates - Primary Plant ..................129

Figure 129 Monthly Seasonal Pattern of Lost Work Day Incidence Rates - Primary Plant .......131

Figure 130 First quarter 1994-2000 Lost Work Day Incidence Rates - Finishing Plant \#1.........133

Figure 131 Second quarter 1994-2000 Lost Work Day Incidence Rates - Finishing Plant \#1 ....133

Figure 132 Third quarter 1994-1999 Lost Work Day Incidence Rates - Finishing Plant \#1 .......134

Figure 133 Fourth quarter 1994-1999 Lost Work Day Incidence Rates - Finishing Plant \#1 .....135

Figure 134 Quarterly Seasonal Index of Lost Work Day Incidence Rates -

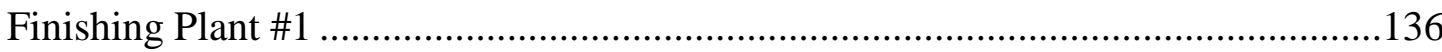

Figure 135 January 1994-2000 Lost Work Day Incidence Rates Finishing Plant \#1 .................137 
Figure 136 February 1994-2000 Lost Work Day Incidence Rates Finishing Plant \#1

Figure 137 March 1994-2000 Lost Work Day Incidence Rates Finishing Plant \#1 ..................138

Figure 138 April 1994-2000 Lost Work Day Incidence Rates Finishing Plant \#1

Figure 139

May 1994-2000 Lost Work Day Incidence Rates Finishing Plant \#1

Figure 140

June 1994-2000 Lost Work Day Incidence Rates - Finishing Plant \#1

Figure 141

July 1994-1999 Lost Work Day Incidence Rates - Finishing Plant \#1

Figure 142

August 1994-1999 Lost Work Day Incidence Rates - Finishing Plant \#1

Figure 143

September 1994-1999 Lost Work Day Incidence Rates - Finishing Plant \#1

Figure 144

October 1994-1999 Lost Work Day Incidence Rates - Finishing Plant \#1 142

Figure 145

November 1994-1999 Lost Work Day Incidence Rates - Finishing Plant \#1

Figure 146

December 1994-1999 Lost Work Day Incidence Rates - Finishing Plant \#1 .144

Figure 147

Monthly Seasonal Pattern of Lost Work Day Incidence Rates -

Finishing Plant \#1

Figure 148 First Quarter 1994-2000 Lost Work Day Incidence Rates -

Finishing Plant \#2

Figure 149 Second Quarter 1994-2000 Lost Work Day Incidence Rates -

Finishing Plant \#2

Figure 150 Third Quarter 1994-1999 Lost Work Day Incidence Rates -

Finishing Plant \#2 .148

Figure 151 Fourth Quarter 1994-1999 Lost Work Day Incidence Rates -

Finishing Plant \#2 .148

Figure 152 Quarterly Seasonal Pattern of Lost Work Day Incidence Rates -

Finishing Plant \#2 150

Figure 153 January 1994-2000 Lost Work Day Incidence Rates - Finishing Plant \#2 .150

Figure 154

February 1994-2000 Lost Work Day Incidence Rates - Finishing Plant \#2 151

Figure 155

March 1994-2000 Lost Work Day Incidence Rates - Finishing Plant \#2 . .151

Figure 156

April 1994-2000 Lost Work Day Incidence Rates - Finishing Plant \#2 . .152

Figure 157

May 1994-2000 Lost Work Day Incidence Rates - Finishing Plant \#2 . 153

Figure 158

June 1994-2000 Lost Work Day Incidence Rates - Finishing Plant \#2

Figure 159

July 1994-1999 Lost Work Day Incidence Rates - Finishing Plant \#2 .154

Figure 160 August 1994-1999 Lost Work Day Incidence Rates - Finishing Plant \#2 .154 
Figure 161 September 1994-1999 Lost Work Day Incidence Rates - Finishing Plant \#2 ..........155

Figure 162 October 1994-1999 Lost Work Day Incidence Rates - Finishing Plant \#2 ..............156

Figure 163 November 1994-1999 Lost Work Day Incidence Rates - Finishing Plant \#2...........156

Figure 164 December 1994-1999 Lost Work Day Incidence Rates - Finishing Plant \#2 ...........157

Figure 165 Monthly Seasonal Pattern of Lost Work day Incidence Rates -

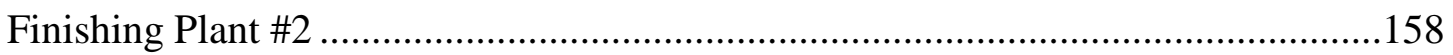

Figure 166 First Quarter 1994-2000 Lost Work Day Incidence Rates - Finishing plant \#3 ........160

Figure 167 Second Quarter 1994-2000 Lost Work Day Incidence Rates - Finishing plant \#3 ...161

Figure 168 Third Quarter 1994-1999 Lost Work Day Incidence Rates - Finishing plant \#3 ......161

Figure 169 Fourth Quarter 1994-1999 Lost Work Day Incidence Rates - Finishing plant \#3.....162

Figure 170 Quarterly Seasonal Index for Lost Work Day Incidence Rates -

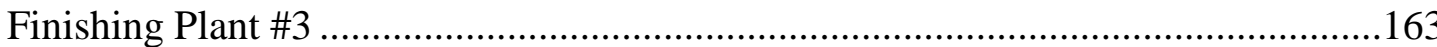

Figure 171 January 1994-2000 Lost Work Day Incidence Rates - Finishing Plant \#3 ...............164

Figure 172 February 1994-2000 Lost Work Day Incidence Rates - Finishing Plant \#3 ..............165

Figure 173 March 1994-2000 Lost Work Day Incidence Rates - Finishing Plant \#3 ................. 165

Figure 174 April 1994-2000 Lost Work Day Incidence Rates - Finishing Plant \#3 ..................166

Figure 175 May 1994-2000 Lost Work Day Incidence Rates - Finishing Plant \#3 ....................167

Figure 176 June 1994-2000 Lost Work Day Incidence Rates - Finishing Plant \#3 ....................167

Figure 177 July 1994-1999 Lost Work Day Incidence Rates - Finishing Plant \#3 _....................168

Figure 178 August 1994-1999 Lost Work Day Incidence Rates - Finishing Plant \#3 _...............168

Figure 179 September 1994-1999 Lost Work Day Incidence Rates - Finishing Plant \#3 ...........169

Figure 180 October 1994-1999 Lost Work Day Incidence Rates - Finishing Plant \#3 ..............169

Figure 181 November 1994-1999 Lost Work Day Incidence Rates - Finishing Plant \#3 ...........170

Figure 182 December 1994-1999 Lost Work Day Incidence Rates - Finishing Plant \#3 ............170

Figure 183 Monthly Seasonal Pattern of Lost Work Day Incidence Rates -

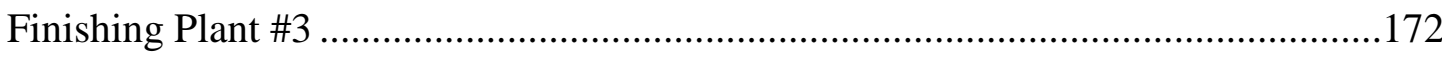

Figure 184 First Quarter 1994-2000 Transitional Incidence Rates - Corporate ........................174

Figure 185 Second Quarter 1994-2000 Transitional Incidence Rates - Corporate ....................174

Figure 186 Third Quarter 1994-1999 Transitional Incidence Rates - Corporate ......................175

Figure 187 Fourth Quarter 1994-1999 Transitional Incidence Rates - Corporate......................176

Figure 188 Quarterly Seasonal Index for Lost Work Day Incidence Rates - Corporate .............177 
Figure 189 January 1994-2000 Transitional Incidence Rates - Corporate ...............................178

Figure 190 February 1994-2000 Transitional Incidence Rates - Corporate .............................178

Figure 191 March 1994-2000 Transitional Incidence Rates - Corporate .................................179

Figure 192 April 1994-2000 Transitional Incidence Rates - Corporate ...................................180

Figure 193 May 1994-2000 Transitional Incidence Rates - Corporate ....................................180

Figure 194 June 1994-2000 Transitional Incidence Rates - Corporate ..................................181

Figure 195 July 1994-1999 Transitional Incidence Rates - Corporate.....................................182

Figure 196 August 1994-1999 Transitional Incidence Rates - Corporate ...............................182

Figure 197 September 1994-1999 Transitional Incidence Rates - Corporate ...........................183

Figure 198 October 1994-1999 Transitional Incidence Rates - Corporate...............................183

Figure 199 November 1994-1999 Transitional Incidence Rates - Corporate............................184

Figure 200 December 1994-1999 Transitional Incidence Rates - Corporate ............................185

Figure 201 Monthly Seasonal Index Pattern of Transitional Incidence Rates - Corporate .........186

Figure 202 First Quarter 1994-2000 Transitional Incidence Rates - Primary Plant ...................188

Figure 203 Second Quarter 1994-2000 Transitional Incidence Rates - Primary Plant...............188

Figure 204 Third Quarter 1994-1999 Transitional Incidence Rates - Primary Plant ..................189

Figure 205 Fourth Quarter 1994-1999 Transitional Incidence Rates - Primary Plant................190

Figure 206 Quarterly Seasonal Index for Transitional Incidence Rates - Primary Plant ............191

Figure 207 January 1994-2000 Transitional Incidence Rates - Primary Plant...........................192

Figure 208 February 1994-2000 Transitional Incidence Rates - Primary Plant.........................192

Figure 209 March 1994-2000 Transitional Incidence Rates - Primary Plant............................193

Figure 210 April 1994-2000 Transitional Incidence Rates - Primary Plant..............................194

Figure 211 May 1994-2000 Transitional Incidence Rates - Primary Plant................................194

Figure 212 June 1994-2000 Transitional Incidence Rates - Primary Plant...............................195

Figure 213 July 1994-1999 Transitional Incidence Rates - Primary Plant ..............................195

Figure 214 August 1994-1999 Transitional Incidence Rates - Primary Plant .........................196

Figure 215 September 1994-1999 Transitional Incidence Rates - Primary Plant.......................197

Figure 216 October 1994-1999 Transitional Incidence Rates - Primary Plant .........................197

Figure 217 November 1994-1999 Transitional Incidence Rates - Primary Plant ......................198

Figure 218 December 1994-1999 Transitional Incidence Rates - Primary Plant.......................198

Figure 219 Monthly Seasonal Pattern of Transitional Incidence Rates Primary Plant ..............200 
Figure 220 First Quarter 1994-2000 Transitional Incidence Rates - Finishing Plant \#1 _...........201

Figure $221 \quad$ Second Quarter 1994-2000 Transitional Incidence Rates - Finishing Plant \#1 ........202

Figure 222 Third Quarter 1994-1999 Transitional Incidence Rates - Finishing Plant \#1 ..........203

Figure 223 Fourth Quarter 1994-1999 Transitional Incidence Rates - Finishing Plant \#1 ........203

Figure 224 Quarterly Seasonal Index for Transitional Incidence Rates - Finishing Plant \#1 .....205

Figure 225 January 1994-2000 Transitional Incidence Rates - Finishing Plant \#1 ...................205

Figure 226 February 1994-2000 Transitional Incidence Rates - Finishing Plant \#1 ................206

Figure 227 March 1994-2000 Transitional Incidence Rates - Finishing Plant \#1 _....................207

Figure 228 April 1994-2000 Transitional Incidence Rates - Finishing Plant \#1 ......................207

Figure 229 May 1994-2000 Transitional Incidence Rates - Finishing Plant \#1 .......................208

Figure 230 June 1994-2000 Transitional Incidence Rates - Finishing Plant \#1 .......................208

Figure 231 July 1994-1999 Transitional Incidence Rates - Finishing Plant \#1 .......................209

Figure 232 August 1994-1999 Transitional Incidence Rates - Finishing Plant \#1...................209

Figure 233 September 1994-1999 Transitional Incidence Rates - Finishing Plant \#1 ...............210

Figure 234 October 1994-1999 Transitional Incidence Rates - Finishing Plant \#1 ..................210

Figure 235 November 1994-1999 Transitional Incidence Rates - Finishing Plant \#1 ...............211

Figure 236 December 1994-1999 Transitional Incidence Rates - Finishing Plant \#1 _...............211

Figure 237 Monthly Seasonal Pattern of Transitional Incidence Rates - Finishing Plant \#1 ......213

Figure 238 First Quarter 1994-2000 Transitional Incidence Rates - Finishing Plant \#2 _...........215

Figure 239 Second Quarter 1994-2000 Transitional Incidence Rates - Finishing Plant \#2 ........215

Figure 240 Third Quarter 1994-1999 Transitional Incidence Rates - Finishing Plant \#2 _..........216

Figure 241 Fourth Quarter 1994-1999 Transitional Incidence Rates - Finishing Plant \#2 ........217

Figure 242 Quarterly Seasonal Index for Transitional Incidence Rates - Finishing Plant \#2 ......218

Figure 243 January 1994-2000 Transitional Incidence Rates - Finishing Plant \#2 ..................219

Figure 244 February 1994-2000 Transitional Incidence Rates - Finishing Plant \#2 .................219

Figure 245 March 1994-2000 Transitional Incidence Rates - Finishing Plant \#2 .....................220

Figure 246 April 1994-2000 Transitional Incidence Rates - Finishing Plant \#2 .....................220

Figure 247 May 1994-2000 Transitional Incidence Rates - Finishing Plant \#2 .......................221

Figure 248 June 1994-2000 Transitional Incidence Rates - Finishing Plant \#2 _......................221

Figure 249 July 1994-1999 Transitional Incidence Rates - Finishing Plant \#2 .......................222

Figure 250 August 1994-1999 Transitional Incidence Rates - Finishing Plant \#2 ....................223 
Figure 251 September 1994-1999 Transitional Incidence Rates - Finishing Plant \#2 2..............223

Figure 252 October 1994-1999 Transitional Incidence Rates - Finishing Plant \#2 ..................224

Figure 253 November 1994-1999 Transitional Incidence Rates - Finishing Plant \#2 ...............224

Figure 254 December 1994-1999 Transitional Incidence Rates - Finishing Plant \#2 ...............225

Figure 255 Seasonal Analysis of Monthly Transitional Data - Finishing Plant \#2 ...................226

Figure 256 First Quarter 1994-2000 Transitional Incidence Rates - Finishing Plant \#3 ............228

Figure 257 Second Quarter 1994-2000 Transitional Incidence Rates - Finishing Plant \#3 ........228

Figure 258 Third Quarter 1994-1999 Transitional Incidence Rates - Finishing Plant \#3 ...........229

Figure 259 Fourth Quarter 1994-1999 Transitional Incidence Rates - Finishing Plant \#3 ..........230

Figure 260 Quarterly Seasonal index for Transitional Incidence Rates - Finishing plant \#3 ......231

Figure 261 January 1994-2000 Transitional Incidence Rates - Finishing Plant \#3 ...................232

Figure 262 February 1994-2000 Transitional Incidence Rates - Finishing Plant \#3 .................232

Figure 263 March 1994-2000 Transitional Incidence Rates - Finishing Plant \#3 .....................233

Figure 264 April 1994-2000 Transitional Incidence Rates - Finishing Plant \#3 ......................233

Figure 265 May 1994-2000 Transitional Incidence Rates - Finishing Plant \#3 ........................234

Figure 266 June 1994-2000 Transitional Incidence Rates - Finishing Plant \#3. ......................234

Figure 267 July 1994-1999 Transitional Incidence Rates - Finishing Plant \#3 ........................235

Figure 268 August 1994-1999 Transitional Incidence Rates - Finishing Plant \#3 ...................236

Figure 269 September 1994-1999 Transitional Incidence Rates - Finishing Plant \#3 _...............236

Figure 270 October 1994-1999 Transitional Incidence Rates - Finishing Plant \#3 ..................237

Figure 271 November 1994-1999 Transitional Incidence Rates - Finishing Plant \#3 ................237

Figure 272 December 1994-1999 Transitional Incidence Rates - Finishing Plant \#3 ...............238

Figure 273 Monthly Seasonal Pattern of Transitional Incidence Rates - Finishing Plant \#3 ....239

Figure 274 First Quarter 1994-2000 Medical Treatment Incidence Rates Corporate.................241

Figure 275 Second Quarter 1994-2000 Medical Treatment Incidence Rates Corporate ............241

Figure 276 Third Quarter 1994-1999 Medical Treatment Incidence Rates Corporate ...............242

Figure 277 Fourth Quarter 1994-1999 Medical Treatment Incidence Rates Corporate .............243

Figure 278 Quarterly Seasonal Index of Medical Treatment Incidence Rates - Corporate.........244

Figure 279 January 1994-2000 Medical Treatment Incidence Rates - Corporate.....................245

Figure 280 February 1994-2000 Medical Treatment Incidence Rates - Corporate...................245

Figure 281 March 1994-2000 Medical Treatment Incidence Rates - Corporate.......................246 
Figure 282 April 1994-2000 Medical Treatment Incidence Rates - Corporate........................247

Figure 283 May 1994-2000 Medical Treatment Incidence Rates - Corporate .........................247

Figure 284 June 1994-2000 Medical Treatment Incidence Rates - Corporate .........................248

Figure 285 July 1994-1999 Medical Treatment Incidence Rates - Corporate...........................248

Figure 286 August 1994-1999 Medical Treatment Incidence Rates - Corporate......................249

Figure 287 September 1994-1999 Medical Treatment Incidence Rates - Corporate .................250

Figure 288 October 1994-1999 Medical Treatment Incidence Rates - Corporate ....................250

Figure 289 November 1994-1999 Medical Treatment Incidence Rates - Corporate ................251

Figure 290 December 1994-1999 Medical Treatment Incidence Rates - Corporate ..................252

Figure 291 Monthly Seasonal Pattern of Medical Treatment Incidence Rates - Corporate ........253

Figure 292 First Quarter 1994-2000 Medical Treatment Incidence Rates - Primary Plant.........254

Figure 293 Second Quarter 1994-2000 Medical Treatment Incidence Rates - Primary Plant ....254

Figure 294 Third Quarter 1994-1999 Medical Treatment Incidence Rates - Primary Plant .......256

Figure 295 Fourth Quarter 1994-1999 Medical Treatment Incidence Rates - Primary Plant .....257

Figure 296 Quarterly Seasonal Index of Medical Treatment Incidence Rates Primary Plant .....258

Figure 297 January 1994-2000 Medical Treatment Incidence Rates - Primary Plant ................259

Figure 298 February 1994-2000 Medical Treatment Incidence Rates - Primary Plant ..............259

Figure 299 March 1994-2000 Medical Treatment Incidence Rates - Primary Plant .................260

Figure 300 April 1994-2000 Medical Treatment Incidence Rates - Primary Plant ...................261

Figure 301 May 1994-2000 Medical Treatment Incidence Rates - Primary Plant ....................261

Figure 302 June 1994-2000 Medical Treatment Incidence Rates - Primary Plant ....................262

Figure 303 July 1994-1999 Medical Treatment Incidence Rates - Primary Plant ....................263

Figure 304 August 1994-1999 Medical Treatment Incidence Rates - Primary Plant .................263

Figure 305 September 1994-1999 Medical Treatment Incidence Rates - Primary Plant............264

Figure 306 October 1994-1999 Medical Treatment Incidence Rates - Primary Plant ................264

Figure 307 November 1994-1999 Medical Treatment Incidence Rates - Primary Plant ............265

Figure 308 December 1994-1999 Medical Treatment Incidence Rates - Primary Plant .............266

Figure 309 Monthly Seasonal Pattern of Medical Treatment Incidence Rates -

Primary Plant

Figure 310 First Quarter 1994-2000 Medical Treatment Incidence Rates -

Finishing Plant \#1 .269 
Figure 311 Second Quarter 1994-2000 Medical Treatment Incidence Rates -

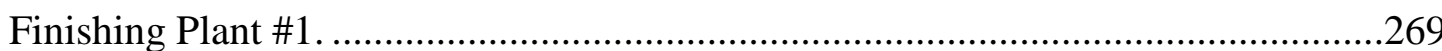

Figure 312 Third Quarter 1994-1999 Medical Treatment Incidence Rates -

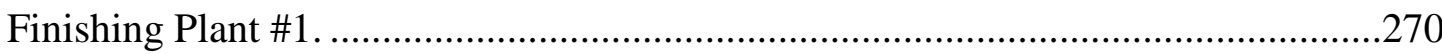

Figure 313 Fourth Quarter 1994-1999 Medical Treatment Incidence Rates -

Finishing Plant \#1 271

Figure 314 Quarterly Seasonal Index for Medical Treatment Incidence Rates -

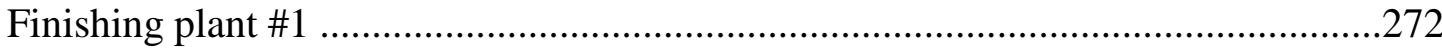

Figure 315 January 1994-2000 Medical Treatment Incidence Rates - Finishing Plant \#1 .........273

Figure 316 February 1994-2000 Medical Treatment Incidence Rates - Finishing Plant \#1 .......273

Figure 317 March 1994-2000 Medical Treatment Incidence Rates - Finishing Plant \#1 ...........274

Figure 318 April 1994-2000 Medical Treatment Incidence Rates - Finishing Plant \#1 .............274

Figure 319 May 1994-2000 Medical Treatment Incidence Rates - Finishing Plant \#1 ..............275

Figure 320 June 1994-2000 Medical Treatment Incidence Rates - Finishing Plant \#1 .............275

Figure 321 July 1994-1999 Medical Treatment Incidence Rates - Finishing Plant \#1 ...............276

Figure 322 August 1994-1999 Medical Treatment Incidence Rates - Finishing Plant \#1 ..........276

Figure 323 September 1994-1999 Medical Treatment Incidence Rates - Finishing Plant \#1 .....277

Figure 324 October 1994-1999 Medical Treatment Incidence Rates - Finishing Plant \#1 .........278

Figure 325 November 1994-1999 Medical Treatment Incidence Rates - Finishing Plant \#1 ......278

Figure 326 December 1994-1999 Medical Treatment Incidence Rates - Finishing Plant \#1 ......279

Figure 327 Monthly Seasonal Pattern of Medical Treatment Incidence Rates -

Finishing Plant \#1 .280

Figure 328 First Quarter 1994-2000 Medical Treatment Incidence Rates -

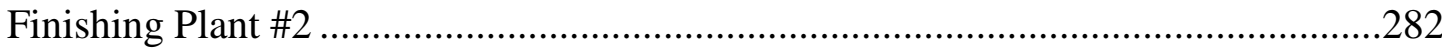

Figure 329 Second Quarter 1994-2000 Medical Treatment Incidence Rates -

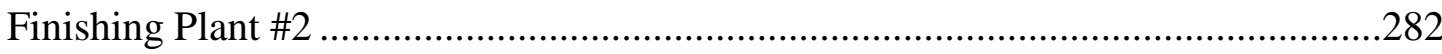

Figure 330 Third Quarter 1994-1999 Medical Treatment Incidence Rates -

Finishing Plant \#2 .283

Figure 331 Fourth Quarter 1994-1999 Medical Treatment Incidence Rates -

Finishing Plant \#2 .284

Figure 332 Quarterly Seasonal Index of Medical Treatment Incidence Rates - . 


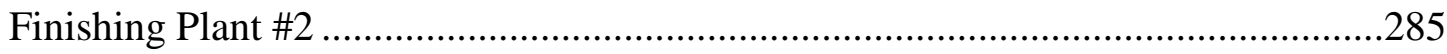

Figure 333 January 1994-2000 Medical Treatment Incidence Rates - Finishing Plant \#2 .........285

Figure 334 February 1994-2000 Medical Treatment Incidence Rates - Finishing Plant \#2 _.......286

Figure 335 March 1994-2000 Medical Treatment Incidence Rates - Finishing Plant \#2 ...........287

Figure 336 April 1994-2000 Medical Treatment Incidence Rates - Finishing Plant \#2 .............287

Figure 337 May 1994-2000 Medical Treatment Incidence Rates - Finishing Plant \#2 _.............288

Figure 338 June 1994-2000 Medical Treatment Incidence Rates - Finishing Plant \#2 ..............288

Figure 339 July 1994-1999 Medical Treatment Incidence Rates - Finishing Plant \#2 _..............289

Figure 340 August 1994-1999 Medical Treatment Incidence Rates - Finishing Plant \#2 ..........290

Figure 341 September 1994-1999 Medical Treatment Incidence Rates - Finishing Plant \#2 .....290

Figure 342 October 1994-1999 Medical Treatment Incidence Rates - Finishing Plant \#2 _.........291

Figure 343 November 1994-1999 Medical Treatment Incidence Rates - Finishing Plant \#2 ......291

Figure 344 December 1994-1999 Medical Treatment Incidence Rates - Finishing Plant \#2 ......292

Figure 345 Monthly Seasonal Pattern of Medical Treatment Incidence Rates -

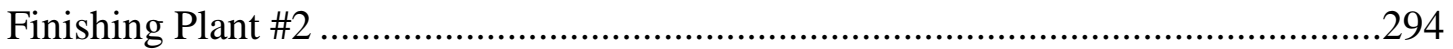

Figure 346 First Quarter1994-2000 Medical Treatment Incidence Rates -

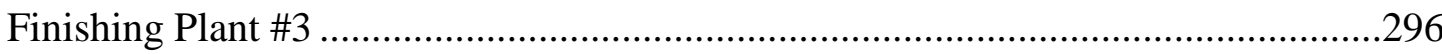

Figure 347 Second Quarter1994-2000 Medical Treatment Incidence Rates -

Finishing Plant \#3 .296

Figure 348 Third Quarter1994-1999 Medical Treatment Incidence Rates -

Finishing Plant \#3

Figure 349 Fourth Quarter1994-1999 Medical Treatment Incidence Rates -

Finishing Plant \#3

Figure 350 Quarterly Seasonal Index of Medical Treatment Incidence Rates -

Finishing plant \#3 .299

Figure 351 January 1994-2000 Medical Treatment Incidence Rates - Finishing Plant \#3 ..........300

Figure 352 February 1994-2000 Medical Treatment Incidence Rates - Finishing Plant \#3 ........300

Figure 353 March 1994-2000 Medical Treatment Incidence Rates - Finishing Plant \#3 ............301

Figure 354 April 1994-2000 Medical Treatment Incidence Rates - Finishing Plant \#3 .............301

Figure 355 May 1994-2000 Medical Treatment Incidence Rates - Finishing Plant \#3 ...............302

Figure 356 June 1994-2000 Medical Treatment Incidence Rates - Finishing Plant \#3 ..............303 
Figure 357 July 1994-1999 Medical Treatment Incidence Rates - Finishing Plant \#3 ...............303

Figure 358 August 1994-1999 Medical Treatment Incidence Rates - Finishing Plant \#3 ...........304

Figure 359 September 1994-1999 Medical Treatment Incidence Rates - Finishing Plant \#3 .....305

Figure 360 October 1994-1999 Medical Treatment Incidence Rates - Finishing Plant \#3 ..........305

Figure 361 November 1994-1999 Medical Treatment Incidence Rates - Finishing Plant \#3 ......306

Figure 362 December 1994-1999 Medical Treatment Incidence Rates - Finishing Plant \#3 ......306

Figure 363 Monthly Seasonal Pattern of Medical Treatment Incidence Rates - .

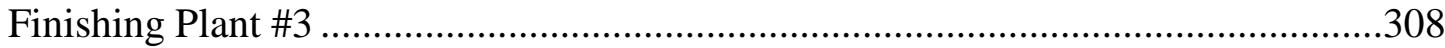




\section{LIST OF TABLES}

Table 1 Annual Production Analysis

Table 2 Number and Percentage of Plant Total OSHA Recordable Incidents

By Plant and Year.

Table 3 OSHA Recordable Incidence Rates Per 100 Full-time Workers - (BLS)

Compared to Corporate. .35

Table 4 Summary of Quarterly OSHA Recordable Incidence Rates Data - Corporate .39

Table 5

Summary of Monthly OSHA Recordable Incidence Rates Data - Corporate. 47

Table 6

Comparison of prior and post work stoppage periods - Corporate .50

Table 7

Summary of Quarterly OSHA Recordable Incidence Rates Data - Primary Plant ...53

Table 8

Summary of Monthly OSHA Recordable Incidence Rates Data - Primary Plant.....61

Table 9

Comparison of Prior and Post Work Stoppage Period - Primary Plant .63

Table 10

Summary of Quarterly OSHA Recordable Incidence Rates Data -

Finishing Plant \#1 .66

Table 11 Summary of Monthly OSHA Recordable Incidence Rates Data -

Finishing Plant \#1 .75

Table 12 Comparison of Prior and Post Work Stoppage Period - Finishing Plant \#1 .77

Table 13 Summary of Quarterly OSHA Recordable Incidence Rates Data -

Finishing Plant \#2 .80

Table 14 Summary of Monthly OSHA Recordable Incidence Rates Data -

Finishing Plant \#2

Table 15 Comparison of Prior and Post Work Stoppage Period -

Finishing Plant \#2

Table 16 Summary of Quarterly OSHA Recordable Incidence Rates Data -

Finishing Plant \#3

Table 17 Summary of Monthly OSHA Recordable Incidence Rates Data -

Finishing Plant \#3

Table 18 Comparison of Prior and Post Work Stoppage Period - Finishing Plant \#3 .............104

Table 19 Summary of Quarterly Lost Work Day Incidence Rates Data - Corporate ..............107

Table 20 Summary of Monthly Lost Work Day Incidence Rates Data - Corporate .116 
Table 21 Comparison of prior and post work stoppage periods - Corporate 118

Table 22 Summary of Quarterly Lost Work Day Incidence Rates Data - Primary Plant 121

Table 23 Summary of Monthly Lost Work Day Incidence Rates Data - Primary Plant.

Table 24 Comparison of prior and post work stoppage periods - Primary Plant

Table 25 Summary of Quarterly Lost Work Day Incidence Rates Data -

Finishing Plant \#1

Table 26 Summary of Monthly Lost Work Day Incidence Rates Data -

Finishing Plant \#1

Table 27 Comparison of prior and post work stoppage periods - Finishing Plant \#1 146

Table 28 Summary of Quarterly Lost Work Day Incidence Rates Data -

Finishing Plant \#2

Table 29 Summary of Monthly Lost Work Day Incidence Rates Data -

Finishing Plant \#2

Table 30 Comparison of prior and post work stoppage periods - Finishing Plant \#2

Table $31 \quad$ Summary of Quarterly Lost Work Day Incidence Rates Data -

Finishing Plant \#3

Table 32 Summary of Monthly Lost Work Day Incidence Rates Data -

Finishing Plant \#3

Table 33 Comparison of prior and post work stoppage periods - Finishing Plant \#3 .............173

Table 34 Summary of Quarterly Transitional Incidence Rates Data - Corporate ...................176

Table 35 Summary of Monthly Transitional Incidence Rates Data - Corporate.....................185

Table 36 Comparison of prior and post work stoppage periods - Corporate ........................187

Table 37 Summary of Quarterly Transitional Incidence Rates Data - Primary Plant .............190

Table 38 Summary of Monthly Transitional Incidence Rates Data - Primary Plant ...............199

Table 39 Comparison of prior and post work stoppage periods - Primary Plant ...................201

Table 40 Summary of Quarterly Transitional Incidence Rates Data -

Finishing Plant \#1 .204

Table 41 Summary of Monthly Transitional Incidence Rates Data -

Finishing Plant \#1 .212

Table 42 Comparison of prior and post work stoppage periods - Finishing Plant \#1 .214

Table 43 Summary of Quarterly Transitional Incidence Rates Data - 
Finishing Plant \#2 217

Table 44 Summary of Monthly Transitional Incidence Rates Data - Finishing Plant \#2 _.......225

Table 45 Comparison of prior and post work stoppage periods - Finishing Plant \#2 .............227

Table 46 Summary of Quarterly Transitional Incidence Rates Data - Finishing Plant \#3 ......230

Table 47 Summary of Monthly Transitional Incidence Rates Data - Finishing Plant \#3 _.......238

Table 48 Comparison of prior and post work stoppage periods - Finishing Plant \#3 .............240

Table 49 Summary of Quarterly Medical Treatment Incidence Rates Data - Corporate.........243

Table $50 \quad$ Summary of Monthly Medical Treatment Incidence Rates Data - Corporate ..........252

Table 51 Comparison of prior and post work stoppage periods - Corporate ........................254

Table 52 Summary of Quarterly Medical Treatment Incidence Rates Data - Primary Plant...257

Table 53 Summary of Monthly Medical Treatment Incidence Rates Data - Primary Plant ....266

Table 54 Comparison prior and post work stoppage periods - Primary Plant .......................268

Table 55 Summary of Quarterly Medical Treatment Incidence Rates Data -

Finishing Plant\#1

Table 56 Summary of Monthly Medical Treatment Incidence Rates Data -

Finishing Plant \#1

Table 57 Comparison Prior and Post Work Stoppage Periods - Finishing Plant \#1

Table 58 Summary of Quarterly Medical Treatment Incidence Rates Data -

Finishing Plant\#2

Table 59 Summary of Monthly Medical Treatment Incidence Rates Data -

Finishing Plant\#2

Table 60 Comparison Prior and Post Work Stoppage Periods - Finishing Plant \#2 _..............295

Table 61 Summary of Quarterly Medical Treatment Incidence Rates Data -

Finishing Plant \#3 .298

Table 62 Summary of Monthly Medical Treatment Incidence Rates Data -

Finishing Plant \#3

Table 63 Comparison Prior and Post Work Stoppage Periods - Finishing Plant \#3 ...............309

Table 64 Rates of Change in OSHA Recordable Incidents and Employee Numbers

Table 65 Quarterly Summary of Highest Incidence Rates within One Year of the

Work Stoppage.

Table 66 Monthly Summary of Highest Incidence Rates within One Year of the 
Work Stoppage.

Table 67 OSHA Recordable Incidence Rates for Nine Months Prior and Subsequent to the Work Stoppage.

Table 68 Lost Work Day Incidence Rates for Nine Months Prior and Subsequent to the Work Stoppage.

Table 69 Transitional Incidence Rates for Nine Months Prior and Subsequent to the Work Stoppage.

Table 70 Medical Treatment Incidence Rates for Nine Months Prior and Subsequent to the Work Stoppage.

Table 71 OSHA Recordable Incidence Rates for the First 24 Months and Last 24 Months

of the Research.

Table 72 Lost Work Day Incidence Rates for the First 24 Months and Last 24 Months of the Research

Table 73 Transitional Incidence Rates for the First 24 Months and Last 24 Months of the Research

Table 74 Medical Treatment Incidence Rates for the First 24 Months and Last 24 Months of the Research

Table 75 OSHA Recordable Incidence Rates for 33 Months Prior and Subsequent to Work Stoppage.

Table 76 Lost Work Day Incidence Rates for 33 Months Prior and Subsequent to Work Stoppage.

Table 77 Transitional Incidence Rates for 33 Months Prior and Subsequent to Work Stoppage .324

Table 78 Medical Treatment Incidence Rates for 33 Months Prior and Subsequent to Work Stoppage .324 


\section{CHAPTER I}

Introduction

\section{America's Transition to Organized Labor and Safety}

Throughout history new technologies have presented safety professionals with numerous challenges for keeping workers safe during their shift and sending them home healthy to their families. On the other hand, new technologies have also assisted safety professionals with the introduction of safe working conditions and procedures. In addition to technology, organized labor has played a critical role in development of safety practices and regulations. This study will examine the effects of organized labor's ultimate negotiation weapon, the strike, on an organization's safety and production systems. A synopsis of the evolution of organized labor over the past two decades offers a perspective on how the strike has become the union's most notorious and effective negotiation tactic. The history of the industrial safety movement provides insight into regulations and agencies that have developed throughout the years. These agencies and their regulations have assisted in meeting the new challenges presented by innovations and inventions in industrial technology.

\section{$\underline{\text { A Changing Nation }}$}

Most Americans, approximately 80\%, were self-employed as farmers and merchants during the early 1800s (Barbash, Lampman, \& Levitan, 1983). The self-employed and rural nature of early America, partially explain the fact that as late as 1850 the nation had only one major steel mill (Petersen, 1989). The idea of large employers was foreign to most Americans during this time when tradespeople and craftspeople had small shops with small numbers of apprentices. Perhaps for this very reason, strikes were uncommon prior to 1850 and usually related to shorter working hours instead of unsafe or unhealthy working conditions (Marcum, 1978). The American work environment experienced drastic changes with the onset of the American Industrial Revolution in the 1850s. Generating profits and attaining production quotas became the primary concerns of managers, while worker safety was trivialized or ignored completely. Musacchio (1975) emphasized that the rapid industrial growth that took place over the next fifty years [during the industrial revolution] led to an exploitation of natural and human 
resources. Men, women, and children operated machinery in factories up to 16 hours a day for wages as small as one dollar a week (Kalis, 1975).

These conditions continued to deteriorate when in the midst of the Industrial Revolution the nation found itself in the middle of a devastating Civil War (1861-1865). Holley and Jennings (1991) stated that demand for supplies to fight the war "refined and encouraged massproduction techniques, concentrating large numbers of semiskilled and unskilled employees under one factory roof' (p. 26). Initially, the general public did not recognize the magnitude of the industrial safety problem, because there were only 1.5 million industrial workers in the country (Mussachio, 1975; Petersen, 1989). However, by 1870 self-employed individuals made up only $33 \%$ of the American workforce with the remaining $67 \%$ working mostly in industrial settings (Barbash, et al., 1983). This presented a situation that created new safety concerns for workers and consequently attracted organized labor to the coal mines and railroads, which were the leading industries at that time (Holley \& Jennings, 1991; Musacchio 1975). The individual workers remained primarily responsible for their own safety, however they now had a strong ally, organized labor, assisting in their battle for a safer place to work.

\section{Organized Labor}

Organized labor had its roots in the many small guilds and joint associations of employers and craftspeople that existed since 1800. Other than the occasional strike for higher wages, these guilds generally pressed for concerns that were mutually beneficial to employees and employers, such as professional standards (Holley \& Jennings, 1991; Kalis, 1975). In 1869 the first national labor organization, the Knights of Labor (KOL) was founded by Uriah S. Stephens. The goals of the KOL were to change existing labor-management relationships so that the depersonalized and specialized aspects of mass production could be avoided and secondly to attain moral betterment for employees and society (Livesay, 1978; Holley \& Jennings, 1991). In order to protect its members from being discharged by employers for participating in a labor organization, the KOL maintained secrecy until 1882 (Holley \& Jennings, 1991). Miernyk (1973) contends that the slow growth of the KOL was in part the result of potential members not believing in the necessity of taking a vow of secrecy. 
At the same time that labor was organizing on a national level, legislation was also being developed to improve working conditions and protect workers. Pursuant to persistent lobbying from anthracite miners, the Pennsylvania legislature passed a mine safety act in 1869, which required safer working conditions and better ventilation in mines. It also authorized a mine inspector, but he had authority only in Schuykill County, Pennsylvania (Musacchio, 1975; Petersen, 1989). Later that year a mine explosion in Luzerne County, Pennsylvania killed 109 miners. According to Petersen (1989), this explosion resulted in lawmakers extending the inspector's authority to all anthracite producing counties. Almost 20 years later, Congress passed laws requiring all coal mines to be inspected for hazardous conditions (Petersen, 1989).

The transition to an industrial nation, and disasters such as the Luzerne explosion, helped generate the steady growth of the KOL in the 1880s, despite its members' secrecy. The organization reached 100,000 members in 1885 and jumped sharply to 700,000 by 1886 (Holley \& Jennings, 1991; Miernyk, 1973; Musacchio, 1975). As stated by Miernyk (1973), one of the major reasons for this unprecedented growth of a labor organization was the successful strike by local assemblies against Jay Gould's railroads in 1885. This KOL orchestrated strike demonstrated to the public that organized labor could take on one of the most powerful financiers, and win. However, the goals described earlier, and its belief that technological advancement could be halted and possibly reversed, would eventually lead to the KOL's demise as an effective organization. (Holley \& Jennings, 1991).

As the KOL lost favor among the American workforce, the American Federation of Labor (AFL) was formed by Samuel Gompers in 1886. This new organization provided an alternative to KOL, with new ideas and tactics for operating in the increasingly mechanized industrial world (Livesay, 1978; Musacchio, 1975). The AFL represented a federation or organization that presented the opportunity for many national unions to pull their strengths while maintaining their separate union status. The AFL's major goal was to improve the material conditions of members, while recognizing the inevitability of mechanization (Livesay, 1978). The strongest tactics employed by the AFL for betterment of its members were strikes and boycotts (Livesay, 1978; Holley \& Jennings, 1991).

The 1892 Homestead Strike (Against Carnegie Steel) and the 1894 Pullman Strike (Against Railroads nationwide) were primarily in retaliation for wage cuts to AFL members 
(Livesay 1978; Holley \& Jennings, 1991). These incidents cost both the companies and employees economical and physical hardships. The companies decreased production, suffered property damage, and lost goodwill with the American public. During the strikes, bargaining unit employees lost wages, jobs, savings, and in some cases their lives (Livesay, 1978; Holley \& Jennings, 1991; Miernyk, 1973). On the other hand, the employees benefited financially and politically from the terms of the settlement agreements and thus the strike became an everpresent threat to management officials operating under questionable business practices or unsafe working conditions (Holley \& Jennings, 1991).

\section{Early Safety Activities}

In addition to the threat of labor strikes, managers in the late 1800s and early 1900s, were concerned with several laws passed by the legislature that required employers and managers to deal increasingly with the safety of workers (Marcum, 1978). For example, the Sherman Antitrust Law passed in 1890, gave the Federal government authority to rule on issues related to safety matters at firms that were engaged in interstate commerce. However, Marcum (1978) contended that these laws were avoided by many employers because the enforcement efforts were weak or nonexistent.

In 1907 the Russell Sage Foundation published the Pittsburgh Survey, which focused on unsafe working conditions. Figures from this survey included 526 on-the-job fatalities and 500 seriously and permanently disabled workers in a single year in Allegheny County, Pennsylvania (Sheridan, 1975). The fact that the survey was limited to the greater Pittsburgh area makes the results even more dramatic. The flurry of safety legislation that would follow this survey was unprecedented. As reported by Sheridan the most notable developments over the next 10 years were:

1908 Nation's first workmen's compensation law covering Federal employees is enacted by Congress.

1909 U.S. Bureau of Labor publishes its findings on the incidence of phossy-jaw among workers in match plants. 
1910

U.S. Bureau of Mines was established.

1911 New York passes the first State workmen's compensation law.

1911 The American Society of Safety Engineers is established.

1912 U.S. Public Health Service expands to include a division of occupational health.

1913 U.S. Department of Labor is established.

1913 National Safety Council is established. 1916 American Occupational Medical Association is chartered. (1975, p. 67)

One of the most significant developments of the time was the adoption of some variation of workers' compensation system by many states. Forman stated that:

By 1921, 46 states had enacted workers' compensation laws. Two years later, the National Council on Compensation Insurance was founded and functioned as a rate-making and rate-administering body for all classes of carriers writing workers' compensation insurance. The cost of work accidents was recognized as a cost of doing business. (1975, p. 72)

To defray some of the cost of doing business, technology developed to protect soldiers who fought in World War I was being adapted to protect the workers of the early 1900s. In 1919 E.W. Bullard designed the first protective safety cap for industrial use. This heavy and somewhat awkward form of head protection was refined over the next few years in order to 
develop a comfortable and effective safety helmet for workers (Forman, 1975). Surplus gas masks were converted into the first personal protective respirators used in an industrial setting. Unfortunately, these surplus masks proved to be unreliable and workers were still losing their lives from poisonings. The Bureau of Mines and the National Safety Council began jointly testing all masks to eliminate poor quality masks. In 1922, the Bureau of mines adopted a dust sampling device called the Impinger as the standard method for taking dust samples (Forman, 1975; Petersen, 1989). Also, in the 1920s the industrial first aid kit, which was adapted from war time safety kits was placed into service (Petersen, 1989).

In the late 1920s the American Engineering Standards Committee (AESC), which was founded in 1918, became known as the American Standards Association. This association would later become the American National Standards Institute (ANSI) (Forman, 1975). At the time that it shed its committee status and became an association, 193 standards regulating occupational safety and health had been approved and 160 were in the works (Petersen, 1989).

\section{$\underline{\text { Labor Strikes }}$}

These developments in safety technology and the institution of standards regulating safety and health were not enough to persuade workers that management was interested in their well-being. The period between World War I and World War II involved an increase in union membership and an unprecedented number of strikes. With an increase of almost one million members between 1917 and 1919 the AFL surpassed the three million members plateau (Holley \& Jennings, 1991). In 1919, over 3,600 strikes involving greater than 4 million workers occurred in the U.S., which had led the world in labor stoppages since 1870 (Zieger, 1994). Of the many industries that experienced strikes by AFL membership in 1919, the steel industry was hardest hit when over 367,000 employees walked off the job in 70 major cities (Holley \& Jennings, 1991; Zieger, 1994). Internal union difficulties, decentralized union leadership, poor financial resources, and successful anti-union tactics employed by companies lead to a victory for management in most of these strikes (Livesay, 1978; Holley \& Jennings, 1991; Miernyk, 1973). Also in 1919, the coal industry was almost paralyzed by a strike that did not end until President Wilson persuaded the miners to accept a temporary wage increase and allow the newly 
appointed Bituminous Coal Commission to rule on other issues. This would be the last largescale victory that unions would have for several years (Holley \& Jennings, 1991).

The 1920s and early 1930s witnessed mass decreases in union membership, which was precipitated by potential members' inability to forget actions taken by unions during recent violent strikes and aggressive employer counteractions to union organization (Livesay, 1978; Holley \& Jennings, 1991; Miernyk, 1973; Zieger, 1994). For instance, during the 1920s companies began competing for safety awards for working without a lost-time incident. In 1926, Carnegie Steel Co. boasted 2,600,000 worker-hours without a lost-time incident; Illinois Steel reported 3,000,000 worker-hours; and Clark Thread Co. over 10,000,000 worker-hours. These records were not the norm, because National Safety Council figures for 1926 showed 24,000 industrial fatalities and over 3,000,000 non-fatal personal injuries in industry, at an estimated cost to business of over one-billion dollars (Forman, 1975; Petersen, 1989).

While the safety movement progressed, occupational health lagged. For the most part, occupational diseases were not clearly understood or properly defined. Many occupational diseases were not specified under disease schedules nor could they meet the court's definition of a "traumatic" injury (Forman, 1975; Petersen, 1989).

Tremendous technology shifts, which occurred during and after World War I, reduced the need for highly skilled labor thus the labor force was becoming increasingly comprised of unskilled and semiskilled production workers. The ranks within the AFL were split as to whether this developing pool of industrial workers should be included in the same organization as the skilled workers (Holley \& Jennings, 1994; Miernyk, 1973; Zieger, 1994). At a 1935 convention AFL members voted not to accept the industrial workers into the ranks of their union. On November 9, 1935, the Committee of Industrial Organizations (CIO) was unofficially formed under the direction of John L. Lewis, the former president of the AFL s United Mine Workers Union (Holley \& Jennings, 1991; Zieger, 1994). The CIO s main objective was to organize the mass production industries. AFL leaders became distraught when they realized that industrial unionism was taking place within their organization. The committee was ordered to disband or leave the AFL. Lead by John L. Lewis the almost one million members left the AFL to form the Congress of Industrial Organizations (CIO), in 1938 (Holley \& Jennings, 1991; Zieger, 1994). 
The late 1930s was marked by an enormous upswing in union membership. Both the AFL and the fledgling CIO experienced significant additions to their ranks (Holley \& Jennings, 1991; Zieger, 1994). According to Holley and Jennings "The CIO affiliate unions had organized $75 \%$ of the steel industry, $70 \%$ of the automobile industry, $65 \%$ of the rubber industry, and about 1/3 of the maritime and textile industries" (1991, p. 46). Many of these increases were a direct result of the willingness of ethnic workers in these trades to become members of organized labor movements (Barbash, et al., 1983).

Perhaps the most significant reason for increased union membership during the late 1930s was the passage of the Wagner Act (The National Labor Relations Act) in 1935. This act established the National Labor Relations Board to define employer unfair labor practices and enforce the legal rights of employees to join unions (Holley and Jennings, 1991; Miernyk, 1973).

With growing numbers and strength, organized labor initiated an act of good faith in 1941 when it announced a no strike pledge to be in force throughout World War II. According to Holley and Jennings (1991), this pledge was short-lived, as labor strikes started occurring again with regularity during 1942 and increased yearly throughout the war. Zieger (1994) stated that these strikes which were mostly nonviolent tests of strength and endurance aimed at increasing wages, accounted for approximately one lost work day per year per employee during the 4 years of the war. Post war concerns of the unions added full employment to the reoccurring demand for higher wages (Holley and Jennings, 1991; Zieger, 1994). In the one year period following the end of the war, over 4,600 strikes involved 5 million workers and resulted in almost 120 million worker-days of idleness, affected almost every major industry (Holley and Jennings, 1991; Zieger, 1994).

Modern day strikes have mostly targeted individual companies and addressed various collective bargaining issues. The company in this study was affected by the longest strike in modern steel history, lasting 316 days from October 1, 1996 through August 16, 1997. The effects of this strike crossed many boundaries, including safety, production, and finance. The full extent of the impact that these effects had on the company's production and safety systems remains to be measured. 


\section{Statement of the Problem}

The problem of this research was to determine the effect of work stoppages on production levels and the frequency of safety related issues such as safety training, safety meetings, audits, inspections, and OSHA recordable injury/illness at a selected steel manufacturer with plants located in Ohio, Pennsylvania and West Virginia.

\section{Purposes of the Research}

The purposes of this research were to:

$1 \quad$ Provide steel manufacturer managers with quantitative safety data;

2 Provide management and members of the safety profession with an assessment of the relationship between work stoppages and safety training, audits, inspections, and OSHA recordable injury/illness at the selected steel manufacturer;

3 Assist management and the workforce in determining the relationship between work stoppages and safety related issues in order to assess any deficiencies that may arise relevant to the work stoppage.

4. To publish the results in safety and trade journals in an effort to disseminate the results to the external groups that would benefit most from this research.

\section{$\underline{\text { Research Hypotheses }}$}

Hypothesis I. It was hypothesized that at the .05 significance level, that production levels would remain constant during the study period.

Hypothesis II. It was hypothesized that at the .05 significance level, there would be no difference between the frequency of safety training, audits, inspections, and OSHA recordable injury/illness for monthly intervals during the period covering two years prior to and two years immediately following the work stoppage. 


\section{$\underline{\text { Assumptions }}$}

It was assumed that:

1 The data provided by the company was complete and accurate;

2 The period of time this research involved was adequate for establishment of identifiable patterns in the data;

3 The organization involved was representative of the norm in the steel industry.

\section{$\underline{\text { Limitations }}$}

Limitations of this research were:

1. This research was limited to data made available by the selected steel manufacturer;

2. Data were not acquired under controlled circumstances;

3. It was not possible to directly select, control, and manipulate the factors necessary to study the inherent cause- and-effect relationships.

\section{$\underline{\text { Procedures }}$}

The study used the following steps and procedures:

Received permission from Corporate safety director at the selected steel manufacturer to review OSHA recordable injury/illness records, training records, audit and inspection records, and related safety records.

Conducted literature searches in the following areas related to work stoppages, safety records, training, unions, and the history of industrial safety:

Databases:

Mountainlynx

NIOSHTIC

Ebscohost; and the following

Internet sites:

OSHA

$\mathrm{NIOSH}$

ANSI 


\section{USWA}

Individual corporations in the study.

Collected OSHA recordable injury/illness data from Corporate medical officers or appropriate safety staff by querying the medical database or analyzing the paper based recordkeeping system.

Collected training data by querying the safety database or examining the paper based recordkeeping system.

Analyzed safety records to determine the frequency and types of OSHA recordable injury/illness, safety training, safety meetings, audits, and inspections. These were analyzed for the entire period and by monthly intervals.

Pre- and post-work stoppage time periods were analyzed to determine if the frequency of the selected safety issues increased or decreased in anticipation of the work stoppage, or during the first six months/year after the strike when increased production levels were likely being stressed.

Statistical analyses were conducted to determine if a statistically significant relationship exists between the work stoppage and the chosen safety issues.

The hypothesis was accepted, or rejected, and findings and conclusions determined, based on the analysis of data.

Recommendations for further research were stated.

\section{Terminology}

Complete Work Stoppage: When for any reason the entire production operation is "ceased" for an "extended" period of time (i.e. major catastrophic event, strike etc.), where extended is defined as a period not less than 1 month. 
First aid: Any one-time treatment and subsequent observation of minor scratches, cuts, burns, splinters, and so forth, which do not ordinarily require medical care. Such treatment and observation are considered first aid even though provided by a physician or registered professional personnel. (Keller, 1993)

Lost work day cases: Cases which involve days away from work or days of restricted work activity, or both. Lost work days do not include the day of injury or onset of illness or any days on which the employee would no have worked even though able to work. (Keller, 1993)

Medical Treatment: Includes treatment of injuries administered by physicians, registered professional personnel, or lay persons (i.e., non-medical personnel). Medical treatment does not include first aid treatment. (Keller, 1993)

Occupational Illness: Of an employee is any abnormal condition or disorder, other than one resulting from an occupational injury, caused by exposure to environmental factors associated with employment. It includes acute and chronic illnesses or diseases, which may be caused by inhalation, absorption, ingestion, or direct contact. (OSHA 200).

Occupational Injury: An injury such as a cut, fracture, sprain, amputation, etc., which results from a work accident or from an exposure involving a single incident in the work environment. (OSHA 200).

OSHA Recordable Incidents: any event that results in:

- Death (must be recorded regardless of the length of time between the injury and death);

- One or more lost workdays;

- Restriction of work or motion;

- Loss of consciousness;

- Transfer to another job; or 
- Medical treatment (other than first aid). (Department of Labor, 1995, p.13)

Partial Work Stoppage: When for any reason one or more but not all major production lines are not operated for a period of time not less than 1 month. (Implicit in this definition is that "maintenance downturns" will not be included).

Work relationship: Established under the OSHA recordkeeping system when the injury or illness results from an event or exposure in the work environment. The work environment is primarily composed of: (1) The employer's premises, and (2) other locations where employees are engaged in work-related activities or are present as a condition of their employment (Keller, 1993). 


\section{CHAPTER II}

Review of Literature

Measurements of Work Stoppage Effects on Safety and Production Systems

\section{$\underline{\text { Introduction }}$}

This chapter begins with a brief description of the Occupational Safety and Health Act, Public Law 91-596, which was signed December 28, 1970. The visions, missions, and responsibilities of the Occupational Safety and Health Administration (OSHA) and the National Institute for Occupational Safety and Health (NIOSH), two agencies created by the OSHAct, are included as background material related to OSHA standards. Highlights from the employers and employees responsibilities under OSHA standards lead to definitions of occupational injuries and illnesses and discussion of the associated OSHA forms. Next, the chapter addresses issues related to measuring safety performance. After a discussion of quantitative safety measurement instruments, the chapter continues with effects of work stoppage on production systems.

\section{Occupational Safety and Health Act}

Irrespective of all the advances in workplace safety achieved by organized labor and employers, in 1970, job-related accidents in the U.S. resulted in more than 14,000 worker deaths, disabling injuries to another 2 million workers, and an estimated 300,000 new cases of occupational disease (U.S. Department of Labor, 1995). These statistics coupled with the associated economic burden of lost production, medical expenses, training costs, and the undeterminable human pain and suffering, led a bipartisan Congress to pass the Occupational Safety and Health Act, Public Law 91-596, in 1970 (Keller, 1993; U.S. Department of Labor, 1993). The first paragraph of the Act stated:

An Act to assure safe and healthful working conditions for working men and women; by authorizing enforcement of the standards developed under the Act; by assisting and encouraging the States in their efforts to assure safe and healthful working conditions; by providing research, information, 
education and training in the field of occupational safety and health; and for other purposes. (Bureau of National Affairs, Inc., 1971, p. 1)

To assist in reaching these goals and objectives the act created the Occupational Safety and Health Administration (OSHA) and the National Institute for Occupational Safety and Health (NIOSH). A brief description of each of these agencies' respective visions, missions, and responsibilities served as the foundation for understanding why analysis of OSHA recordable injuries/illnesses, required training conducted, audits and inspections was crucial in measuring the effectiveness of safety system performance.

\section{Occupational Safety and Health Administration (OSHA)}

Vision: OSHA's vision is to make America's workplaces the safest in the world. OSHA is striving to eliminate workplace injuries, illnesses, and deaths so that all of America's workers can return home safely every day. To realize this vision, workplace environments must be characterized by a genuine commitment to workplace safety and health shared by both employers and workers, and the necessary training, resources, and support systems must be in place to make this happen (U.S. Department of Labor, 1997).

Mission: As defined in its enabling legislation, P.L. 91-596, the Occupational Safety and Health Act of 1970, OSHA's mission is to "Assure so far as possible every working man and woman in the Nation safe and healthful working conditions." This mandate involves the application of a set of tools by OSHA (e.g., standards development, enforcement, compliance assistance) which enable employers to maintain safe and healthful workplaces (U.S. Department of Labor, 1997).

Responsibilities: According to the U.S. Department of Labor's booklet, All About OSHA, the Occupational Safety and Health Administration (OSHA) was created within the Department of Labor to : encourage employers and employees to implement safety and health programs aimed at reduction of workplace hazards; develop innovative ways 
of dealing with occupational safety and health problems through research; establish employee and employer responsibilities and rights dealing with better safety and health conditions; create a universal reporting and recordkeeping system for monitoring occupational injuries and illnesses; establish training programs for safety and health personnel; develop and effectively enforce mandatory safety and health standards; and encourage the development of state occupational safety and health programs (DOL, 1995).

\section{$\underline{\text { National Institute for Occupational Safety and Health (NIOSH) }}$}

Vision: Delivering on the Nation's promise: safety and health at work for all people through research and prevention (DHHS, 1997).

Mission: Provide national and world leadership to prevent work-related illness, injury, and death by gathering information, conducting scientific research, and translating the knowledge gained into products and services (DHHS, 1997).

Responsibilities: According to the NIOSH Strategic Plan 1997 - 2002 published by the U.S. Department of Health and Human Services NIOSH was formed under the OSHAct with the following responsibilities: determine workplace hazards; identify causes of occupational injuries and illnesses; recognize and develop ways of controlling hazards introduced by new technologies and work practices; train safety and health professionals in all aspects of safety; and recommend occupational safety and health standards to the proper authoritative agencies, such as OSHA (D HHS, 1997, pp.1-2)

\section{OSHA Standards}

Legally enforceable standards promulgated by OSHA "may require conditions, or the adoption or use of one or more practices, means, methods or processes reasonably necessary and appropriate to protect workers on the job" (DOL, 1995, p. 5). Employers are responsible for familiarizing themselves with OSHA standards that apply to the nature of their work. If personal protective equipment is necessary for performing a job 
or task, it is the employer's responsibility to ensure that each worker is provided with the equipment and trained in its proper use. Employees are responsible for actions and conduct, which may affect their own safety. Therefore, they need to comply with the rules and regulations that cover operations or procedures they perform during a normal workday. Employers can assist workers' compliance efforts by providing them with training related to performing their duties efficiently and safely (DOL, 1995).

Employers must follow the Act's general duty clause for instances when OSHA has not promulgated specific standards. The general duty clause of the Act states that: "Each employer shall furnish to each of his employees employment and a place of employment which is free from recognized hazards that are causing or are likely to cause death or serious physical harm to his employees" (OSHAct, Public Law 91-596, Sec. 5(a) (1)).

\section{OSHA Required Recordkeeping and Reporting}

Occupational injuries and illnesses had not been systematically recorded or monitored prior to institution of the OSHAct of 1970. After the OSHAct was signed into Law, the Occupational Safety and Health Administration became the agency responsible for centralized nationwide collection of consistent information regarding occupational health and safety problems, which include occupational injuries and illnesses.

An occupational injury is any injury such as a cut, fracture, sprain or amputation that results from a work-related accident or from exposure involving a single incident in the work environment. An occupational illness is any abnormal condition or disorder, other than one resulting from an occupational injury, caused by exposure to environmental factors associated with employment. Included are acute and chronic illnesses or diseases, which may be caused by inhalation, absorption, ingestion or direct contact with toxic substances or harmful agents (DOL, 1995, pp. 1213).

All occupational illnesses must be recorded regardless of severity. All occupational injuries must be recorded if they result in:

- Death (must be recorded regardless of the length of time 
between the injury and death);

- One or more lost workdays;

- Restriction of work or motion;

- Loss of consciousness;

- Transfer to another job; or

- Medical treatment (other than first aid) (DOL, 1995, p. 13).

\section{$\underline{\text { Injury and Illness Records }}$}

The only two injury and illness reporting forms required by OSHA are the OSHA No. 200, Log and Summary of Occupational Injuries and Illnesses and the OSHA No. 101, Supplementary Record of Occupational Injuries and Illnesses. These two forms, which are maintained on a calendar year basis, must be on file for five years at the place of employment. At any time these forms are subject to inspection by OSHA, Health and Human Services (HHS), Bureau of Labor Statistics (BLS), or the designated state agency (DOL, 1995).

All work related injuries or illnesses that classify as recordable must be entered on the OSHA 200 Log as early as practicable, but never later than six working days after the employer learns of the injury or illness. If a worker dies in a work-related injury, or three or more employees are hospitalized as a result of a single workplace incident, the incident must be verbally reported to the nearest OSHA office within 8 hours of occurrence. If the incident is not immediately reportable, but it results in an employee fatality or the hospitalization of three or more employees within 30 days of the incident, the employer must verbally report the incident to the nearest OSHA office within 8 hours (U.S. Department of Labor, 1997).

The OSHA 101 form, which supplements OSHA 200 form, contains much more detail about each injury or illness. Completion of the OSHA 101 is also required within six working days from the time the employer learns of the work-related injury or illness (Blosser, 1992, DOL, 1995).

These two forms provide information, which provides the basis for determining the effectiveness of the involved company's safety system's performance (O'Brien, 1998; 
Shannon, Mayr, \& Haines, 1997). In some firms, the numbers recorded on these two OSHA forms provide the entire measurement of safety effectiveness (O'Brien, 1998).

\section{Measuring Work Stoppage Effects on Safety Performance}

Thirty years after the Act was first enacted, employers were experiencing a continuously changing work environment which required increased levels of regulations, training, audits, inspections and recordkeeping to assure a safe and healthful workplace (Keller, 1993). Several articles have attempted to provide assessments of these safety instruments' effectiveness (O’Brien, 1998; Shannon, Mayr, \& Haines, 1997; Zahlis, 1995).

In a 1998 study, O'Brien asserted that unlike other aspects of a business, safety is routinely measured by a single number -- Occupational Safety and Health Administration (OSHA) recordable injury/illness. O'Brien stated that these numbers alone can be misleading and suggested that measuring OSHA recordable frequencies is merely the place to start measuring safety performance. Combining results-oriented metrics such as OSHA recordables, lost-time accidents and severity rates provided a more valuable measurement instrument for internal and external safety measurement (O'Brien, 1998; Shannon, Mayr, \& Haines, 1997). The value of these instruments is apparent when comparing an organization's performance to that of another organization in the same or differing industry. The criteria used for determining OSHA recordable injury/illness are the same for all industries in the United States. As Blosser stated in the Primer on Occupational Safety and Health published by Bureau of National Affairs, Inc., (1992) an OSHA recordable injury/illness must be kept on record for a period of five years after the year to which they relate.

The frequency of OSHA recordables is a quantifiable number that can be evaluated for an individual organization compared between organizations or compared to a national average for the industry in question. A relatively new school of thought among safety management employs these quantitative instruments in conjunction with many less quantifiable measures of assessment, such as safety training, safety meetings, audits, inspections, recorded unsafe behaviors, and perception surveys (O'Brien; Zahlis, 1995; Petersen, 1998). The individual effectiveness of these instruments is difficult to 
determine, but the most common measure used for evaluation of safety programs is injury rate (Shannon, Mayr, \& Haines, 1997).

Data for OSHA recordable injury/illness is readily available because of recordkeeping regulation requirements. Likewise, training required by OSHA standards must also be recorded in order for it to be counted as having been conducted (Blosser, 1992). OSHA standards require that training be conducted in more than 100 areas aimed at reducing risk factors for injury and disease (Keller, 1993). In Petersen's 1989 text, he stated that for employers, the costs of not conducting OSHA required training is assessed in higher injury/illness rates and frequencies, higher worker's compensation rates and fines levied against the organization during an OSHA inspection. For employees, the costs of not receiving the training are on a more personal level and include debilitating injury, incapacitating illness or death (Petersen, 1989).

OSHA developed voluntary guidelines for required occupational safety and health training in order to alleviate some of the burden of conducting the instruction and disseminating the information that workers need to minimize the risk of injury or property damage (Keller, 1993). Because of the flexible nature of the guidelines, employers can develop training programs in many areas using the same fundamental template. OSHA designed the guidelines in a fashion that encourages the employer to customize each training program for maximum effectiveness (Keller, 1993). In addition to training, common proactive management instruments include audits and inspections, which are safety tools available for attempting to alleviate the costs of occupational injury and illness.

\section{$\underline{\text { Safety Audits and Inspections }}$}

Audits generally are a measure of performance conducted by upper and middle management. Periodic audits should be performed with greater frequency when changes occur to the organization's operations, workforce or governmental regulations (Sandler, 1997). The true value of an audit is the learning experience that it provides to all members of the audit team. Management and workers can use the information gathered through the audit to adapt and change safety concerns at all levels (Sandler, 1997). 
An approach growing in popularity, because of its increased effectiveness, is to have a team comprised of safety specialists and management to conduct an audit of a manager's department in order to present the manager with what needs improvement and suggested ways to make the improvements (Brauer, 1994). Caution must be exercised to keep this useful approach to auditing from becoming an instrument of blame or ridicule (Brauer, 1994; Sandler, 1997). Plant-wide or departmental audits are conducted as learning instruments that, as stated by Brauer (1994): "challenge existing policies, procedures, and practices and their underlying concepts and principles" (p.520). These improvement tools should examine current results and look for methods to improve future results.

Some questions that are typical of a safety audit include:

- Are written instructions for the operation in place?

- Are the instructions current: Has the process changed? Do engineering drawings reflect the modification? Have modifications been reviewed for process safety?

- Do the operators follow the written instructions?

- Is the equipment correct for the process?

- Are reactants handled and stored correctly?

- Are necessary items of personal protective equipment in the correct location?

- Is ventilation sufficient? (Brauer, 1994, p. 521).

Primary safety inspections, those intended to locate hazards, are the responsibility of the line supervisor (Petersen, 1989). Safety inspections are conducted as part of an ongoing proactive approach to accident prevention. General and detailed are two types of inspections conducted routinely by organizations practicing proactive or preventive safety management (Brauer, 1994).

General inspections are typically walk through events that do not target specific equipment or departments, but rather, consider a broad range of safety concerns (Brauer, 1994). Checklists are usually the tool of choice for conducting a general inspection. These checklists are most effective when they are tailored to the demands of each plant or 
department. Supervisors and employees should design these checklist instruments with the following goals in mind:

- To check equipment machines, devices, and tools to ensure that they conform to OSHA and company safety standards and practices.

- $\quad$ To check materials and chemicals used in laboratories and manufacturing processes to ensure that no uncontrolled and unmonitored health, fire, and/or explosion hazards have been created.

- To check on the adequacy and proper use of personal protective equipment, machine and equipment guards, and safety devices.

- To check within the work place such factors as illumination, ventilation, noise levels, radiation, the monitoring system for exposure to toxic materials, the periodic medical examination, the audiometric test procedures, and medical services.

- To check working surfaces, stairs, ramps, ladders, and fire protection equipment for compliance with applicable standards and safe practices.

- To give critical attention to sanitation, housekeeping, food handling, waste disposal, and materials storage (DeReamer, 1980, p. 244).

These same goals should be employed when developing detailed inspection instruments. In addition, items specific to the activity or equipment involved must be inCorporated to make a detailed inspection checklist effective (Brauer, 1994).

Note

Analysis of OSHA recordable injuries/illnesses, training completed, and audits and inspections conducted, was the starting point for determining the effect that the recent major work stoppage had on this organization. Several other items also were examined to determine the extent of the effect the work stoppage had on this organization's safety system. 


\section{Measuring Work Stoppage Effects on Production Systems}

Work stoppages directly effect productivity in many ways. Plants that manage to continue production during strikes often experience reductions in output per worker hour and material shortages (Flaherty, 1987). Flaherty stated that "immediately before or after a strike, productivity can be adversely affected by capacity-straining attempts to amass inventories" (p. 588). He contended that it was just as likely that the opposite result, production levels may push closer to the organization's optimum performance level, may occur.

In 1997, Business First - Columbus, reported that steel production in Ohio was down by more than 11 percent the first half of 1997, mostly as a direct result of a strike [Wheeling-Pittsburgh Steel, Corporation] that idled four Ohio plants. Because of this strike, Ohio Steel Data reported to Bureau of Labor Statistics (BLS) that, at Ohio's nine steel producing plants', production levels for the first half of 1997 were off by over 1 million tons when compared to the same period in 1996.

Kennan (1986), stated that the number of strikes tend to increase during expansionary phases of the economy. On the other hand, during periods when the economy is contracting, the number of strikes decreases. For 1998, the BLS reported that all measures of work stoppage activity, involving over 1,000 workers, increased compared to 1997 . The summary reported that the 34 major work stoppages, which originated in 1998, involved 387, 000 workers and resulted in 5.1 million days of idleness. The private sector was hardest hit with 30 of these work stoppages, while the remaining 4 were primarily state and local government events in the educational services area. McMurdy(1998) stated that:

The resurgence of union activity has come about for several reasons. Technology and free trade have contributed to an increasingly global focus in business strategy and economic policy. That trend has been reinforced by a recent rapid-fire round of cross-border mergers and acquisitions. Those have replaced familiar faces in business and brought renewed employee anxiety about job security. Confronted with the pace and magnitude of such seismic change, workers have sought comfort in unions (p. 37). 
With the resurgence of union activity in the American workplace, it is almost inevitable that more and more organizations will be directly affected by a major work stoppage. This research will provide an assessment of the relationship between work stoppages and frequency of training, audits, inspections, and injury/illness rates and frequencies prior to the work stoppage and immediately following the work stoppage. Production levels will also be analyzed to see what impact the work stoppage had on pre and postproduction levels. 


\section{CHAPTER III}

Methodology

\section{Statement of Problem}

The problem of this research was to determine the effect of work stoppages on production levels and the frequency of safety related issues such as safety training, safety meetings, audits, inspections, and OSHA recordable injury/illness at a selected steel manufacturer located in Ohio, Pennsylvania and West Virginia.

\section{$\underline{\text { Research Hypotheses }}$}

Hypothesis I. It was hypothesized that at the .05 significance level, that production levels would remain constant during the study period.

Hypothesis II. It was hypothesized that at the .05 significance level, there would be no difference between the frequency of safety training, audits, inspections, and OSHA recordable injury/illness for monthly intervals during the period covering two years prior to and two years immediately following the work stoppage.

\section{$\underline{\text { Population }}$}

The company being studied in this case has a long steel-making history. The company was formed from the merger of three small independent companies, including one that started operations as a cut nail producing plant in 1852. After the Civil War the demand for nails declined and this company diversified into production of steel sheets, galvanized roofing, tin plates and steel tubes. The second company started operations in 1875 as a producer of steel sheets and tin products. The third company founded in 1901, produced corrugated roofing, siding, and related products. These three companies merged in the 1960s to form the company that is being studied.

After experiencing initial success as an organization, the company went through a turbulent period that eventually resulted in company management filing for Chapter 11 bankruptcy in the mid 1980s. One of the concessions made by the bargaining unit, in 
order to assist the company with recovery from bankruptcy, involved the loss of over 600 union jobs.

Many of the remaining workers are second and third generation steel workers and have lived through good and bad times with the company both as workers and family members of workers. The recent major work stoppage was mostly the result of demands from the bargaining unit that the defined benefit pension plan monthly amounts be increased for current and future retirees. The work stoppage, which lasted for 316 days, ended with an increase in pension amounts awarded to past and future retirees. As a result, a large number of employees, approximately 1,000, decided to retire almost immediately after the work stoppage was resolved and the new contract was ratified. The bargaining unit, which has decreased through attrition over the years, currently consists of just under 4,000 workers. Both primary and finishing operations are performed by employees of the company in its plants, which are located throughout a tri-state area.

\section{$\underline{\text { Procedures }}$}

A literature search related to work stoppages, safety records, training, unions, and the history of industrial safety was conducted through the following means:

Databases:

Mountainlynx

NIOSHTIC

Ebscohost; and the following

Internet sites:

OSHA

$\mathrm{NIOSH}$

ANSI

USWA

Individual corporation in the study.

The results of the literature search were presented in Chapters I and II. The review revealed that OSHA recordable injuries and illnesses were the most universal method of measuring a company's safety performance. As such, the information contained on the 
required OSHA recordkeeping forms provided the foundation for the analysis presented in this document.

Permission was received from the Manager, Corporate Safety to review electronic and paper records related to the company's safety performance (See Appendix A). This review will take place over a period of several weeks. Databases and paper records were examined with the assistance of the company's medical officer. The electronic system provided information on an individual, departmental, and divisional level of occupational injury/illness, safety training, safety contacts, OSHA citations and audits and inspections conducted. Frequencies of these and other variables were analyzed for a two-year period prior to and a two-year period after the major work stoppage to determine the impact on safety and production systems resulting from the work stoppage.

In an effort to gauge the company's safety system performance prior to and after the work stoppage, the OSHA 200 logs and OSHA 101 summaries were examined for a period of two and one half years prior to and two and one half years following the work stoppage to determine the number of OSHA recordable injuries and illnesses recorded each month (approximately $30-40$ per month) during the study period. Any occupational illness must be recorded on the OSHA 200 and 101 forms as must any event that results in death: (must be recorded regardless of the length of time between the injury and death); one or more lost workdays; restriction of work or motion; loss of consciousness; transfer to another job; or medical treatment (other than first aid) (Department of Labor, 1995, p.13). Any codes, numbers, or names used to identify individual cases were not presented in this document. Specifics associated with individual cases were not the focus of this research, instead frequencies were reported in the aggregate. These frequencies were analyzed from monthly and annual perspectives.

Injury and illness frequencies represent only a portion of the overall safety system performance. Injury incidence rates were calculated according to BLS techniques which included the following formula:

(Sum of characteristic reported) X 200,000

Incidence rates $=\quad$ Sum of the number of hours worked 
Where incidence rates was calculated using OSHA recordable injuries without lost work days, lost work day incidents, illnesses, and fatalities as the variable "Sum of the characteristic reported". The BLS handbook of methods defined the 200,000 multiplier as being "the base of hours worked by 100 full-time employees in 1 year" [On-line] (U.S. Department of Labor, 1997, p74). The results of this stage of the analysis were compared with BLS numbers from the Annual Survey of Occupational Injuries and Illnesses. This gave an indication of whether the trends at this company were following the industry trends or if they were influenced by the work stoppage and its associated effects on the safety and production systems.

A period of two and one half years prior to the work stoppage was analyzed to determine if the frequency of the selected safety issues increased or decreased in anticipation of the work stoppage. Also a period of two and one half years after the work stoppage was analyzed to determine what the post work stoppage effects were on the selected safety issues.

Productivity changes were measured through a series of indices beginning with the simplest measure of production, steel output measured in tons divided by the number of employees. The second measure employed was steel output divided by the total number of employee hours. The third index consisted of dividing the index of output by the index of workers. The index of output is the ratio of current year output to base year output. The index of workers is the ratio of current year employment to base year employment. The last index used to measure productivity was derived by dividing the index of output by the index of employee hours. The index of employee hours is the ratio of current year employee hours to base year employee hours [On-line] (U.S. Department of Labor, 1997, pp. 103-109).

These quantitative analyses provided the basis for rejecting or "accepting" the null hypotheses. The relationship between work stoppages and safety related issues, as well as, any deficiencies or advances that may have arisen before, during, or after the work stoppage were presented in support of the rejection or "acceptance" of the null hypotheses. Conclusions were drawn from the research and specific benefits for the company's safety department, and broad based benefits for the safety profession were provided. Finally, recommendations for further research were stated. 


\section{CHAPTER IV}

Analysis of Data

The data that served as the basis for this research was obtained through site visits to the company's steel mills. A computerized safety records management system was queried to determine the frequencies of variables reported in this research. The data were analyzed on two levels, Corporate-wide statistics and individual plant level statistics. The individual plants included in the research were a primary plant and 3 finishing plants. Additionally, the data were analyzed on a monthly, quarterly and annual basis.

\section{$\underline{\text { Production Analysis }}$}

This research used four indices to determine the productivity of the company. Index 1 was steel output measured in tons divided by the number of workers. The second index was steel output divided by the total number of worker hours. Index 3 was calculated by determining the ratio of current year output per worker to base year output per worker. To maintain a proportional comparison for the partial years it was necessary to reduce the Index 3 base year amount by $25 \%$ for $1996,75 \%$ for 1997 , and $50 \%$ for 2000. The fourth index was calculated using the ratio of current year output per worker hour to base year output per worker hour. Table 1 illustrates the resulting indices using 1994 as the base year.

\section{Table 1}

$\underline{\text { Annual Production Analysis }}$

\begin{tabular}{|l|c|c|c|c|c|c|c|}
\hline \multicolumn{2}{|c|}{ Corporate-wide Productivity Measures } \\
\hline & 1994 & 1995 & $\begin{array}{c}1996 \\
\text { Jan.-Sept. }\end{array}$ & $\begin{array}{c}1997 \\
\text { Oct.-Dec. }\end{array}$ & 1998 & $\begin{array}{c}2000 \\
\text { Jan.-June }\end{array}$ \\
\hline Steel Output (Tons) & $2,270,000$ & $2,199,000$ & $1,781,894$ & 662,993 & $2,445,929$ & $2,435,586$ & $1,260,138$ \\
\hline Labor-workers & 4625 & 4598 & 4565 & 3100 & 3518 & 3668 & 3654 \\
\hline Labor-hours & $9,397,930$ & $9,103,945$ & $6,605,760$ & $1,648,328$ & $7,268,215$ & $7,380,320$ & $3,735,029$ \\
\hline Index1-Output/worker & & & & & & & 344.87 \\
\hline Index2- & 490.81 & 478.25 & 390.34 & 213.87 & 695.26 & 664.01 & 3 \\
\hline
\end{tabular}




\begin{tabular}{|l|c|c|c|c|c|c|c|}
\hline Output /worker hour & 0.241543 & 0.241544 & 0.269749 & 0.402222 & 0.336524 & 0.330011 & 0.337384 \\
\hline $\begin{array}{l}\text { Index3-(Worker) } \\
\text { Index1/Base year }\end{array}$ & 1.00 & 0.974410 & 1.063968 & 1.742996 & 1.416556 & 1.352886 & 1.405310 \\
Index1 & 1.00 & 1.000004 & 1.116774 & 1.66522 & 1.393226 & 1.366262 & 1.396787 \\
\hline $\begin{array}{l}\text { Index4-(Worker hour) } \\
\text { Index2/Base year } \\
\text { Index2 }\end{array}$ & & & & & & & \\
\hline
\end{tabular}

The output/worker can be misleading because it does not account for overtime worked. The output/worker hour index is more representative of the production function, because it factors in the number of overtime hours worked.

Compared to the base year, production per worker hour increased substantially between 1994 and 2000. The peak performance was in the last quarter of 1997, which was the first quarter after the end of the work stoppage. After the peak year, production leveled off again. This led to the assumption that a new base year should be selected. The first complete year after the end of the work stoppage would be the reasonable choice.

Converting the raw index into a ratio of indices created a more informative result, that measured the changes in the relationship between output and the hours used to produce the output. Comparisons between periods were demonstrated using the ratios of indices.

\section{Training Analysis}

Training data were only available electronically for 1999 and 2000. It was determined that previous years of data had been purged from the training database.

The intent of this research had been to determine the relationship between pre work stoppage periods and post work stoppage periods for various safety related issues. But because the pre work stoppage periods and half of the post work stoppage periods were inaccessible, the decision was made to forgo formal analysis of the training records.

Confidentiality concerns also prevented information from the injury database and the training database from being matched. For this reason it also was not possible to determine how recently the injured employee had been trained in the area related to preventing their injury. 


\section{$\underline{\text { Audits and Inspections Analysis }}$}

Recognizing that safety programs were already established and functioning, the corporation started to focus on risk management in 2000. Early in 2000 the focus was combining risk management and safety management.

Prior to the work stoppage, department supervisors conducted monthly checklist inspections. After the work stoppage, the checklist inspection form was changed to inCorporate questions that required the supervisors to provide written explanations of items on the checklist.

Additionally, the joint safety committee and the safety superintendents started conducting monthly walk-around inspections/audits after the work stoppage.

Access to the completed audits and inspections would have required visits to each department within the organization. Considering the state of corporate and labor relations at the time that this research was conducted, it was determined byu the corporation that it was not appropriate to conduct these visits. Therefore the focus of this research was conducted solely on OSHA recordable incidents and incidence rates.

\section{OSHA Recordable Analysis}

\section{Corporate Analysis of OSHA Recordable Incidents}

On a whole, the corporation experienced a total of 3499 OSHA recordable incidents during the five and one-half year operating period covered by this research. Table 2 is a summary of the annual incidents by plant and percent of plant total. Almost half, or $46 \%$, of the total OSHA recordable incidents occurred during the first two years of this study period. Additionally, the Primary Plant, which employs over $50 \%$ of the workers, accounted for $71 \%$ of the total corporate incidents. 
Table 2

$\underline{\text { Number and Percentage of Plant Total OSHA Recordable Incidents By Plant and Year }}$

\begin{tabular}{|c|c|c|c|c|c|c|c|c|c|c|}
\hline \multirow{2}{*}{ Year } & \multicolumn{2}{|c|}{ Corporate } & \multicolumn{2}{|c|}{$\begin{array}{l}\text { Primary } \\
\text { Plant }\end{array}$} & \multicolumn{2}{|c|}{$\begin{array}{l}\text { Finishing } \\
\text { Plant \#1 }\end{array}$} & \multicolumn{2}{|c|}{$\begin{array}{c}\text { Finishing } \\
\text { Plant \#2 }\end{array}$} & \multicolumn{2}{|c|}{$\begin{array}{l}\text { Finishing } \\
\text { Plant \#3 }\end{array}$} \\
\hline & Number & Percent & Number & Percent & Number & Percent & Number & Percent & Number & Percent \\
\hline 1994 & 850 & 24 & 591 & 24 & 152 & 33 & 40 & 17 & 67 & 21 \\
\hline 1995 & 760 & 22 & 502 & 20 & 131 & 29 & 66 & 28 & 61 & 19 \\
\hline $\begin{array}{l}1996 \\
\text { (Jan. - Sept.) }\end{array}$ & 515 & 15 & 366 & 15 & 65 & 14 & 48 & 21 & 36 & 11 \\
\hline $\begin{array}{l}1997 \\
\text { (Oct. - Dec.) }\end{array}$ & 130 & 4 & 100 & 4 & 12 & 3 & 5 & 2 & 13 & 4 \\
\hline 1998 & 619 & 18 & 460 & 18 & 52 & 11 & 32 & 14 & 75 & 23 \\
\hline 1999 & 422 & 12 & 314 & 13 & 27 & 6 & 30 & 13 & 51 & 16 \\
\hline $\begin{array}{l}2000 \\
\text { (Jan. - June) }\end{array}$ & 203 & 6 & 157 & 6 & 18 & 4 & 11 & 5 & 17 & 5 \\
\hline Total & 3499 & $101 *$ & 2490 & 100 & 457 & 100 & 232 & 100 & 320 & $99 *$ \\
\hline
\end{tabular}

* Percents do not sum to $100 \%$ because of rounding.

Note: 1996, 1997 and 2000 are partial years.

\section{$\underline{\text { Trend Analysis }}$}

Overall a decreasing trend was experienced, corporate-wide, for the OSHA recordable incidents. The 850 total recordable incidents in 1994 were more than double that of the 422 recorded in 1999, the last complete year in this study. Because of the duration of the work stoppage, only partial years of data were available for 1996 and 1997. The work stoppage involved the last quarter of 1996 through the third quarter of 1997. For trend analysis purposes, summing the corresponding quarters for the previous year and subsequent year and dividing by two, created an average that was used in the missing quarters. This allowed the data to be annualized and compared with the nonaffected years. For the year 2000, actual numbers were used to provide annualized data (See Figure 1). 


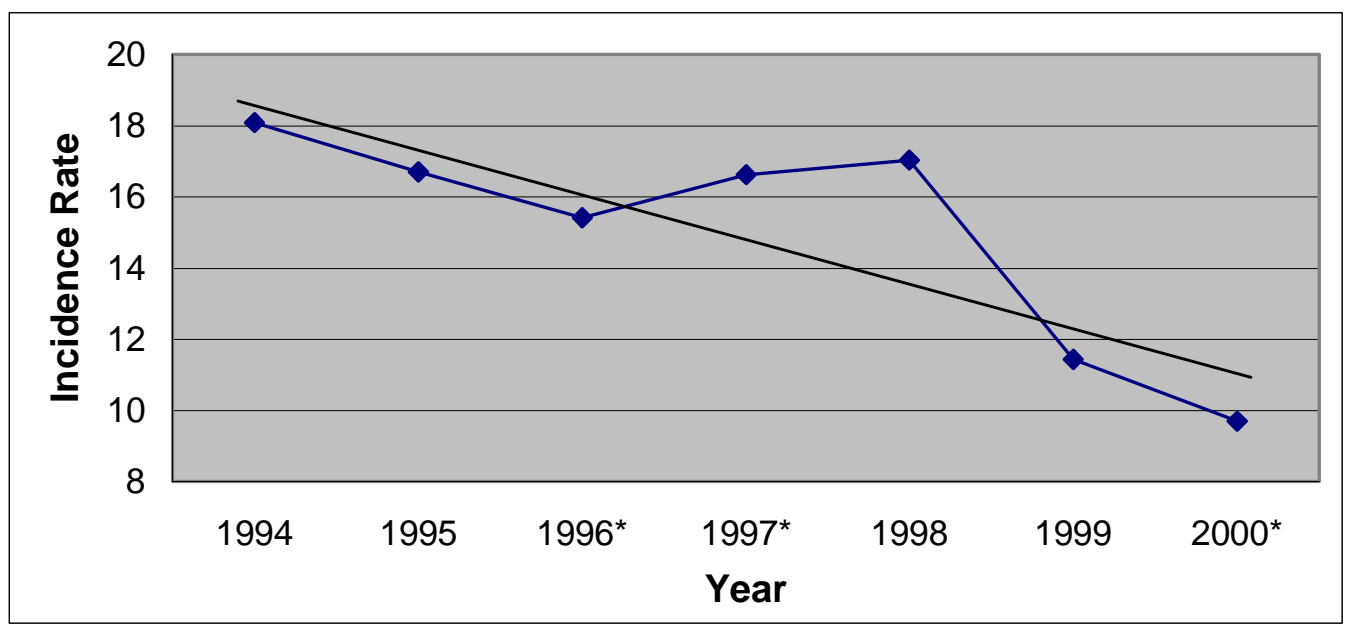

Figure 2. OSHA Recordable Incidence Rates - Annualized Numbers and Trend

\section{Comparison of OSHA Recordable Incidence Rates to Control}

The Bureau of Labor Statistics (BLS) nonfatal occupational injury and illness (OSHA Recordable) incidence rates per 100 full-time workers were used as the control for comparison of the Corporate incidence rates. Standard Industrial Classification (SIC) code 3300, primary metal industries, was the selected BLS category for comparison with the overall corporation incidence rates. As illustrated in Table 3, the Corporate OSHA recordable incidence rates were higher than the BLS industry incidence rates for the first five years of this study. In 1995, the Corporate incidence rate was only $1.2 \%$ higher than the BLS industry incidence rates. In 1998, the first full year of operations following the work stoppage, the Corporate rate was $21.4 \%$ higher than the BLS industry incidence rates. In 1999, the last available period of BLS data, the Corporate incidence rate was $12.6 \%$ lower than the BLS industry incidence rates. 
Table 3

OSHA Recordable Incidence Rates Per 100 Full-time Workers - (BLS) Compared to Corporate

\begin{tabular}{|l|l|l|l|}
\hline Year & $\begin{array}{l}\text { BLS } \\
\text { Incidence Rates }\end{array}$ & $\begin{array}{l}\text { Corporate } \\
\text { Incidence Rates }\end{array}$ & $\begin{array}{l}\text { Corporate Percent Higher (H) } \\
\text { or Lower (L) }\end{array}$ \\
\hline 1994 & 16.8 & 18.1 & $7.7 \%(\mathrm{H})$ \\
\hline 1995 & 16.5 & 16.7 & $1.2 \%(\mathrm{H})$ \\
\hline $1996($ Jan. - Sept.)* & 15.0 & 15.6 & $4.0 \%(\mathrm{H})$ \\
\hline $1997($ Oct. - Dec.)* & 15.0 & 15.8 & $5.3 \%(\mathrm{H})$ \\
\hline 1998 & 14.0 & 17.0 & $21.4 \%(\mathrm{H})$ \\
\hline 1999 & 12.9 & 11.4 & $12.6 \%(\mathrm{~L})$ \\
\hline 2000 (Jan. - June) $^{*}$ & Not Available & 9.9 & Not Available \\
\hline
\end{tabular}

*Numerator values were annualized using the method previously described

In Figure 3 the downward slope of the trend line indicates that the overall recordable incidence rate declined for the corporation. The steepness of the trend line illustrates how rapidly the organization's safety performance improved in terms of decreasing incidence rates for OSHA recordable incidents. The 1997 and 1998 incidence rates were above the trend line. In contrast to the overall decreasing trend, the incidence rate change for the period between 1996 and 1997 rose by almost 8\%, while the incidence rate change for the 1997 to 1998 period increased by almost two and one-half percent. The largest drop in the incidence rate, almost 33\%, was experienced between the 1998 and 1999 period. The second largest decrease was in the following period, which experienced a $15 \%$ decrease.

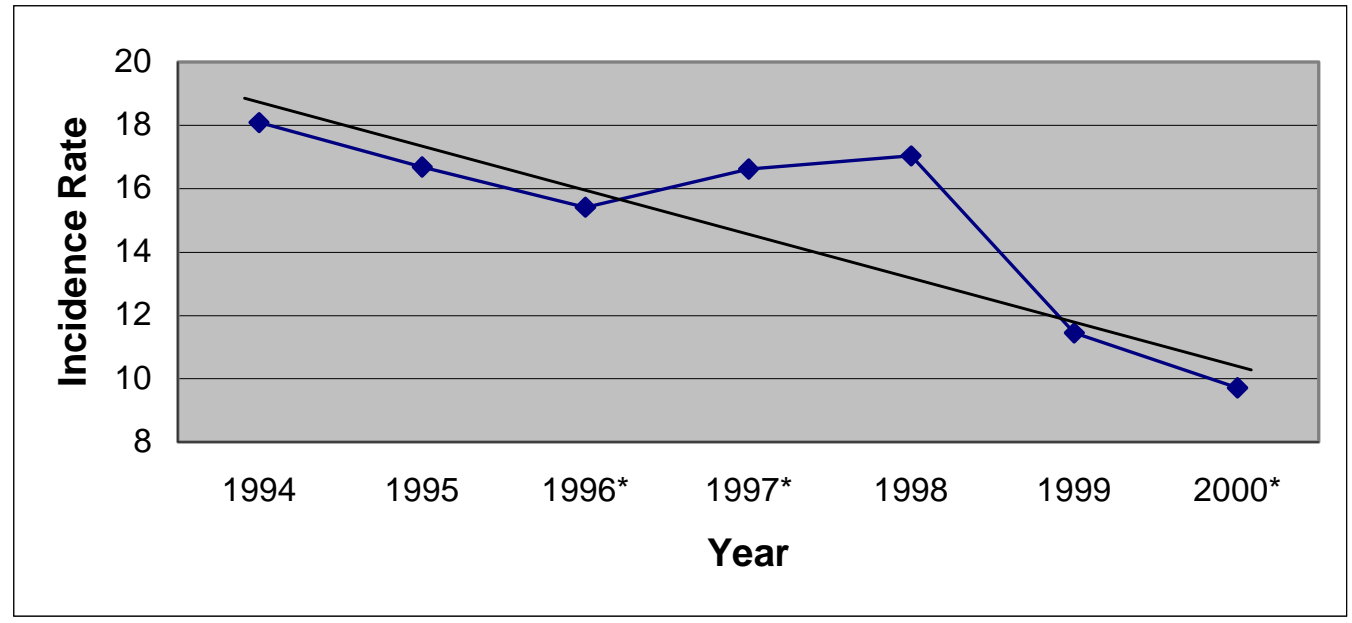

Figure 3. Corporate-wide OSHA Recordable Incidence Rates 


\section{Control Charts}

Control limits were established for the entire study period, on a quarterly basis and for monthly intervals. Safety and health professionals use control charts, which are based on confidence intervals, to report positive or negative changes in magnitude of incidence rate over successive, contiguous time periods. The upper control limits (UCL) and the lower control limits (LCL) are calculated at the .05 level of significance and therefore the probability of an incident rate exceeding the limits by chance alone is minimal.

\section{Quarterly Analysis of OSHA Recordable Data - Corporate}

Figure 4 presents the yearly first quarter Corporate-wide OSHA recordable incidence rates in a control chart. The UCL established for the first quarter incidence rate was only exceeded by the 1994 incidence rate. It was followed by several years of incidence rates within the control limits. The lowest first quarter incidence rate, which was recorded in 2000, was over $46 \%$ lower than the highest of this study period. Although within the control limits, the first quarter of 1998, the incidence rate for the period immediately following the work stoppage, was more than one-third higher than that of 1999 and more than one-quarter higher for the same period in the preceding year.

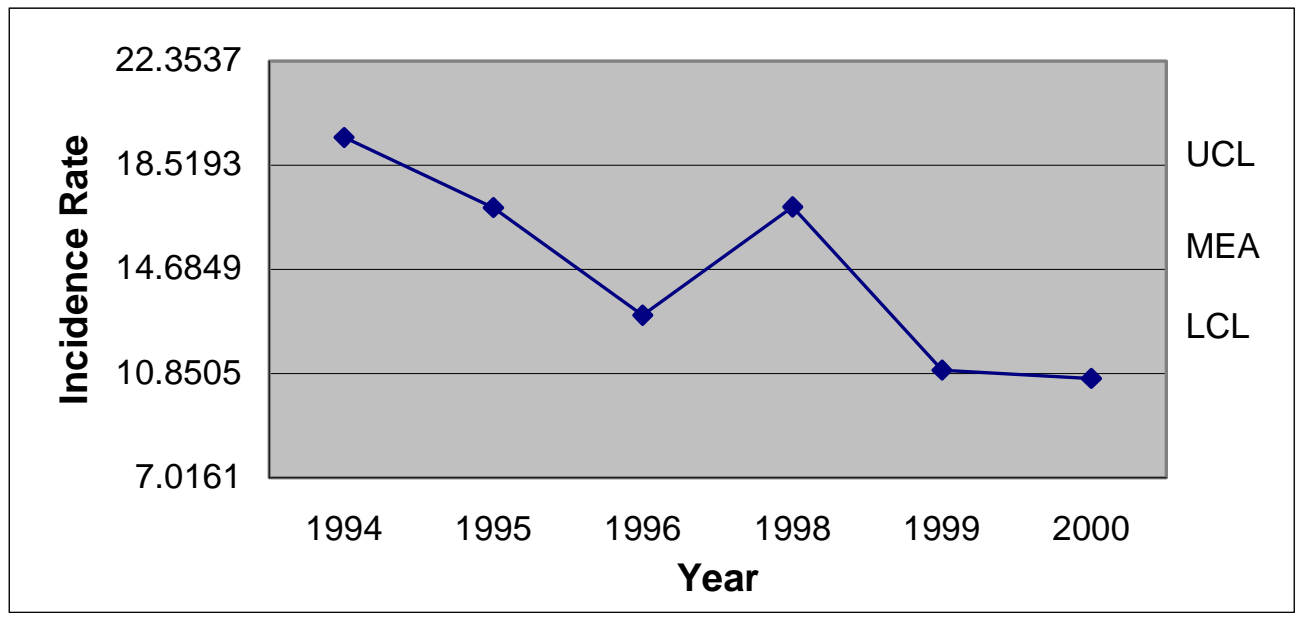

Note: No operations in first quarter of 1997

Figure 4. First Quarter 1994-2000 OSHA Recordable Incidence Rates - Corporate 
Annual second quarter Corporate-wide OSHA recordable incidence rates are represented in Figure 5. The only incidence rate that appeared above the UCL was for the period immediately following the work stoppage. The 1998 rate of 20.38969 was $8 \%$ above the next highest rate that occurred in the second quarter of 1994. Additionally it was almost $47 \%$ greater than the lowest second quarter rate, recorded in 1999. Two consecutive years, 1999 and 2000, experienced incidence rates below the LCL.

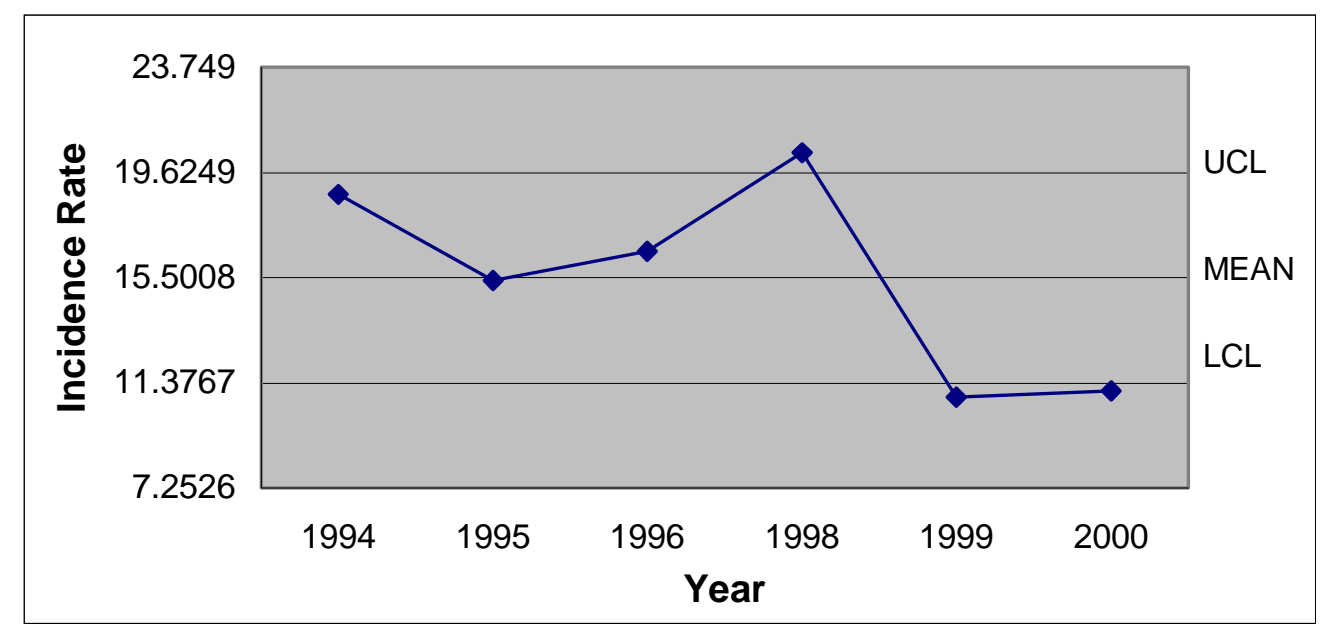

Note: No operations in second quarter of 1997.

Figure 5. Second Quarter 1994-2000 OSHA Recordable Incidence Rates - Corporate

Corporate-wide OSHA recordable incidence rates for the third quarters are presented in Figure 6. The only year that did not appear within the control limits was 1999, which was below the LCL. The 1999 rate of 12.63 was $39 \%$ lower than the highest third quarter rate, which was recorded in 1994. The third quarter of 1996, which was the last period before the work stoppage, was almost equal to the third quarter of 1998, the first full year immediately following the work stoppage. 


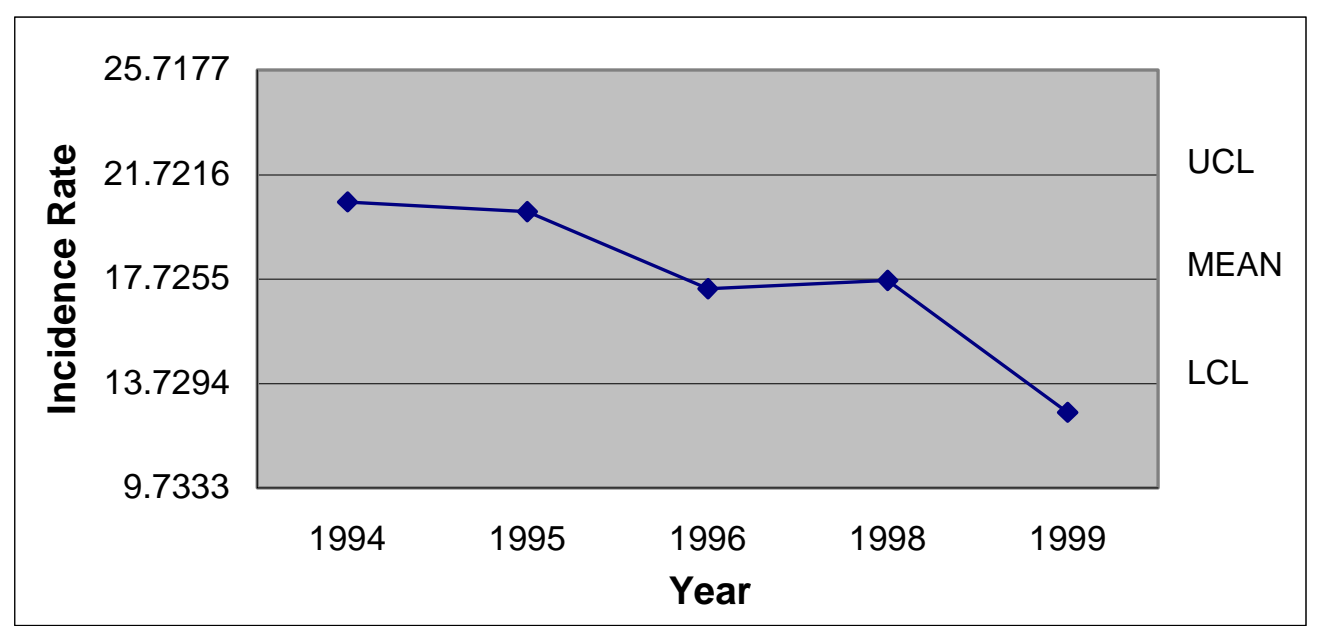

Note: No operations in third quarter 1997

Figure 6. Third Quarter 1994-1999 OSHA Recordable Incidence Rates - Corporate

Fourth quarter Corporate-wide OSHA recordable incidence rates are illustrated in Figure 7. Two incidence rates were found to be outside the control limits-one above the UCL and one below the LCL. The highest incidence rate, which occurred in 1997, the first period immediately following the work stoppage, was almost $30 \%$ higher than the lowest rate that was recorded in 1999.

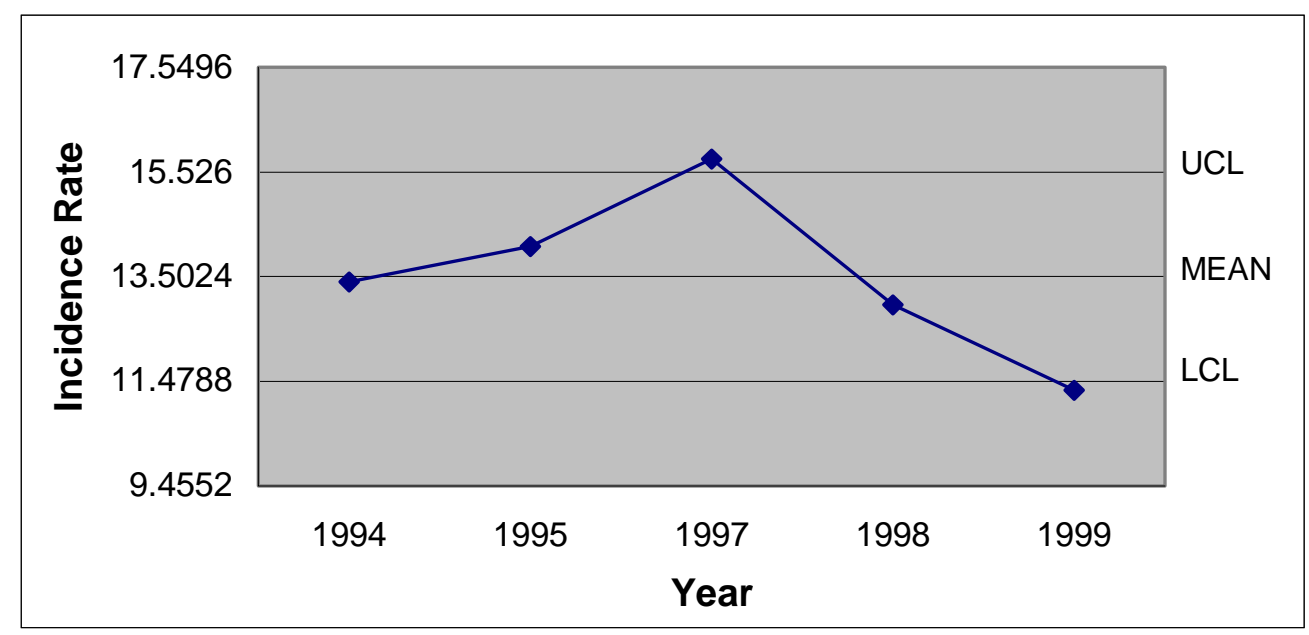

Note: No operations in fourth quarter of 1996.

Figure 7. Fourth Quarter 1994-1999 OSHA Recordable Incidence Rates - Corporate

Table 4 presents the quarterly results for OSHA recordable incidence rates based on control limits that were established for the entire period. UCL, LCL, mean, and 
standard deviation values are presented at the bottom of the table. Incidence rates that were outside of the control limits were indicated with an asterisk.

Table 4

Summary of Quarterly OSHA Recordable Incidence Rates Data - Corporate

\begin{tabular}{|l|l|l|l|l|}
\hline & $1^{\text {st }}$ Quarter & $2^{\text {nd }}$ Quarter & $3^{\text {rd }}$ Quarter & $4^{\text {th }}$ Quarter \\
\hline 1994 & $19.533^{*}$ & 18.773 & 20.679 & 13.396 \\
\hline 1995 & 16.960 & 15.404 & 20.305 & 14.082 \\
\hline 1996 & 12.986 & 16.542 & 17.346 & N/A \\
\hline 1997 & N/A & N/A & N/A & $15.774^{*}$ \\
\hline 1998 & 16.983 & $20.390^{*}$ & 17.662 & 12.953 \\
\hline 1999 & 10.974 & $10.823^{* *}$ & $12.635^{* *}$ & $11.307^{* *}$ \\
\hline 2000 & $10.672^{* *}$ & $11.073^{* *}$ & N/A & N/A \\
\hline UCL & 18.519 & 19.625 & 21.722 & 15.526 \\
\hline Mean & 14.685 & 15.501 & 17.726 & 13.502 \\
\hline LCL & 10.851 & 11.377 & 13.729 & 11.479 \\
\hline SD & 1.491 & 1.604 & 1.440 & 0.729 \\
\hline
\end{tabular}

*Greater than UCL

**Less than LCL

Seasonal Analysis of OSHA Recordable Data - Corporate

Seasonal indices were created through a series of calculations. First the quarterly individual incidence rate was divided by the quarterly average for the year. These indices were averaged by quarterly period over the appropriate years. The result was the quarterly seasonal index presented in Figure 8. The third quarter had the highest seasonal index, while the fourth quarter recorded the lowest seasonal index. The first and second quarters were close to 1.0 . 


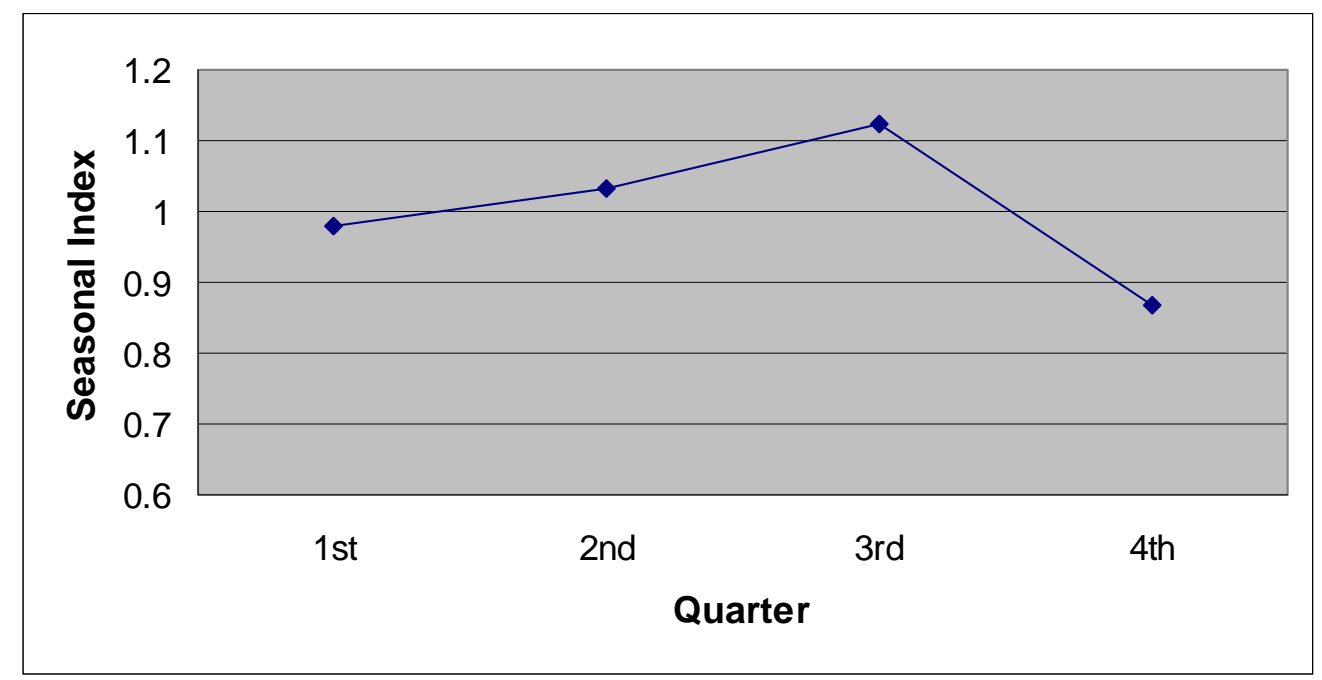

Figure 8. Quarterly Seasonal Index for OSHA Recordable Incidence Rates - Corporate

\section{Monthly Analysis of OSHA Recordable Data - Corporate}

The incidence rates for the month of January in each year 1994-2000 are presented in Figure 9. January 1994 experienced the highest incidence rate, which was $45 \%$ greater than the lowest January incidence rate recorded in 2000. Although the January 1998 incidence rate was within the control limits, it reversed the declining trend that was experienced prior to the work stoppage. The incidence rates for January 1999 and 2000 reestablished the declining trend that was interrupted by January 1998, which was the period immediately following the work stoppage.

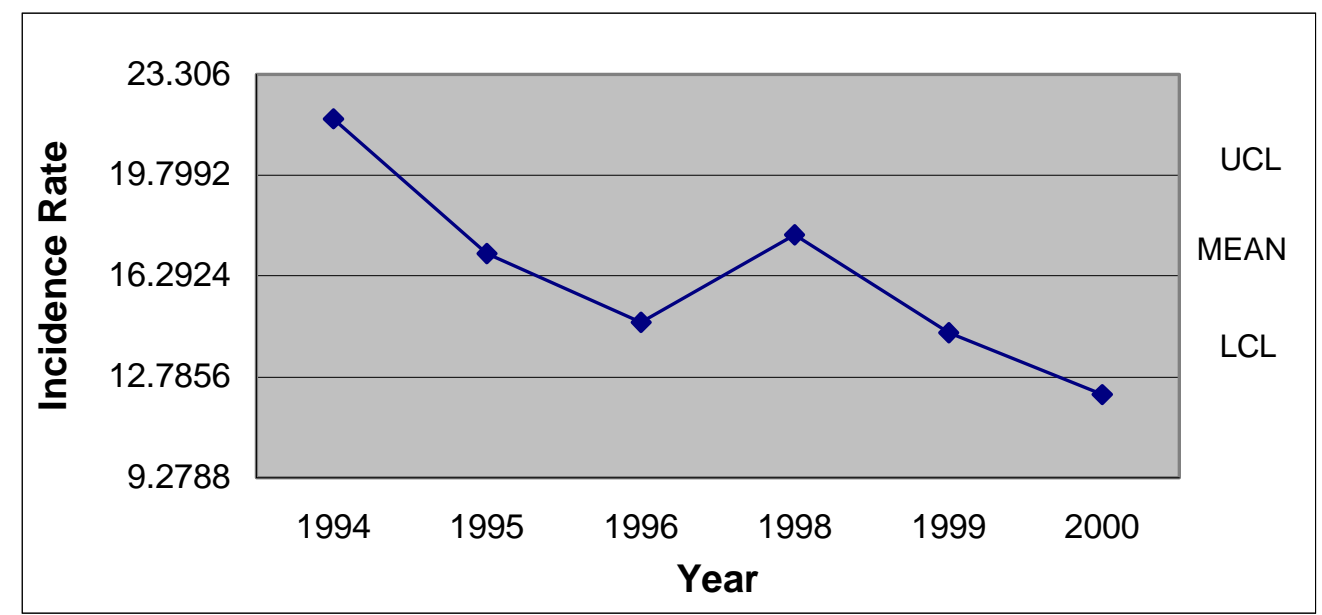

Note: No operations in January 1997.

Figure 9. January 1994-2000 OSHA Recordable Incidence Rates - Corporate 
Figure 10 illustrates the February incidence rates for each year of this research. The 21.78 incidence rate experienced in 1994 was over 60\% greater than the 1999 incidence rate, which was the lowest recorded in this study period. Again, the 1998 incidence rate was within the control limits but interrupted the declining trend that occurred prior to the work stoppage. The 1999 incidence rate that appeared below the LCL was followed by a $10 \%$ increase in the last year of the research.

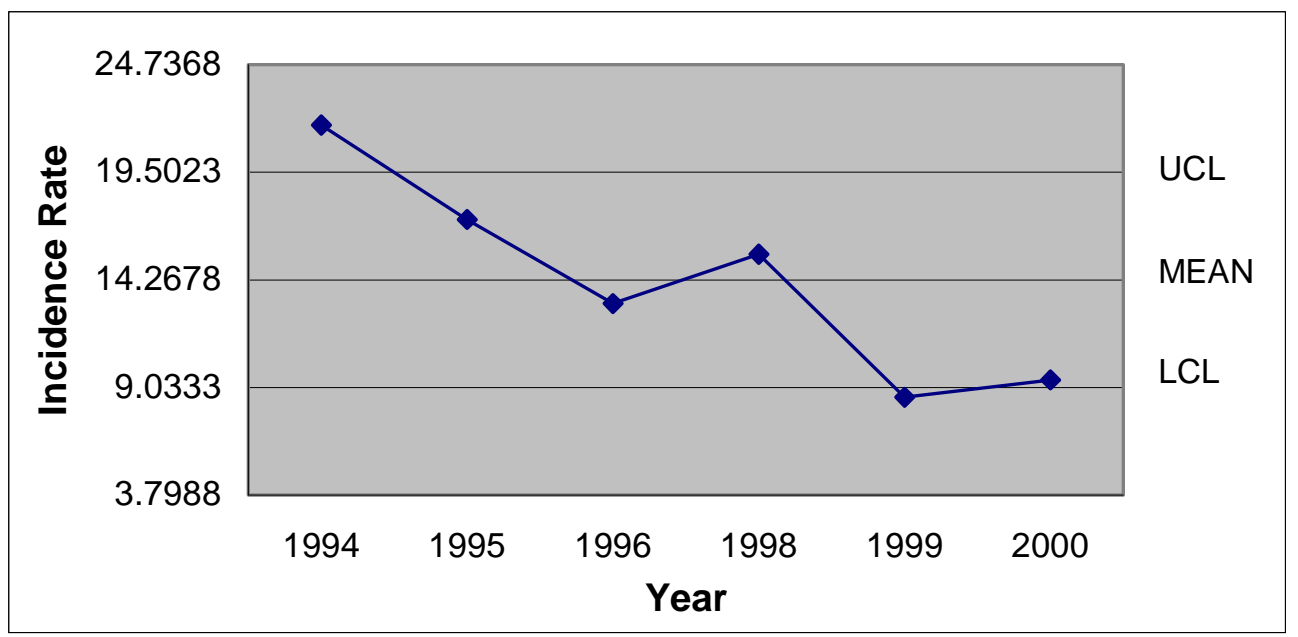

Note: No operations in February 1997.

Figure 10. February 1994-2000 OSHA Recordable Incidence Rates - Corporate

For the month of March, the 10\% increase in the incidence rate that occurred between 1994 and 1995 was followed by a decrease of one-third for the last pre work stoppage period. The first post work stoppage period was almost 60\% higher than March of 1996 and March of 1999 (See Figure 11). 


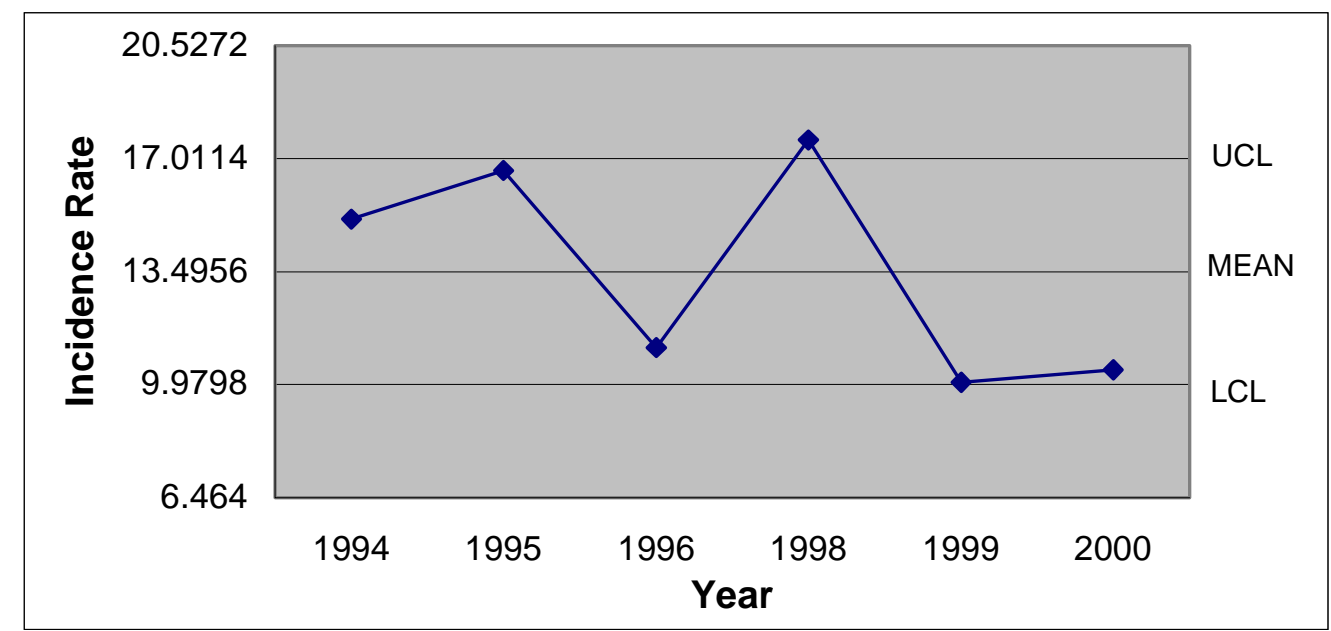

Note: No operations in March 1997.

Figure 11. March 1994-2000 OSHA Recordable Incidence Rates - Corporate

The month of April held almost constant for the first two years of the study. These years were followed by a 15\% increase in March of 1996 and an additional 19\% for the highest April incidence rate which occurred in 1998. The next year experienced a $37 \%$ drop in incidence rate and the last year an additional 13\% decrease (See Figure 12).

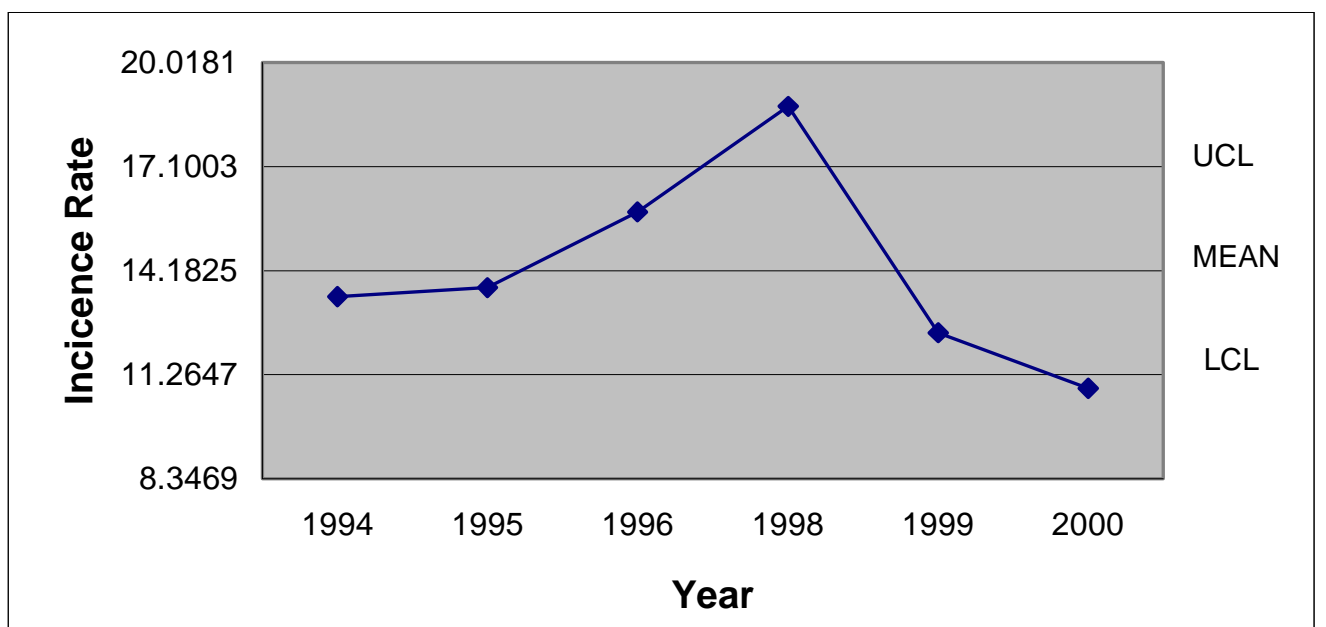

Note: No operations in April 1997.

Figure 12. April 1994-2000 OSHA Recordable Incidence Rates - Corporate

May incidence rates were the highest in 1998 and the lowest in 1999. The difference between these two periods was over $60 \%$. May of the last year was $15 \%$ 
greater than the 1999 low, but remained almost 25\% lower than the initial year of the research period (See Figure 13).

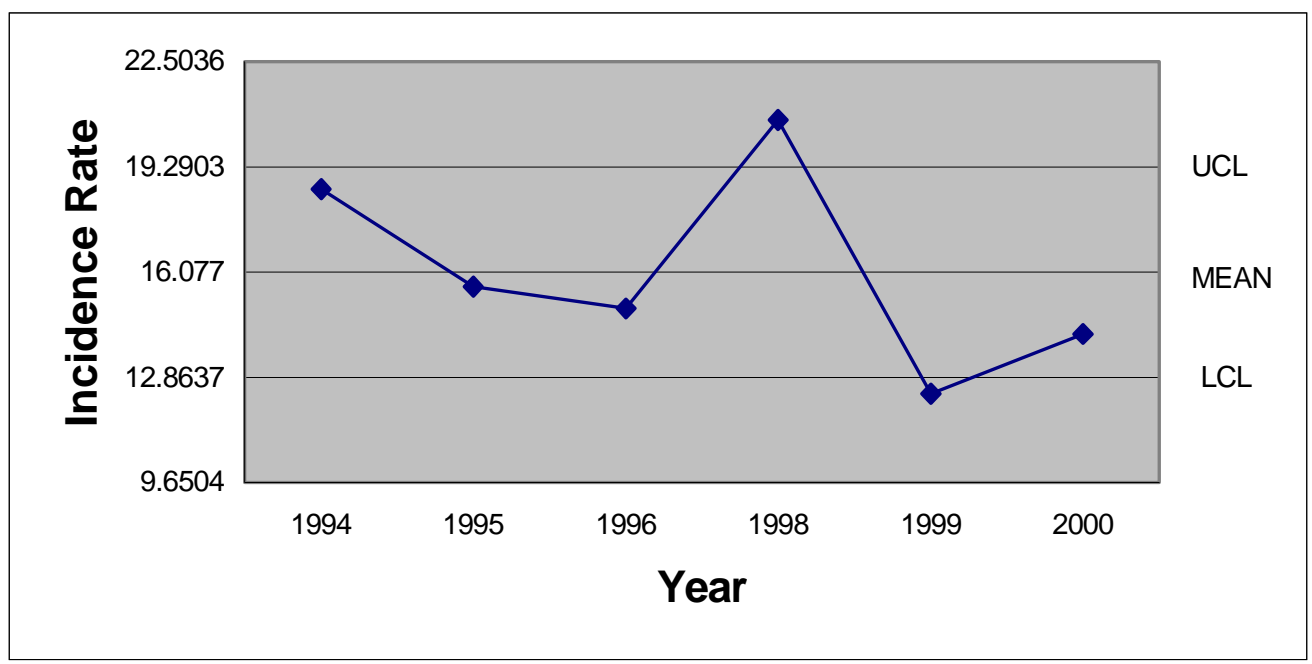

Note: No operations in May 1997.

Figure 13. May 1994-2000 OSHA Recordable Incidence Rates - Corporate

June of 1994 was above the UCL, while both June of 1999 and 2000 were below the LCL. The largest decrease between annual periods was a 65\% drop experienced between 1998 and 1999. Other than the high incidence rate in 1994, the next highest rates occurred in June of 1996 and 1998, the years with months of June closest to the work stoppage (Figure 14).

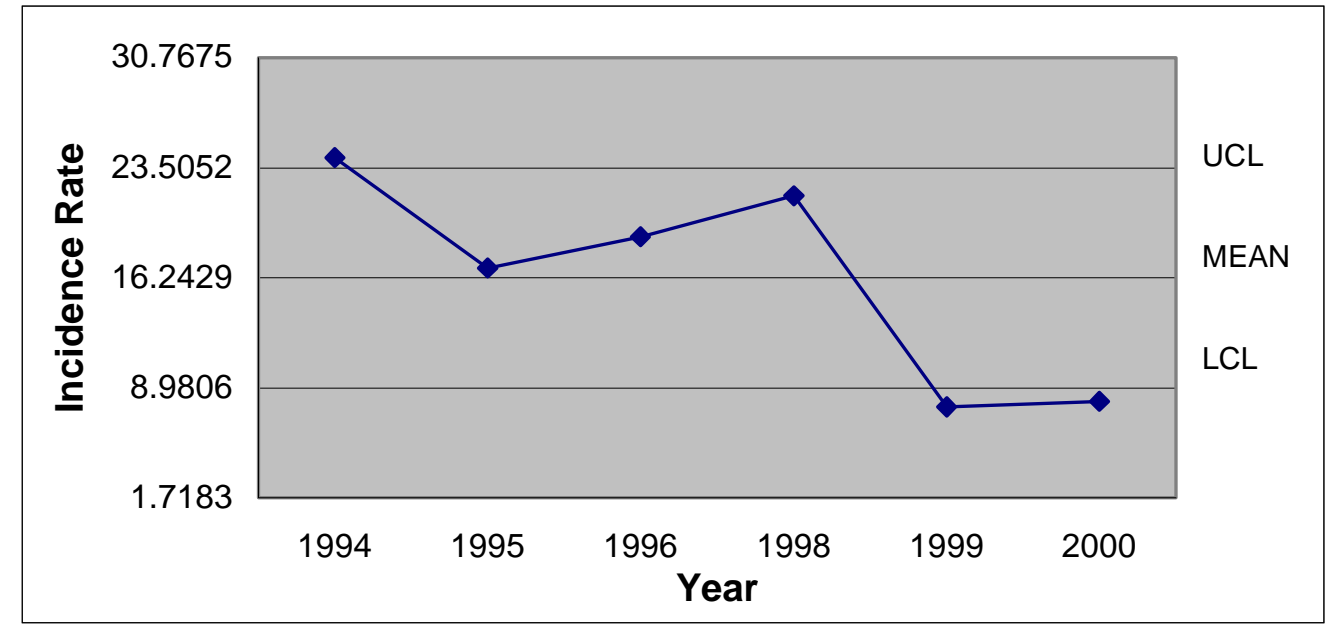

Note: No operations in June 1997.

Figure 14. June 1994-2000 OSHA Recordable Incidence Rates - Corporate 
Figure 15 shows that July of 1994 had the highest incidence rate for the five months of July in this study. July of 1999, the last month of July in this study, experienced the lowest incidence rate. The remaining years were clustered closely around the mean.

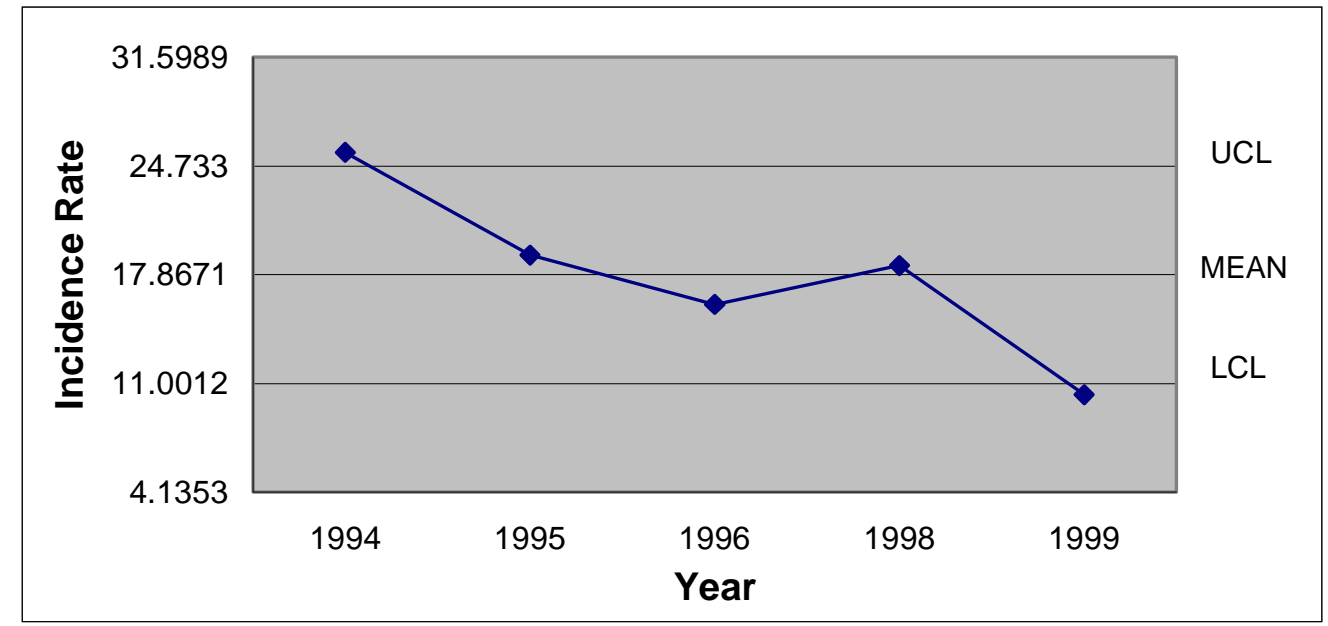

Note: No operations in July 1997.

Figure 15. July 1994-1999 OSHA Recordable Incidence Rates - Corporate

The highest recorded incidence rate for the month of August in this study occurred in 1995. This rate was $17 \%$ greater than the rate recorded in the previous year. The next year experienced the second lowest incidence rate for the month of August, a decrease of $30 \%$ from the 1995 rate. The August incidence rates closest in time to the work stoppage were both below the mean incidence rate (See Figure 16).

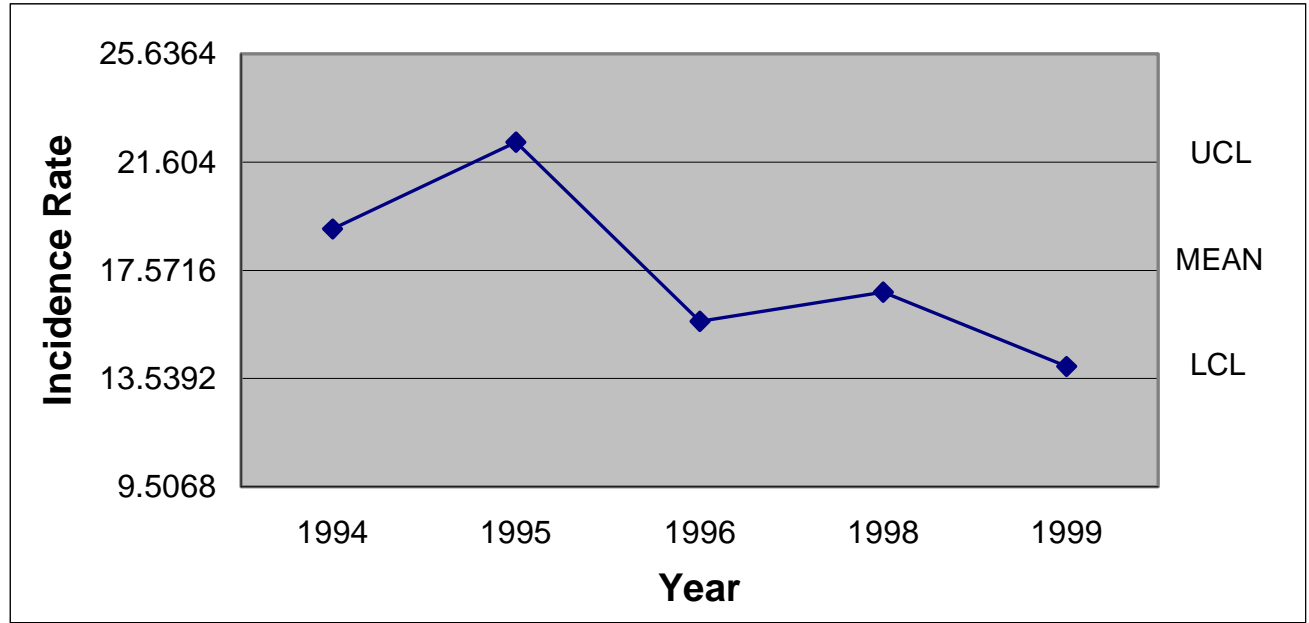

Note: No operations in August 1997.

Figure 16. August 1994-1999 OSHA Recordable Incidence Rates - Corporate 
September of 1996, the month immediately preceding the work stoppage, experienced an incidence rate almost 9\% greater than that of any other month of September in this research. For the month of September an increasing trend was experienced prior to the work stoppage and a decreasing trend followed the work stoppage (See Figure 17).

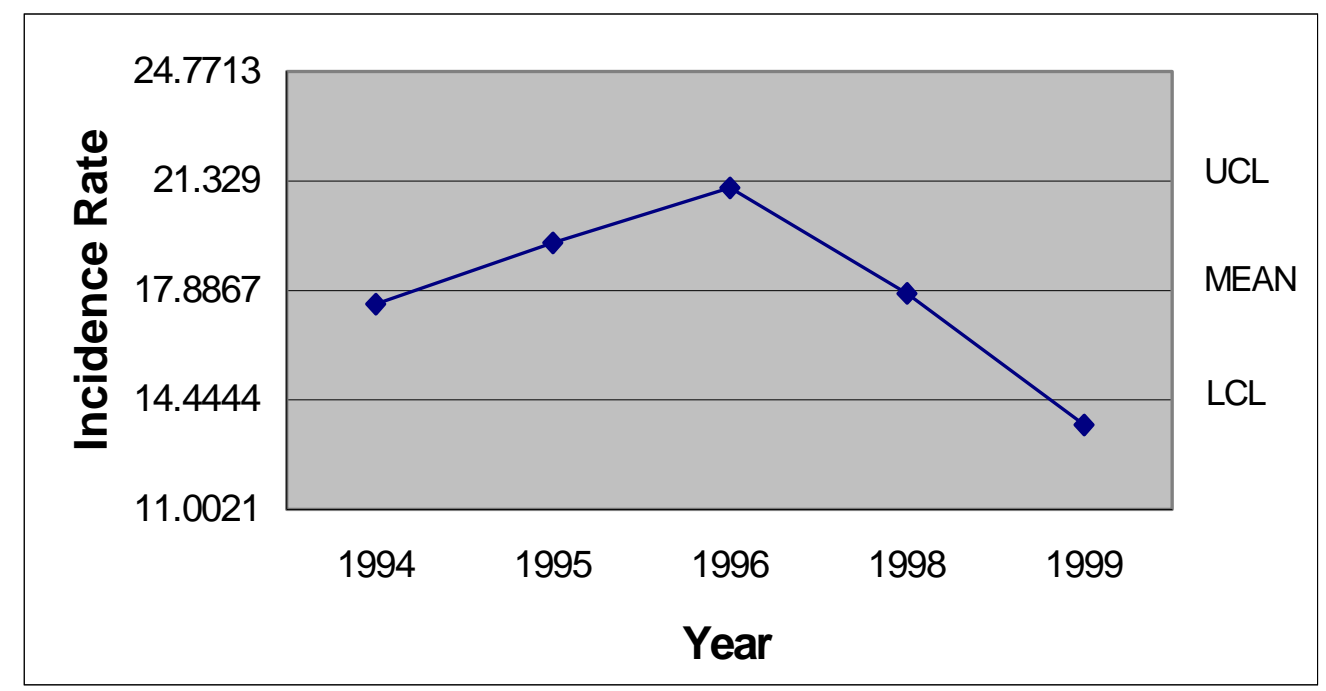

Note: No operations in September 1997

Figure 17. September 1994-1999 OSHA Recordable Incidence Rates - Corporate

October of 1997, the first month of work following the work stoppage, experienced an incidence rate higher than any other year of the research period. However, it was only 5\% greater than the October 1998 incidence rate. The October 1999 incidence rate was the only incidence rate to appear below the LCL (See Figure 18). 


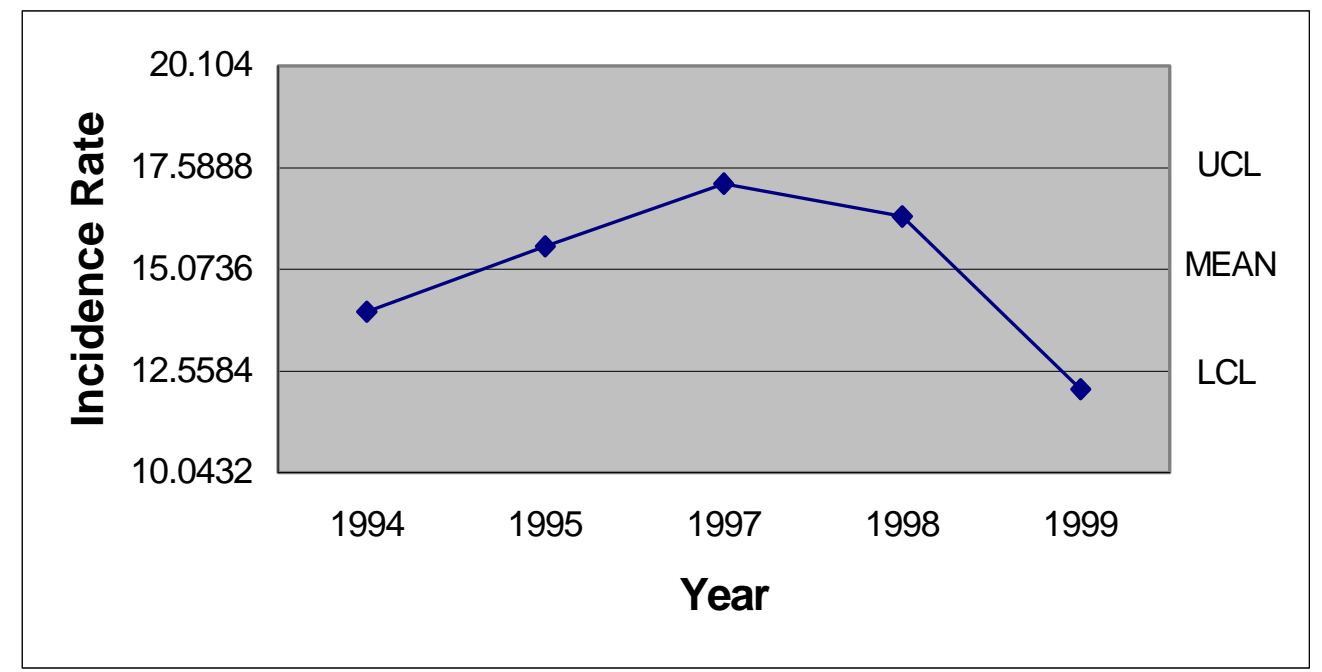

Note: No operations in October 1996

Figure 18. October 1994-1999 OSHA Recordable Incidence Rates - Corporate

As illustrated in Figure 19, the lowest November incidence rate occurred during the period immediately following the work stoppage. The incidence rates were trending downward for all years except 1999. An increase of nearly 25\% occurred between 1998 and 1999.

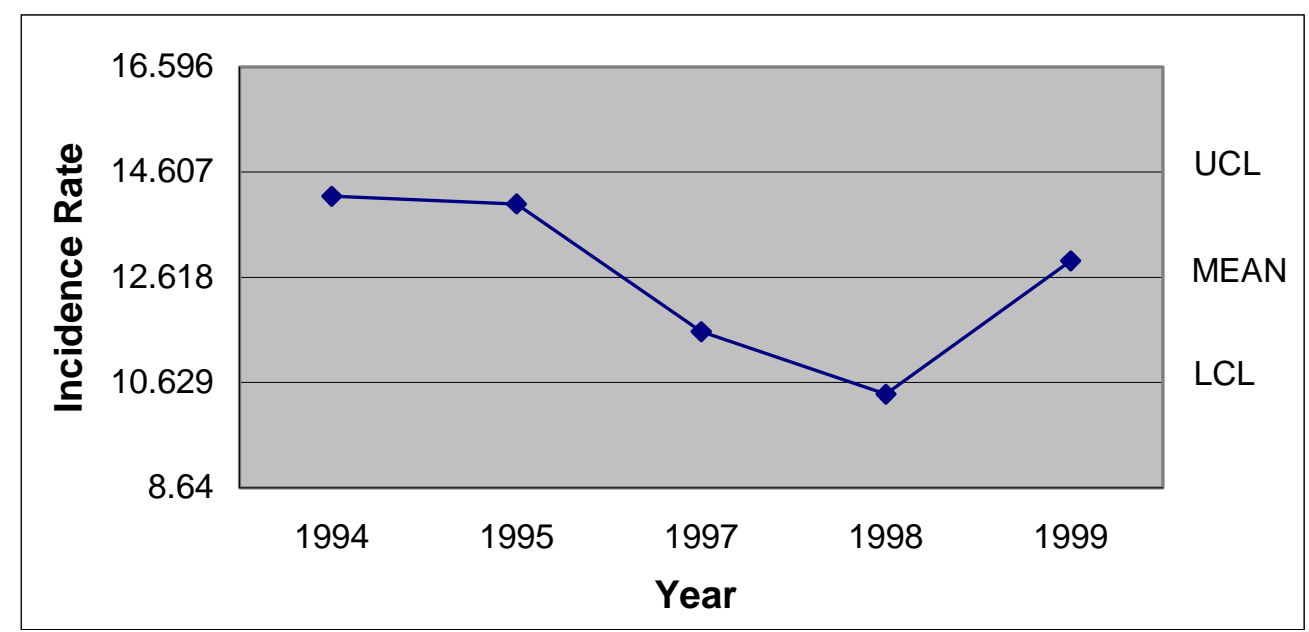

Note: No operations in November 1996

Figure 19. November 1994-1999 OSHA Recordable Incidence Rates - Corporate 
December incidence rates were highest in 1997, the period immediately following the work stoppage. That year the incidence rate was $45 \%$ higher than December of the previous year. This increase was followed by a decrease of 35\% from December 1998 to December 1999 (See Figure 20).

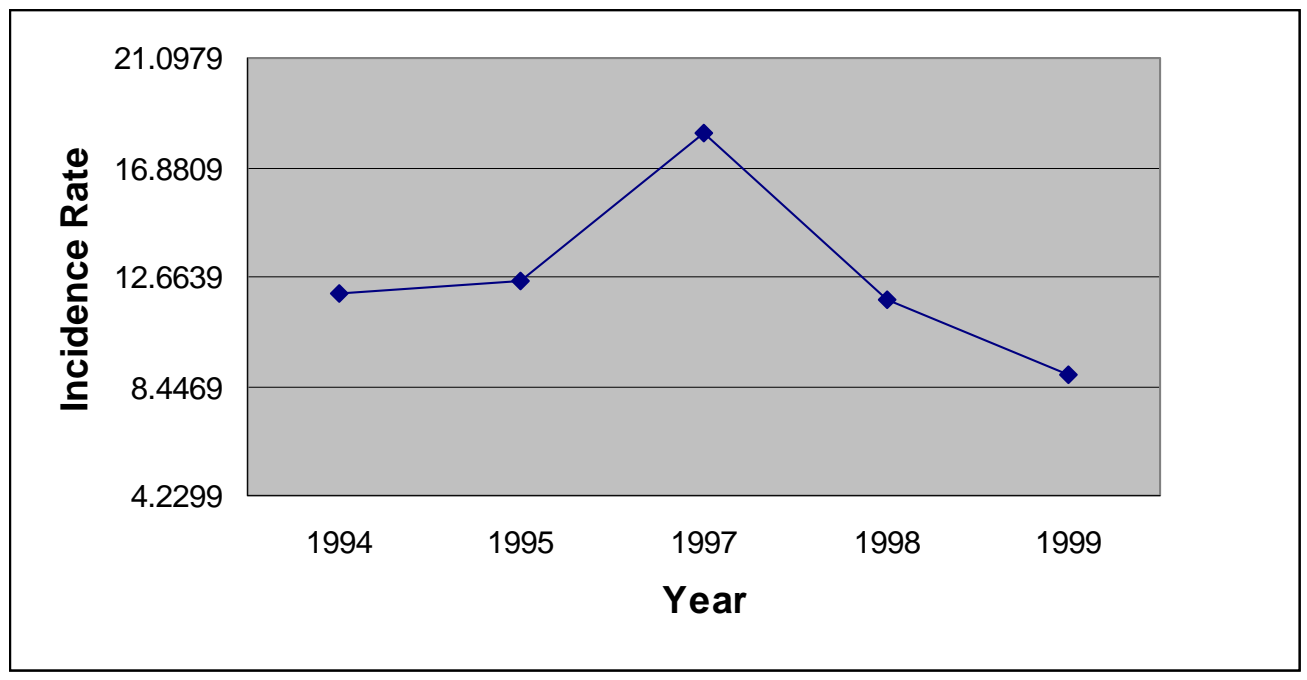

Note: No operations in December 1996

Figure 20. December 1994-1999 OSHA Recordable Incidence Rates - Corporate

Table 5 presents the monthly incidence rates for each year of the study period, as well as, the UCL, mean, LCL, and standard deviation. Nineteen ninety-six and 1997 were partial years because of the work stoppage and only the first six months of 2000 were included in the research.

Table 5

Summary of Monthly OSHA Recordable Incidence Rates Data - Corporate

\begin{tabular}{|l|l|l|l|l|l|l|l|l|l|l|l|l|}
\hline & Jan. & Feb. & Mar. & Apr. & May & June & July & Aug. & Sept. & Oct. & Nov. & Dec. \\
\hline 1994 & 21.752 & 21.784 & 15.136 & 13.449 & 18.614 & 24.174 & 25.577 & 19.106 & 17.466 & 14.028 & 14.150 & 12.005 \\
\hline 1995 & 17.073 & 17.207 & 16.631 & 13.78 & 15.623 & 16.900 & 19.077 & 22.337 & 19.386 & 15.649 & 14.005 & 12.516 \\
\hline 1996 & 14.697 & 13.127 & 11.122 & 15.835 & 14.956 & 18.948 & 15.988 & 15.663 & 21.123 & N/A & N/A & N/A \\
\hline 1997 & N/A & N/A & N/A & N/A & N/A & N/A & N/A & N/A & N/A & 17.198 & 11.593 & 18.183 \\
\hline 1998 & 17.725 & 15.533 & 17.590 & 18.785 & 20.724 & 21.648 & 18.416 & 16.763 & 17.797 & 16.382 & 10.415 & 11.743 \\
\hline 1999 & 14.331 & 8.553 & 10.060 & 12.441 & 12.367 & 7.710 & 10.277 & 13.988 & 13.662 & 12.112 & 12.927 & 8.871 \\
\hline
\end{tabular}




\begin{tabular}{|l|l|l|l|l|l|l|l|l|l|l|l|l|}
\hline 2000 & 12.176 & 9.403 & 10.434 & 10.877 & 14.178 & 8.076 & N/A & N/A & N/A & N/A & N/A & N/A \\
\hline UCL & 19.799 & 19.502 & 17.011 & 17.100 & 19.290 & 23.505 & 24.733 & 21.604 & 21.329 & 17.589 & 14.607 & 16.881 \\
\hline Mean & 16.292 & 14.268 & 13.496 & 14.182 & 16.077 & 16.243 & 17.867 & 17.572 & 17.887 & 15.074 & 12.618 & 12.664 \\
\hline LCL & 12.786 & 9.033 & 9.980 & 11.265 & 12.864 & 8.981 & 11.001 & 13.539 & 14.444 & 12.558 & 10.629 & 8.447 \\
\hline SD & 1.364 & 2.036 & 1.367 & 1.135 & 1.250 & 2.824 & 2.473 & 1.453 & 1.234 & 0.906 & 0.717 & 1.512 \\
\hline
\end{tabular}

Seasonal Analysis of Monthly OSHA Recordable Incidence Rates - Corporate

The same seasonal index calculations as described in the quarterly analysis section, were used to generate the monthly seasonal index figures that are presented in Figure 21. The highest seasonal index figures occurred in October, December, January, and May.

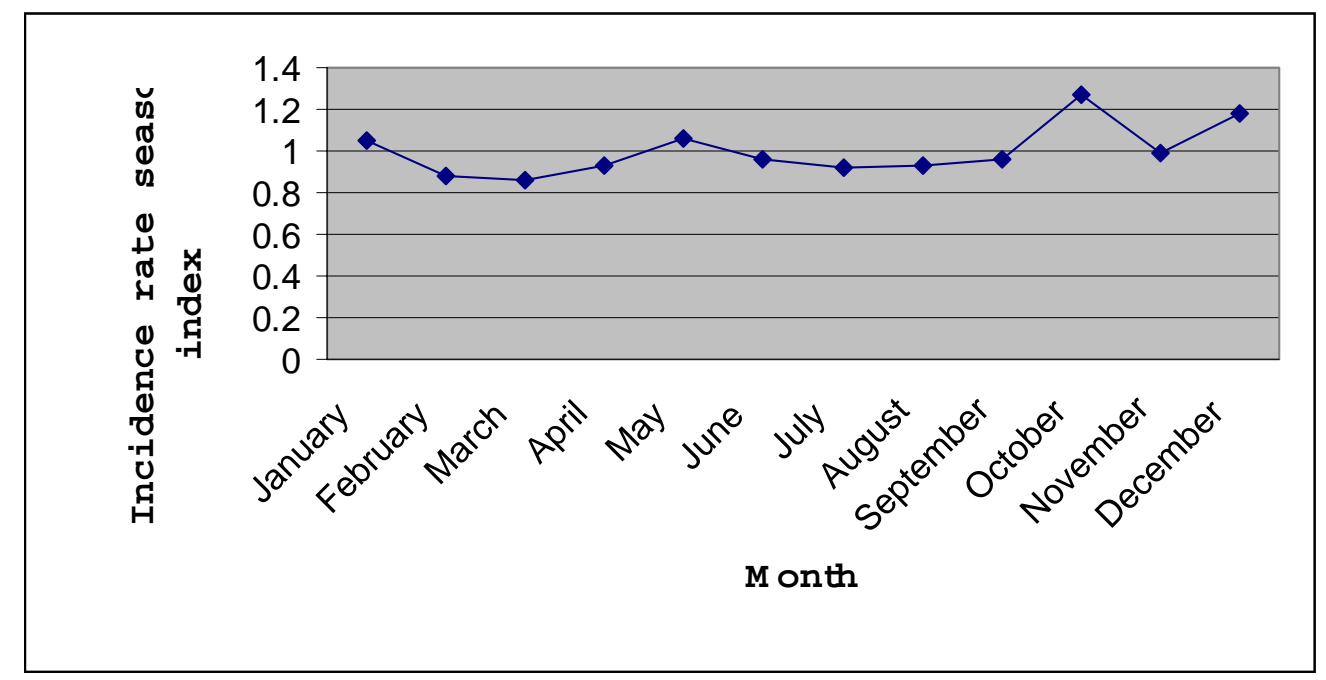

Figure 21. Monthly Seasonal Pattern of OSHA Recordable Incidence Rates.

\section{Testing the Periodic Statistical Relationship - Corporate}

All 33 months prior to and subsequent to the work stoppage

For the entire 33 months prior to the work stoppage and the 33 post work stoppage months a comparison of incidence rate was calculated using the following comparison formula: 


$$
\begin{aligned}
& \left|\frac{A_{1}}{H_{1}}-\frac{A_{2}}{H_{2}}\right| \\
& \sqrt{\left(\frac{A_{1}+A_{2}}{H_{1}+H_{2}}\right)\left(1-\frac{A_{1}+A_{2}}{H_{1}+H_{2}}\right)\left(\frac{1}{H_{1}}+\frac{1}{H_{2}}\right)}
\end{aligned}
$$

Where:

$\mathrm{A}=$ Incidents per period

$\mathrm{H}=$ Hours per period

The 6.08 calculated result was higher than the 1.96 significance level t value. This number indicated a statistically significant decrease in incidence rates for the 33 month period following the work stoppage, compared to the 33 months prior to the work stoppage.

First 24 months and last 24 months of the research period

The same comparison formula was applied to OSHA recordable incidence rates for the first 24 months of the period and the last 24 months of the period. These time periods excluded the nine months prior to and immediately following the work stoppage. At the same .05 significance level of 1.96 a statistically significant decrease in the incidence rate was recorded.

Nine Month Intervals Prior to and Subsequent to the Work Stoppage

Nine months prior to the work stoppage and nine months post work stoppage were chosen as intervals of analysis because contract negotiations started nine months prior to the work stoppage. The result of this calculation, 2.07, was compared to the .05 statistical significant level of probability using the $t$ tables, which was 1.96 for this procedure. Because the calculated amount exceeded the significance level, a statistically significant increase in incidence rates occurred between the two periods. 
Table 6

Comparison of Prior and Post Work Stoppage Periods

\begin{tabular}{|c|c|c|c|c|}
\hline \multirow[b]{2}{*}{ Time Period } & \multicolumn{2}{|c|}{ Corporate-wide Incidence Rates } & \multirow[b]{2}{*}{ Critical t Value } & \multirow[b]{2}{*}{$\begin{array}{l}\text { Calculated } \\
\text { Comparison Value }\end{array}$} \\
\hline & $\begin{array}{l}\text { Prior to } \\
\text { Work Stoppage }\end{array}$ & $\begin{array}{l}\text { Post } \\
\text { Work Stoppage }\end{array}$ & & \\
\hline 9 Months & 15.59 & 17.79 & 1.96 & $2.07 *$ \\
\hline 24 Months & 17.40 & 12.26 & 1.96 & $8.46^{* *}$ \\
\hline 33 Months & 16.93 & 13.72 & 1.96 & $6.08 * *$ \\
\hline
\end{tabular}

* Indicates a statistically significant increase

** Indicates a statistically significant decrease

\section{$\underline{\text { Primary Plant Analysis }}$}

Quarterly Analysis of OSHA Recordable Data - Primary Plant

A $19 \%$ declined at the Primary Plant in 1995 and an additional 11\% decline in 1996 followed the highest first quarter incidence rates, which was recorded in 1994. The declining trend for OSHA recordable incidence rate was interrupted by an increase between the last period prior to the work stoppage, 1996, and the first period after the work stoppage, 1998. This increase was followed the next year by an incidence rate below the LCL (See Figure 22).

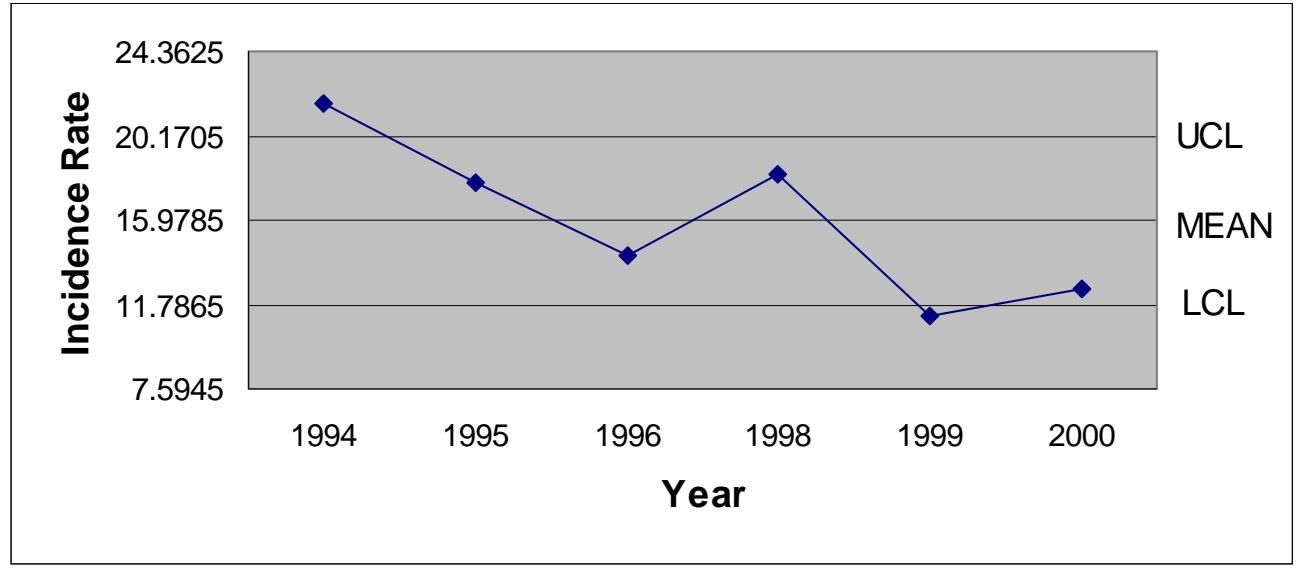

Note: No operations in first quarter 1997

Figure 22. First Quarter 1994-2000 OSHA Recordable Incidence Rates - Primary Plant 
The 1998 Primary Plant incidence rate, 21.77, was above the UCL and the 2000 incidence rate, 12.56, was below the LCL. The largest difference between periods occurred between 1998, the first period after the work stoppage, and 1999, a decrease of almost 40\% (See Figure 23).

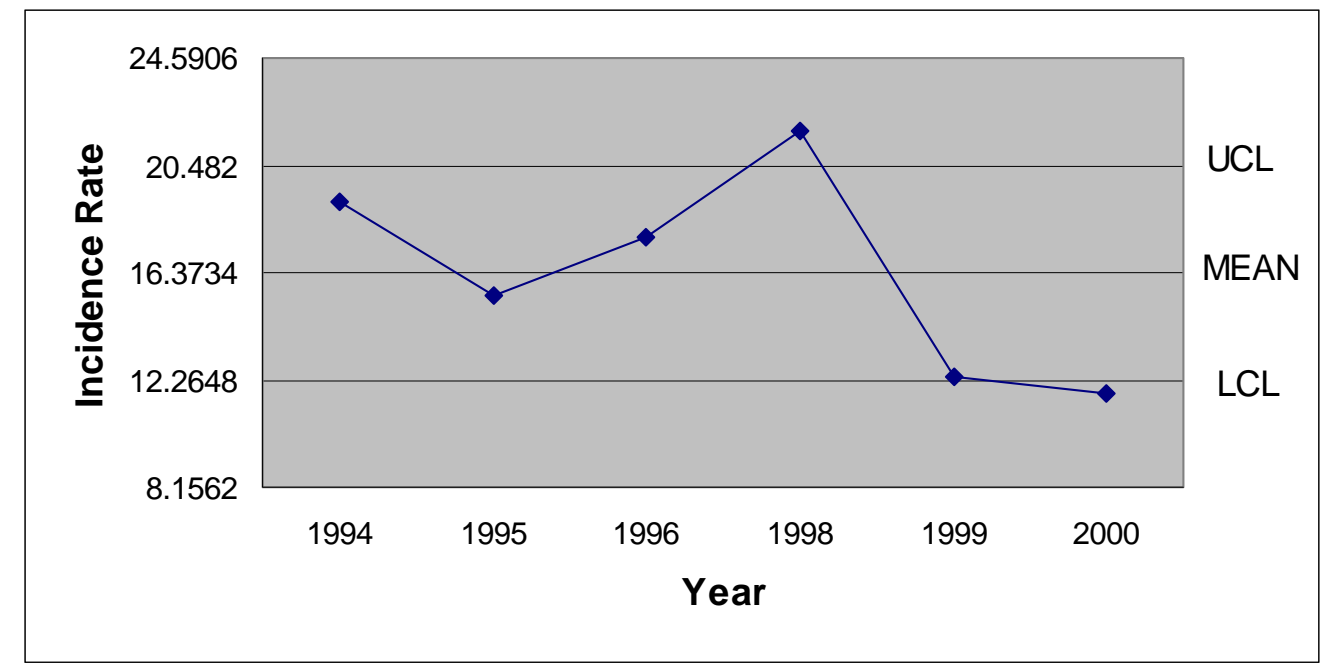

Note: No operations second quarter 1997

Figure 23. Second Quarter 1994-2000 OSHA Recordable Incidence Rates - Primary Plant

As illustrated in Figure 24, the highest incidence rate occurred at the Primary Plant in 1994, and was 44\% greater than the lowest rate recorded in 1999. The middle three periods were clustered around the mean. The 25\% decrease between 1998 and 1999 was almost equaled by the 21\% decrease recorded between 1994 and 1995. 


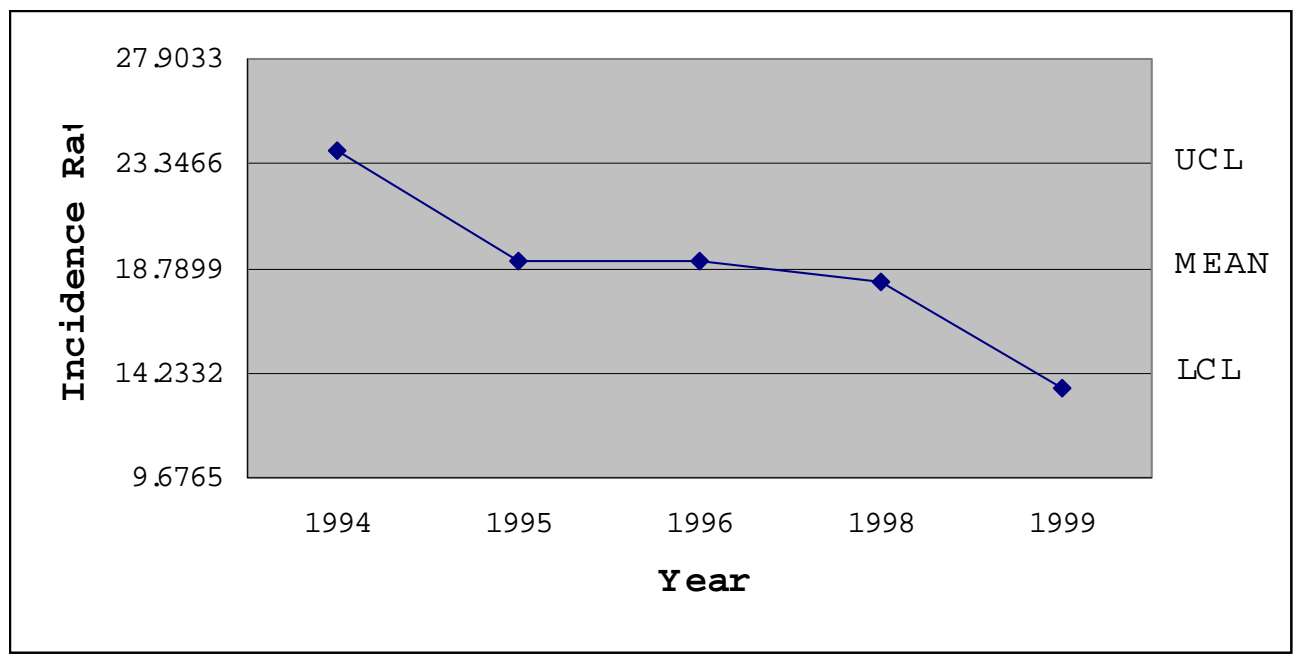

Note: No operations third quarter 1997

Figure 24. Third Quarter 1994-1999 OSHA Recordable Incidence Rates - Primary Plant

The Primary Plant's highest fourth quarter incidence rate was recorded in the first quarter after the work stoppage, fourth quarter 1997. The remaining years fourth quarter incidence rates were within the control limits. However, the lowest fourth quarter incidence rate, which was recorded in 1999, was $29 \%$ lower than the highest fourth quarter rate (See Figure 25).

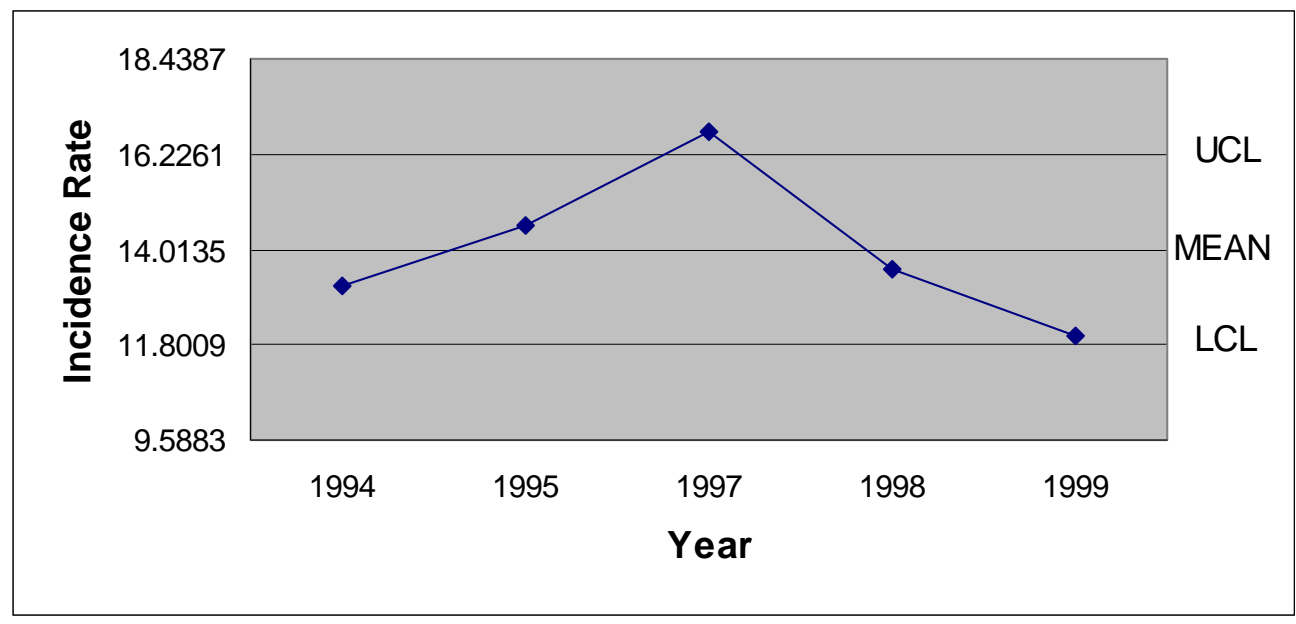

Note: No operations fourth quarter 1996

Figure 25. Fourth Quarter 1994-1999 OSHA Recordable Incidence Rates - Primary Plant 
Table 7 presents the Primary Plant's quarterly OSHA recordable incidence rates in a summary format. The UCL, LCL, mean, and standard deviation values are presented below the individual quarter statistics.

\section{Table 7}

$\underline{\text { Summary of Quarterly OSHA Recordable Incidence Rates Data - Primary Plant }}$

\begin{tabular}{|l|r|r|r|r|}
\hline & \multicolumn{1}{|c|}{$1^{\text {st }}$ Quarter } & \multicolumn{1}{|c|}{$2^{\text {nd }}$ Quarter } & \multicolumn{1}{c|}{$3^{\text {rd }}$ Quarter } & $4^{\text {th }}$ Quarter \\
\hline 1994 & 21.794 & 19.124 & 23.946 & 13.157 \\
\hline 1995 & 17.800 & 15.491 & 19.105 & 14.564 \\
\hline 1996 & 14.185 & 17.731 & 19.108 & N/A \\
\hline 1997 & $\mathrm{~N} / \mathrm{A}$ & $\mathrm{N} / \mathrm{A}$ & $\mathrm{N} / \mathrm{A}$ & 16.754 \\
\hline 1998 & 18.285 & 21.766 & 18.171 & 13.567 \\
\hline 1999 & 11.246 & 12.386 & 13.620 & 12.024 \\
\hline 2000 & 12.561 & 11.742 & $\mathrm{~N} / \mathrm{A}$ & N/A \\
\hline UCL & 20.171 & 20.482 & 23.347 & 16.226 \\
\hline MEAN & 15.979 & 16.373 & 18.790 & 14.013 \\
\hline LCL & 11.787 & 12.265 & 14.233 & 11.801 \\
\hline SD & 1.631 & 1.598 & 1.641 & .797 \\
\hline
\end{tabular}

Seasonal Analysis of Quarterly OSHA Recordable Incidence Rates Data - Primary Plant

The results of the quarterly seasonal index calculations are presented in Figure 26.

The incidence rates seasonal index indicates that the third quarter experienced the highest seasonal incidence rate for the study period. The lowest seasonal incidence rate was recorded for the fourth quarter period. 


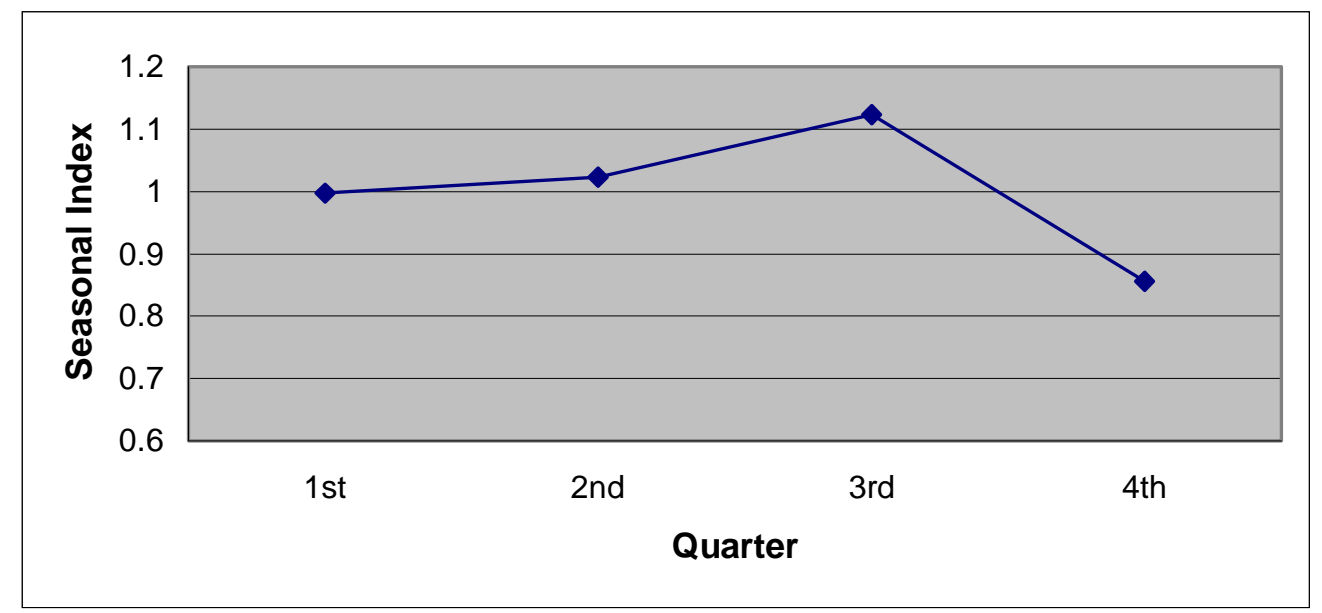

Figure 26. Quarterly Seasonal Index for OSHA Recordable Incidence Rates - Primary Plant

Monthly Analysis of OSHA Recordable Data - Primary Plant

As illustrated in Figure 27, the only Primary Plant January incidence rate appearing above the UCL was recorded in 1994. All of the remaining incidence rate was within the control limits, although the 1998 incidence rate shows a markedly higher rate than the January rates in the preceding and subsequent years.

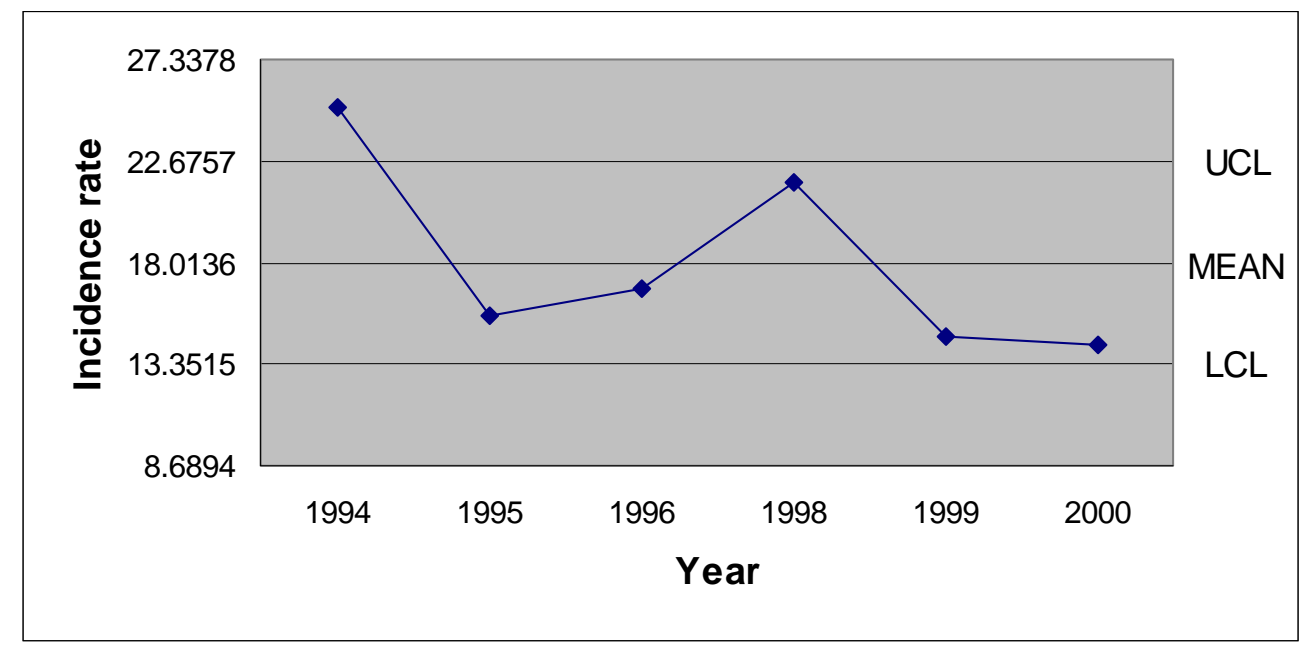

Note: No operations in January 1997

Figure 27. January 1994-2000 OSHA Recordable Incidence Rates - Primary Plant 
The February incidence rates for the Primary Plant were on a declining pattern until 1998, which experienced a 15\% increase over the preceding 1996 rate. This was followed by a 46\% decrease between the 1998 and 1999 periods and a 39\% increase over the next subsequent period (See Figure 28).

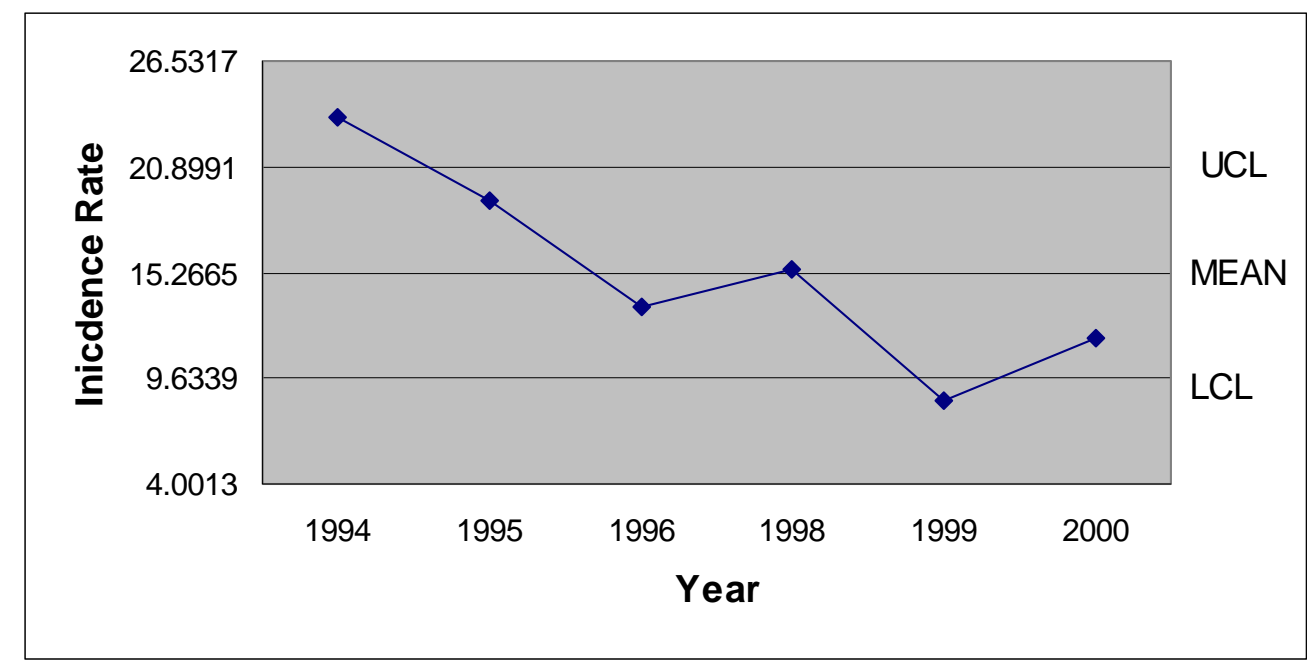

Note: No operations in February 1997

Figure 28. February 1994-2000 OSHA Recordable Incidence Rates - Primary Plant

As indicated in Figure 29, the March incidence rates at the Primary Plant experienced a zigzag pattern with peaks in 1995 and 1998. The 1995 peak was followed by a steep decline for the period preceding the work stoppage. The period immediately following the work stoppage was the next highest and was followed by an equally steep decrease. 


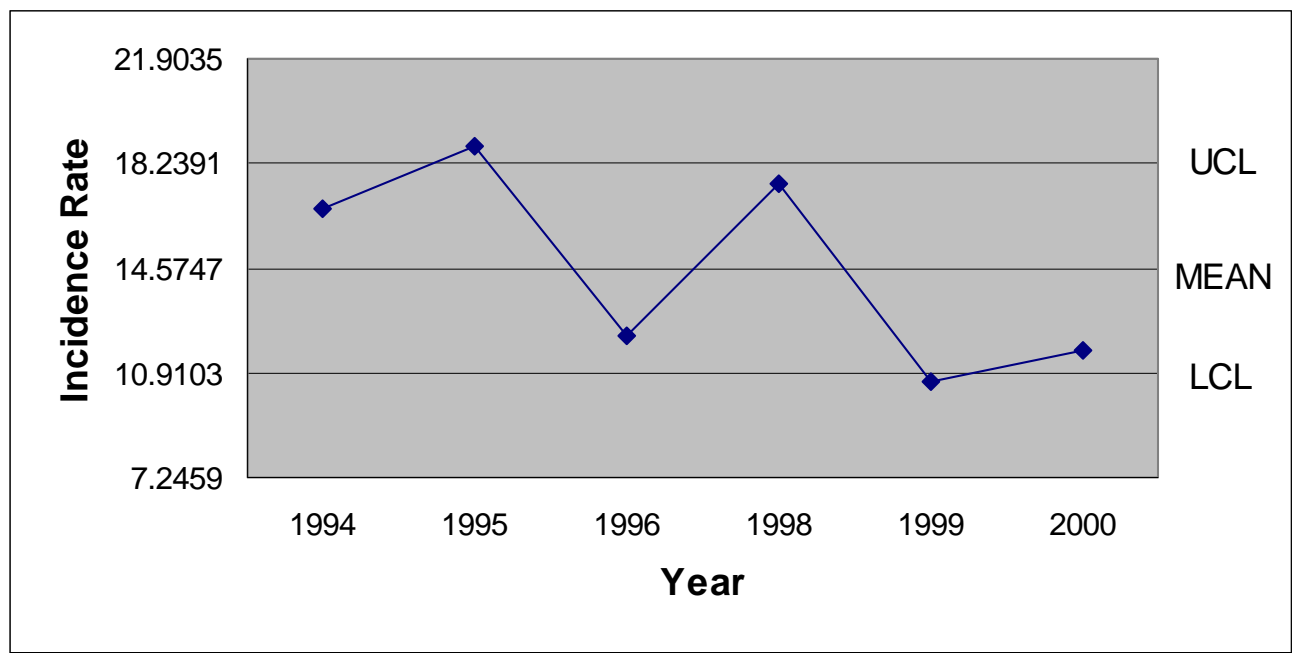

Note: No operations in March 1997

Figure 29. March 1994-2000 OSHA Recordable Incidence Rates - Primary Plant

For the April incidence rates at the Primary Plant, one rate, 1998, appears above the UCL. An increasing trend was experienced for April prior to the work stoppage and immediately following it. Currently a decreasing trend is evident for the month of April (See Figure 30).

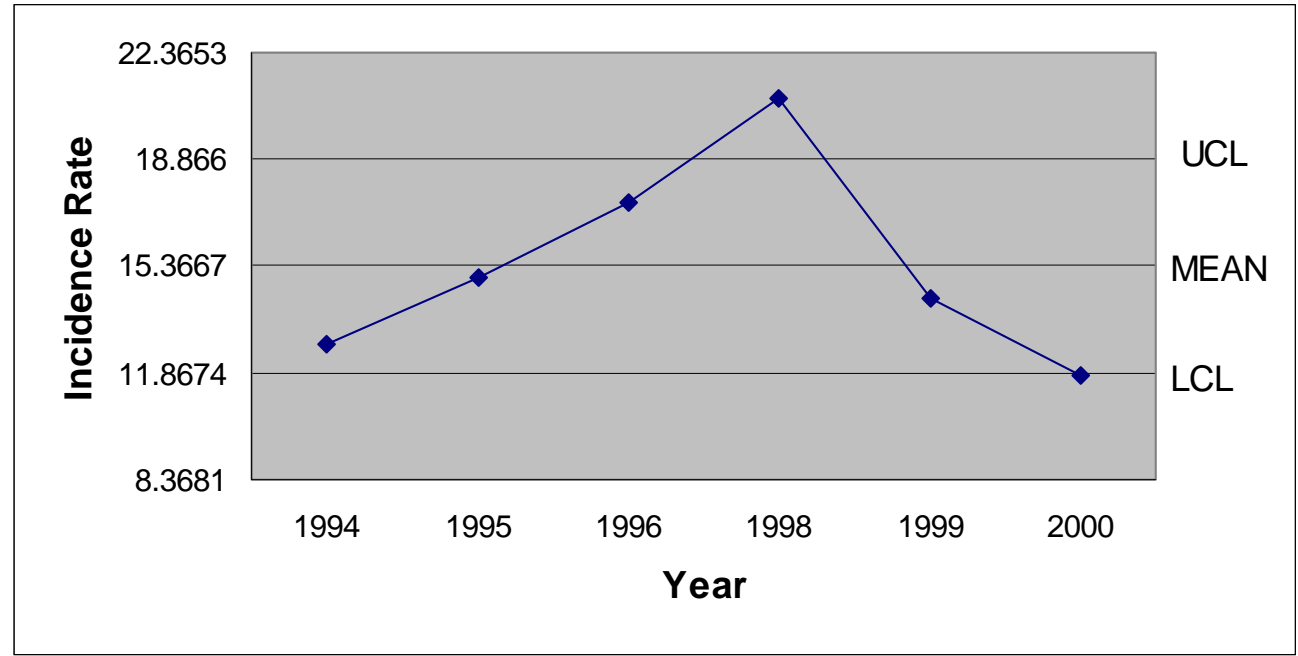

Note: No operations in April 1997

Figure 30. April 1994-2000 OSHA Recordable Incidence Rates - Primary Plant 
Figure 31 indicated that the 1994 May incidence rate at the Primary Plant was above the UCL, but was followed by a two year period of declining incidence rates for the month. The highest incidence rate for May occurred in 1998. It was bordered on both sides by considerably lower incidence rates.

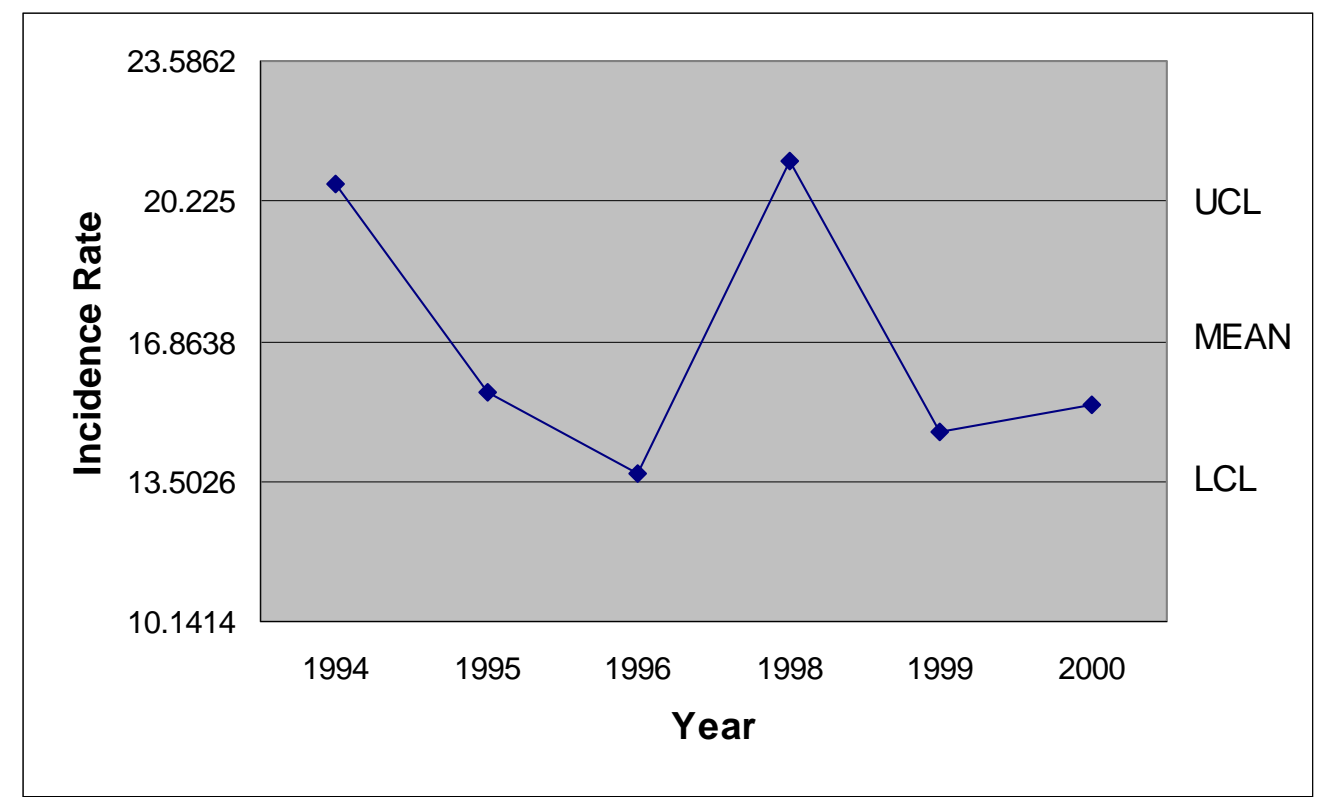

Note: No operations in May 1997

Figure 31. May 1994-2000 OSHA Recordable Incidence Rates - Primary Plant

June 1994 at the Primary Plant had the highest incidence rate for the month. The 1995 rate was lower, and then an increasing trend appeared for the next two consecutive years. This period was followed by a 65\% decrease in incidence rate between 1998 and 1999. Both the 1999 and 2000 June incidence rates were below the LCL (See Figure 32). 


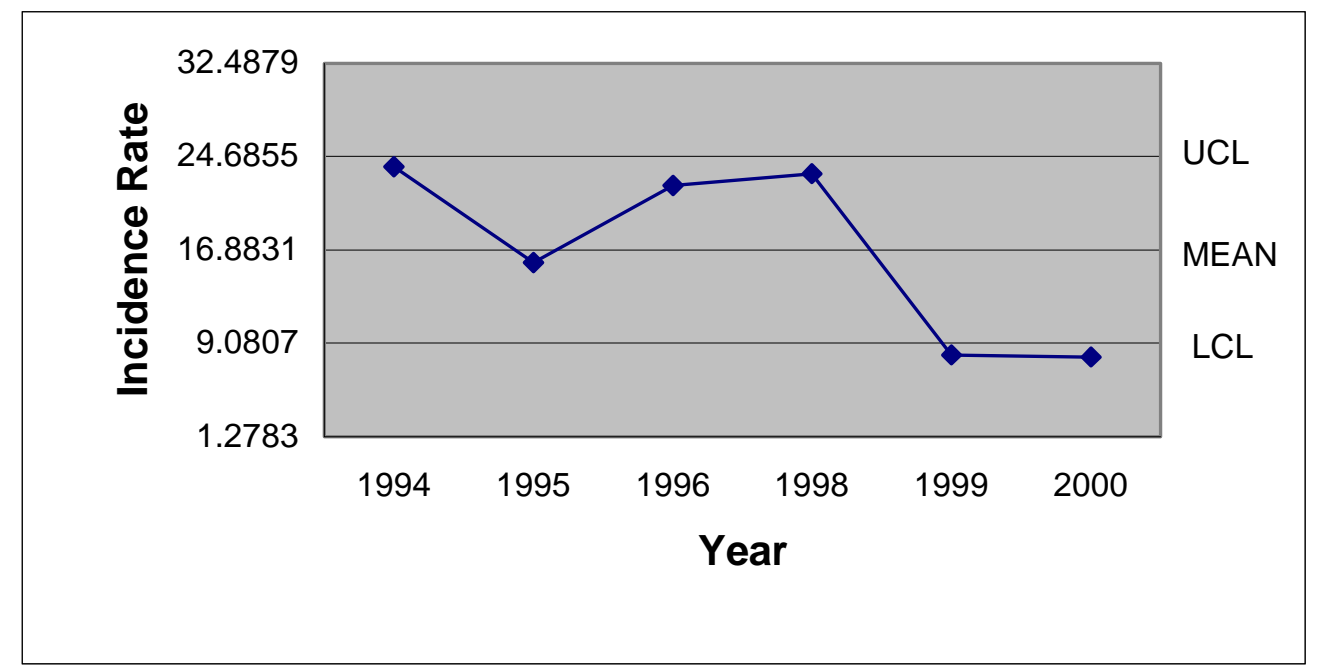

Note: No operations in June 1997

Figure 32. June 1994-2000 OSHA Recordable Incidence Rates - Primary Plant

One incidence rate for the month of July appeared higher than the UCL at the Primary Plant, July 1994. The incidence rates for 1995 through 1997 were clustered around the mean, while the 1999 incidence rate was just above the LCL (see Figure 33).

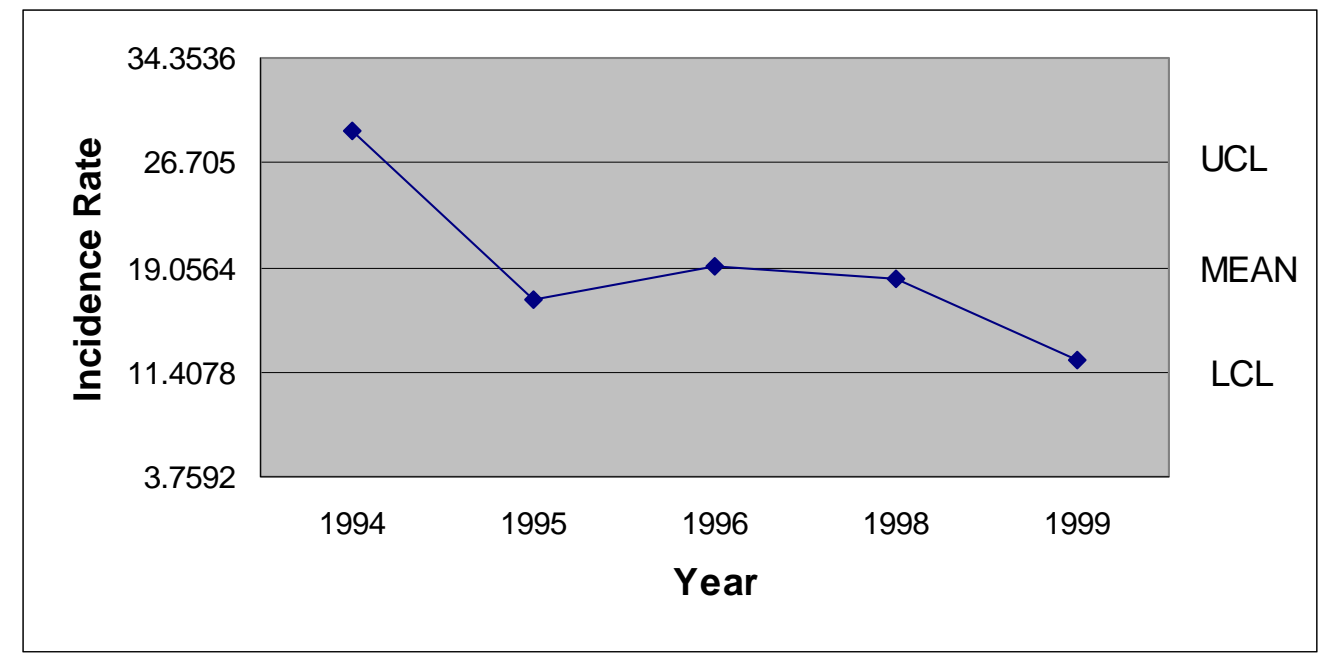

Note: No operations in July 1997

Figure 33. July 1994-1999 OSHA Recordable Incidence Rates - Primary Plant

Figure 34 illustrates a declining trend for the month of August. However, the decline was interrupted by an increase between 1996 and 1998. The 23.31 incidence rate 
in 1994 at the Primary Plant was 38\% higher than the lowest August incidence rate, which occurred in 1999.

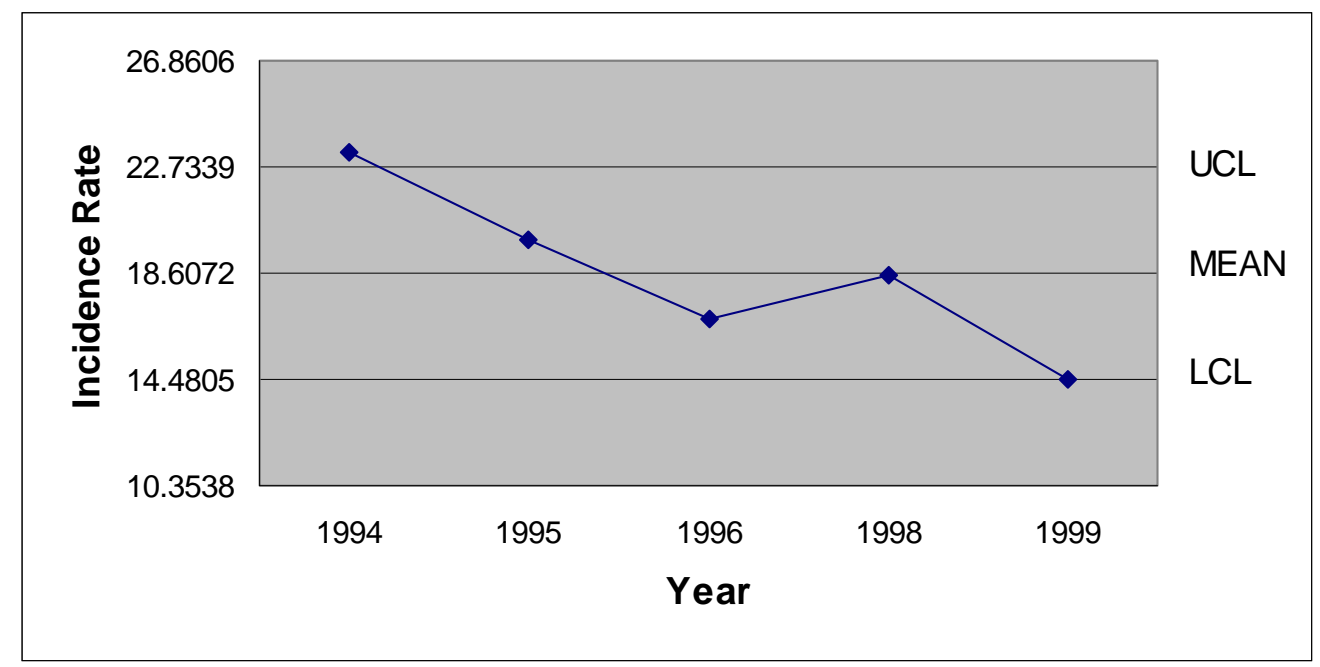

Note: No operations in August 1997

Figure 34. August 1994-1999 OSHA Recordable Incidence Rates - Primary Plant

A peak marked the September incidence rates in 1996, the last month of operations 1994 at the Primary Plant before the work stoppage. Prior to the peak, a gradual rise in the September incidence rate was apparent. Immediately following the peak years the incidence rates started a substantial decline that included a 1999 incidence rate below the LCL (See Figure 35).

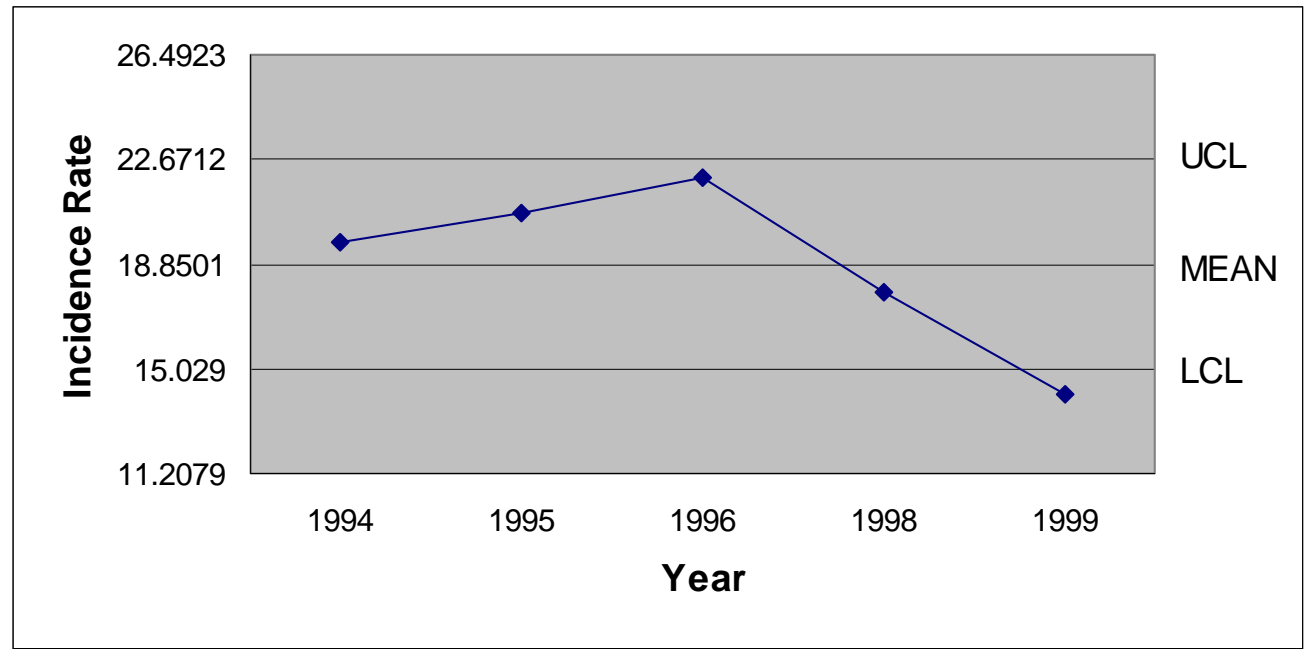

Note: No operations in September 1997

Figure 35. September 1994-1999 OSHA Recordable Incidence Rates - Primary Plant 
As illustrated in Figure 36 the October Primary Plant incidence rates for 1997 and 1998 were the highest and differed by only 0.09. One of the highest incidence rates, October 1997, was the first month of operations after the work stoppage. The steepest decrease in incidence rates, almost 40\%, occurred between 1998 and 1999.

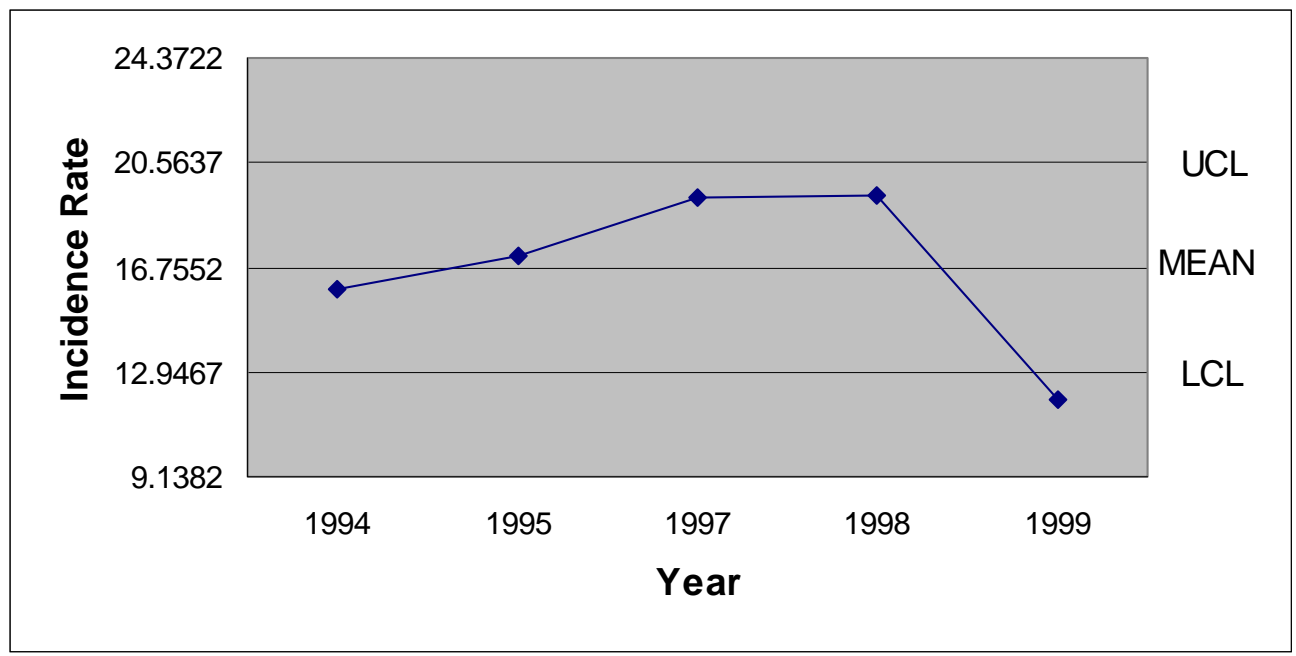

Note: No operations in October 1996

Figure 36. October 1994-1999 OSHA Recordable Incidence Rates - Primary Plant

November incidence rates at the Priamry Plant experienced a peak in 1999, which was 0.2 greater than the next highest rate from 1994. As indicated in Figure 37, a declining trend was occurring until the 1998 to 1999 incidence rate increase of almost $68 \%$.

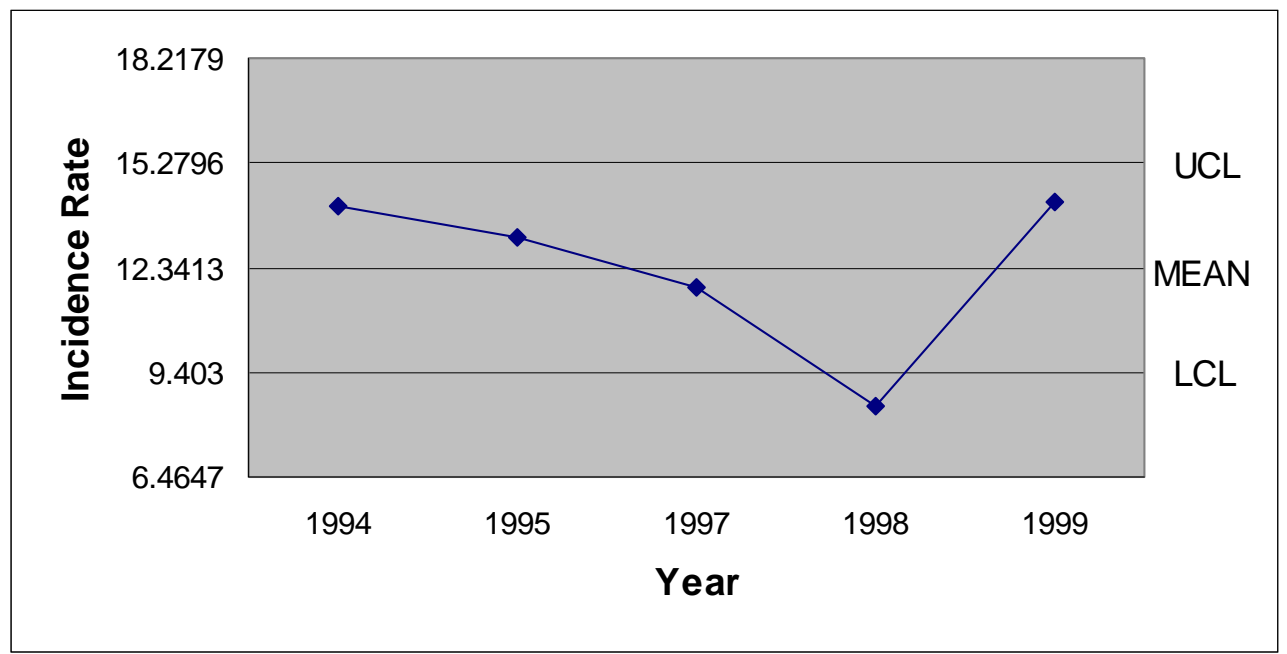

Note: No operations in November 1996

Figure 37. November 1994-1999 OSHA Recordable Incidence Rates - Primary Plant 
Figure 38 shows that the highest Primary Plant incidence rate for the month of December occurred in 1997, the period immediately following the work stoppage. Prior to the work stoppage an increasing trend was evident. This trend began to reverse during the second period after the work stoppage.

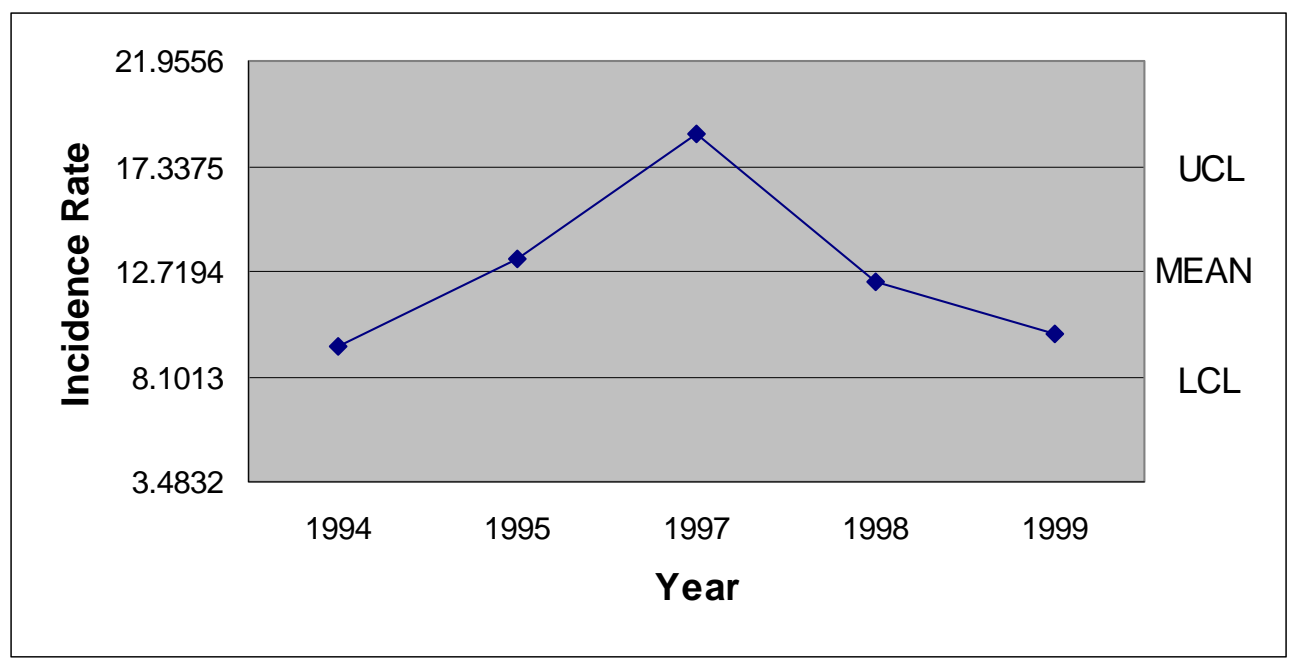

Note: No operations in December 1996

Figure 38. December 1994-1999 OSHA Recordable Incidence Rates - Primary Plant

Table 8 contains the monthly incidence rates for each year of the study period, as well as the UCL, mean, LCL, and standard deviation. Nineteen ninety-six and 1997 were partial years because of the work stoppage and only the first six months of 2000 were included in the research.

Table 8

Summary of Monthly OSHA Recordable Incidence Rates Data - Primary Plant

\begin{tabular}{|l|l|l|l|l|l|l|l|l|l|l|l|l|}
\hline & Jan. & Feb. & Mar. & Apr. & May & June & July & Aug. & Sept. & Oct. & Nov. & Dec. \\
\hline 1994 & 25.167 & 23.485 & 16.627 & 12.787 & 20.627 & 23.867 & 29.040 & 23.312 & 19.627 & 15.976 & 14.055 & 9.384 \\
\hline 1995 & 15.543 & 19.066 & 18.824 & 14.997 & 15.646 & 15.826 & 16.662 & 19.938 & 20.699 & 17.162 & 13.192 & 13.248 \\
\hline 1996 & 16.806 & 13.422 & 12.199 & 17.468 & 13.700 & 22.292 & 19.075 & 16.807 & 22.028 & N/A & N/A & N/A \\
\hline 1997 & N/A & N/A & N/A & N/A & N/A & N/A & N/A & N/A & N/A & 19.310 & 11.787 & 18.727 \\
\hline 1998 & 21.742 & 15.404 & 17.533 & 20.878 & 21.177 & 23.247 & 18.210 & 18.498 & 17.809 & 19.402 & 8.471 & 12.290 \\
\hline 1999 & 14.577 & 8.461 & 10.589 & 14.283 & 14.700 & 8.100 & 12.296 & 14.480 & 14.087 & 11.925 & 14.201 & 9.948 \\
\hline 2000 & 14.245 & 11.762 & 11.677 & 11.787 & 15.334 & 7.966 & N/A & N/A & N/A & N/A & N/A & N/A \\
\hline UCL & 22.676 & 20.899 & 18.239 & 18.866 & 20.225 & 24.685 & 26.705 & 22.734 & 22.671 & 20.564 & 15.279 & 17.338 \\
\hline
\end{tabular}




\begin{tabular}{|l|l|l|l|l|l|l|l|l|l|l|l|l|}
\hline Mean & 18.014 & 15.267 & 14.575 & 15.367 & 16.864 & 16.883 & 19.056 & 18.607 & 18.850 & 16.755 & 12.341 & 12.719 \\
\hline LCL & 13.351 & 9.634 & 10.910 & 11.867 & 13.503 & 9.081 & 11.408 & 14.480 & 15.029 & 12.947 & 9.403 & 8.101 \\
\hline SD & 1.813 & 2.191 & 1.425 & 1.361 & 1.307 & 3.035 & 2.755 & 1.487 & 1.376 & 1.372 & 1.058 & 1.664 \\
\hline
\end{tabular}

Seasonal Analysis of Monthly OSHA Recordable Incidence Rates Data - Primary Plant

The highest seasonal index measurement for the Primary Plant occurred in the month of September. July, August, and January were also relatively high compared with the remaining months. The lowest seasonal index was recorded in the month of December (See Figure 39).

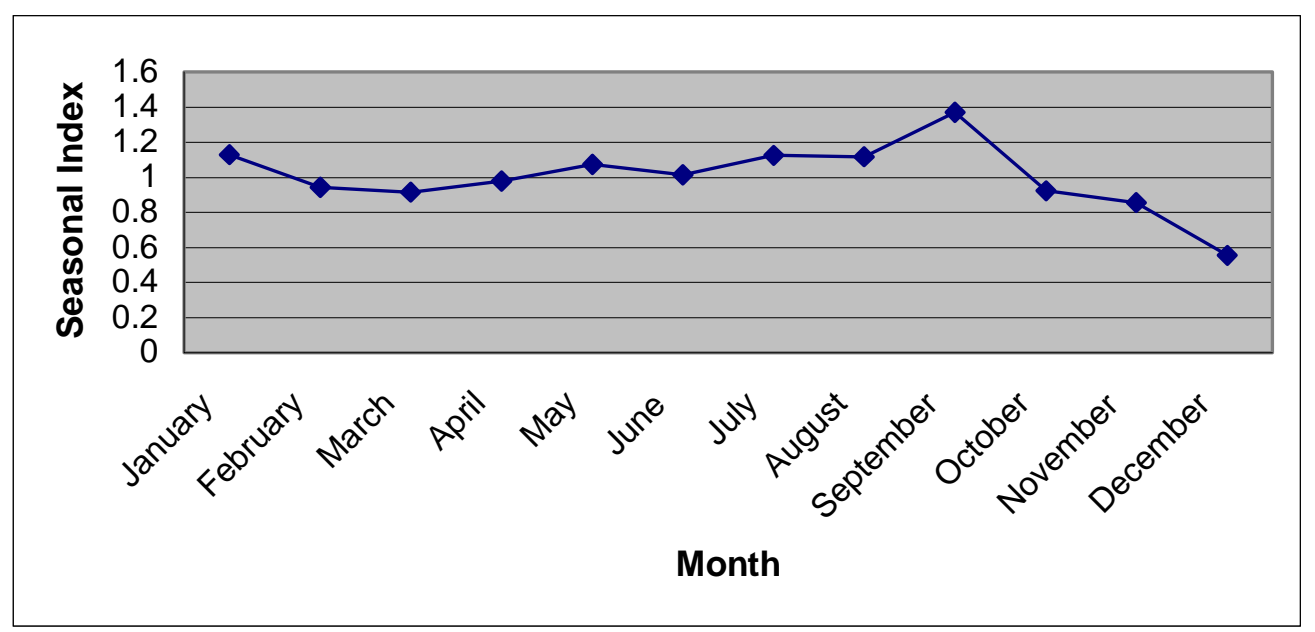

Figure 39. Monthly Seasonal Pattern of OSHA Recordable Incidence Rates - Primary Plant

\section{Testing the Periodic Statistical Relationship - Primary Plant}

\section{All 33 Months Prior to and Subsequent to the Work Stoppage}

For the entire 33 months prior to the work stoppage and the 33 post work stoppage months at the Primary Plant, a comparison of incidence rate was calculated. The calculated result, 4.68 was higher than the 1.96 significance level $t$ value. This indicated that a statistically significant decrease occurred in incidence rates for the 33 month period following the work stoppage, compared to the 33 months prior to the work stoppage. Table 9 contains the results of the comparison for all 3 time periods. 
First 24 Months and Last 24 Months of the Research Period

The same comparison formula was applied to OSHA recordable incidence rates for the first 24 months of the period and the last 24 months of the period at the Primary Plant. These time periods excluded the nine months prior to and immediately following the work stoppage. At the same .05 significance level of 1.96 a statistically significant decrease in incidence rate was recorded.

Nine Month Intervals Prior to and Subsequent to the Work Stoppage

The result of using the comparison formula for the nine month intervals at the Primary Plant was 1.51. Compared to the 1.96 statistically significant t value at the .05 level of probability, the calculated $t$ indicated that a significant increase in incidence rates did not occur between the two periods.

Table 9

Comparison of Prior and Post Work Stoppage Period - Primary Plant

\begin{tabular}{|c|c|c|c|c|}
\hline \multirow[b]{2}{*}{ Time Period } & \multicolumn{2}{|c|}{ Primary Plant Incidence Rates } & \multirow[b]{2}{*}{ Critical t Value } & \multirow[b]{2}{*}{$\begin{array}{l}\text { Calculated } \\
\text { Comparison Value }\end{array}$} \\
\hline & $\begin{array}{l}\text { Prior to } \\
\text { Work Stoppage }\end{array}$ & $\begin{array}{l}\text { Post } \\
\text { Work Stoppage }\end{array}$ & & \\
\hline 9 Months & 16.96 & 18.98 & 1.96 & 1.51 \\
\hline 24 Months & 18.12 & 13.18 & 1.96 & $6.54 * *$ \\
\hline 33 Months & 17.81 & 14.73 & 1.96 & $4.68 * *$ \\
\hline
\end{tabular}

* Indicates a statistically significant increase

** Indicates a statistically significant decrease

Finishing Plant \#1 Analysis

\section{Quarterly Analysis of OSHA Recordable Data - Finishing Plant \#1}

Finishing Plant \#1 experienced a declining trend in OSHA recordable incidence rates for the period 1994 through 1999. A slight increase was experienced between 1999 and 2000. The highest first quarter incidence rate, which occurred in 1994, was almost $80 \%$ higher than the lowest first quarter rate, which was recorded in 1999 (See Figure 40). 


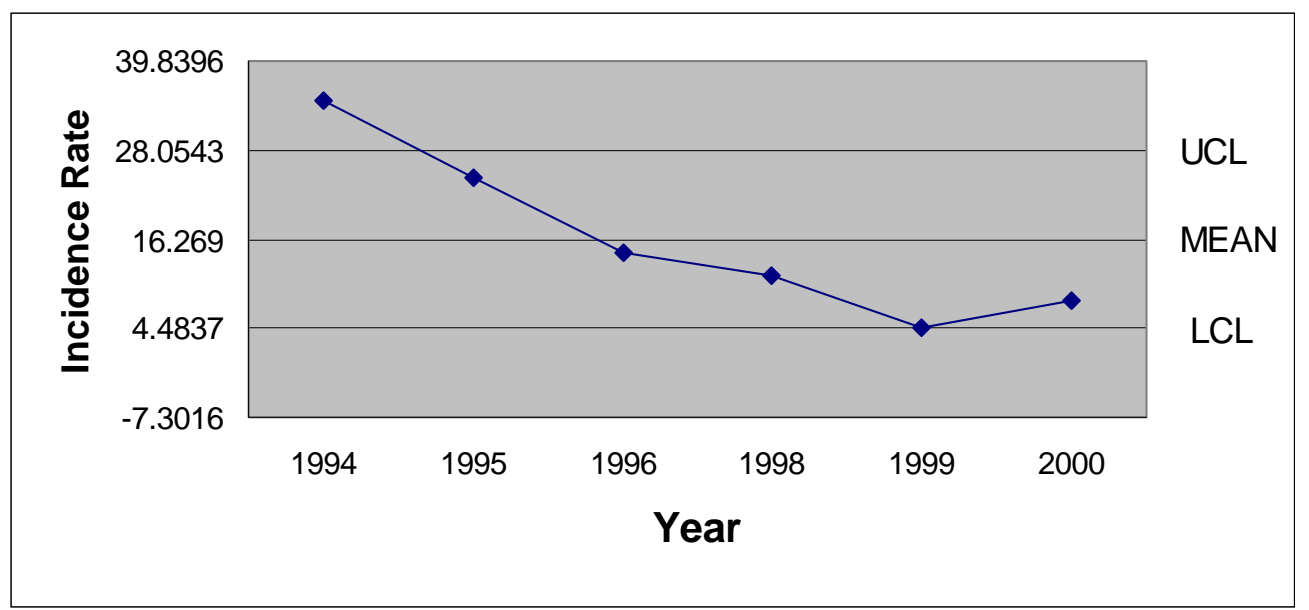

Note: No operations in first quarter 1997

Figure 40. First Quarter 1994-2000 OSHA Recordable Incidence Rates-Finishing Plant \#1

For the second quarter incidence rates, Finishing Plant \#1 experienced a high of 39.05 in 1994 and a low of 8.01 in 1999 . The trend was a steadily decreasing incidence rate for the 1994 through 1999 period. A slight increase in rates was recorded for the 1999 to 2000 first quarter time periods (See Figure 41).

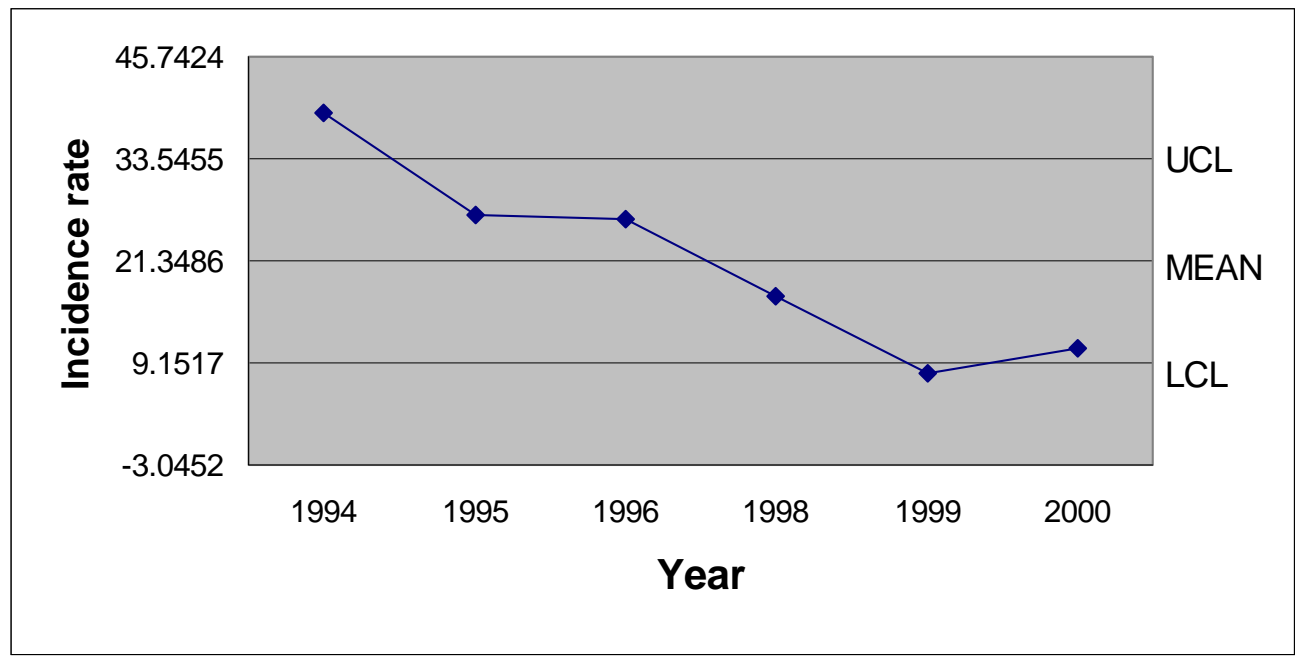

Note: No operations in second quarter 1997

Figure 41. Second Quarter 1994-2000 OSHA Recordable Incidence Rates - Finishing Plant \#1 
Figure 42 shows that 1995 had the highest third quarter incidence rate at Finishing Plant \#1, while 1999 had the lowest. The relationship between these two periods illustrates a more than $75 \%$ decrease in the incidence rate. The remaining three periods were clustered relatively closely to the mean.

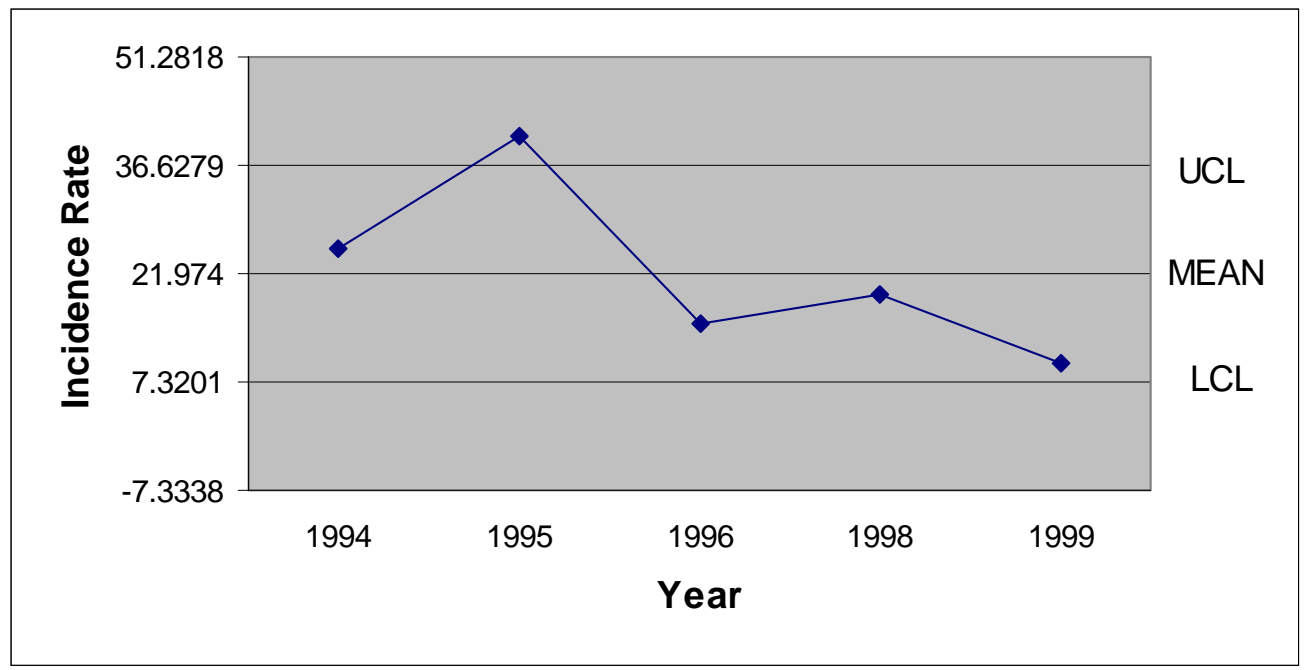

Note: No operations in third quarter 1997

Figure 42. Third Quarter 1994-1999 OSHA Recordable Incidence Rates - Finishing Plant \#1

The only fourth quarter incidence rate at Finishing Plant \#1 falling outside the control limits occurred below the LCL in 1999. The 1995 fourth quarter incidence rate of 20.88 was almost over the UCL. A declining trend was recorded between 1995 and 1999. Overall a 65\% decline was recorded between the fourth quarter high in 1995 and the low in 1999 (See Figure 43). 


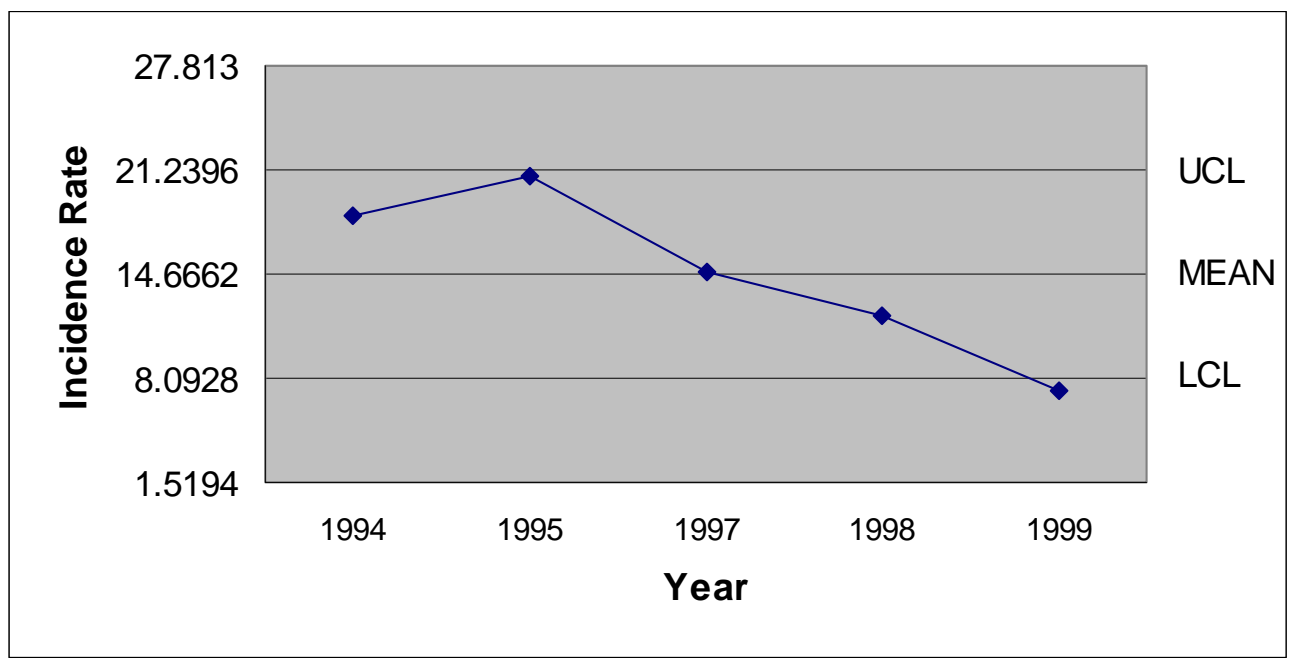

Note: No operations in fourth quarter 1996

Figure 43. Fourth Quarter 1994-1999 OSHA Recordable Incidence Rates - Finishing Plant \#1

Table 10 presents the quarterly summary of OSHA recordable incidence rates for Finishing Plant \#1. The incidence rates, UCL, mean, LCL, and standard deviations are presented for each year of the study.

Table 10

Summary of Quarterly OSHA Recordable Incidence Rates Data - Finishing Plant \#1

\begin{tabular}{|l|r|r|r|r|}
\hline & $1^{\text {st }}$ Quarter & \multicolumn{1}{|c|}{$2^{\text {nd }}$ Quarter } & $3^{\text {rd }}$ Quarter & \multicolumn{1}{c|}{$4^{\text {th }}$ Quarter } \\
\hline 1994 & 34.677 & 39.053 & 25.226 & 18.304 \\
\hline 1995 & 24.305 & 26.938 & 40.564 & 20.881 \\
\hline 1996 & 14.379 & 26.226 & 15.111 & N/A \\
\hline 1997 & N/A & N/A & 19.060 & 14.763 \\
\hline 1998 & 11.371 & 16.996 & 9.909 & 12.015 \\
\hline 1999 & 4.678 & 8.009 & N/A & N/A \\
\hline 2000 & 8.205 & 10.870 & 36.628 & 21.240 \\
\hline UCL & 28.054 & 33.545 & 21.974 & 14.666 \\
\hline MEAN & 16.269 & 21.349 & 7.320 & 8.093 \\
\hline LCL & 4.484 & 9.152 & 5.279 & 2.368 \\
\hline SD & 4.584 & 4.744 & & 19.369 \\
\hline
\end{tabular}




\section{Seasonal Analysis of Quarterly OSHA Recordable Incidence Rates Data - Finishing}

\section{$\underline{\text { Plant \#1 }}$}

The results of the quarterly seasonal index calculations for Finishing Plant \#1 are presented in Figure 44. The incidence rates seasonal index indicates that the second quarter had the highest seasonal index and the third quarter was a very close second. The seasonal indices for the first and fourth quarters were almost $20 \%$ lower than the second quarter's index.

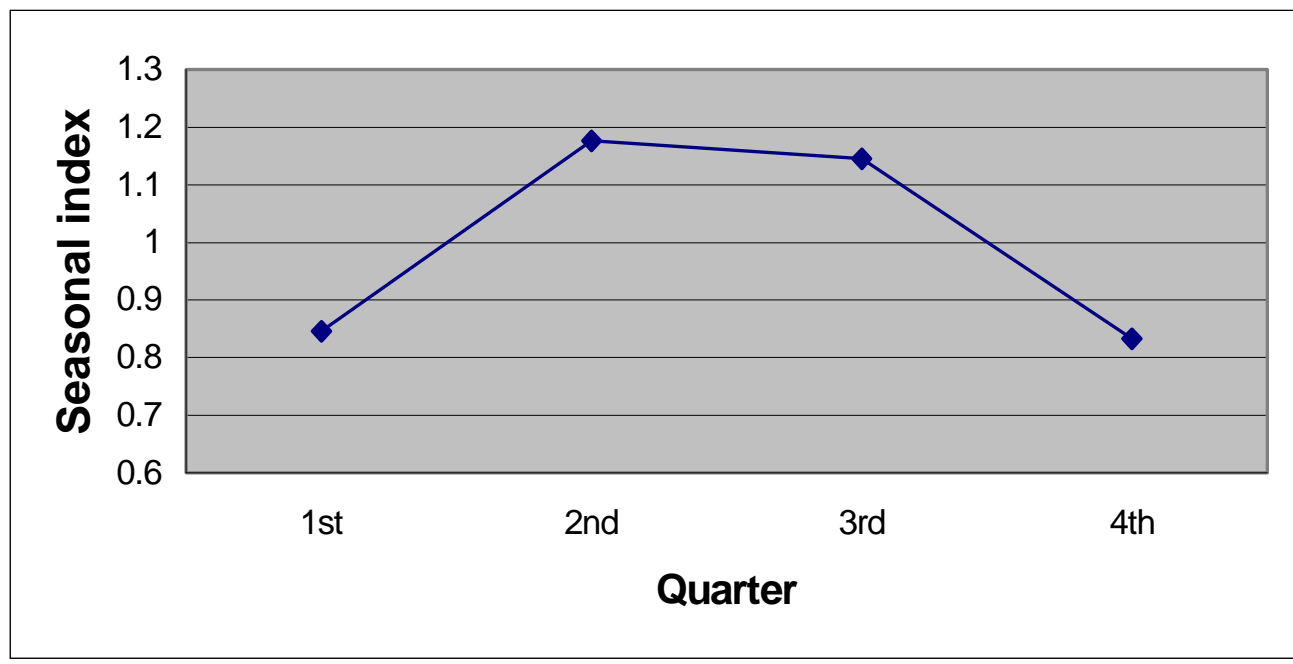

Figure 44. Quarterly Seasonal Index for OSHA Recordable Incidence Rates - Finishing Plant \#1

\section{Monthly Analysis of OSHA Recordable Data - Finishing Plant \#1}

Figure 45 indicates a downward trend for the month of January during the 1994 through 1998 period at Finishing Plant \#1. The total decrease from the high of 35.49 to the low of 6.63 was $82 \%$. The incidence rates experienced an increasing trend from 1998 to 2000 but remained below the mean. 


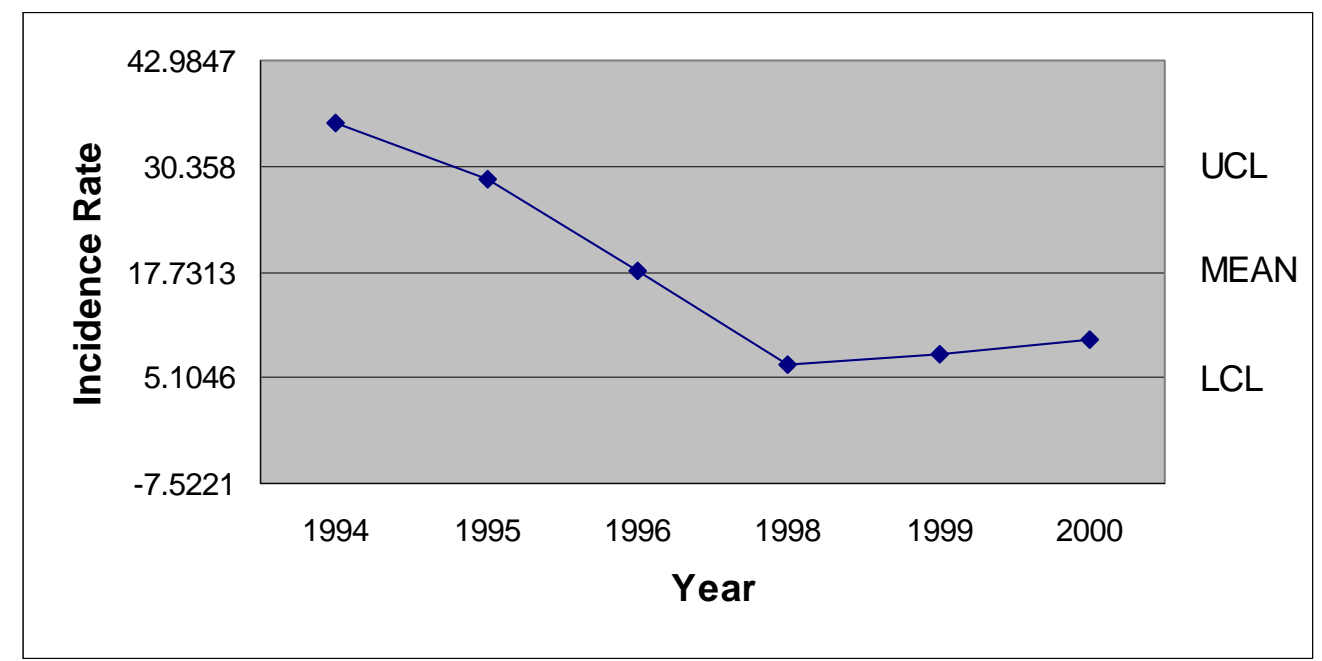

Note: No operations in January 1997

Figure 45. January 1994-2000 OSHA Recordable Incidence Rates - Finishing Plant \#1

The incidence rates for Finishing Plant \#1 experienced a consistent decline from 1994 through 1999 for the month of February. The difference between the 1994 high of 38.48 and the 1999 low of 3.47 was a $91 \%$ decrease in incidence rate. The incidence rate recorded in February 2000 was slightly higher than the lowest rate, which was recorded in the previous year (See Figure 46).

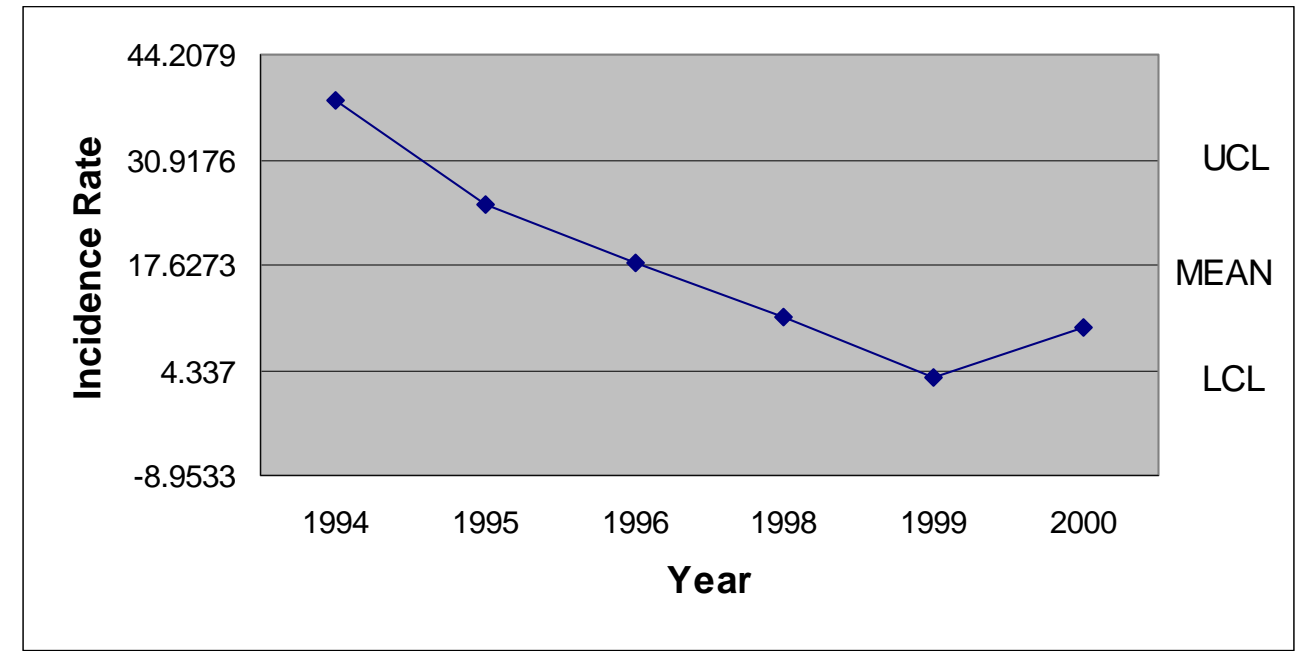

Note: No operations in February 1997

Figure 46. February 1994-2000 OSHA Recordable Incidence Rates - Finishing Plant \#1 
March incidence rates for Finishing Plant \#1 experienced a decline from 1994 through 1996, the year the work stoppage started (See Figure 47). During the first complete year of operations following the work stoppage the incidence rate rose slightly above the mean. This increase was followed by a decrease to the LCL in 1999 and a slight increase above the LCL in 2000.

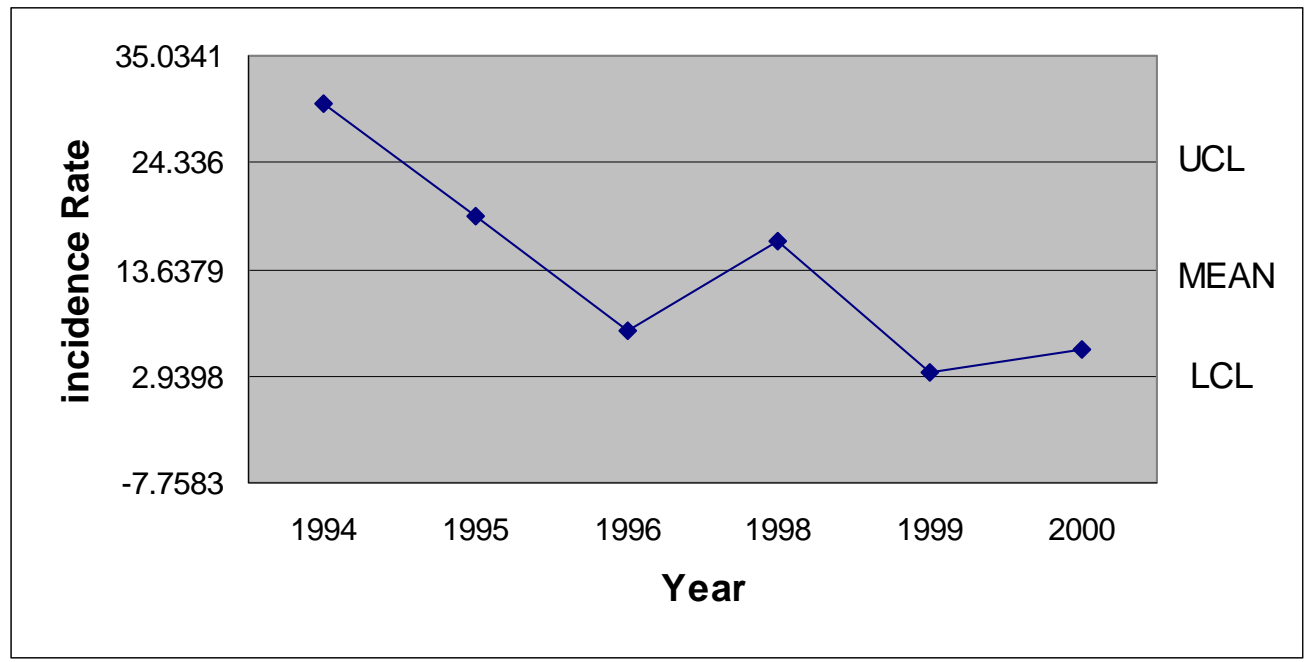

Note: No operations in March 1997

Figure 47. March 1994-2000 OSHA Recordable Incidence Rates - Finishing Plant \#1

For the month of April, the only incidence rate above the UCL for Finishing Plant \#1 occurred in 1994. April 1995 was close to the mean, while 1996 and 1998 appeared between the mean and the UCL. The last two months of April in this study were both recorded below the LCL of 4.78 (See Figure 48). 


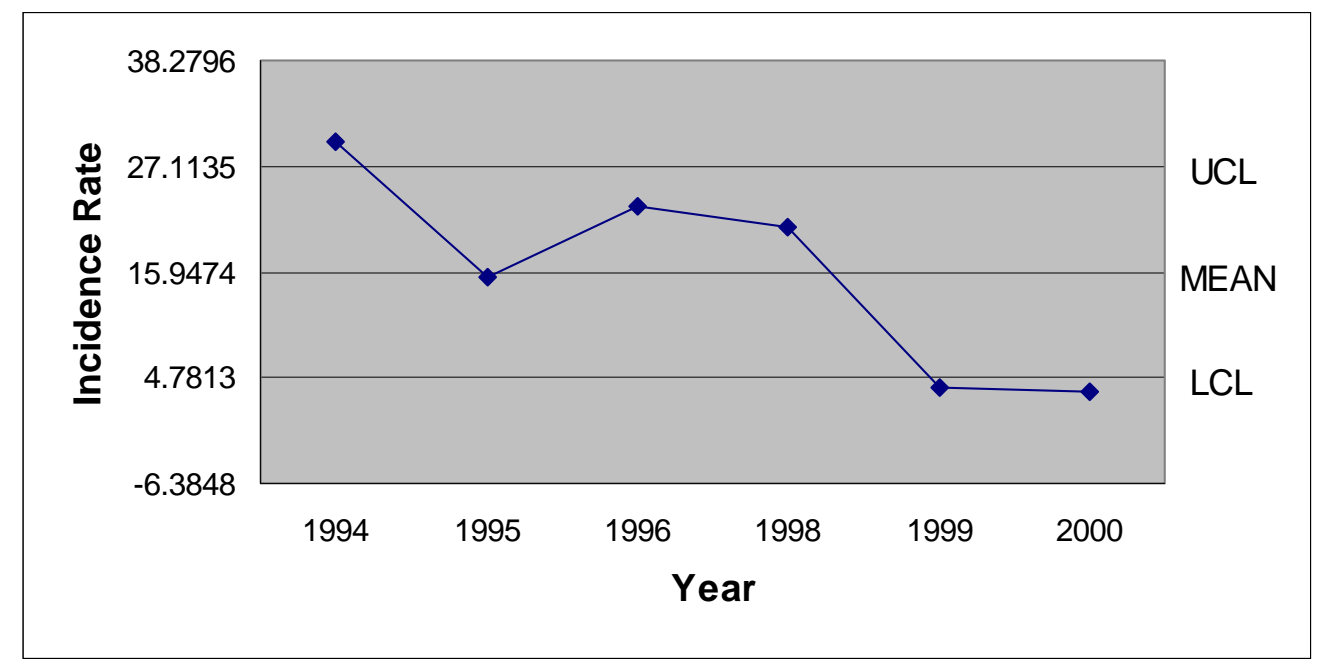

Note: No operations in April 1997

Figure 48. April 1994-2000 OSHA Recordable Incidence Rates - Finishing Plant \#1

As indicated in Figure 49, the highest incidence rate at Finishing Plant \#1, recorded in May 1994, was barely above the UCL, as was the incidence rate for May 1996. The period between May 1996 and May 1998 experienced a decrease from above the UCL to below the LCL. After the low in 1998, the incidence rate edged upward almost to the mean.

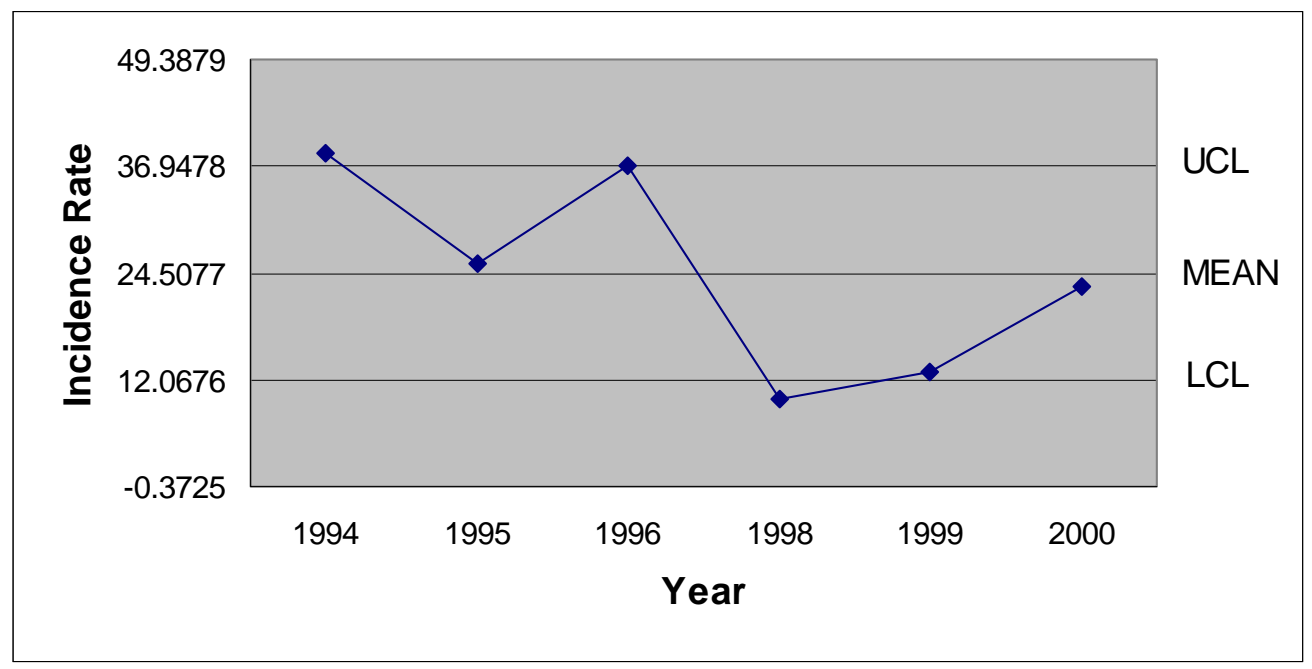

Note: No operations in May 1997

Figure 49. May 1994-2000 OSHA Recordable Incidence Rates - Finishing Plant \#1 
Finishing Plant \#1 experienced an incidence rate of 49.33 in June 1994. This was followed by two years with consecutively lower incidence rates. A slight increase was seen between 1996 and 1998. The last two years of the research bordered on the LCL of 5.03 (See Figure 50).

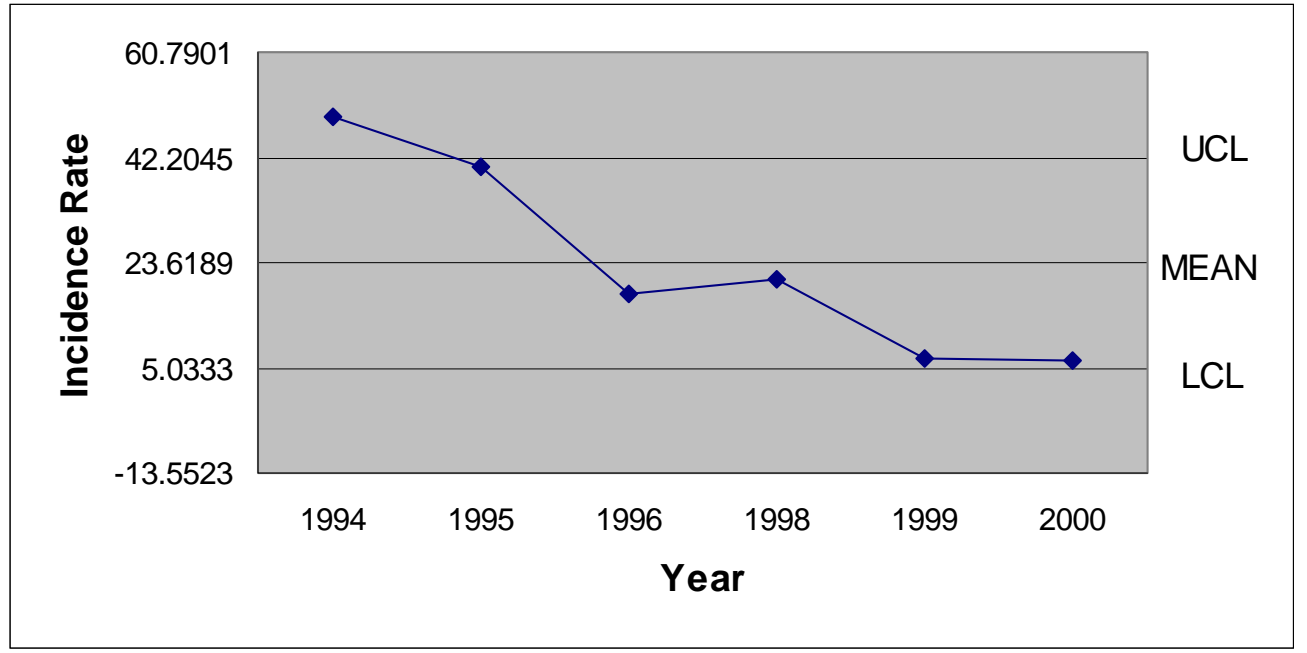

Note: No operations in June 1997

Figure 50. June 1994-2000 OSHA Recordable Incidence Rates - Finishing Plant \#1

The highest incidence rates in Finishing Plant \#1 occurred during the month of July, 1995. It was preceded by an incidence rate almost exactly between the mean and the UCL. The year immediately following the high was 85\% lower. In 1998 the incidence rate rose back to 16.79 and then dropped to 3.36 in 1999 (See Figure 51). 


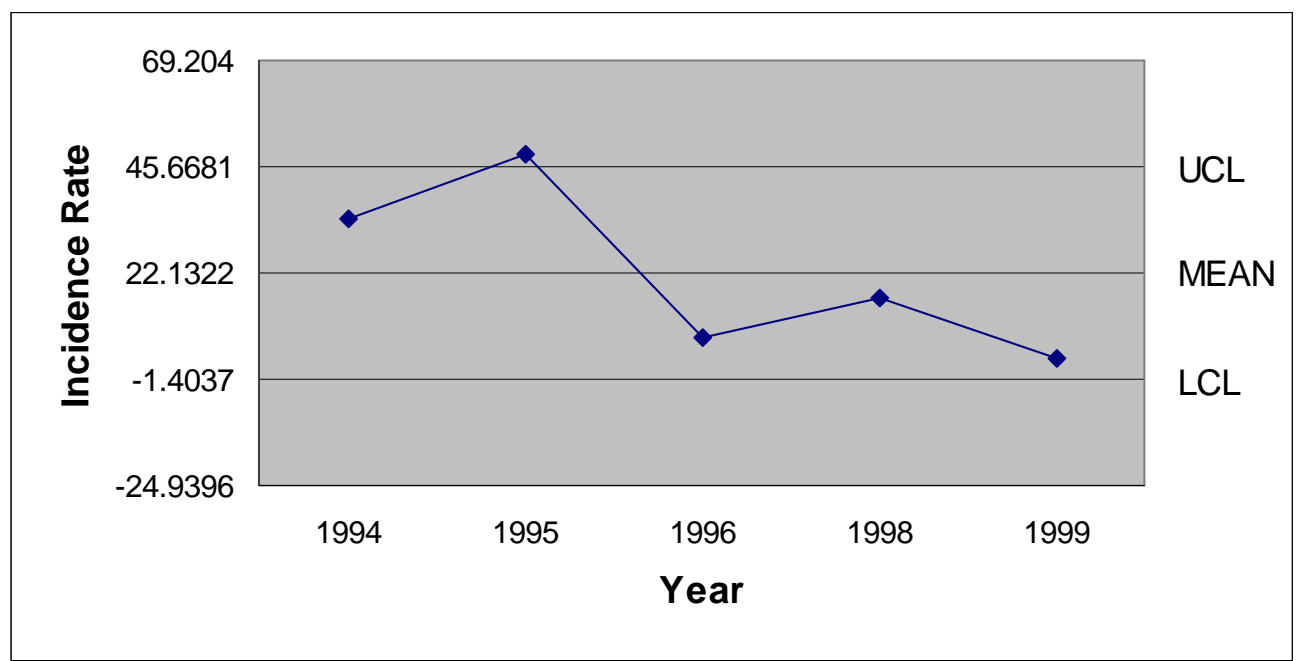

Note: No operations in July 1997

Figure 51. July 1994-1999 OSHA Recordable Incidence Rates - Finishing Plant \#1

The August 1995 incidence rate in Finishing Plant \#1 exceeded any of the other August rates by slightly over $80 \%$. The lowest August incidence rate of 9.96 occurred in 1998. The 1994, 1996 and 1999 incidence rates were all relatively close to the mean (See Figure 52).

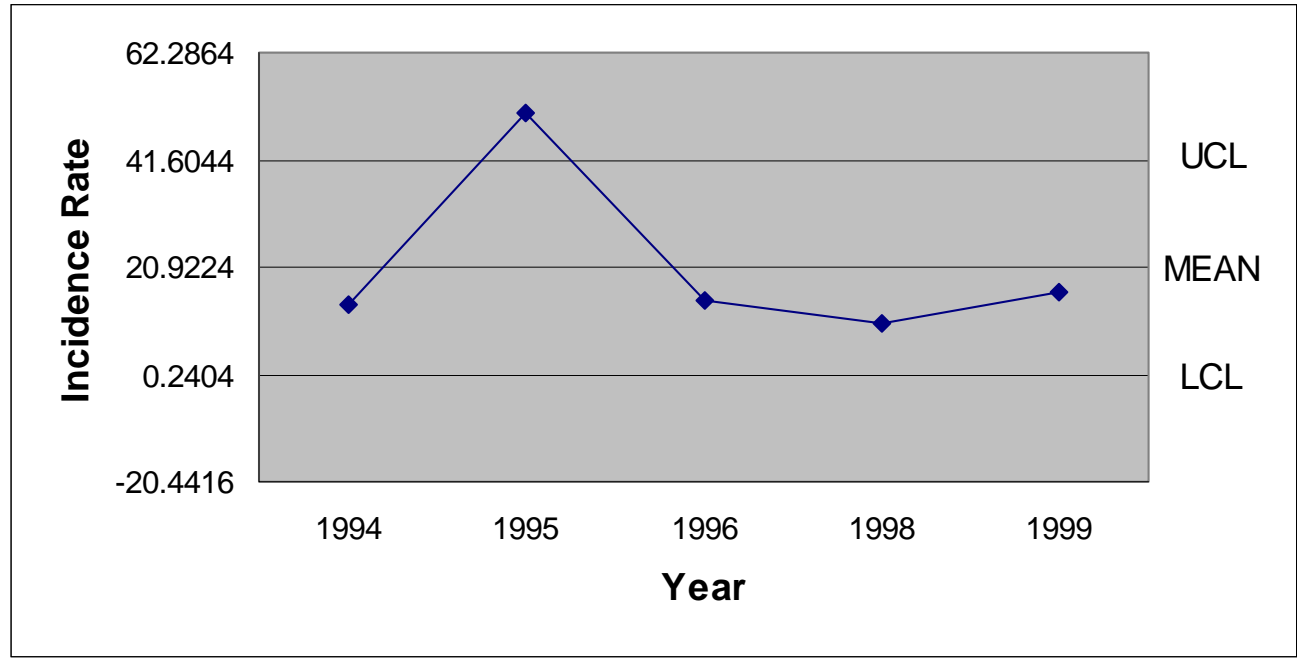

Note: No operations in August 1997

Figure 52. August 1994-1999 OSHA Recordable Incidence Rates - Finishing Plant \#1 
For the month of September the only incidence rate at Finishing Plant \#1 appearing outside the control limits was 1999, which was below the LCL. It was preceded the previous year by the highest incidence rate for the month of September (See Figure 53).

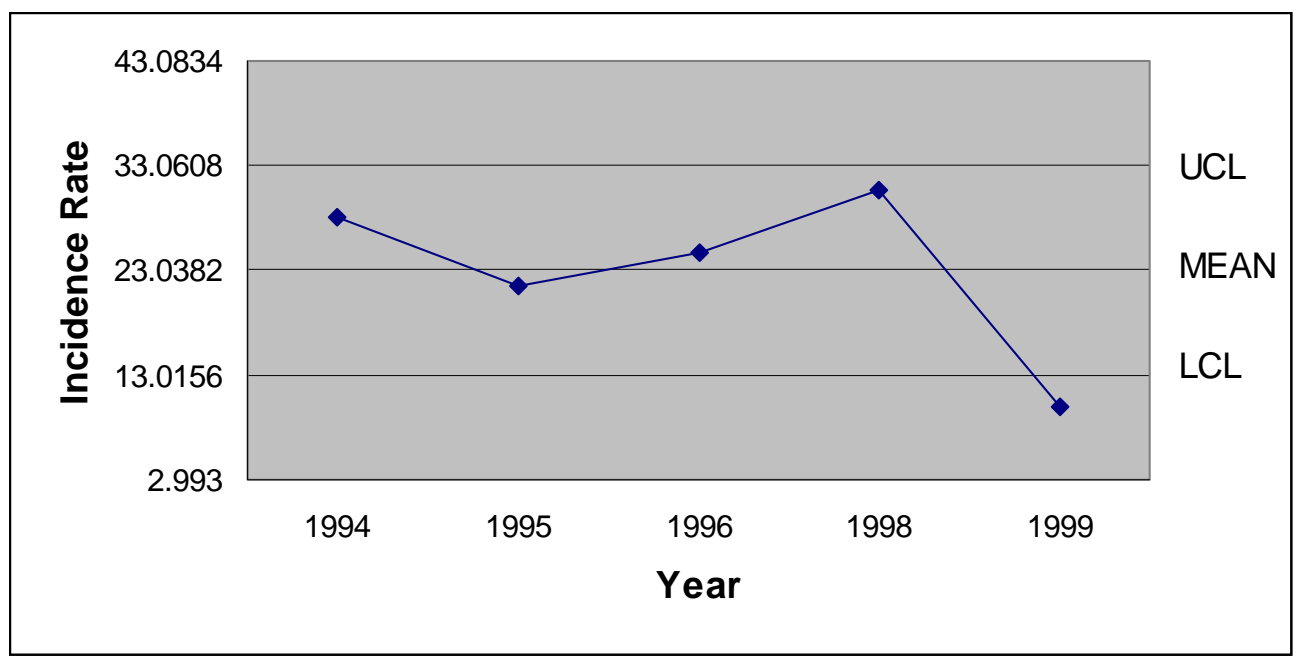

Note: No operations in September 1997

Figure 53. September 1994-1999 OSHA Recordable Incidence Rates - Finishing Plant $\# 1$

For Finishing Plant \#1 the incidence rates for the month of October decreased from slightly below the UCL in 1994 to slightly below the mean in 1995 (See Figure 54). The incidence rate rose above the mean again in 1997, but then dropped below the mean in 1998 and below the LCL in 1999. 


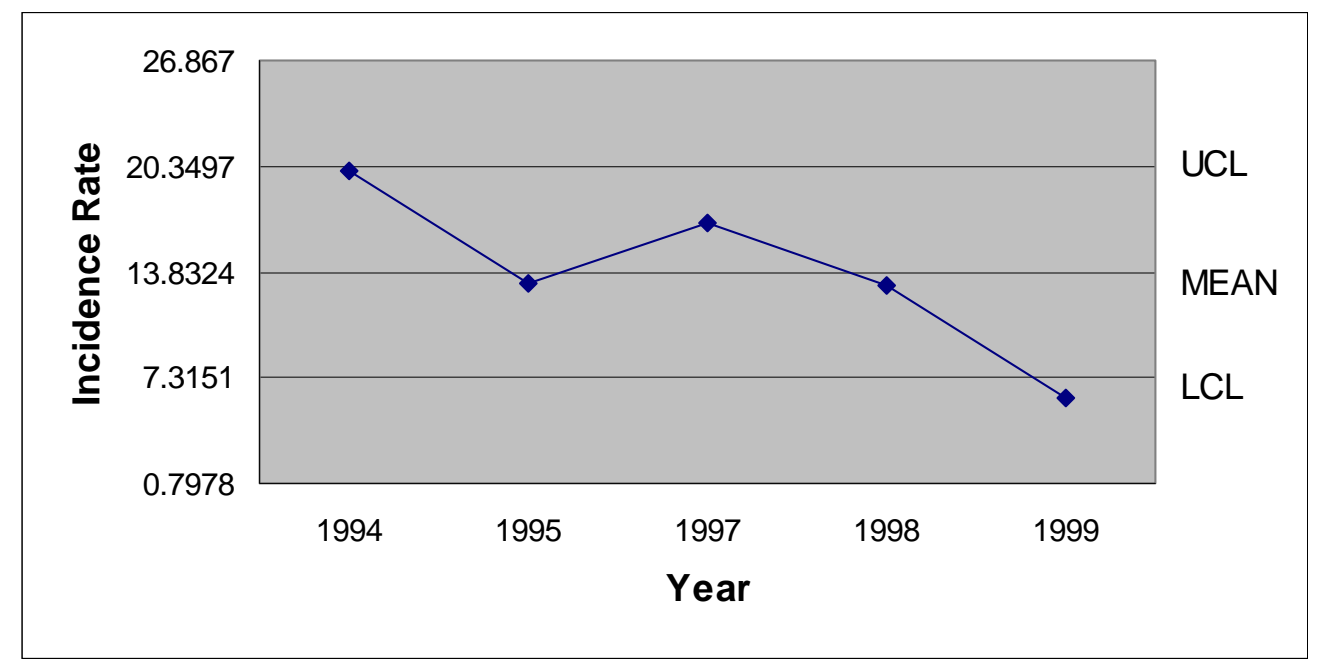

Note: No operations in October 1996

Figure 54. October 1994-1999 OSHA Recordable Incidence Rates - Finishing Plant \#1

As indicated in Figure 55, all incidence rates were within the control limits for the month of November at Finishing Plant \#1, except 1995. The highest incidence rate was more than double the lowest incidence rate. The 1994, 1998, and 1999 incidence rates were below the mean.

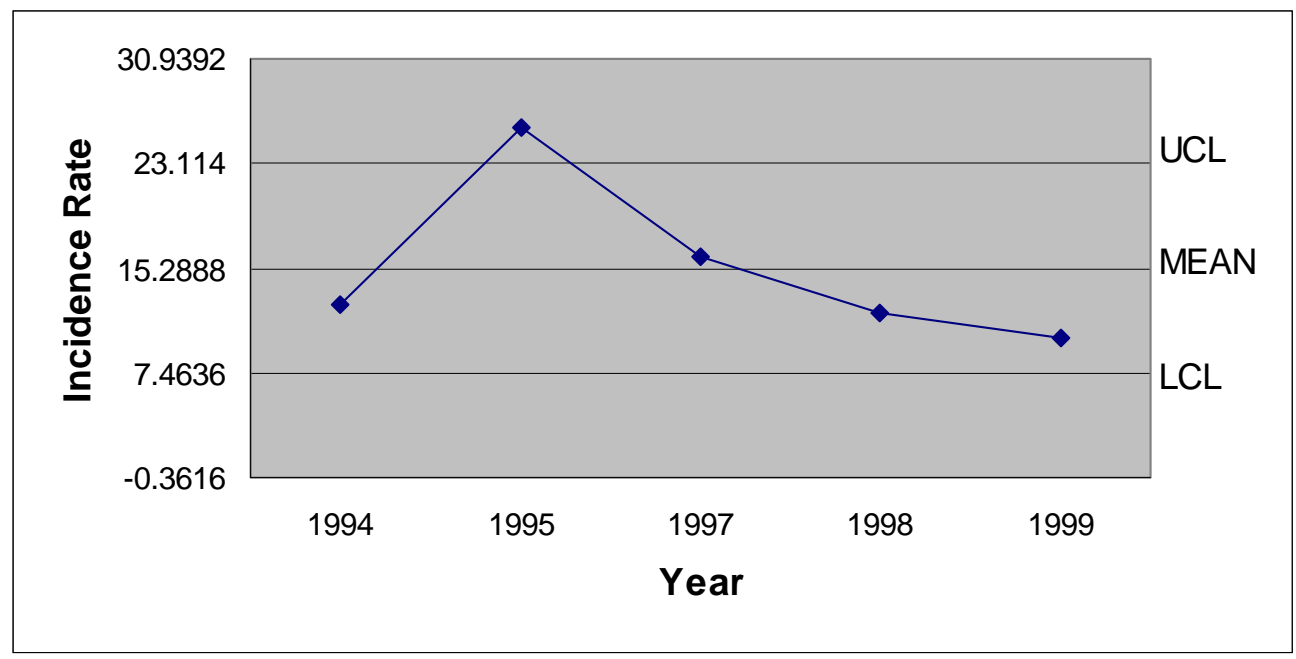

Note: No operations in November 1996

Figure 55. November 1994-1999 OSHA Recordable Incidence Rates - Finishing Plant $\# 1$ 
As shown in Figure 56, the month of December's highest incidence rate at Finishing Plant \#1 occurred in 1995. After the high in 1995, a decrease of over $50 \%$ was recorded for the next year. The following year remained at about the same level, while the final year decreased by over $40 \%$.

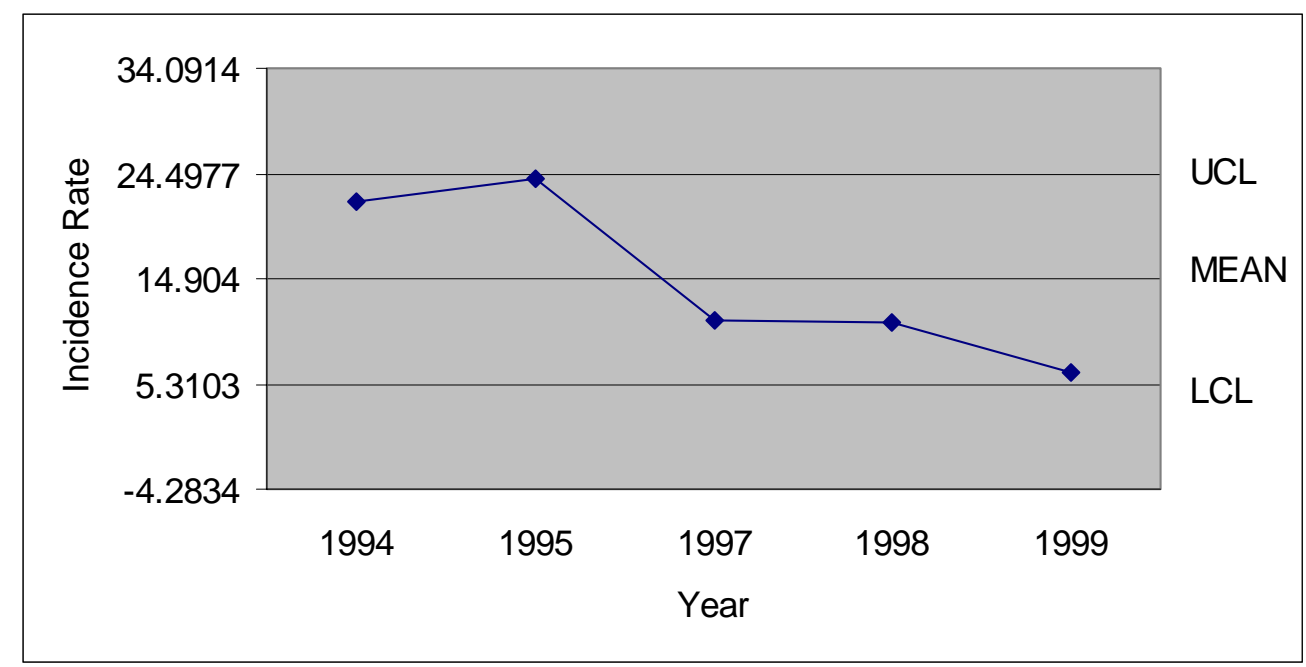

Note: No operations in December 1996

Figure 56. December 1994-1999 OSHA Recordable Incidence Rates - Finishing Plant $\# 1$

Table 11 presents the monthly incidence rates for each year of the study period at Finishing Plant \#1, as well as the UCL, mean, LCL, and standard deviation. Nineteen ninety-six and 1997 are partial years because of the work stoppage and only the first six months of 2000 were included in the research.

Table 11

Summary of Monthly OSHA Recordable Incidence Rates Data - Finishing Plant \#1

\begin{tabular}{|l|l|l|l|l|l|l|l|l|l|l|l|l|}
\hline & Jan. & Feb. & Mar. & Apr. & May & June & July & Aug. & Sept. & Oct. & Nov. & Dec. \\
\hline 1994 & 35.490 & 38.483 & 30.155 & 29.607 & 38.538 & 49.328 & 34.176 & 13.549 & 28.141 & 20.094 & 12.503 & 22.019 \\
\hline 1995 & 28.787 & 25.247 & 18.986 & 15.338 & 25.715 & 40.463 & 48.647 & 50.448 & 21.525 & 13.175 & 25.839 & 24.085 \\
\hline 1996 & 17.955 & 17.945 & 7.456 & 22.950 & 37.007 & 18.204 & 7.692 & 14.557 & 24.780 & N/A & N/A & N/A \\
\hline 1997 & N/A & N/A & N/A & N/A & N/A & N/A & N/A & N/A & N/A & 16.870 & 16.154 & 11.158 \\
\hline 1998 & 6.635 & 11.015 & 16.362 & 20.685 & 9.916 & 20.693 & 16.787 & 9.956 & 30.743 & 12.978 & 11.942 & 10.995 \\
\hline
\end{tabular}




\begin{tabular}{|l|l|l|l|l|l|l|l|l|l|l|l|l|}
\hline 1999 & 7.794 & 3.471 & 3.222 & 3.226 & 13.009 & 6.565 & 3.358 & 16.102 & 10.001 & 6.045 & 10.006 & 6.264 \\
\hline 2000 & 9.727 & 9.603 & 5.646 & 5.646 & 22.861 & 6.462 & N/A & N/A & N/A & N/A & N/A & N/A \\
\hline UCL & 30.358 & 30.918 & 24.336 & 24.336 & 36.948 & 42.205 & 45.668 & 41.604 & 33.061 & 20.350 & 23.114 & 24.498 \\
\hline Mean & 17.731 & 17.627 & 13.638 & 13.638 & 24.508 & 23.619 & 22.132 & 20.922 & 13.016 & 13.832 & 15.289 & 14.904 \\
\hline LCL & 5.105 & 4.337 & 2.940 & 2.940 & 12.068 & 5.033 & -1.404 & 0.240 & 3.610 & 7.315 & 7.464 & 5.310 \\
\hline SD & 4.911 & 5.169 & 4.161 & 4.343 & 4.839 & 7.229 & 8.478 & 7.450 & 3.610 & 2.348 & 2.819 & 3.456 \\
\hline
\end{tabular}

$\underline{\text { Seasonal Analysis of OSHA Recordable Data- Finishing Plant \#1 }}$

The seasonal index calculations were used to generate the monthly seasonal index figures, presented in Figure 57. The highest seasonal indexes occurred between May and September. May recorded the highest seasonal index for Finishing Plant \#1 and September recorded the second highest. The lowest seasonal index was recorded in March.

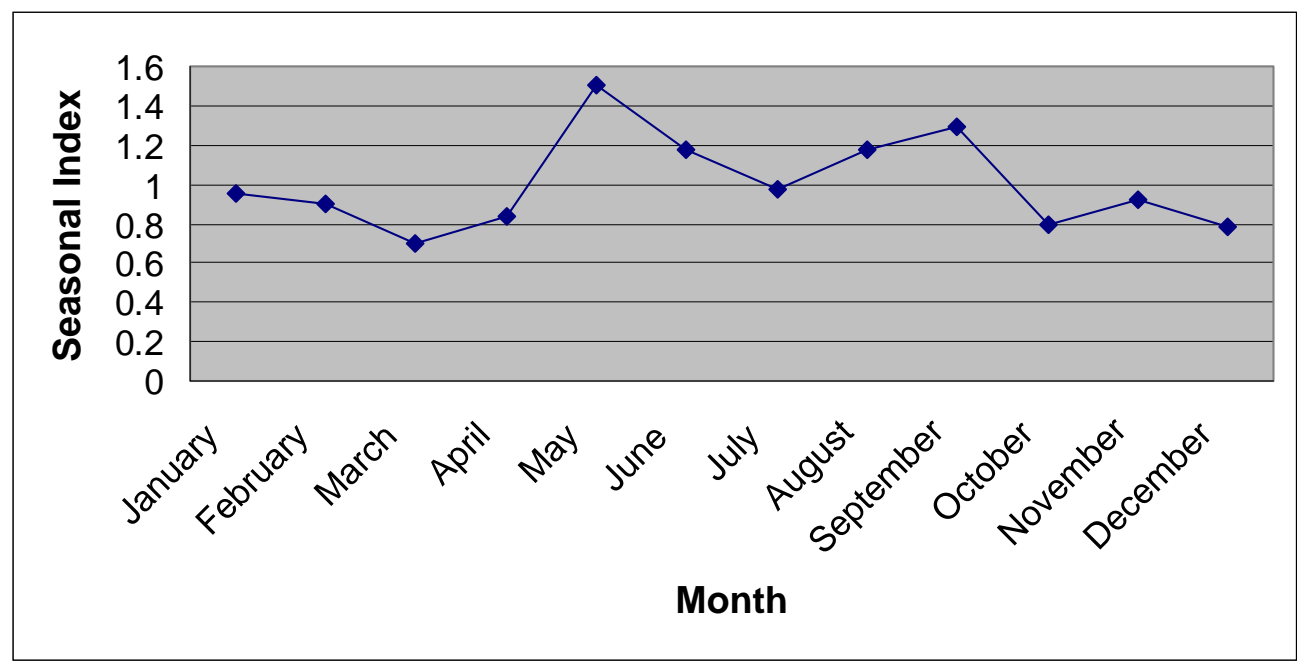

Figure 57. Monthly Seasonal Pattern of OSHA Recordable Incidence Rates - Finishing Plant \#1

\section{Testing the Periodic Statistical Relationship}

\section{All 33 Months Prior to and Subsequent to the Work Stoppage}

A comparison of incidence rate was calculated for the entire 33 months prior to the work stoppage and the 33 post work stoppage months at Finishing Plant \#1. The 8.01 calculated amount was greater than the 1.96 significant $t$ value. This indicated a statistically significant decrease in the incidence rates for the 33-month period following 
the work stoppage, compared to the 33 months prior to the work stoppage.

First 24 Months and Last 24 Months of the Research Period

The same comparison formula was applied to OSHA recordable incidence rates for the first 24 months of the research period and the last 24 months of the period at Finishing Plant \#1. These time periods excluded the nine months prior to and immediately following the work stoppage. The calculated amount was 8.41 and the .05 significance level amount was 1.96. Therefore, a statistically significant decrease in the incidence rate was recorded between these periods.

\section{Nine Month Intervals Prior to and Subsequent to the Work Stoppage}

The result of using the comparison formula, 1.26, was less than the 1.96 level of significance at the .05 level of significance. Because this calculated amount was less than the significance level, it was found that a statistically significant decrease in incidence rates did not occur between these nine-month intervals (See Table 12).

\section{Table 12}

Comparison of Prior and Post Work Stoppage Period - Finishing Plant \#1

\begin{tabular}{|l|l|l|l|l|}
\hline \multirow{2}{*}{ Time period } & \multicolumn{2}{|l|}{ Finishing Plant \#1 Incidence Rates } & \multirow{2}{*}{ Critical t value } & Calculated \\
\cline { 2 - 5 } & $\begin{array}{l}\text { Prior to } \\
\text { work stoppage }\end{array}$ & $\begin{array}{l}\text { Post } \\
\text { work stoppage }\end{array}$ & 1.96 & 1.26 \\
\hline 9 Months & 18.63 & 14.37 & 1.96 & $8.41^{* *}$ \\
\hline 24 Months & 28.84 & 9.99 & 1.96 & $8.01 * *$ \\
\hline 33 Months & 26.16 & 11.14 & & \\
\hline
\end{tabular}

* Indicates a statistically significant increase

** Indicates a statistically significant decrease

\section{Finishing Plant \#2 Analysis}

\section{Quarterly Analysis of OSHA Recordable Data - Finishing Plant \#2}

Finishing Plant \#2 experienced the highest first quarter incidence rate in 1996. The lowest first quarter incidence rate occurred in 2000. An increasing pattern was 
evident in the first three years and then a decreasing pattern developed over the next three periods (See Figure 58).

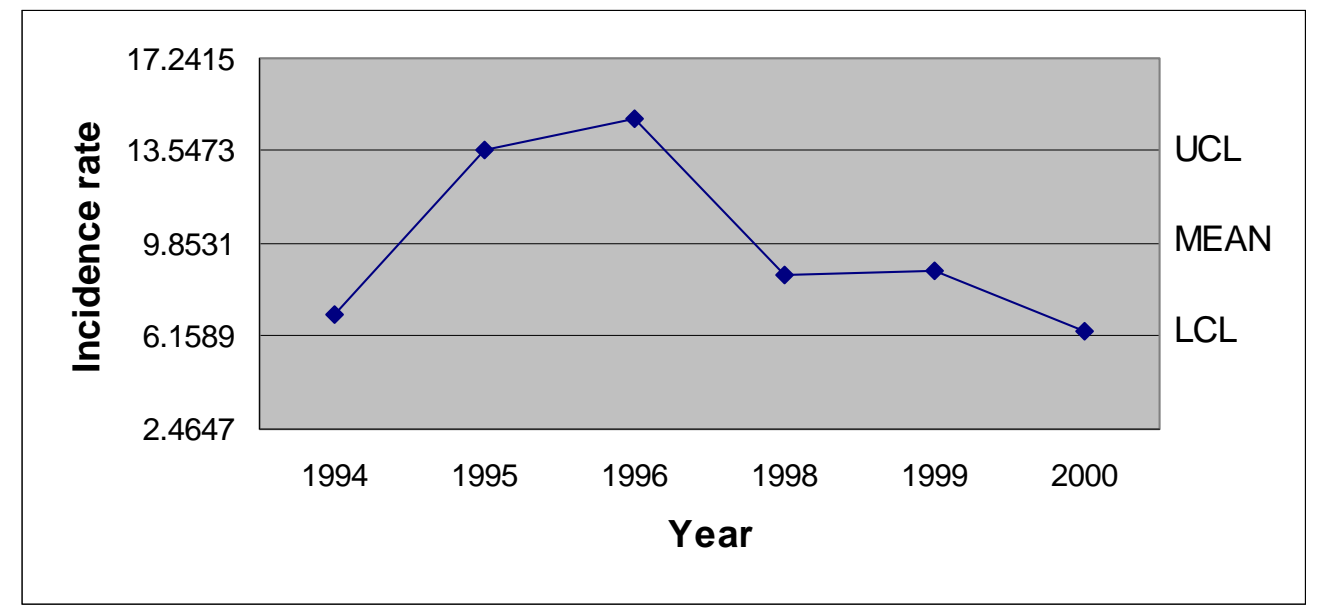

Note: No operations in first quarter of 1997

Figure 58. First Quarter 1994-2000 OSHA Recordable Incidence Rates - Finishing Plant \#2

Figure 59 illustrates the zigzag pattern experienced during the second quarter at Finishing Plant \#2. The first peak was in 1995 when the incidence rate fell just below the UCL. The second peak was the highest second quarter incidence rate and occurred in 1998. The highest incidence rate, 14.45, was followed in the next year by the lowest incidence rate, 6.31 . 


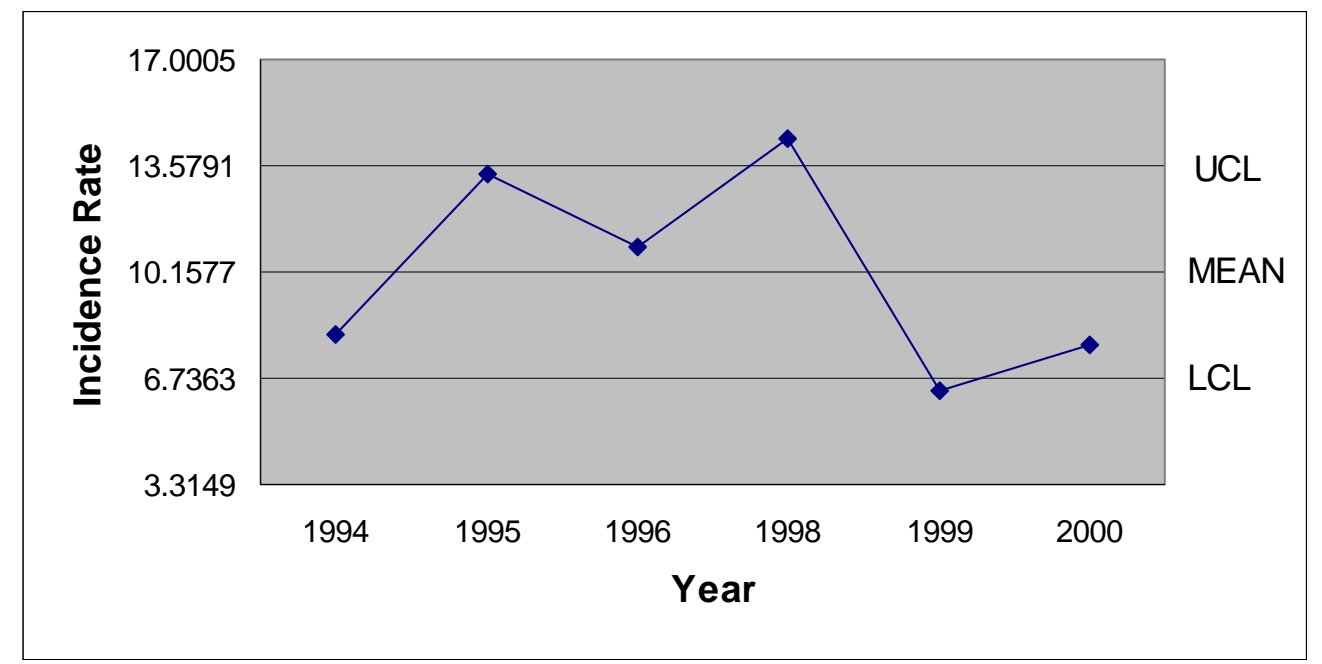

Note: No operations in second quarter of 1997

Figure 59. Second Quarter 1994-2000 OSHA Recordable Incidence Rates - Finishing Plant \#2

The lowest third quarter incidence rate at Finishing Plant \#2, 11.72, occurred in 1994 and was followed the next year by the highest incidence rate, 20.38. The next two periods, 1996 and 1998, decreased in magnitude to a point close to the LCL. The incidence rate for 1999, the last third quarter period in this study, was just below the mean (See Figure 60).

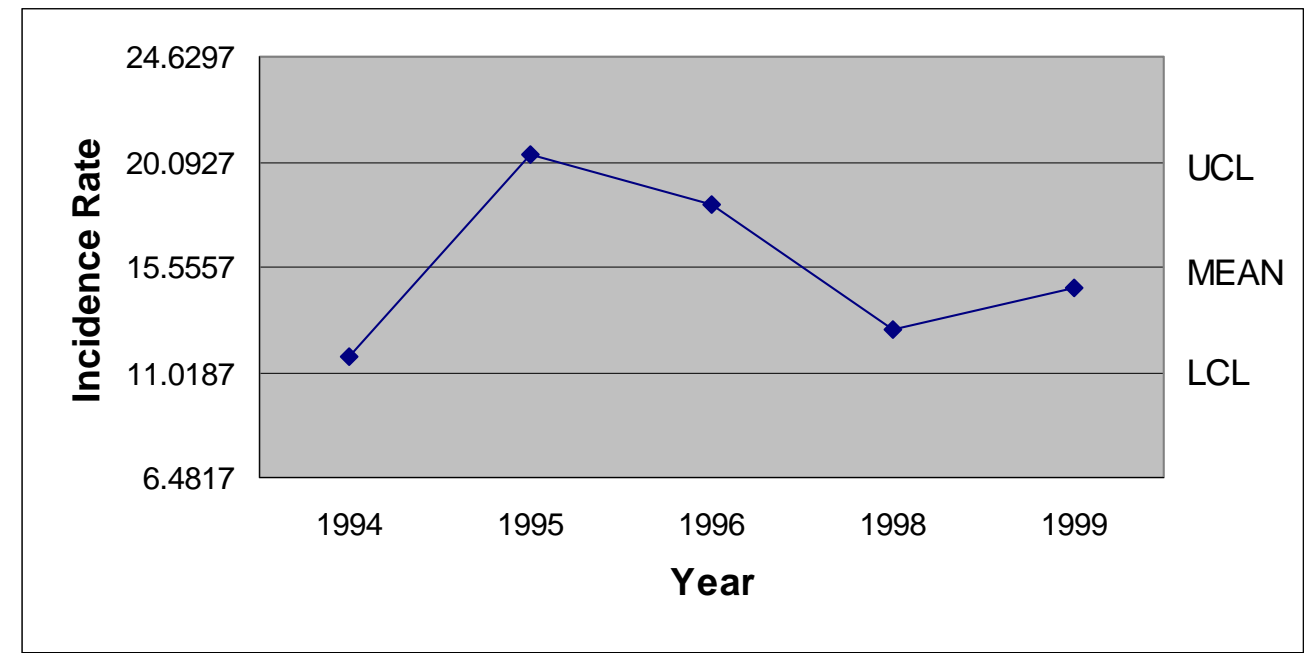

Note: No operations in third quarter of 1997

Figure 60. Third Quarter 1994-1999 OSHA Recordable Incidence Rates - Finishing Plant \#2 
Finishing Plant \#2 experienced an incidence rate just above the mean in 1994 and an incidence rate above the UCL in 1995. The 1995 fourth quarter rate was followed in subsequent years by three incidence rates below the mean but above the LCL (See Figure $61)$.

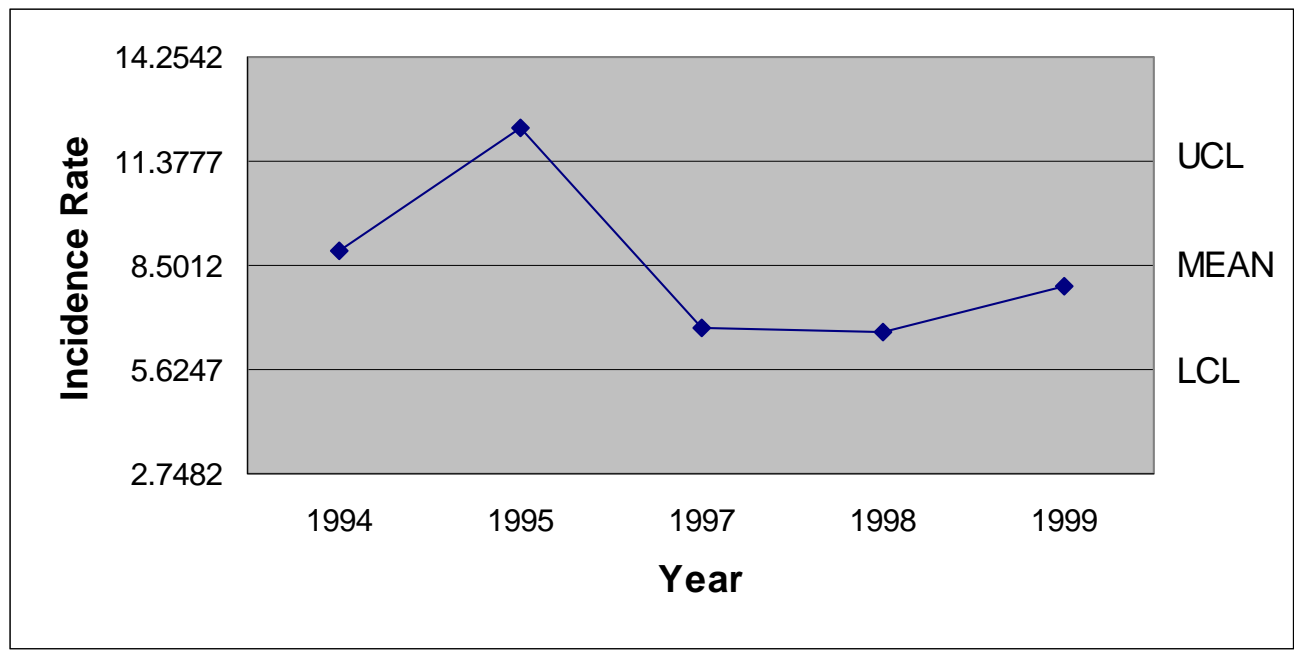

Note: No operations in fourth quarter of 1996

Figure 61. Fourth Quarter 1994-1999 OSHA Recordable Incidence Rates - Finishing Plant \#2

Table 13 contains Finishing Plant \#2's quarterly OSHA recordable incidence rates in a summary format. The UCL, LCL, mean, and standard deviation values are presented below the individual quarter statistics (See Table 13).

Table 13

Summary of Quarterly OSHA Recordable Incidence Rates Data - Finishing Plant \#2

\begin{tabular}{|l|r|r|r|r|}
\hline & \multicolumn{1}{|c|}{$1^{\text {st }}$ Quarter } & \multicolumn{1}{c|}{$2^{\text {nd }}$ Quarter } & $3^{\text {rd }}$ Quarter & \multicolumn{1}{c|}{$4^{\text {th }}$ Quarter } \\
\hline 1994 & 7.027 & 8.120 & 11.718 & 8.908 \\
\hline 1995 & 13.582 & 13.303 & 20.376 & 12.299 \\
\hline 1996 & 14.839 & 10.954 & 18.235 & 0.00 \\
\hline 1997 & 0.00 & 0.00 & 0.00 & 6.756 \\
\hline 1998 & 8.577 & 14.427 & 12.836 & 6.633 \\
\hline
\end{tabular}




\begin{tabular}{|l|r|r|r|r|}
\hline 1999 & 8.751 & 6.309 & 14.613 & 7.910 \\
\hline 2000 & 6.341 & 7.833 & 0.00 & 0.00 \\
\hline UCL & 13.547 & 13.579 & 20.093 & 11.377 \\
\hline MEAN & 9.853 & 10.158 & 15.556 & 8.501 \\
\hline LCL & 6.159 & 6.736 & 11.019 & 5.623 \\
\hline SD & 1.437 & 1.331 & 1.634 & 1.036 \\
\hline
\end{tabular}

\section{$\underline{\text { Seasonal Analysis of OSHA Recordable Data - Finishing Plant \#2 }}$}

Figure 62 contains the results of the quarterly seasonal index calculations. The incidence rates seasonal index indicates that the third quarter experienced the highest seasonal incidence rate for Finishing Plant \#2. The fourth quarter recorded the lowest seasonal index and was barely lower than the first quarter's seasonal index.

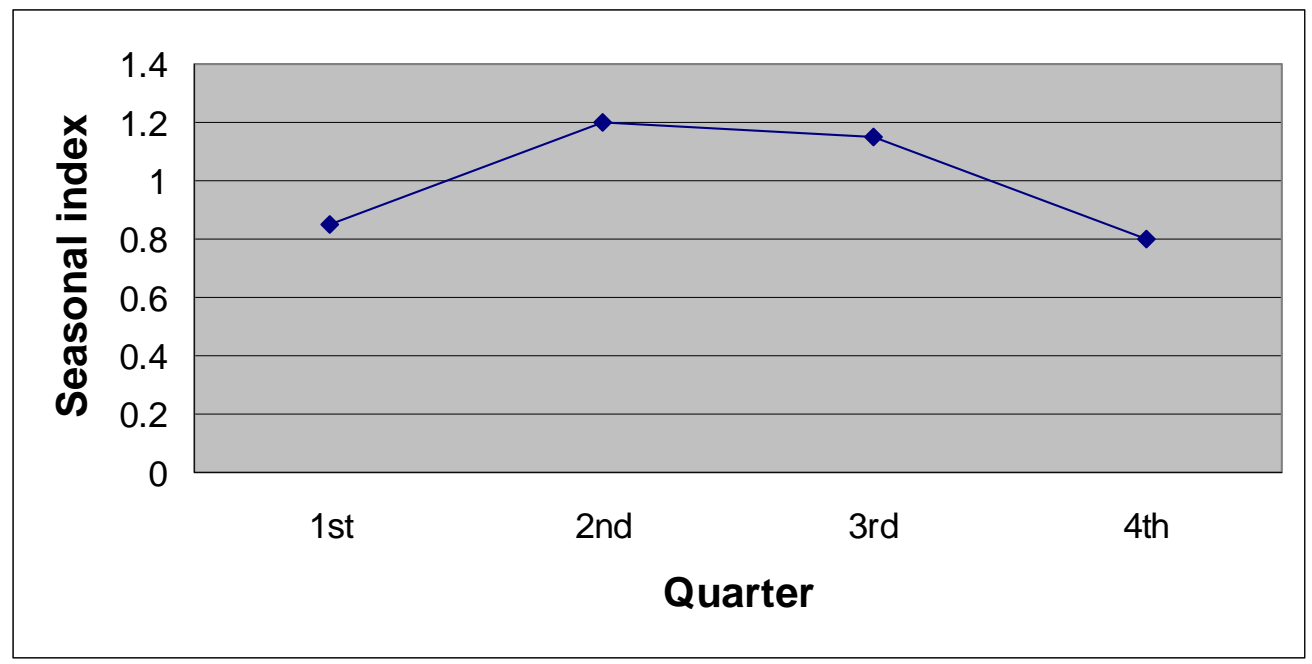

Figure 62. Quarterly Seasonal Index for OSHA Recordable Incidence Rates - Finishing Plant \#1

\section{Monthly Analysis of OSHA Recordable Data - Finishing Plant \#2}

Figure 63 shows the January 1994 incidence rate at Finishing Plant \#2 as being just above the LCL, while the 1995 incidence rate is almost on the UCL, and the 1996 incidence rate is above the UCL. This increasing trend was followed by a sharp decrease 
of over $71 \%$ in January 1998, the period immediately following the work stoppage. An increase in 1999 and an almost level incidence rate in 2000 followed the decrease.

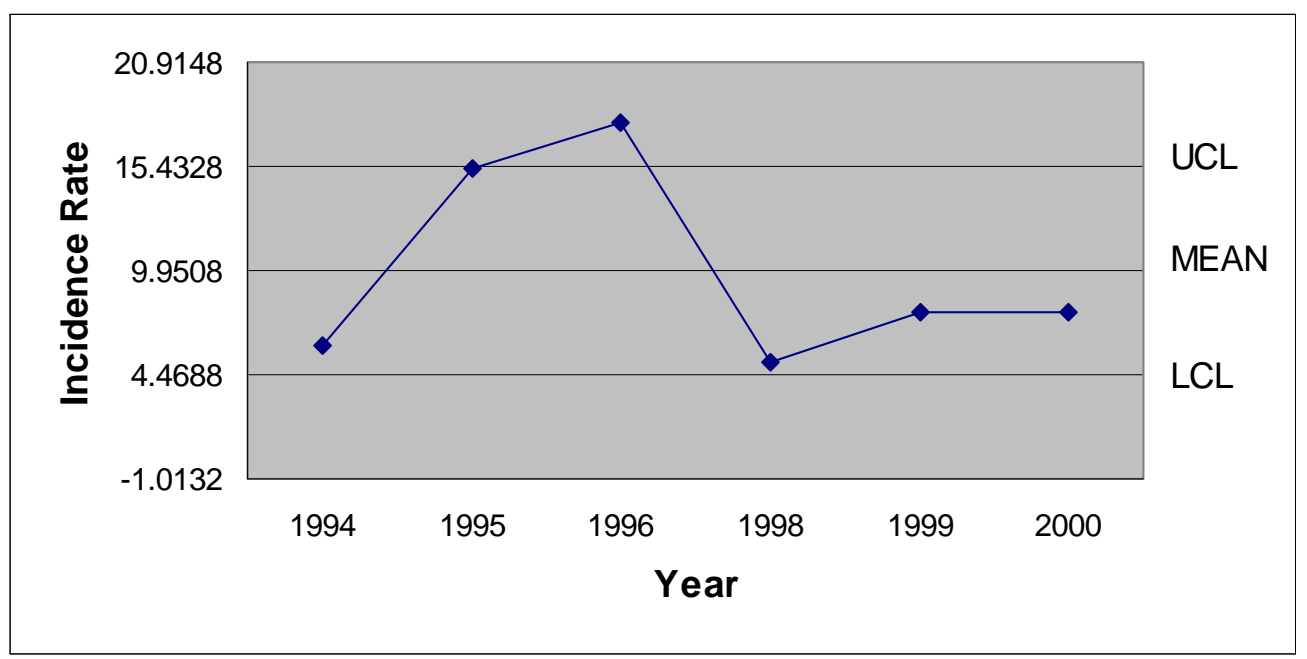

Note: No operations in January 1997

Figure 63. January 1994-2000 OSHA Recordable Incidence Rates - Finishing Plant \#2

The highest incidence rate at Finishing Plant \#2 for the month of February occurred in 1996. The lowest incidence rate occurred in 1999 and was followed by an almost identical rate in 2000. The decrease in incidence rate magnitude from 1996 to 2000 was $80 \%$ (See Figure 64).

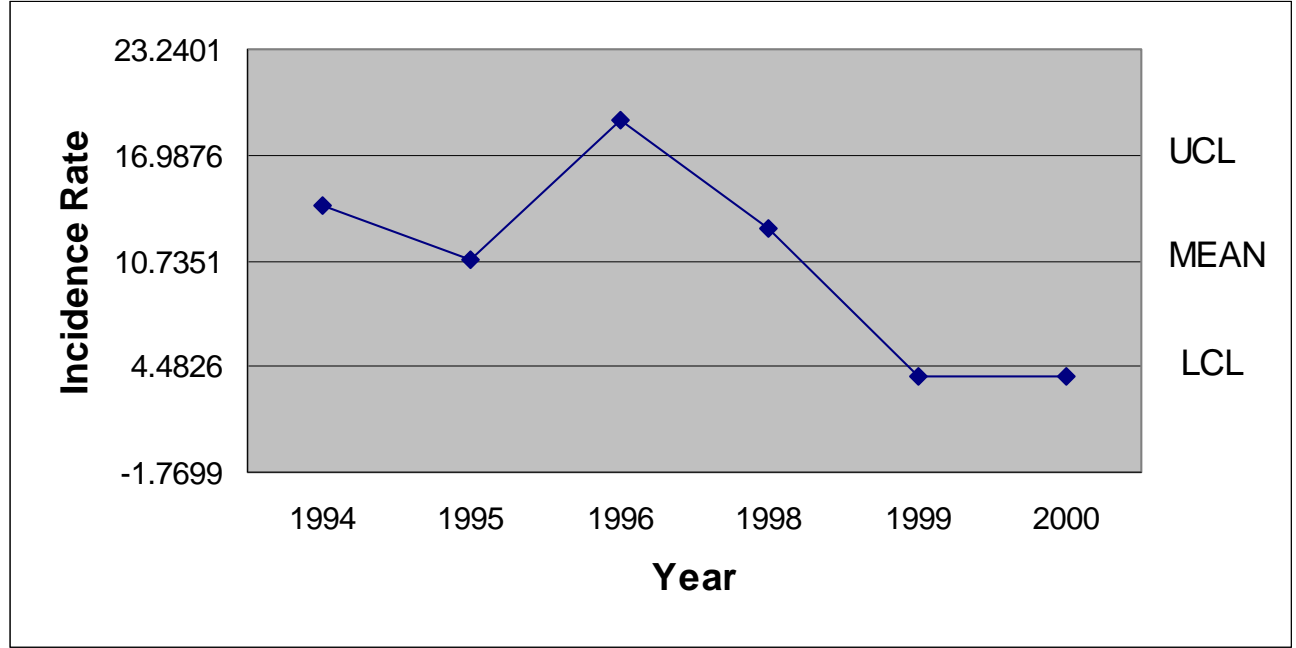

Note: No operations in February 1997

Figure 64. February 1994-2000 OSHA Recordable Incidence Rates - Finishing Plant \#2 
The lowest incidence rate experienced by Finishing Plant \#2 for the month of March was 2.222 in 1994. It was followed in 1995 by an incidence rate above the UCL. The next two years dropped below the mean and then 1999 jumped above the UCL. The incidence rate for the last year of this research appeared below the mean (See Figure 65).

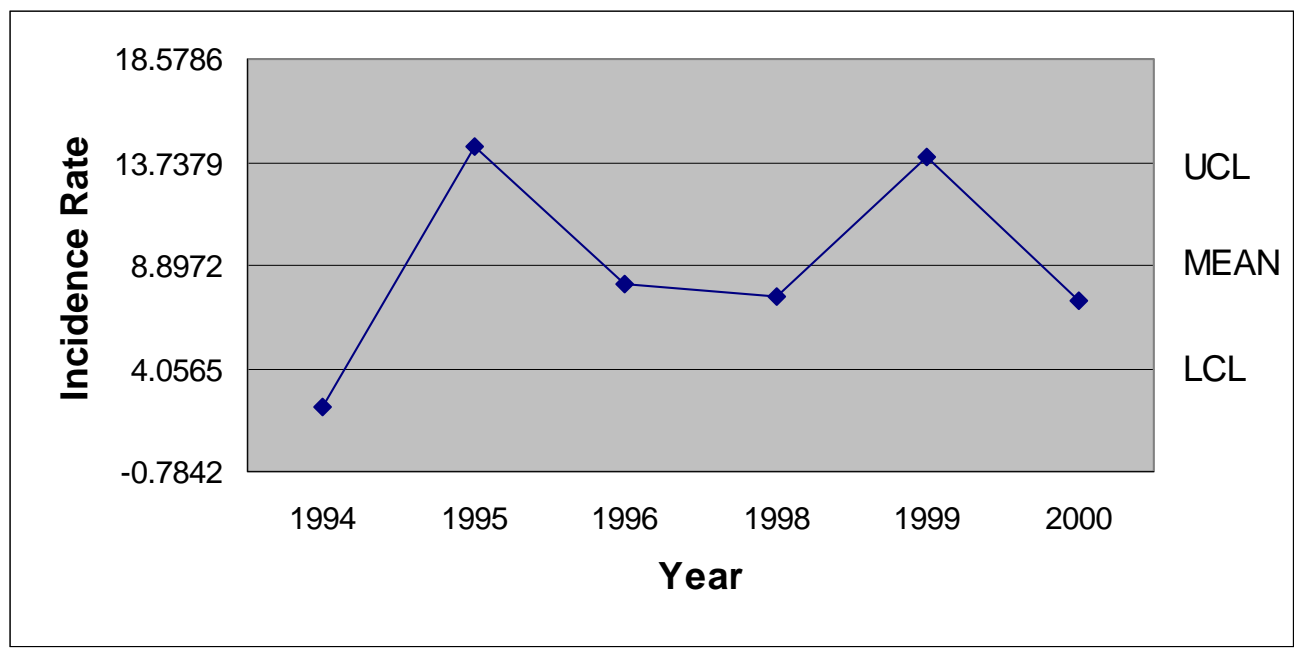

Note: No operations in March 1997

Figure 65. March 1994-2000 OSHA Recordable Incidence Rates - Finishing Plant \#2

As indicated in Figure 66, the incidence rate of 2.81 recorded at Finishing Plant \#2 in 1994 was only $18 \%$ of the magnitude of the 16.09 incidence rate recorded in 1995. Consecutive decreases were experienced in the next two years, while consecutive increases were experienced in the last two years. 


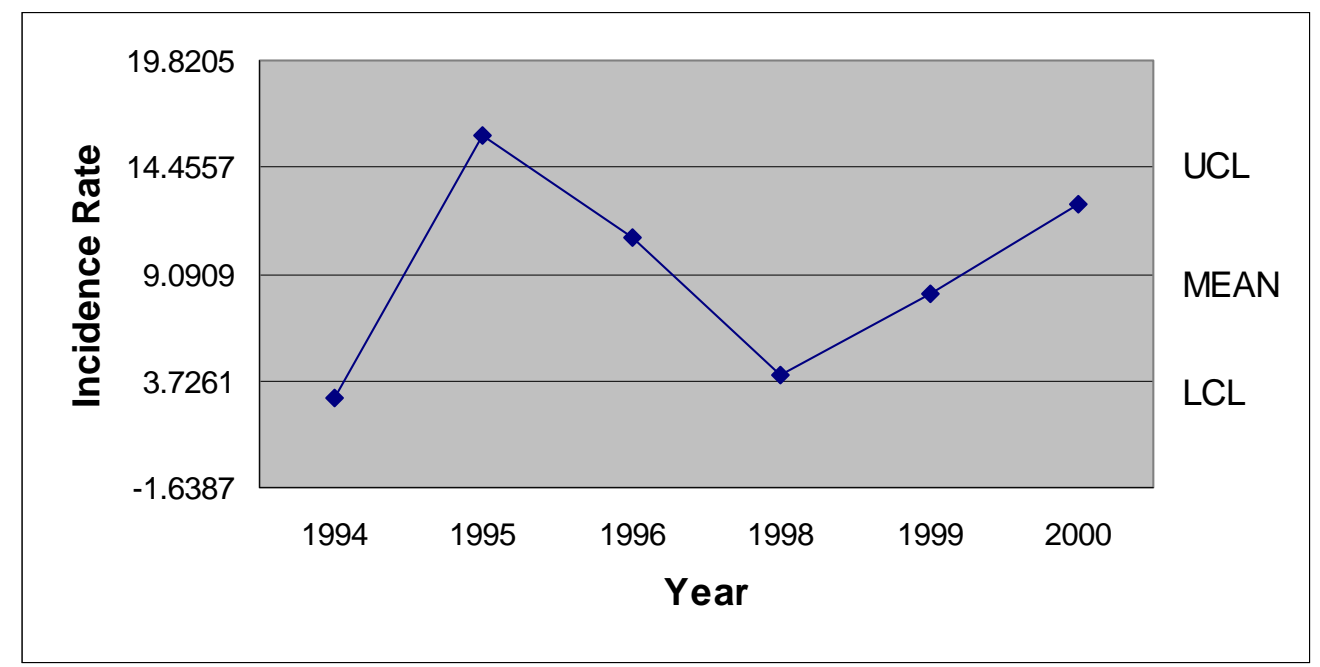

Note: No operations in April 1997

Figure 66. April 1994-2000 OSHA Recordable Incidence Rates - Finishing Plant \#2

May incidence rate at Finishing Plant \#2 experienced a gradual decline from just above the mean in 1994 to just below the mean in 1996. For the next period, 1998, the incidence rate was above the UCL. The 19.44 incidence rate recorded in 1998 was followed by a year without any May incidents and a low incidence rate of 3.78 in May 2000 (See Figure 67).

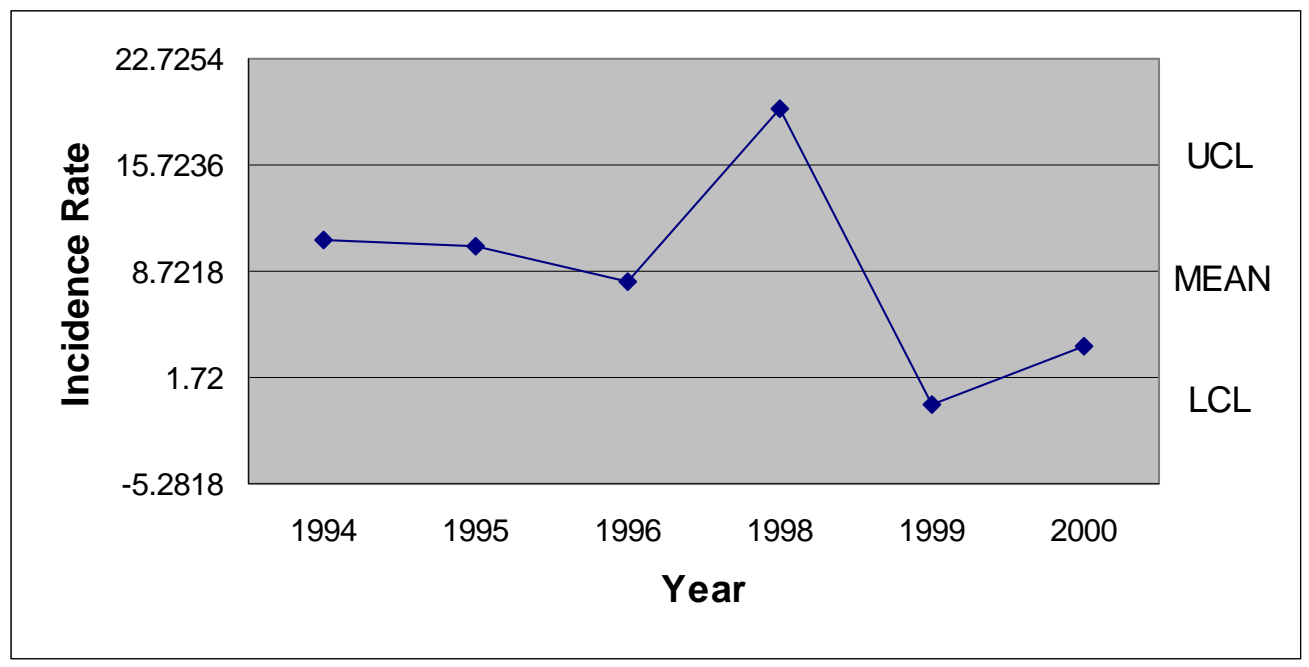

Note: No operations in May 1997

Figure 67. May 1994-2000 OSHA Recordable Incidence Rates - Finishing Plant \#2 
Figure 68 illustrates a steadily increasing trend in incidence rates from 1994 to 1998 at Finishing Plant \#2. A decrease in magnitude of over $40 \%$ in 1999 and a further decrease to just below the LCL in 2000 followed the peak in 1998.

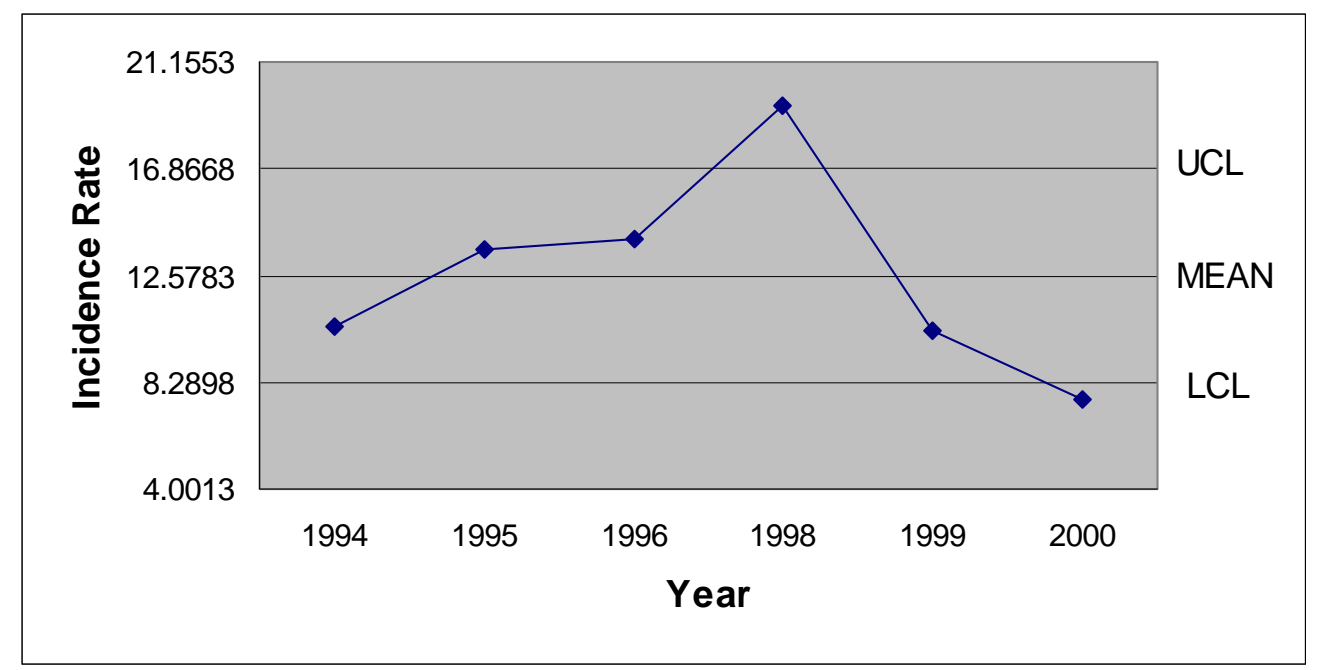

Note: No operations in June 1997

Figure 68. June 1994-2000 OSHA Recordable Incidence Rates - Finishing Plant \#2

For the month of July at Finishing Plant \#2, the lowest incidence rate was recorded in 1994 and was followed the next year by the highest incidence rate (See Figure 69). The 1998 incidence rate almost equaled the highest incidence rate. The 1998 peak was followed by a decline to a level between the mean and the LCL in 1999. 


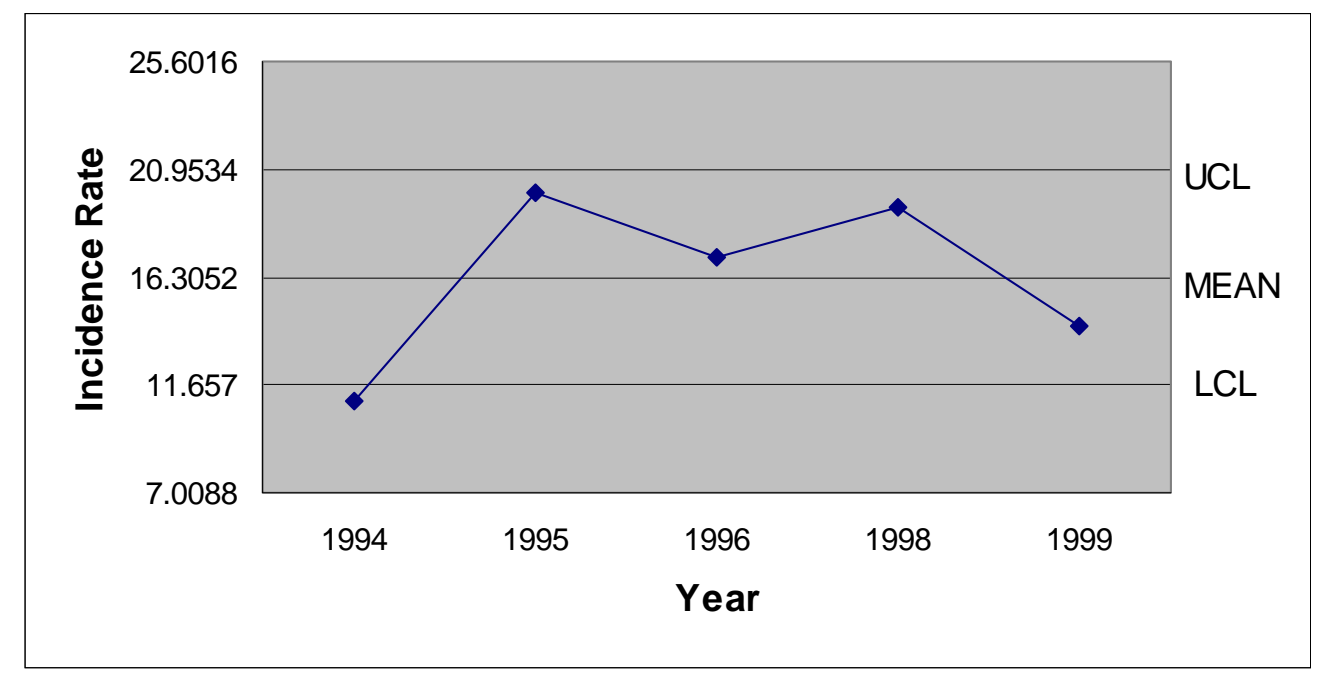

Note: No operations in July 1997

Figure 69. July 1994-1999 OSHA Recordable Incidence Rates - Finishing Plant \#2

The highest August incidence rate at Finishing Plant \#2 was just below the UCL in 1995. The next year the incidence rate was just below the mean and in 1999 the incidence rate fell to just below the LCL (See Figure 70).

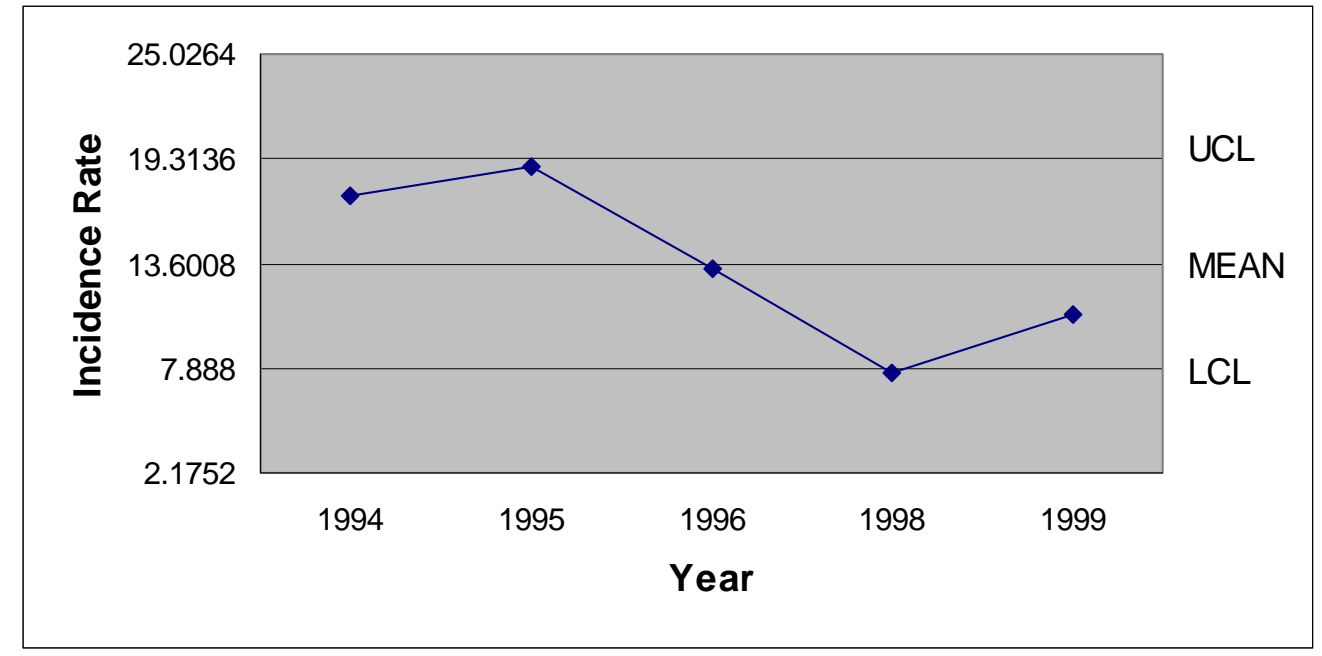

Note: No operations in August 1997

Figure 70. August 1994-1999 OSHA Recordable Incidence Rates - Finishing Plant \#2

As illustrated in Figure 71, the lowest September incidence rate at Finishing Plant \#2 occurred in 1994 and was followed by two years with higher incidence rates. The 
1996 incidence rate was the highest for the study period. In September 1998 the incidence rate again decreased to below the mean. However the 1999 incidence rate was recorded just above the mean.

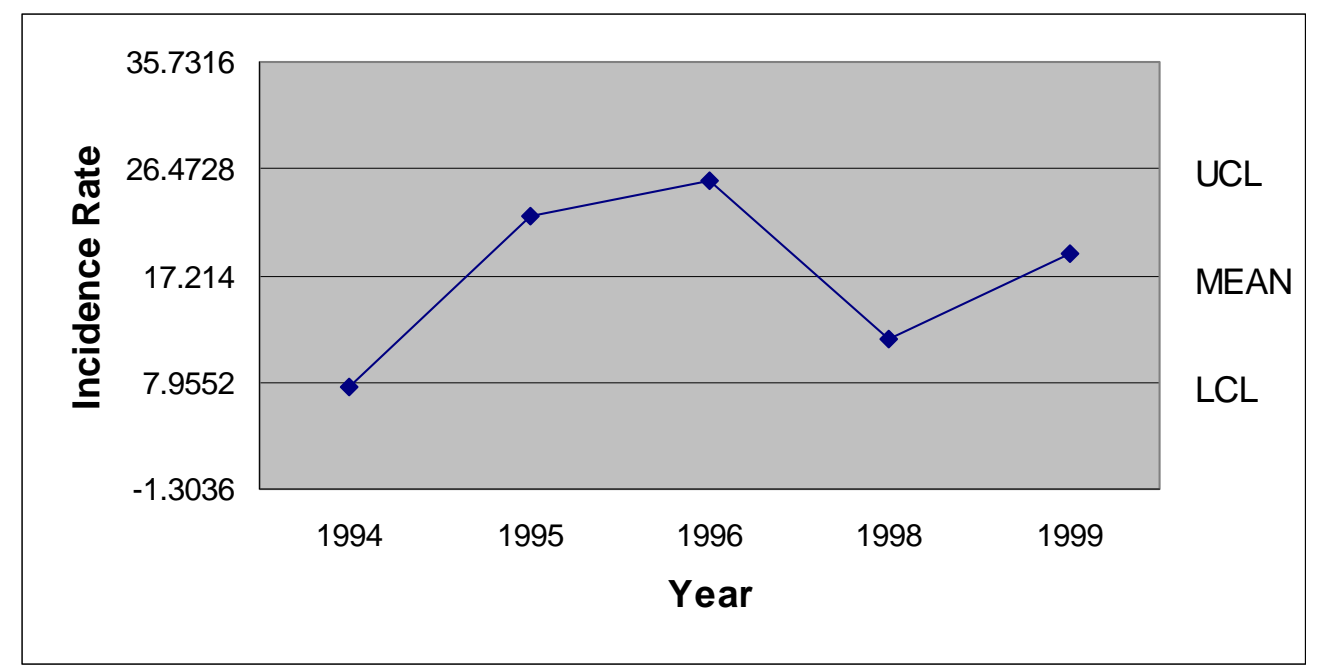

Note: No operations in September 1997

Figure 71. September 1994-1999 OSHA Recordable Incidence Rates - Finishing Plant \#2

The 1995 October incidence rate was the highest for the month during the period researched at Finishing Plant \#2. It was flanked by the lowest and next to the lowest rates, 1994 and 1997 respectively. The 1998 and 1999 incidence rates appeared just above the mean and were almost identical (See Figure 72). 


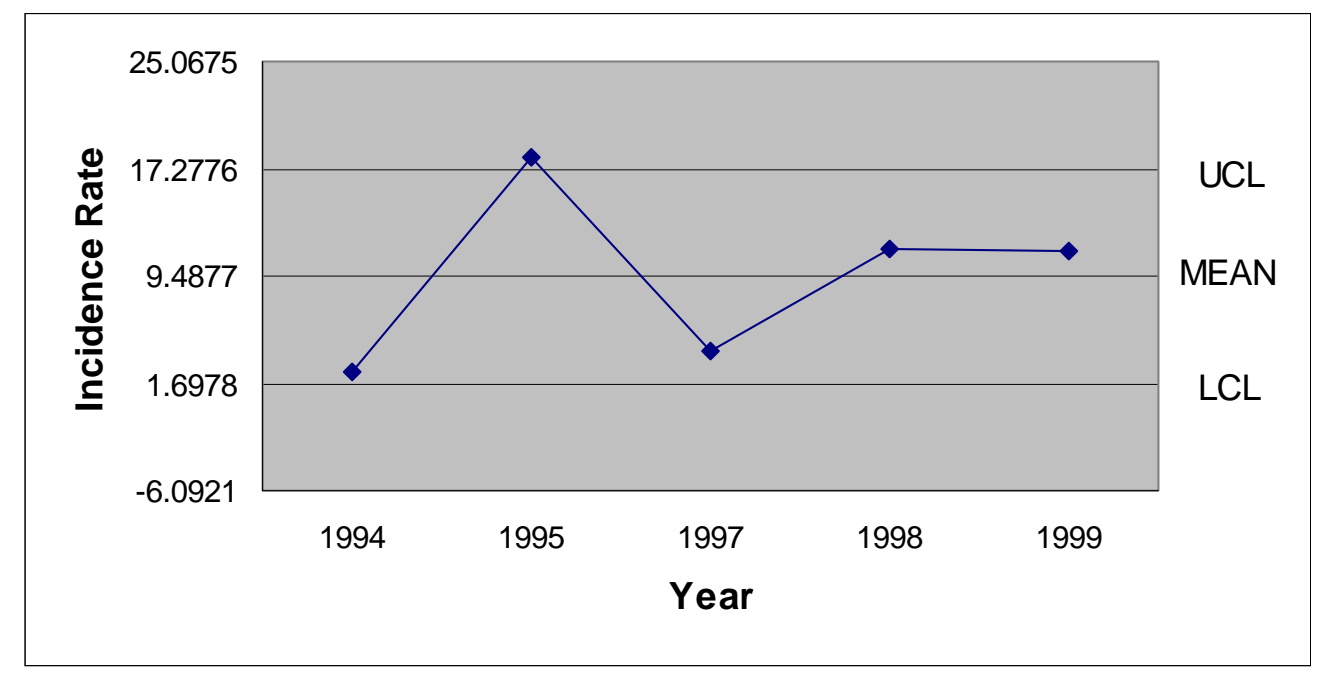

Note: No operations in October 1996

Figure 72. October 1994-1999 OSHA Recordable Incidence Rates - Finishing Plant \#2

The month of November at Finishing Plant \#2 experienced a decreasing trend from 1994 through1998. The 1994 incidence rate was above the UCL and the 1998 rate was below the LCL. The overall magnitude decrease between 1994 and 1998 was almost $70 \%$. The incidence rate for 1999 increased to just below the mean incidence rate of 9.48 (See Figure 73).

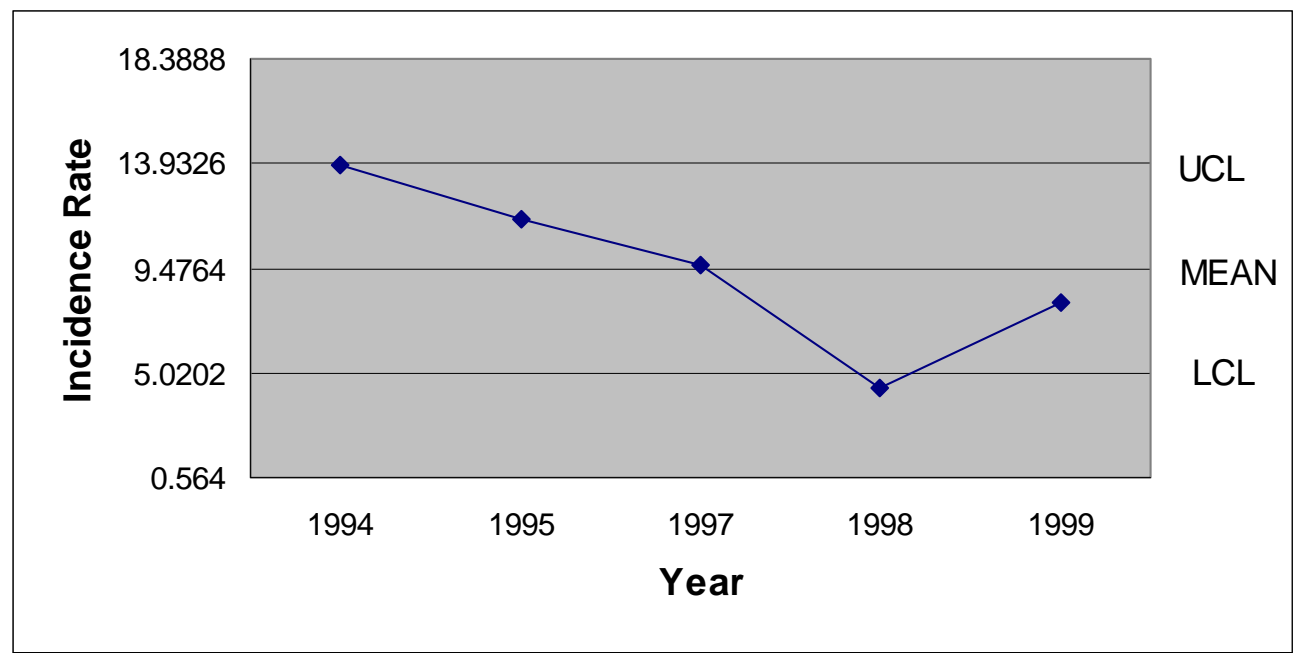

Note: No operations in November 1996

Figure 73. November 1994-1999 OSHA Recordable Incidence Rates - Finishing Plant \#2 
Finishing Plant \#2 experienced its highest December incidence rate in 1997 (See Figure 74). The lowest December rate followed in 1998. All of the incidence rates were within the control limits for the month of December.

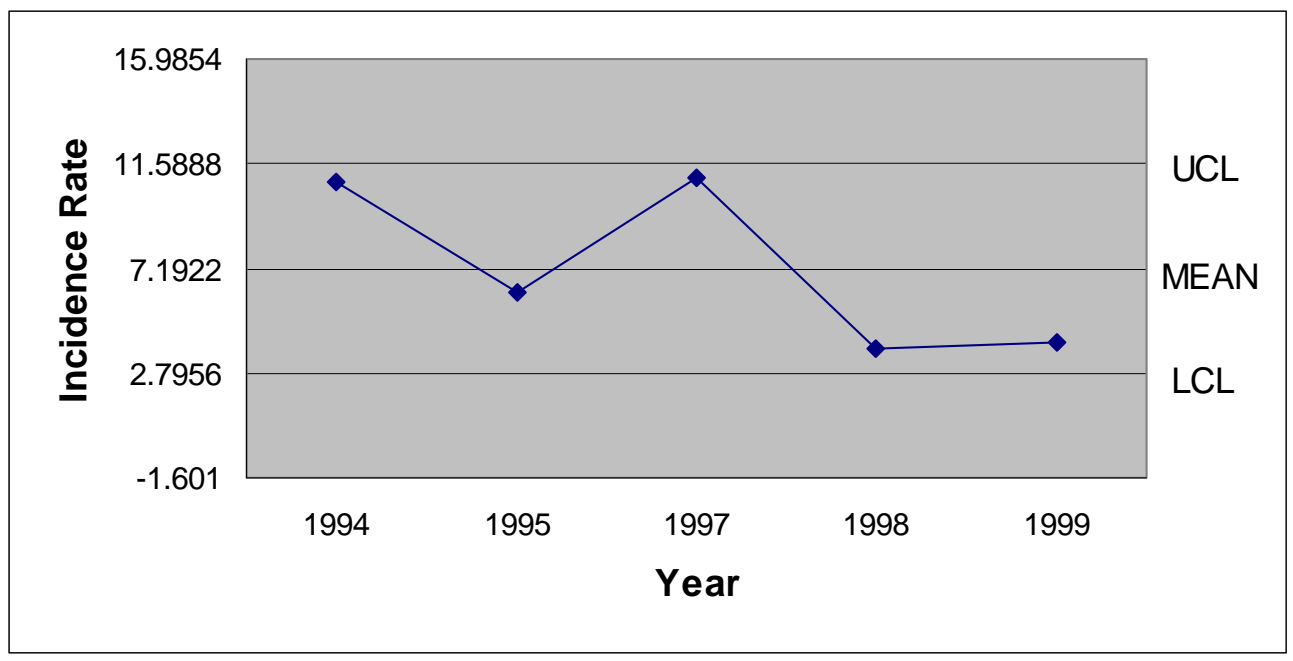

Note: No operations in December 1996

Figure 74. December 1994-1999 OSHA Recordable Incidence Rates - Finishing Plant \#2

Table14 presents the monthly incidence rates for each year of the study period, as well as, the UCL, mean, LCL, and standard deviation. Because of the work stoppage, 1996 and 1997 were partial years and only the first six months of 2000 were included in the research.

Table 14

$\underline{\text { Summary of Monthly OSHA Recordable Incidence Rates Data - Finishing Plant \#1 }}$

\begin{tabular}{|l|l|l|l|l|l|l|l|l|l|l|l|l|}
\hline & Jan. & Feb. & Mar. & Apr. & May & June & July & Aug. & Sept. & Oct. & Nov. & Dec. \\
\hline 1994 & 6.024 & 14.028 & 2.222 & 2.812 & 10.757 & 10.503 & 10.956 & 17.345 & 7.530 & 2.547 & 13.827 & 10.857 \\
\hline 1995 & 15.277 & 10.802 & 14.459 & 16.095 & 10.313 & 13.626 & 19.931 & 18.831 & 22.424 & 18.053 & 11.595 & 6.167 \\
\hline 1996 & 17.704 & 19.066 & 8.061 & 10.932 & 8.035 & 14.036 & 17.183 & 13.345 & 25.417 & N/A & N/A & N/A \\
\hline 1997 & N/A & N/A & N/A & N/A & N/A & N/A & N/A & N/A & N/A & 4.111 & 9.569 & 11.025 \\
\hline 1998 & 5.156 & 12.704 & 7.423 & 4.047 & 19.441 & 19.367 & 19.295 & 7.620 & 11.653 & 11.429 & 4.382 & 3.801 \\
\hline
\end{tabular}




\begin{tabular}{|l|l|l|l|l|l|l|l|l|l|l|l|l|}
\hline 1999 & 7.792 & 3.903 & 13.936 & 8.067 & 0.00 & 10.348 & 14.161 & 10.864 & 19.045 & 11.297 & 8.008 & 4.111 \\
\hline 2000 & 7.751 & 3.908 & 7.283 & 12.593 & 3.784 & 7.591 & N/A & N/A & N/A & N/A & N/A & N/A \\
\hline UCL & 15.433 & 16.988 & 13.738 & 14.456 & 15.723 & 16.867 & 20.953 & 19.314 & 26.473 & 17.278 & 13.932 & 11.589 \\
\hline Mean & 9.951 & 10.735 & 8.897 & 9.091 & 8.722 & 12.578 & 16.305 & 13.601 & 17.214 & 9.488 & 9.476 & 7.192 \\
\hline LCL & 4.469 & 4.483 & 4.056 & 3.726 & 1.720 & 8.290 & 11.657 & 7.888 & 7.955 & 1.698 & 5.020 & 2.796 \\
\hline SD & 2.132 & 2.432 & 1.883 & 2.087 & 2.723 & 1.668 & 1.674 & 2.058 & 3.335 & 2.806 & 1.605 & 1.584 \\
\hline
\end{tabular}

Seasonal Analysis of Monthly OSHA Recordable Data - Finishing Plant \#2

The seasonal index for Finishing Plant \#2 indicated that the highest seasonal index for incidence rates occurred in the month of October. The next highest seasonal indices were in July, August, and June respectively. The lowest seasonal index occurred in December, while May demonstrated the second lowest seasonal index (See Figure 75).

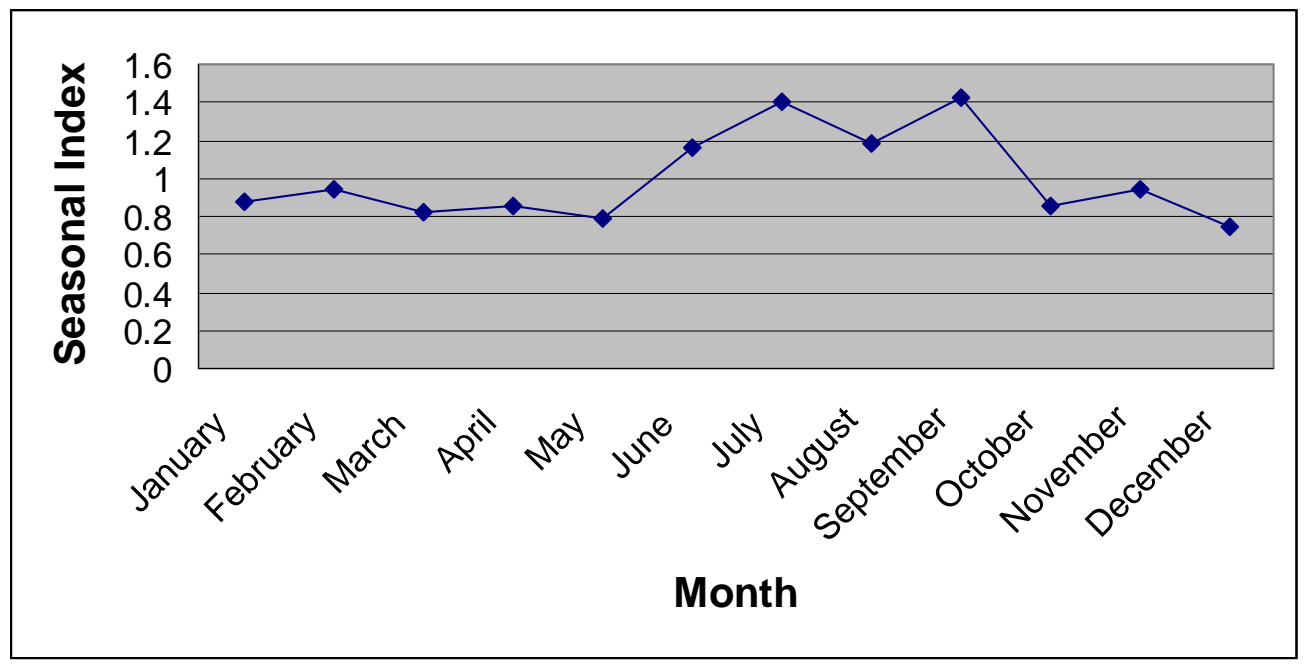

Figure 75. Monthly Seasonal Pattern of OSHA Recordable Incidence Rates - Finishing Plant \#2

Testing the Periodic Statistical Relationship at Finishing Plant \#2 All 33 months prior to and subsequent to the work stoppage

The result of the incidence rates comparison formula, 2.18, was greater than the critical $t$ value of 1.96. Therefore a statistically significant decrease in incidence rates occurred at Finishing Plant \#2 between the 33 months prior to the work stoppage and the 33 months subsequent to the work stoppage. 
First 24 months and last 24 months of the research period

Application of the incidence rates comparison formula to the first 24 months and last 24 months of the work stoppage at Finishing Plant \#2 resulted in a 1.72 value, which is less than the critical $t$ value of 1.96. This indicated that a significant decrease in incidence rates did not occur between the two time periods.

\section{Nine Month Intervals Prior to and Subsequent to the Work Stoppage}

The incidence rates for the nine months subsequent to the work stoppage at Finishing Plant \#2 was lower than the incidence rates for nine months prior to the work stoppage. However, statistically the difference was not significant. The 1.31 calculated value was lower than the critical t value of 1.994 (See Table 15).

Table 15

Comparison of Prior and Post Work Stoppage Period - Finishing Plant \#2

\begin{tabular}{|l|l|l|l|l|}
\hline \multirow{2}{*}{ Time Period } & \multicolumn{2}{|l|}{ Finishing Plant \#2 Incidence Rates } & \multirow{2}{*}{ Critical t Value } & $\begin{array}{l}\text { Calculated } \\
\text { Comparison Value }\end{array}$ \\
\cline { 2 - 5 } & $\begin{array}{l}\text { Prior to } \\
\text { Work Stoppage }\end{array}$ & $\begin{array}{l}\text { Post } \\
\text { Work Stoppage }\end{array}$ & 1.994 & 1.31 \\
\hline 9 Months & 14.68 & 8.95 & 1.96 & 1.72 \\
\hline 24 Months & 11.88 & 9.34 & 1.96 & $2.18^{* *}$ \\
\hline
\end{tabular}

* Indicates a statistically significant increase

** Indicates a statistically significant decrease

Finishing Plant \#3 Analysis

\section{Quarterly Analysis of OSHA Recordable Data - Finishing Plant \#3}

The 1998 incidence rate at Finishing Plant \#3 was almost 4 times greater than the lowest rate, which was recorded in 1996. The increase from a 5.06 incidence rate to a 19.54 incidence rate is seen in Figure 76. This increase to above the UCL was followed in 1999 with a $20 \%$ decrease in incidence rate. The incidence rate decreased again between 1999 and 2000 to a level almost equal to the lowest first quarter incidence rate for the study period. 


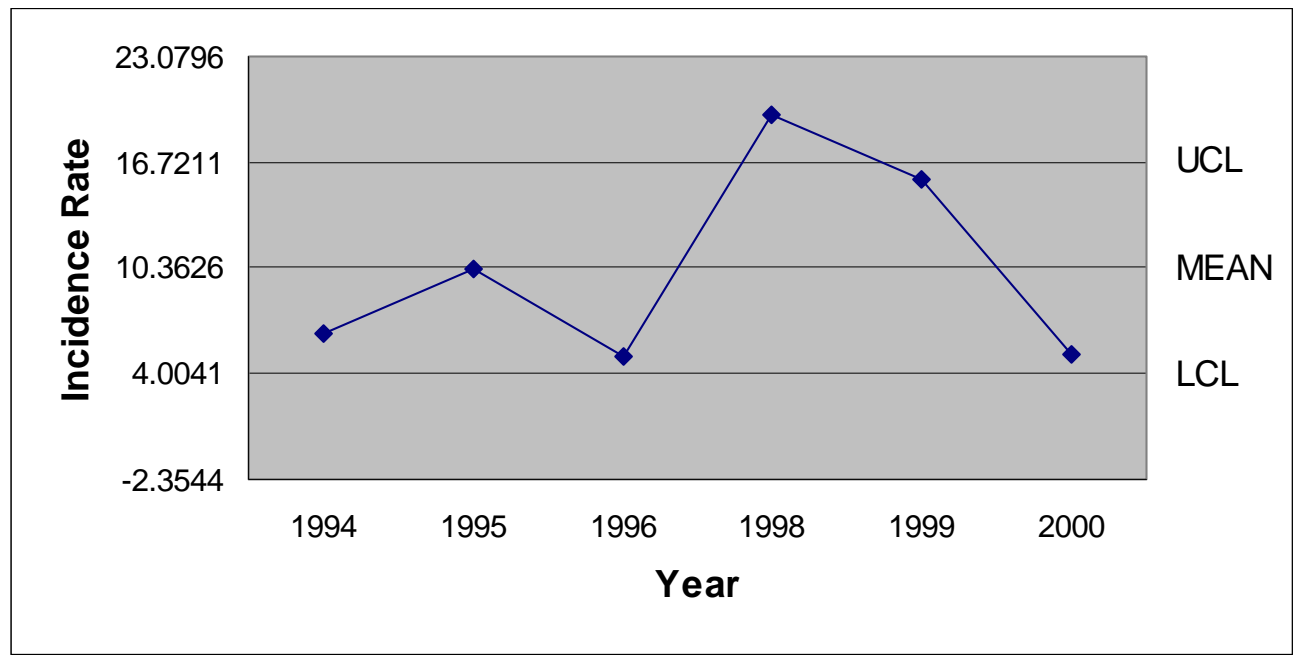

Note: No first quarter operations in 1997

Figure 76. First Quarter 1994-2000 OSHA Recordable Incidence Rates - Finishing Plant \#3

The second quarter at Finishing Plant \#3 demonstrated a pattern similar to the pattern of the first quarter (See Figure 77). The highest incidence rate was recorded in 1998 and the lowest in 1999. The 1996 incidence rate, which preceded the large increase of 1998, was the second lowest incidence rate for the study period.

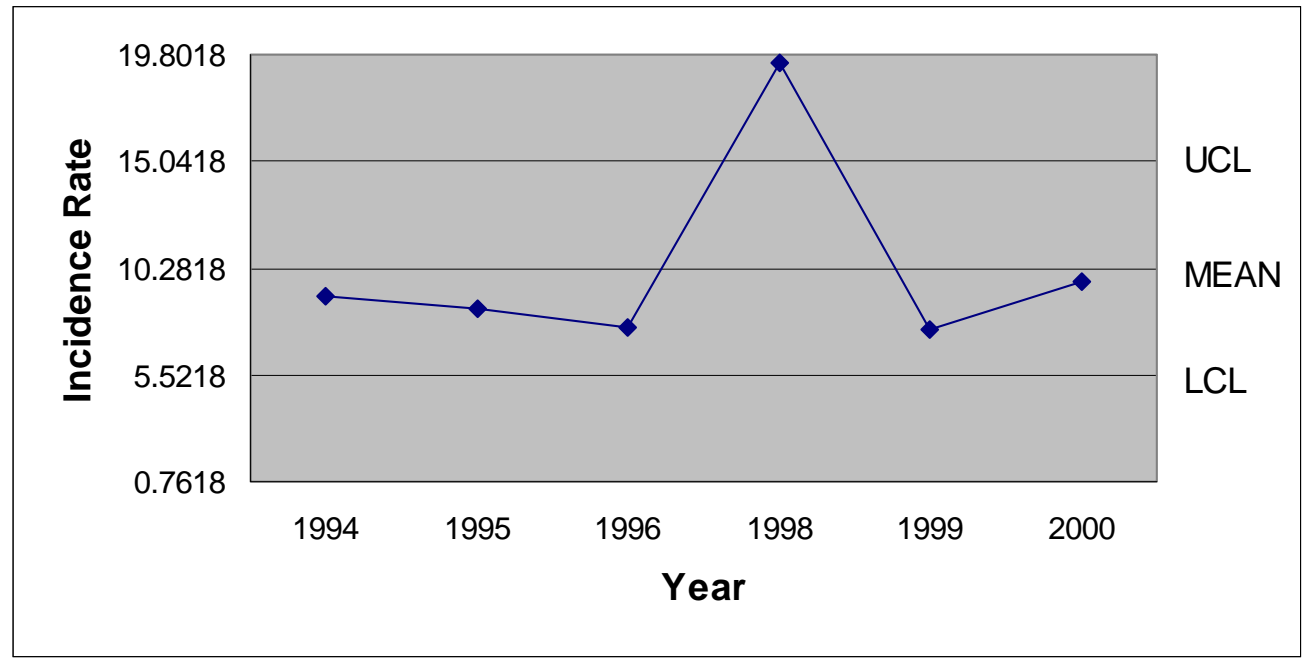

Note: No operations in second quarter 1997

Figure 77. Second Quarter 1994-2000 OSHA Recordable Incidence Rates - Finishing Plant \#3 
Though not as large of a change from period to period, the third quarter at Finishing Plant \#3 experienced almost the same pattern as the first two quarters. The highest third quarter incidence rate was in 1998 and the lowest was in 1999. The 1995 and 1996 incidence rates were clustered close to the mean (See Figure 78).

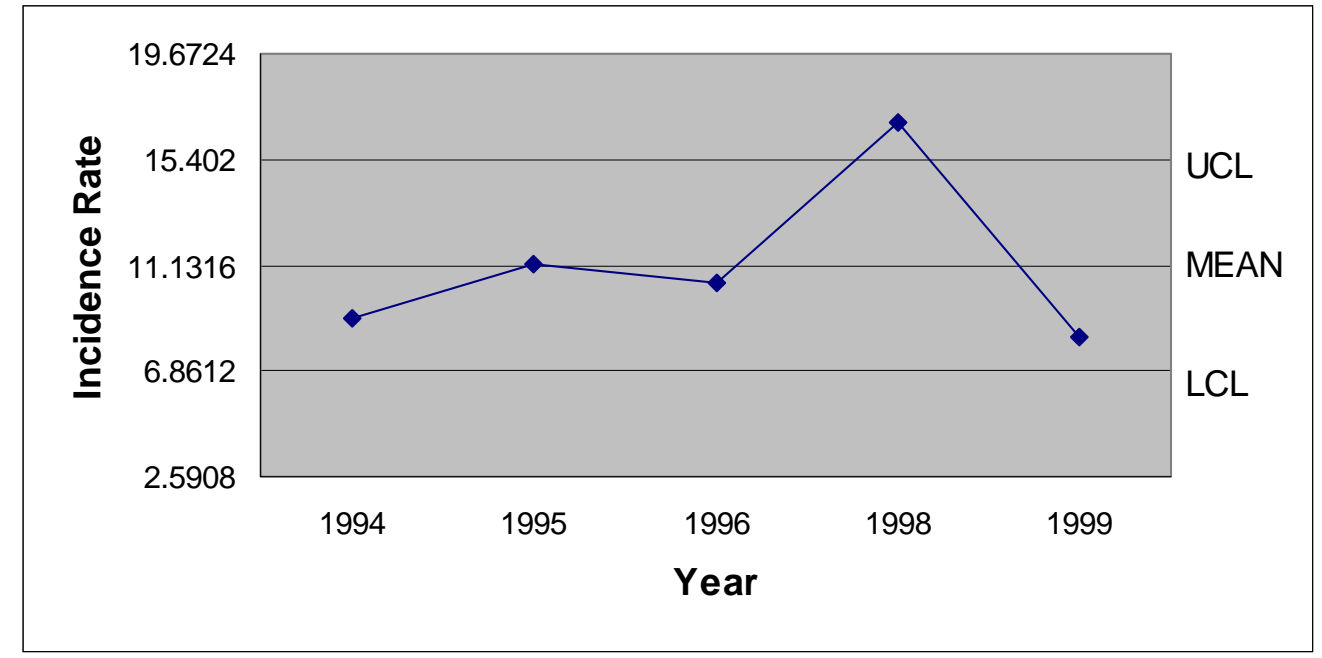

Note: No operations in third quarter 1997

Figure 78. Third Quarter 1994-2000 OSHA Recordable Incidence Rates - Finishing Plant \#3

Unlike the first through third quarters, where the highest incidence rate at Finishing Plant \#3 occurred in the year following the work stoppage, the highest incidence rate for the fourth quarter was the period immediately preceding the work stoppage, 1996 (See Figure 79). The lowest fourth quarter incidence rate occurred in below the LCL in 1995. 


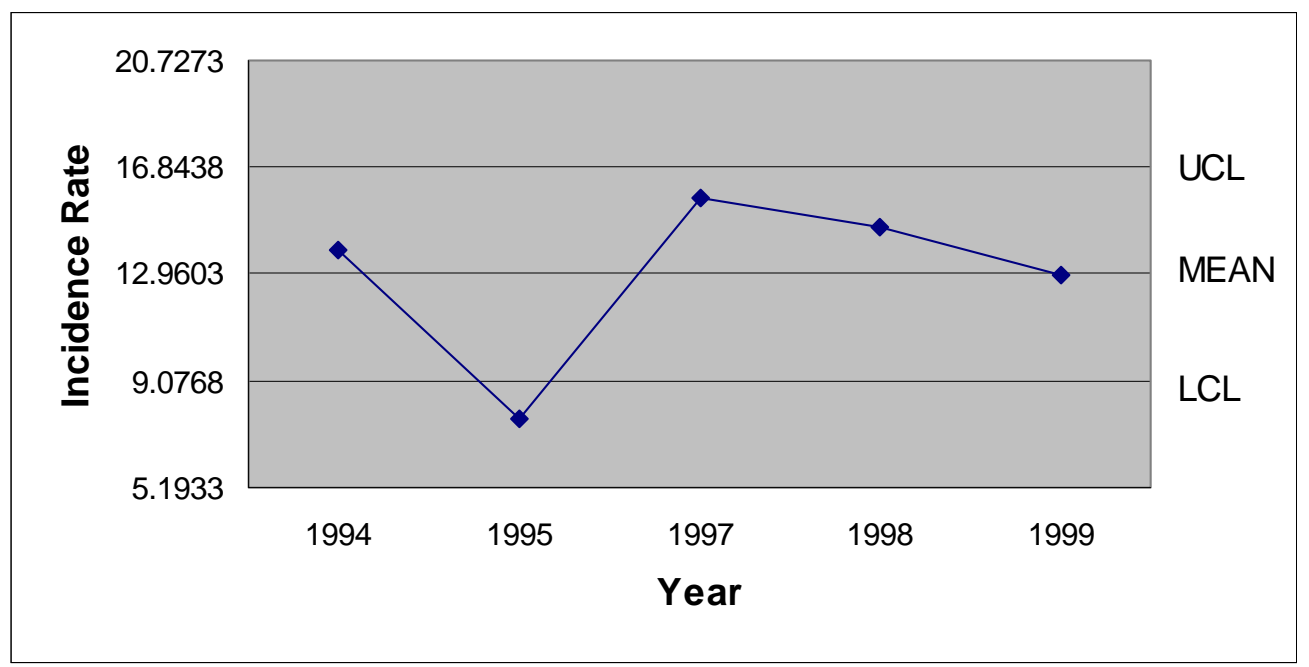

Note: No operations in fourth quarter 1996

Figure 79. Fourth Quarter 1994-2000 OSHA Recordable Incidence Rates - Finishing Plant \#3

Table 16 presents the Finishing Plant \#3 quarterly incidence rates for each year of the study period, as well as the UCL, mean, LCL, and standard deviation. Nineteen ninety-six and 1997 were partial years because of the work stoppage and only the first six months of 2000 were included in the research.

Table 16

Summary of Quarterly OSHA Recordable Incidence Rates Data - Finishing Plant \#3

\begin{tabular}{|l|r|r|r|r|}
\hline & $1^{\text {st }}$ Quarter & $2^{\text {nd }}$ Quarter & $3^{\text {rd }}$ Quarter & $4^{\text {th }}$ Quarter \\
\hline 1994 & 6.468 & 9.004 & 8.984 & 13.799 \\
\hline 1995 & 10.284 & 8.438 & 11.138 & 7.689 \\
\hline 1996 & 5.062 & 7.662 & 10.383 & N/A \\
\hline 1997 & N/A & N/A & 15 & 15.730 \\
\hline 1998 & 19.541 & 19.392 & 16.934 & 14.686 \\
\hline 1999 & 15.701 & 7.531 & 8.219 & 12.897 \\
\hline 2000 & 51.120 & 9.665 & N/A & N/A \\
\hline UCL & 16.721 & 15.042 & 15.402 & 16.844 \\
\hline MEAN & 10.363 & 10.282 & 11.132 & 12.960 \\
\hline LCL & 4.004 & 5.522 & 6.861 & 9.077 \\
\hline SD & 2.473 & 1.851 & 1.538 & 1.399 \\
\hline
\end{tabular}




\section{$\underline{\text { Seasonal Analysis of OSHA Recordable Data - Finishing Plant \#3 }}$}

Finishing Plant \#3 experienced the highest seasonal index in the fourth quarter. The lowest seasonal index occurred in the first quarter. The difference between the first quarter seasonal index and the fourth quarter seasonal index was 12\% (See Figure 80).

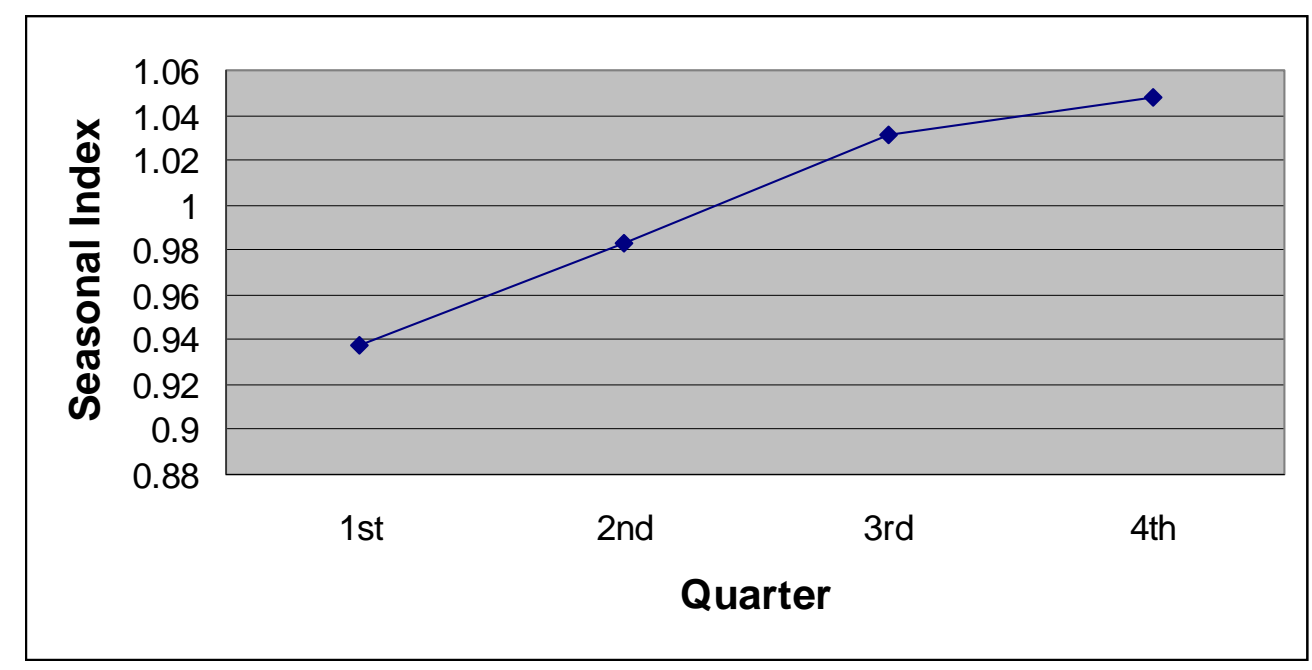

Figure 80. Quarterly Seasonal Pattern of OSHA Recordable Incidence Rates - Finishing Plant \#3

Monthly Analysis of OSHA Recordable Data - Finishing Plant \#3

For the month of January, the highest incidence rate 22.191 at Finishing Plant \#3 occurred above the UCL in 1999. January 1996 did not experience any OSHA recordable incidents and therefore had an incidence rate of 0.00 . The remaining four January incidence rates were within the control limits (See Figure 81). 


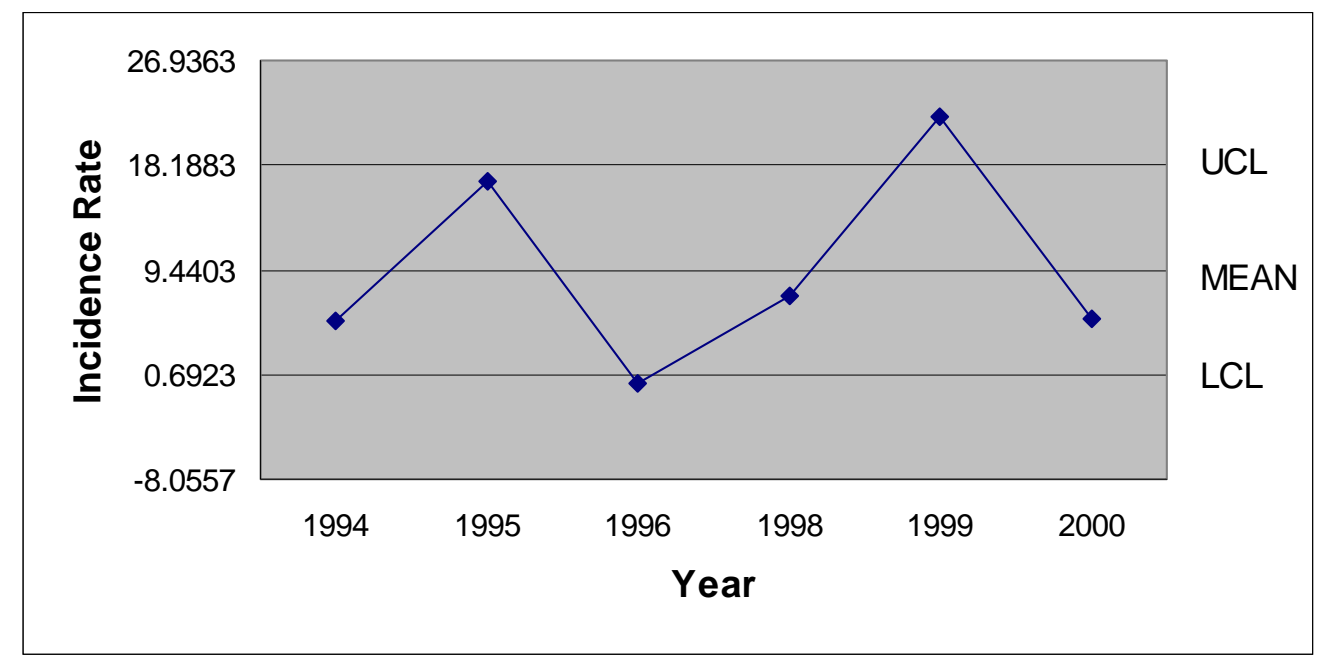

Note: No operations in January 1997

Figure 81. January 1994-2000 OSHA Recordable Incidence Rates - Finishing Plant \#3

The 1994, 1995, and 1996 incidence rates for February at Finishing Plant \#3 were between the LCL and the mean. This period of relatively steady incidence rate was followed by the 22.466 incidence rate experienced in February 1998 that was above the 18.2328 UCL. The 1999 rate dropped below the UCL and the 2000 incidence rate was below the LCL of 0.7778 (See Figure 82).

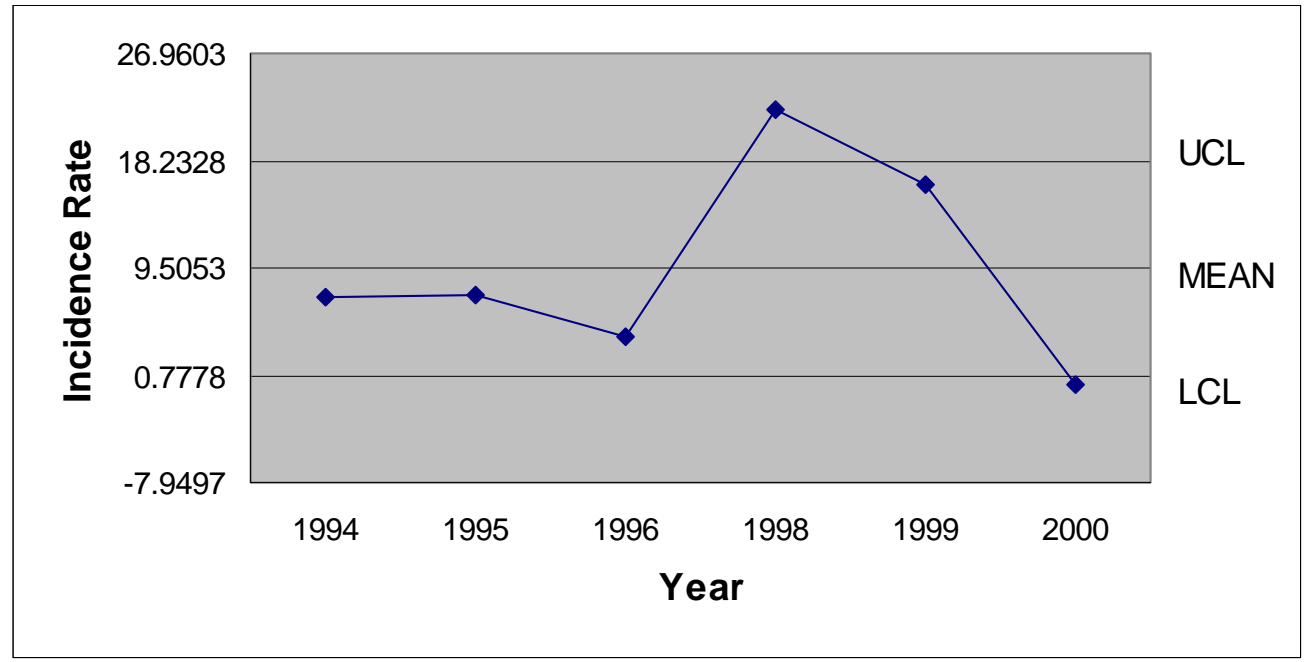

Note: No operations in February 1997

Figure 82. February 1994-2000 OSHA Recordable Incidence Rates - Finishing Plant \#3 
During March, Finishing Plant \#3 experienced 5 periods of incidence rates between the mean and the LCL. The 1998 incidence rate, which was above the UCL, was the only March rate not within the control limits. The 1998 incidence rate was more than double any other March incidence rate (See Figure 83).

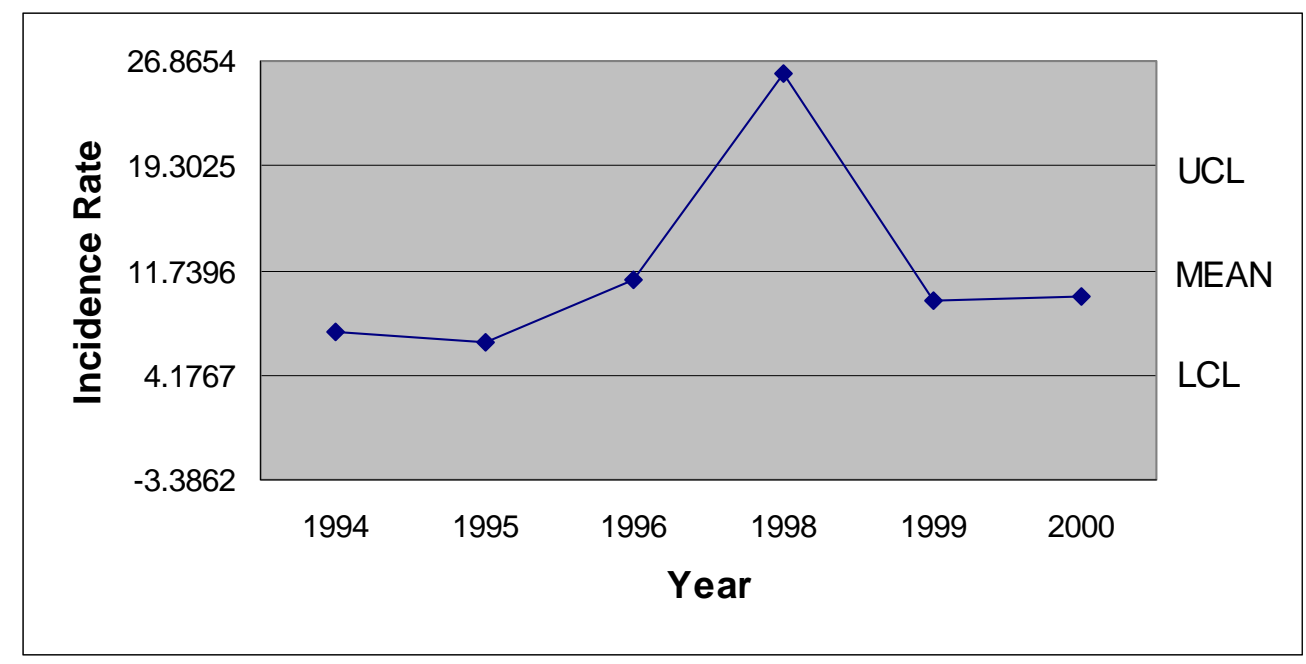

Note: No operations in March 1997

Figure 83. March 1994-2000 OSHA Recordable Incidence Rates - Finishing Plant \#3

The April incidence rate at Finishing Plant \#3 moved from just above the mean in 1994 to below the LCL in 1995 and then barely above the LCL in 1996 (See Figure 84). The highest incidence rate occurred the next period, 1998, and was followed in 1999 and 2000 with incidence rates close to the mean. 


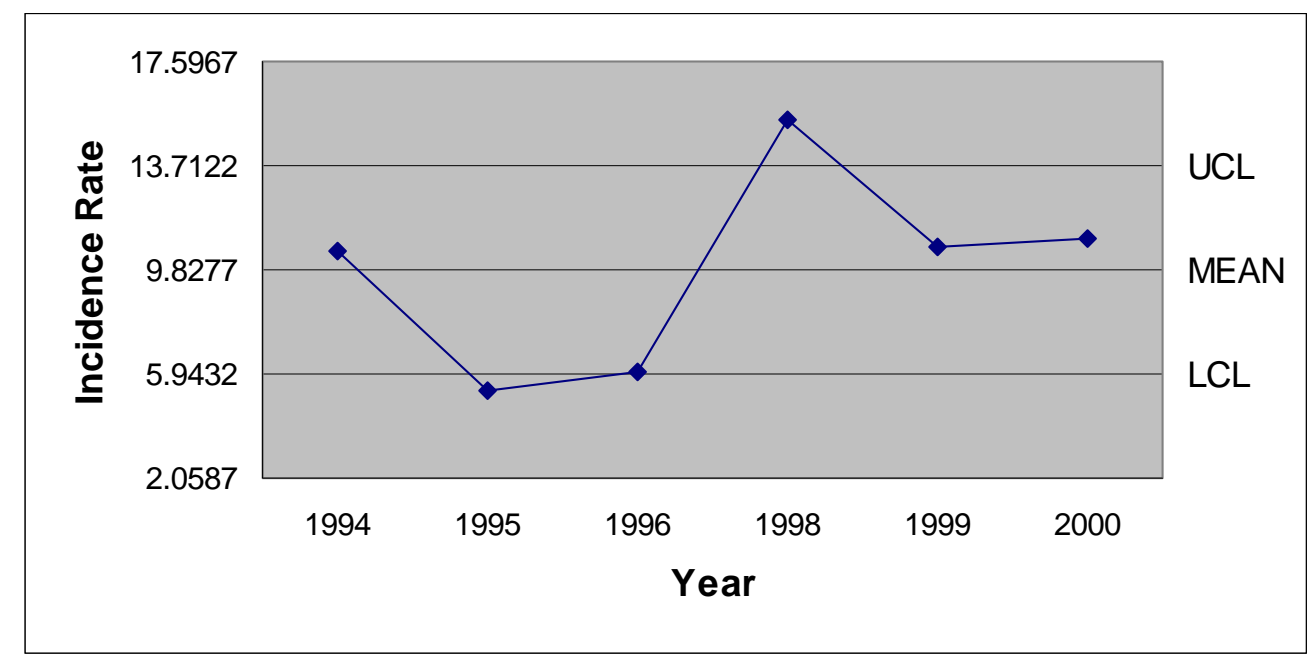

Note: No operations in April 1997

Figure 84. April 1994-2000 OSHA Recordable Incidence Rates - Finishing Plant \#3

There were no OSHA recordable incidents in May 1994 at Finishing Plant \#3. The remaining years experienced incidence rates close to the 10.6393 mean with the exception of 1998 which had an experience rate of 27.2638 (See Figure 85).

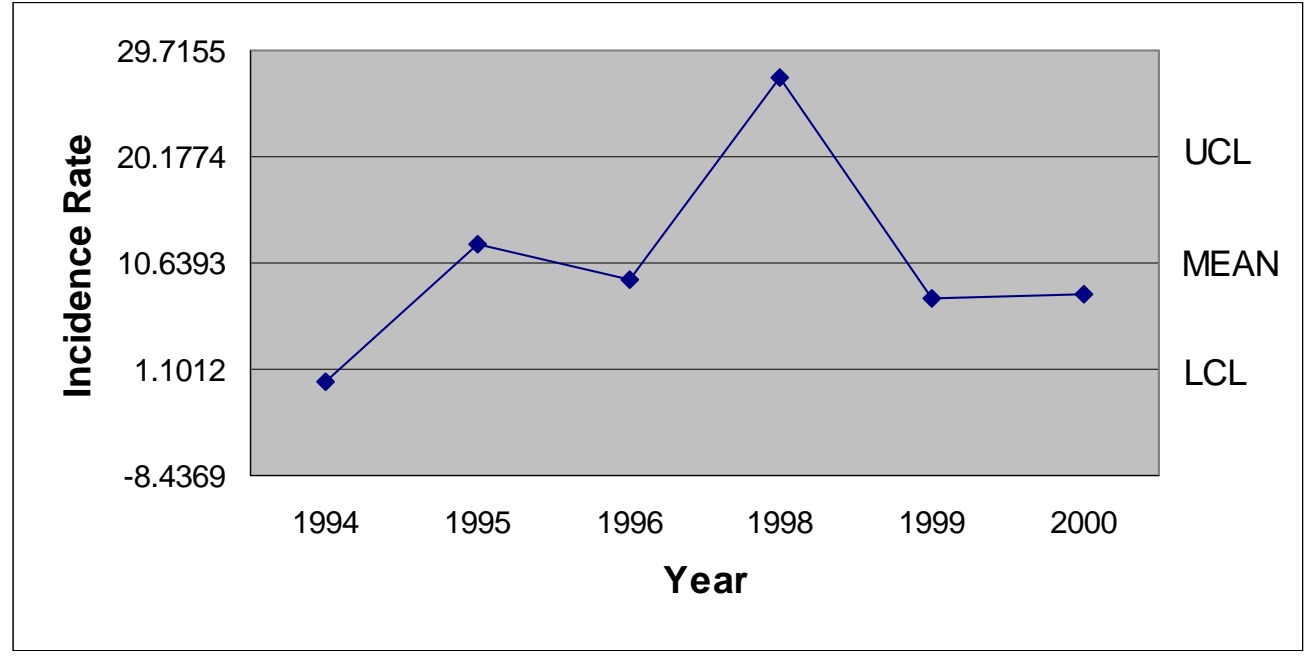

Note: No operations in May 1997

Figure 85. May 1994-2000 OSHA Recordable Incidence Rates - Finishing Plant \#3

The highest June incidence rate at Finishing Plant \#3 occurred in 1994 (See Figure 86). The next two periods were between the mean and the LCL. In 1998 the incidence rate returned to a level above the upper control limit. The second highest peak 
was followed in 1999 with an incidence rate below the LCL. In 2000 the June incidence rate increased to a level close to the mean.

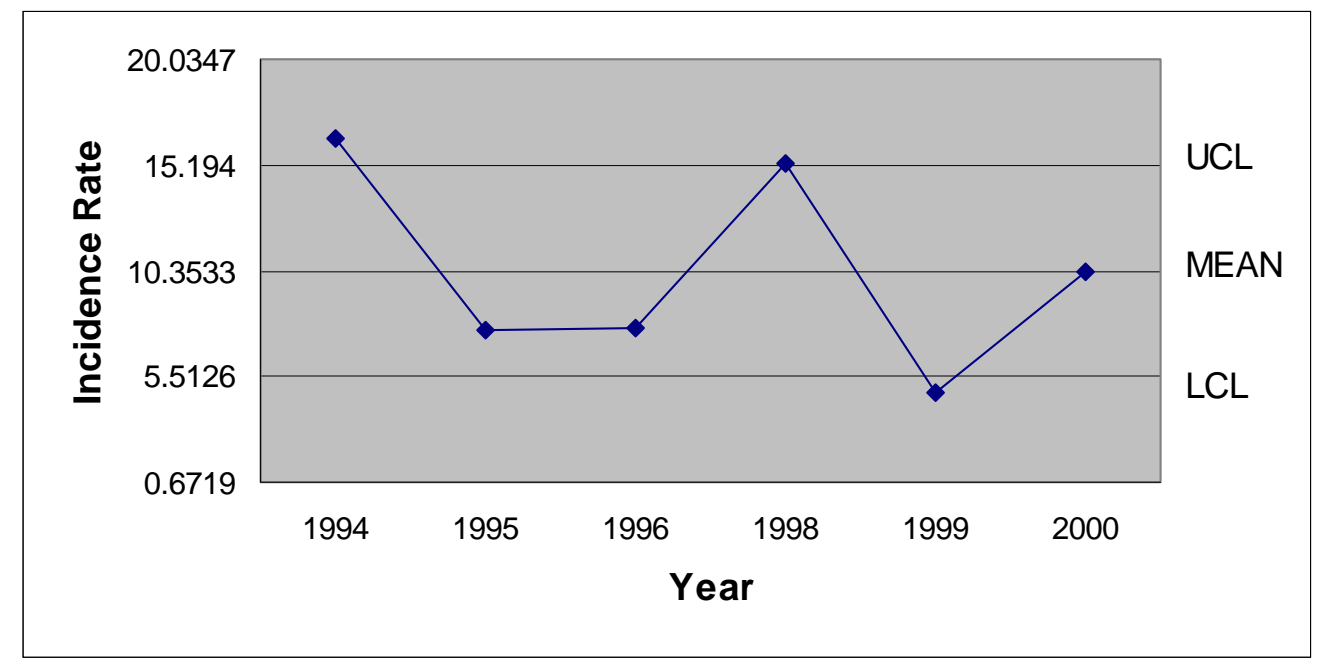

Note: No operations in June 1997

Figure 86. June 1994-2000 OSHA Recordable Incidence Rates - Finishing Plant \#3

The 1994 incidence rate at Finishing Plant \#3, which was between the mean and the UCL, was followed by two periods below the mean. In 1998 the July incidence rate increased to a level above the UCL. And in 1999 the lowest incidence rate, just above the LCL was recorded (See Figure 87).

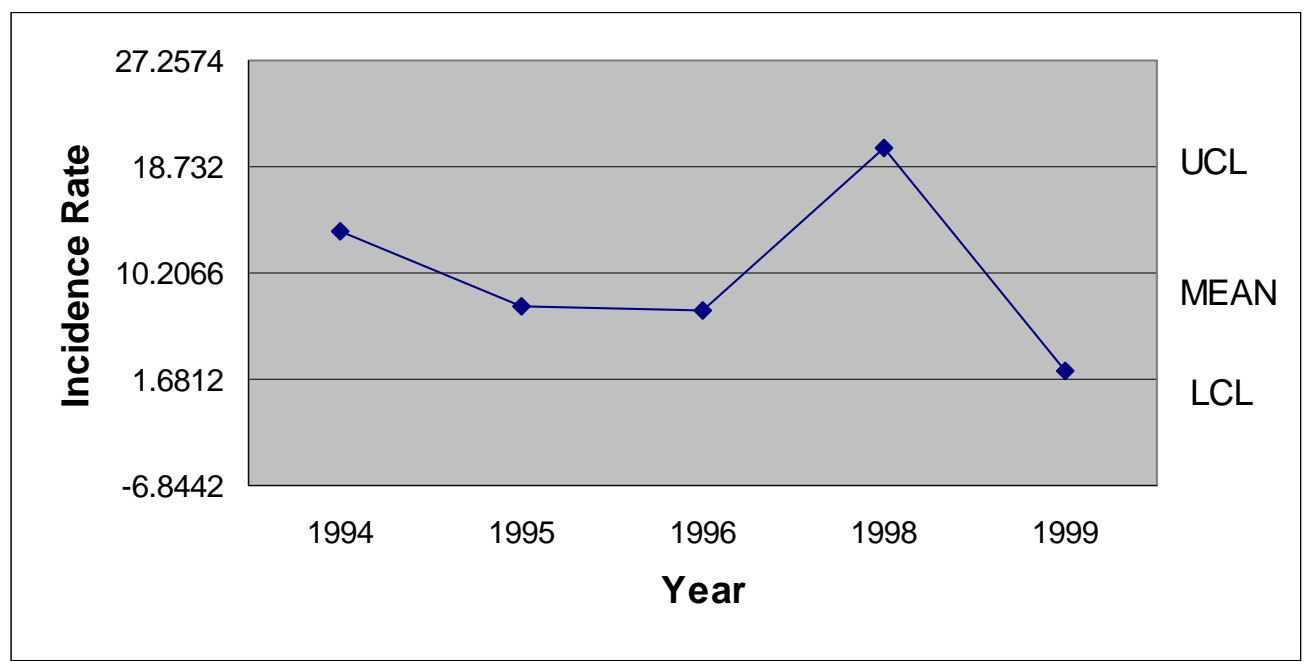

Note: No operations in July 1997

Figure 87. July 1994-1999 OSHA Recordable Incidence Rates - Finishing Plant \#3 
A low in 1994 and a high in 1998 marked the zigzag appearance of the August Finishing Plant \#3 incidence rates. The highest incidence rate was almost 3 times greater than the lowest incidence rate. The 1995, 1996, and 1999 incidence rates were clustered around the mean (See Figure 88).

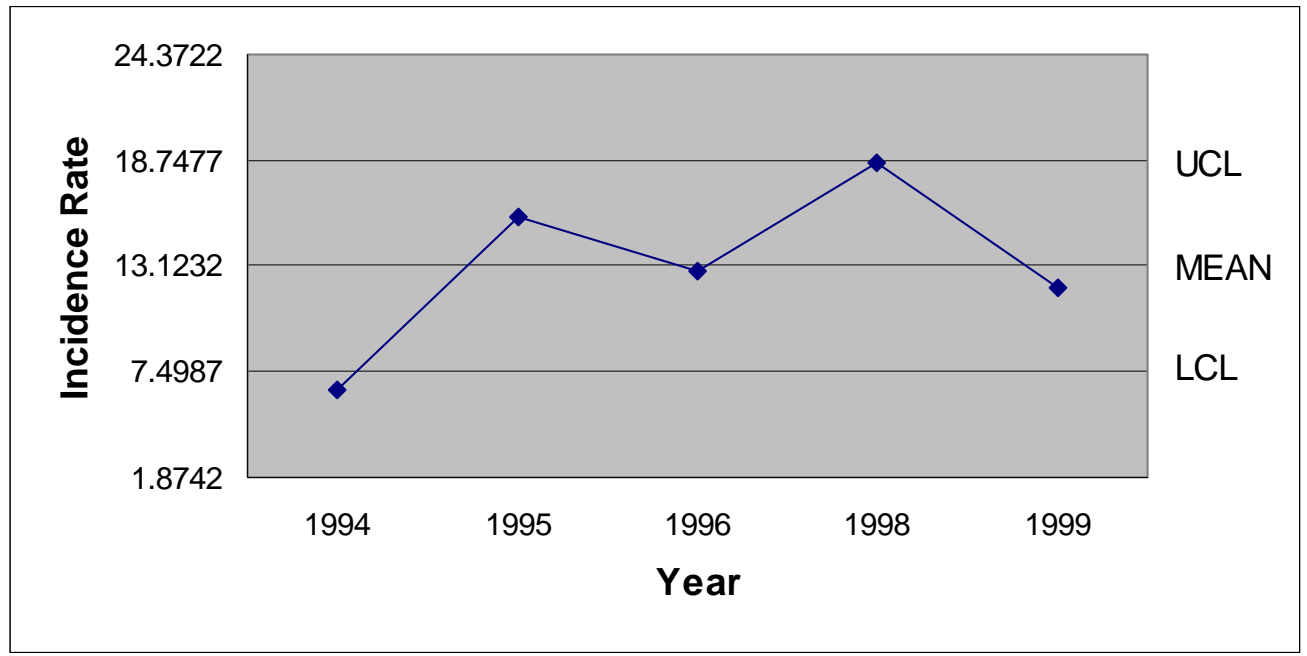

Note: No operations in August 1997

Figure 88. August 1994-1999 OSHA Recordable Incidence Rates - Finishing Plant \#3

Incidence rates for the month of September increased steadily at Finishing Plant \#3 from 1994 through 1996 (See Figure 89). The highest incidence rate was experienced in 1998, just barely higher than the 1996 level. The 1998 high was followed by a slight decrease in 1999.

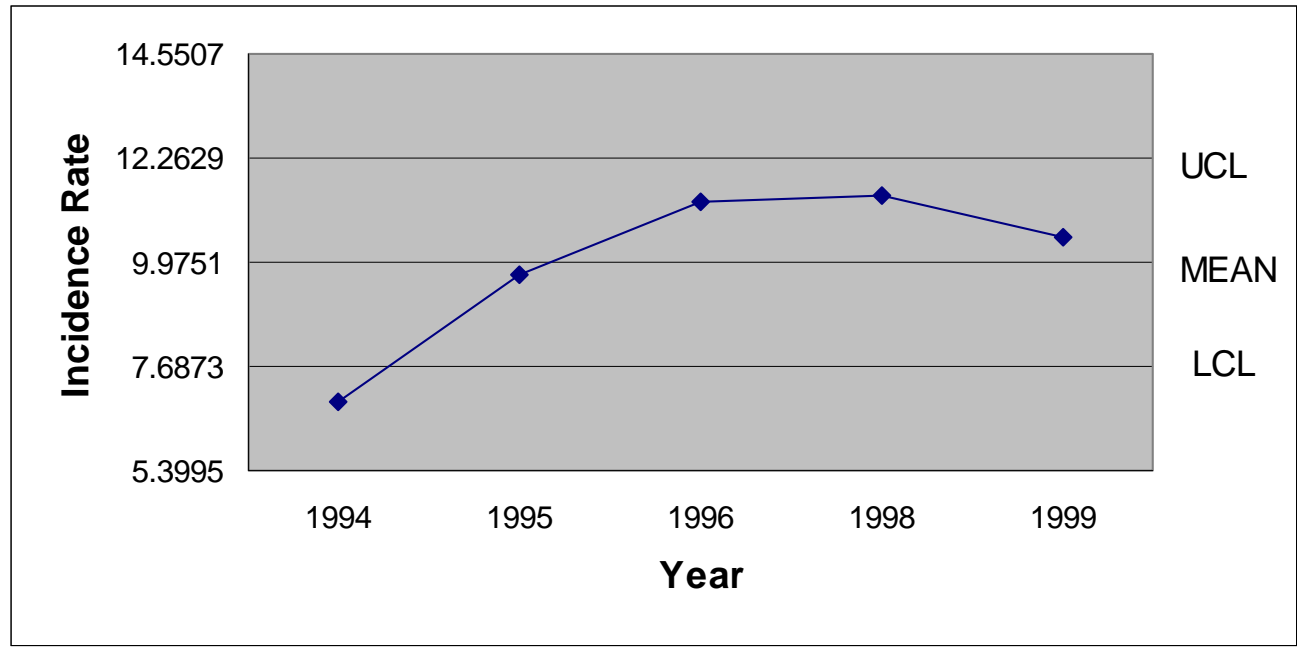

Note: No operations in September 1997

Figure 89. September 1994-1999 OSHA Recordable Incidence Rates - Finishing Plant \#3 
The first two months of October in the study period were just below the mean. In 1997 the incidence rate at Finishing Plant \#3 was between the mean and the UCL. The incidence rate decreased to just above the LCL in 1998 and increased to a level above the UCL in 1999 (See Figure 90).

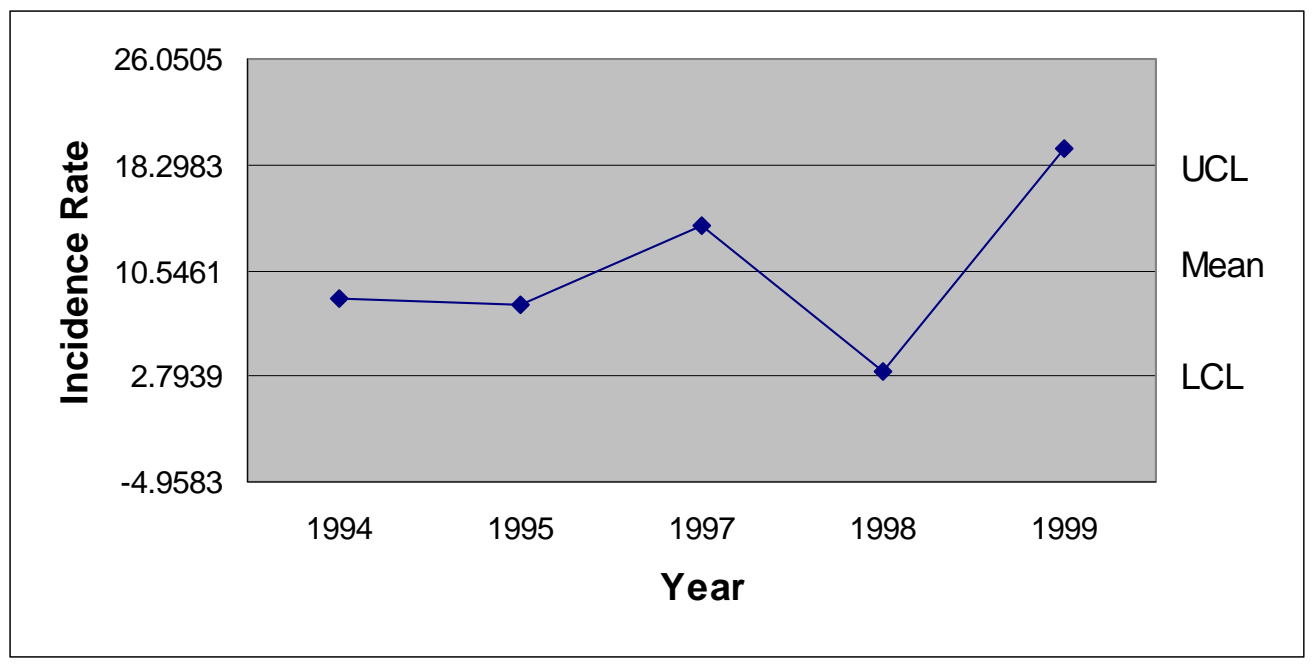

Note: No operations in October 1996

Figure 90. October 1994-1999 OSHA Recordable Incidence Rates - Finishing Plant \#3

The November incidence rates at Finishing Plant \#3 experienced a declining trend through the low of 7.558 recorded in 1997 (See Figure 91). In 1998 the highest November incidence rate was experienced. The next year the November 1999 incidence rate returned to a level within the control limits.

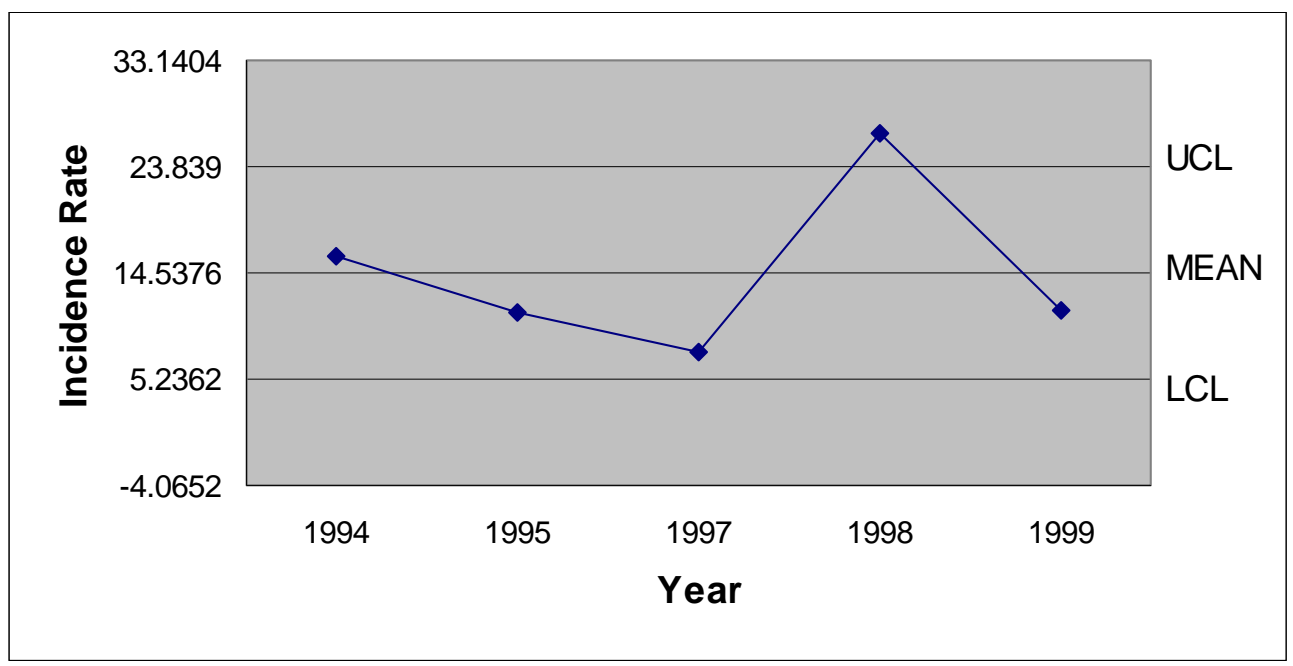

Note: No operations in November 1996

Figure 91. November 1994-1999 OSHA Recordable Incidence Rates - Finishing Plant \#3 
The lowest December incidence rate at Finishing Plant \#3, recorded in 1995, was followed by the highest incidence rate for the month of December. After the high in 1997, the incidence rate declined through 1999 (See Figure 92).

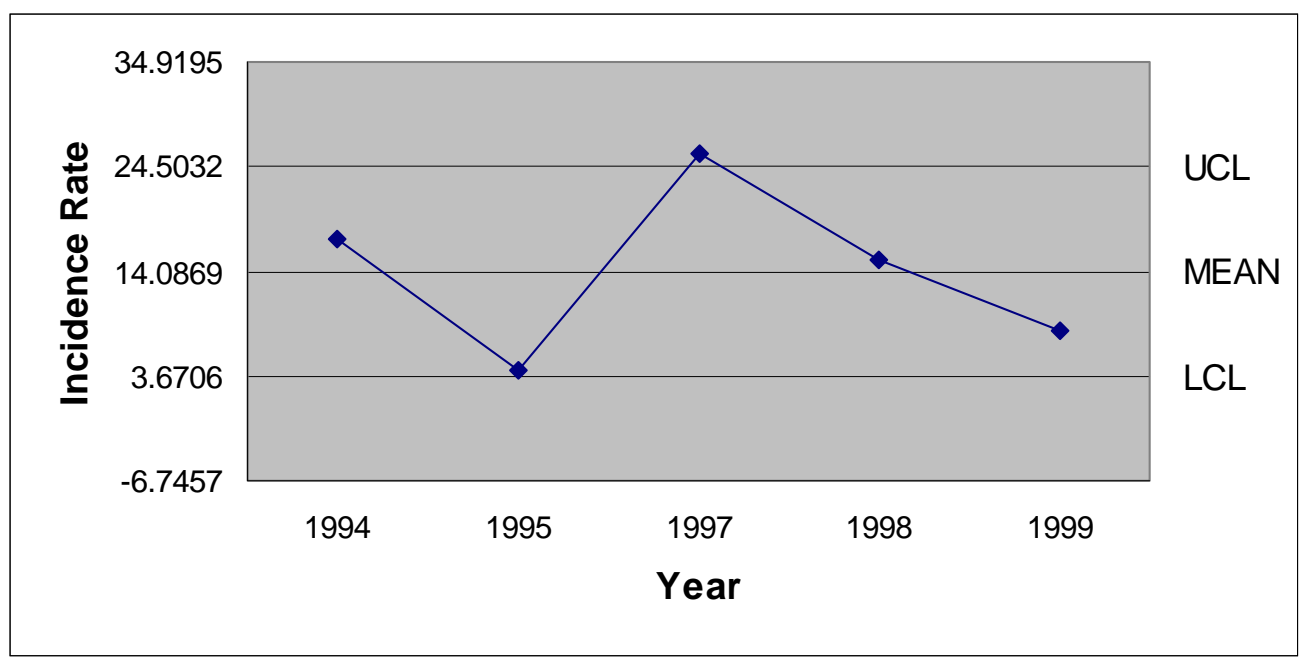

Note: No operations in December 1996

Figure 92. December 1994-1999 OSHA Recordable Incidence Rates - Finishing Plant \#3

Table 17 presents the monthly incidence rates for each year of the study period, as well as, the UCL, mean, LCL, and standard deviation. 1996 and 1997 were partial years because of the work stoppage and only the first six months of 2000 were included in the research.

Table 17

$\underline{\text { Summary of Monthly OSHA Recordable Incidence Rates Data - Finishing Plant \#3 }}$

\begin{tabular}{|l|l|l|l|l|l|l|l|l|l|l|l|l|}
\hline & Jan. & Feb. & Mar. & Apr. & May & June & July & Aug. & Sept. & Oct. & Nov. & Dec. \\
\hline 1994 & 5.102 & 7.122 & 7.258 & 10.540 & 0.00 & 16.413 & 13.621 & 6.500 & 6.917 & 8.416 & 15.941 & 17.226 \\
\hline 1995 & 16.833 & 7.325 & 6.555 & 5.338 & 12.253 & 7.607 & 7.593 & 15.676 & 9.704 & 8.041 & 11.084 & 4.149 \\
\hline 1996 & 0.00 & 3.882 & 11.064 & 5.996 & 9.080 & 7.764 & 7.220 & 12.850 & 11.307 & N/A & N/A & N/A \\
\hline 1997 & N/A & N/A & N/A & N/A & N/A & N/A & N/A & N/A & N/A & 13.795 & 7.558 & 25.748 \\
\hline 1998 & 7.230 & 22.466 & 26.034 & 15.395 & 27.264 & 15.272 & 20.211 & 18.627 & 11.417 & 3.065 & 26.836 & 15.205 \\
\hline 1999 & 22.191 & 16.234 & 9.606 & 10.690 & 7.471 & 4.769 & 2.387 & 11.963 & 10.530 & 19.413 & 11.270 & 8.107 \\
\hline 2000 & 5.286 & 0.00 & 9.921 & 11.007 & 7.767 & 10.296 & N/A & N/A & N/A & N/A & N/A & N/A \\
\hline
\end{tabular}




\begin{tabular}{|l|l|l|l|l|l|l|l|l|l|l|l|l|}
\hline UCL & 18.188 & 18.233 & 19.302 & 13.712 & 20.177 & 15.194 & 18.732 & 18.748 & 12.263 & 18.298 & 23.839 & 24.503 \\
\hline Mean & 9.440 & 3.395 & 11.740 & 9.828 & 10.639 & 10.353 & 10.207 & 13.123 & 9.975 & 10.546 & 14.538 & 14.087 \\
\hline LCL & 0.692 & 0.778 & 4.177 & 5.943 & 1.101 & 5.513 & 1.681 & 7.500 & 7.687 & 2.794 & 5.236 & 3.671 \\
\hline SD & 3.403 & 3.395 & 2.942 & 1.511 & 3.710 & 1.883 & 3.071 & 2.026 & 0.824 & 2.793 & 3.351 & 3.752 \\
\hline
\end{tabular}

$\underline{\text { Seasonal Analysis of Monthly OSHA Recordable Data - Finishing Plant \#3 }}$

The seasonal index calculation was used to generate the monthly seasonal index figures that are presented in Figure 93. The highest seasonal index was calculated for the month of August, the next highest was recorded in November. The month of February had the lowest seasonal index for Finishing Plant \#3 OSHA recordable incidence rates.

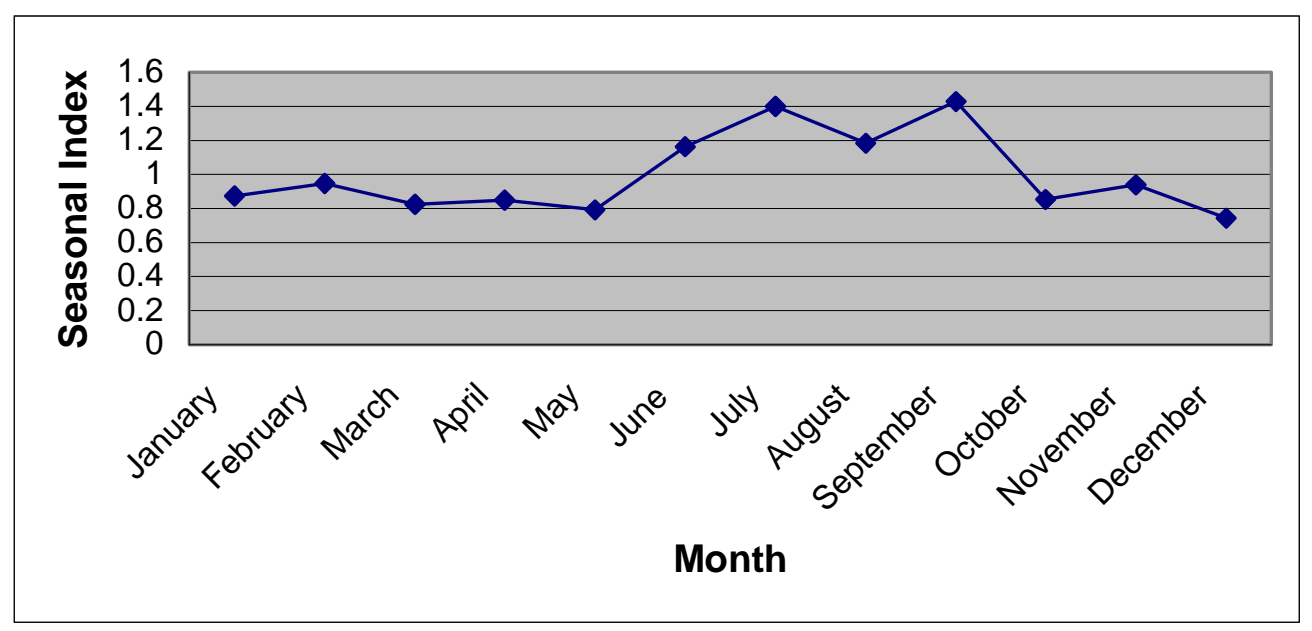

Figure 93. Monthly Seasonal Pattern of OSHA Recordable Incidence Rates - Finishing Plant \#3

Testing the statistical relationship of OSHA Recordable Data at Finishing Plant \#3 All 33 months prior to and subsequent to the work stoppage

For the entire 33 months prior to the work stoppage and the 33 months post work stoppage, a comparison of incidence rate was calculated. The 3.256 calculated value was greater than the 1.96 critical $t$ value. This indicated that a significant increase in incidence rates occurred between the prior and post work stoppage periods. 
First 24 months and last 24 months of the research period

The incidence rates comparison calculation was applied to the first 24 months and the last 24 months of the research period. These time periods excluded the nine months prior to and immediately following the work stoppage. At the .05 level of significance the calculated value of 1.218 was less than the 1.96 critical $t$ value. This indicated that a significant increase in incidence rate was not present between these periods.

Nine month intervals prior to and subsequent to the work stoppage

The result of the incidence rate comparison formula, 4.214 was greater than the 1.987 significant $t$ value at the .05 significance level. This indicated that a statistically significant increase in incidence rates occurred between these two periods (See Table 18).

Table 18

Comparison of Prior and Post Work Stoppage Period - Finishing Plant \#3

\begin{tabular}{|c|c|c|c|c|}
\hline \multirow[b]{2}{*}{ Time Period } & \multicolumn{2}{|c|}{ Finishing Plant \#3 Incidence Rates } & \multirow[b]{2}{*}{ Critical t Value } & \multirow[b]{2}{*}{$\begin{array}{l}\text { Calculated } \\
\text { Comparison Value }\end{array}$} \\
\hline & $\begin{array}{l}\text { Prior to } \\
\text { Work Stoppage }\end{array}$ & $\begin{array}{l}\text { Post } \\
\text { Work Stoppage }\end{array}$ & & \\
\hline 9 Months & 7.680 & 18.426 & 1.987 & $4.214 *$ \\
\hline 24 Months & 9.514 & 11.186 & 1.96 & $1.218^{*}$ \\
\hline 33 Months & 9.040 & 12.985 & 1.96 & $3.256 *$ \\
\hline
\end{tabular}

* Indicates a statistically significant increase

** Indicates a statistically significant decrease

\section{Corporate Analysis of Lost Work Day Data}

\section{Quarterly Analysis of Lost Work Day Data - Corporate}

As illustrated in Figure 94, the lowest first quarter lost work day incidence rate occurred below the LCL in 1996 . The 1996 rate of 0.8894 was more than tripled by the 2.7933 incidence rate recorded in the first quarter of 1998. The remaining four first quarter incidence rates were clustered around the mean, with the first two periods below the mean and the last two periods above the mean.

Note: No operations in first quarter 1997 


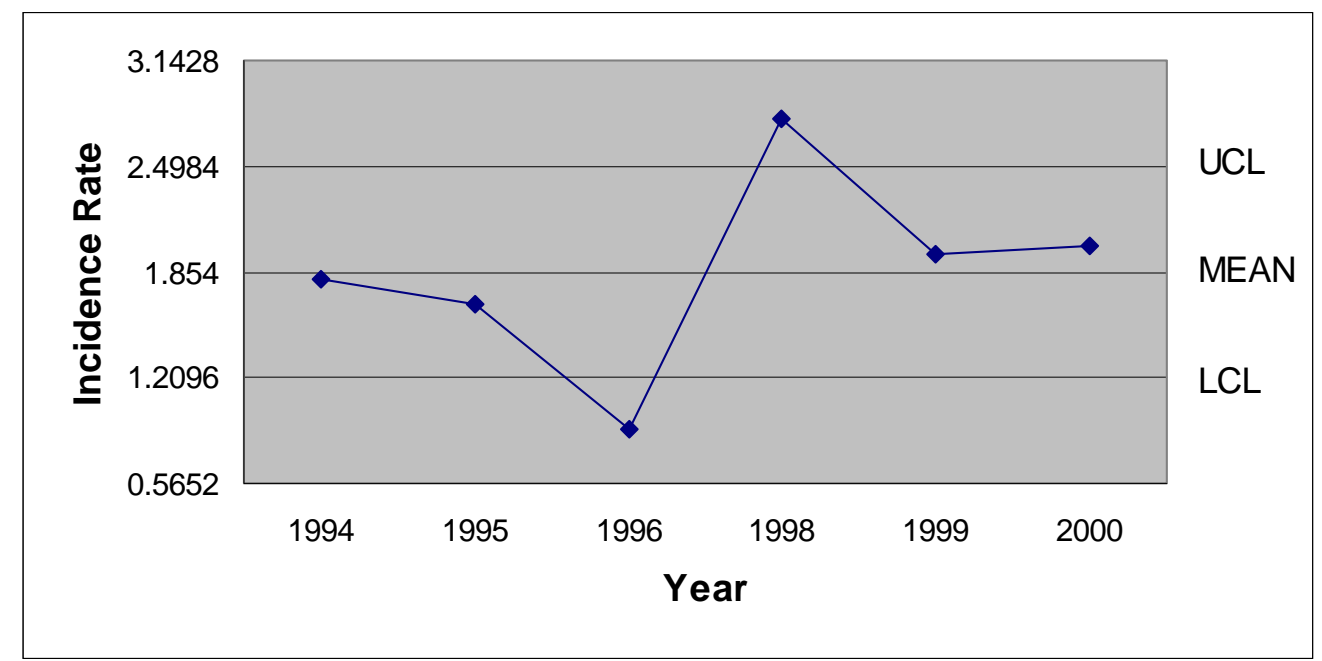

Figure 94. First Quarter 1994-2000 Lost Work Day Incidence Rates - Corporate

As was the case with the first quarter rates, the lowest second quarter Corporate incidence rate occurred in 1996. This lowest rate, which occurred in the last second quarter period prior to the work stoppage, was more than tripled by the 1998 second quarter incidence rate, which was the second quarter immediately following the work stoppage (See Figure 95).

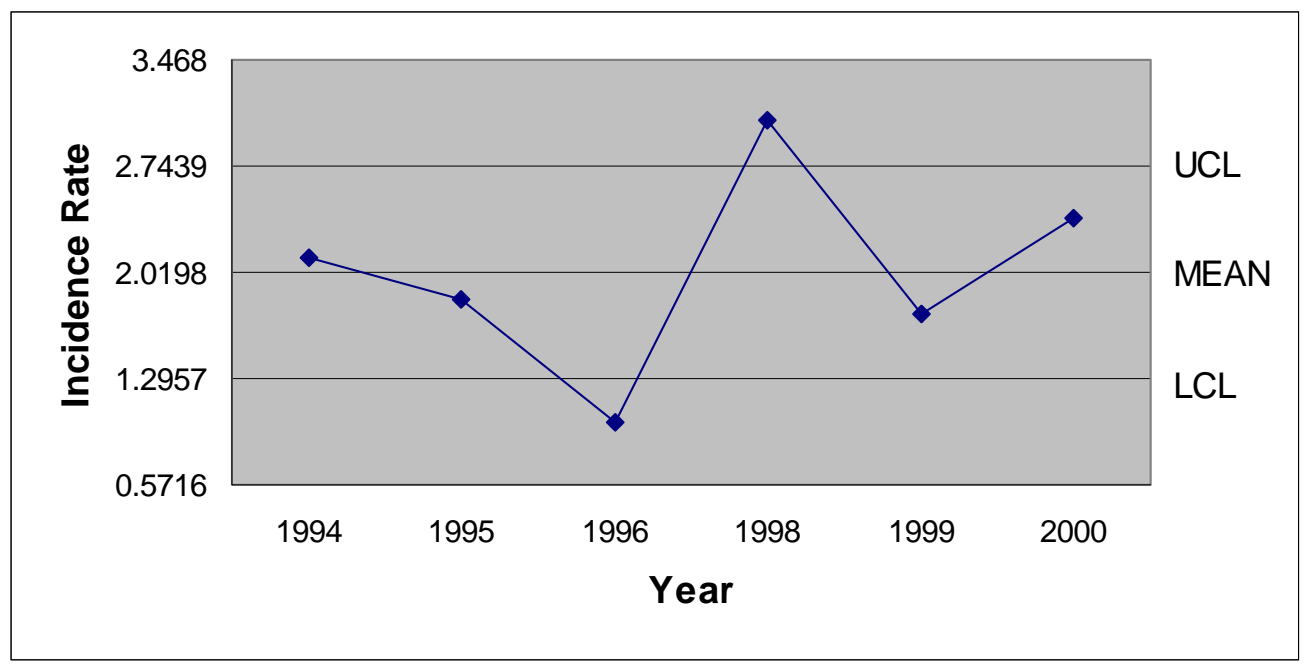

Note: No operations in second quarter 1997

Figure 95. Second Quarter 1994-2000 Lost Work Day Incidence Rates - Corporate

The first three third quarter periods of Corporate incidence rates were recorded between the LCL and the mean. The lowest third quarter rate was recorded in 1996 and 
the highest was recorded just above the UCL in the following period, 1998 (See Figure 96).

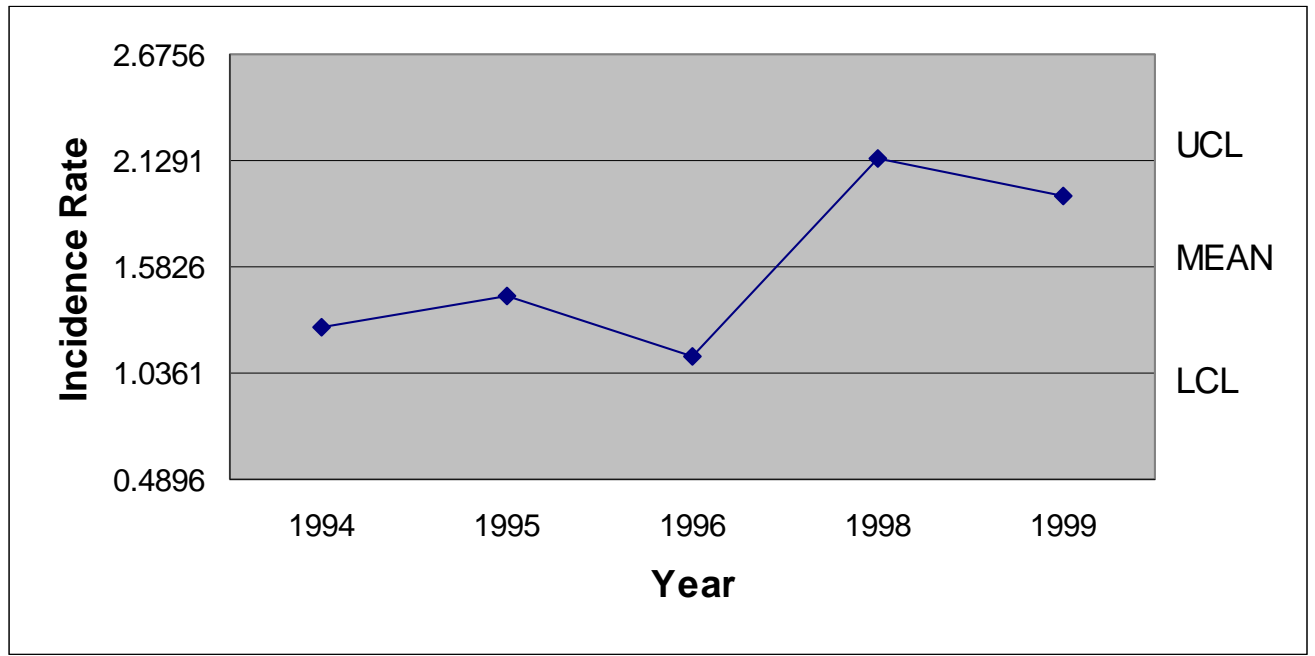

Note: No operations in third quarter 1997

Figure 96. Third Quarter 1994-1999 Lost Work Day Incidence Rates - Corporate

The highest fourth quarter Corporate incidence rate occurred in 1997, the first period of operations after the work stoppage. The 1997 incidence rate of 4.1254 was almost double the magnitude of any other fourth quarter (See Figure 97).

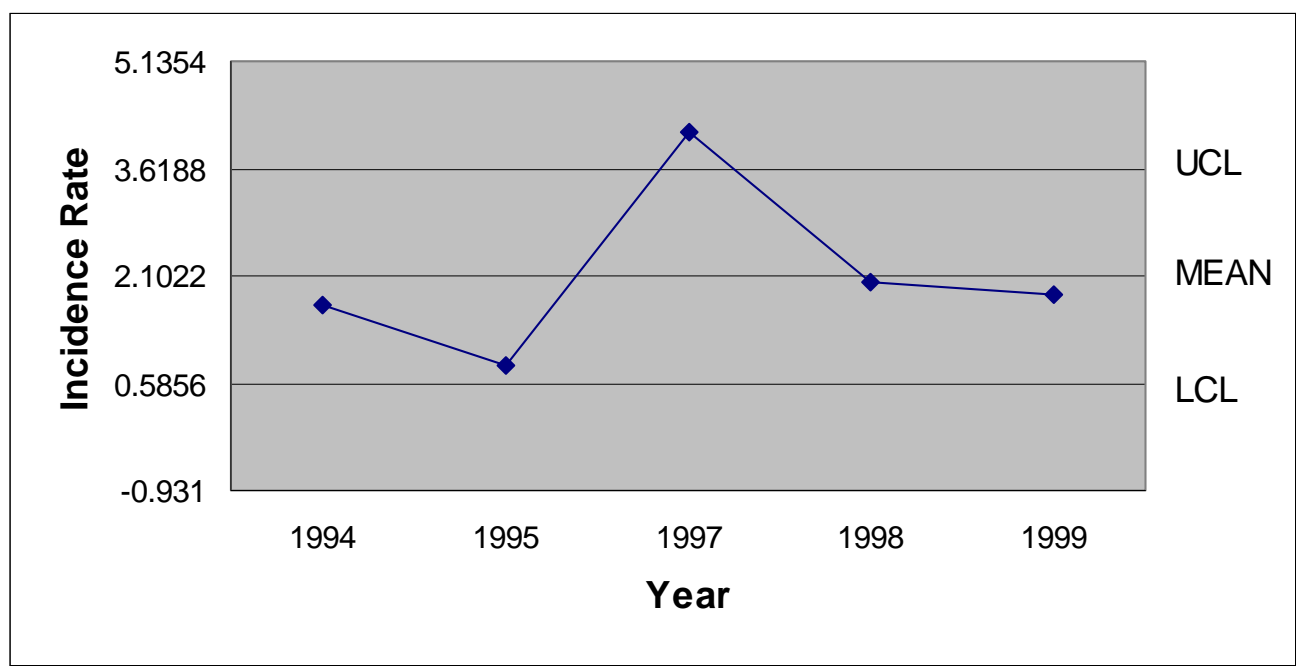

Note: No operations in fourth quarter 1996

Figure 97. Fourth Quarter 1994-1999 Lost Work Day Incidence Rates - Corporate 
Table 19 presents the quarterly incidence rates for each year of the study period, as well as, the UCL, mean, LCL, and standard deviation. Nineteen ninety-six and 1997 are partial years because of the work stoppage and only the first six months of 2000 were included in the research.

Table 19

$\underline{\text { Summary of Quarterly Lost Work Day Incidence Rates Data - Corporate }}$

\begin{tabular}{|l|l|l|l|l|}
\hline & $1^{\text {st }}$ Quarter & $2^{\text {nd }}$ Quarter & $3^{\text {rd }}$ Quarter & $4^{\text {th }}$ Quarter \\
\hline 1994 & 1.815 & 2.114 & 1.271 & 1.696 \\
\hline 1995 & 1.663 & 1.838 & 1.438 & 0.823 \\
\hline 1996 & 0.889 & 0.994 & 1.119 & N/A \\
\hline 1997 & N/A & N/A & N/A & 4.125 \\
\hline 1998 & 2.793 & 3.053 & 2.141 & 2.027 \\
\hline 1999 & 1.956 & 1.732 & 1.944 & 1.840 \\
\hline 2000 & 2.008 & 2.388 & N/A & N/A \\
\hline UCL & 2.498 & 2.744 & 2.129 & 3.619 \\
\hline MEAN & 1.854 & 2.020 & 1.583 & 2.102 \\
\hline LCL & 1.210 & 1.296 & 1.036 & 0.586 \\
\hline SD & 0.251 & 0.282 & 0.197 & 0.546 \\
\hline
\end{tabular}

\section{$\underline{\text { Seasonal Analysis of Lost Work Day Data - Corporate }}$}

The results of the quarterly seasonal index calculations of Corporate lost work day incidence rates are presented in Figure 98. The incidence rates seasonal index indicated that the second quarter had the highest seasonal index and the first quarter had the second highest. The fourth quarter index was the lowest, almost $30 \%$ lower than the second quarter index. 


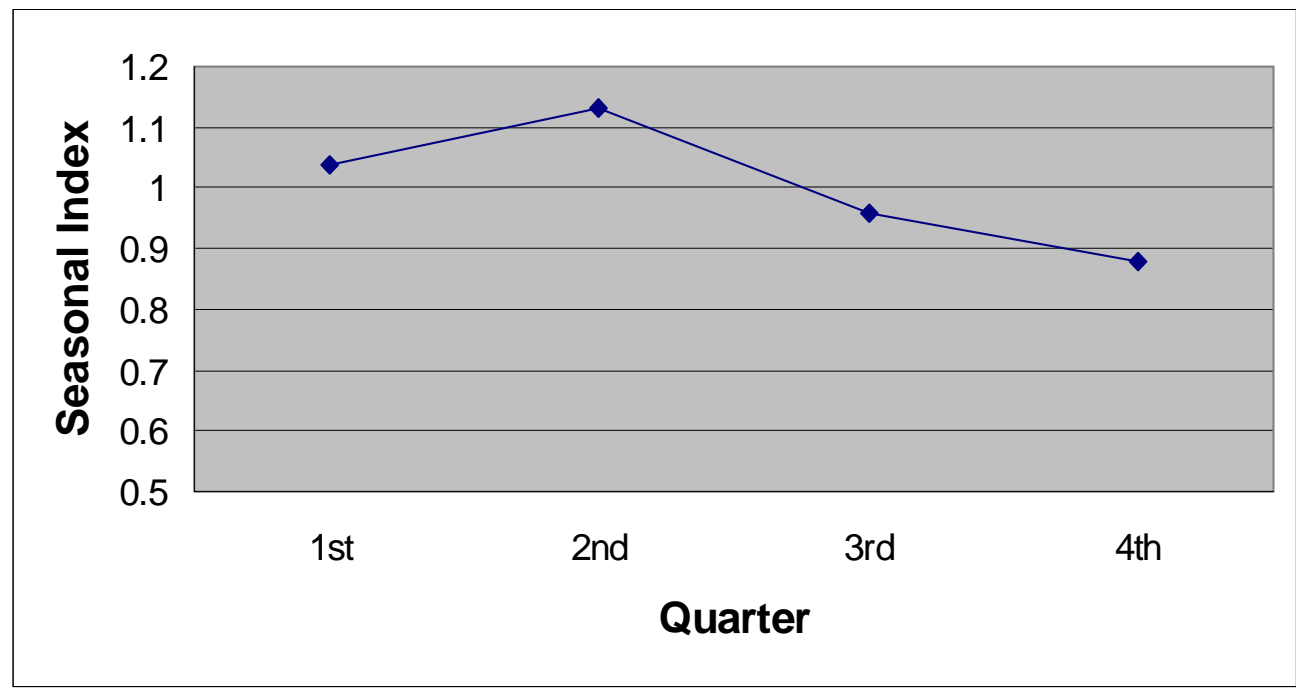

Figure 98. Quarterly Seasonal Pattern of Lost Work Day Incidence Rates - Corporate

\section{Monthly Analysis of Lost Work Day Data - Corporate}

Figure 99 illustrates the January Corporate lost work day incidence rates for 1994 through 2000. The lowest incidence rate occurred in 1996 and was followed in 1998 by the highest January incidence rate, which was over four times greater in magnitude than the 1996 rate. The remaining four incidence rates were clustered around the mean.

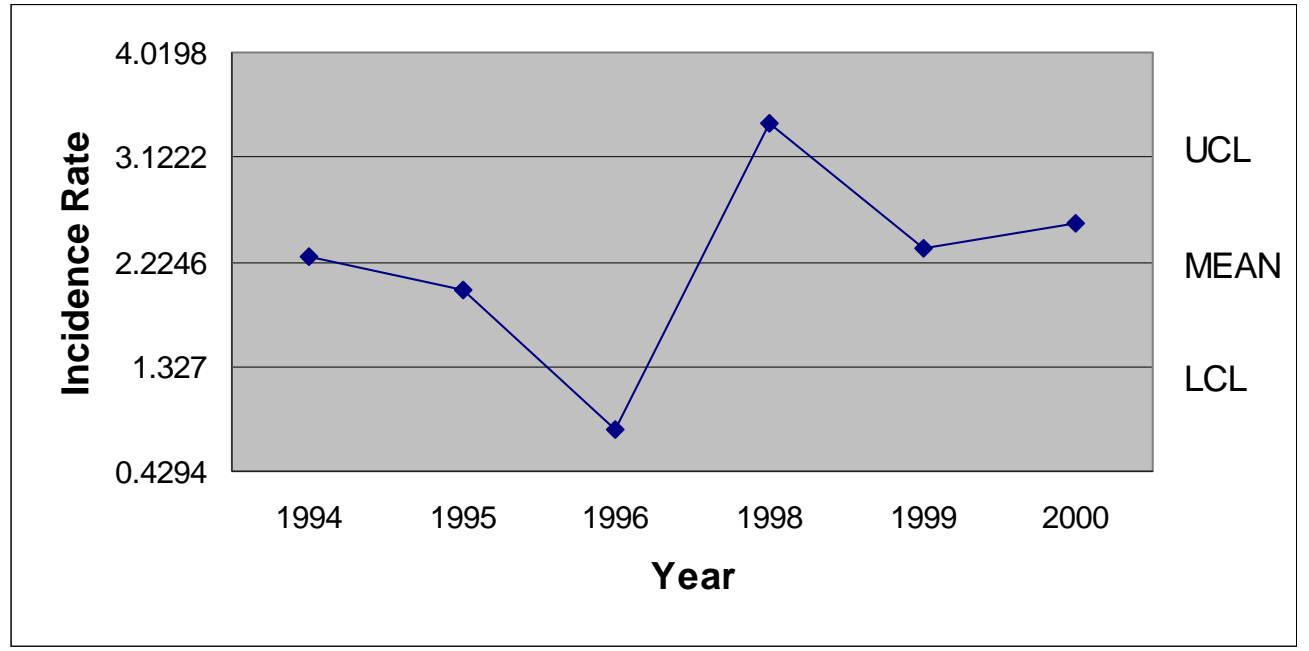

Note: No operations in January 1997

Figure 99. January 1994-2000 Lost Work Day Incidence Rates - Corporate 
The first two years researched recorded February incidence rates for Corporate lost work day incidence rates just above the mean. In 1996 the incidence rate dropped to below the LCL and in 1998 it jumped to above the UCL. The high in 1998 was over two and one-quarter times the magnitude of the 1996 rate. Immediately following the high the incidence rate was recorded below the mean in 1999 (See Figure 100).

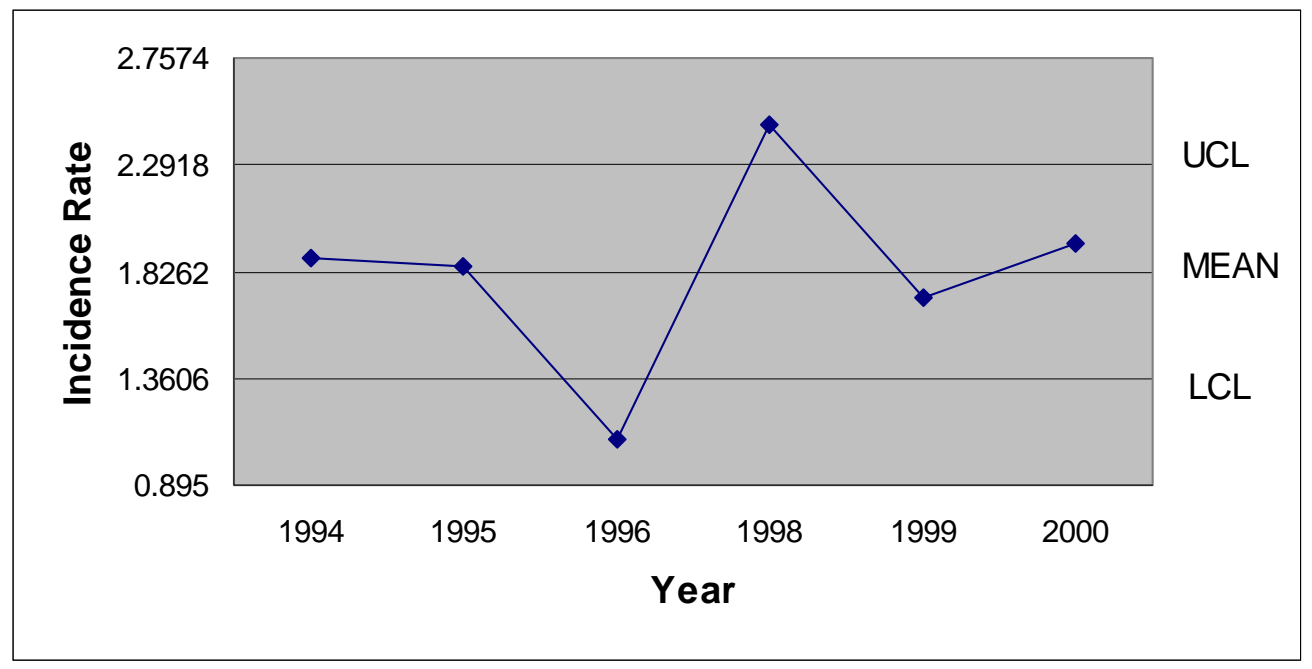

Note: No operations in February 1997

Figure 100. February 1994-2000 Lost Work Day Incidence Rates - Corporate

Figure 101 illustrates that a steadily decreasing trend in Corporate incidence rates occurred during March for the first three years of the research period. The 1996 incidence rate of 0.7945 was followed in 1998 with an incidence rate of 2.5129, indicating a threefold increase in incidence rate between the low and the high. After the 1998 peak, the incidence rate decreased in 1999 and continued to decrease to the mean in 2000. 


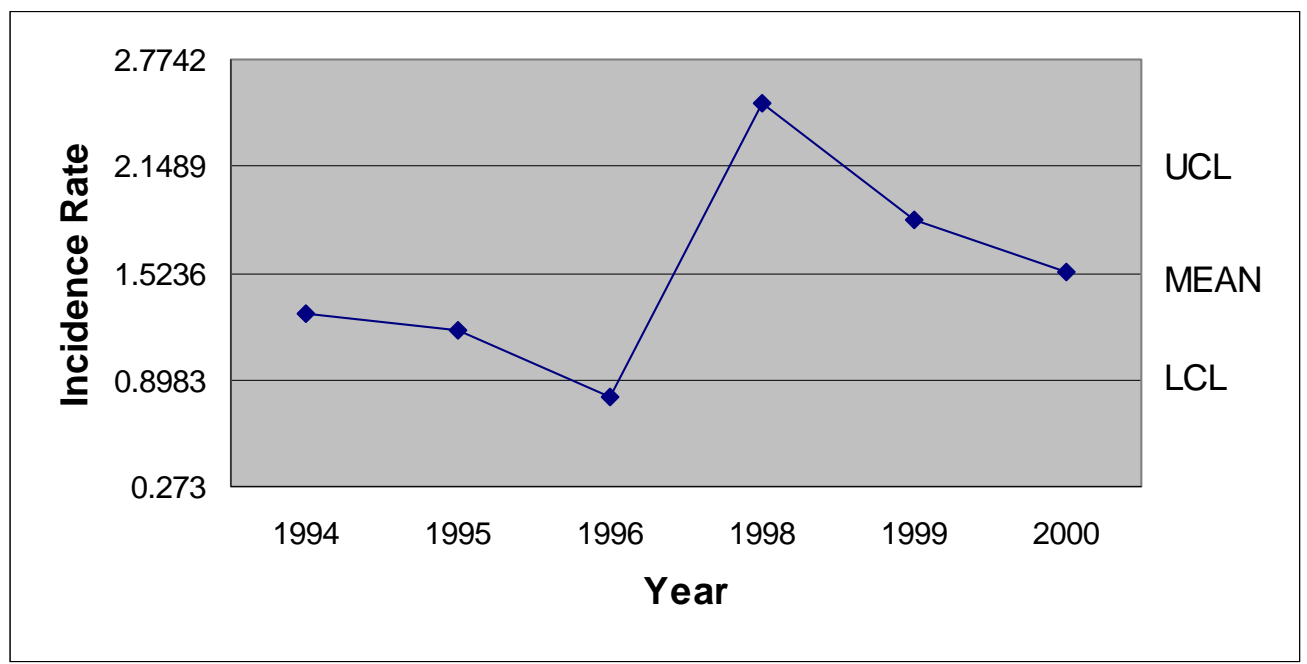

Note: No operations in March 1997

Figure 101. March 1994-2000 Lost Work Day Incidence Rates - Corporate

The April Corporate incidence rate for the initial period in this study was between the mean and the UCL. Each of the next two years recorded incidence rates at close to the LCL. This trend was interrupted in 1998 by the highest April incidence rate for this study period. The 1998 rate, 2.6365 was above the UCL. It was followed in 1999 with an incidence rate just above the LCL, and in 2000 with an incidence rate almost returning to the UCL (See Figure 102).

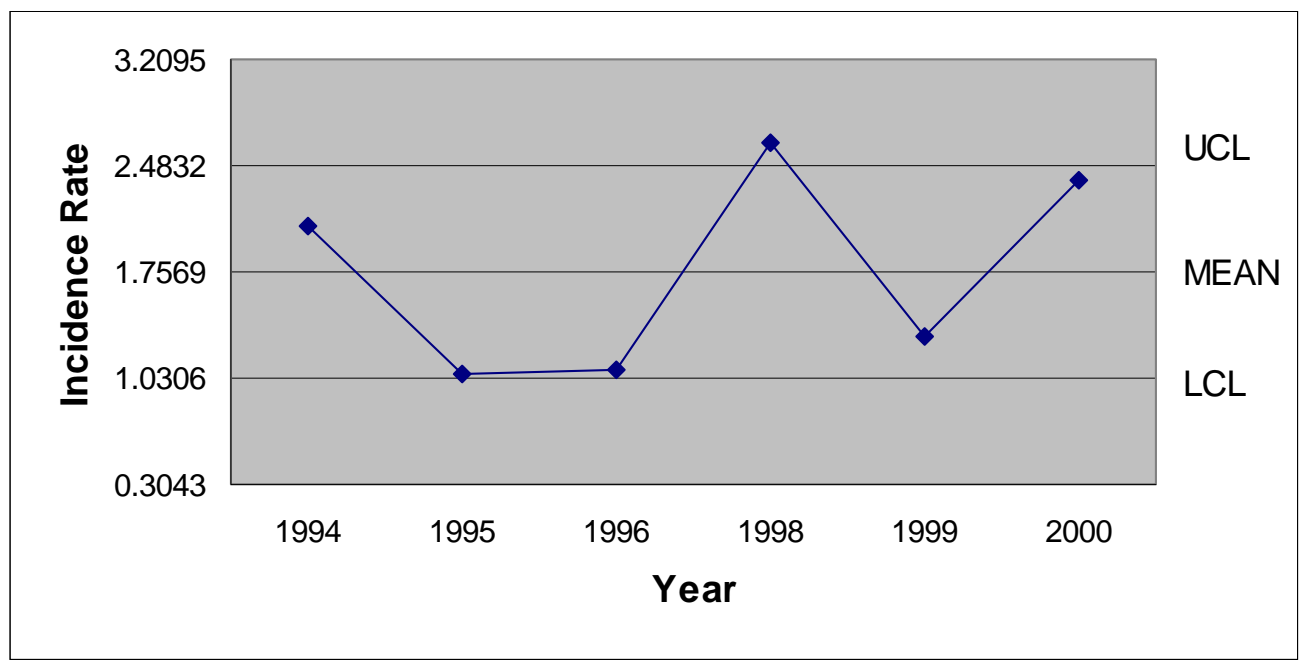

Note: No operations in April 1997

Figure 102. April 1994-2000 Lost Work Day Incidence Rates - Corporate 
Figure 103 illustrates a zigzag effect that started in May 1994 for the Corporate incidence rate below the LCL and ended in 2000 above the UCL. The largest increase in magnitude between periods occurred between 1994 and 1995. This was followed in the next period with a decrease of almost the same magnitude.

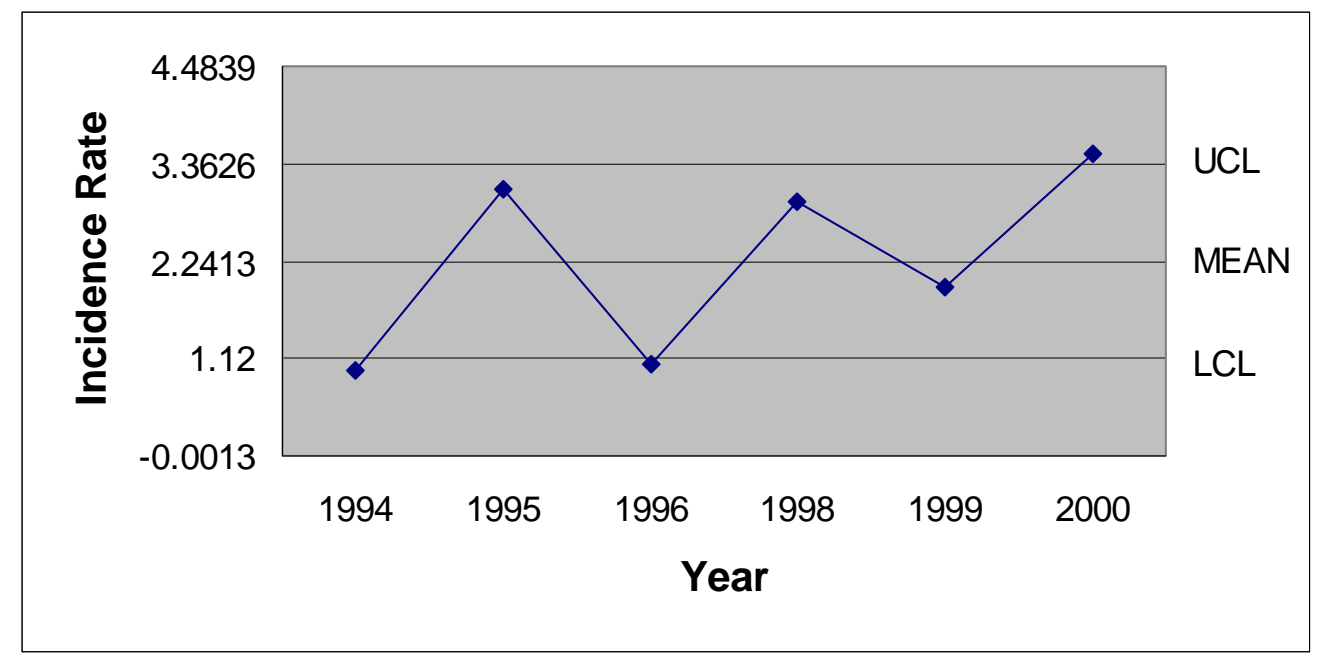

Note: No operations in May 1997

Figure 103. May 1994-2000 Lost Work Day Incidence Rates - Corporate

Figure 104 shows two periods, 1994 and 1998 of the Corporate incidence rates, above the UCL, while one period 1996 is just below the LCL. The highest June rate, which was recorded in 1998, was over four times greater than the lowest rate that was recorded in 1996. 


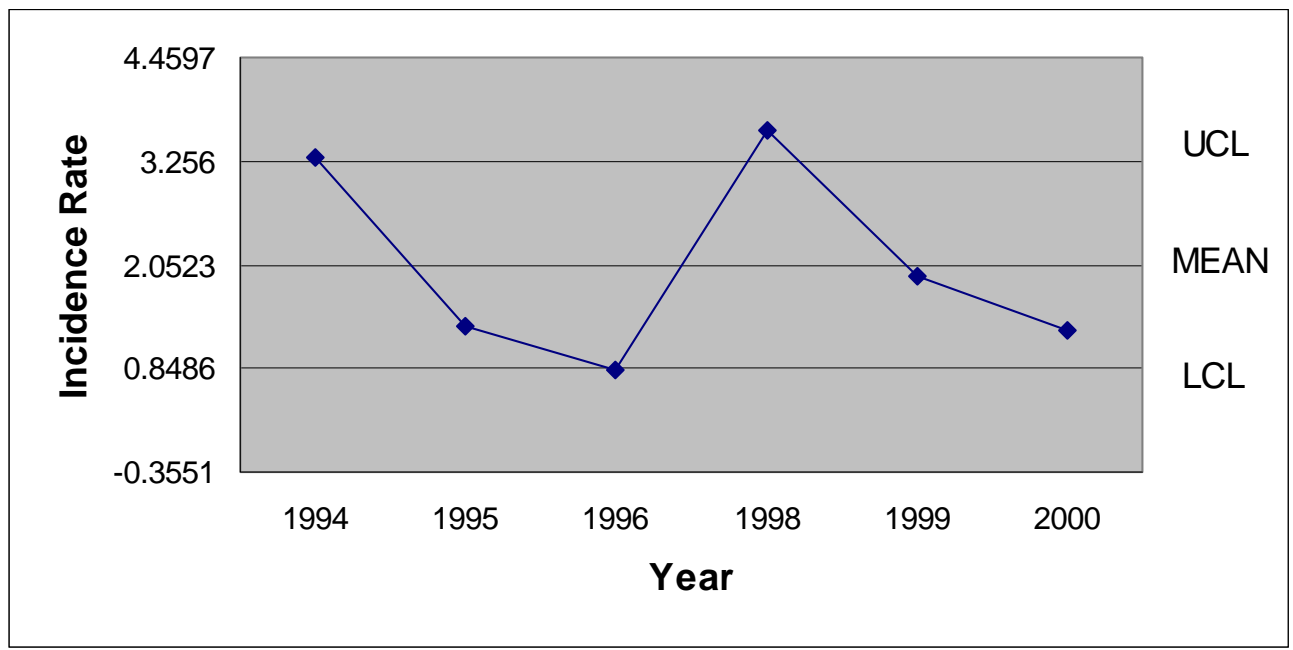

Note: No operations in June 1997

Figure 104. June 1994-2000 Lost Work Day Incidence Rates - Corporate

The first three July Corporate incidence rates were recorded between the mean and the LCL. The lowest rate, July 1996, was followed by two periods of increasing incidence rates. In 1998 the rate was just above the mean and in 1999 the rate was above the UCL (See Figure 105).

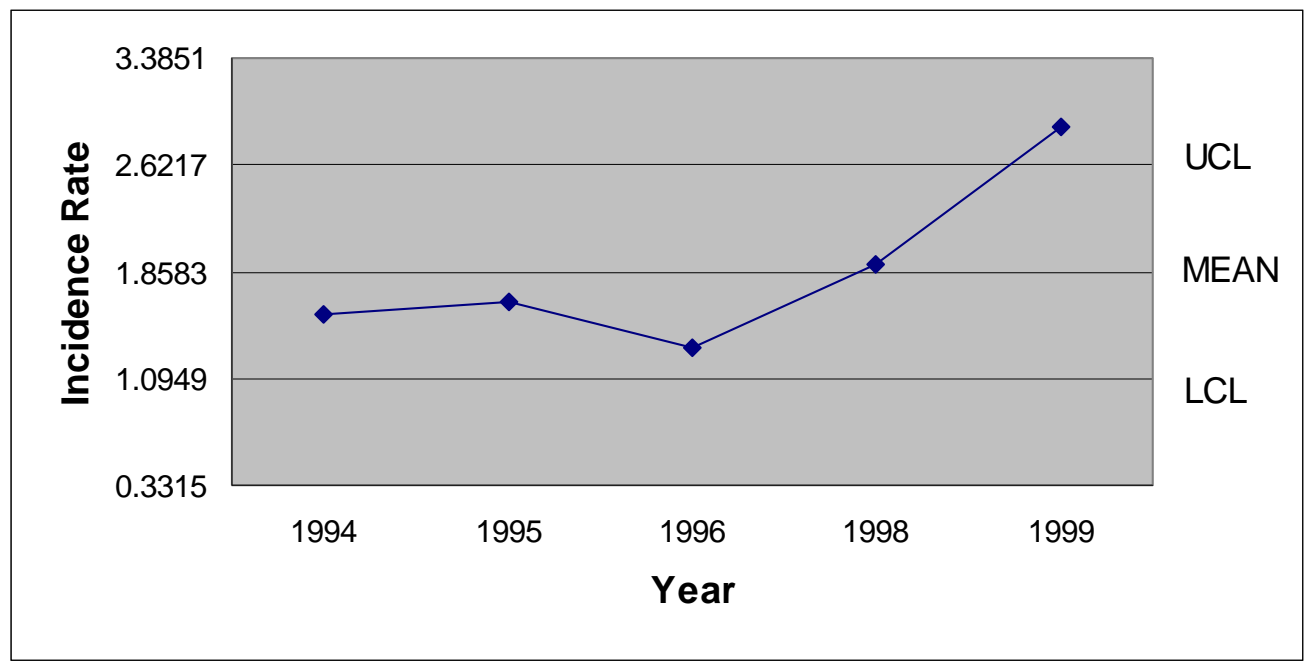

Note: No operations in July 1997

Figure 105. July 1994-1999 Lost Work Day Incidence Rates - Corporate 
The 1994 August Corporate incidence rate was the lowest recorded for this month over the study period. After the 1994 rate, which was recorded below the LCL, the 1995 rate rose to a level above the mean. The rate was between the LCL and the mean in 1996 and increased to a level just below the UCL in 1998. The 1998 high was followed by a decrease in 1999 to a level between the mean and the UCL (See Figure 106).

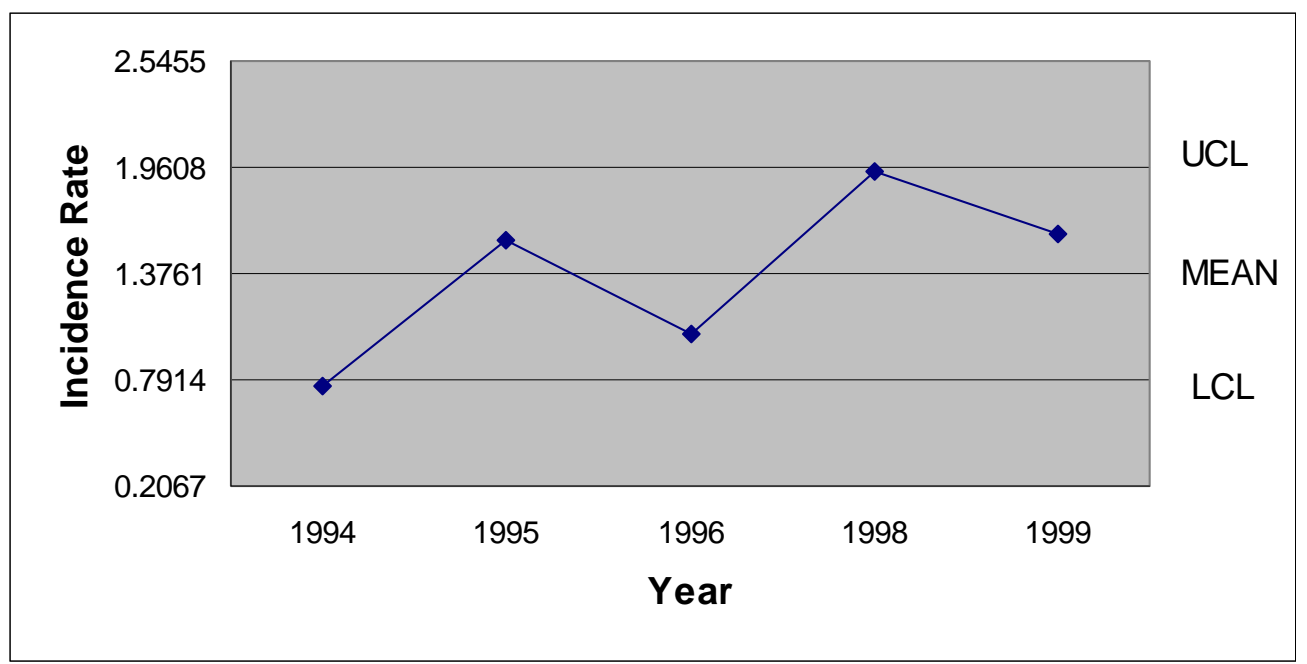

Note: No operations in August 1997

Figure 106. August 1994-1999 Lost Work Day Incidence Rates - Corporate

As illustrated in Figure 107, the first three years experienced a gradual decrease in Corporate incidence rates, which was followed by a sharp increase in September 1998. This increase was followed by a decrease to a level below the mean in 1999. 


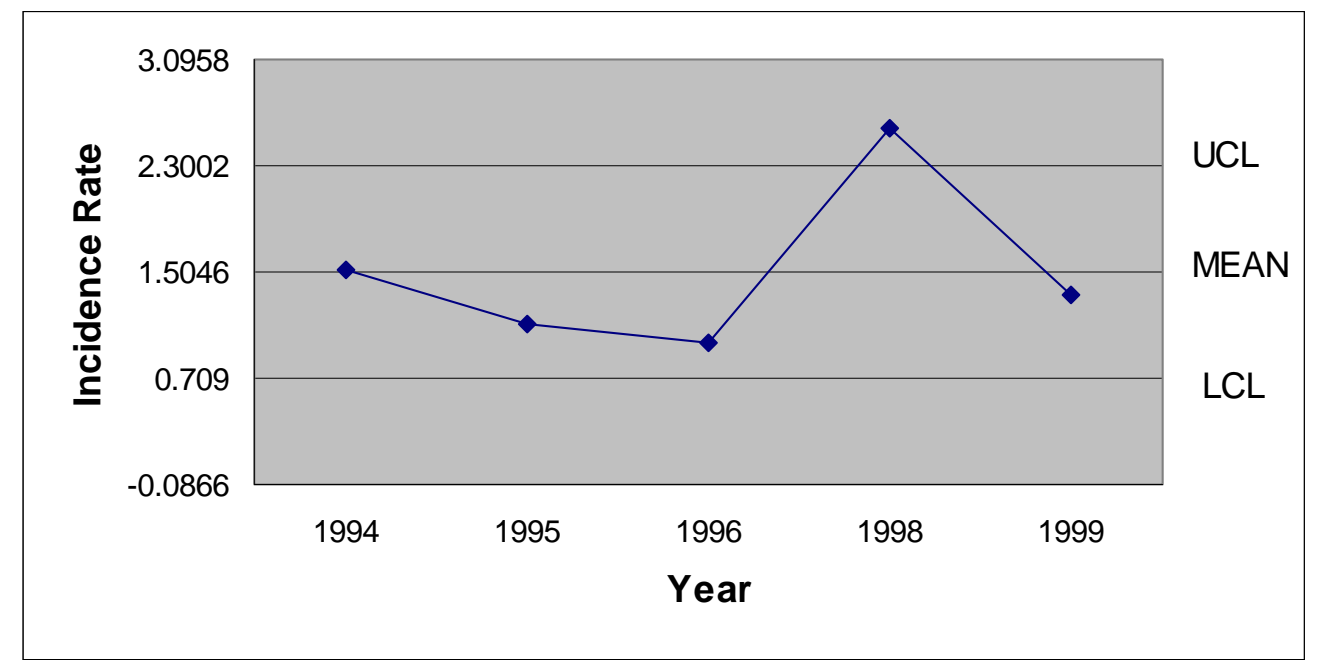

Note: No operations in September 1997

Figure 107. September 1994-1999 Lost Work Day Incidence Rates - Corporate

October Corporate incidence rates are illustrated in Figure 108. All October incidence rates were within the established control limits. The lowest rate was in 1995, only 0.089 above the LCL. In 1997, the next period of operation, the highest incidence rate was recorded. The rate for 1998 was slightly lower than the 1997 high. The final October of the study period was recorded just above the LCL.

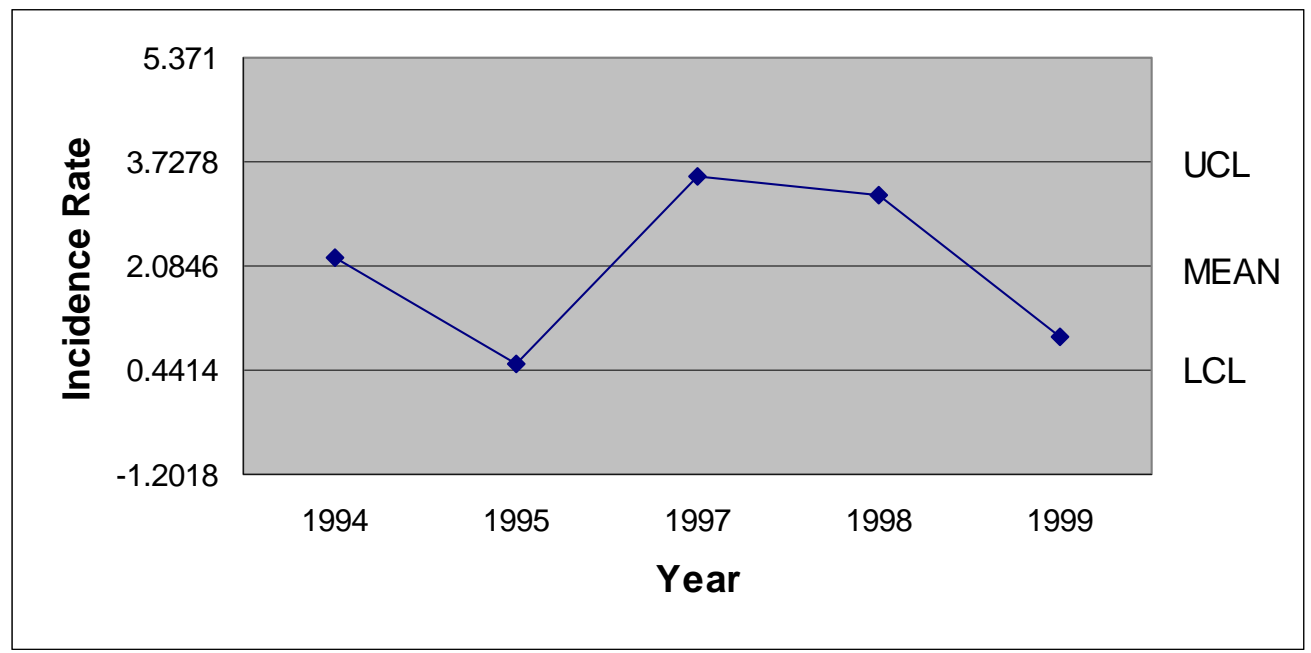

Note: No operations in October 1996

Figure 108. October 1994-1999 Lost Work Day Incidence Rates - Corporate 
November was marked initially by two low years of Corporate incidence rates. These rates, which were close to the LCL, were followed by a 1997 rate above the UCL. In 1998, the incidence rate was just below the mean and in 1999, the incidence rate was between the mean and the UCL (See Figure 109).

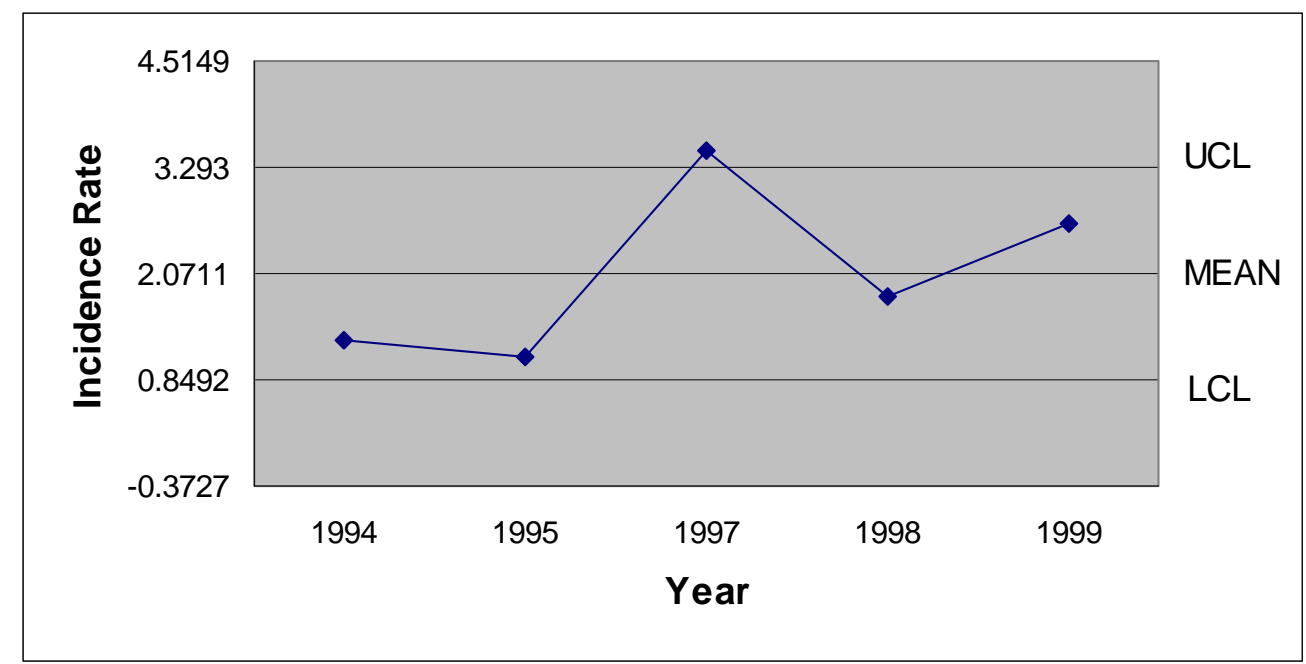

Note: No operations in November 1996

Figure 109. November 1994-1999 Lost Work Day Incidence Rates - Corporate

The December Corporate incidence rates resemble a bell shaped curve. The highest incidence rate occurred in 1997, the middle year of the research period. The previous two periods were almost identical to the succeeding two periods (See Figure 110). 


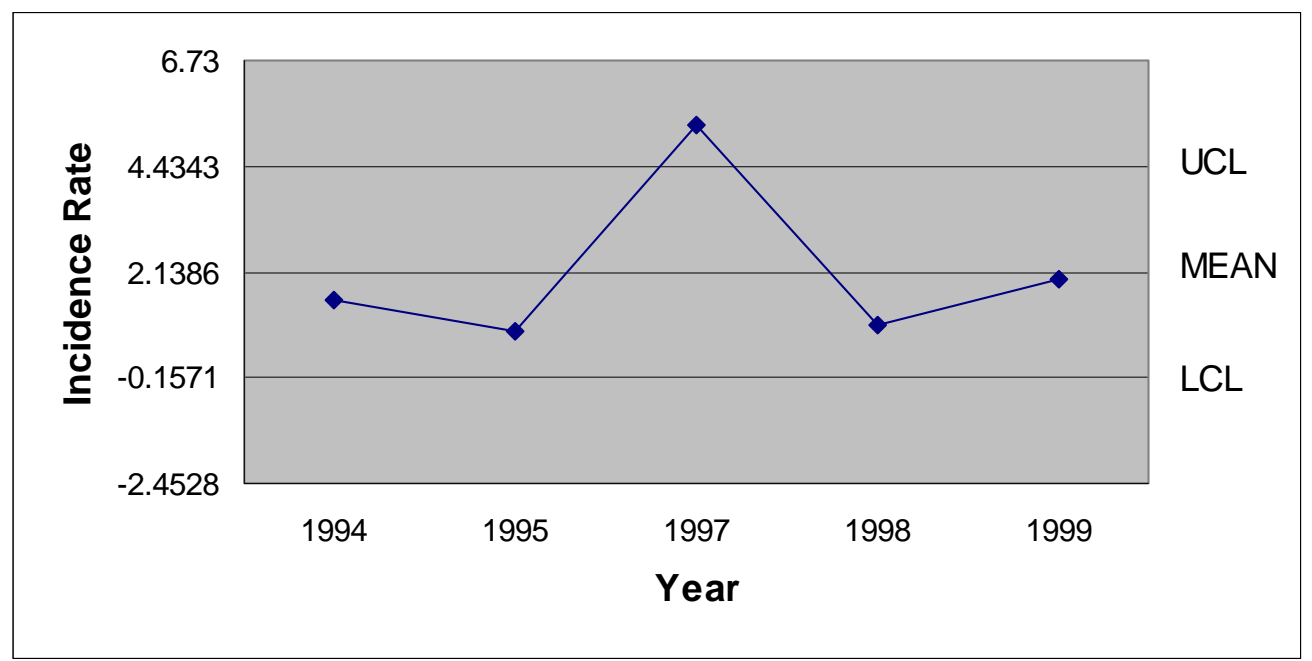

Note: No operations in December 1996

Figure 110. December 1994-1999 Lost Work Day Incidence Rates - Corporate

Table 20 presents the Corporate monthly incidence rates for each year of the study period, as well as the UCL, mean, LCL, and standard deviation. Nineteen ninetysix and 1997 are partial years because of the work stoppage and only the first six months of 2000 were included in the research.

Table 20

Summary of Monthly Lost Work Day Incidence Rates Data - Corporate

\begin{tabular}{|l|c|c|c|c|c|c|c|c|c|c|c|c|}
\hline & Jan. & Feb. & Mar. & Apr. & May & June & July & Aug. & Sept. & Oct. & Nov. & Dec. \\
\hline 1994 & 2.276 & 1.883 & 1.283 & 2.069 & 0.993 & 3.308 & 1.550 & 0.754 & 1.519 & 2.215 & 1.310 & 1.533 \\
\hline 1995 & 1.979 & 1.853 & 1.188 & 1.055 & 3.073 & 1.341 & 1.635 & 1.558 & 1.108 & 0.530 & 1.120 & 0.834 \\
\hline 1996 & 0.787 & 1.094 & 0.795 & 1.092 & 1.500 & 0.836 & 1.310 & 1.044 & 0.975 & N/A & N/A & N/A \\
\hline 1997 & N/A & N/A & N/A & N/A & N/A & N/A & N/A & N/A & N/A & 3.510 & 3.478 & 5.348 \\
\hline 1998 & 3.409 & 2.471 & 2.513 & 2.636 & 2.914 & 3.608 & 1.905 & 1.934 & 2.589 & 3.212 & 1.796 & 1.007 \\
\hline 1999 & 2.333 & 1.711 & 1.829 & 1.310 & 1.953 & 1.928 & 2.890 & 1.590 & 1.333 & 0.956 & 2.652 & 1.971 \\
\hline 2000 & 2.563 & 1.946 & 1.534 & 2.379 & 3.466 & 1.292 & N/A & N/A & N/A & N/A & N/A & N/A \\
\hline UCL & 3.122 & 2.292 & 2.149 & 2.483 & 3.363 & 3.256 & 2.622 & 1.961 & 2.300 & 3.728 & 3.293 & 4.434 \\
\hline MEAN & 2.225 & 1.826 & 1.524 & 1.757 & 2.241 & 2.052 & 1.858 & 1.376 & 1.505 & 2.085 & 2.071 & 2.139 \\
\hline LCL & 1.327 & 1.361 & 0.898 & 1.031 & 1.120 & 0.849 & 1.095 & 0.791 & 0.709 & 0.441 & 0.849 & -0.157 \\
\hline SD & 0.349 & 0.181 & 0.243 & 0.282 & 0.436 & 0.468 & 0.275 & 0.211 & 0.287 & 0.592 & 0.440 & 0.827 \\
\hline
\end{tabular}




\section{$\underline{\text { Seasonal Analysis of Lost Work Day Data - Corporate }}$}

The seasonal index calculation was used to generate the monthly seasonal index figures of Corporate incidence rates that are presented in Figure 111. January had the second highest seasonal index. The highest lost work day seasonal index occurred in May, which was followed by the third and fourth highest months. August, the lowest seasonal index, was followed by a period of relatively stable seasonal indexes through December.

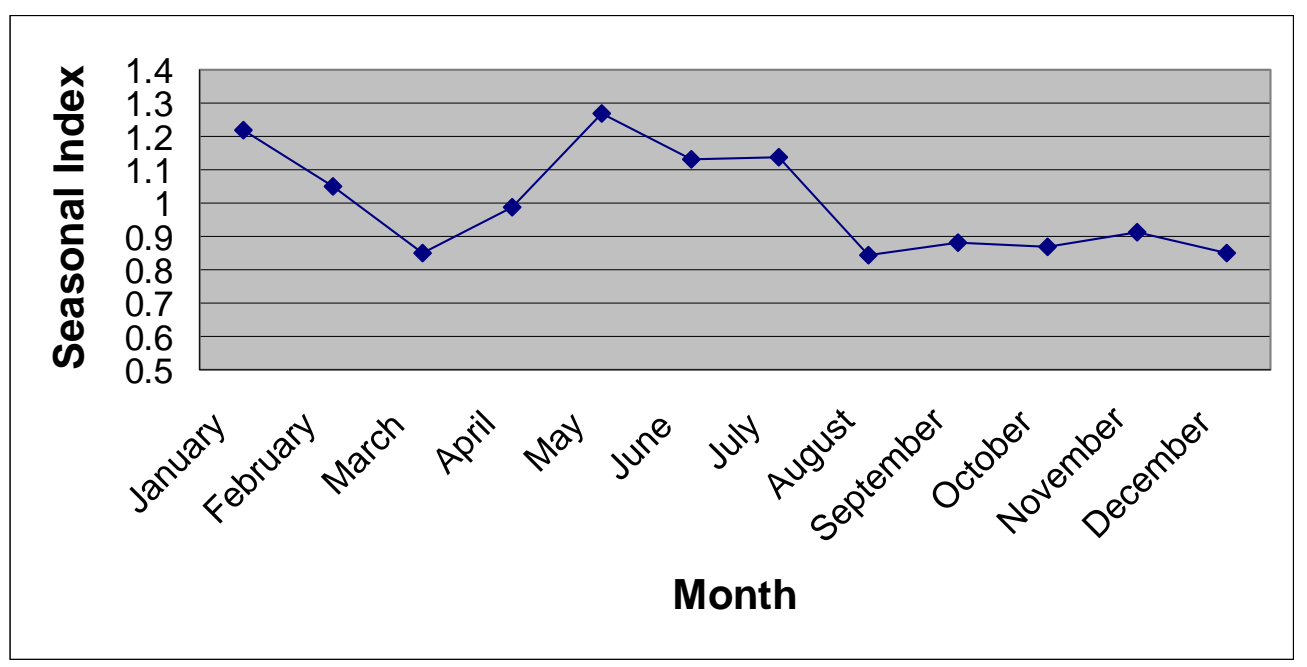

Figure 111. Monthly Seasonal Pattern of Lost Work day Incidence Rates -Corporate

\section{Testing the statistical relationship of Lost Work Day Data - Corporate}

All 33 months prior to and subsequent to the work stoppage

For the entire 33 months prior to the work stoppage and the 33 post work stoppage months the comparison $t$ value for the Corporate lost work day incidence rates was 5.025. Because this calculated amount exceeded the 1.96 critical t value, a statistically significant increase occurred between incidence rates for these two periods.

First 24 months and last 24 months of the research period

The same formula was applied to lost work day incidence rates for the first 24 months and the last 24 months of the period. These time periods excluded the nine months prior to and immediately following the work stoppage. Using the same 1.96 
critical t value, the calculated amount, 2.0028, indicated a statistically significant increase in lost work day incidence rates between the two periods.

Nine month intervals prior to and subsequent to the work stoppage

Comparison of the Corporate OSHA recordable incidence rates for the nine months preceding the work stoppage and the nine months following the work stoppage was accomplished using The comparison formula. The result of this calculation, 6.209, was greater than the critical $t$ value of 1.96 , for a .05 statistical significance level. Because the calculated amount exceeded the significance level by a sizeable amount, it was found that a large statistically significant increase in incidence rates occurred between the two periods.

Table 21 provides a summary of the Corporate comparison periods associated with the work stoppage. The incidence rates prior to the work stoppage and those following the work stoppage are listed, as are the critical t values and the calculated comparison values.

\section{Table 21}

Comparison of prior and post work stoppage periods - Corporate

\begin{tabular}{|c|c|c|c|c|}
\hline \multirow[b]{2}{*}{ Time Period } & \multicolumn{2}{|c|}{ Corporate-wide Incidence Rates } & \multirow[b]{2}{*}{ Critical t Value } & \multirow[b]{2}{*}{$\begin{array}{l}\text { Calculated } \\
\text { Comparison Value }\end{array}$} \\
\hline & $\begin{array}{l}\text { Prior to } \\
\text { Work Stoppage }\end{array}$ & $\begin{array}{l}\text { Post } \\
\text { Work Stoppage }\end{array}$ & & \\
\hline 9 Months & 0.999 & 3.30 & 1.96 & $6.209 *$ \\
\hline 24 Months & 1.59 & 2.01 & 1.96 & $2.003 *$ \\
\hline 33 Months & 1.43 & 2.35 & 1.96 & $5.015^{*}$ \\
\hline
\end{tabular}

* Indicates a statistically significant increase

** Indicates a statistically significant decrease

\section{$\underline{\text { Primary Plant Analysis }}$}

\section{Quarterly Analysis of Lost Work Day Data - Primary Plant}

As illustrated in Figure 112, the lowest Primary Plant first quarter incidence rate, 1996, was followed by the highest first quarter incidence rate, 1998. The 1998 incidence 
rate was almost four times greater than the 1996 incidence rate. The 1999 first quarter incidence rate returned to a level just above the mean.

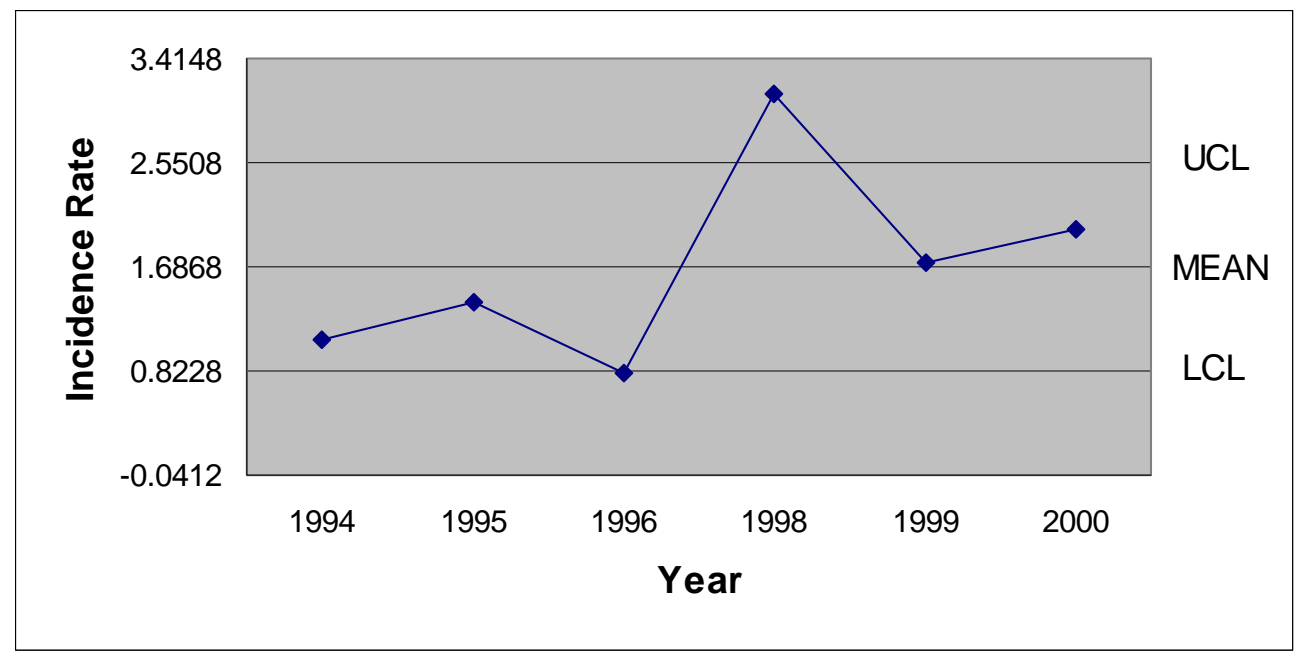

No operations in first quarter 1997

Figure 112. First Quarter 1994-2000 Corporate Lost Work Day Incidence Rates Primary Plant

The first two second quarter Primary Plant incidence rate for this research period were between the LCL and the mean. In 1996 the second quarter incidence rate was recorded below the LCL. This lowest rate, 0.693 was followed in 1998 with the highest rate, 3.470. The remaining two periods were between the mean and the UCL (See Figure 113). 


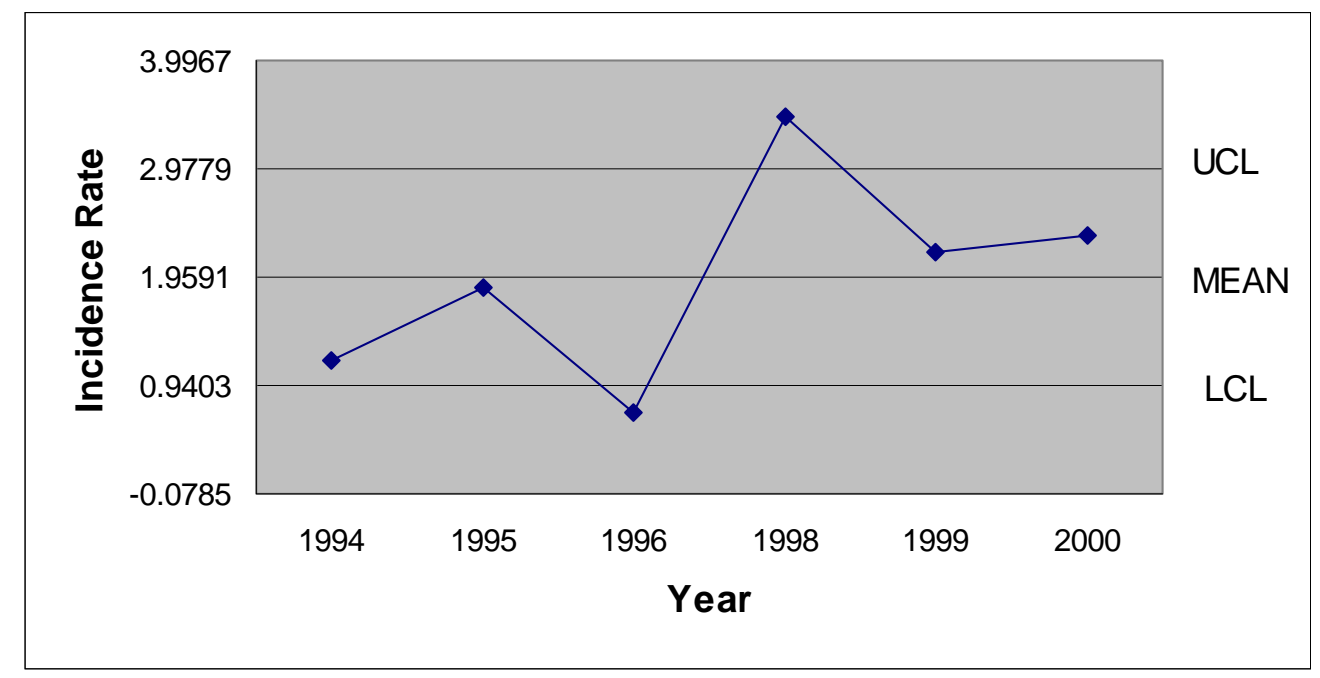

Note: No operations in second quarter 1997

Figure 113. Second Quarter 1994-2000 Corporate Lost Work Day Incidence Rates Primary Plant

The 1994 third quarter Primary Plant incidence rate was just below the LCL making it the lowest third quarter incidence rate for this study period. The next two years recorded incidence rates below the mean. In 1998 the incidence rate was between the mean and the UCL. The incidence rate edged its way above the UCL in 1999 when the highest third quarter incidence rate of 2.534 was recorded (See Figure 114).

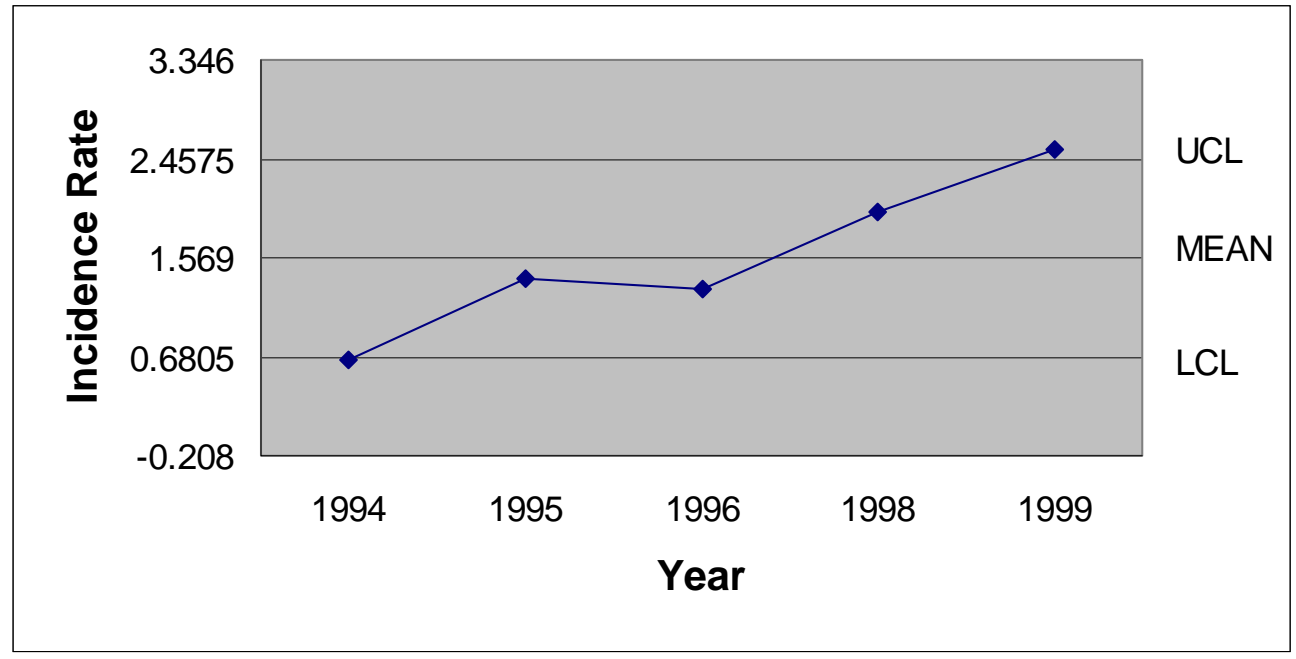

Note: No operations in third quarter 1997

Figure 114. Third Quarter 1994-1999 Corporate Lost Work Day Incidence Rates Primary Plant 
As illustrated in Figure 115, the 1994 and 1995 Primary Plant fourth quarter lost work day incidence rates were close to the LCL. These two low periods were followed in 1997 with the highest fourth quarter incidence rate recorded during the study period. The last two years recorded fourth quarter incidence rates close to the mean.

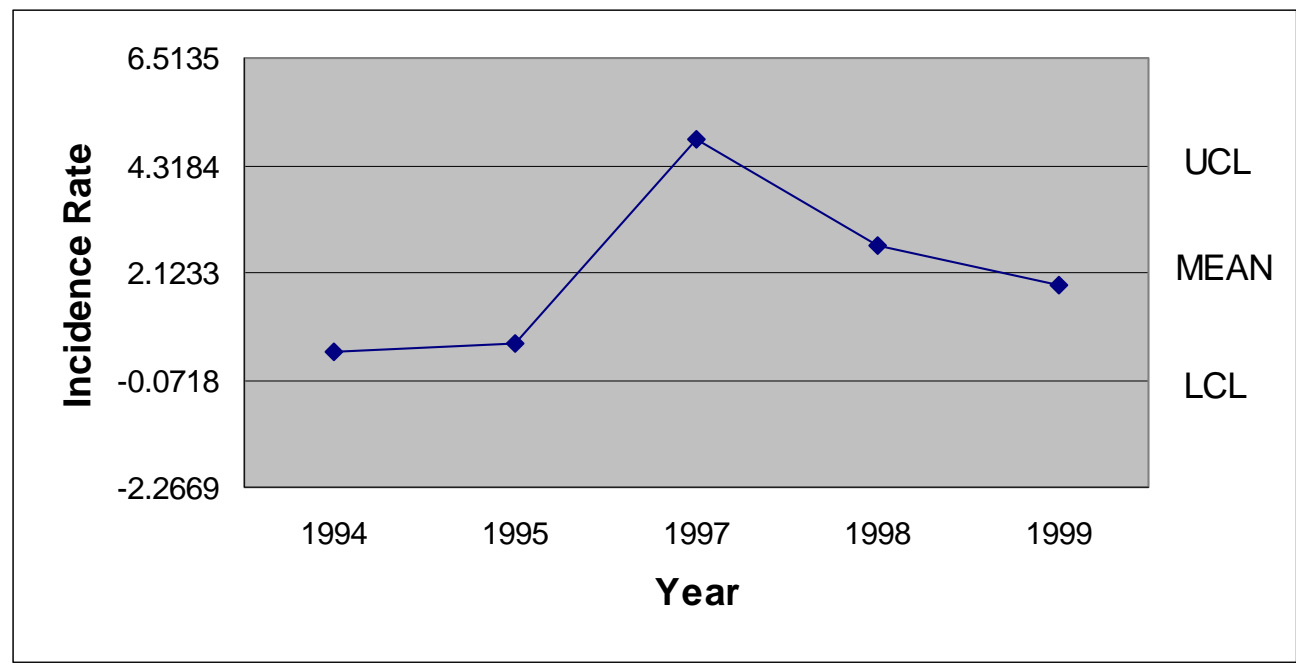

Figure 115. Fourth Quarter 1994-1999 Corporate Lost Work Day Incidence Rates Primary Plant

Table 22 presents the Primary Plant's quarterly incidence rates for each year of the study period, as well as, the UCL, mean, LCL, and standard deviation. Nineteen ninety-six and 1997 are partial years because of the work stoppage and only the first six months of 2000 were included in the research.

Table 22

$\underline{\text { Summary of Quarterly Lost Work Day Incidence Rates Data - Primary Plant }}$

\begin{tabular}{|l|l|l|l|l|}
\hline & $1^{\text {st }}$ Quarter & $2^{\text {nd }}$ Quarter & $3^{\text {rd }}$ Quarter & $4^{\text {th }}$ Quarter \\
\hline 1994 & 1.076 & 1.179 & 0.658 & 0.521 \\
\hline 1995 & 1.399 & 1.870 & 1.374 & 0.681 \\
\hline 1996 & 0.811 & 0.693 & 1.293 & N/A \\
\hline 1997 & N/A & N/A & N/A & 4.859 \\
\hline 1998 & 3.126 & 3.470 & 1.985 & 2.682 \\
\hline
\end{tabular}




\begin{tabular}{|l|l|l|l|l|}
\hline 1999 & 1.718 & 2.195 & 2.534 & 1.874 \\
\hline 2000 & 1.991 & 2.348 & N/A & N/A \\
\hline UCL & 2.551 & 2.978 & 2.457 & 4.318 \\
\hline MEAN & 1.687 & 1.959 & 1.569 & 2.123 \\
\hline LCL & 0.823 & 0.940 & 0.680 & -0.072 \\
\hline SD & 0.336 & 0.396 & 0.320 & 0.791 \\
\hline
\end{tabular}

$\underline{\text { Seasonal Analysis of Lost Work Day Data - Primary Plant }}$

The results of the quarterly seasonal index calculations are presented in Figure

116. The second quarter experienced the highest quarterly seasonal index for the Primary Plant. The first and third quarter seasonal index amounts were almost identical. The lowest seasonal index figure was recorded for the fourth quarter.

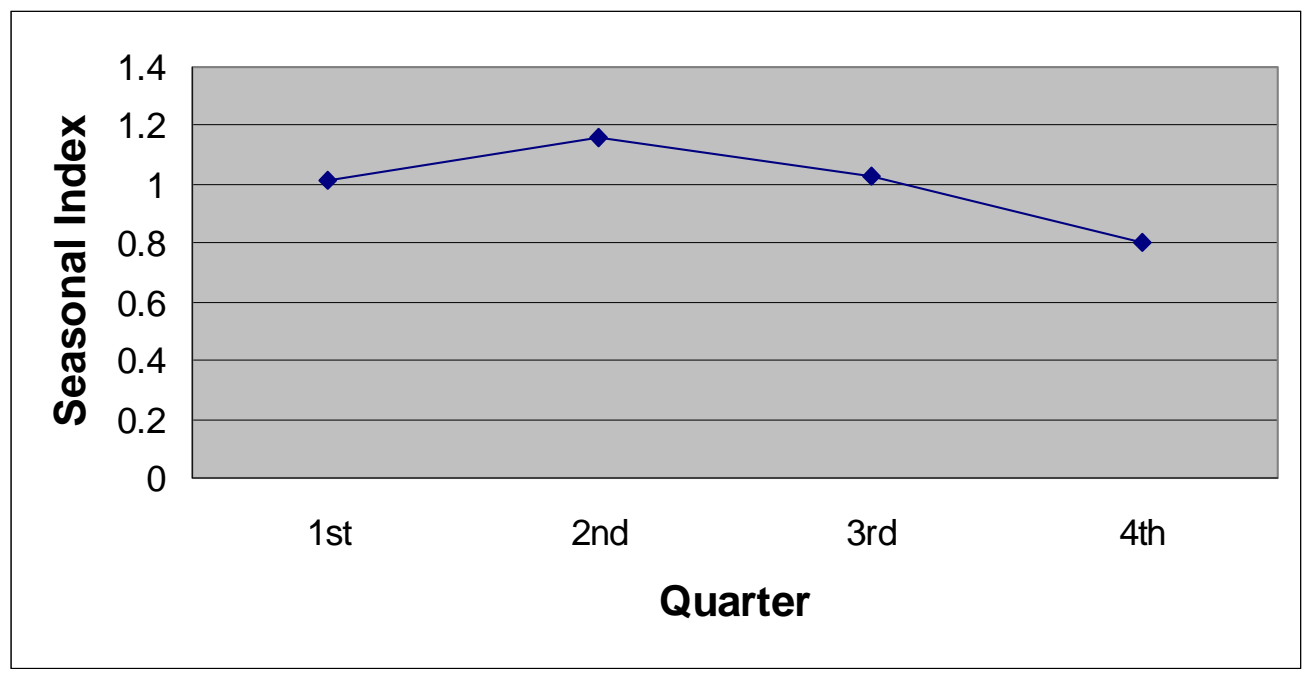

Figure 116. Quarterly Seasonal Index of Lost Work Day Incidence Rates - Primary Plant

\section{Monthly Analysis of Lost Work Day Date - Primary Plant}

The first three years of January lost work day incidence rates at the Primary Plant experienced a decreasing trend from above the mean to just above the LCL. As illustrated in Figure 117, the incidence rate went from just above the LCL in 1996 to a level above the UCL in 1998. This six-fold increase was followed in 1999 with a decrease to a level between the LCL and the mean. In the final January of this study the incidence rate was recorded just above the mean. 


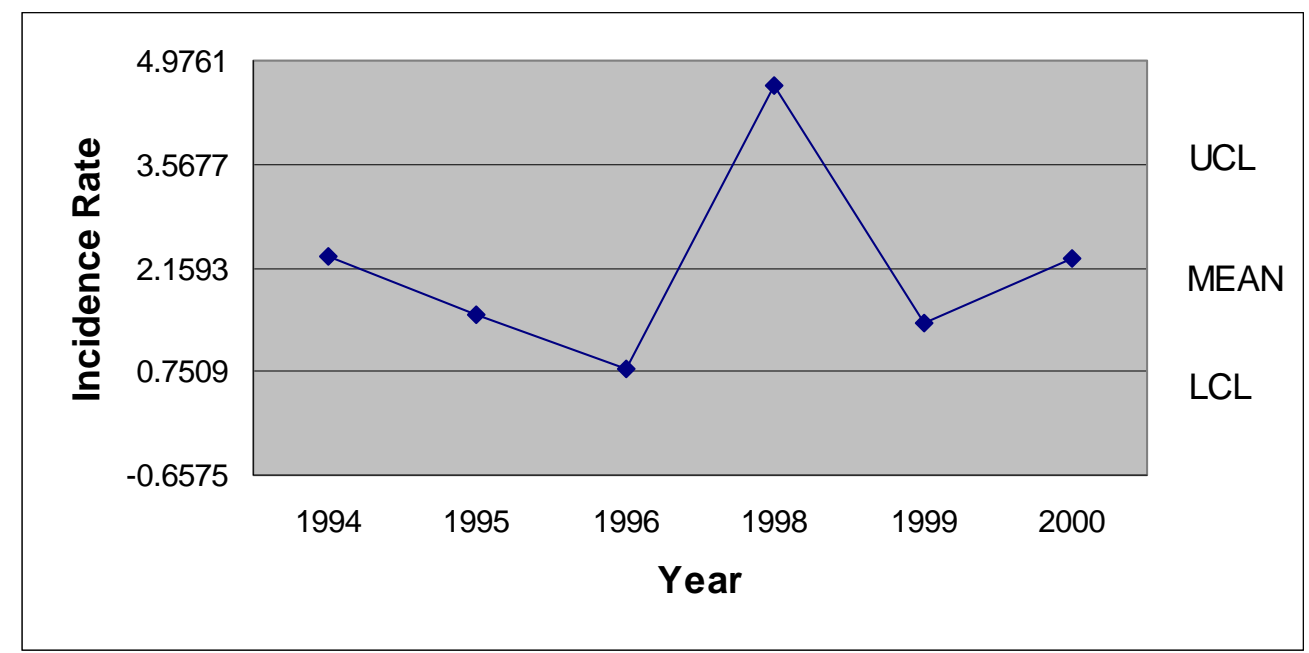

Note: No operations in January 1997

Figure 117. January 1994-2000 Lost Work Day Incidence Rates - Primary Plant

Figure 118 illustrates the upward trending zigzag effect that was experienced by the Primary Plant in the month of February. The lowest February incidence rate occurred in 1994, below the LCL. The incidence rates zigzagged to a high just below the UCL in 1998.

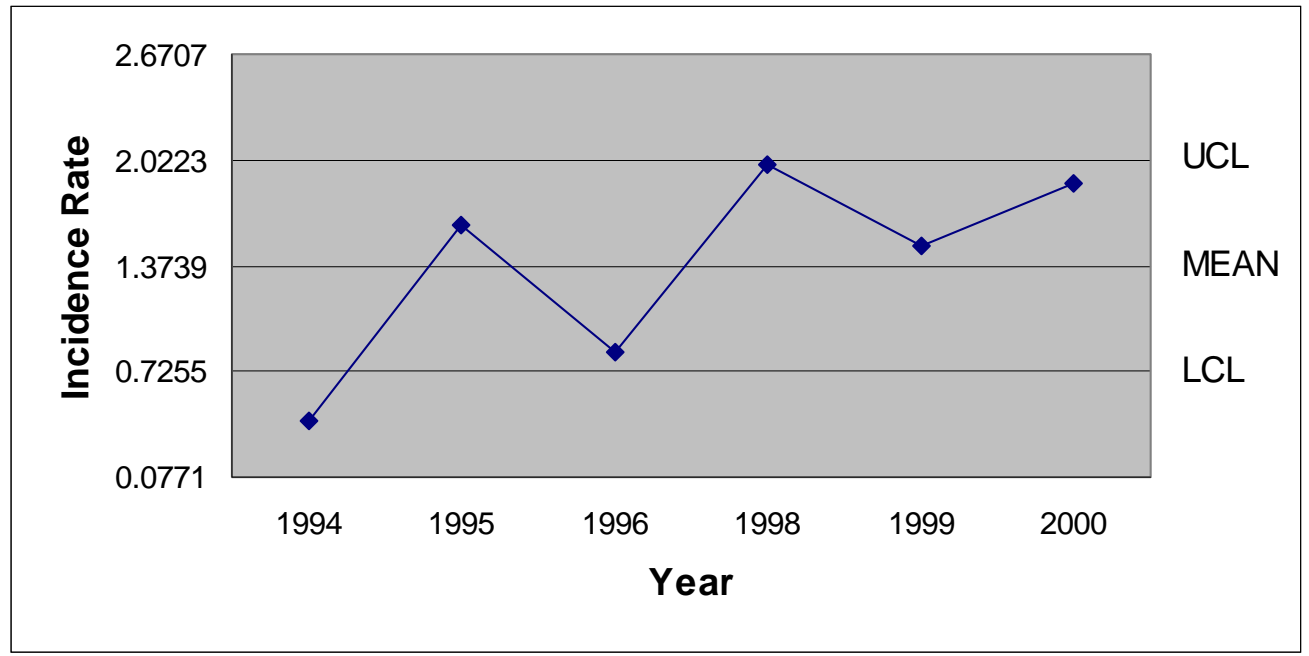

Note: No operations in February 1997

Figure 118. February 1994-2000 Lost Work Day Incidence Rates - Primary Plant 
March incidence rates at the Primary Plant were well below the mean for the first three years of this research. However, in 1998 the March incidence rates climbed to a level above the UCL. This peak was followed the next two periods by consecutive decreases in incidence rates (See Figure 119).

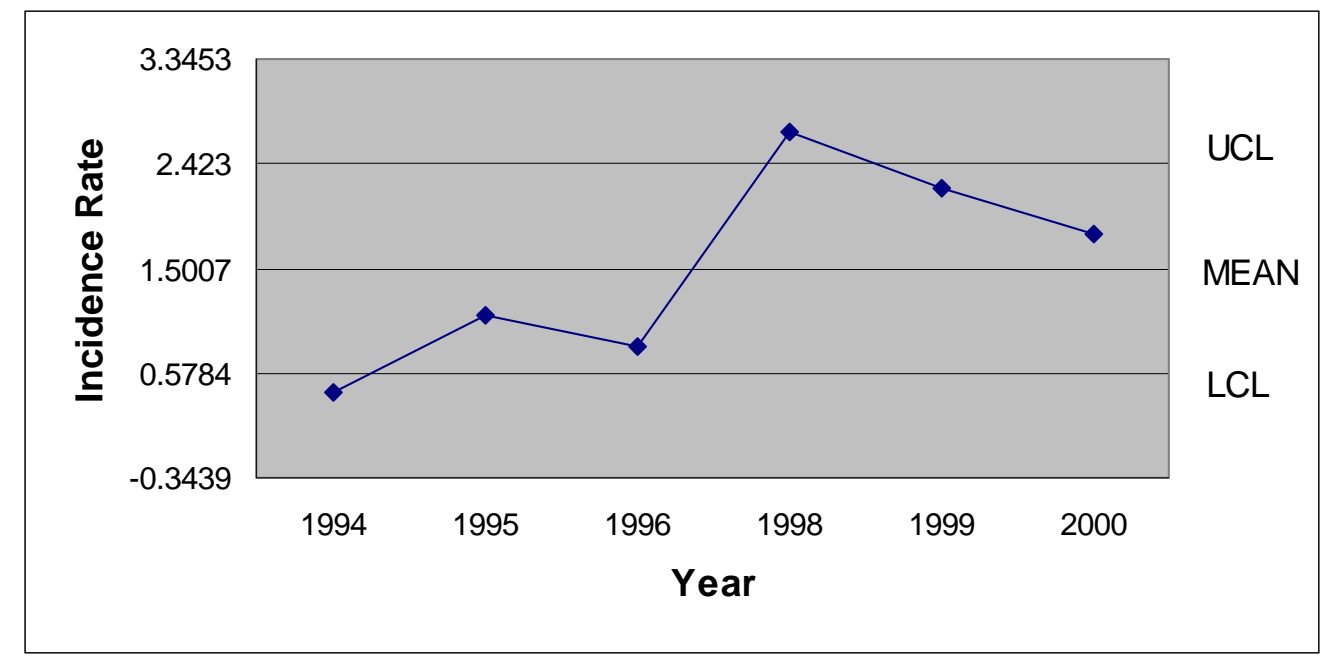

Note: No operations in March 1997

Figure 119. March 1994-2000 Lost Work Day Incidence Rates - Primary Plant

The lowest April incidence rate at the Primary Plant occurred below the LCL in 1994. The next two years recorded incidence rates just below the mean. In 1998 the incidence rate was above the UCL, making it the highest April incidence rate for the study period. A decrease of almost 30\% occurred between the April 1998 and April 1999 rates. This was offset with an increase to just below the UCL in April 2000 (See Figure 120). 


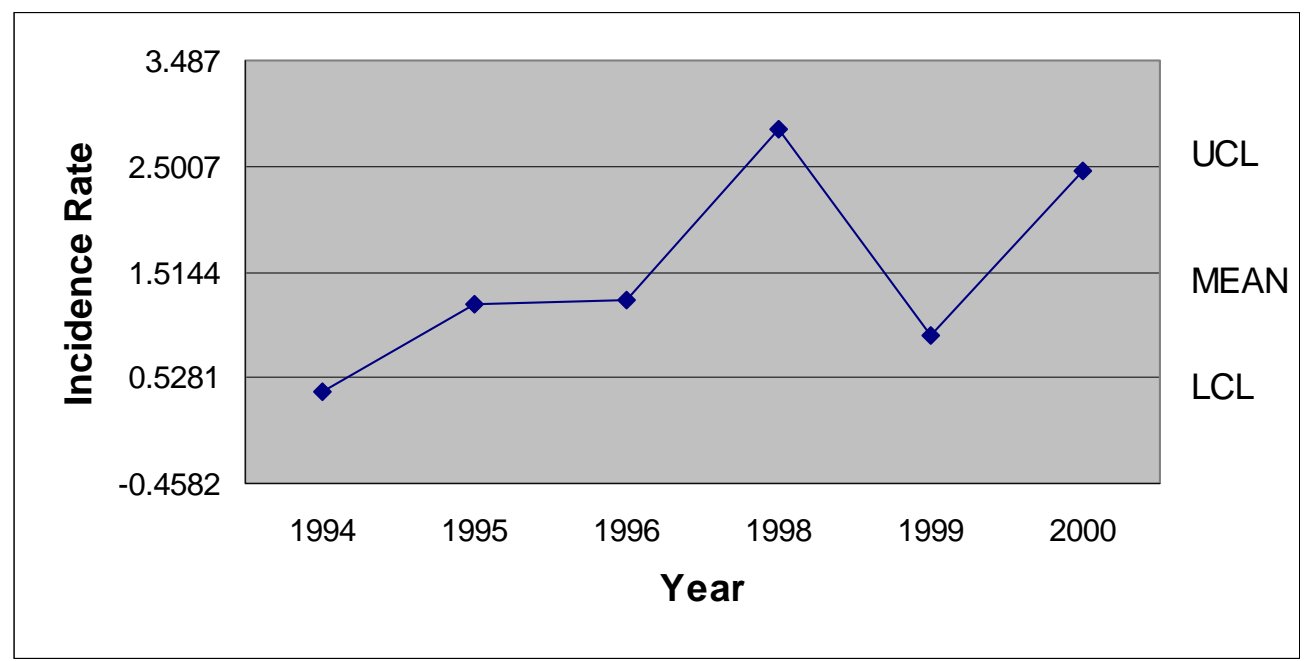

Note: No operations in April 1997

Figure 120. April 1994-2000 Lost Work Day Incidence Rates - Primary Plant

The lowest Primary Plant incidence rate for the month of May occurred in 1996. As illustrated in Figure 121, the highest incidence rate was in 2000, but was almost matched by the 1995 and 1998 incidence rates.

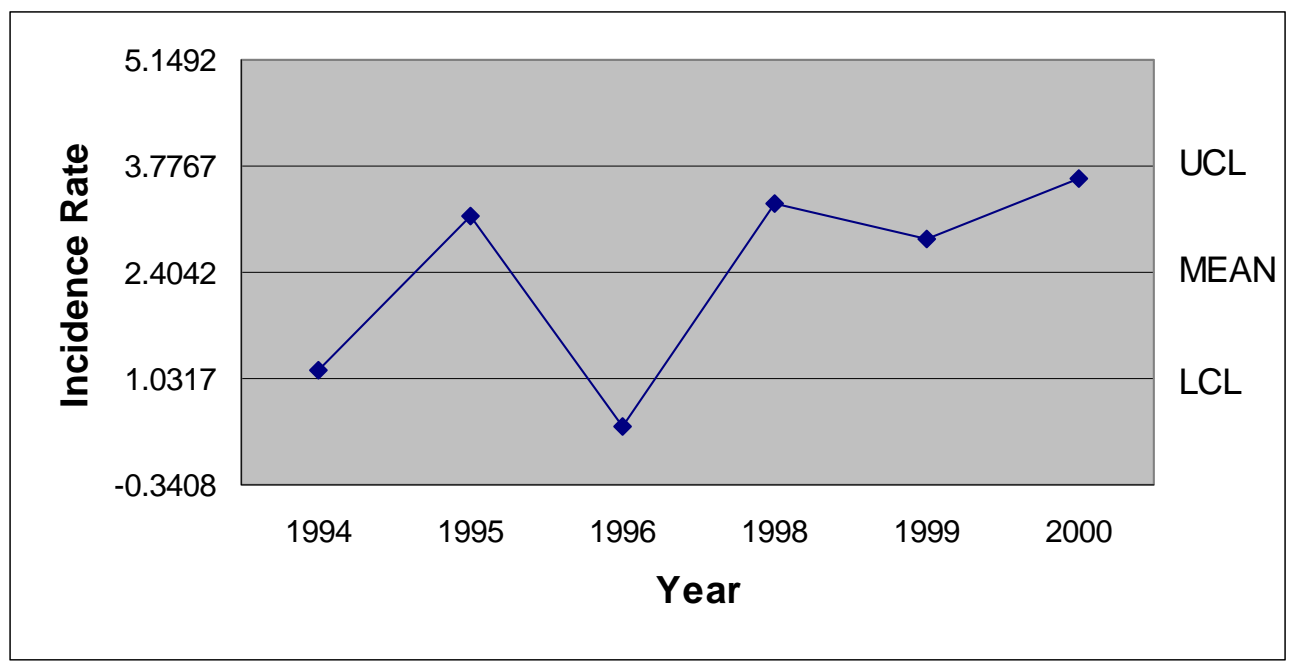

Note: No operations in May 1997

Figure 121. May 1994-2000 Lost Work Day Incidence Rates - Primary Plant

The June Primary Plant incidence rate decreased from barely above the mean in 1994 to just below the LCL in 1996. The 1996 low was followed by the 1998 high, a 
level above the UCL. The incidence rate for 1999 decreased to a level between the mean and the UCL. The last June period in the study was close to the LCL (See Figure 122).

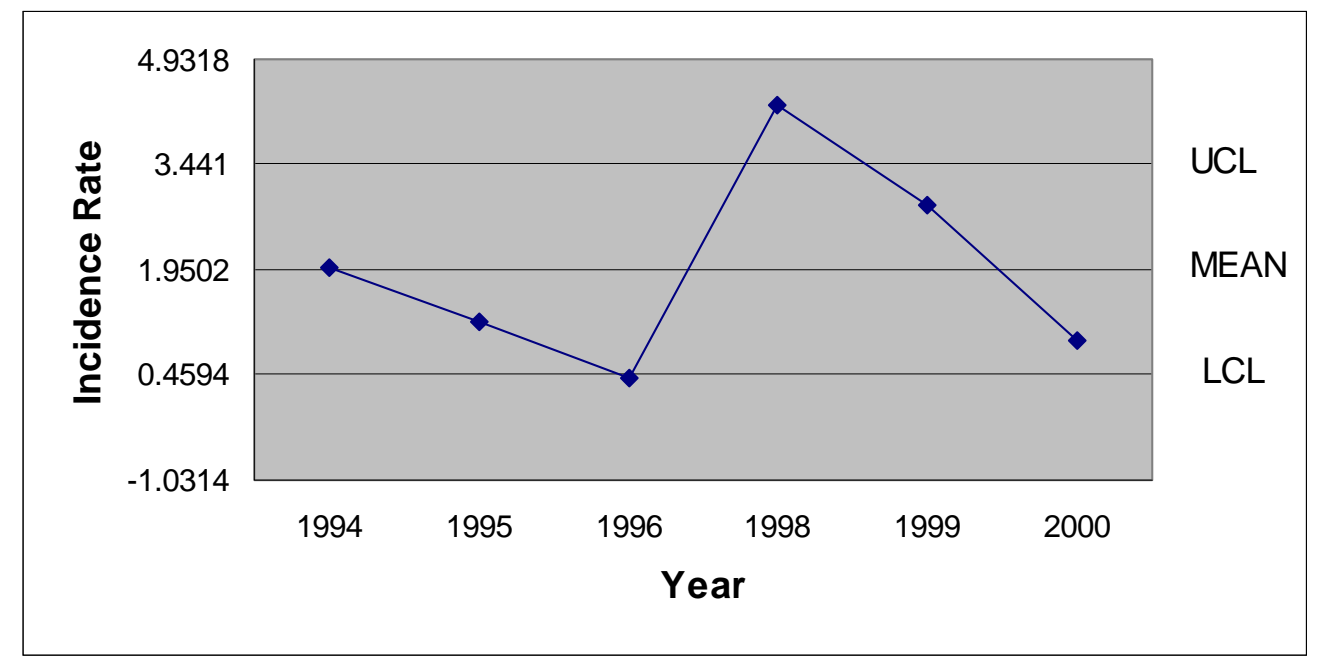

Note: No operations in June 1997

Figure 122. June 1994-2000 Lost Work Day Incidence Rates - Primary Plant

July Primary Plant incidence rates were marked by a low in 1994 close to the LCL, that was followed the next three years with incidence rates just below the mean. The last month of July figure was recorded above the UCL in 1999 (See Figure 123).

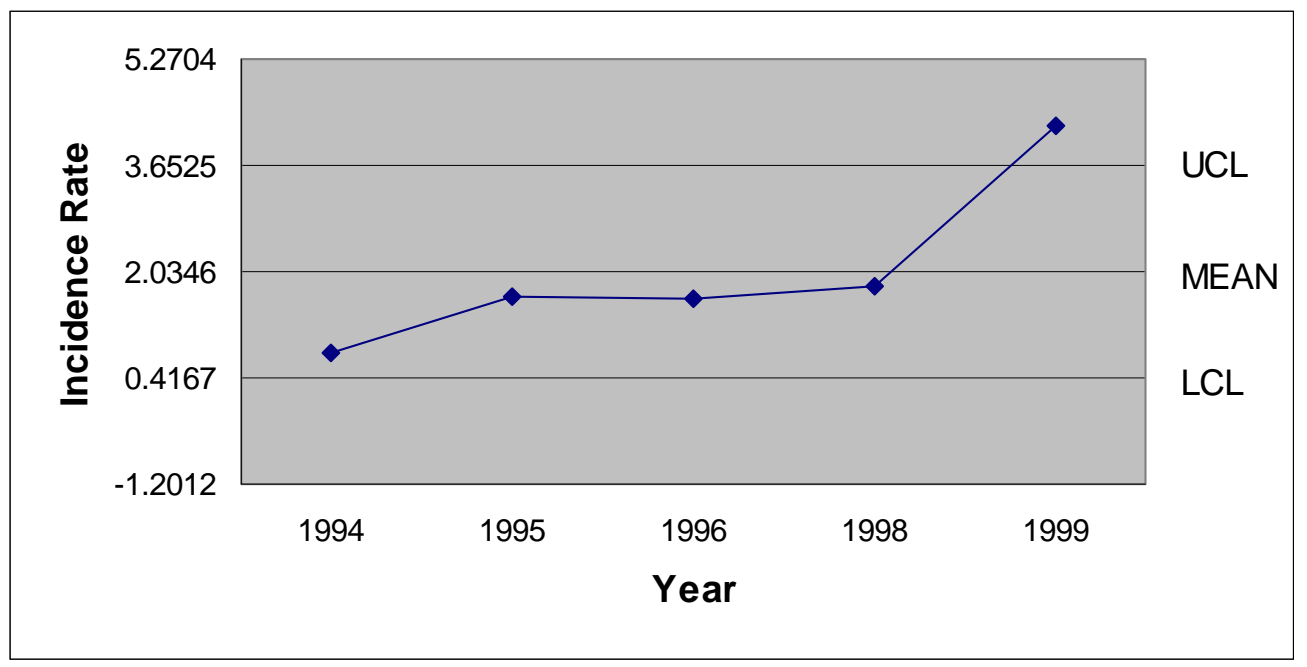

Note: No operations in July 1997

Figure 123. July 1994-1999 Lost Work Day Incidence Rates - Primary Plant 
The lowest Primary Plant August incidence rate was recorded in 1994 below the LCL. The highest August incidence rate occurred in 1998 following a two-year period with incidence rates just above the mean. The highest incidence rate, which was below the UCL, was followed in 1999 with a rate barely above the mean (See Figure 124).

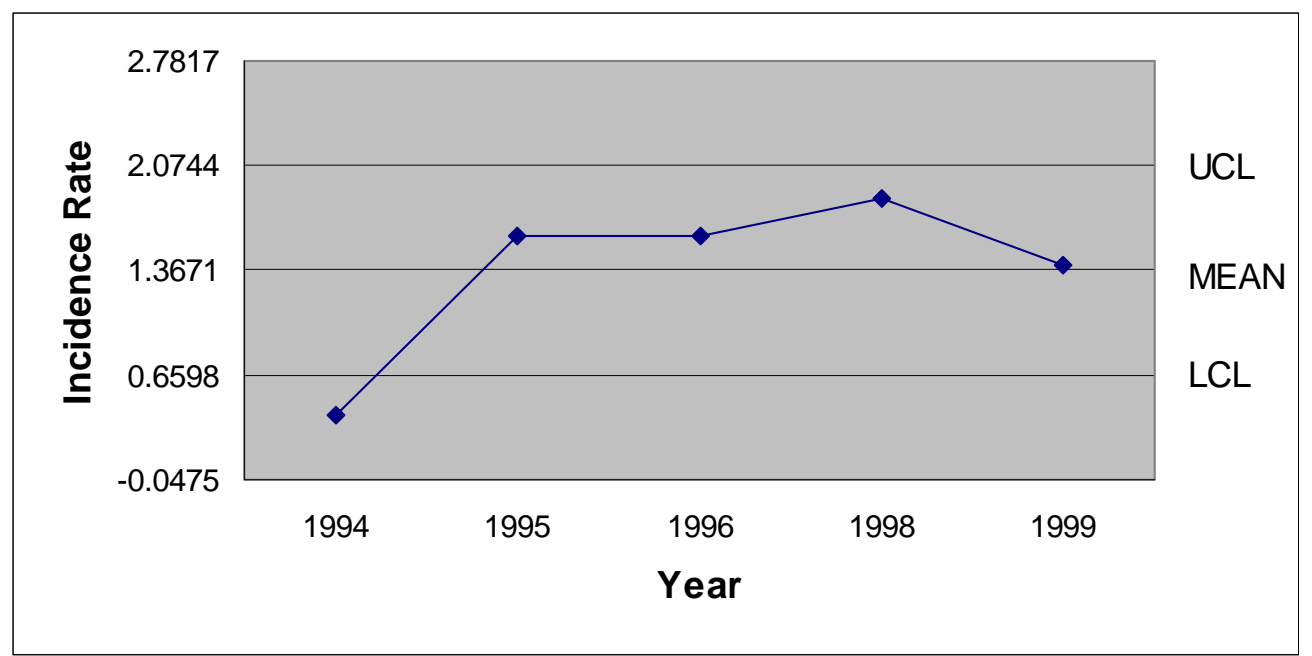

Note: No operations in August 1997

Figure 124. August 1994-1999 Lost Work Day Incidence Rates - Primary Plant

Figure 125 illustrates the pattern exhibited by the Primary Plant September incidence rate. The lowest September incidence rate recorded in 1996 was followed in the next period of operations by the highest incidence rate. Although the last month of September in this research study was the second highest incidence rate, it was below the UCL.

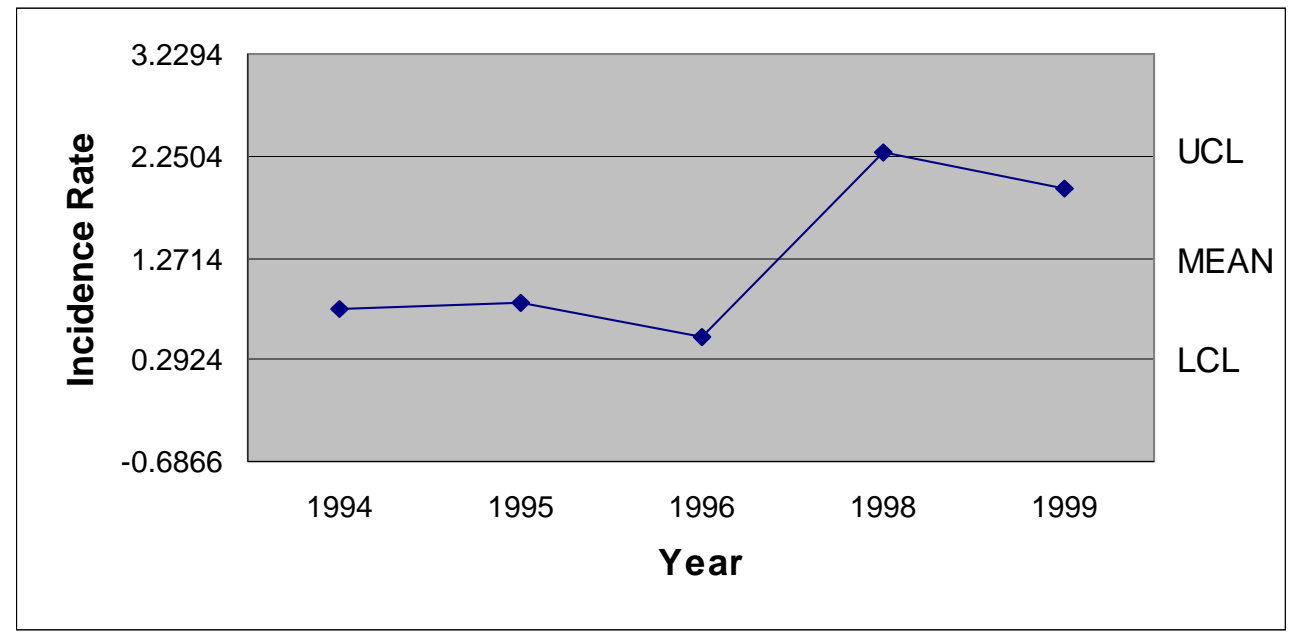

Note: No operations in September 1997

Figure 125. September 1994-1999 Lost Work Day Incidence Rates - Primary Plant 
October 1994 had the lowest incidence rate for the period of operations covered by this research. The highest rate of 4.061 was recorded in 1998, with the 1997 rate of 3.961 almost equaling it. A decrease of almost 80\% occurred between the 1998 and 1999 October incidence rates (See Figure 126).

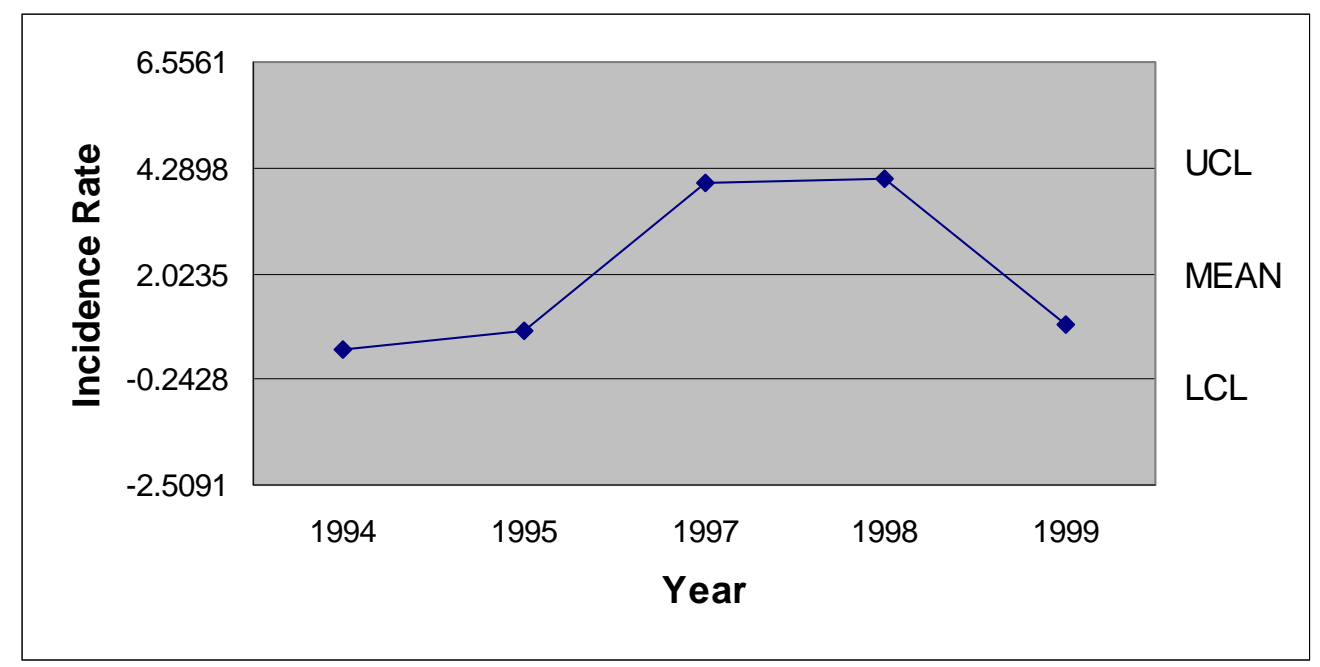

Note: No operations in October 1996

Figure 126. October 1994-1999 Lost Work Day Incidence Rates - Primary Plant

As illustrated in Figure 127, the November 1994 and 1995 Primary Plant incidence rates were close to the LCL. The highest incidence rate, recorded in 1997, was ten times greater in magnitude than the low recorded in November 1995. The 1997 high was followed by two consecutive periods recorded just above the mean. 


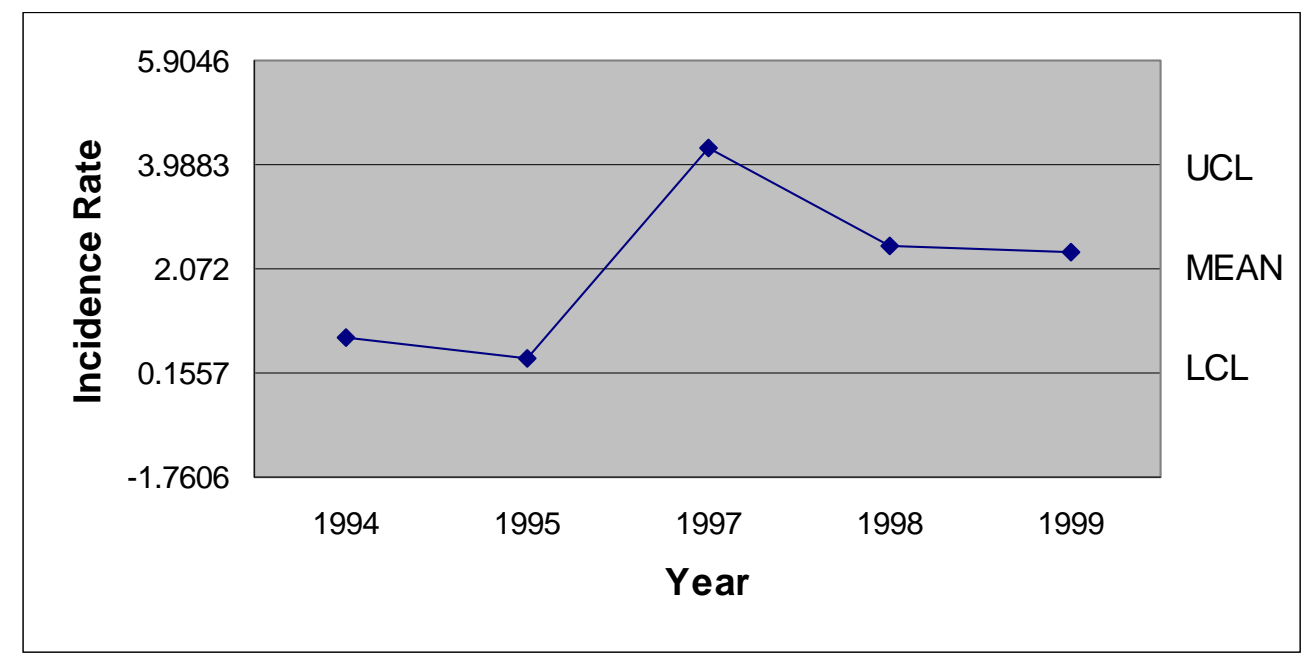

Note: No operations in November 1996

Figure 127. November 1994-1999 Lost Work Day Incidence Rates - Primary Plant

The lowest December Primary Plant incidence rate occurred in 1994. The 1995 incidence rate increased a little from the 1994 level and the 1997 incidence rate increased to a level above the UCL. This increase was followed in 1998 by a sharp decrease from the 1997 high. In 1999 the rate rebounded to a level just surpassing the mean (See Figure 128).

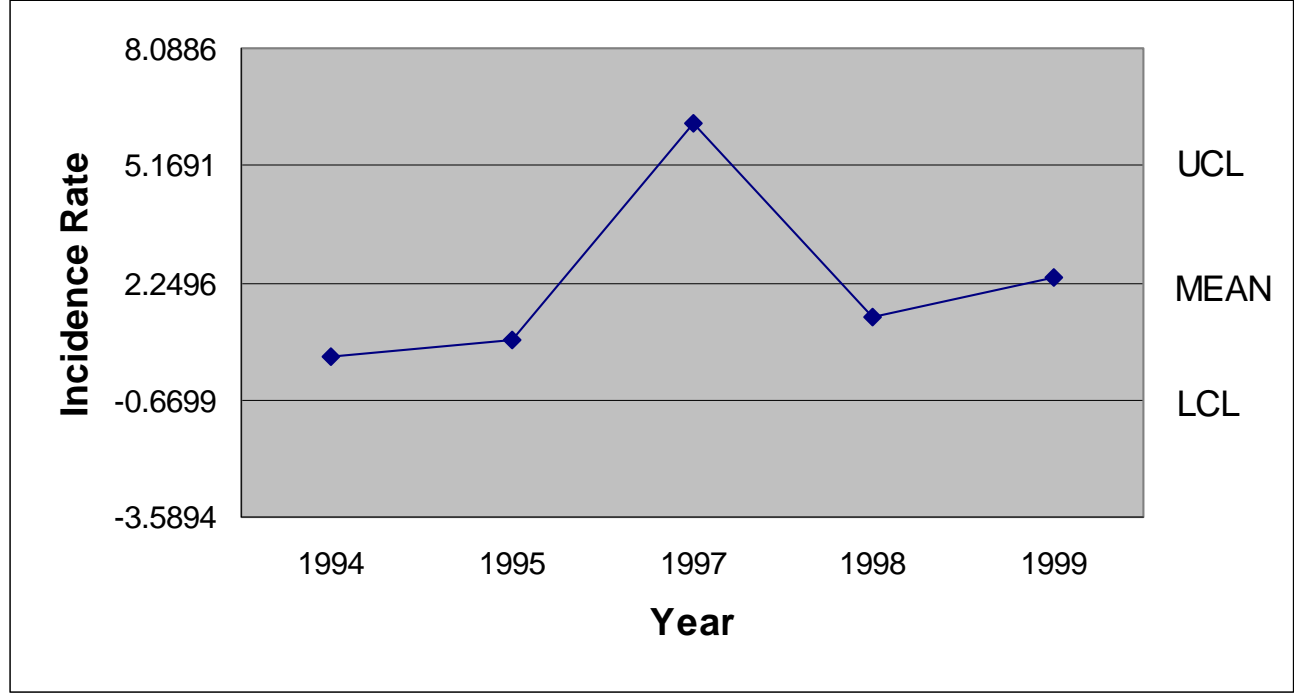

Note: No operations in December 1996

Figure 128. December 1994-1999 Lost Work Day Incidence Rates - Primary Plant 
Table 23 presents the monthly Primary Plant incidence rates for each year of the study period, as well as the UCL, mean, LCL, and standard deviation. Nineteen ninetysix and 1997 are partial years because of the work stoppage and only the first six months of 2000 were included in the research.

Table 23.

Summary of Monthly Lost Work Day Incidence Rates Data - Primary Plant

\begin{tabular}{|l|c|c|c|c|c|c|c|c|c|c|c|c|}
\hline & Jan. & Feb. & Mar. & Apr. & May & June & July & Aug. & Sept. & Oct. & Nov. & Dec. \\
\hline 1994 & 2.323 & 0.419 & 0.406 & 0.400 & 1.146 & 1.989 & 0.807 & 0.389 & 0.785 & 0.380 & 0.803 & 0.391 \\
\hline 1995 & 1.516 & 1.623 & 1.086 & 1.216 & 3.129 & 1.217 & 1.666 & 1.595 & 0.845 & 0.798 & 0.412 & 0.828 \\
\hline 1996 & 0.782 & 0.839 & 0.813 & 1.248 & 0.403 & 0.429 & 1.623 & 1.601 & 0.501 & N/A & N/A & N/A \\
\hline 1997 & N/A & N/A & N/A & N/A & N/A & N/A & N/A & N/A & N/A & 3.961 & 4.286 & 6.242 \\
\hline 1998 & 4.626 & 1.988 & 2.697 & 2.847 & 3.294 & 4.270 & 1.821 & 1.850 & 2.283 & 4.061 & 2.491 & 1.418 \\
\hline 1999 & 1.411 & 1.493 & 2.206 & 0.921 & 2.845 & 2.859 & 4.256 & 1.401 & 1.943 & 0.917 & 2.367 & 2.369 \\
\hline 2000 & 2.298 & 1.882 & 1.796 & 2.456 & 3.608 & 0.937 & N/A & N/A & N/A & N/A & N/A & N/A \\
\hline UCL & 3.568 & 2.022 & 2.423 & 2.501 & 3.777 & 3.441 & 3.653 & 2.074 & 2.250 & 4.290 & 3.988 & 5.169 \\
\hline MEAN & 2.159 & 1.374 & 1.504 & 1.515 & 2.404 & 1.950 & 2.035 & 1.367 & 1.271 & 2.024 & 2.072 & 2.250 \\
\hline LCL & 0.751 & 0.726 & 0.578 & 0.528 & 1.032 & 0.459 & 0.417 & 0.660 & 0.292 & -0.243 & 0.156 & -0.670 \\
\hline SD & 0.548 & 0.252 & 0.359 & 0.384 & 0.534 & 0.580 & 0.583 & 0.255 & 0.353 & 0.816 & 0.690 & 1.052 \\
\hline
\end{tabular}

$\underline{\text { Seasonal Analysis of Lost Work Day Data - Primary Plant }}$

The seasonal index calculation was used to generate the Primary Plant monthly seasonal index figures presented in Figure 128. The highest seasonal index occurred in May, while January and July were practically tied for second highest. The only other relatively high seasonal index was June. The majority of the other seasonal index figures gravitated toward the 0.8 level. 


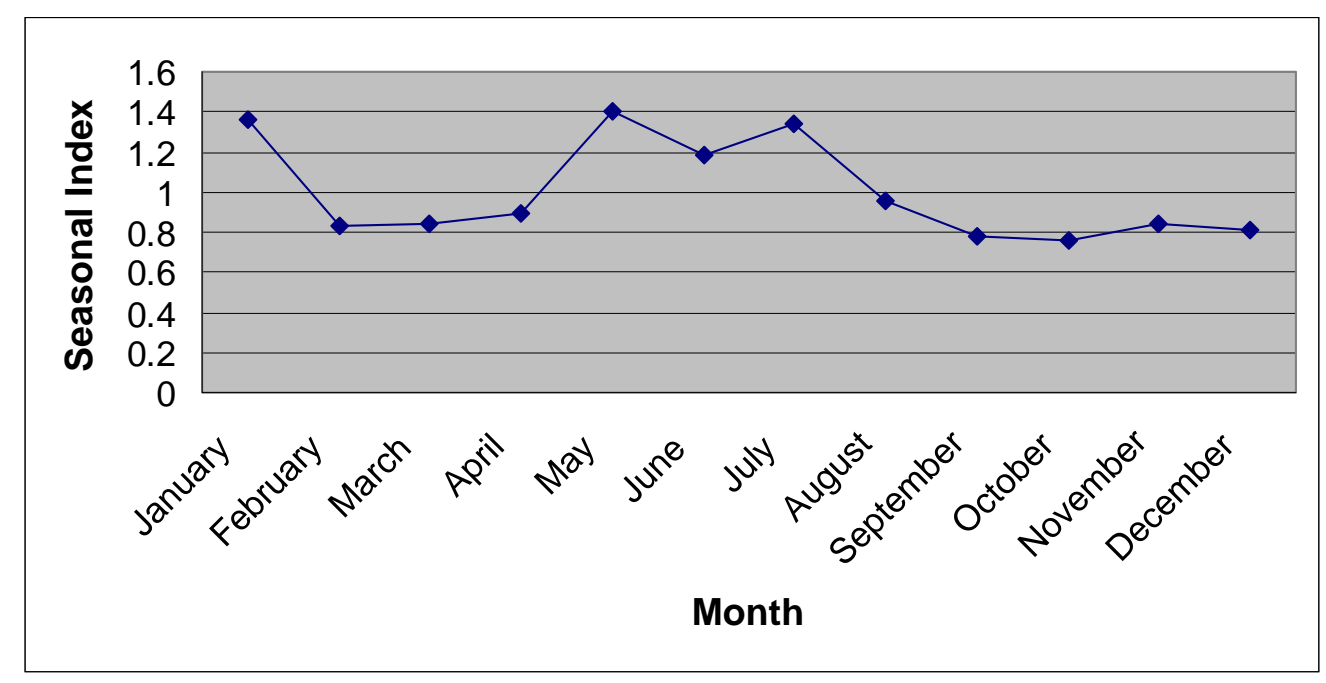

Figure 129. Monthly seasonal pattern of Lost Work day incidence Rates - Primary Plant

\section{Testing the Statistical Relationship of Lost Work Day Data - Primary Plant} All 33 months prior to and subsequent to the work stoppage

For the entire 33 months prior to the work stoppage and the 33 post work stoppage months at the Primary Plant, the comparison calculated amount was 7.181. This amount is in excess of the 1.96 critical t value. Therefore a statistically significant increase in incidence rates occurred between the period prior to the work stoppage and the period following the work stoppage.

First 24 months and last 24 months of the research period

The comparison formula was applied to the Primary Plant incidence rates for the first 24 months and last 24 months of the research period. These time periods excluded the nine months prior to and immediately following the work stoppage. Using the 1.96 critical $t$ value, the calculated amount of 4.476 is greater, thus indicating a statistically significant increase in incidence rates between the 24 month periods.

Nine month intervals prior to and subsequent to the work stoppage

Comparison of the Primary Plant lost work day incidence rates for the nine months preceding and the nine months following the work stoppage was accomplished using The comparison formula. The result of this calculation, 6.041, was greater than the critical t value of 1.987 , indicating a .05 statistical level of significance. Because the 
calculated amount exceeded the level of significance, it was found that a statistically significant increase in incidence rates occurred between the two periods.

Table 24 is a summary of the comparison periods associated with the work stoppage. The incidence rates prior to the work stoppage and those following the work stoppage are listed, as are the critical t values and the calculated comparison values.

Table 24

Comparison of prior and post work stoppage periods - Primary Plant

\begin{tabular}{|l|l|l|l|l|}
\hline \multirow{2}{*}{ Time Period } & \multicolumn{2}{|l|}{ Primary Plant Incidence Rates } & \multirow{2}{*}{ Critical t Value } & Calculated \\
\cline { 2 - 5 } & $\begin{array}{l}\text { Prior to } \\
\text { Work Stoppage }\end{array}$ & $\begin{array}{l}\text { Post } \\
\text { Work Stoppage }\end{array}$ & & 1.987 \\
\hline 9 Months & 0.927 & 3.795 & 1.96 & $6.041^{*}$ \\
\hline 24 Months & 1.09 & 2.164 & 1.96 & $4.476^{*}$ \\
\hline 33 Months & 1.05 & 2.60 & $7.18^{*}$ \\
\hline
\end{tabular}

* Indicates a statistically significant increase

** Indicates a statistically significant decrease

Finishing Plant \#1 Analysis

Quarterly Analysis of Lost Work Day Data - Finishing Plant \#1

The highest first quarter incidence rate at Finishing Plant \#1 occurred in 1994. As illustrated in Figure 130, this high was followed by two sharply decreasing periods. These steep declines were followed by two years of incidence rates close to the LCL. The last period increased to a level just below the mean. 


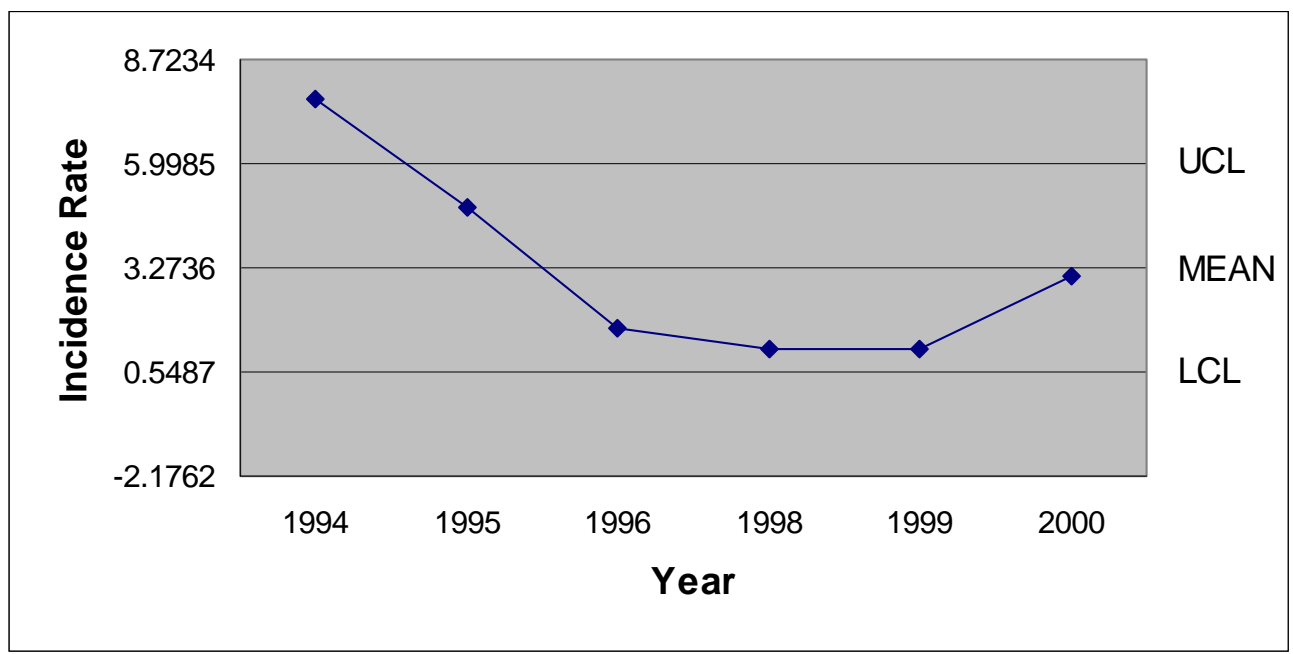

Note: No operations in first quarter 1997

Figure 130. First quarter 1994-2000 Lost Work Day Incidence Rates - Finishing Plant \#1

The highest second quarter Finishing Plant \#1 incidence rate was in 1994. There were not any second quarter lost work day incidents recorded in 1999. After the low in 1999, the incidence rate was above the mean in 2000 (See Figure 131).

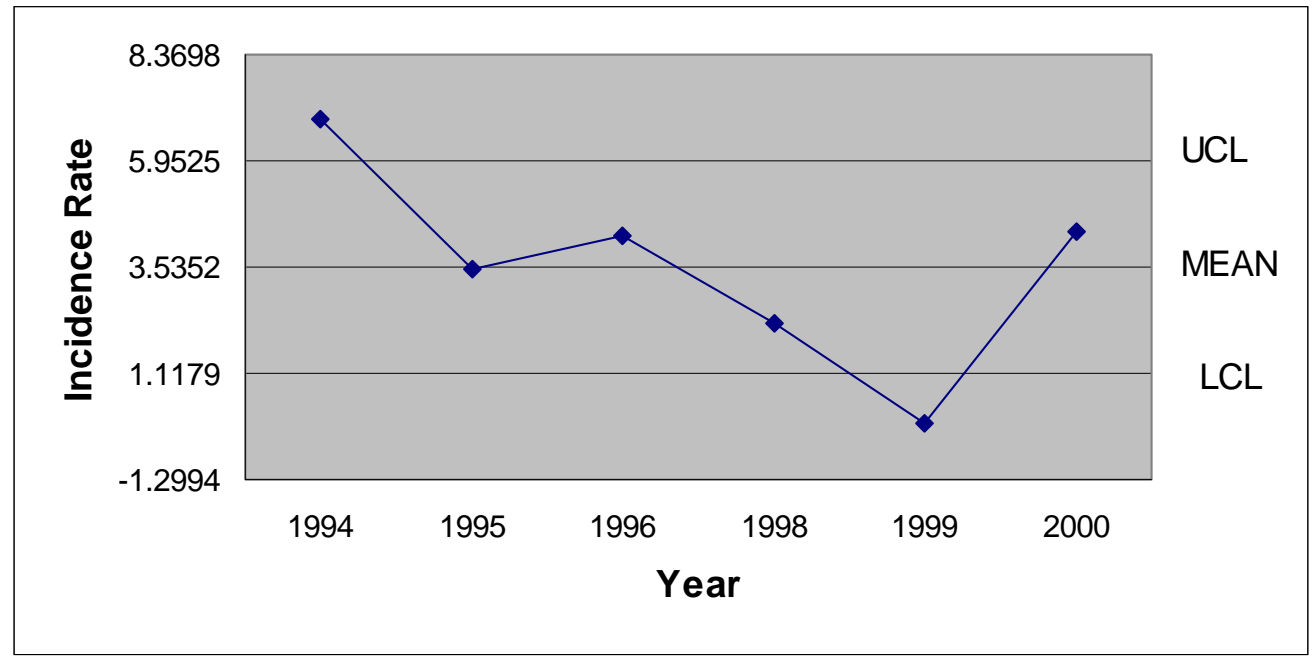

Note: No operations in second quarter 1997

Figure 131. Second quarter 1994-2000 Lost Work Day Incidence Rates - Finishing Plant $\# 1$ 
As illustrated in Figure 132, the third quarter lost work day incidence rates were following a steadily declining trend until they bottomed out in 1996. The next third quarter period of operations, 1998, experienced the highest third quarter rate for Finishing Plant \#1. Although, none of the incidence rates were outside the control limits, 1999 did not record any lost work day incidents and was therefore the lowest third quarter rate.

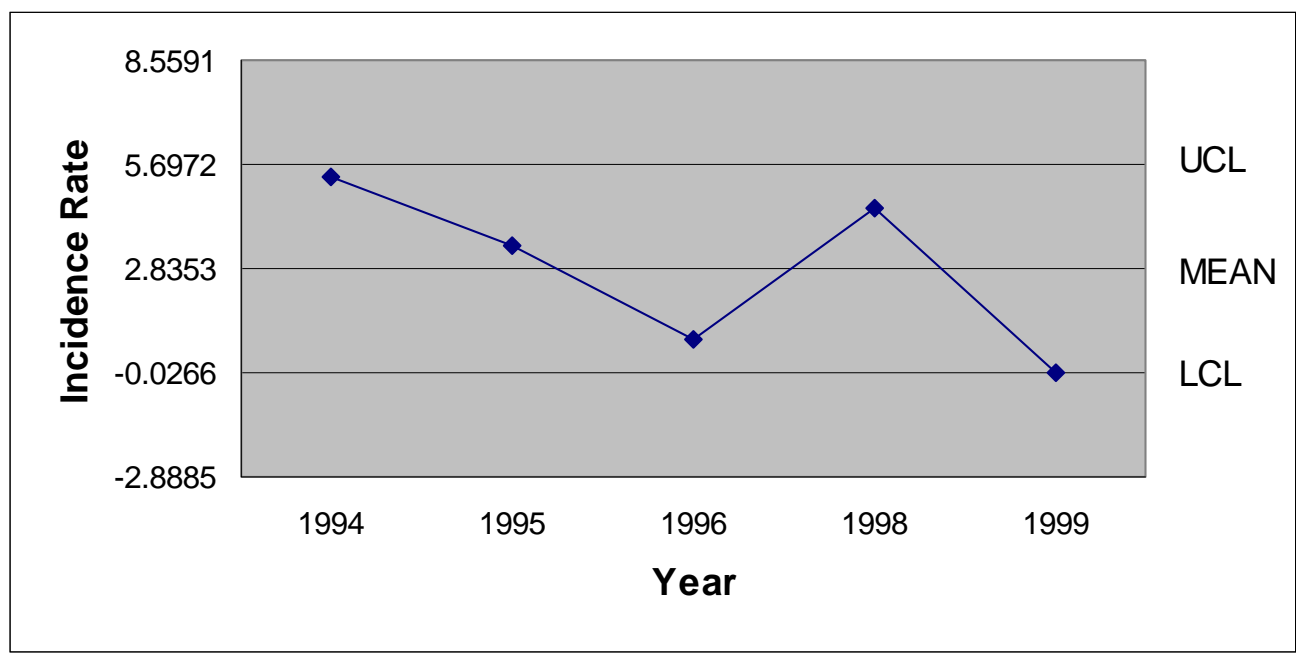

Note: No operations in third quarter 1997

Figure 132. Third quarter 1994-1999 Lost Work Day Incidence Rates - Finishing Plant \#1

The fourth quarter of 1998 at Finishing Plant \#1 did not experience any lost work day incidents. The highest lost work day incidence rate occurred in 1994. The 1995 and 1996 incidence rates appeared below the mean, while the 1999 incidence rate was barely above the mean (See Figure 133). 


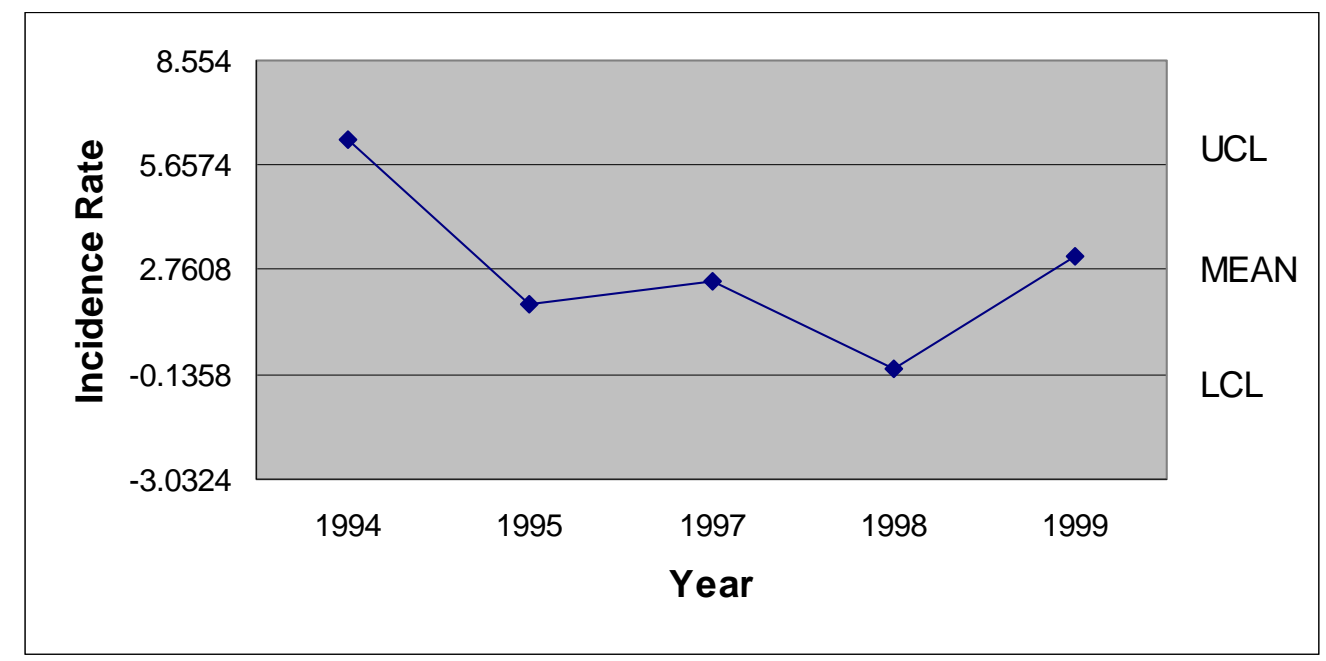

Note: No operations in fourth quarter 1996

Figure 133. Fourth quarter 1994-1999 Lost Work Day Incidence Rates - Finishing Plant \#1

Table 25 presents the Finishing Plant \#1 quarterly incidence rates for each year of the study period, as well as the UCL, mean, LCL, and standard deviation. Nineteen ninety-six and 1997 are partial years because of the work stoppage and only the first six months of 2000 were included in the research.

Table 25

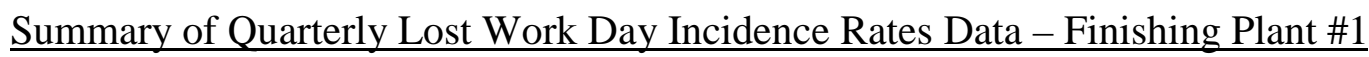

\begin{tabular}{|l|l|l|l|l|}
\hline & $1^{\text {st }}$ Quarter & $2^{\text {nd }}$ Quarter & $3^{\text {rd }}$ Quarter & $4^{\text {th }}$ Quarter \\
\hline 1994 & 7.706 & 6.892 & 5.351 & 6.367 \\
\hline 1995 & 4.861 & 3.476 & 3.452 & 1.816 \\
\hline 1996 & 1.692 & 4.230 & 0.889 & N/A \\
\hline 1997 & N/A & N/A & N/A & 2.460 \\
\hline 1998 & 1.137 & 2.266 & 4.485 & 0.00 \\
\hline 1999 & 1.169 & 0.00 & 0.00 & 3.158 \\
\hline 2000 & 3.077 & 4.348 & N/A & N/A \\
\hline UCL & 5.999 & 5.953 & 5.697 & 5.656 \\
\hline MEAN & 3.274 & 3.535 & 2.835 & 2.760 \\
\hline LCL & 0.549 & 1.118 & -0.027 & -0.136 \\
\hline SD & 1.060 & 0.940 & 1.031 & 1.043 \\
\hline
\end{tabular}




\section{Seasonal Analysis of Lost Work Day Data - Finishing Plant \#1}

The results of the Finishing Plant \#1quarterly seasonal index calculations are presented in Figure 134. The incidence rates seasonal index indicated that the third quarter had the lowest seasonal index for Finishing Plant \#1. The highest seasonal index was recorded at almost 1.1 for the fourth quarter.

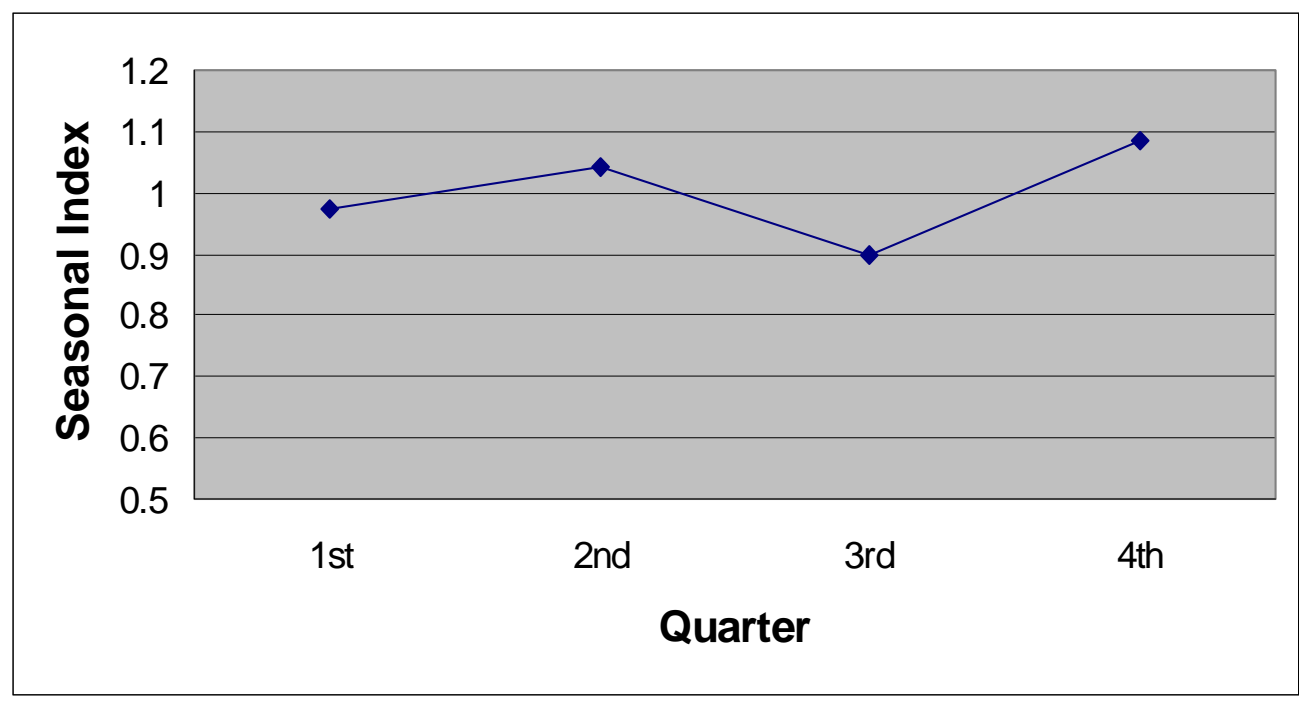

Figure 134. Quarterly Seasonal Index of Lost Work Day Incidence Rates - Finishing Plant \#1

\section{Monthly Analysis of Lost Work Day Data - Finishing Plant \#1}

January 1994 recorded an incidence rate just below the UCL at Finishing Plant \#1. This rate was surpassed by the 1995 incidence rate, which was above the UCL. The 1996 incidence rate was between the mean and the LCL, while the 1998 incidence rate was recorded below the LCL. Nineteen ninety-nine and 2000 experienced incidence rates barely below the mean (See Figure 135). 


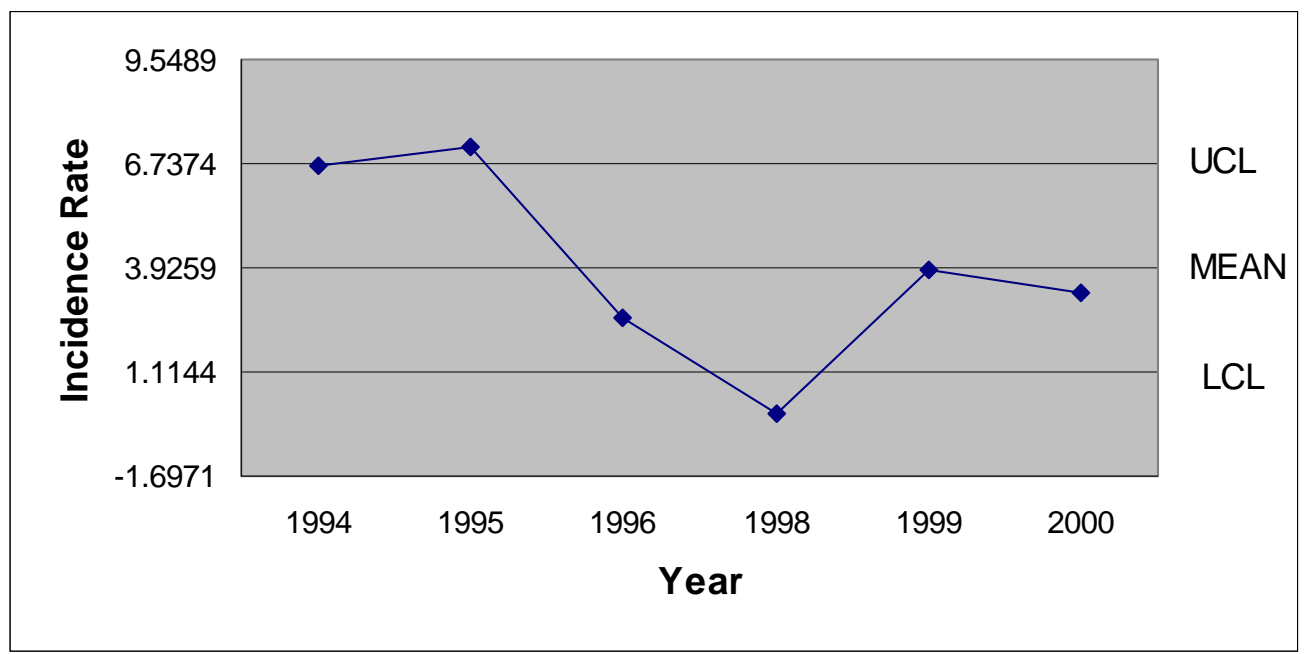

Note: No operations in January 1997

Figure 135. January 1994-2000 Lost Work Day Incidence Rates - Finishing Plant \#1

The 9.621 incidence rate recorded by Finishing Plant \#1 in 1994 was much greater than the 0.00 incidence rate recorded in 1999, a year that did not experience any lost work day incidents in the month of February. The remaining four periods were within the control limits (See Figure 136).

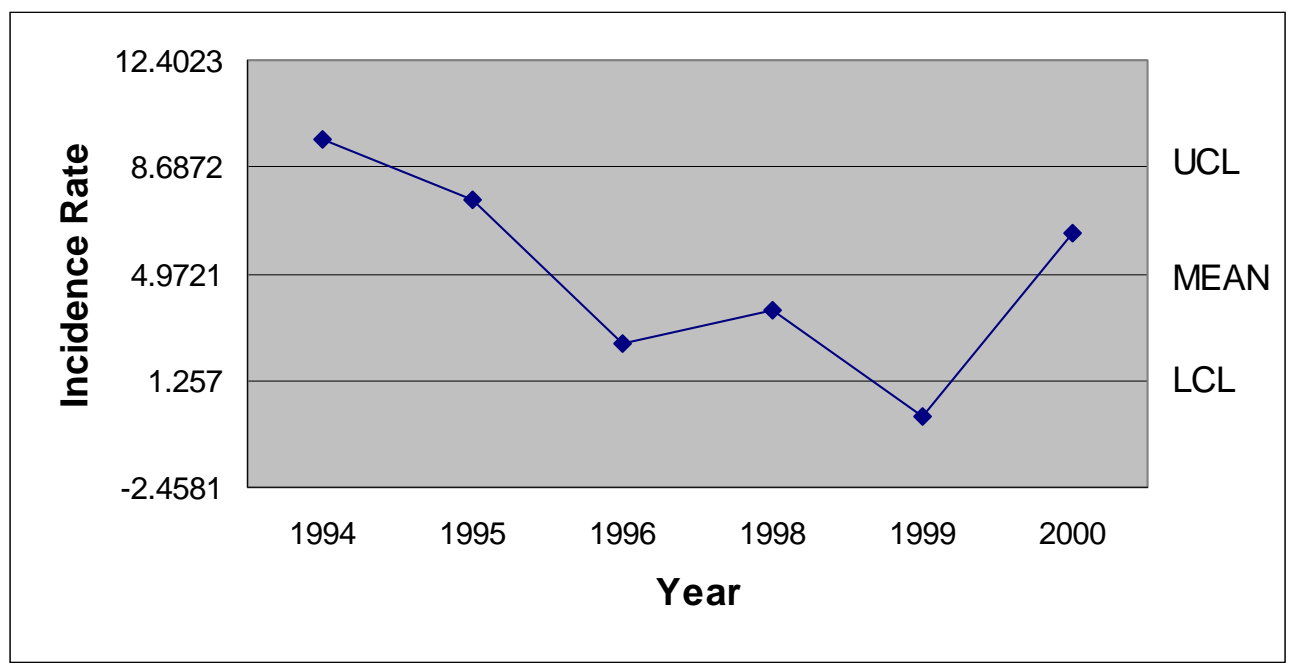

Note: No operations in February 1997

Figure 136. February 1994-2000 Lost Work Day Incidence Rates - Finishing Plant \#1 
In 1994 the March lost work day incidence rate at Finishing Plant \#1 was 6.959. As illustrated in Figure 137, the month of March did not experience any lost work day incidents during the remainder of the research period.

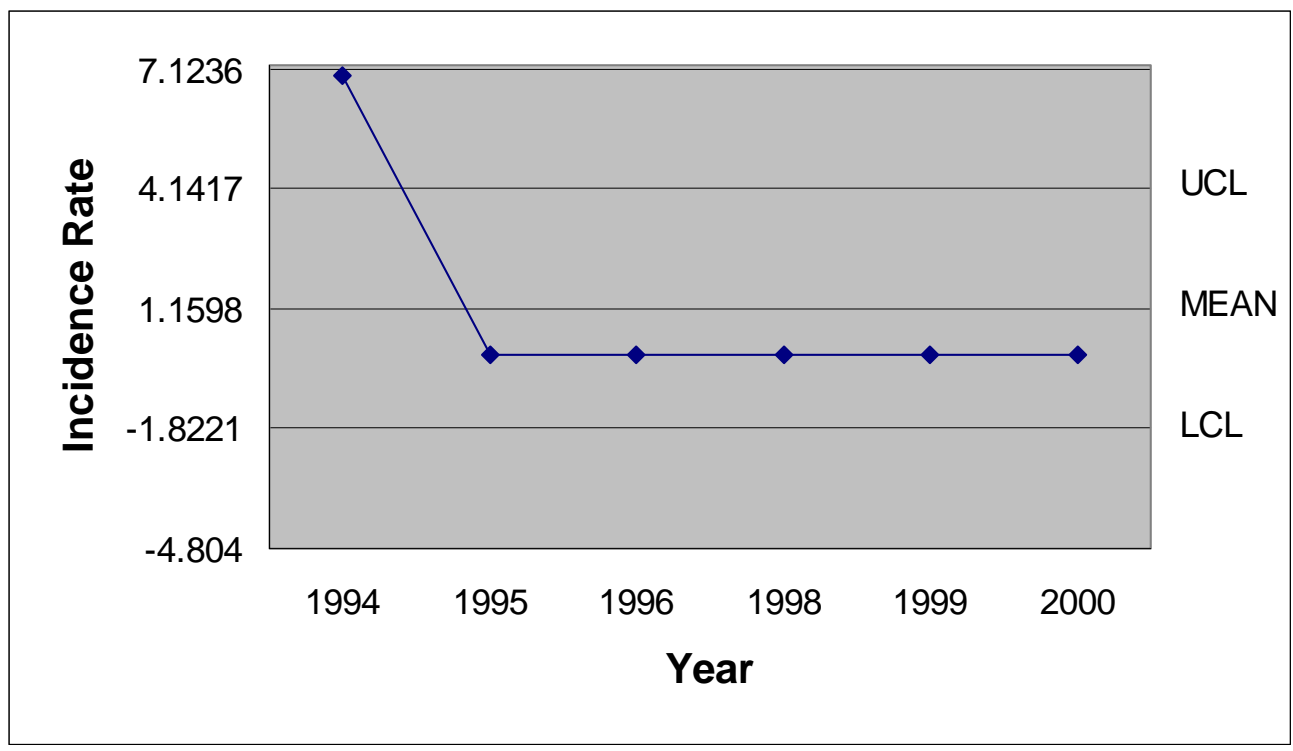

Note: No operations in March 1997

Figure 137. March 1994-2000 Lost Work Day Incidence Rates - Finishing Plant \#1

During this research period, April 1995, 1999, and 2000 did not experience any lost work day incidents at Finishing Plant \#1. The 1996 incidence rate of 2.550 was just below the mean. The April 1998 incidence rate of 6.895 was barely above the April 1994 incidence rate of 6.833 (See Figure 138). 


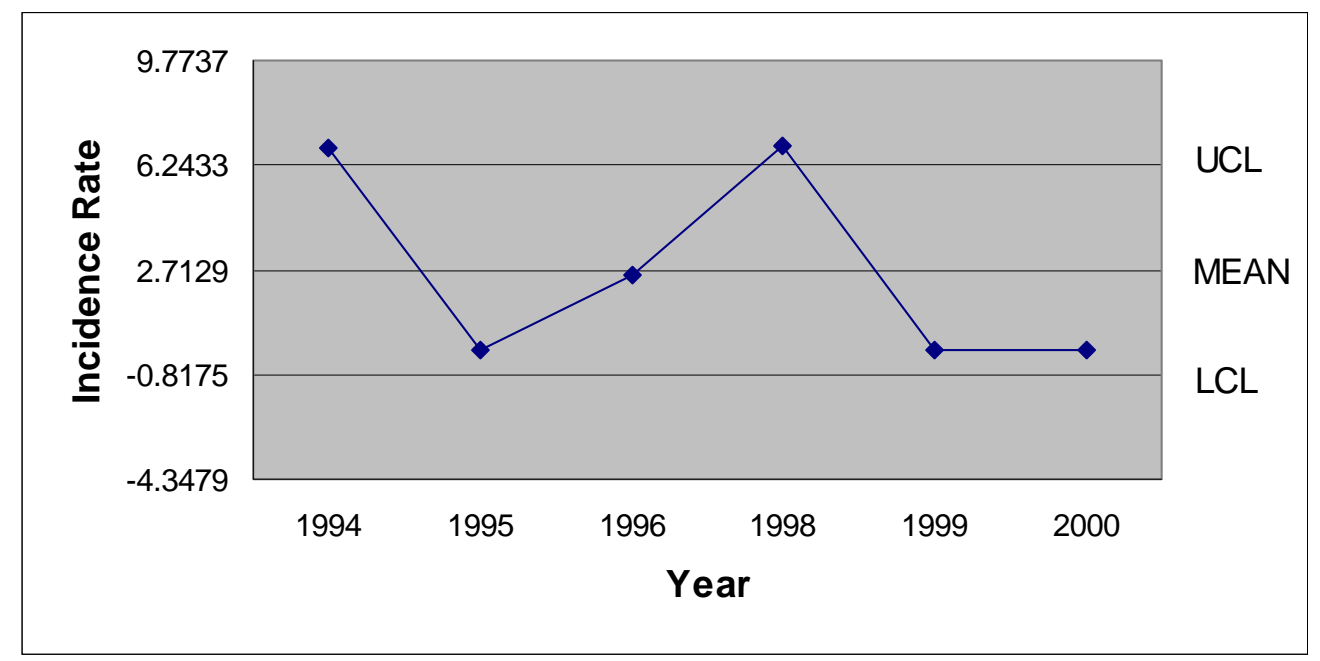

Note: No operations in April 1997

Figure 138. April 1994-2000 Lost Work Day Incidence Rates - Finishing Plant \#1

As illustrated in Figure 139, the month of May experienced an increasing pattern over the first three years of this study. In 1998 and 1999, Finishing Plant \#1 did not have any lost work day incidents. These two years were followed in 2000 with an incidence rate of 9.798, which was above the UCL.

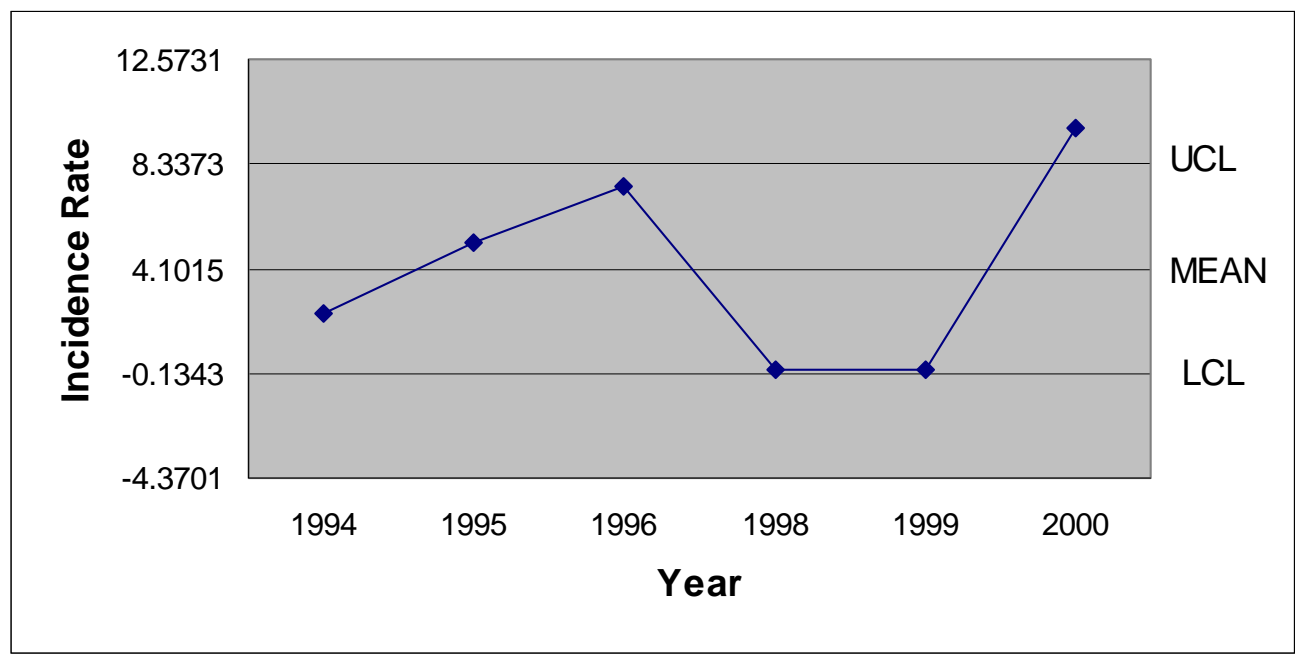

Note: No operations in April 1997

Figure 139. May 1994-2000 Lost Work Day Incidence Rates - Finishing Plant \#1 
The lost work day incidence rate at Finishing Plant \#1 decreased by over 50\% between June 1994 and June 1995. This decrease was followed by additional decreases over the next two years. In 1998 and 1999 there were no lost work day incidents recorded for the month. June 2000 experienced a lost work day incidence rate of 3.231 (See Figure 140).

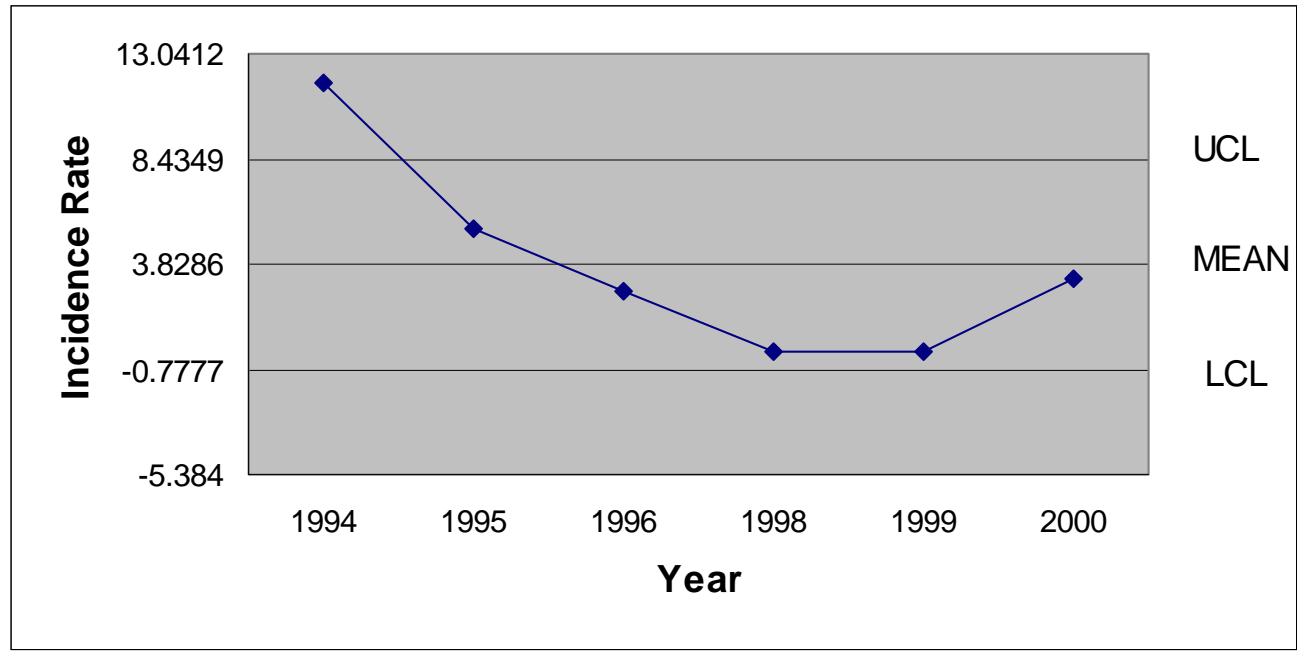

Note: No operations in June 1997

Figure 140. June 1994-2000 Lost Work Day Incidence Rates - Finishing Plant \#1

The highest July lost work day incidence rate at Finishing Plant \#1 occurred in the second year of this research, 1995. Every July that had operations during this research period was within the lost work day incidence rates' control limits, except 1999, which was below the LCL (See Figure 141). 


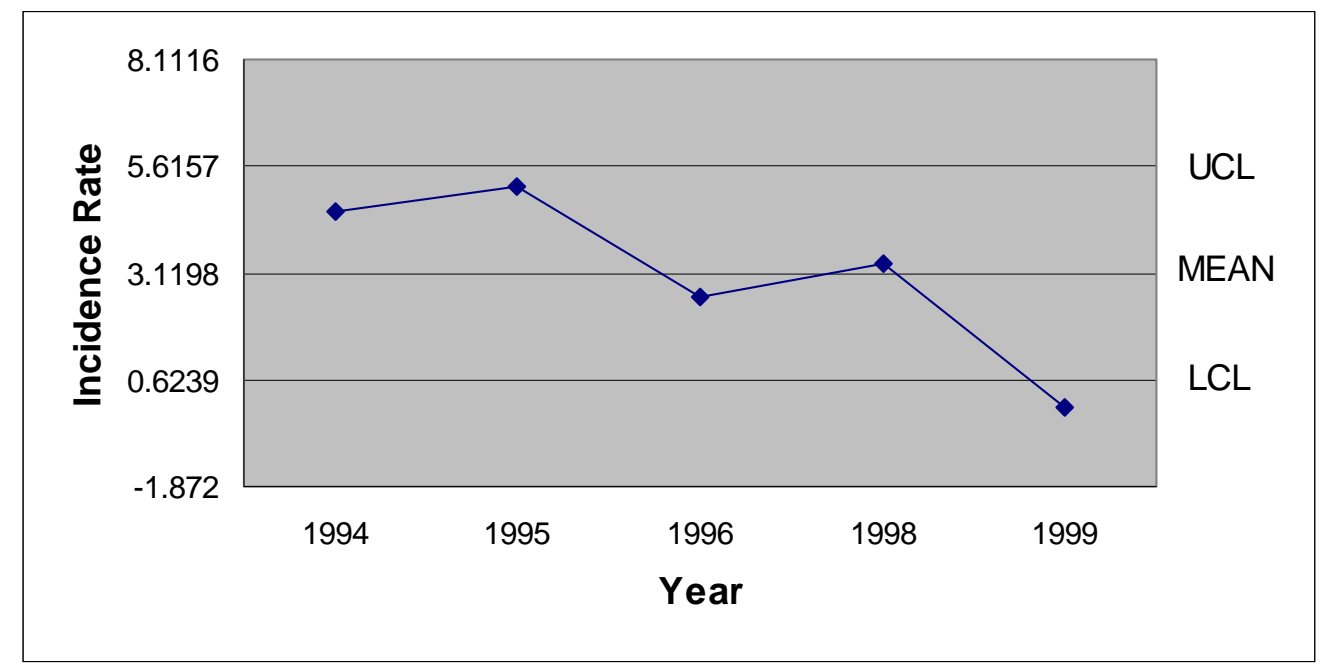

Note: No operations in July 1997

Figure 141. July 1994-1999 Lost Work Day Incidence Rates - Finishing Plant \#1

As illustrated in Figure 142, the zero incidence rates recorded in August 1996 and August 1999 at Finishing Plant \#1were separated by a 3.319 incidence rate in 1998. The first two periods experienced incidence rates between the mean and the UCL.

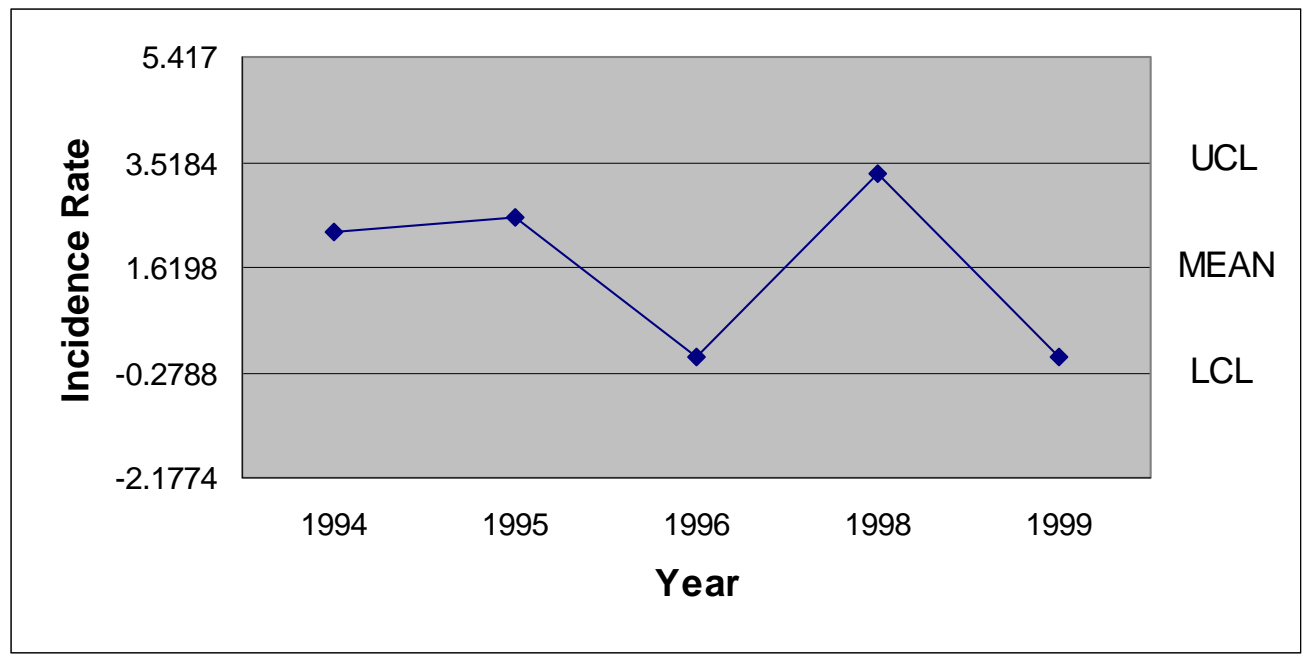

Note: No operations in August 1997

Figure 142. August 1994-1999 Lost Work Day Incidence Rates - Finishing Plant \#1

The highest September incidence rate at Finishing Plant \#1 was experienced in 1994, the first year of the research period. A 1998 incidence rate between the UCL and 
the mean separated the two zero incidence rates that occurred in September 1996 and 1999 (See Figure 143).

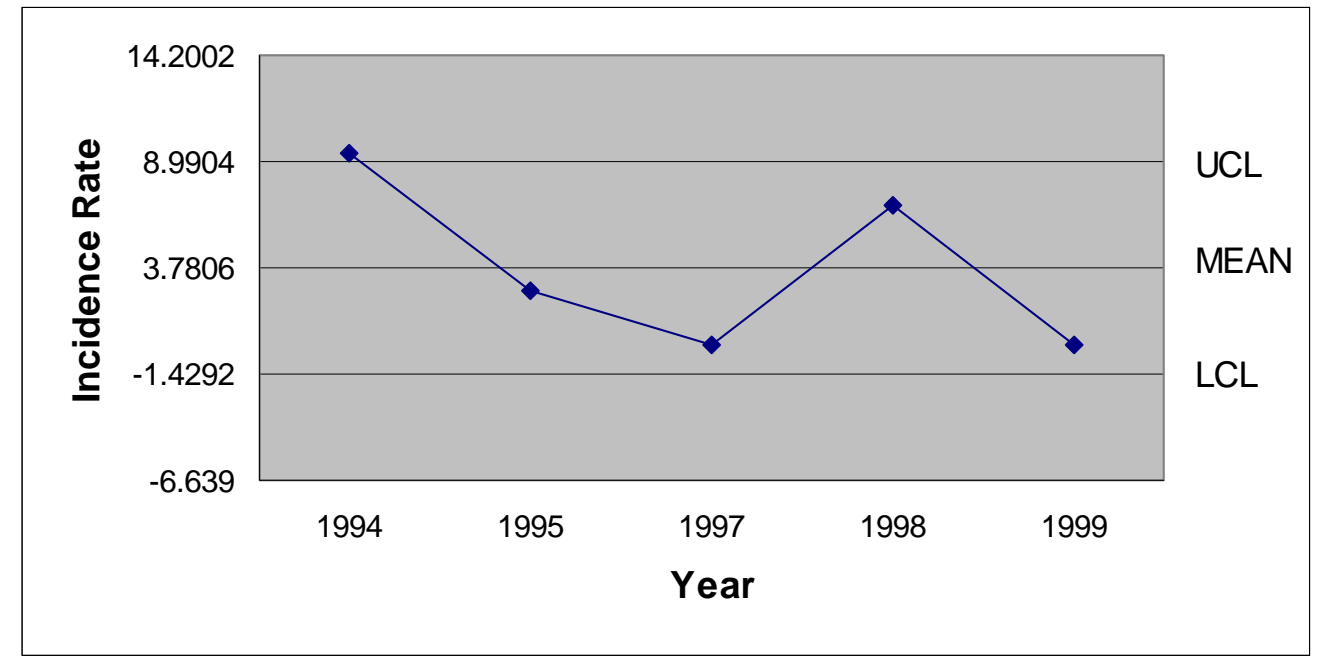

Note: No operations in September 1997

Figure 143. September 1994-1999 Lost Work Day Incidence Rates - Finishing Plant \#1

Figure 144 graphically illustrates the highest October lost work day incidence rate of 11.163, which occurred at Finishing Plant \#1 in 1994. October 1995, 1998, and 1999 recorded incidence rates of zero. The 1997 incidence rate of 3.374 was above the mean, but within the control limits.

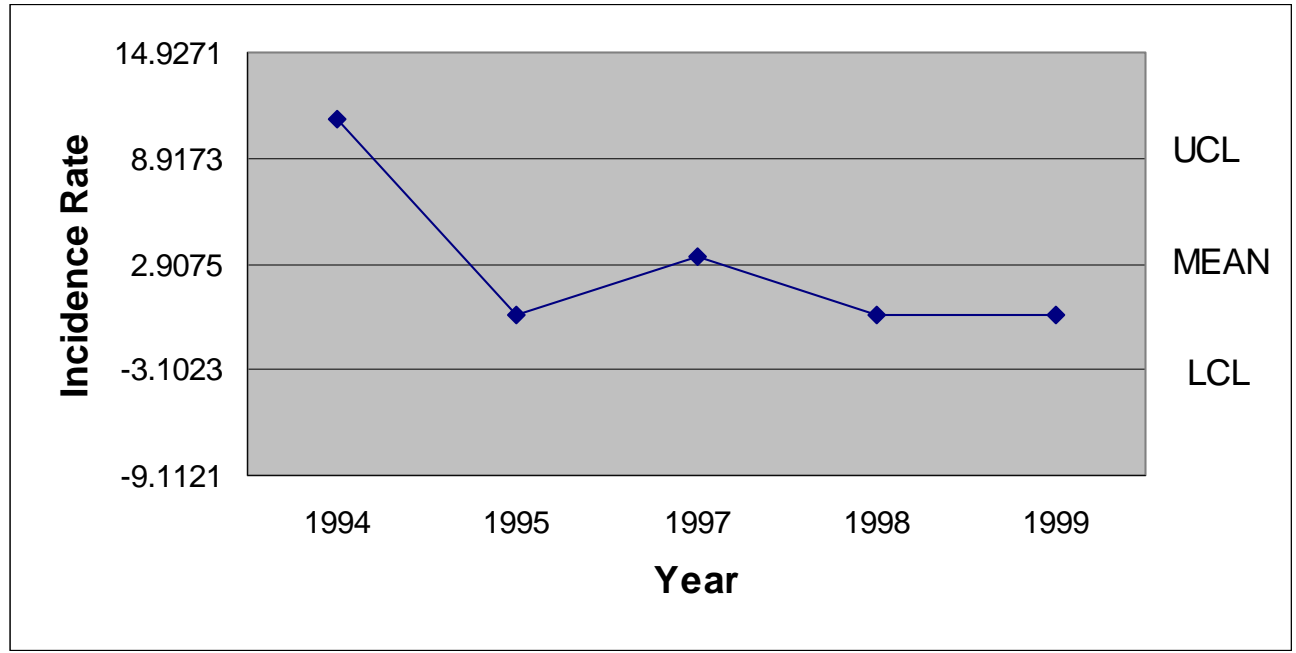

Note: No operations in October 1996

Figure 144. October 1994-1999 Lost Work Day Incidence Rates - Finishing Plant \#1 
November incidence rates at Finishing Plant \#1 for 1994 and 1995 were recorded just over the mean of 2.4085. The following two periods, 1997 and 1998, both experienced a zero incidence rates for November. In 1999 the November incidence rate was recorded above the UCL at a level of 6.671 (See Figure 145).

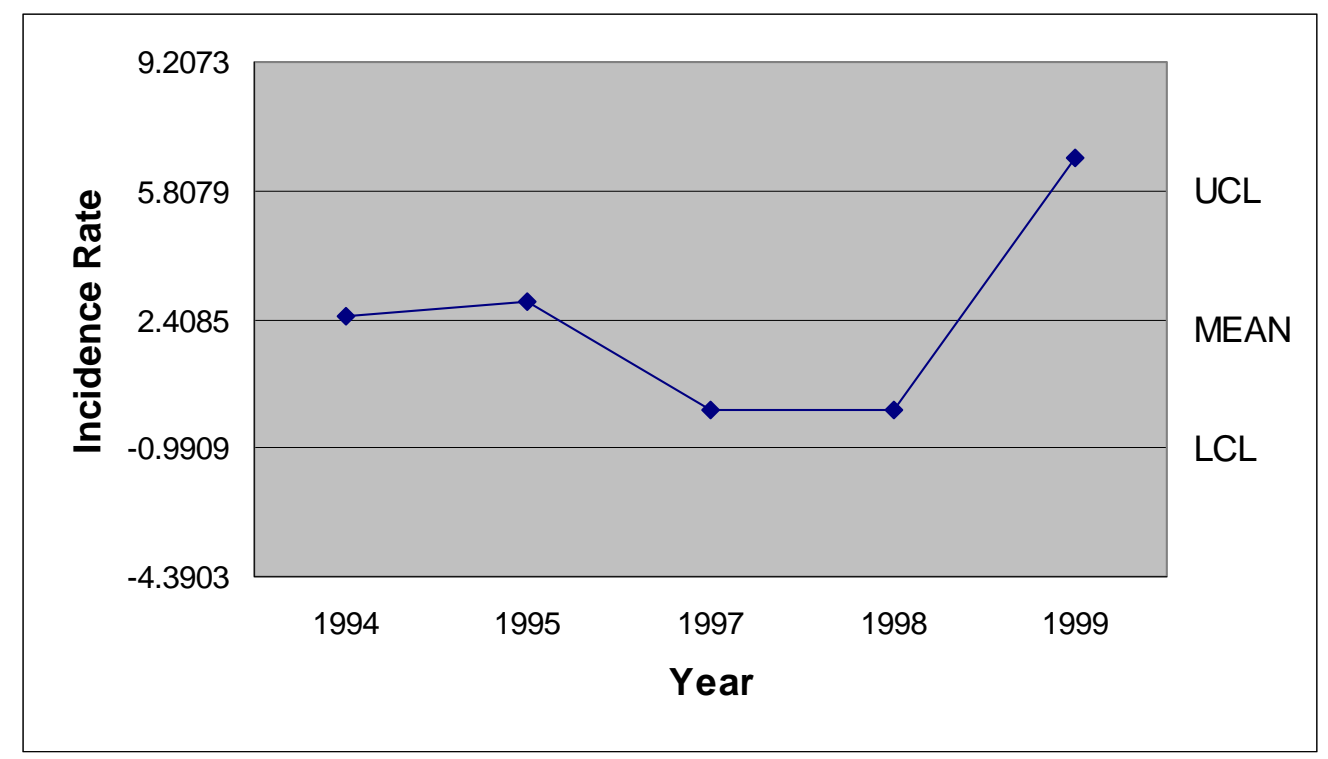

Note: No operations in November 1996

Figure 145. November 1994-1999 Lost Work Day Incidence Rates - Finishing Plant \#1

As illustrated in Figure 146, the highest December lost work day incidence rate at Finishing Plant \#1 occurred in 1994. The only incidence rate appearing outside the control limits for the month of December was recorded below the LCL in 1999. The remaining three December months were clustered close to the mean. 


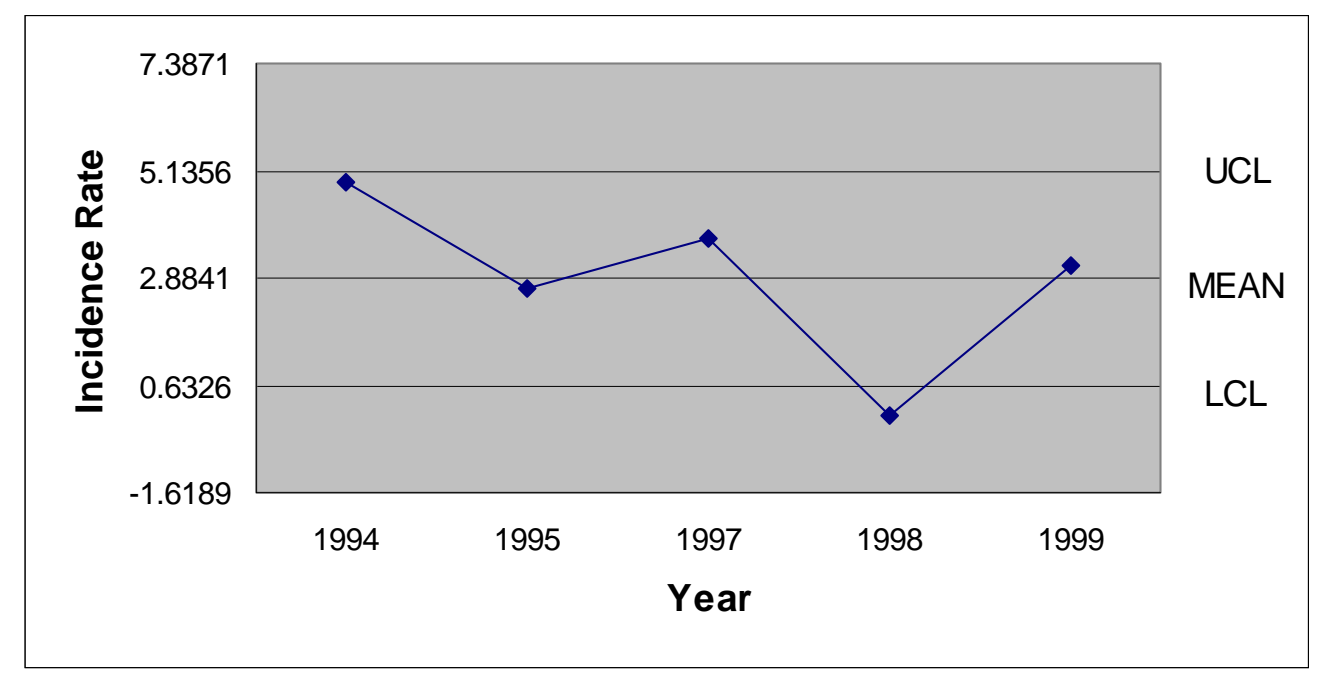

Note: No operations in December 1996

Figure 146. December 1994-1999 Lost Work Day Incidence Rates - Finishing Plant \#1

Table 26 presents the monthly incidence rates at Finishing Plant \#1 for each year of the study period, as well as the UCL, mean, LCL, and standard deviation. Nineteen ninety-six and 1997 are partial years because of the work stoppage and only the first six months of 2000 were included in the research.

Table 26

$\underline{\text { Summary of Monthly Lost Work Day Incidence Rates Data - Finishing Plant \#1 }}$

\begin{tabular}{|l|c|c|c|c|c|c|c|c|c|c|c|c|}
\hline & Jan. & Feb. & Mar. & Apr. & May & June & July & Aug. & Sept. & Oct. & Nov. & Dec. \\
\hline 1994 & 6.654 & 9.621 & 6.959 & 6.832 & 2.267 & 11.745 & 4.557 & 2.258 & 9.380 & 11.163 & 2.501 & 4.893 \\
\hline 1995 & 7.197 & 7.574 & 0.000 & 0.000 & 5.143 & 5.395 & 5.121 & 2.522 & 2.691 & 0.000 & 2.871 & 2.676 \\
\hline 1996 & 2.565 & 2.564 & 0.000 & 2.550 & 7.401 & 2.601 & 2.564 & 0.000 & 0.000 & N/A & N/A & N/A \\
\hline 1997 & N/A & N/A & N/A & N/A & N/A & N/A & N/A & N/A & N/A & 3.374 & 0.000 & 3.719 \\
\hline 1998 & 0.000 & 3.672 & 0.000 & 6.895 & 0.000 & 0.000 & 3.357 & 3.319 & 6.832 & 0.000 & 0.000 & 0.000 \\
\hline 1999 & 3.897 & 0.000 & 0.000 & 0.000 & 0.000 & 0.000 & 0.000 & 0.000 & 0.000 & 0.000 & 6.671 & 3.132 \\
\hline 2000 & 3.242 & 6.402 & 0.000 & 0.000 & 9.798 & 3.231 & N/A & N/A & N/A & N/A & N/A & N/A \\
\hline UCL & 6.737 & 8.687 & 4.142 & 6.243 & 8.337 & 8.435 & 5.616 & 3.518 & 8.990 & 8.917 & 5.808 & 5.136 \\
\hline MEAN & 3.926 & 4.972 & 1.160 & 2.713 & 4.101 & 3.829 & 3.120 & 1.620 & 3.781 & 2.907 & 2.408 & 2.884 \\
\hline LCL & 1.114 & 1.257 & -1.822 & -0.817 & -0.134 & -0.778 & 0.624 & -0.279 & -1.429 & -3.102 & -0.991 & 0.633 \\
\hline SD & 1.094 & 1.445 & 1.160 & 1.373 & 1.648 & 1.792 & 0.899 & 0.684 & 1.877 & 2.165 & 1.225 & 0.811 \\
\hline
\end{tabular}




\section{Seasonal Analysis of Lost Work Day Data - Finishing Plant \#1}

The seasonal index calculation for Finishing Plant \#1 was used to generate the monthly seasonal index figures that are presented in Figure 147. January had the highest seasonal index. The months of February and November had almost identical seasonal index figures, making them the second highest months. The lowest seasonal index was March.

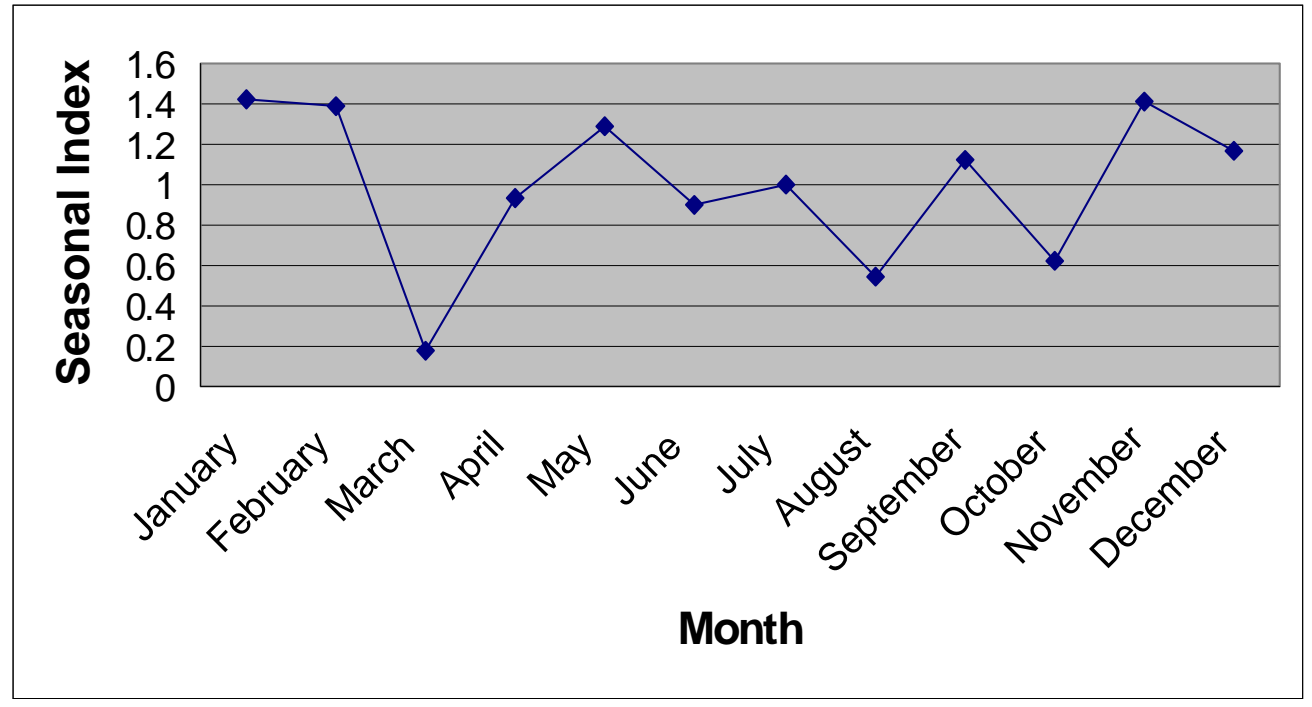

Figure 147. Monthly Seasonal Pattern of Lost Work Day Incidence Rates - Finishing Plant \#1

Testing the statistical relationship of Lost Work Day Data - Finishing Plant \#1 All 33 Months Prior to and Subsequent to the Work Stoppage

For the entire 33 months prior to the work stoppage and the 33 post work stoppage months at Finishing Plant \#1 the comparison t value was 1.991. Because the calculated amount of 2.991 was greater than the critical $t$ value, a statistically significant decrease in incidence rates occurred between the two periods.

\section{First 24 Months and Last 24 Months of the Research Period}

The same formula was applied to the lost work day incidence rates at Finishing Plant \#1 for the first 24 months and the last 24 months of the research period. These time periods excluded the nine months prior to and immediately following the work stoppage. 
Using a critical t value of 1.997 , the calculated amount, 3.144, was greater, thus indicating a statistically significant decrease in incidence rates occurred between the two periods.

\section{Nine Month Intervals Prior to and Subsequent to the Work Stoppage}

Comparison of the lost work day incidence rates for the nine months preceding the work stoppage and the nine months following the work stoppage at Finishing Plant \#1 was accomplished using The comparison formula. The result of this calculation, 0.292, was less than the 2.160 critical t value, therefore a statistically significant decrease in incidence rates did not occur between these two periods.

Table 27 provides a summary of the comparison periods associated with the work stoppage. The incidence rates prior to the work stoppage and those following the work stoppage are listed, as are the critical t values and the calculated comparison values.

\section{Table 27}

Comparison of prior and post work stoppage periods - Finishing Plant \#1

\begin{tabular}{|c|c|c|c|c|}
\hline \multirow[b]{2}{*}{ Time Period } & \multicolumn{2}{|c|}{ Finishing Plant \#1 Incidence Rates } & \multirow[b]{2}{*}{ Critical t Value } & \multirow[b]{2}{*}{$\begin{array}{l}\text { Calculated } \\
\text { Comparison Value }\end{array}$} \\
\hline & $\begin{array}{l}\text { Prior to } \\
\text { Work Stoppage }\end{array}$ & $\begin{array}{l}\text { Post } \\
\text { Work Stoppage }\end{array}$ & & \\
\hline 9 Months & 2.29 & 1.94 & 2.160 & 0.292 \\
\hline 24 Months & 5.09 & 2.08 & 1.997 & $3.144 * *$ \\
\hline 33 Months & 4.36 & 2.04 & 1.991 & $2.991 * *$ \\
\hline
\end{tabular}

* Indicates a statistically significant increase

** Indicates a statistically significant decrease

\section{Finishing Plant \#2 Analysis}

\section{Quarterly Analysis of Lost Work Day Data - Finishing Plant \#2}

As illustrated in Figure 148, the first two first quarter periods at Finishing Plant \#2 did not experience any lost work day incidents. In 1996 the incidence rate was above the mean and in 1998 it continued to rise to a level above the UCL. However, in 1999 the incidence rate decreased to a level between the mean and the UCL. The incidence rate was below the mean in 2000 . 


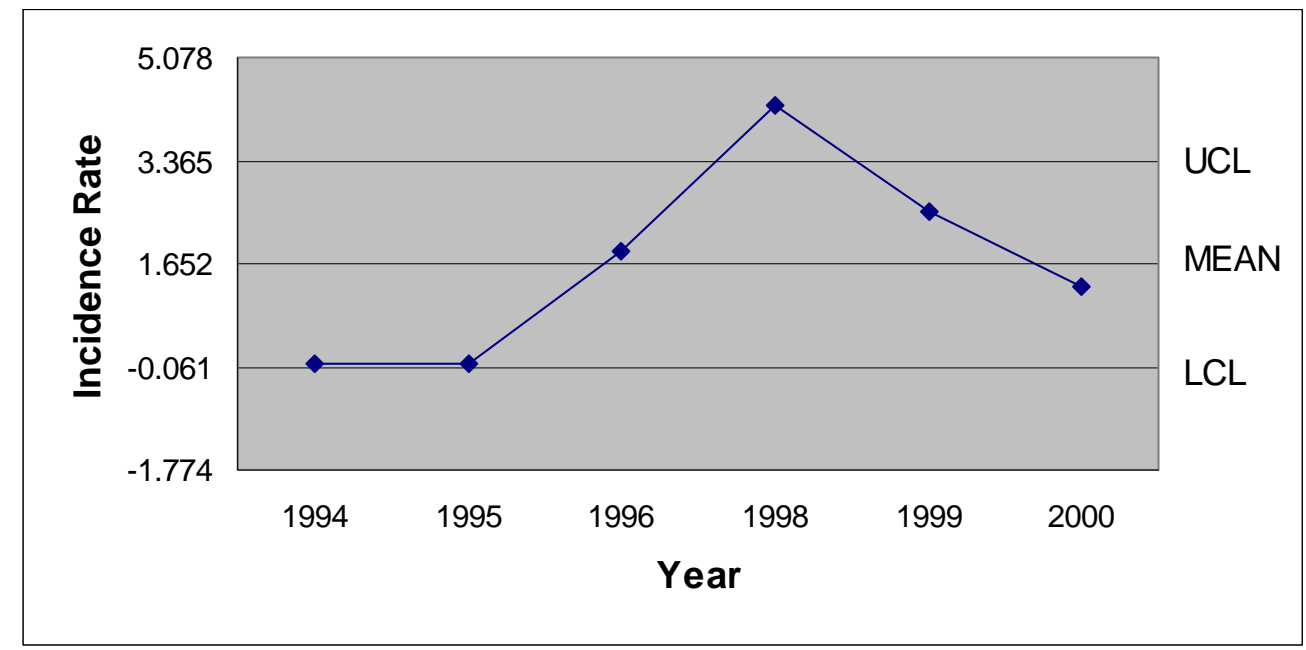

Note: No operations in first quarter 1997

Figure 148. First Quarter 1994-2000 Lost Work Day Incidence Rates - Finishing Plant \#2

The highest second quarter incidence rate at Finishing Plant \#2, 2.661, occurred in 1995. It was almost duplicated in 1998, with a rate of 2.623. The lowest second quarter incidence rate occurred in 1994, a year that did not experience any lost work day incidents. As illustrated in Figure 149, the remaining three incidence rates were below the mean.

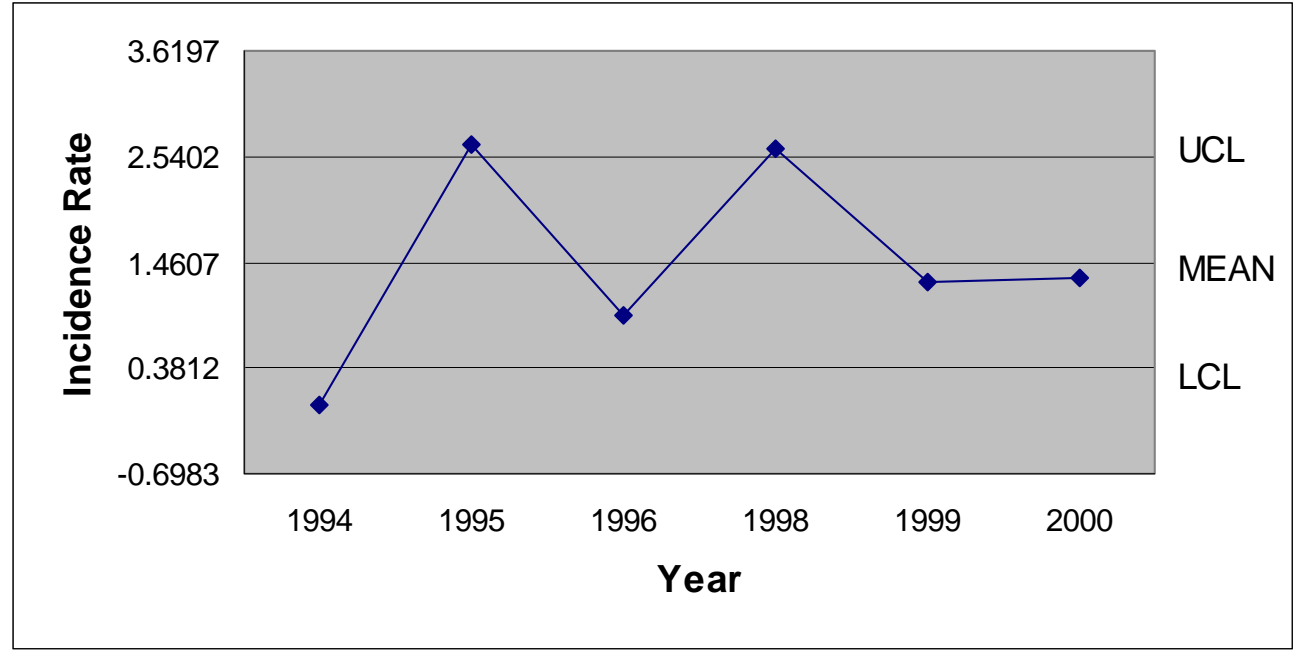

Note: No operations in second quarter 1997

Figure 149. Second Quarter 1994-2000 Lost Work Day Incidence Rates - Finishing Plant \#2 
The third quarter lowest incidence rate of 0.00 occurred at Finishing Plant \#2 in 1994 and was repeated in 1999. The remaining three third quarter rates were recorded between the mean and the UCL. The 1998 incidence rate of 2.567 was the highest third quarter rate recorded for Finishing Plant \#2 during this research period (See Figure 150).

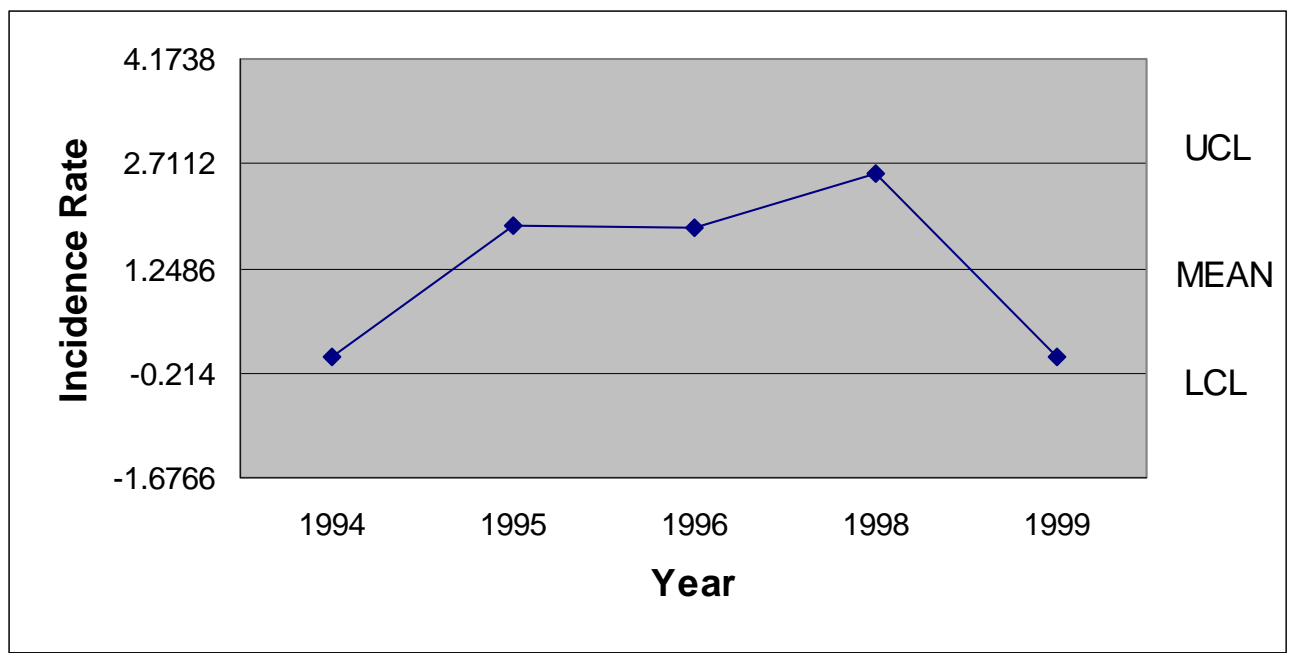

Note: No operations in third quarter 1997

Figure 150. Third Quarter 1994-1999 Lost Work Day Incidence Rates - Finishing Plant \#2

The fourth quarter lost work day incidence rates for Finishing Plant \#2 were marked by three of the five periods recording incidence rates of 0.00 . The highest incidence rate, 1.578 , occurred in 1997. The only other nonzero fourth quarter incidence rate was 1.327, recorded in 1998 (See Figure 151).

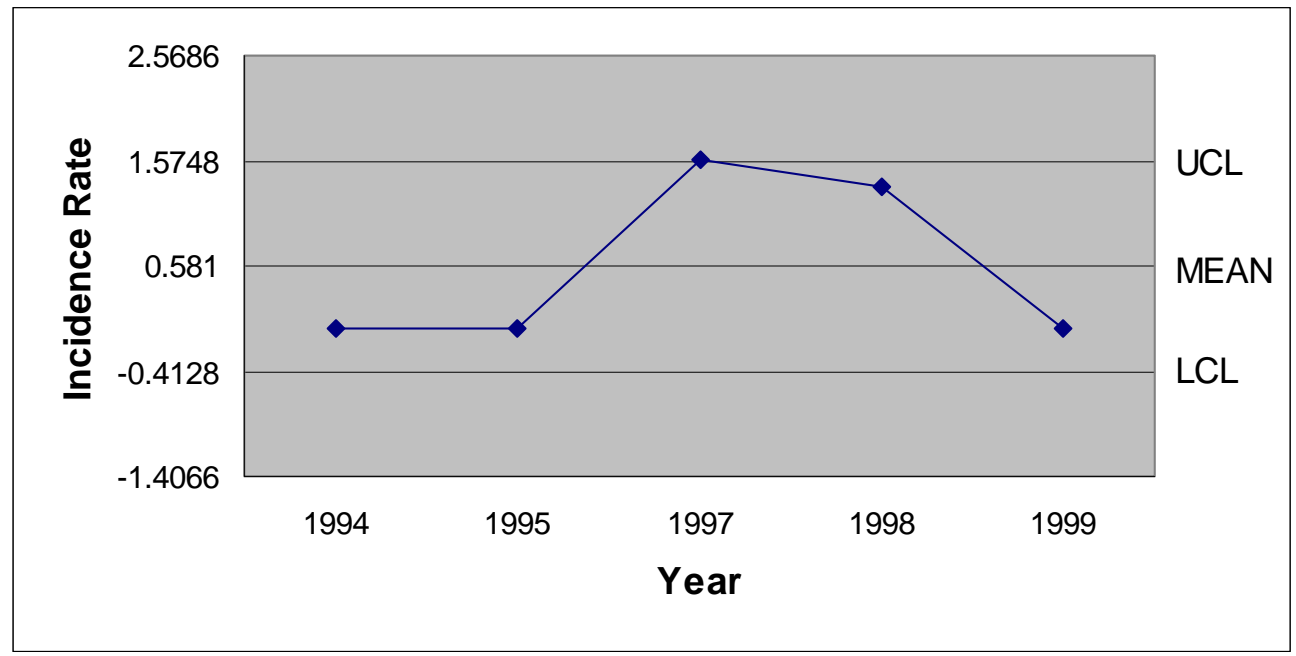

Note: No operations in fourth quarter 1996

Figure 151. Fourth Quarter 1994-1999 Lost Work Day Incidence Rates - Finishing Plant \#2 
Table 28 presents the quarterly incidence rates at Finishing Plant \#2 for each year of the study period, as well as the UCL, mean, LCL, and standard deviation. Nineteen ninety-six and 1997 are partial years because of the work stoppage and only the first six months of 2000 were included in the research.

Table 28

Summary of Quarterly Lost Work Day Incidence Rates Data - Finishing Plant \#2

\begin{tabular}{|l|l|l|l|l|}
\hline & $1^{\text {st }}$ Quarter & $2^{\text {nd }}$ Quarter & $3^{\text {rd }}$ Quarter & $4^{\text {th }}$ Quarter \\
\hline 1994 & 0.000 & 0.000 & 0.000 & 0.000 \\
\hline 1995 & 0.000 & 2.661 & 1.852 & 0.000 \\
\hline 1996 & 1.855 & 0.913 & 1.823 & N/A \\
\hline 1997 & N/A & N/A & N/A & 1.578 \\
\hline 1998 & 4.289 & 2.623 & 2.567 & 1.327 \\
\hline 1999 & 2.500 & 1.262 & 0.000 & 0.000 \\
\hline 2000 & 1.268 & 1.305 & N/A & N/A \\
\hline UCL & 3.365 & 2.540 & 2.711 & 1.575 \\
\hline MEAN & 1.652 & 1.461 & 1.249 & 0.581 \\
\hline LCL & -0.061 & 0.381 & -0.214 & -0.413 \\
\hline SD & 0.666 & 0.420 & 0.527 & 0.358 \\
\hline
\end{tabular}

$\underline{\text { Seasonal Analysis of Lost Work Day Data - Finishing Plant \#2 }}$

The results of the quarterly seasonal index calculations for Finishing Plant \#2 are depicted in Figure 152. The lost work day incidence rates seasonal index indicated that the first quarter had the highest seasonal index and the fourth quarter the lowest. The fourth quarter was almost $70 \%$ lower than the first quarter seasonal index. 


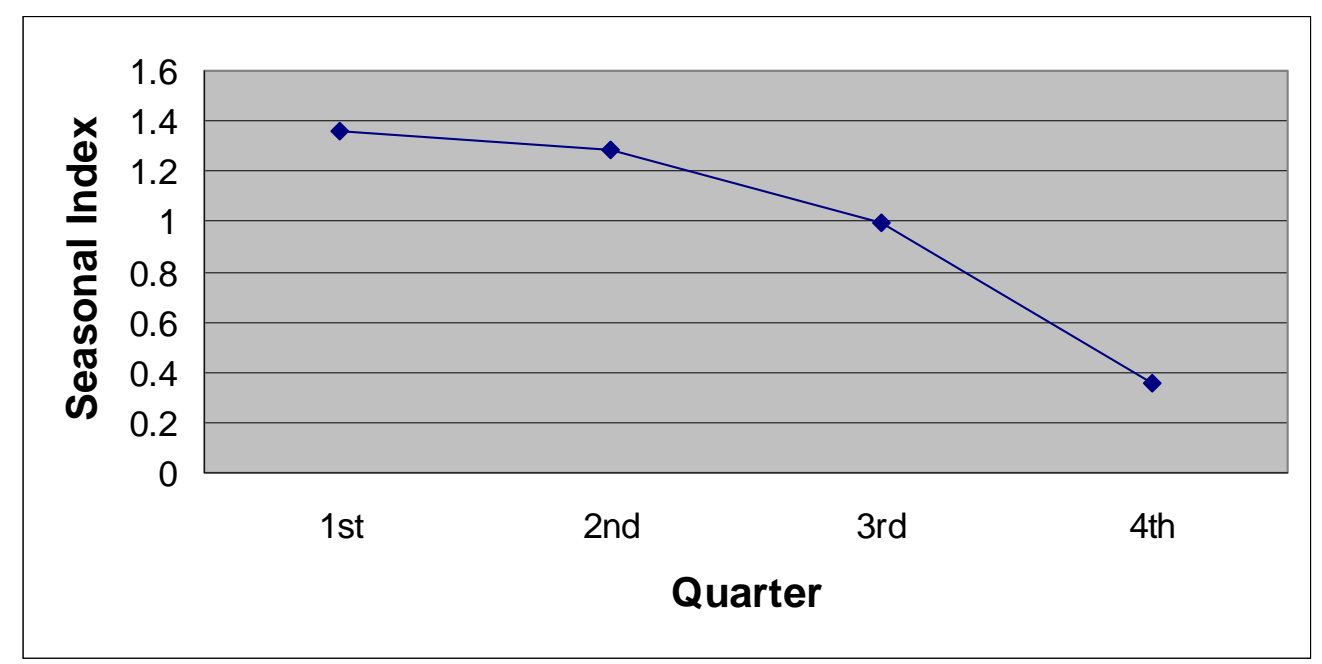

Figure 152. Quarterly Seasonal Pattern of Lost Work Day Incidence Rates - Finishing Plant \#2

\section{Monthly Analysis of Lost Work Day Data - Finishing Plant \#2}

The first four Januarys in this research period did not experience any lost work day incidents at Finishing Plant \#2. In 1999 the incidence rate jumped to 3.896, which was almost equaled the next year with a 3.876 incidence rate (See Figure 153).

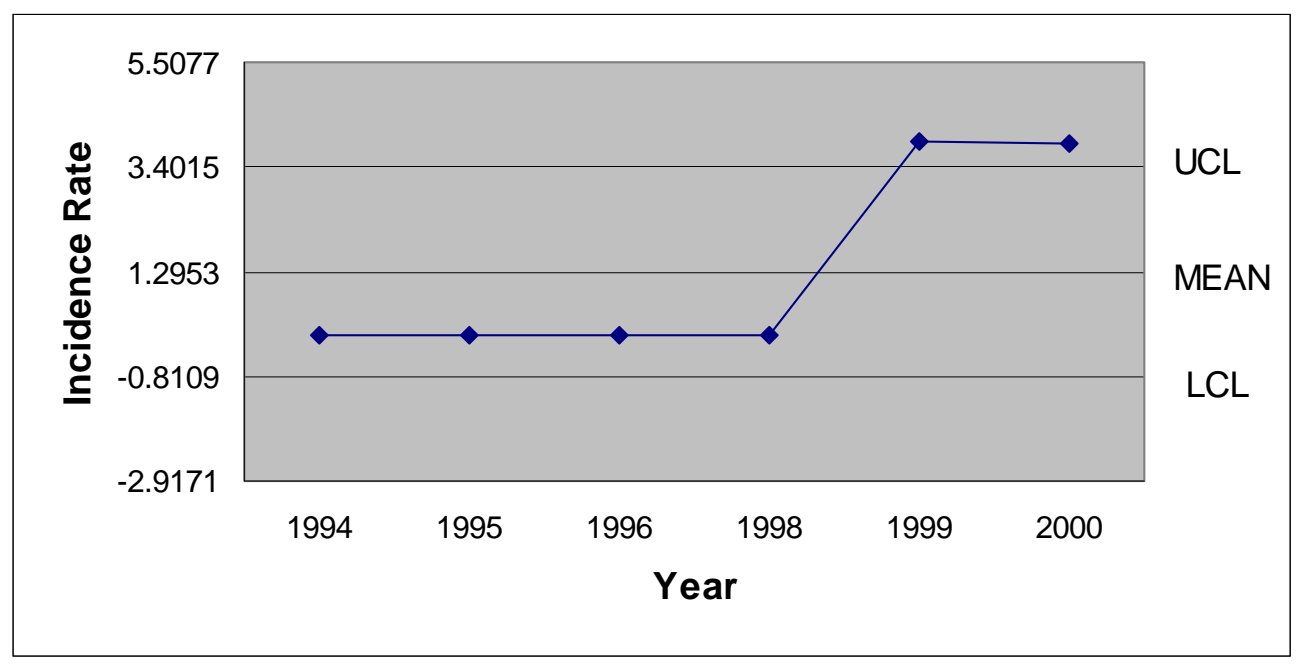

Note: No operations in January 1997

Figure 153. January 1994-2000 Lost Work Day Incidence Rates - Finishing Plant \#2 
Over the research period, the first two and the last two months of February recorded incidence rates of 0.00 for Finishing Plant \#2. The highest incidence rate, 4.235, occurred above the UCL in 1998. The only other nonzero incidence rate occurred the previous period (See Figure 154).

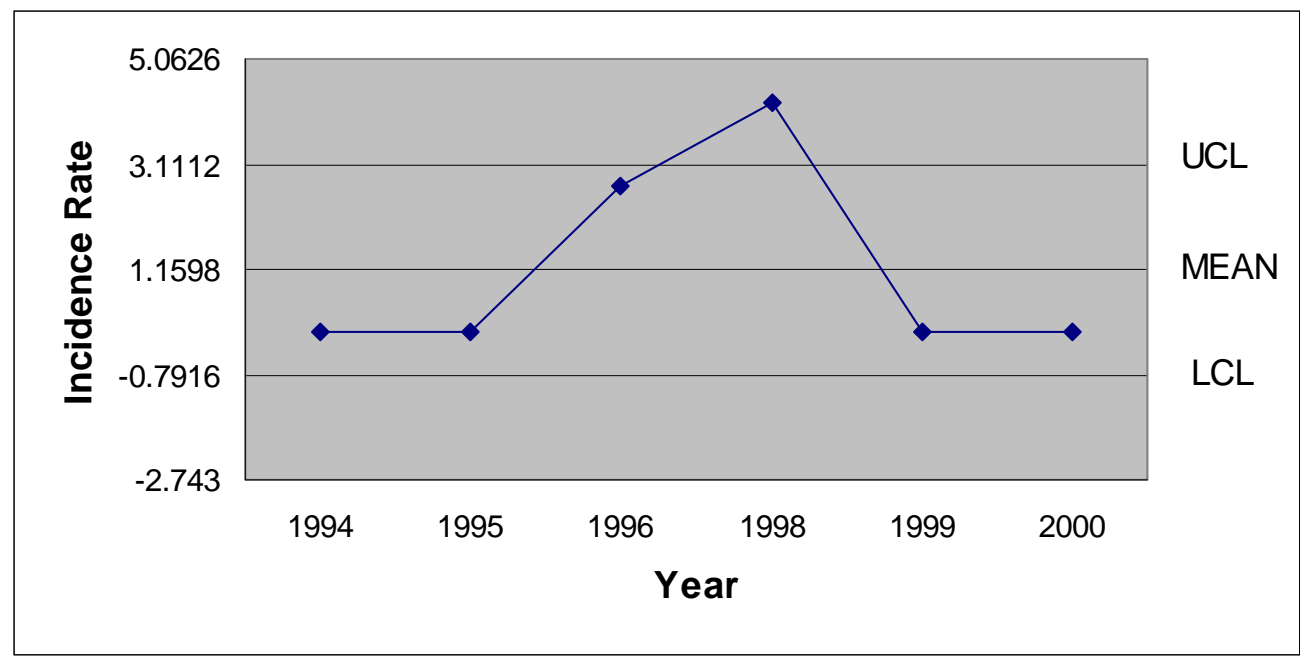

Note: No operations in February 1997

Figure 154. February 1994-2000 Lost Work Day Incidence Rates - Finishing Plant \#2

March 1998 recorded the highest incidence rate at Finishing Plant \#2, 7.423, which was above the UCL. The surrounding 1996 and 1999 incidence rates were close to the mean. Lost work day incidence rates of 0.000 were recorded for March of 1994, 1995, and 2000 (See Figure 155).

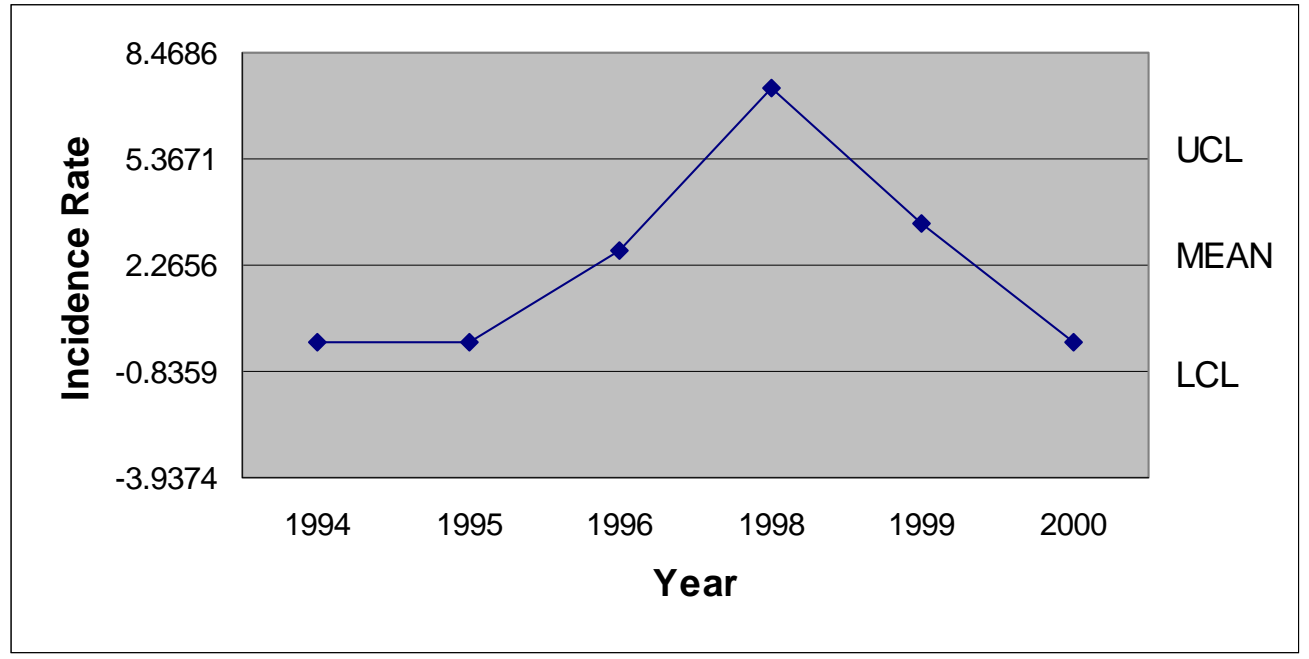

Note: No operations in March 1997

Figure 155. March 1994-2000 Lost Work Day Incidence Rates - Finishing Plant \#2 
April 1995 was the only nonzero incidence rate for the first four years of the research period Finishing Plant \#2. In 1999 the incidence rate edged above the UCL and was followed in 2000 with a second consecutive year above the UCL (See Figure 156).

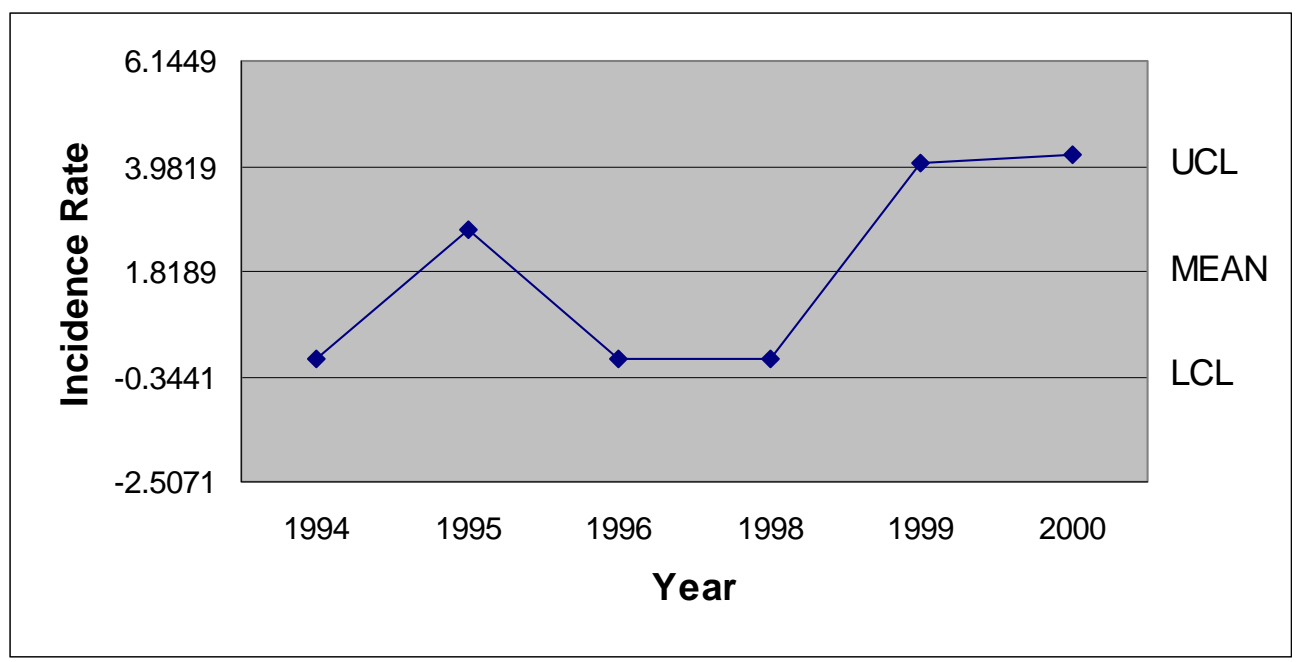

Note: No operations in April 1997

Figure 156. April 1994-2000 Lost Work Day Incidence Rates - Finishing Plant \#2

For the month of May at Finishing Plant \#2, four years, 1994, 1996, 1999, and 2000 did not experience any lost work day incidents. May 1995 had the highest May incidence rate recorded during the research period, 5.157. The only other year with a nonzero incidence rate for the month of May was 1998 with an incidence rate just below the UCL (See Figure 157). 


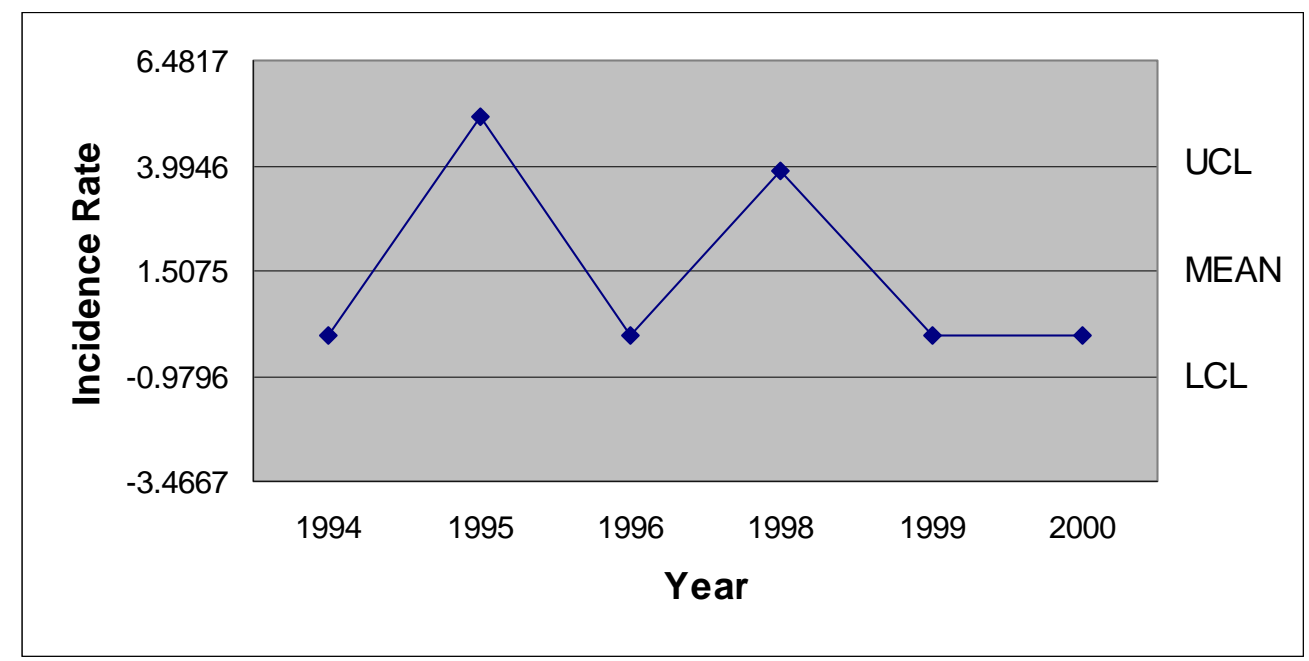

Note: No operations in May 1997

Figure 157. May 1994-2000 Lost Work Day Incidence Rates - Finishing Plant \#2

As illustrated in Figure 158, Finishing Plant \#2 had only two nonzero incidence rates for the month of June, 1996 and 1998. The 1996 incidence rate was just below the UCL, while the 1998 rate of 3.873 was above the UCL.

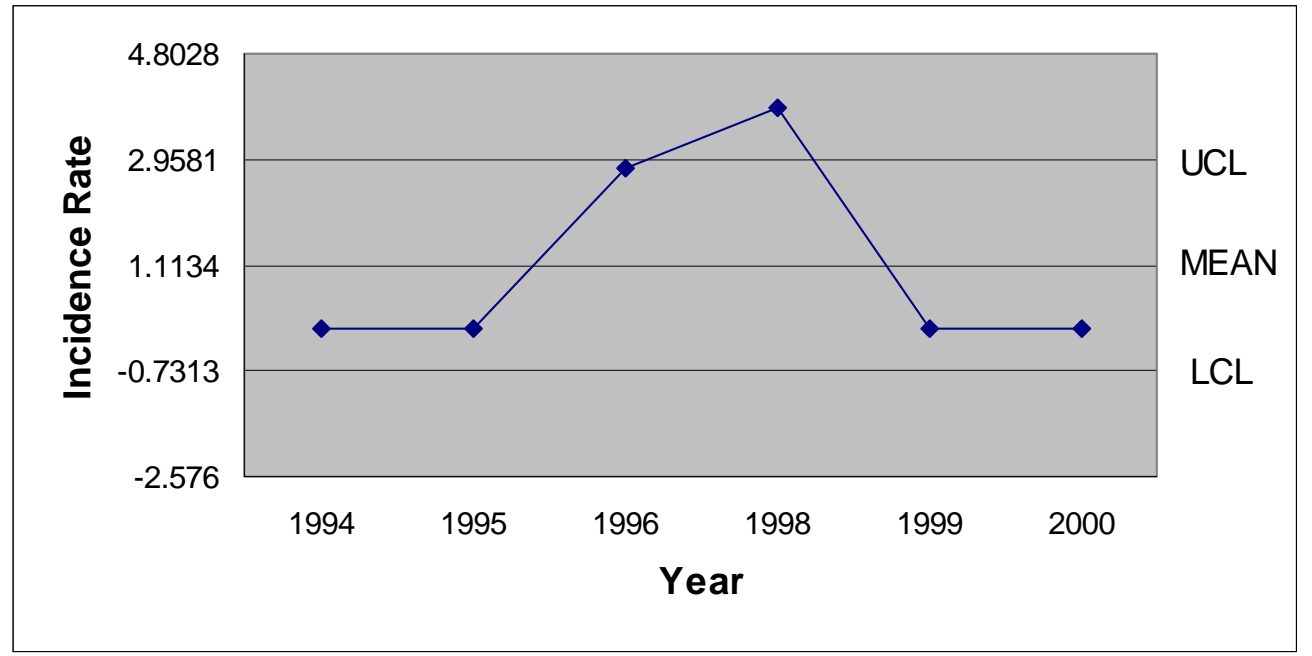

Note: No operations in June 1997

Figure 158. June 1994-2000 Lost Work Day Incidence Rates - Finishing Plant \#2

During the research period, there were no lost work day incidents in the month of July at Finishing Plant \#2. This created a situation where the UCL, mean, and LCL were all zero (See Figure 159). 


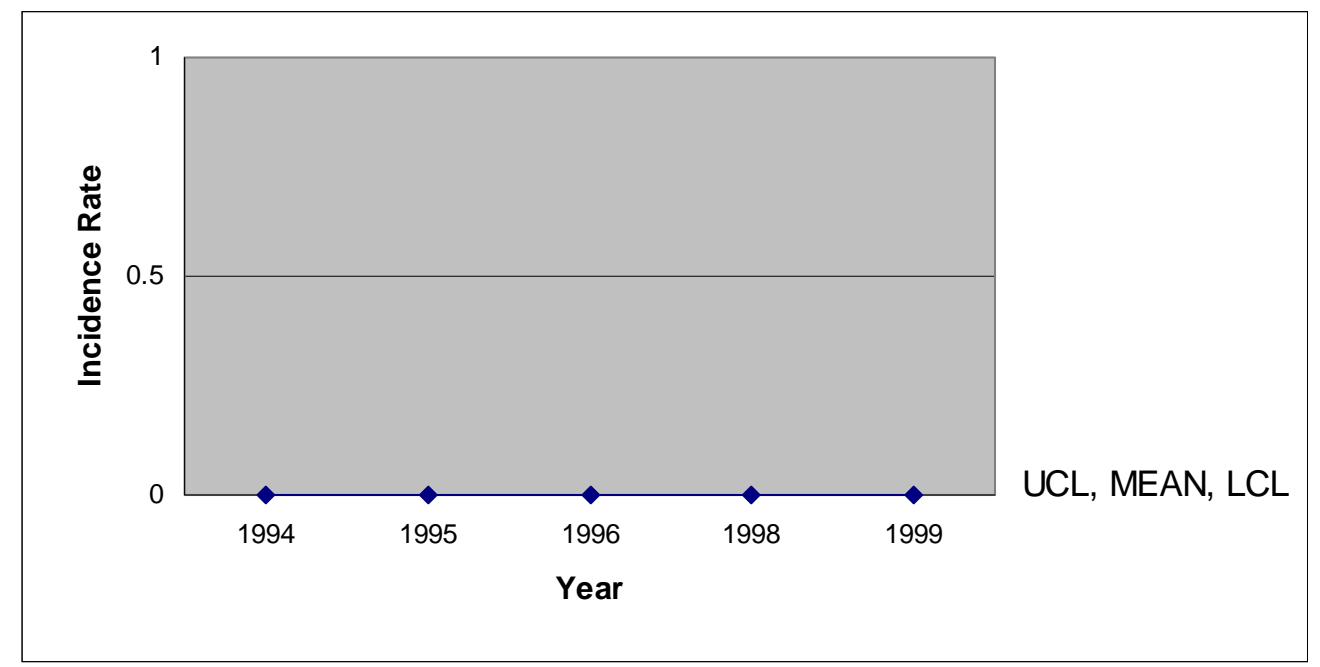

Note: No operations in July 1997

Figure 159. July 1994-1999 Lost Work Day Incidence Rates - Finishing Plant \#2

As illustrated in Figure 160, at Finishing Plant \#2 August 1994, 1996, and 1999 did not have any lost work day incidents. The highest incidence rate occurred above the UCL in 1998. The only other nonzero incidence rate month of August recorded an incidence rate between the mean and the UCL in 1995.

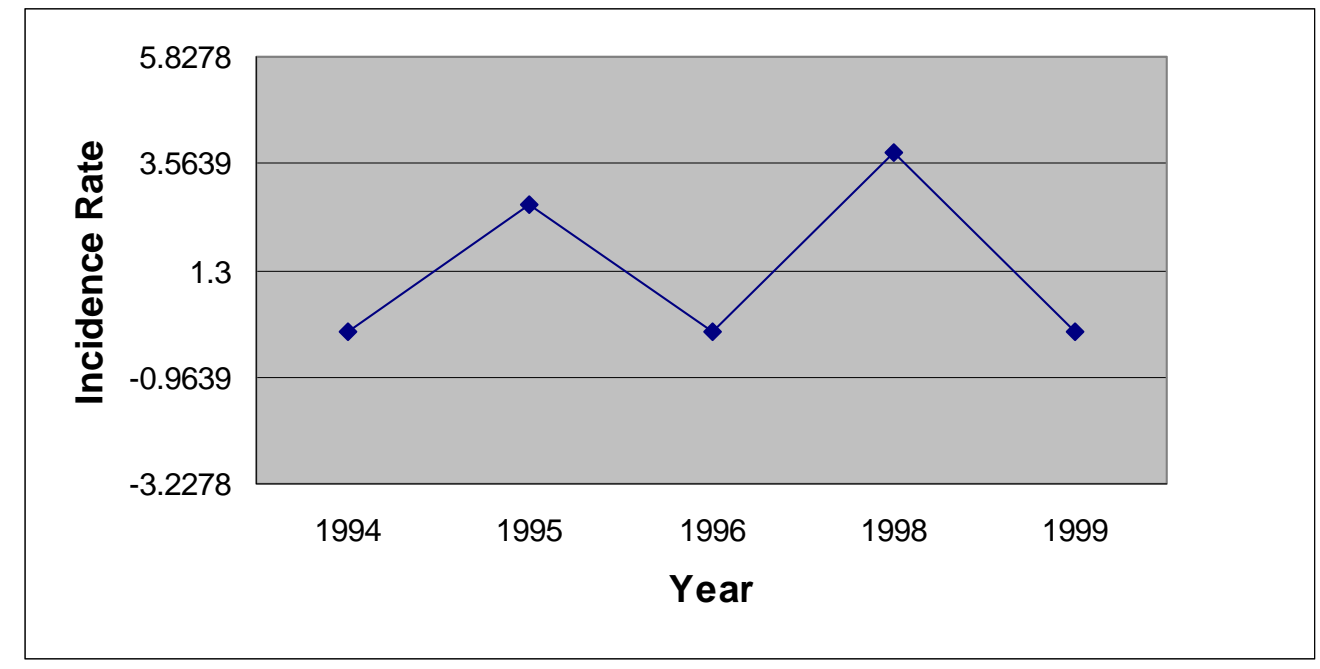

Note: No operations in August 1997

Figure 160. August 1994-1999 Lost Work Day Incidence Rates - Finishing Plant \#2 
The beginning period, 1994, and the ending period, 1999, both recorded zero lost work day incidents for the month of September at Finishing Plant \#2. The 1995 incidence rate was just above the mean, while the 1996 incidence rate was just above the UCL. The 1998 September lost work day incidence rate was between the mean and the UCL (See Figure 161).

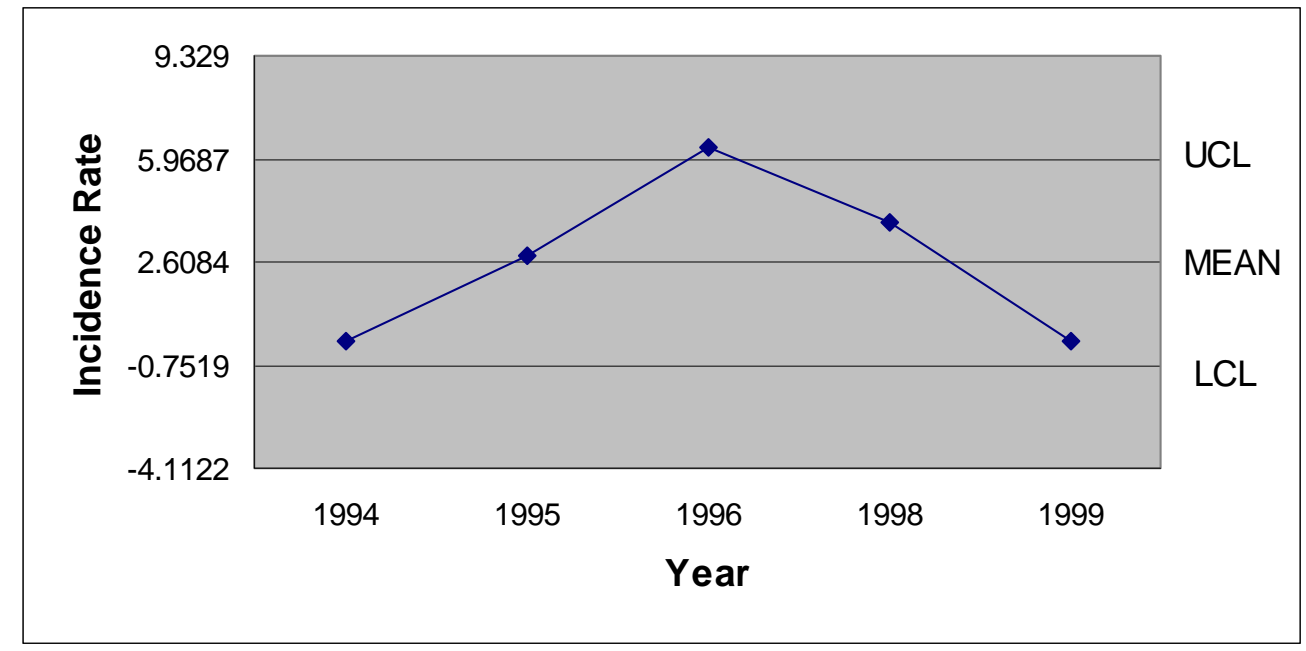

Note: No operations in September 1997

Figure 161. September 1994-1999 Lost Work Day Incidence Rates - Finishing Plant \#2

As illustrated in Figure 162, the only nonzero year for the month of October at Finishing Plant \#2 was 1998. The 3.810 incidence rate recorded in 1998 was above the UCL of 2.877 . 


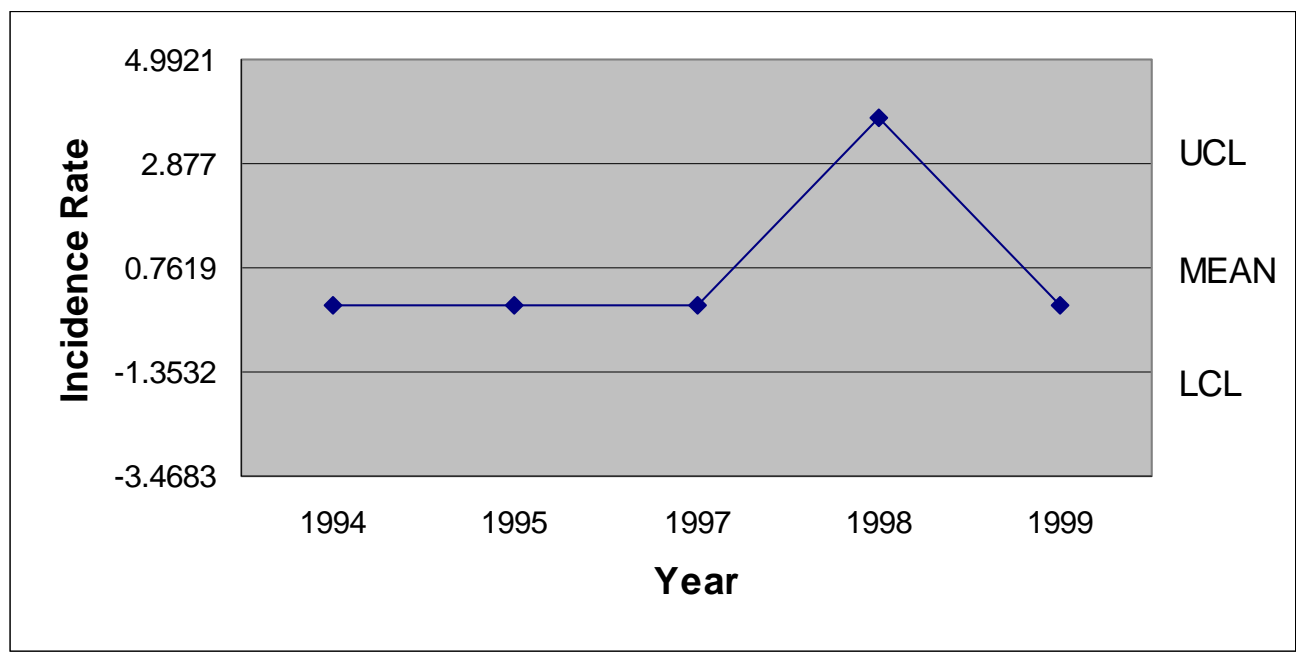

Note: No operations in October 1996

Figure 162. October 1994-1999 Lost Work Day Incidence Rates - Finishing Plant \#2

During the research period, there were no lost work day incidents in the month of November at Finishing Plant \#2. This created a situation where the UCL, mean, and LCL were all zero (See Figure 163).

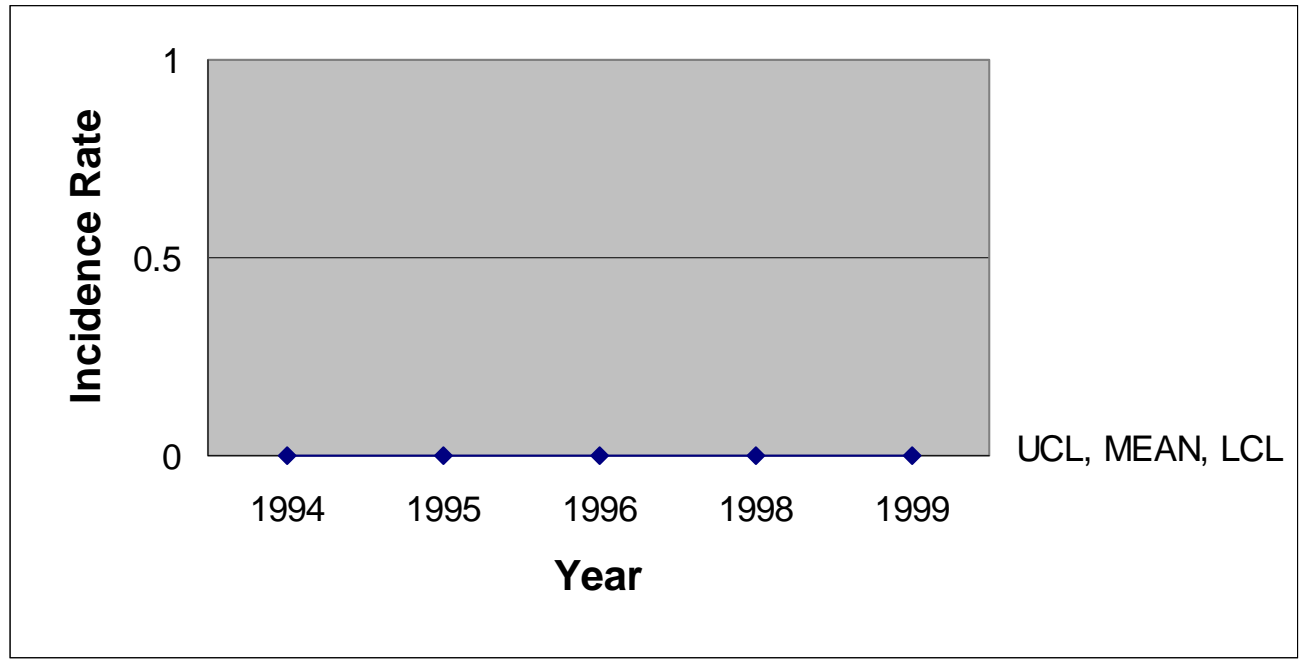

Note: No operations in November 1996

Figure 163. November 1994-1999 Lost Work Day Incidence Rates - Finishing Plant \#2 
For the month of December, the only nonzero lost work day incidence rate at Finishing Plant \#2 occurred in 1997. The 5.513 December 1997 incidence rate was above the 4.1632 UCL established for December (See Figure 164).

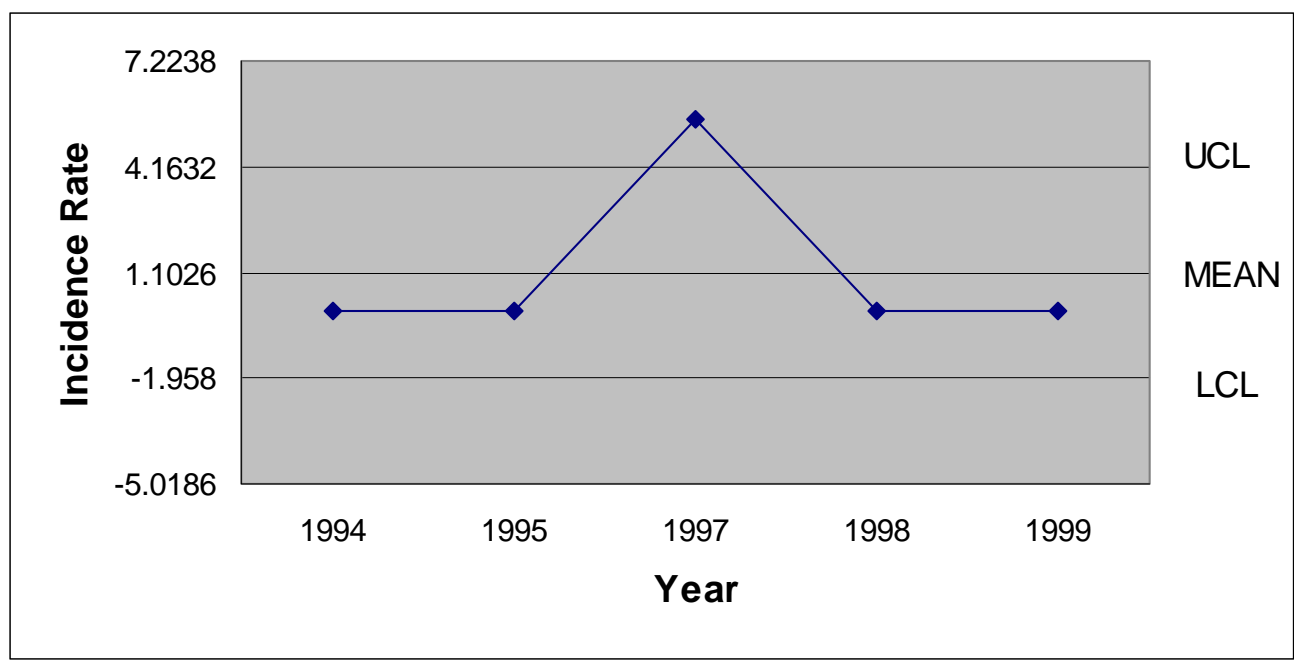

Note: No operations in December 1996

Figure 164. December 1994-1999 Lost Work Day Incidence Rates - Finishing Plant \#2

Table 29 presents the monthly incidence rates at Finishing Plant \#2 for each year of the study period, as well as the UCL, mean, LCL, and standard deviation. Nineteen ninety-six and 1997 are partial years because of the work stoppage and only the first six months of 2000 were included in the research.

Table 29

Summary of Monthly Lost Work Day Incidence Rates Data - Finishing Plant \#2

\begin{tabular}{|l|l|l|l|l|}
\hline & $1^{\text {st }}$ Quarter & $2^{\text {nd }}$ Quarter & $3^{\text {rd }}$ Quarter & $4^{\text {th }}$ Quarter \\
\hline 1994 & 0.000 & 0.000 & 0.000 & 0.000 \\
\hline 1995 & 0.000 & 2.661 & 1.852 & 0.000 \\
\hline 1996 & 1.855 & 0.913 & 1.823 & N/A \\
\hline 1997 & N/A & N/A & N/A & 1.578 \\
\hline 1998 & 4.289 & 2.623 & 2.567 & 1.327 \\
\hline 1999 & 2.500 & 1.262 & 0.000 & 0.000 \\
\hline
\end{tabular}




\begin{tabular}{|l|l|l|l|l|}
\hline 2000 & 1.268 & 1.305 & N/A & N/A \\
\hline UCL & 3.365 & 2.540 & 2.711 & 1.575 \\
\hline MEAN & 1.652 & 1.461 & 1.249 & 0.591 \\
\hline LCL & -0.061 & 0.381 & -0.214 & -0.413 \\
\hline SD & 0.666 & 0.420 & 0.527 & 0.358 \\
\hline
\end{tabular}

Seasonal Analysis of Lost Work Day Data - Finishing Plant \#2

The seasonal index calculation was used to generate the monthly seasonal index figures that are presented in Figure 166. April experienced the highest seasonal index for Finishing Plant \#2, while September experienced the second highest. The lowest seasonal index figures, 0.00 , for Finishing Plant \#2 were recorded in July and November, both months did not experience any lost work day incidents during the study period.

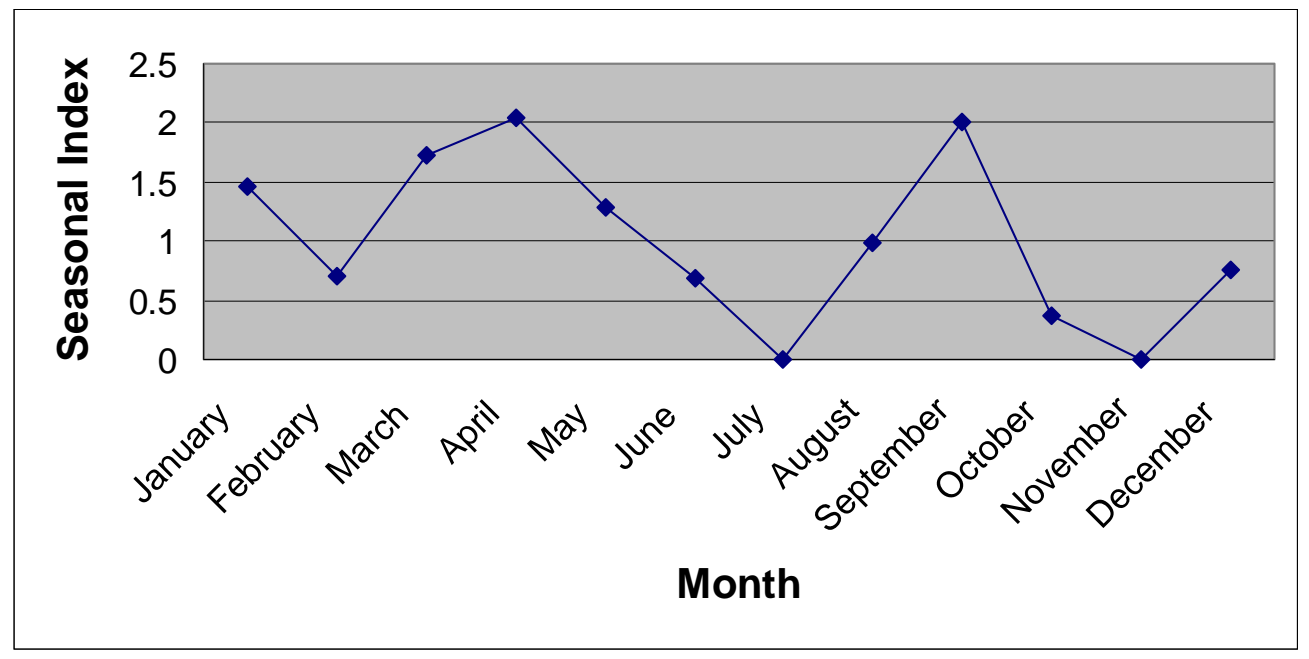

Figure 165. Monthly Seasonal Pattern of Lost Work Day Incidence Rates - Finishing Plant \#2

Testing the Statistical Relationship of Lost Work Day Data - Finishing Plant \#2 All 33 Months Prior to and Subsequent to the Work Stoppage

For the entire 33 months prior to the work stoppage and the 33 post work stoppage months the comparison $t$ value was 1.761 . Because this calculated amount was 
less than the critical t value of 2.069 , a statistically significant increase in incidence rates did not occur between the pre and post work stoppage periods at Finishing Plant \#2.

\section{First 24 Months and Last 24 Months of the Research Period}

The same formula was applied to lost work day incidence rates at Finishing Plant \#2 for the first 24 months and the last 24 months of the period. These time periods excluded the nine months prior to and the immediately following the work stoppage. The calculated amount of 1.140 was less than the critical $t$ value of 2.179 . Thus it can be stated that a statistically significant increase in incidence rates did not occur between the two periods at Finishing Plant \#2.

Nine Month Intervals Prior to and Subsequent to the Work Stoppage

Comparison of the lost work day incidence rate at Finishing Plant \#2 for the nine months preceding the work stoppage and the nine months following the work stoppage was accomplished using The comparison formula. The result of this calculation, 1.053 was less than the critical $t$ value of 2.228 . Therefore it can be stated with a $95 \%$ confidence level that there was not a statistically significant increase in incidence rates between the two periods.

Table 30

Comparison of Prior and Post Work Stoppage Periods - Finishing Plant \#2

\begin{tabular}{|c|c|c|c|c|}
\hline \multirow[b]{2}{*}{ Time Period } & \multicolumn{2}{|c|}{ Finishing Plant \#2 Incidence Rates } & \multirow[b]{2}{*}{ Critical t Value } & \multirow[b]{2}{*}{$\begin{array}{l}\text { Calculated } \\
\text { Comparison Value }\end{array}$} \\
\hline & $\begin{array}{l}\text { Prior to } \\
\text { Work Stoppage }\end{array}$ & $\begin{array}{l}\text { Post } \\
\text { Work Stoppage }\end{array}$ & & \\
\hline 9 Months & 1.53 & 2.86 & 2.228 & 1.053 \\
\hline 24 Months & 0.56 & 1.28 & 2.179 & 1.140 \\
\hline 33 Months & 0.82 & 1.68 & 2.069 & 1.761 \\
\hline
\end{tabular}

* Indicates a statistically significant increase

** Indicates a statistically significant decrease 
Finishing Plant \#3 Analysis

\section{Quarterly Analysis of Lost Work Day Data - Finishing Plant \#3}

The 1994 and 1995 lost work day incidence rates for Finishing Plant \#3 were barely above the mean. The first quarter of 1996 did not have any lost work day incidences at this plant. Following the low in 1996, the 1997 first quarter rate was between the LCL and the mean. In 1999 the highest lost work day incidence rate of 3.489 was recorded above the UCL. The last year of the research period had a fourth quarter incidence rate of 1.707 (See Figure 166).

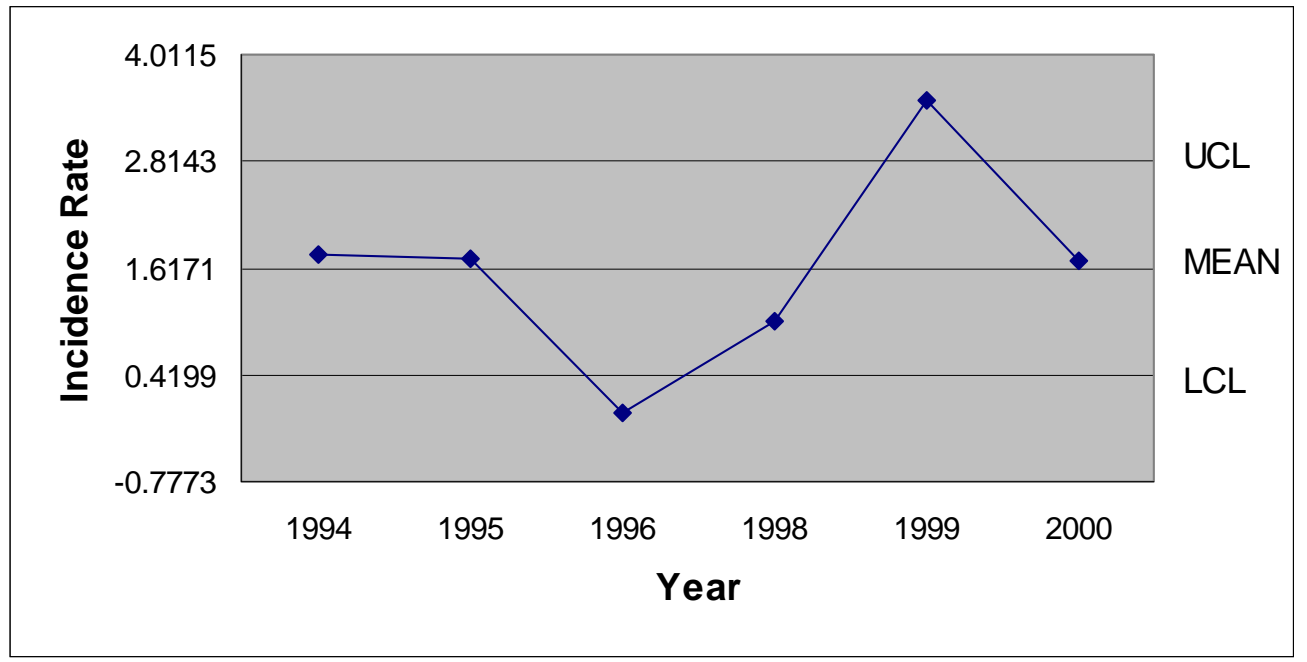

Note: No operations in first quarter 1997

Figure 166. First Quarter 1994-2000 Lost Work Day Incidence Rates - Finishing Plant \#3

The only second quarter incidence rate at Finishing Plant \#3 appearing outside the control limits was above the UCL in 1994. It was followed in 1995 and 1996 with 0.00 incidence rate. The incidence rate was just above the mean in 1998 and 2000, while the incidence rate dipped below the mean in 1999 (See Figure 167). 


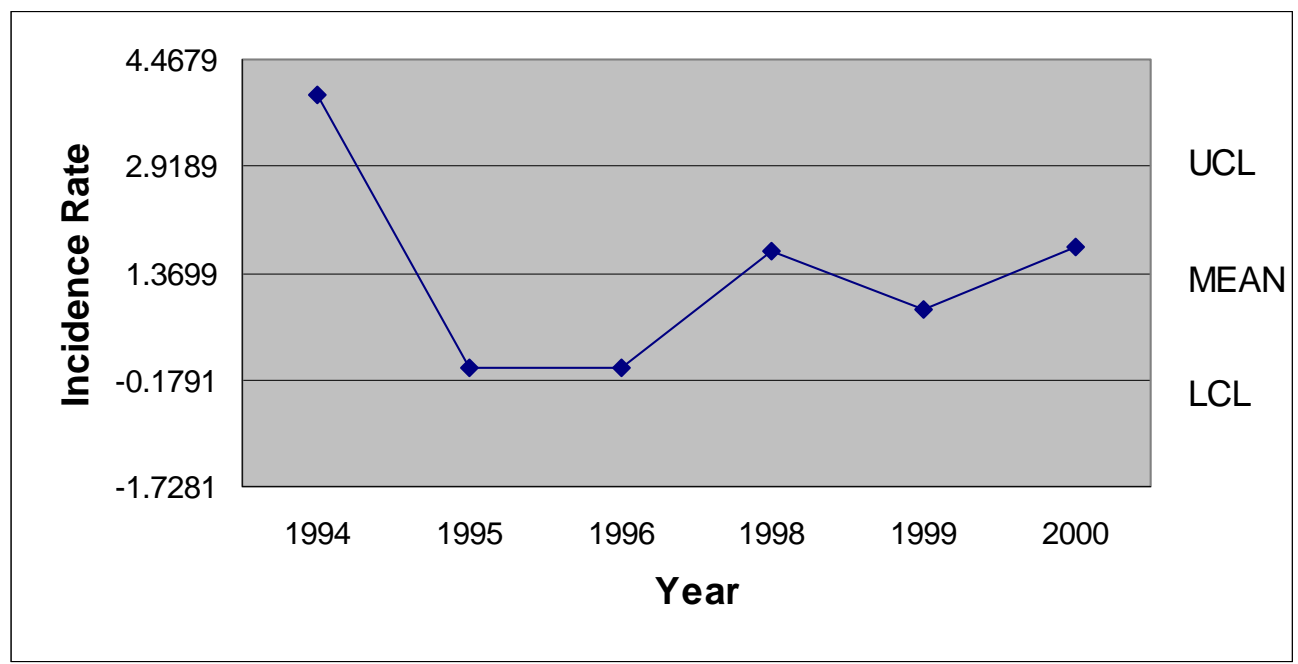

Note: No operations in second quarter 1997

Figure 167. Second Quarter 1994-2000 Lost Work Day Incidence Rates - Finishing Plant \#3

The highest third quarter incidence rate at Finishing Plant \#3 was close to the UCL in 1994. Third quarter incidence rates for 1994 and 1995 were both 0.00. In 1998 the incidence rate edged above the mean with a rate of 0.891 . The third quarter rate for 1999 was almost as high as the 1994 rate (See Figure 168).

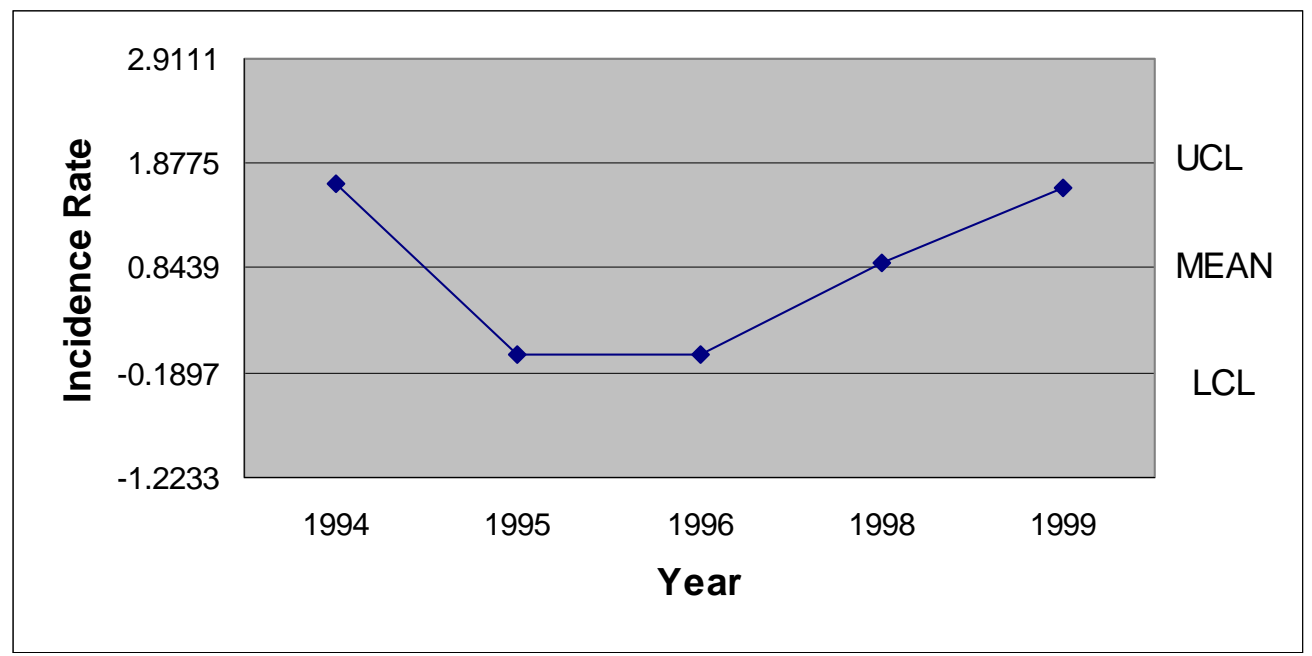

Note: No operations in third quarter 1997

Figure 168. Third Quarter 1994-1999 Lost Work Day Incidence Rates - Finishing Plant \#3 
As illustrated in Figure 169, the 4.600 incidence rate recorded in the fourth quarter of 1994 was the highest fourth quarter rate at Finishing Plant \#3 for the research period. A nearly 70\% decrease in incidence rate occurred between 1994 and 1995. The lowest incidence rate occurred in 1998, a year that did not experience any fourth quarter lost work day incidents. The remaining two years, 1997 and 1999, were close to the mean.

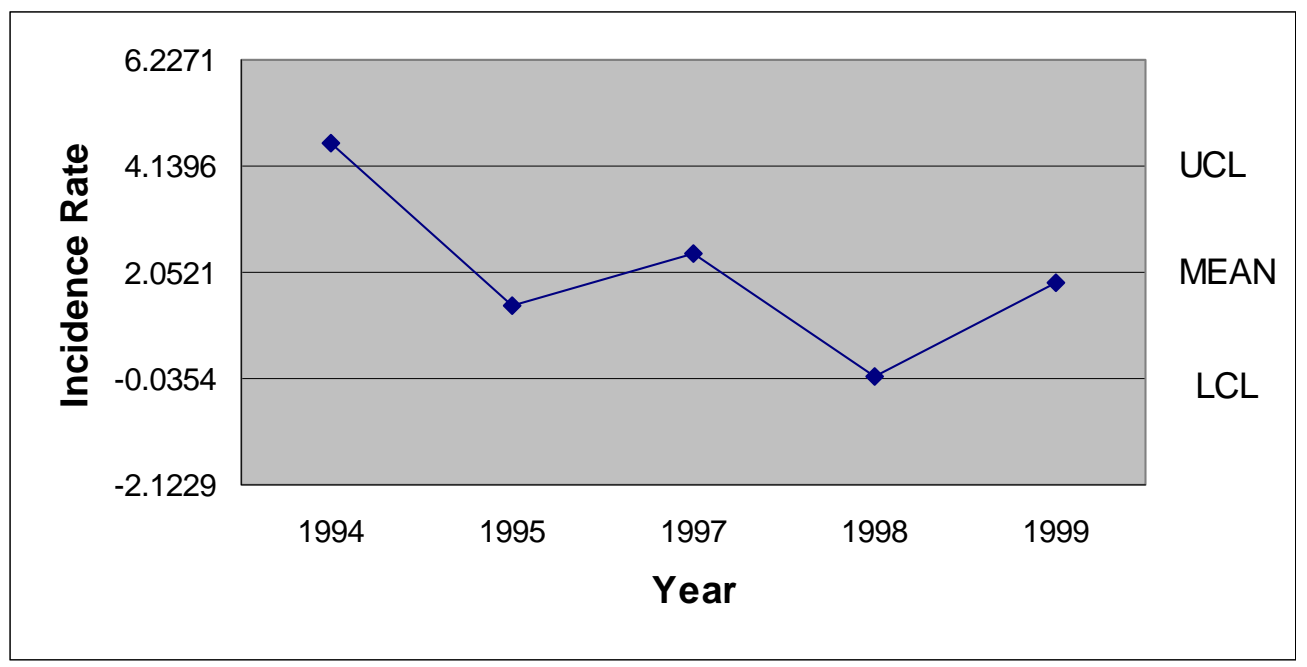

Note: No operations in fourth quarter 1996

Figure 169. Fourth Quarter 1994-1999 Lost Work Day Incidence Rates- Finishing Plant \#3

Table 31 presents the quarterly incidence rates at Finishing Plant \#3 for each year of the study period, as well as the UCL, mean, LCL, and standard deviation. Nineteen Ninety-six and 1997 are partial years because of the work stoppage and only the first six months of 2000 were included in the research.

Table 31

Summary of Quarterly Lost Work Day Incidence Rates Data - Finishing Plant \#3

\begin{tabular}{|l|l|l|l|l|}
\hline & $1^{\text {st }}$ Quarter & $2^{\text {nd }}$ Quarter & $3^{\text {rd }}$ Quarter & $4^{\text {th }}$ Quarter \\
\hline 1994 & 1.764 & 3.939 & 2.837 & 4.600 \\
\hline 1995 & 1.714 & 0.000 & 0.000 & 1.398 \\
\hline
\end{tabular}




\begin{tabular}{|l|l|l|l|l|}
\hline 1996 & 0.000 & 0.000 & 0.000 & N/A \\
\hline 1997 & N/A & N/A & N/A & 2.420 \\
\hline 1998 & 1.028 & 1.686 & 0.891 & 0.000 \\
\hline 1999 & 3.489 & 0.837 & 1.644 & 1.842 \\
\hline 2000 & 1.707 & 1.757 & N/A & N/A \\
\hline UCL & 2.814 & 2.919 & 1.878 & 4.139 \\
\hline MEAN & 1.617 & 1.370 & 0.844 & 2.052 \\
\hline LCL & 0.420 & -0.179 & -0.190 & -0.035 \\
\hline SD & 0.466 & 0.602 & 0.372 & 0.752 \\
\hline
\end{tabular}

$\underline{\text { Seasonal Analysis of Lost Work Day Data - Finishing Plant \#3 }}$

The results of the quarterly seasonal index calculations for Finishing Plant \#3 are presented in Figure 170. The incidence rates seasonal index indicated that the first quarter experienced the highest seasonal index and the fourth quarter the second highest. The lowest seasonal index occurred in the third quarter. The third quarter was more than $50 \%$ lower than the first quarter seasonal index.

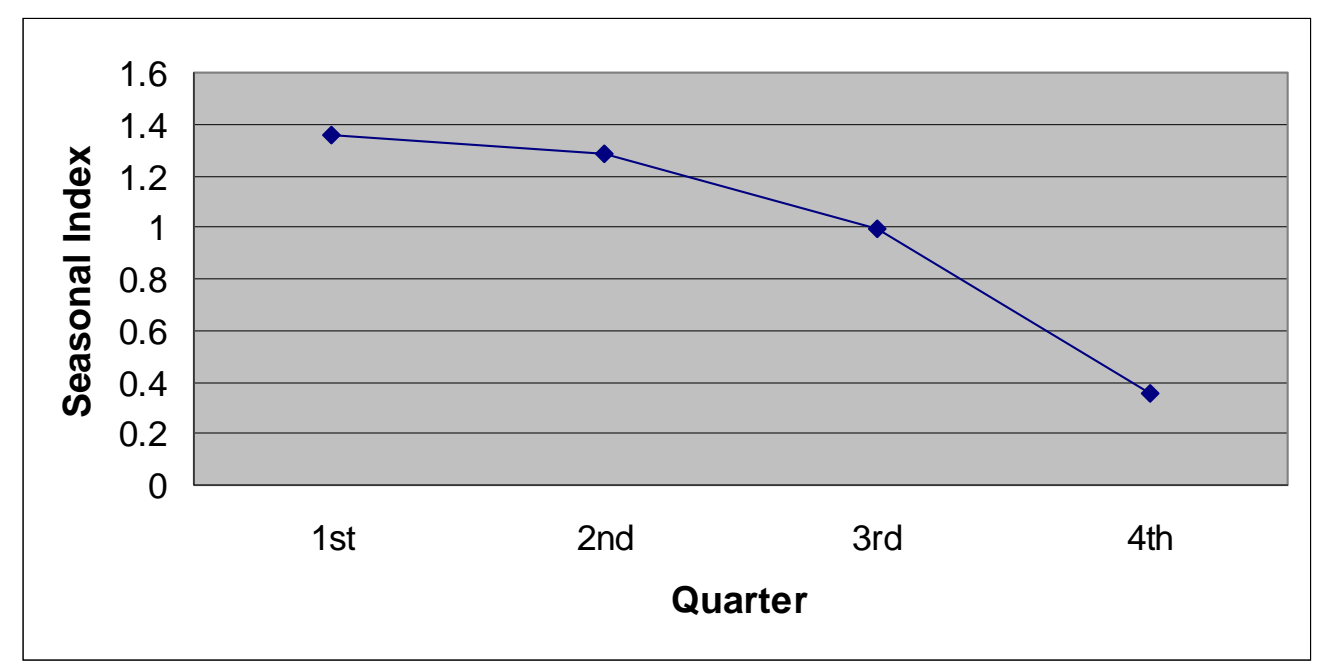

Figure 170. Quarterly Seasonal Index for Lost Work Day Incidence Rates - Finishing Plant \#3 


\section{Monthly Analysis of Lost Work Day Data - Finishing Plant \#3}

Finishing Plant \#3 experienced three periods, 1994, 1996, and 1998, without a lost work day incident in the month of January. The highest January lost work day incidence rate occurred in 1999 (See Figure 171).

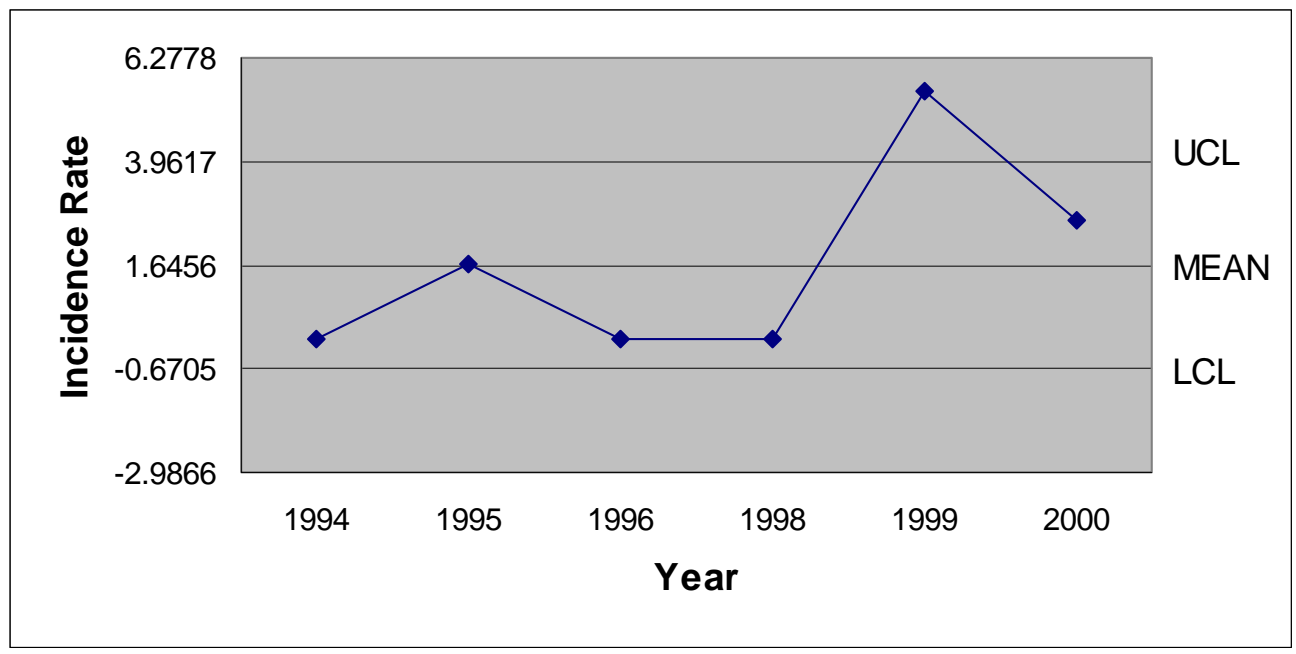

Note: No operations in January 1997

Figure 171. January 1994-2000 Lost Work Day Incidence Rates - Finishing Plant \#3

The highest lost work day incidence rate, 5.413, recorded in February 1999 at Finishing Plant \#3 was followed the next year with a February that did not have any lost work day incidents. February 1995 and 1996 also recorded zero lost work day incidents for Finishing Plant \#3. The incidence rates for 1994 and 1998 were between the mean and the UCL (See Figure 172). 


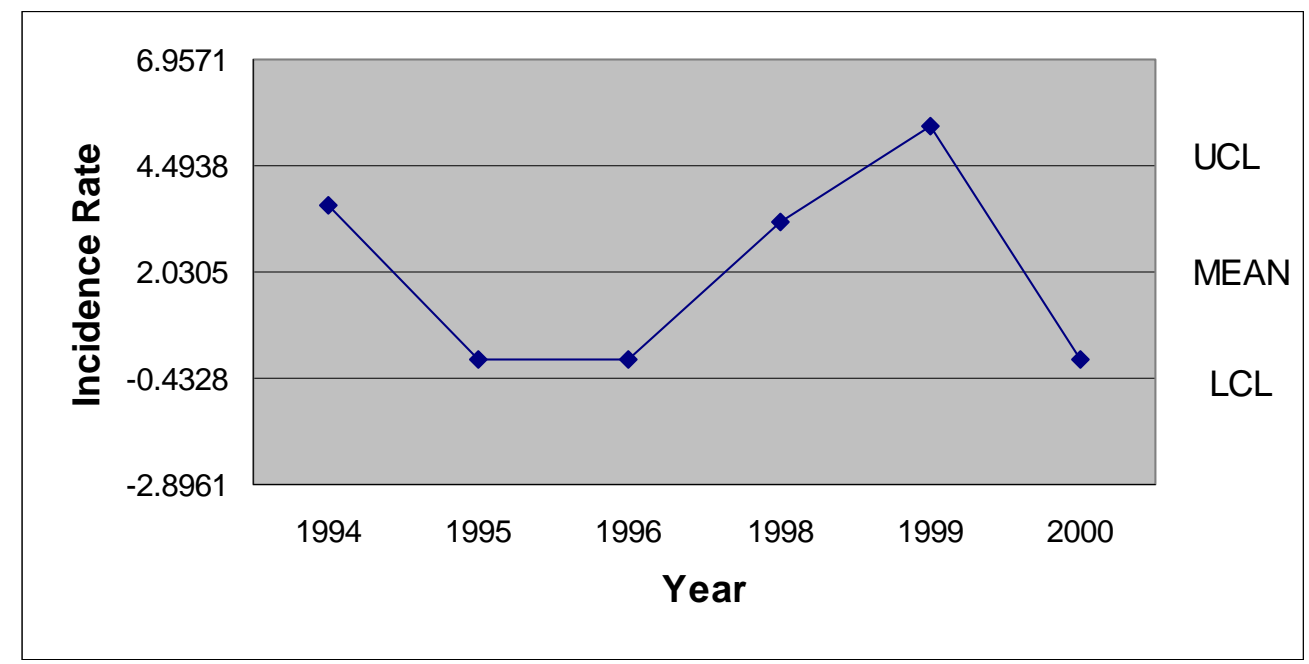

Note: No operations in February 1997

Figure 172. February 1994-2000 Lost Work Day Incidence Rates - Finishing Plant \#3

As illustrated in Figure 173, the March 1994 incidence rate at Finishing Plant \#3 was between the mean and the UCL. The following year's incidence rate was above the UCL, making it the highest March incidence rate during this study period. The high was followed by three consecutive years of 0.000 incidence rates for the month. The March 2000 incidence rate broke this streak with an incidence rate just below the UCL.

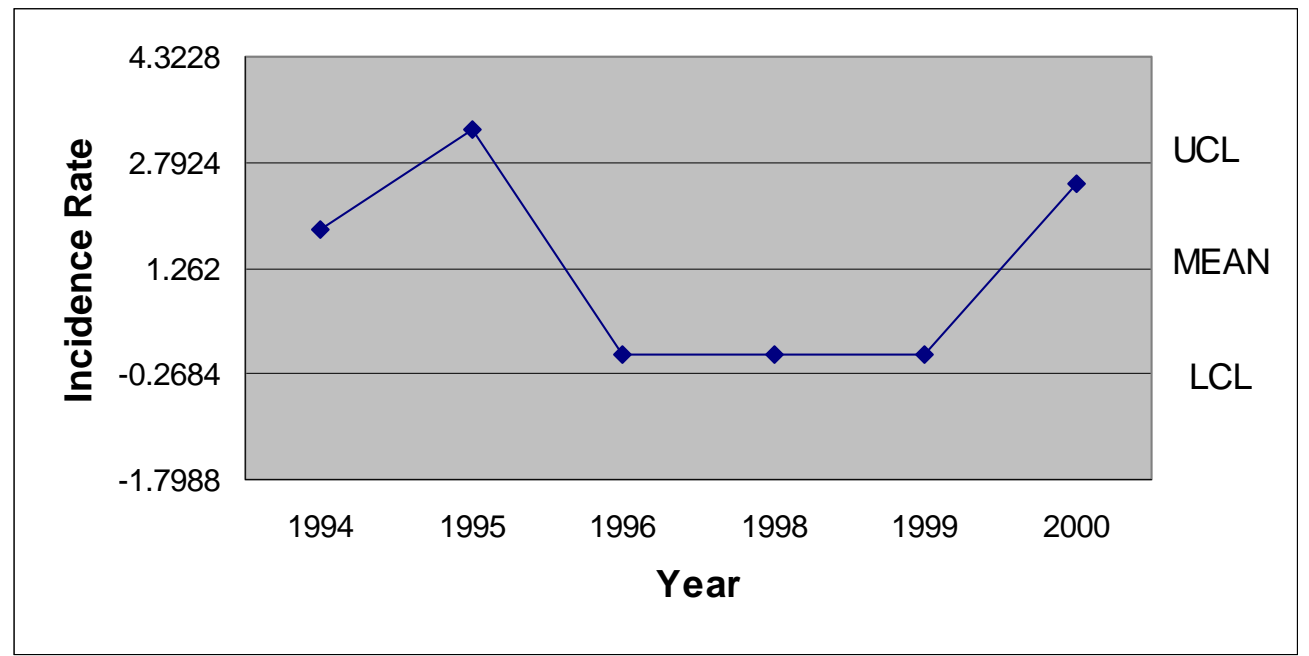

Note: No operations in March 1997

Figure 173. March 1994-2000 Lost Work Day Incidence Rates - Finishing Plant \#3 
April 1994 was the highest incidence rate recorded during the research period at Finishing Plant \#3. The high of 7.027 was followed by three years with zero incidents during the month of April. The last two years had incidence rates just above the mean (See Figure 174).

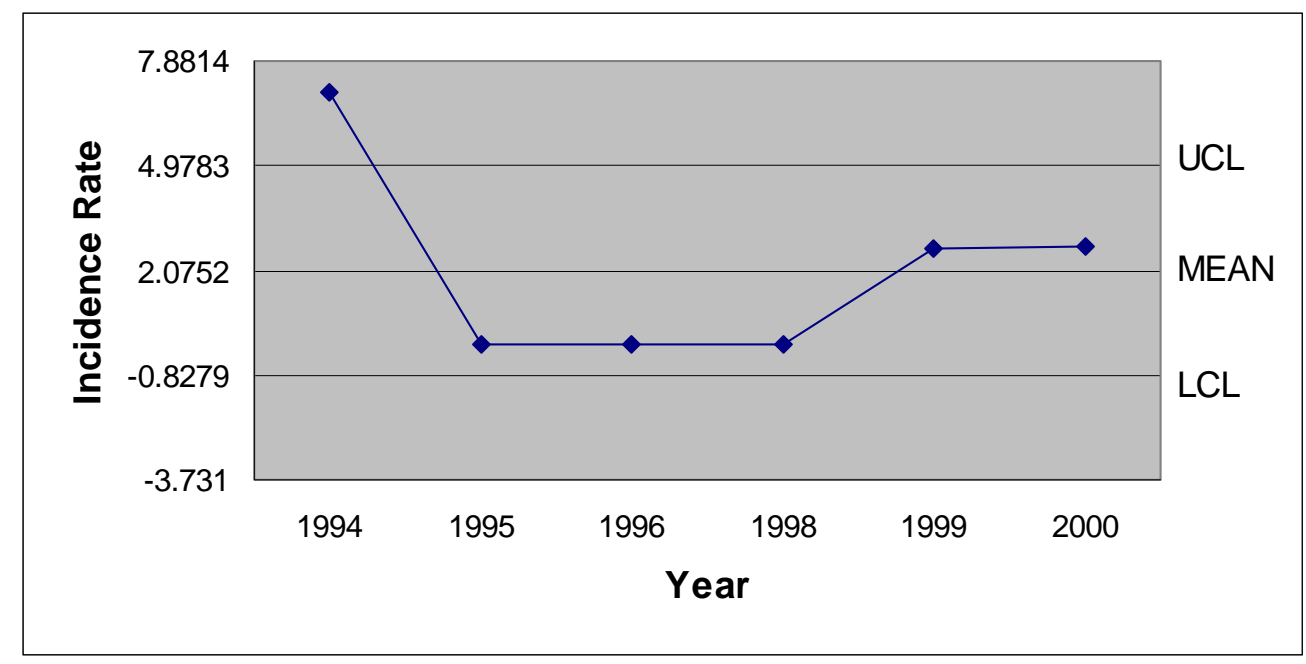

Note: No operations in April 1997

Figure 174. April 1994-2000 Lost Work Day Incidence Rates - Finishing Plant \#3

The only nonzero May incidence rate at Finishing Plant \#3 occurred in 1998. The 2.479 incidence rate was surrounded by 0.00 incidence rates for the three preceding and two succeeding periods (See Figure 175). 


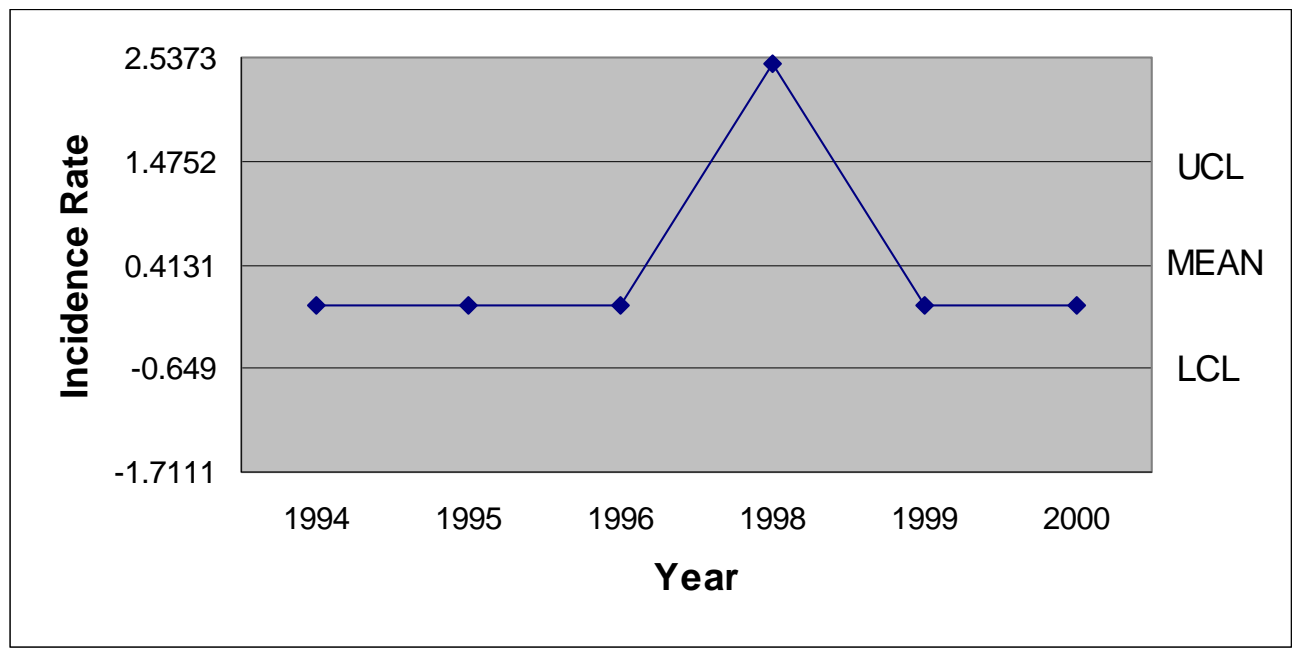

Note: No operations in May 1997

Figure 175. May 1994-2000 Lost Work Day Incidence Rates - Finishing Plant \#3

As illustrated in Figure 176, the highest June lost work day incidence rate at Finishing Plant \#3 occurred in 1994. The next two years recorded 0.00 incidence rates. In 1998 the incidence rate was between the mean and the UCL. The 1999 incidence rate was just above the LCL and was followed in 2000 with an incidence rate between the mean and the UCL.

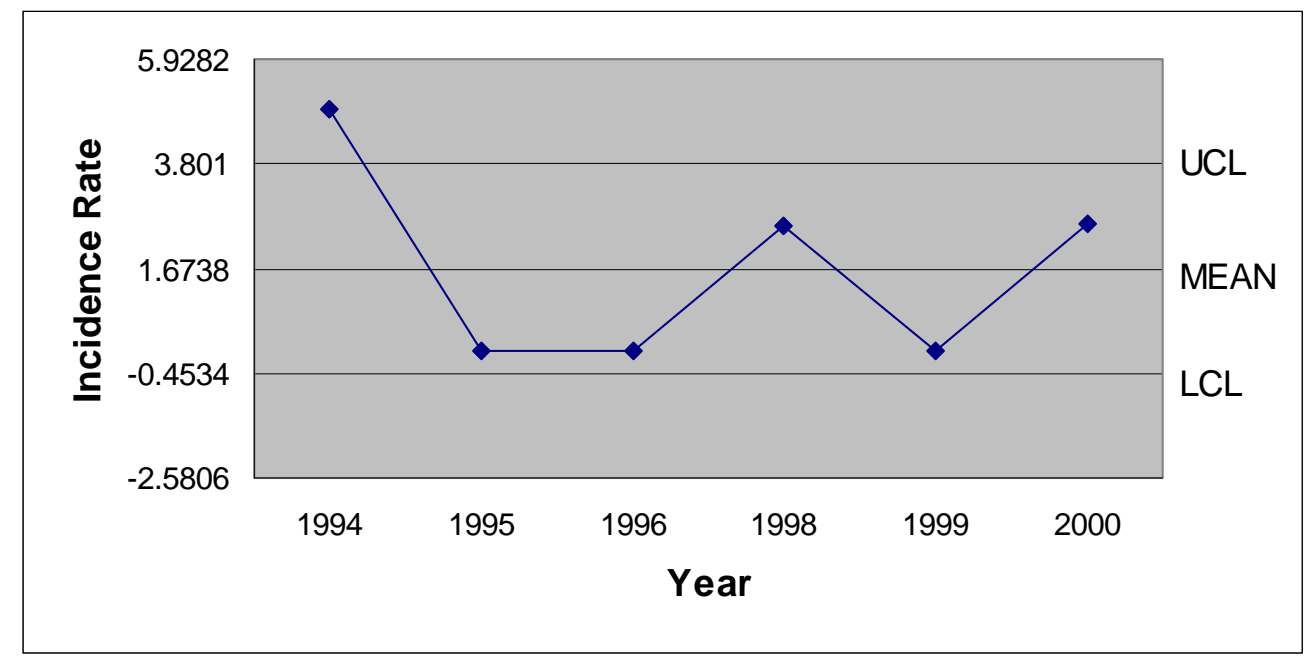

Note: No operations in June 1997

Figure 176. June 1994-2000 Lost Work Day Incidence Rates - Finishing Plant \#3 
The highest July incidence rate, 3.405, for Finishing Plant \#3 was recorded in 1994. The only other nonzero incidence rate recorded for the month of July was between the mean and the UCL in 1998 (See Figure 177).

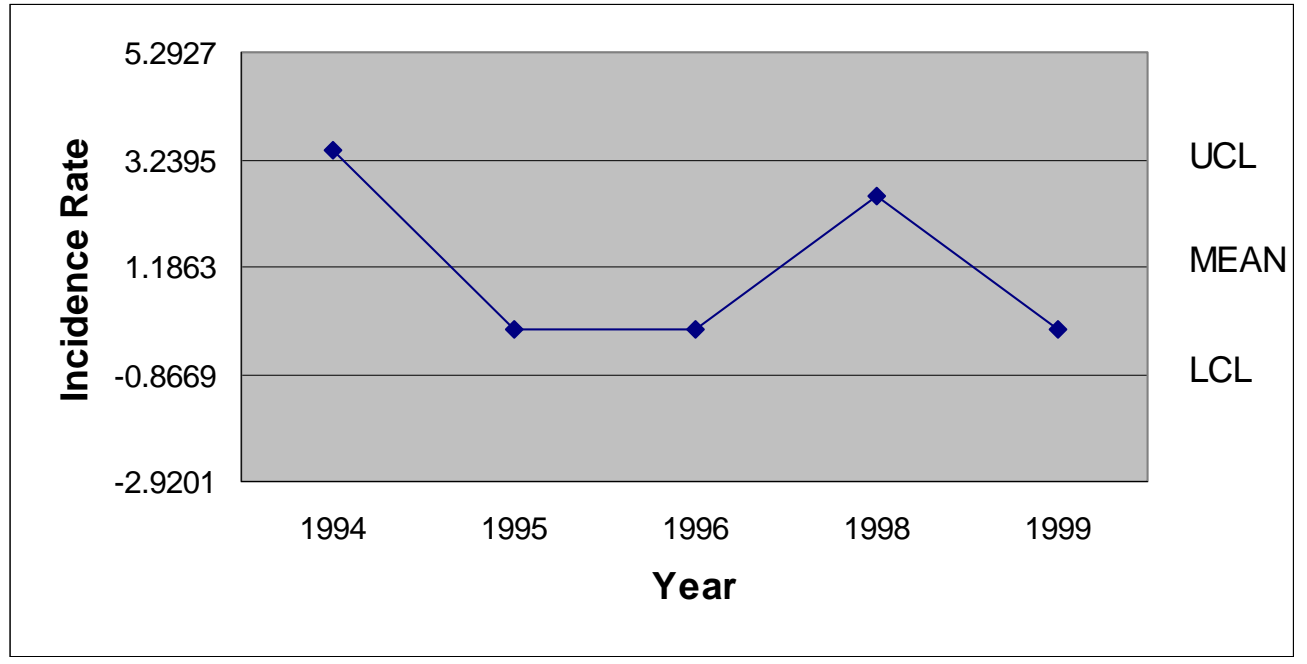

Note: No operations in July 1997

Figure 177. July 1994-1999 Lost Work Day Incidence Rates - Finishing Plant \#3

The 1994 August incidence rate of 1.625 at Finishing Plant \#3 was just above the mean. The following three-year period recorded incidence rates of 0.000. In 1999, the incidence rate was above the UCL (See Figure 178).

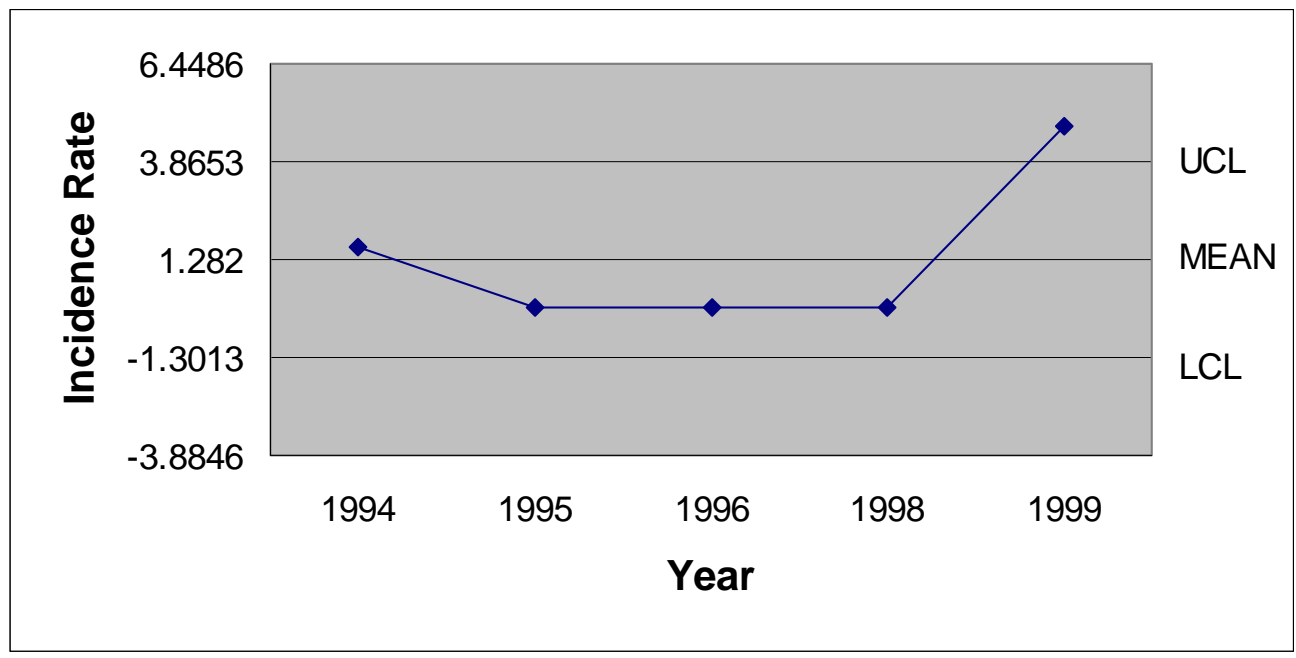

Note: No operations in August 1997

Figure 178. August 1994-1999 Lost Work Day Incidence Rates - Finishing Plant \#3 
During the research period, there were not any lost work day incidents in the month of September at Finishing Plant \#3. This created a situation where the UCL, mean, and LCL were all zero (See Figure 179).

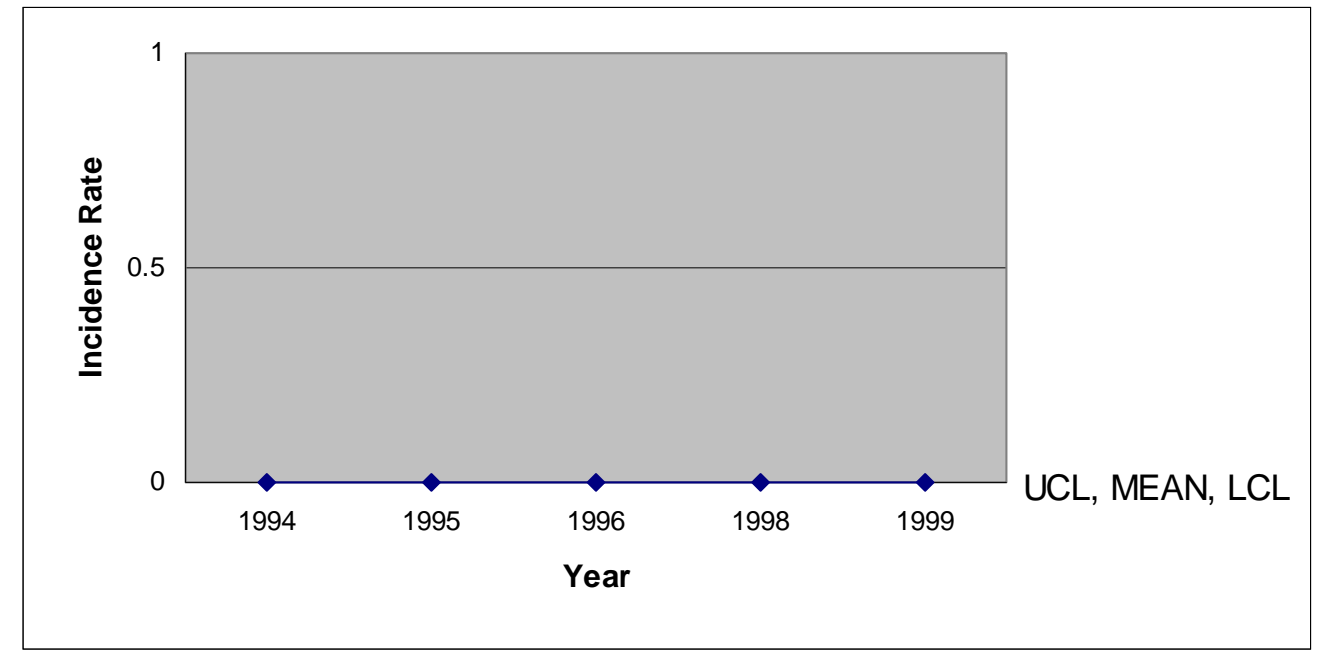

Note: No operations in September 1997

Figure 179. September 1994-1999 Lost Work Day Incidence Rates - Finishing Plant \#3

The October 1994 incidence rate of 5.050 at Finishing Plant \#3 was barely above the UCL. The remaining four months of October during the study period were within the established control limits. October 1995 and 1998 were close to the LCL, while October 1997 and 1999 were above the mean (See Figure 180).

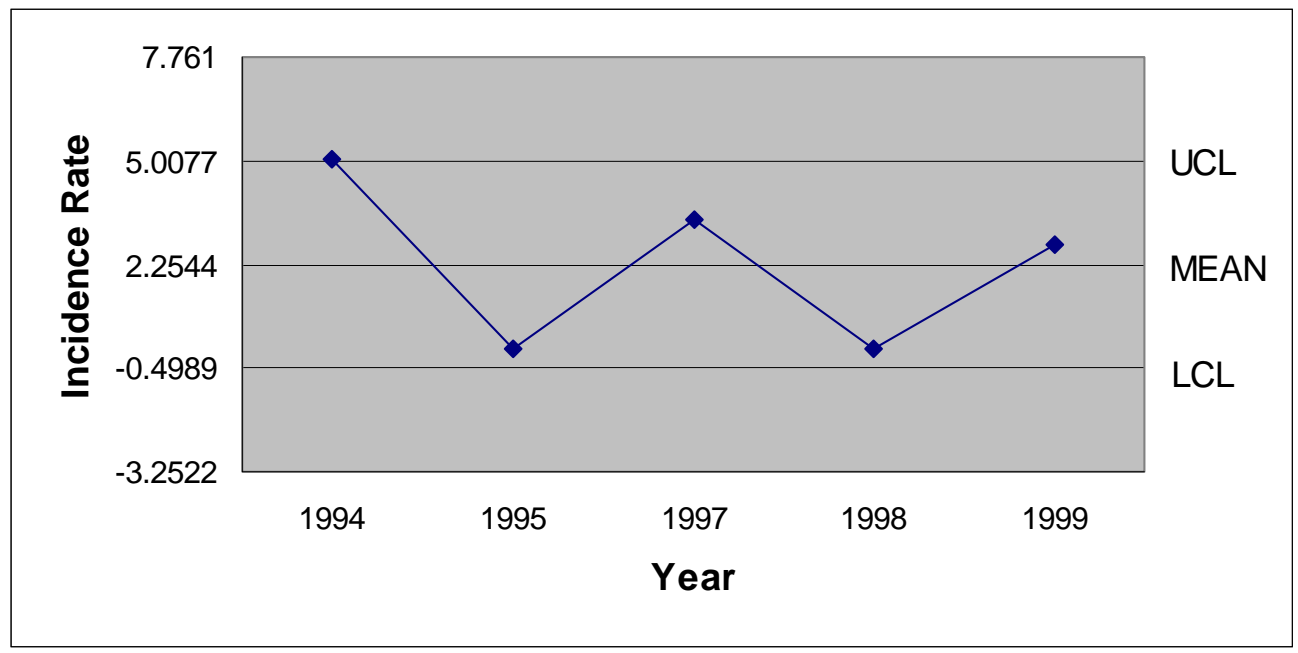

Note: No operations in October 1996.

Figure 180. October 1994-1999 Lost Work Day Incidence Rates - Finishing Plant \#3 
The first three years of this study experienced incidence rates for November at Finishing Plant \#3 between the mean and the UCL, with 1995 being the highest for the entire research period. These three years above the mean were followed by a year without any lost work day incidents in the month of November. In 1999 the incidence rate of 2.818 was just below the mean (See Figure 181).

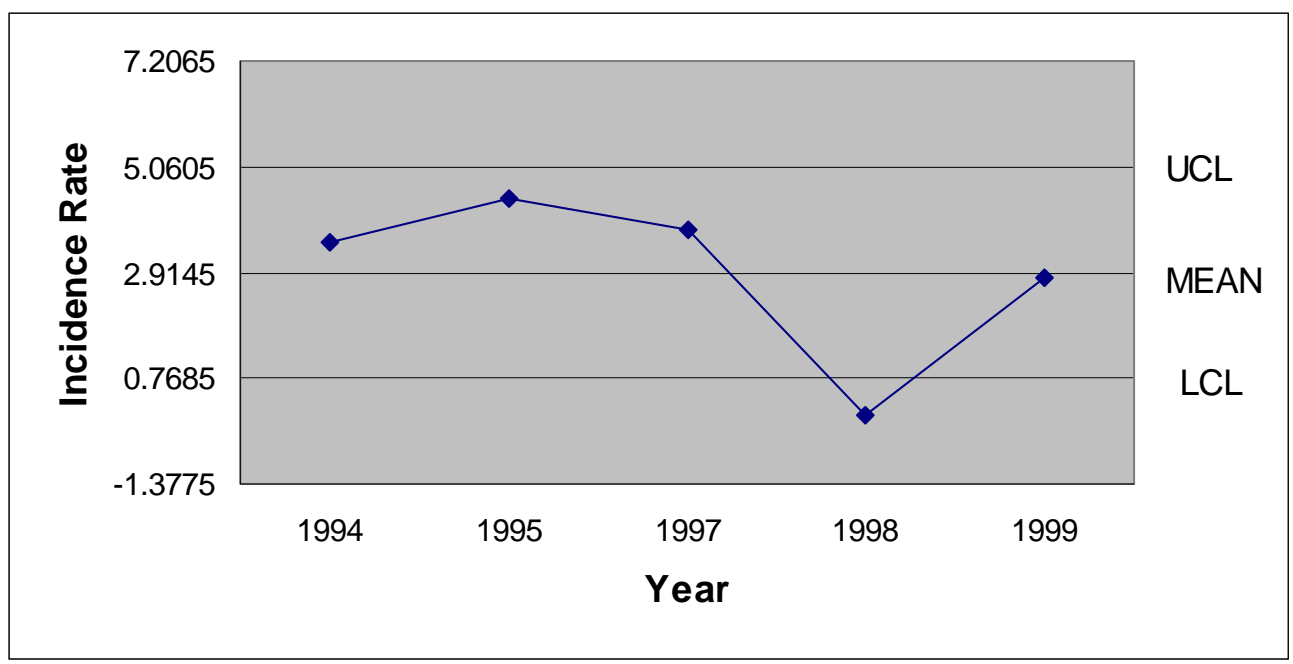

Note: No operations in November 1996

Figure 181. November 1994-1999 Lost Work Day Incidence Rates - Finishing Plant \#3

The December 1995 incidence rate of 5.168 at Finishing Plant \#3 was the only nonzero incidence rate recorded in the month of December during the study period (See Figure 182).

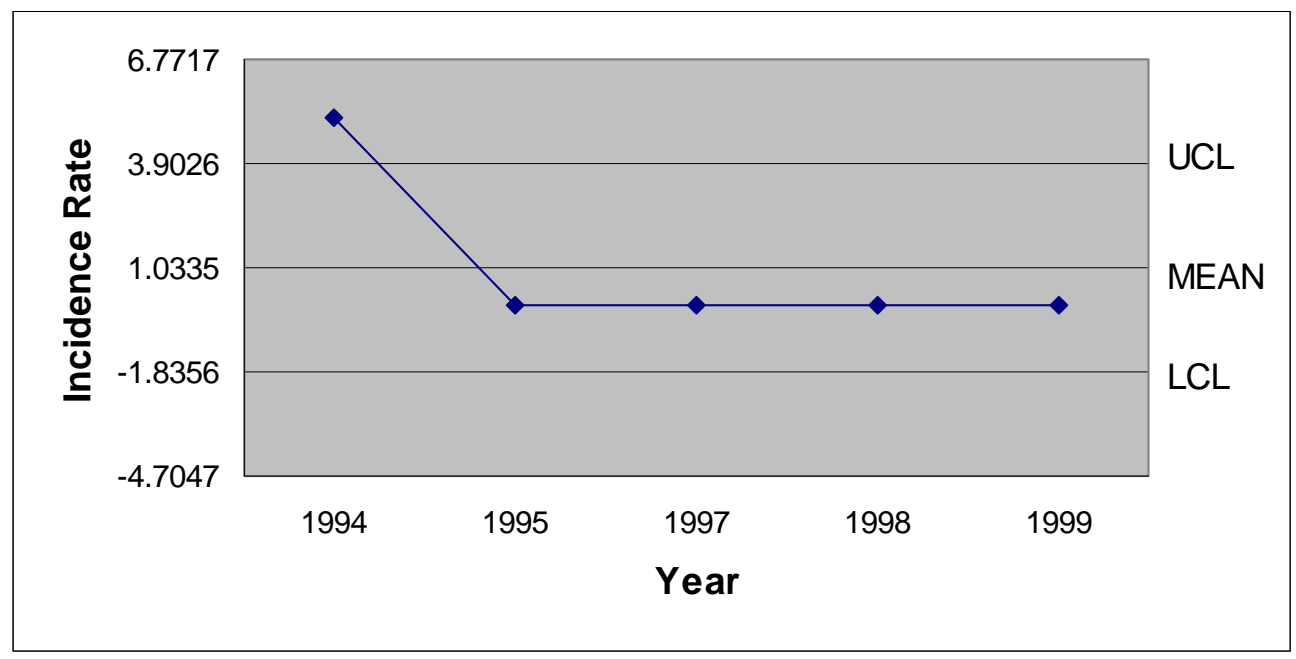

Note: No operations in December 1996

Figure 182. December 1994-1999 Lost Work Day Incidence Rates - Finishing Plant \#3 
Table 32 presents the monthly incidence rates at Finishing Plant \#3 for each year of the study period, as well as the UCL, mean, LCL, and standard deviation. Nineteen ninety six and 1997 are partial years because of the work stoppage and only the first six months of 2000 were included in the research.

Table 32

$\underline{\text { Summary of Monthly Lost Work Day Incidence Rates Data - Finishing Plant \#3 }}$

\begin{tabular}{|l|l|l|l|l|}
\hline & $1^{\text {st }}$ Quarter & $2^{\text {nd }}$ Quarter & $3^{\text {rd }}$ Quarter & $4^{\text {th }}$ Quarter \\
\hline 1994 & 1.764 & 3.939 & 1.684 & 4.600 \\
\hline 1995 & 1.714 & 0.000 & 0.000 & 1.398 \\
\hline 1996 & 0.000 & 0.000 & 0.000 & N/A \\
\hline 1997 & N/A & N/A & N/A & 2.420 \\
\hline 1998 & 1.028 & 1.686 & 0.891 & 0.000 \\
\hline 1999 & 3.489 & 0.837 & 1.644 & 1.842 \\
\hline 2000 & 1.707 & 1.757 & N/A & N/A \\
\hline UCL & 2.814 & 2.919 & 1.878 & 4.139 \\
\hline MEAN & 1.617 & 1.370 & 0.844 & 2.052 \\
\hline LCL & 0.420 & -0.179 & -0.190 & -0.035 \\
\hline SD & 0.466 & 0.602 & 0.372 & 0.752 \\
\hline
\end{tabular}

$\underline{\text { Seasonal Analysis of Lost Work Day Data - Finishing Plant \#3 }}$

The seasonal index calculation for Finishing Plant \#3 was used to generate the monthly seasonal index figures that are presented in Figure 183. The highest seasonal index figure occurred in November. The November figure was $40 \%$ greater than any other month's seasonal index amount. The month of September, which did not experience a lost work day incident during this research period, recorded the lowest seasonal index. 


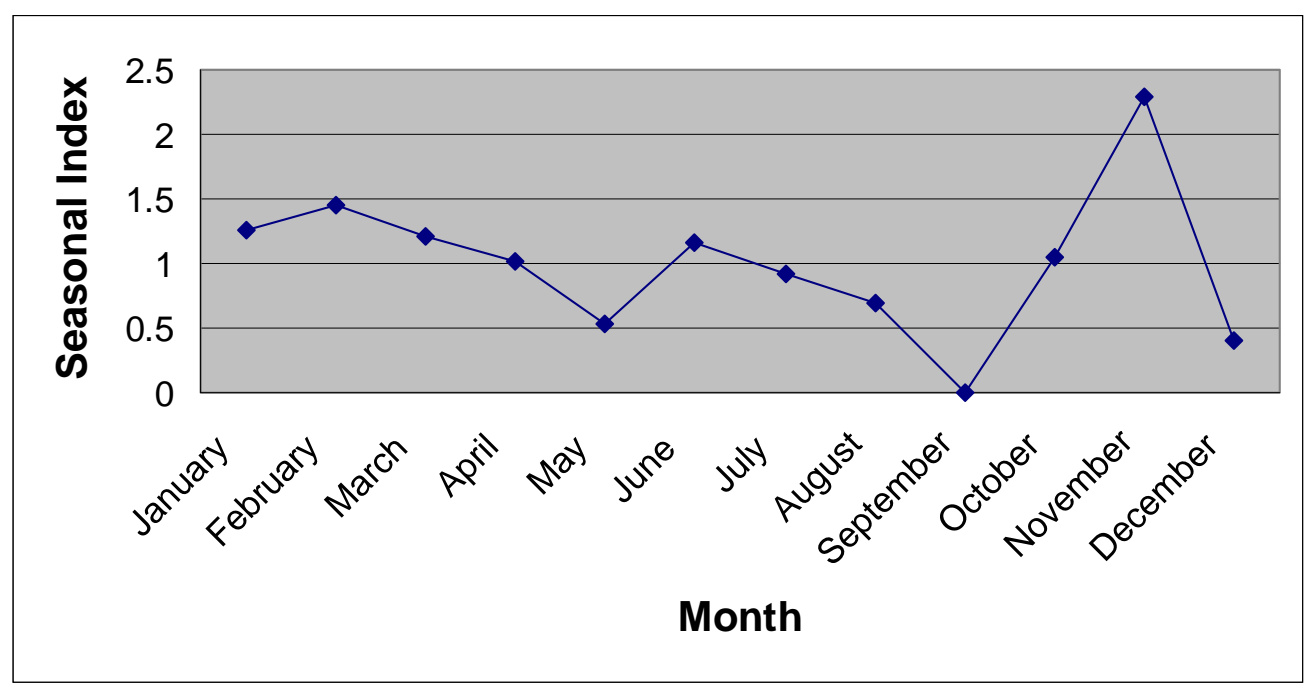

Figure 183. Monthly Seasonal Pattern of Lost Work Day Incidence Rates - Finishing Plant \#3

Testing the Statistical Relationship of Lost Work Day Data - Finishing Plant \#3 All 33 Months Prior to and Subsequent to the Work Stoppage

For the entire 33 months prior to the work stoppage and the 33 post work stoppage months at Finishing Plant \#3 the comparison t value was 0.327. Because this calculated amount is less than the 2.020 critical $t$ value, it can be stated that a statistically significant increase in incidence rates did not occur between the two periods.

First 24 Months and Last 24 Months of the Research Period

The same formula was applied to lost work day incidence rates for the first 24 months and the last 24 months of the period. These time periods excluded the nine months prior to and immediately following the work stoppage. The calculated amount, 0.6655 , was less than the 2.023 critical $t$ value. This indicates that a statistically significant decrease in incidence rates did not occur at Finishing Plant \#3 between the periods.

Nine Month Intervals Prior to and Subsequent to the Work Stoppage

Comparison of the lost work day incidence rates for the nine months preceding the work stoppage and the nine months following the work stoppage at Finishing Plant \#3 
was accomplished using The comparison formula. The result of this calculation, 8.872, was greater than the critical t value of 2.776 , for a .05 statistical significance level. Because the calculated amount exceeds the significance level, a statistically significant increase in incidence rates occurred between the two periods (See Table 33).

Table 33

Comparison of prior and post work stoppage periods - Finishing Plant \#3

\begin{tabular}{|l|l|l|l|l|}
\hline \multirow{2}{*}{ Time Period } & Finishing Plant \#3 Incidence Rates & \multirow{2}{*}{ Critical t Value } & \multirow{2}{*}{$\begin{array}{l}\text { Calculated } \\
\text { Comparison Value }\end{array}$} \\
\cline { 2 - 5 } & $\begin{array}{l}\text { Prior to } \\
\text { Work Stoppage }\end{array}$ & $\begin{array}{l}\text { Post } \\
\text { Work Stoppage }\end{array}$ & & $8.872 *$ \\
\hline 9 Months & 0.000 & 1.675 & 2.776 & 0.6655 \\
\hline 33 Months & 1.933 & 1.551 & 2.020 & 0.327 \\
\hline
\end{tabular}

* Indicates a statistically significant increase

** Indicates a statistically significant decrease

\section{$\underline{\text { Corporate Analysis }}$}

\section{Quarterly Analysis of Transitional Incidence Rates - Corporate}

The highest Corporate first quarter incidence rates for transitional injuries occurred in 1998. The lowest rate, almost 70\% lower than the highest, occurred in the first quarter of 2000. The remaining incidence rates were within the control limits, however the first quarter 1995 incidence rate was almost equal to the UCL (See Figure 184). 


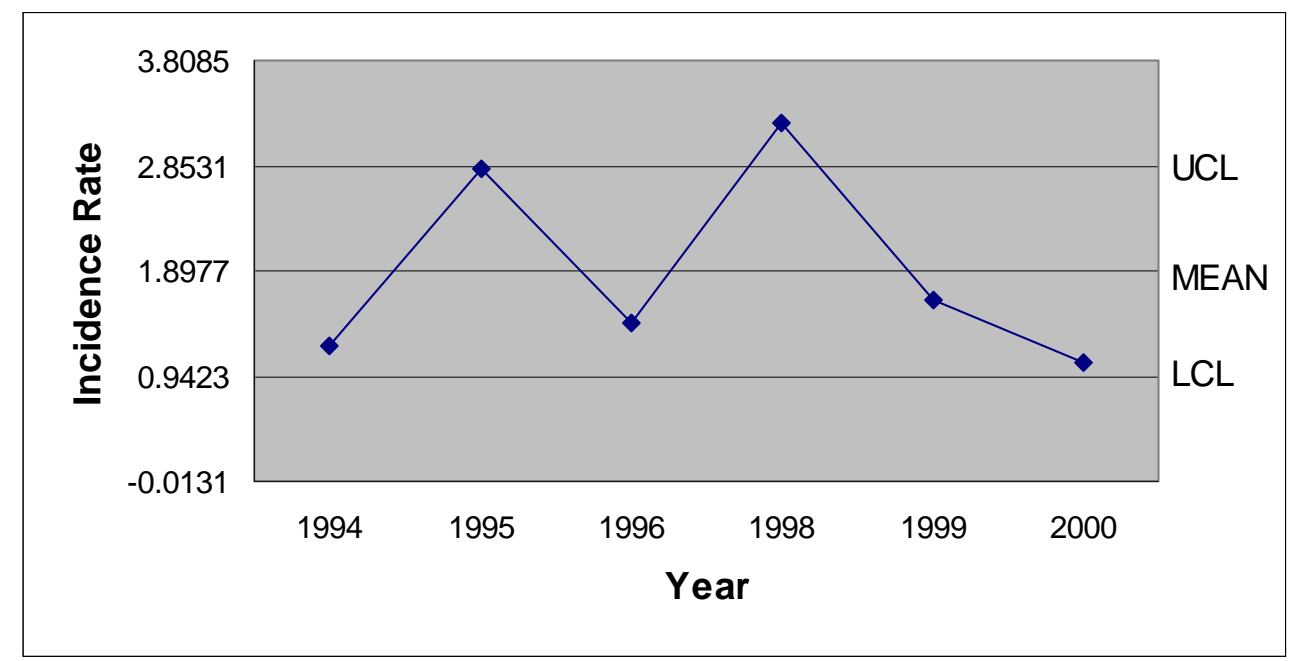

Note: No operations in first quarter 1997

Figure 184. First Quarter 1994-2000 Transitional Incidence Rates - Corporate

As illustrated in Figure 185, the 1994 Corporate transitional incidence rate for the second quarter of 0.676 was below the LCL. The 1995 and 1996 incidence rates were between the mean and the UCL. In 1998 the incidence rates increased to a level above the UCL. A nearly 75\% decrease in incidence rates magnitude occurred between 1998 and 1999.

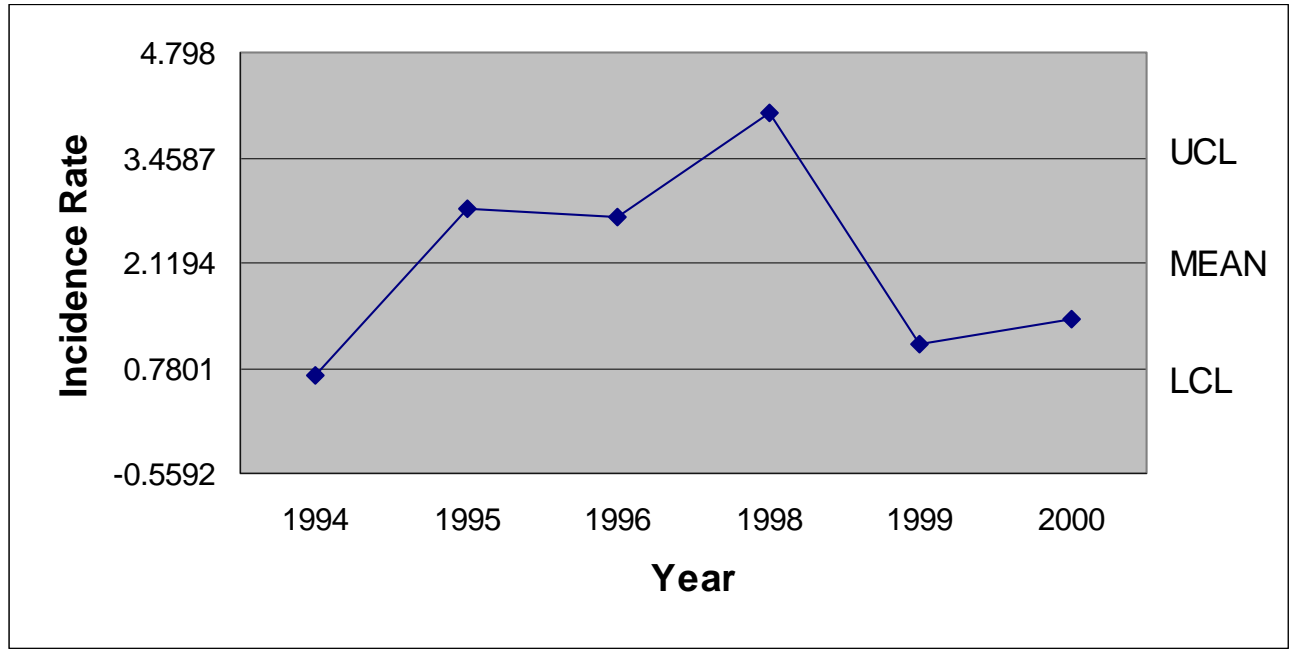

Note: No operations in second quarter 1997

Figure 185. Second Quarter 1994-2000 Transitional Incidence Rates - Corporate 
The lowest Corporate transitional incidence rates for the third quarter in 1994 was followed in 1995 by the second highest incidence rates, which was almost three times higher than the 1994 low. The next three years experienced incidence rates between the mean and the UCL. The 1998 incidence rate of 2.997 was the highest incidence rates recorded for the third quarter (See Figure 186).

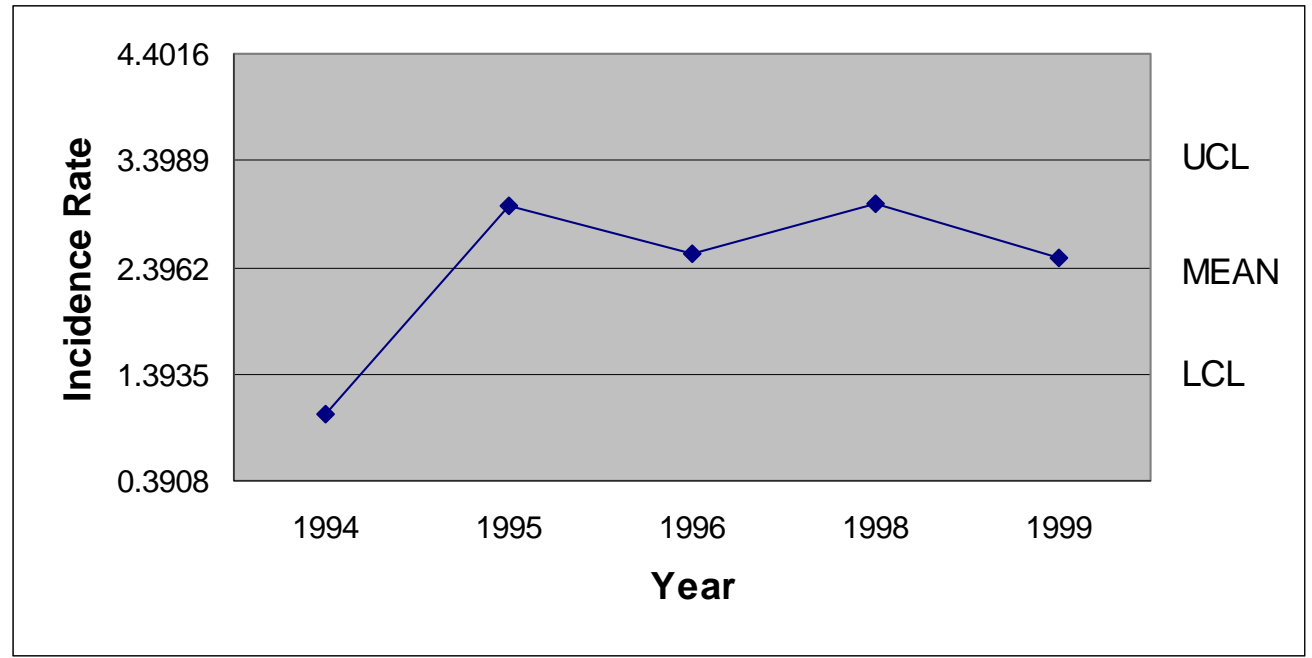

Note: No operations in third quarter 1997

Figure 186. Third Quarter 1994-1999 Transitional Incidence Rates - Corporate

Figure 187 illustrates the fourth quarter transitional incidence rates for the corporation. The 1994 incidence rate, which was below the mean, was followed in 1995 with the second highest incidence rates. The next fourth quarter period, 1997, recorded the lowest transitional incidence rates. The lowest incidence rate was followed in 1998 by the highest transitional incidence rates, which was almost 10 times greater in magnitude than the 1997 rate. 


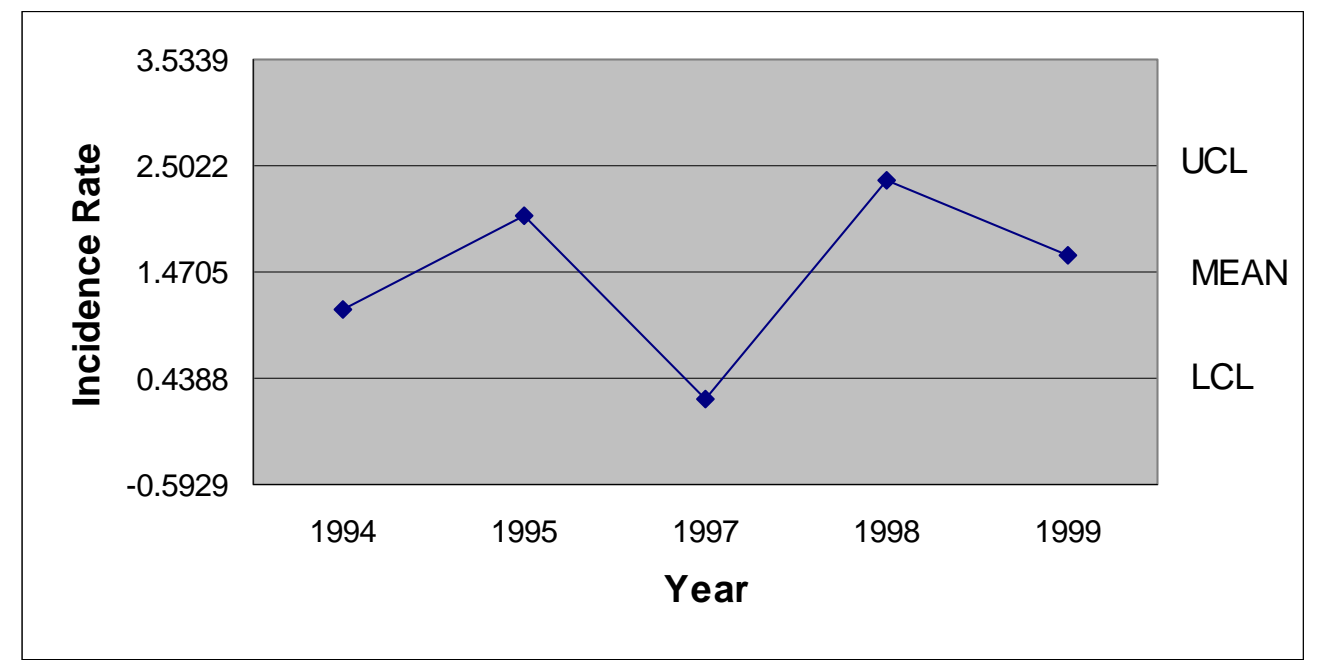

Note: No operations in fourth quarter 1996

Figure 187. Fourth Quarter 1994-1999 Transitional Incidence Rates - Corporate

Table 34 presents the Corporate quarterly incidence rates for each year of the study period, as well as the UCL, mean, LCL, and standard deviation. Nineteen ninetysix and 1997 are partial years because of the work stoppage and only the first six months of 2000 were included in the research.

Table 34

$\underline{\text { Summary of Quarterly Transitional Incidence Rates Data - Corporate }}$

\begin{tabular}{|l|l|l|l|l|}
\hline & $1^{\text {st }}$ Quarter & $2^{\text {nd }}$ Quarter & $3^{\text {rd }}$ Quarter & $4^{\text {th }}$ Quarter \\
\hline 1994 & 1.210 & 0.676 & 1.017 & 1.102 \\
\hline 1995 & 2.827 & 2.801 & 2.965 & 2.01 \\
\hline 1996 & 1.423 & 2.712 & 2.518 & N/A \\
\hline 1997 & N/A & N/A & N/A & 0.243 \\
\hline 1998 & 3.240 & 4.034 & 2.997 & 2.365 \\
\hline 1999 & 1.630 & 1.082 & 2.484 & 1.631 \\
\hline 2000 & 1.057 & 1.411 & N/A & N/A \\
\hline UCL & 2.853 & 3.459 & 3.399 & 2.502 \\
\hline MEAN & 1.898 & 2.120 & 2.396 & 1.471 \\
\hline LCL & 0.942 & 0.780 & 1.393 & 0.439 \\
\hline SD & 0.372 & 0.521 & 0.361 & 0.372 \\
\hline
\end{tabular}




\section{$\underline{\text { Seasonal Analysis of Transitional Data - Corporate }}$}

The results of the Corporate quarterly seasonal index calculations are presented in Figure 188. The third quarter seasonal index was the highest for transitional injuries. The highest seasonal index was almost 20\% greater in magnitude than the lowest seasonal index, recorded in the fourth quarter.

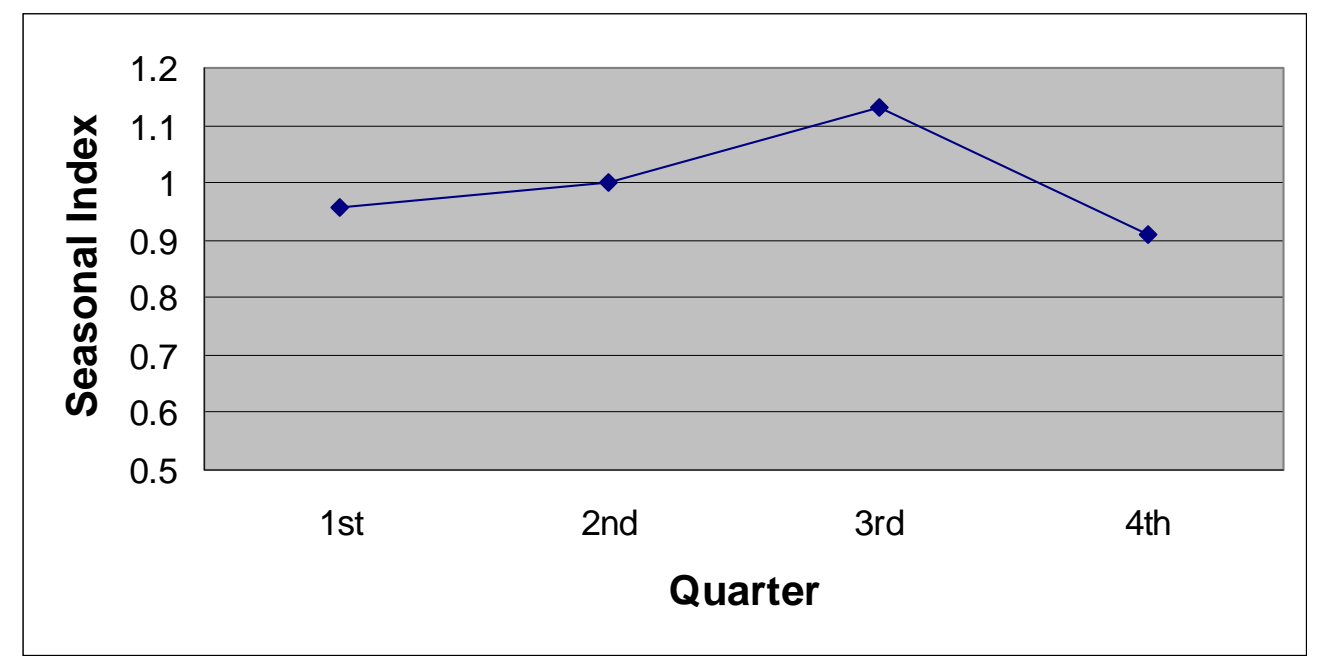

Figure 188. Quarterly Seasonal Index for Lost Work Day Incidence Rates - Corporate

\section{Monthly Analysis of Transitional Data - Corporate}

As illustrated in Figure 189, the 1.050 incidence rates recorded in 1996 was the lowest Corporate January transitional incidence rates during the study period. The 1996 low was followed in 1998 with a rate more than two and one half times greater in magnitude. The last two periods gravitated towards the mean. 


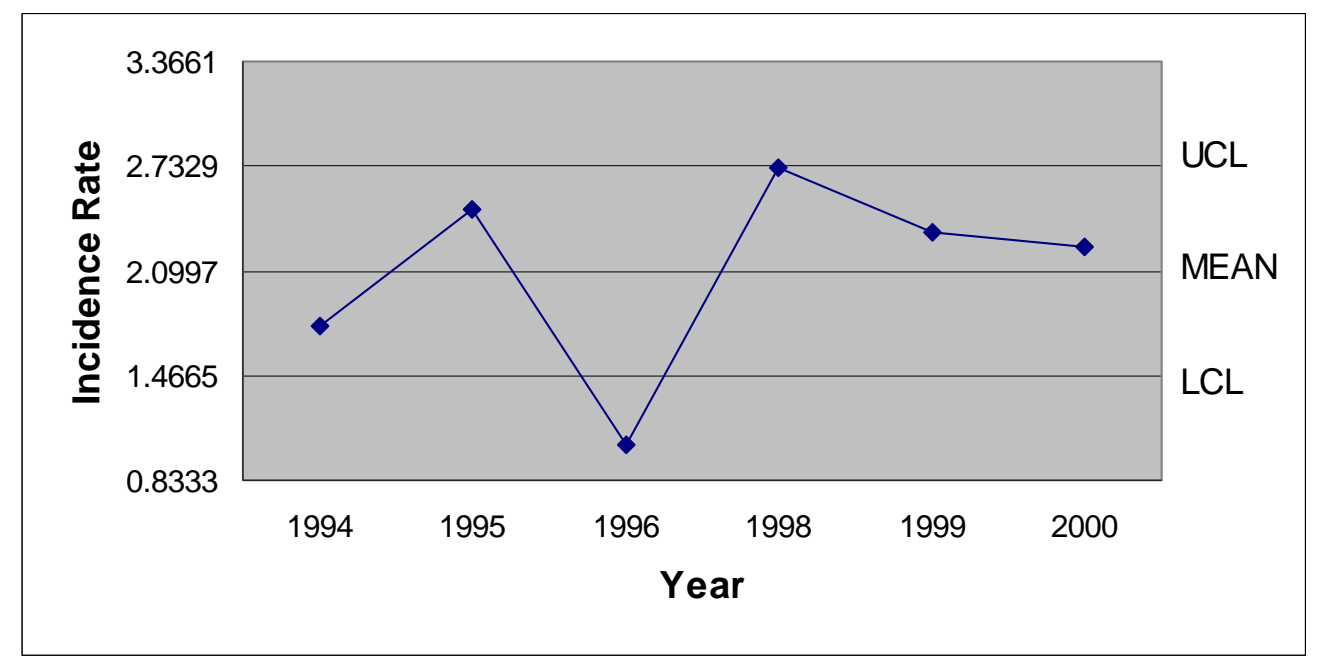

Note: No operations in January 1997

Figure 189. January 1994-2000 Transitional Incidence Rates - Corporate

Every February Corporate transitional incidence rate was above the LCL.

However, the 1994 and 2000 incidence rates were close to the LCL. The February 1998 incidence rate was the highest recorded for the month. The high was followed by a sharp decline to the 1999 level below the mean and then another decline in 2000 to just above the LCL (See Figure 190).

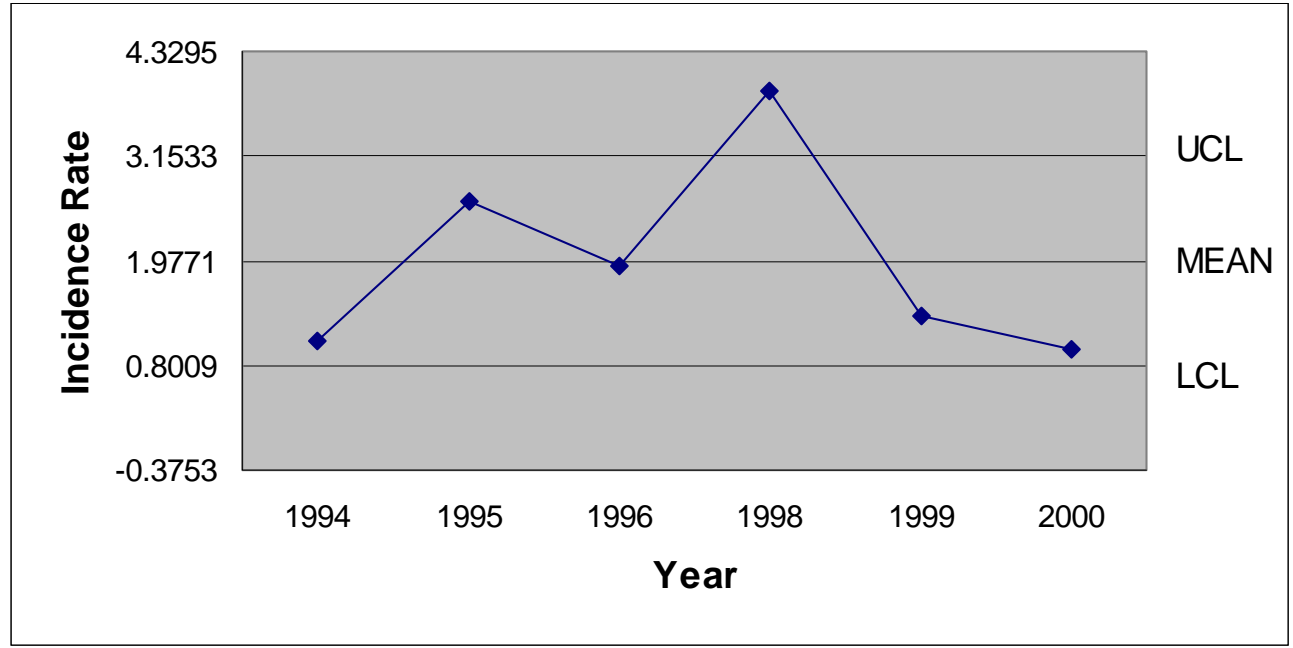

Note: No operations in February 1997

Figure 190. February 1994-2000 Transitional Incidence Rates - Corporate 
The 0.770 Corporate transitional incidence rate recorded in 1994 was followed in 1995 with the highest March incidence rates for the entire study period. In 1996 the incidence rates decreased to below the mean and rose above the UCL again in 1998. The 1999 incidence rate was between the mean and the LCL and the 2000 incidence rate was 0.00 (See Figure 191).

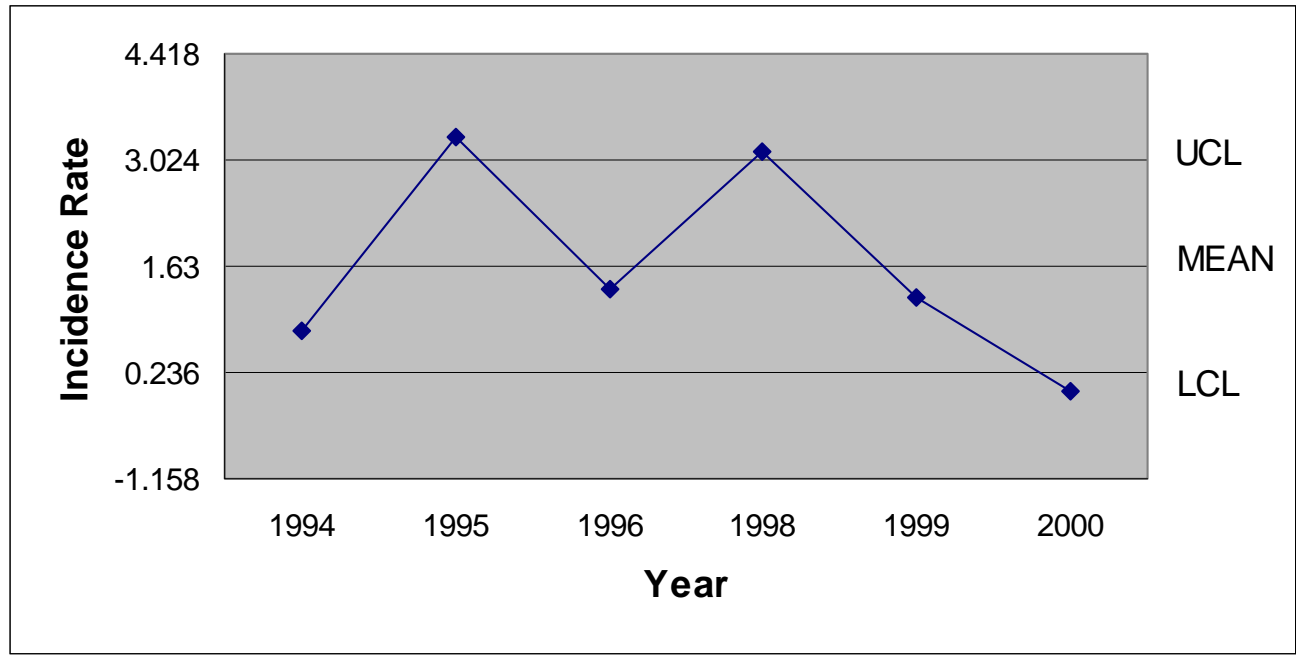

Note: No operations in March 1997

Figure 191. March 1994-2000 Transitional Incidence Rates - Corporate

As illustrated in Figure 192, The 0.259 Corporate transitional incidence rate recorded in April 1994 was the lowest April rate for the research period. The highest April incidence rates, 5.181, was recorded in 1998. The high was almost 18 times greater than the low. In 1999 and 2000 the incidence rate was between the mean and the LCL. 


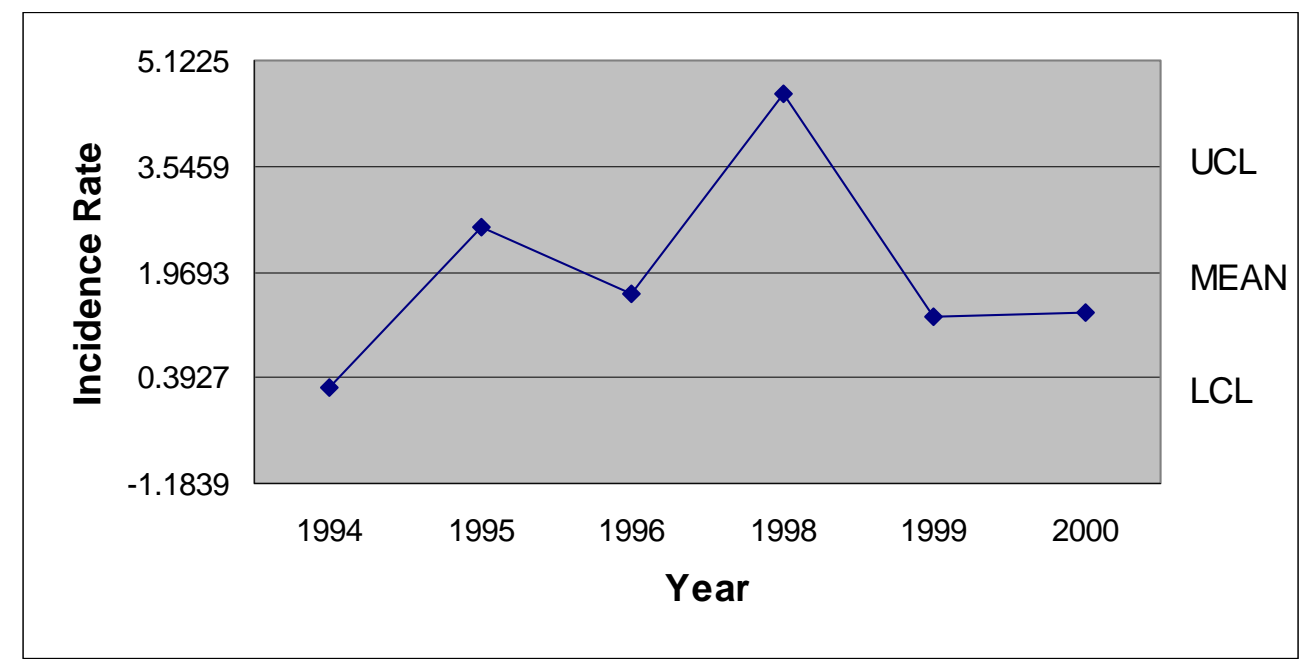

Note: No operations in April 1997

Figure 192. April 1994-2000 Transitional Incidence Rates - Corporate

During the study period, May 1994 was the lowest Corporate transitional incidence rate on record for the month. The incidence rate was close to the mean for the next two years, and in 1998 the incidence rate was above the UCL. In 1999 the incidence rate was nearly $75 \%$ lower than the high recorded the previous year (See Figure 193).

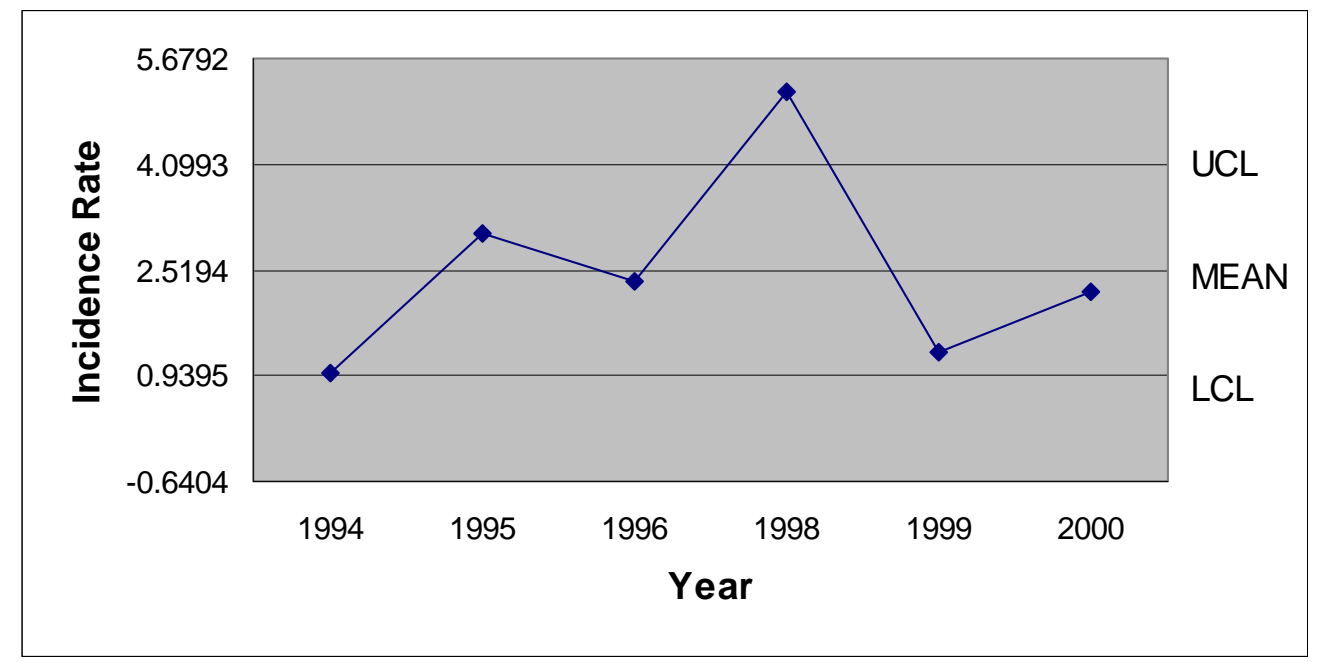

Note: No operations in May 1997

Figure 193. May 1994-2000 Transitional Incidence Rates - Corporate 
The peak in 1996 marked a period of increasing Corporate transitional incidence rates for the month of June. An almost identical two-year period of decreases occurred between 1996 and 1999. In 1999, the transitional incidence rate was the lowest for the research period, however the June 2000 incidence rate was only slightly higher (See Figure 194).

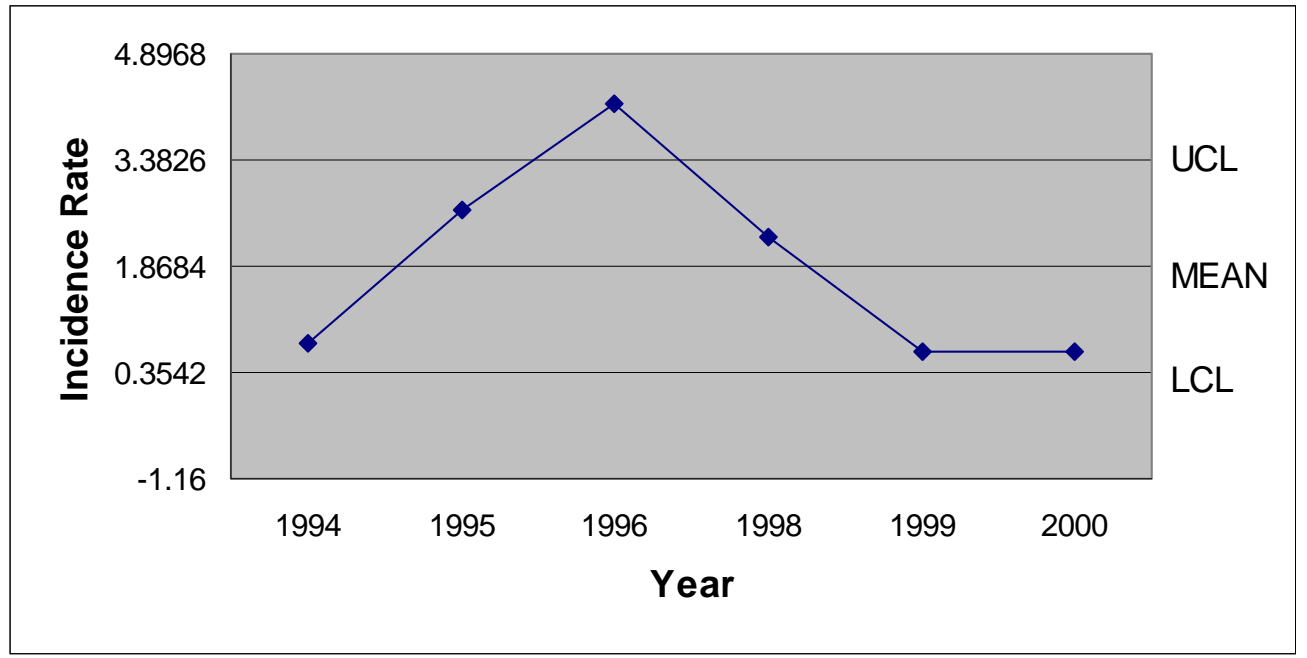

Note: No operations in June 1997

Figure 194. June 1994-2000 Transitional Incidence Rates - Corporate

As illustrated in Figure 195, the 0.775 Corporate incidence rate recorded in July 1994 was the lowest transitional incidence rates for the month. July of the next year experienced the highest incidence rates, 2.998. In 1996 the incidence rates dipped below the mean and the next two years had incidence rates between the mean and the UCL. 


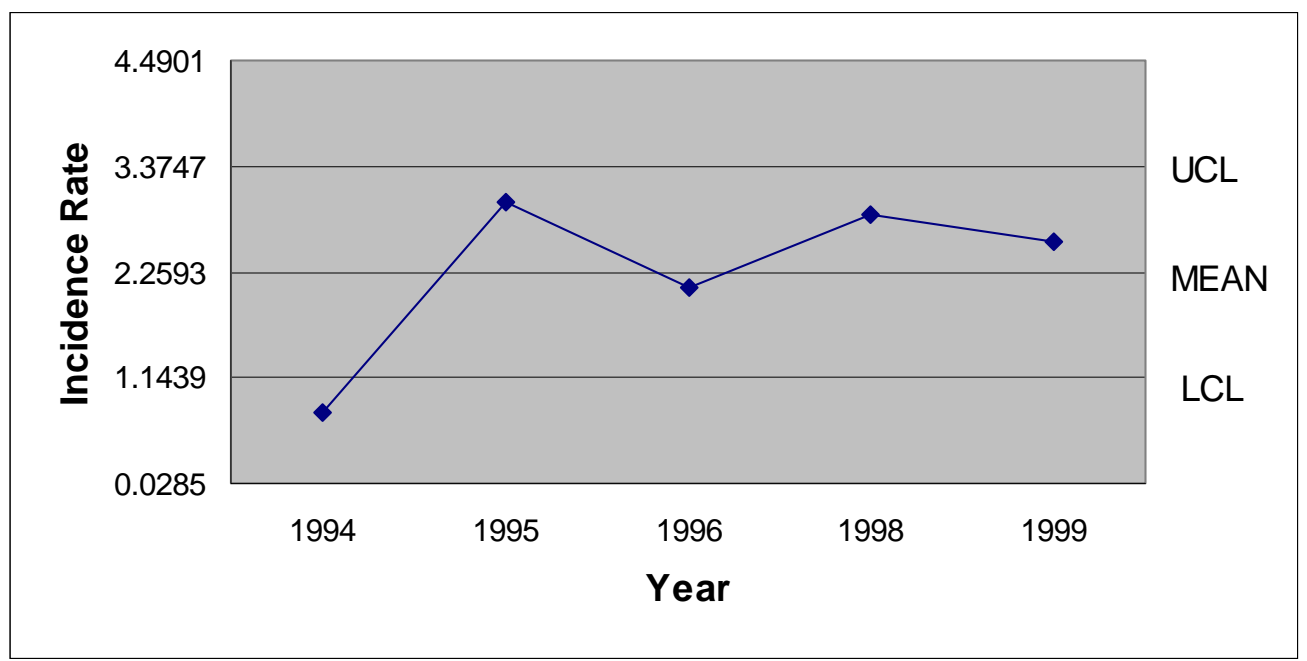

Note: No operations in July 1997

Figure 195. July 1994-1999 Transitional Incidence Rates - Corporate

The lowest August incidence rate occurred in 1994 and was followed the next year by the highest August transitional incidence rates. The following three periods were clustered around the mean (See Figure 196).

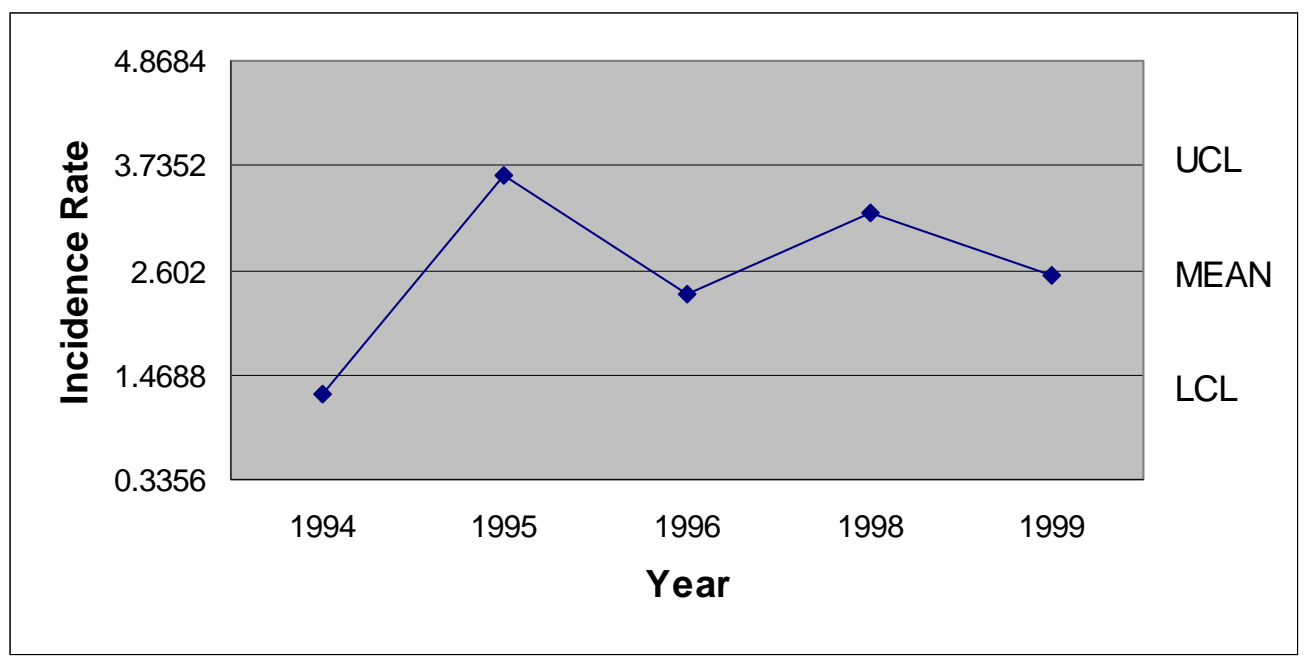

Note: No operations in August 1997

Figure 196. August 1994-1999 Transitional Incidence Rates - Corporate 
The September Corporate transitional incidence rate was below the mean during1994 and 1995. In 1996 the incidence rates approached the UCL, but gradually decreased to a level barely below the mean over the next two years (See Figure 197).

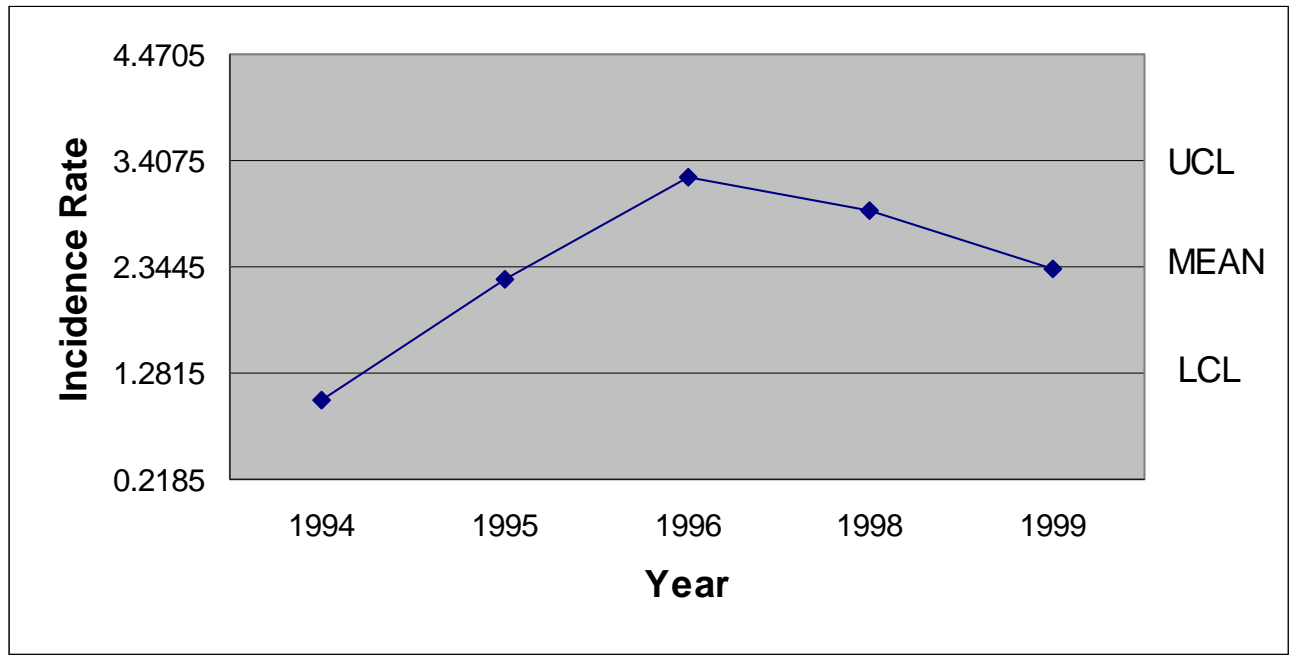

Note: No operations in September 1997

Figure 197. September 1994-1999 Transitional Incidence Rates - Corporate

The highest October Corporate transitional incidence rates, which occurred in 1998, was preceded the following year by an October that did not experience any transitional incidents (See Figure 198).

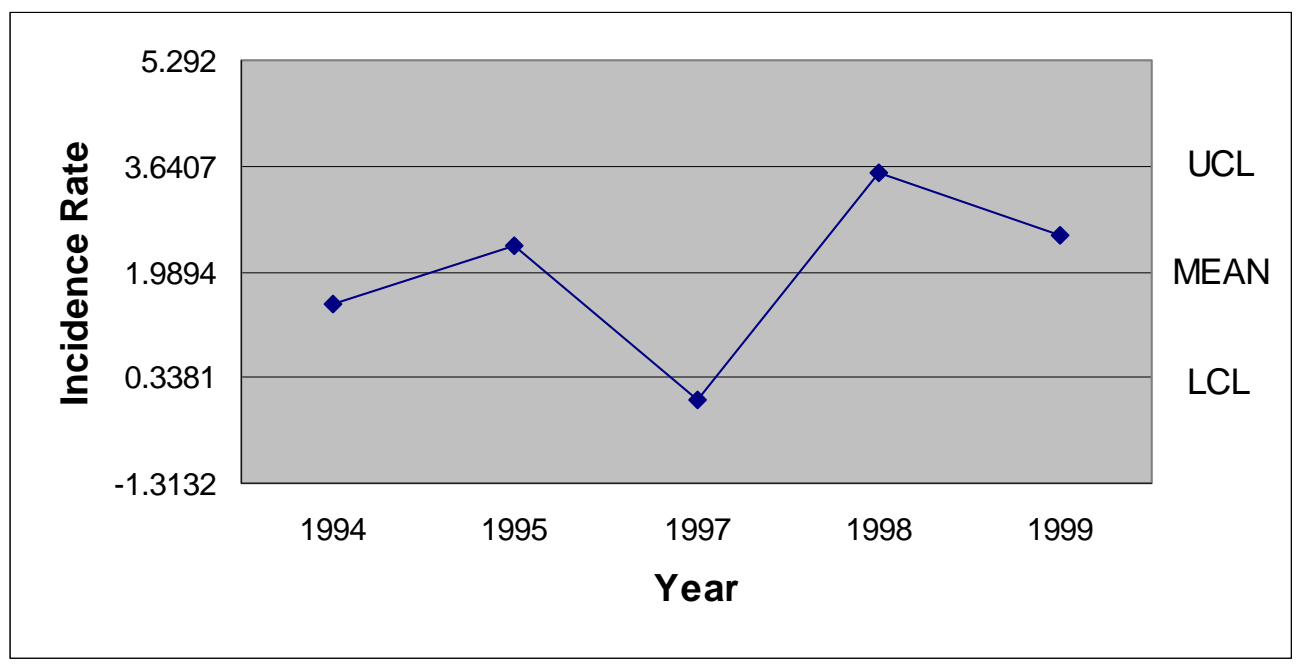

Note: No operations in October 1996

Figure 198. October 1994-1999 Transitional Incidence Rates - Corporate 
As illustrated in Figure 199, the highest November Corporate transitional incidence rate occurred in 1995 and was followed the next year by a month of November without any transitional incidents. The remaining three periods were within the control limits and were clustered around the mean.

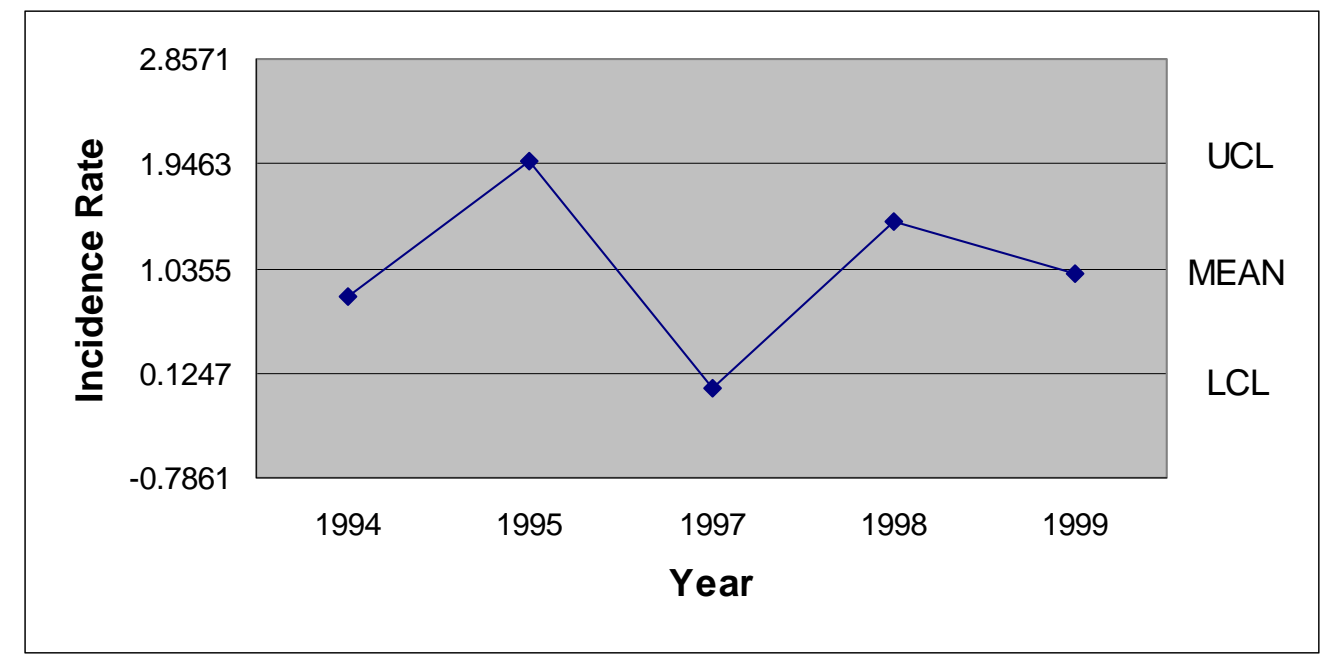

Note: No operations in November 1996

Figure 199. November 1994-1999 Transitional Incidence Rates - Corporate

The December 1995 transitional incidence rate was more than 60\% higher than the 1994 rate. Figure 200 illustrates how this increase was followed by a decrease to the LCL in 1997. The low recorded in 1997 was followed the next year with a high that was almost three times greater in magnitude. 


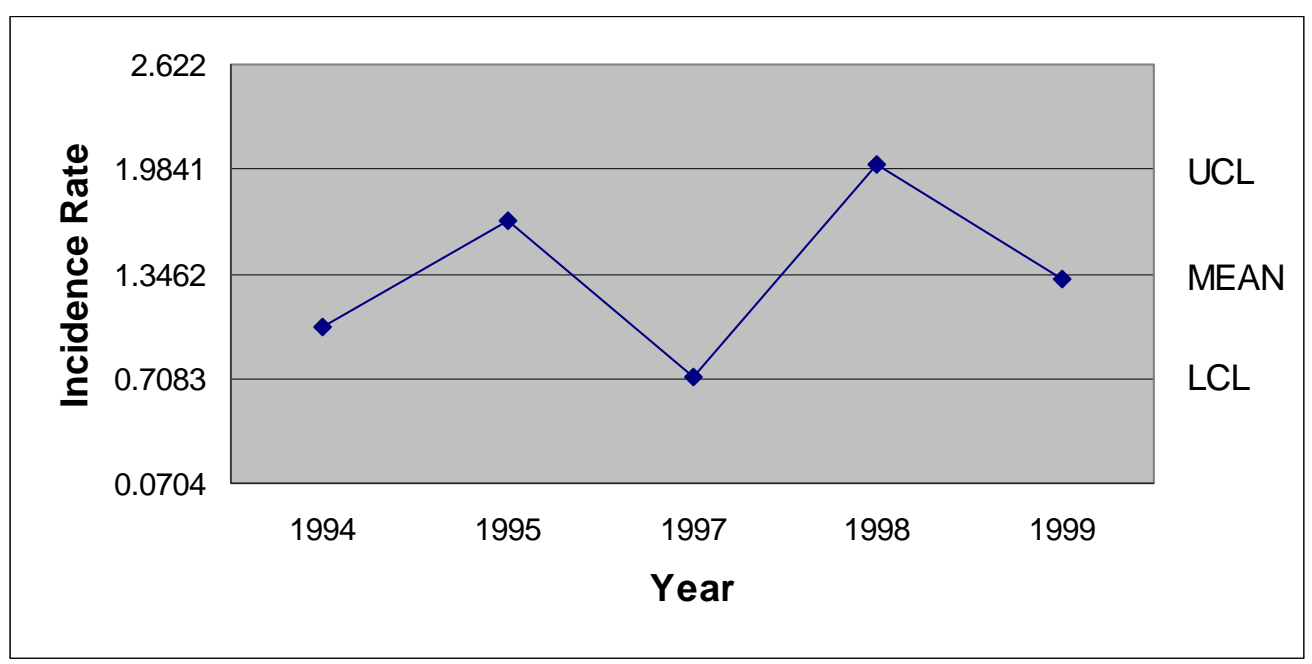

Note: No operations in December 1996

Figure 200. December 1994-1999 Transitional Incidence Rates - Corporate

Table 35 presents the monthly Corporate transitional incidence rates for each year of the study period, as well as the UCL, mean, LCL, and standard deviation. Because of the work stoppage, 1996 and 1997 were partial years and only the first six months of 2000 were included in the research.

Table 35

$\underline{\text { Summary of Monthly Transitional Incidence Rates Data - Corporate }}$

\begin{tabular}{|l|l|l|l|l|l|l|l|l|l|l|l|l|}
\hline & Jan. & Feb. & Mar. & Apr. & May & June & July & Aug. & Sept. & Oct. & Nov. & Dec. \\
\hline 1994 & 1.771 & 1.076 & 0.770 & 0.259 & 0.993 & 0.763 & 0.775 & 1.257 & 1.013 & 1.477 & 0.786 & 1.022 \\
\hline 1995 & 2.474 & 2.647 & 3.326 & 2.636 & 3.073 & 2.683 & 2.998 & 3.636 & 2.215 & 2.387 & 1.961 & 1.669 \\
\hline 1996 & 1.050 & 1.914 & 1.324 & 1.638 & 2.362 & 4.180 & 2.097 & 2.349 & 3.250 & N/A & N/A & N/A \\
\hline 1997 & N/A & N/A & N/A & N/A & N/A & N/A & N/A & N/A & N/A & 0.000 & 0.000 & 0.713 \\
\hline 1998 & 2.727 & 3.883 & 3.141 & 4.614 & 5.181 & 2.296 & 2.858 & 3.224 & 2.912 & 3.533 & 1.437 & 2.013 \\
\hline 1999 & 2.333 & 1.368 & 1.219 & 1.310 & 1.302 & 0.643 & 2.569 & 2.543 & 2.333 & 2.550 & 0.994 & 1.314 \\
\hline 2000 & 2.423 & 0.973 & 0.000 & 1.360 & 2.205 & 0.646 & N/A & N/A & N/A & N/A & N/A & N/A \\
\hline UCL & 2.733 & 3.153 & 3.024 & 3.546 & 4.099 & 3.383 & 3.375 & 3.735 & 3.407 & 3.641 & 1.946 & 1.984 \\
\hline Mean & 2.100 & 1.977 & 1.630 & 1.970 & 2.519 & 1.868 & 2.259 & 2.602 & 2.344 & 1.989 & 1.036 & 1.346 \\
\hline LCL & 1.466 & 0.801 & 0.236 & 0.393 & 0.939 & 0.354 & 1.144 & 1.469 & 1.282 & 0.338 & 0.125 & 0.708 \\
\hline SD & 0.246 & 0.457 & 0.542 & 0.613 & 0.614 & 0.589 & 0.402 & 0.408 & 0.383 & 0.595 & 0.328 & 0.230 \\
\hline
\end{tabular}




\section{$\underline{\text { Seasonal Analysis of Transitional Incidence Rates - Corporate }}$}

The seasonal index calculation was used to generate the Corporate monthly seasonal index figures that are presented in Figure 201. January, May, August, and December had almost identical seasonal index figures, with May as the highest. The lowest seasonal index was recorded in the month of November.

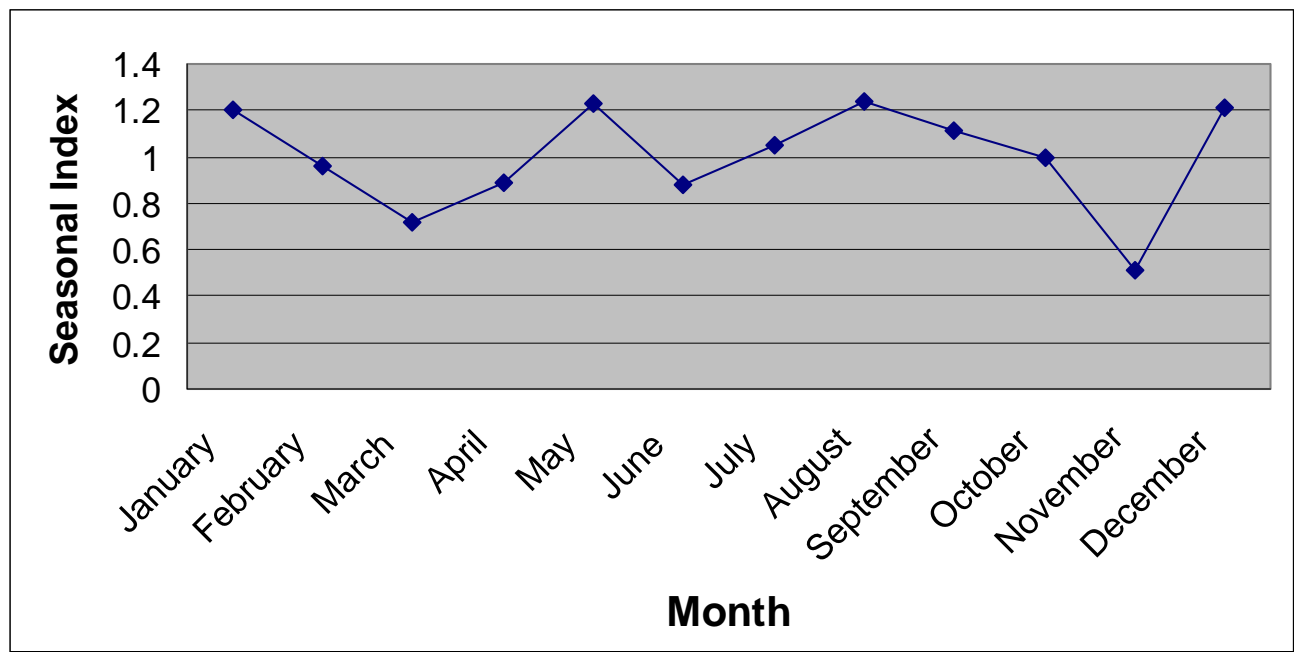

Figure 201. Monthly Seasonal Index Pattern of Transitional Incidence Rates - Corporate

Testing the Statistical Relationship of Transitional Incidence rates - Corporate

\section{All 33 Months Prior to and Subsequent to the Work Stoppage}

For the entire 33 months prior to the work stoppage and the 33 post work stoppage months the comparison $t$ value was 4.194. Because the calculated amount exceeded the 1.96 critical t value, a statistically significant decrease in incidence rates occurred between the two periods.

First 24 Months and Last 24 Months of the Research Period

The same formula was applied to the Corporate transitional incidence rates for the first 24 months and the last 24 months of the research period. These time periods excluded the nine months prior to and immediately following the work stoppage. Using the 1.96 critical $t$ value, the calculated amount of 0.636 , indicated that a statistically significant increase in incidence rates did not occur between the two periods. 


\section{$\underline{\text { Nine Month Intervals Prior to and Subsequent to the Work Stoppage }}$}

Comparison of the Corporate transitional incidence rates for the nine months preceding the work stoppage and the nine months immediately following the work stoppage was accomplished using The comparison formula. The result of this calculation, 0.919, was less than the 1.96 critical t value. Therefore it can be stated that at the .05 level of significance, there was not a statistically significant increase between the two periods. See the summary of all three periods presented in Table 36 .

Table 36

Comparison of prior and post work stoppage periods - Corporate

\begin{tabular}{|c|c|c|c|c|}
\hline \multirow[b]{2}{*}{ Time Period } & \multicolumn{2}{|c|}{ Corporate-wide Incidence Rates } & \multirow[b]{2}{*}{ Critical t Value } & \multirow[b]{2}{*}{$\begin{array}{l}\text { Calculated } \\
\text { Comparison Value }\end{array}$} \\
\hline & $\begin{array}{l}\text { Prior to } \\
\text { Work Stoppage }\end{array}$ & $\begin{array}{l}\text { Post } \\
\text { Work Stoppage }\end{array}$ & & \\
\hline 9 Months & 2.210 & 2.579 & 1.96 & 0.919 \\
\hline 24 Months & 1.816 & 1.829 & 1.96 & 0.635 \\
\hline 33 Months & 2.406 & 1.617 & 1.96 & $4.194 * *$ \\
\hline
\end{tabular}

* Indicates a statistically significant increase

** Indicates a statistically significant decrease

\section{Primary Plant Analysis}

Quarterly Analysis of Transitional Data - Primary Plant

The first quarter transitional incidence rates for the Primary Plant included four years between the LCL and the mean, one just below the UCL, and one above the UCL. The highest incidence rate was in 1998, a rate more than three times greater than the lowest first quarter rate, which was recorded in 2000 (See Figure 202). 


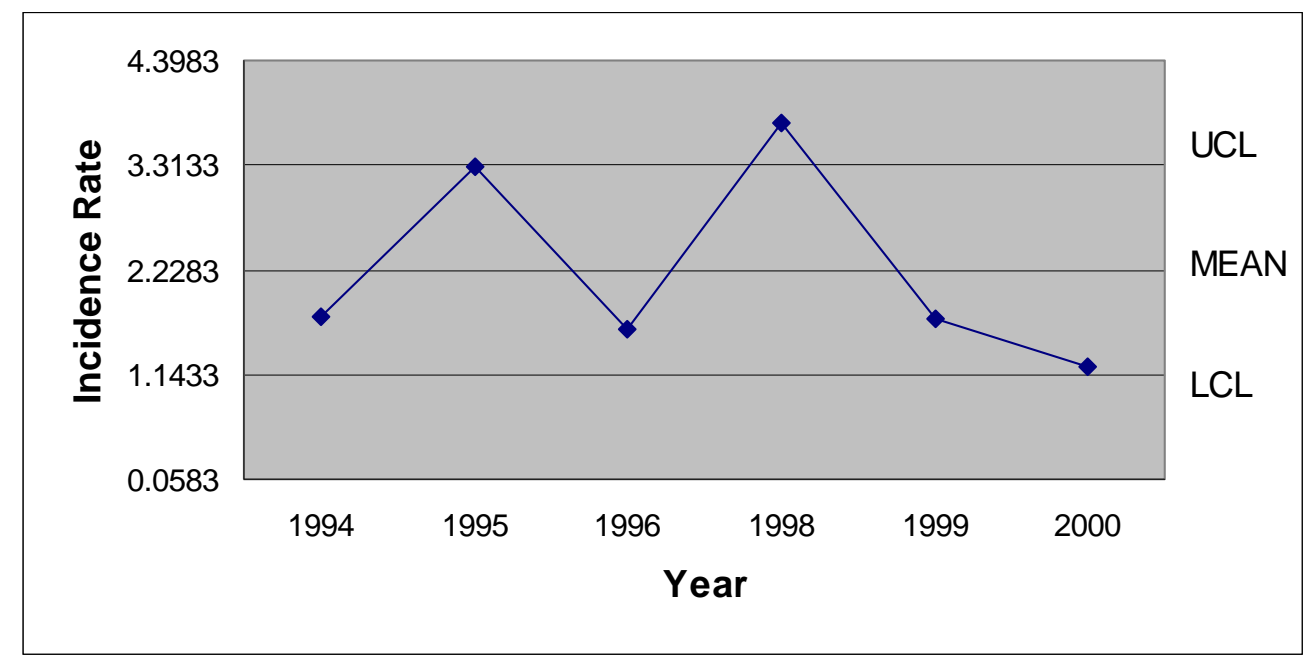

Note: No operations in first quarter 1997

Figure 202. First Quarter 1994-2000 Transitional Incidence Rates - Primary Plant

The lowest second quarter transitional incidence rate $s$ at the Primary Plant occurred in 1994. From the low of 0.917 , the incidence rate climbed to the high of 3.943 in 1998. The high was followed by a decrease of nearly $65 \%$ to the 1999 level. The incidence rate s for the first quarter of 2000 was almost identical to the 1999 rate (See Figure 203).

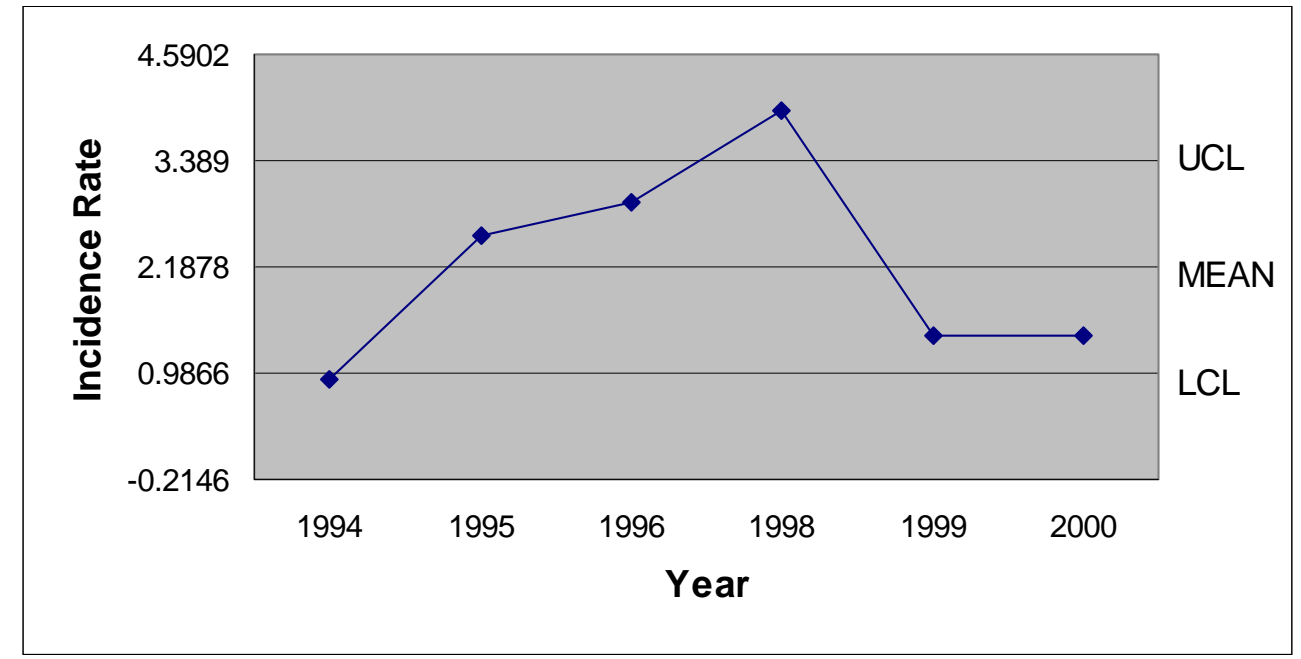

Note: No operations in second quarter 1997

Figure 203. Second Quarter 1994-2000 Transitional Incidence Rates - Primary Plant 
Third quarter 1994 was the only third quarter transitional incidence rate at the Primary Plant to appear below the LCL. The next two years were close to the mean. In 1998 the incidence rate of 3.512 was just below the UCL and in 1999 the third quarter incidence rate was between the mean and the UCL (See Figure 204).

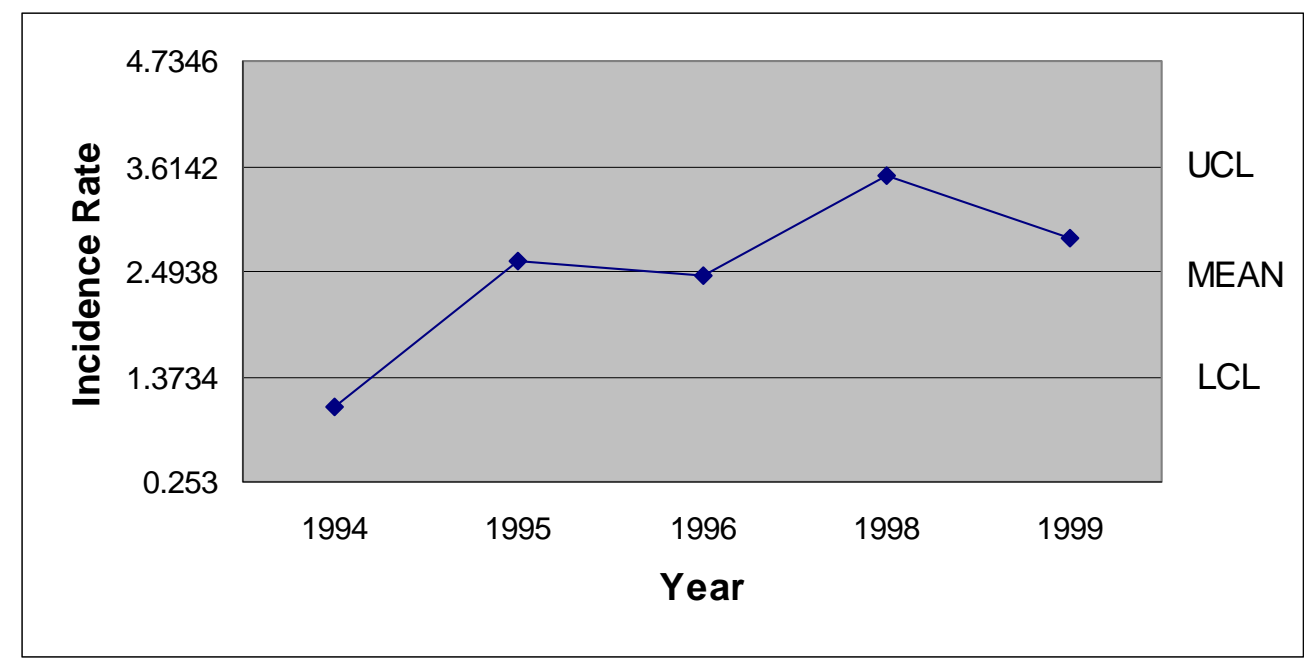

Note: No operations in third quarter 1997

Figure 204. Third Quarter 1994-1999 Transitional Incidence Rates - Primary Plant

The fourth quarter transitional incidence rates for the Primary Plant were variable in nature. The second highest fourth quarter incidence rate preceded the lowest rate, which occurred in 1997 and was followed in 1998 by the highest rate (See Figure 205). 


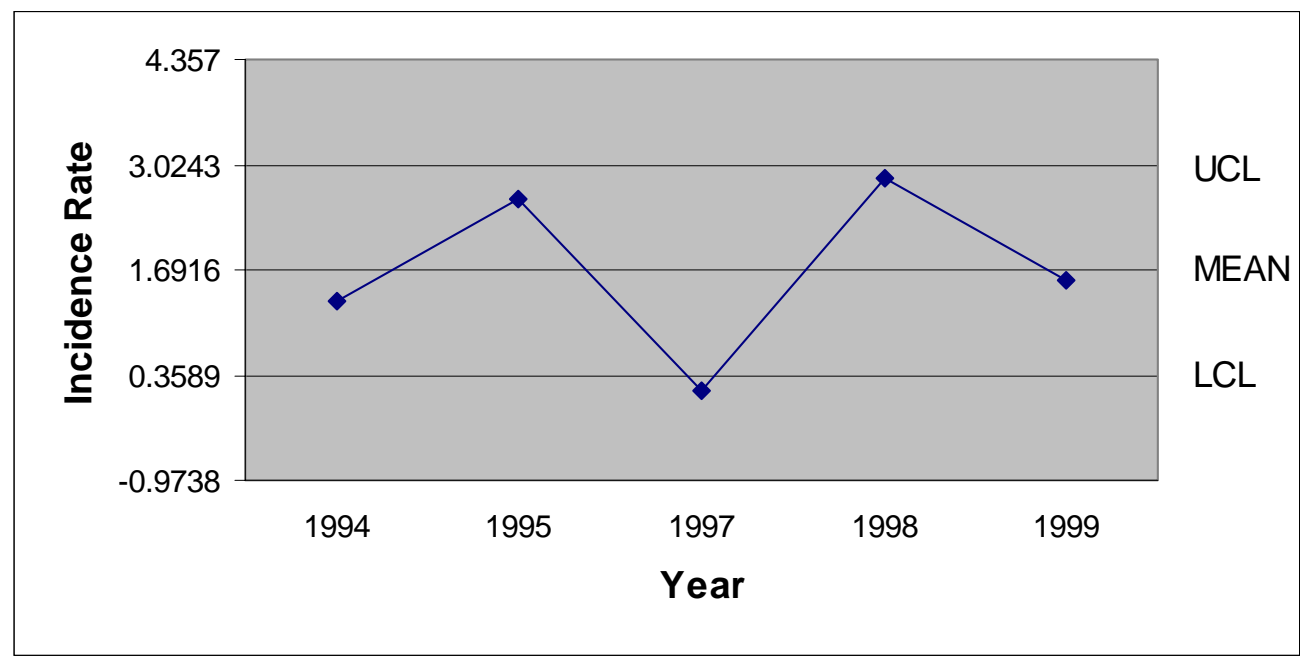

Note: No operations in fourth quarter 1996

Figure 205. Fourth Quarter 1994-1999 Transitional Incidence Rates - Primary Plant.

Table 37 presents the Primary Plant quarterly incidence rates for each year of the study period, as well as the UCL, mean, LCL, and standard deviation. Nineteen ninetysix and 1997 are partial years because of the work stoppage and only the first six months of 2000 were included in the research.

Table 37

$\underline{\text { Summary of Quarterly Transitional Incidence Rates Data - Primary Plant }}$

\begin{tabular}{|l|l|l|l|l|}
\hline & $1^{\text {st }}$ Quarter & $2^{\text {nd }}$ Quarter & $3^{\text {rd }}$ Quarter & $4^{\text {th }}$ Quarter \\
\hline 1994 & 1.749 & 0.917 & 1.053 & 1.303 \\
\hline 1995 & 3.306 & 2.537 & 2.611 & 2.586 \\
\hline 1996 & 1.621 & 2.909 & 2.442 & N/A \\
\hline 1997 & N/A & N/A & N/A & 0.168 \\
\hline 1998 & 3.751 & 3.943 & 3.512 & 2.840 \\
\hline 1999 & 1.718 & 1.411 & 2.851 & 1.562 \\
\hline 2000 & 1.225 & 1.409 & N/A & N/A \\
\hline UCL & 3.313 & 3.389 & 3.614 & 3.024 \\
\hline MEAN & 2.228 & 2.188 & 2.494 & 1.692 \\
\hline LCL & 1.143 & 0.987 & 1.373 & 0.359 \\
\hline SD & 0.422 & 0.467 & 0.404 & 0.480 \\
\hline
\end{tabular}




\section{$\underline{\text { Seasonal Analysis of Transitional Data - Primary Plant }}$}

The results of the Primary Plant quarterly seasonal index calculations are presented in Figure 206. The incidence rates seasonal index indicated that the third quarter experienced the highest seasonal index and the first quarter had the second highest. The lowest seasonal index was recorded for the fourth quarter.

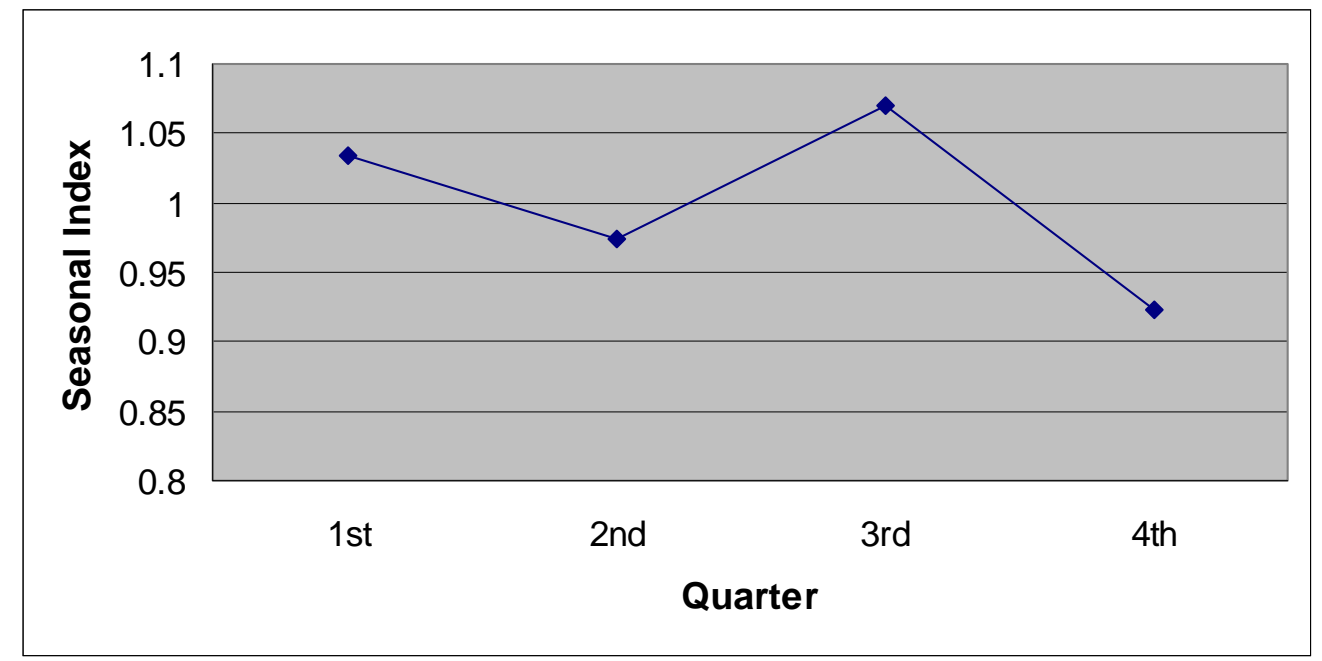

Figure 206. Quarterly Seasonal Index for Transitional Incidence Rates - Primary Plant

\section{$\underline{\text { Monthly Analysis of Transitional Data - Primary Plant }}$}

Figure 207 illustrates the transitional incidence rates at the Primary Plant for January 1994 through 2000. The lowest incidence rate, 0.758, occurred in 1995. January 1998 recorded the highest incidence rate, 3.238, which was more than four times greater than the lowest rate. In 1999 and 2000 the incidence rates were between the mean and the UCL. 


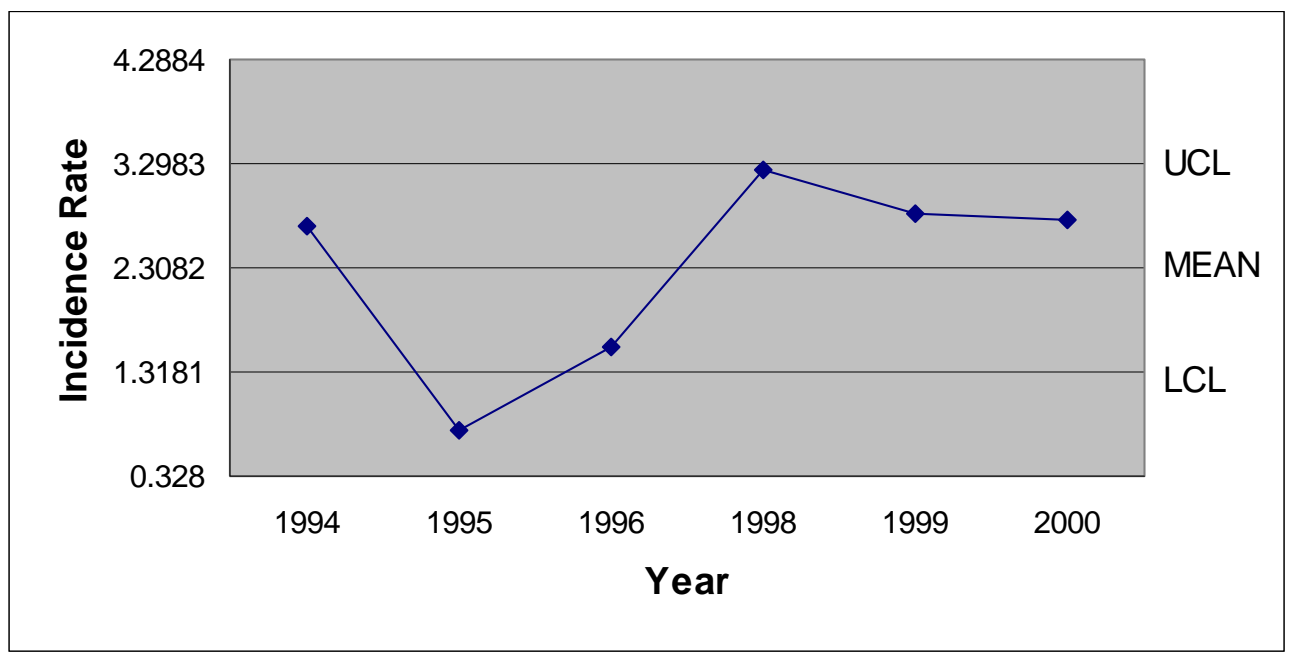

Note: No operations in January 1997

Figure 207. January 1994-2000 Transitional Incidence Rates - Primary Plant

The Primary Plant's February transitional incidence rates went through many peaks and valleys before leveling off in 1999 and 2000. As illustrated in Figure 208, 1994 and 1996 recorded incidence rates close to the mean. The 1995 incidence rate was just below the UCL, while the highest incidence rate was recorded above the UCL in 1998.

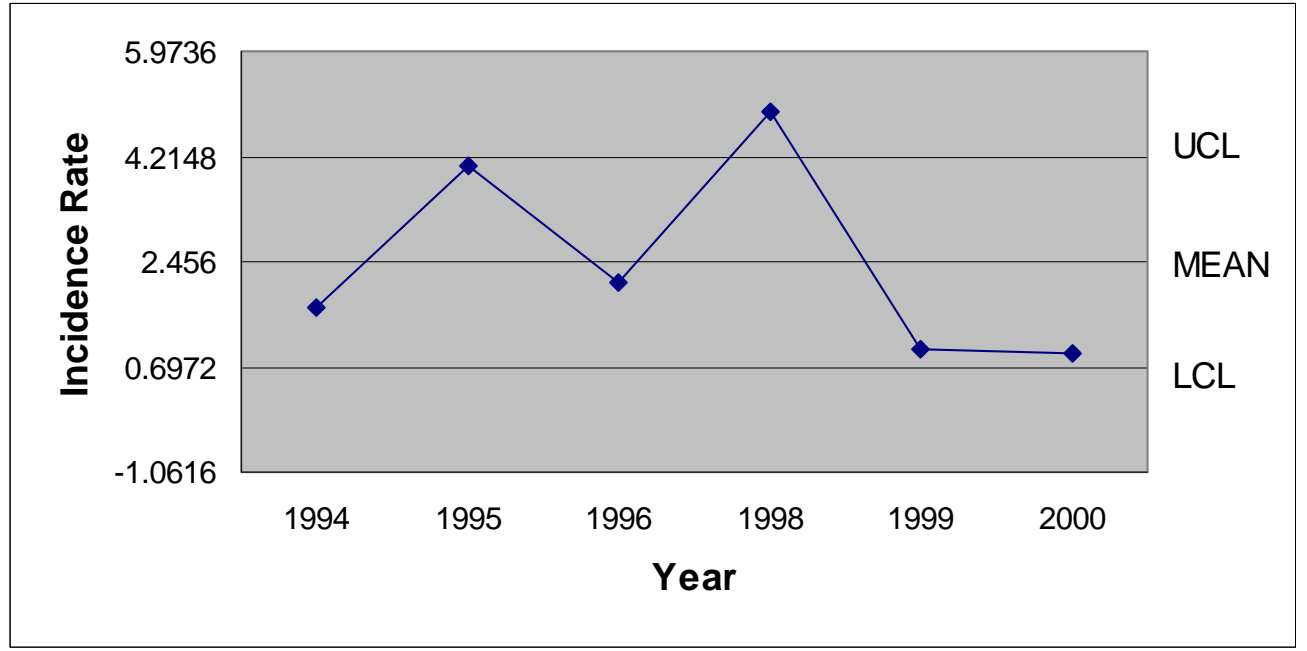

Note: No operations in February 1997

Figure 208. February 1994-2000 Transitional Incidence Rates - Primary Plant 
The highest March Primary Plant incidence rates, which occurred in 1995, was six times greater than the preceding year's incidence rates and four times greater than the following year's incidence rates. March 2000 did not experience any transitional incidents and therefore was the lowest March on record during the research period (See Figure 209).

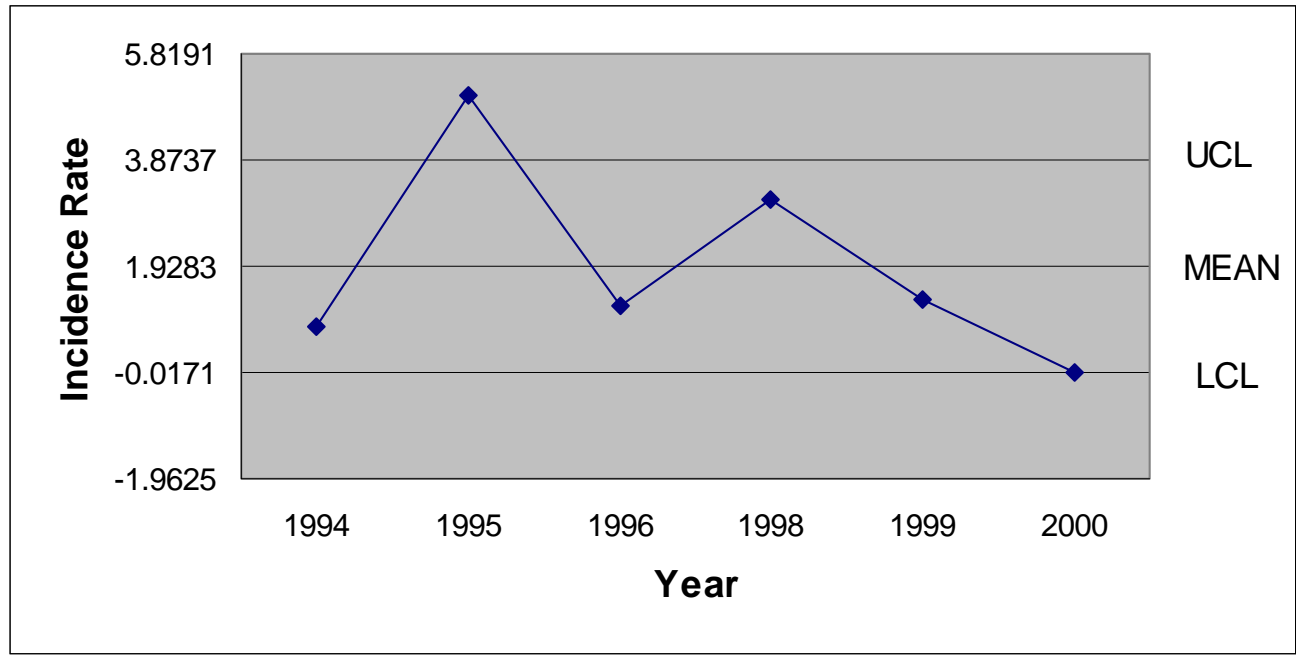

Note: No operations in March 1997

Figure 209. March 1994-2000 Transitional Incidence Rates - Primary Plant

After three years within the control limits, the April Primary Plant incidence rates increased to a level above the UCL in 1998. This increase was followed by a nearly $80 \%$ decrease in to the 1999 incidence rates of 1.382. The decrease continued in April 2000, with a rate of 0.982, but this did not match the low recorded in 1994 (See Figure 210). 


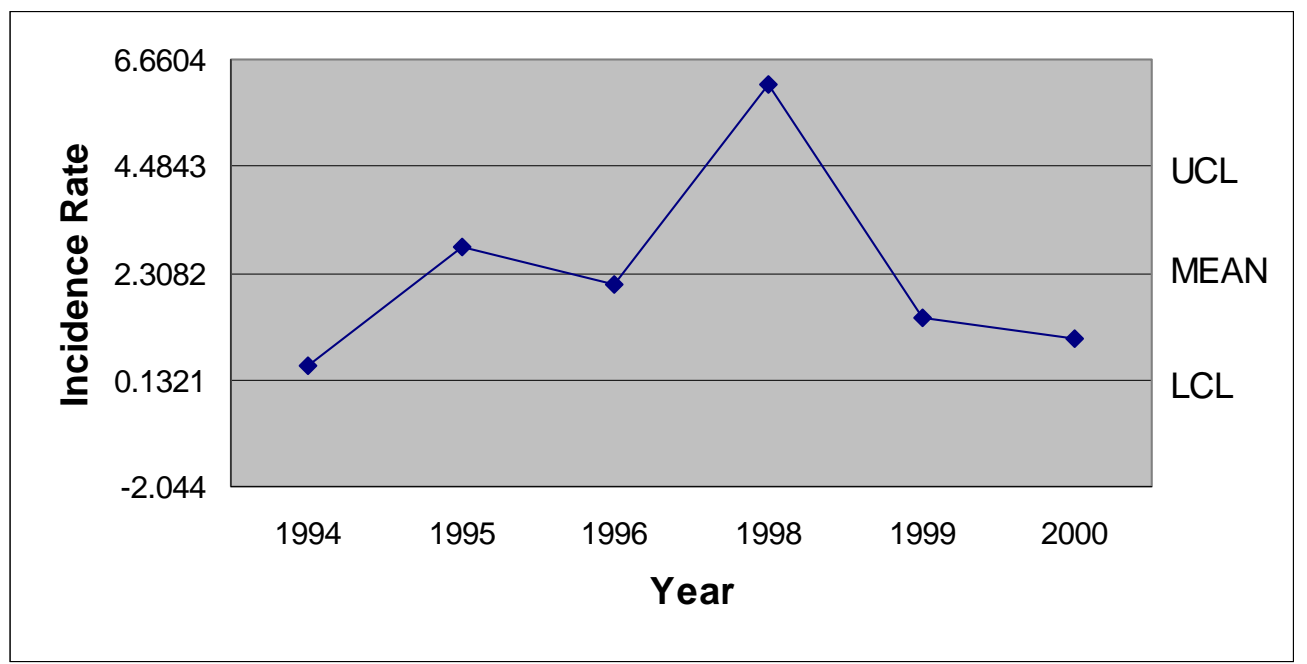

Note: No operations in April 1997

Figure 210. April 1994-2000 Transitional Incidence Rates - Primary Plant

In May 1994 the Primary Plant transitional incidence rate was below the LCL. It increased to above the mean in 1995 and then dipped below the mean in 1996. An increase in May 1997 to above the UCL was followed in 1999 with a decrease of over $50 \%$ (See Figure 211).

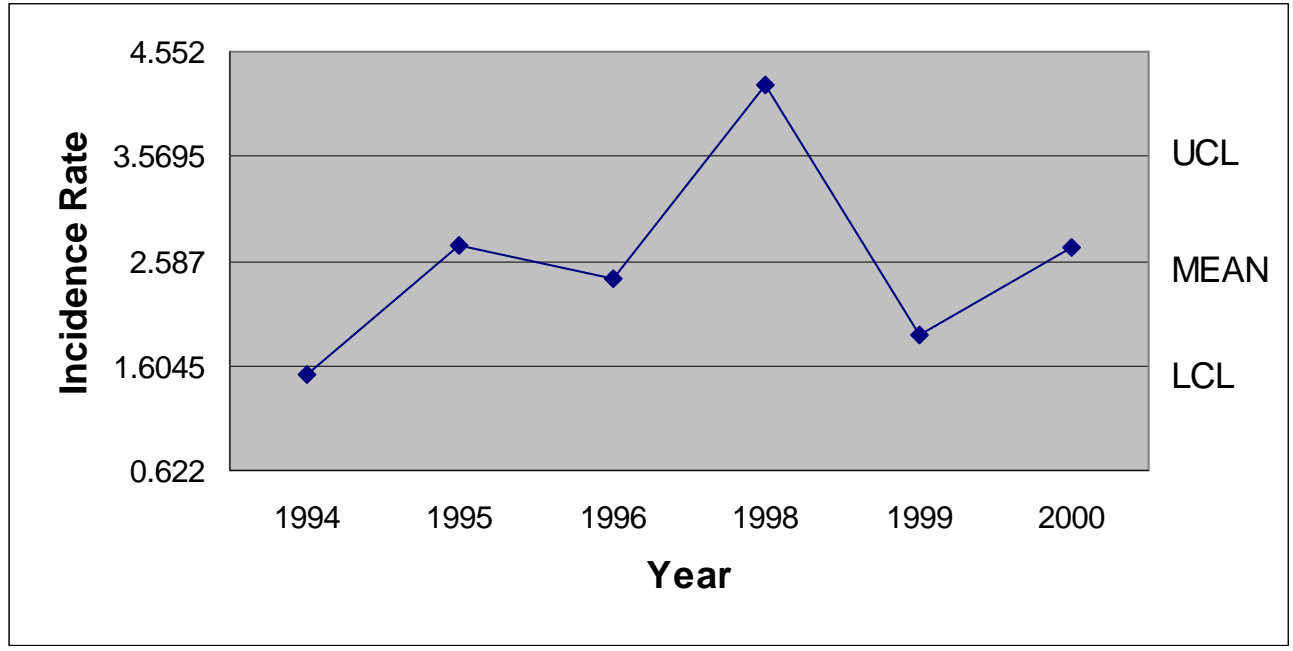

Note: No operations in May 1997

Figure 211. May 1994-2000 Transitional Incidence Rates - Primary Plant 
Figure 212 illustrates an increasing pattern for June incidence rates at the Primary Plant for the first three years of the research. After peaking in 1996, the incidence rate dropped below the mean in 1998 and has steadily trended toward the LCL through 2000.

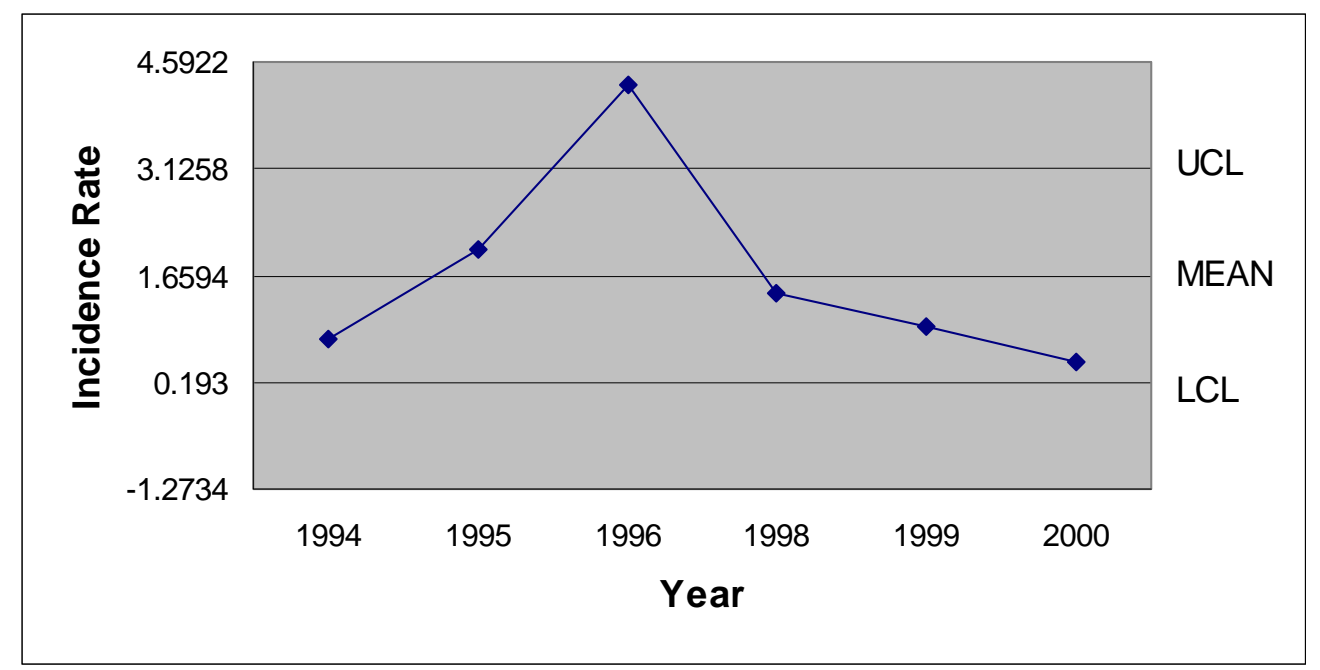

Note: No operations in June 1997

Figure 212. June 1994-2000 Transitional Incidence Rates - Primary Plant

In 1994 the Primary Plant transitional incidence rates for July was below the LCL. In 1995 through 1998 the incidence rates remained just above the mean. The 1999 incidence rate was approaching the UCL (See Figure 213).

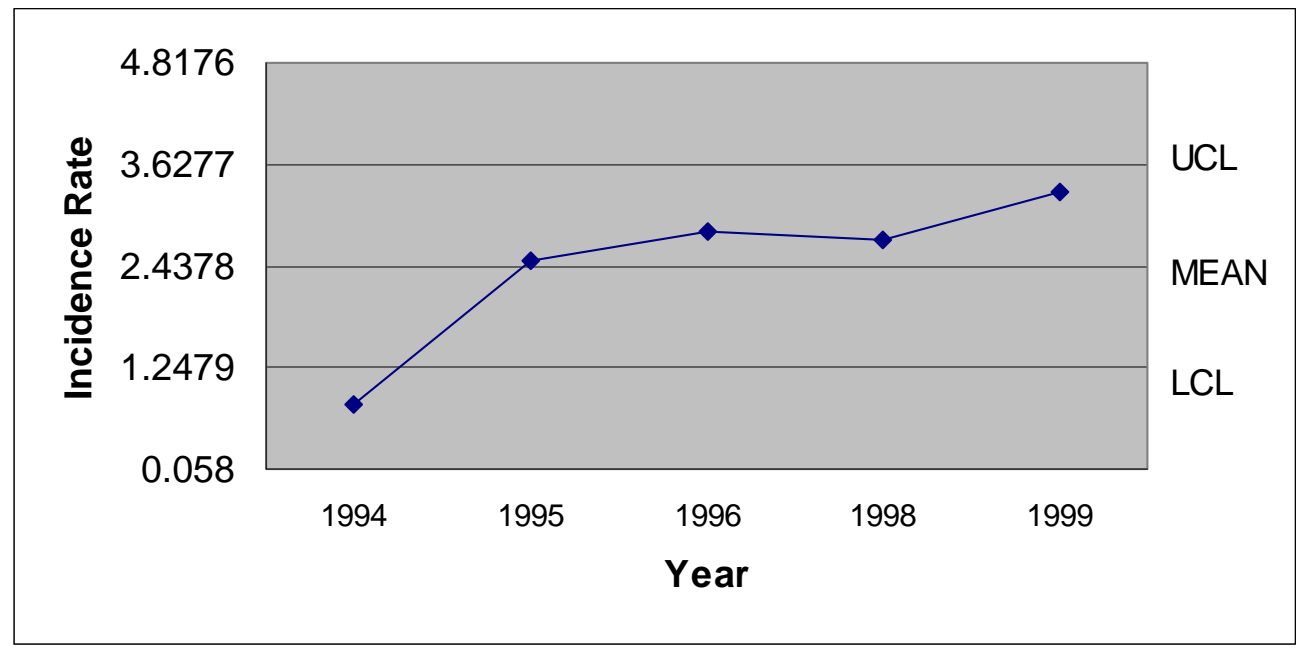

Note: No operations in July 1997

Figure 213. July 1994-1999 Transitional Incidence Rates - Primary Plant 
The 1994 August Primary Plant incidence rate was almost on the LCL line. In 1995 the incidence rate was above the mean and was followed by the second lowest August in 1996, just below the mean. The highest transitional incidence rates occurred in 1998 when the incidence rate was recorded above the UCL (See Figure 214).

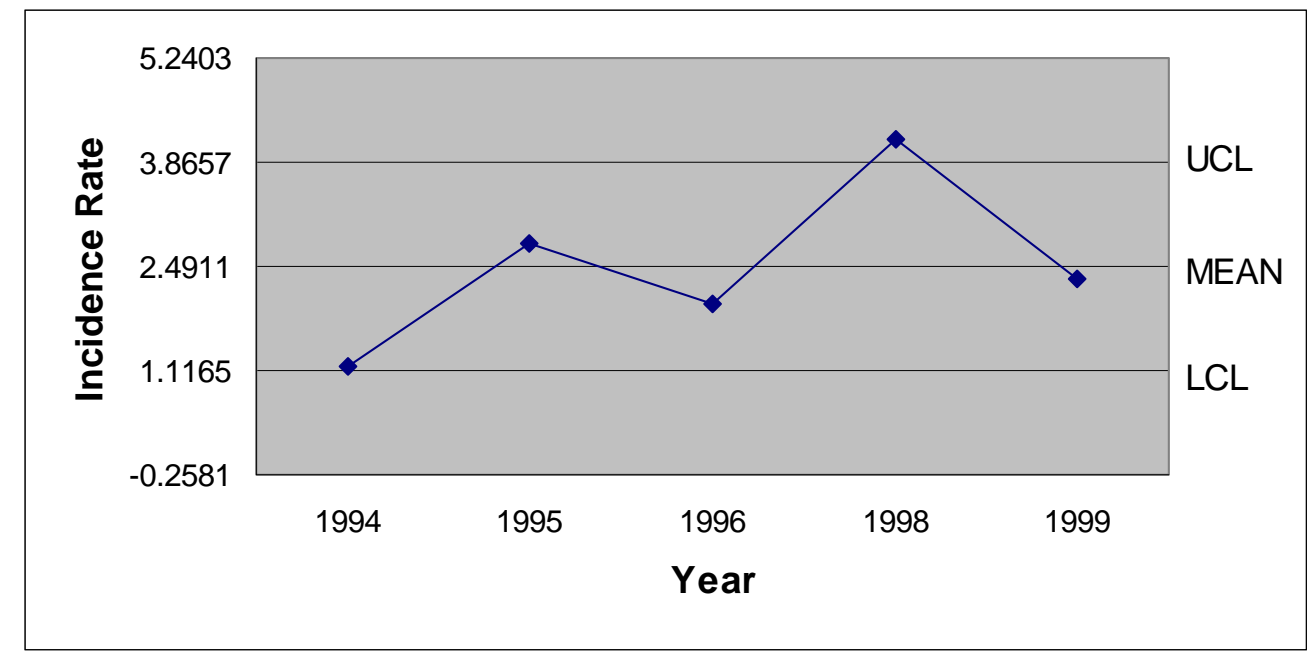

Note: No operations in August 1997

Figure 214. August 1994-1999 Transitional Incidence Rates - Primary Plant

The lowest Primary Plant September incidence rate was recorded in 1994. The 1995 and 1996 incidence rates were almost equal to the mean. In 1998 the incidence rates rose to a level just below the UCL. In 1999 the September transitional incidence rate was close to the mean (See Figure 215). 


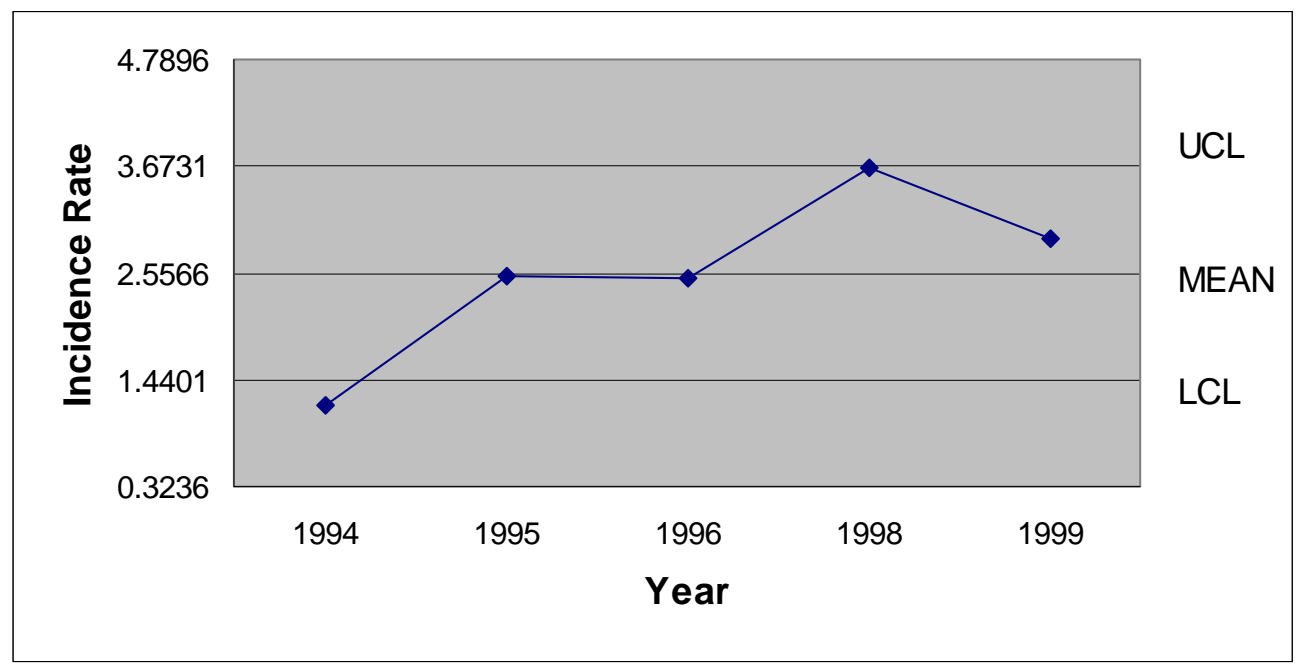

Note: No operations in September 1997.

Figure 215. September 1994-1999 Transitional Incidence Rates - Primary Plant

For the month of October the only Primary Plant transitional incidence rates that appear outside the control limits were the 1997 low and the 1998 high. In 1997 there were no transitional incidents recorded for the month of October (See Figure 216).

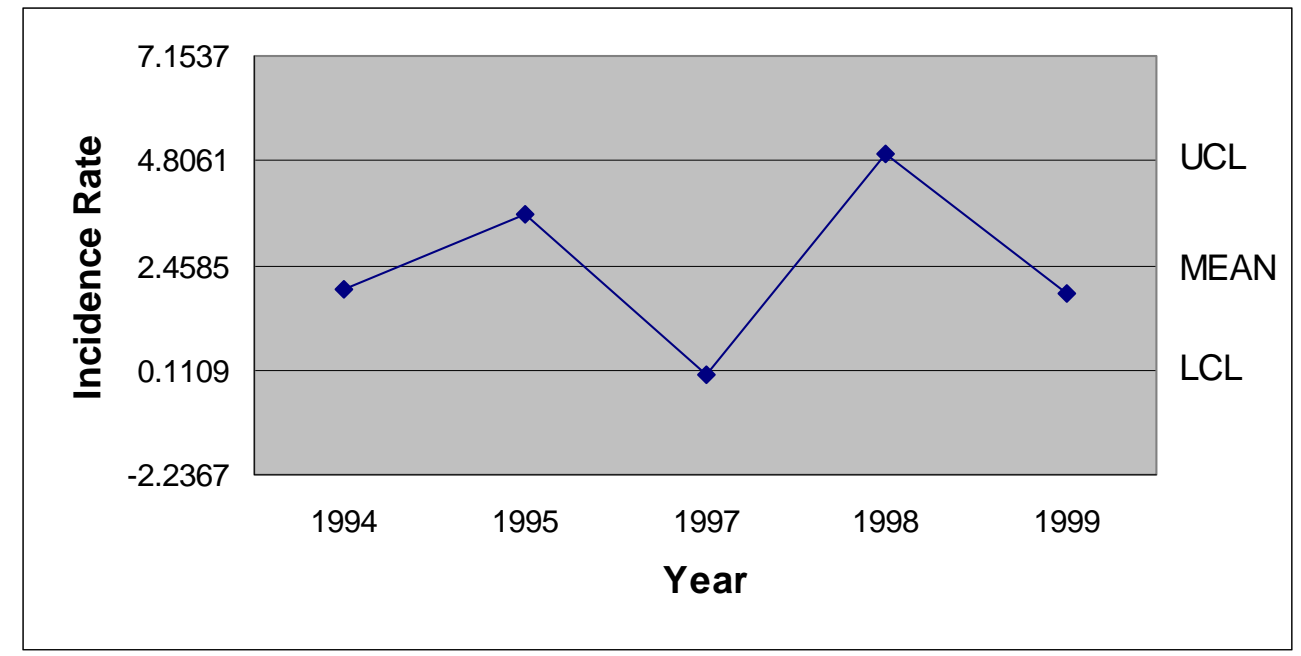

Note: No operations in October 1996

Figure 216. October 1994-1999 Transitional Incidence Rates - Primary Plant 
Figure 217 illustrates the variability that the incidence rates experienced at the Primary Plant in November, before leveling off the last two years close to the mean. The high was recorded above the UCL in 1995 and the low of 0.00 was recorded in 1997.

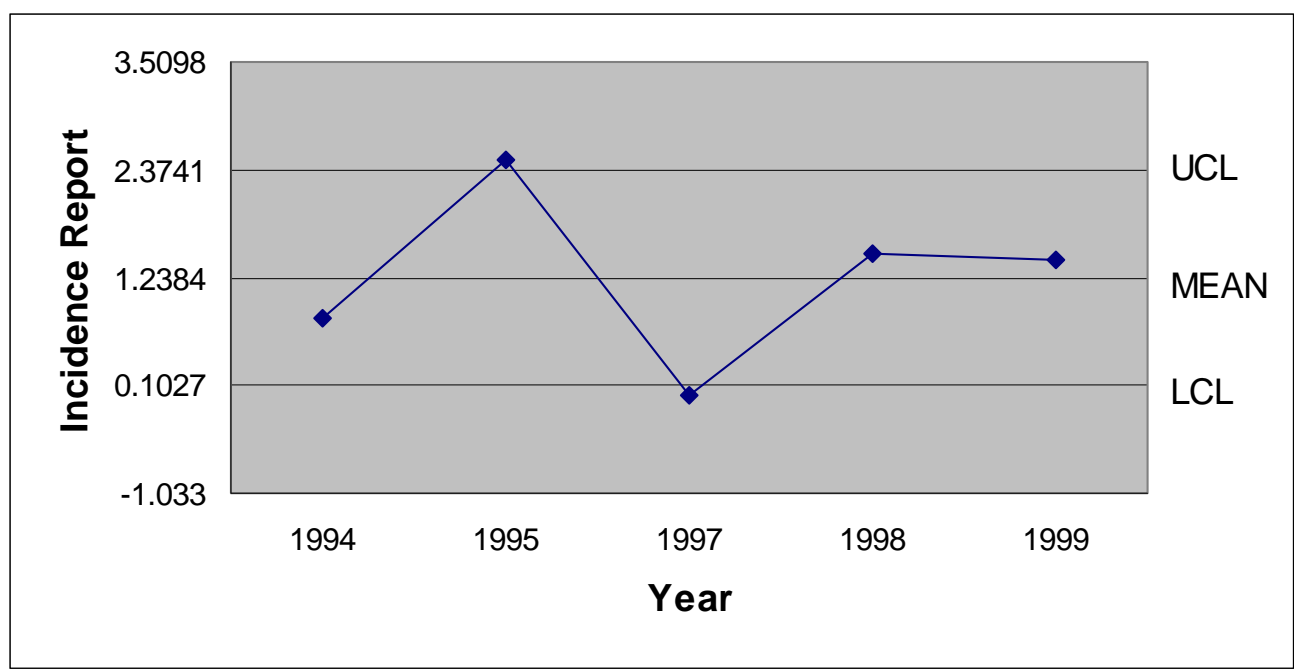

Note: No operations in November 1996

Figure 217. November 1994-1999 Transitional Incidence Rates - Primary Plant

The lowest December Primary Plant transitional incidence rates of 0.480, which was recorded in 1997, was followed in 1998 by the highest incidence rates. The highest December incidence rate was four times greater than the lowest (See Figure 218).

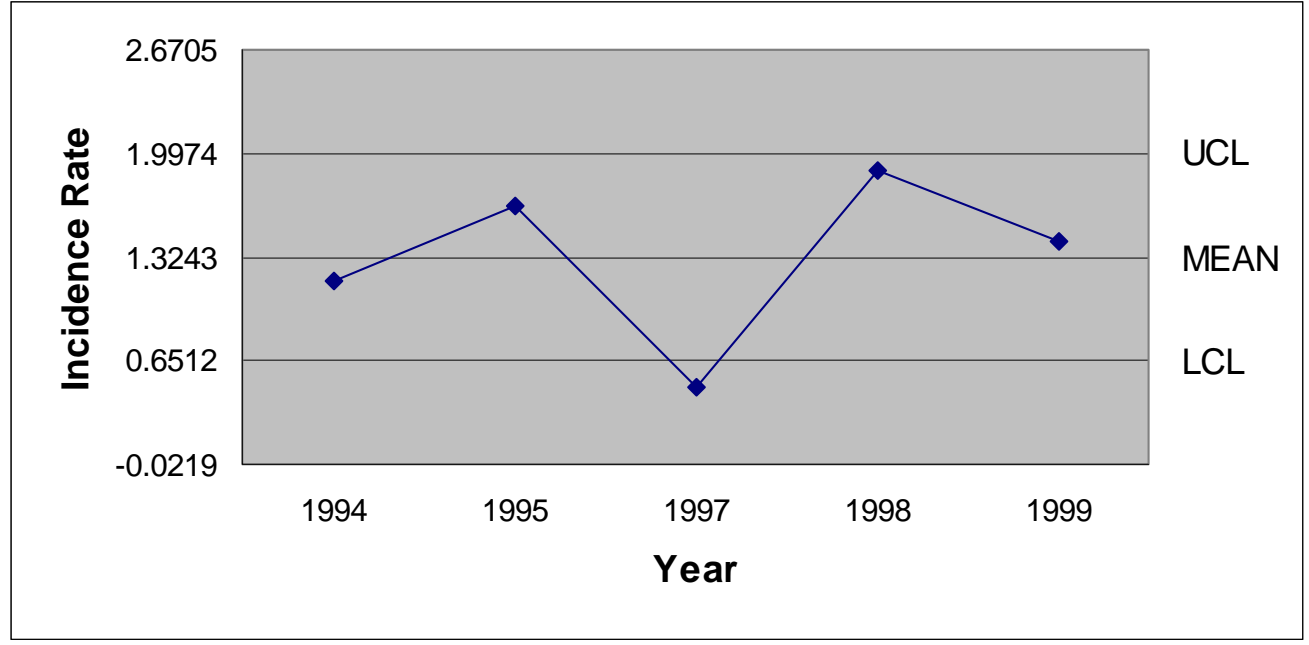

Note: No operations in December 1996

Figure 218. December 1994-1999 Transitional Incidence Rates - Primary Plant 
Table 38 presents the Primary Plant monthly incidence rates for each year of the study period, as well as the UCL, mean, LCL, and standard deviation. Nineteen ninetysix and 1997 were partial years because of the work stoppage and only the first six months of 2000 were included in the research.

Table 38

$\underline{\text { Summary of Monthly Transitional Incidence Rates Data - Primary Plant }}$

\begin{tabular}{|l|l|l|l|l|l|l|l|l|l|l|l|l|}
\hline & Jan. & Feb. & Mar. & Apr. & May & June & July & Aug. & Sept. & Oct. & Nov. & Dec. \\
\hline 1994 & 2.710 & 1.677 & 0.811 & 0.400 & 1.528 & 0.796 & 0.807 & 1.166 & 1.178 & 1.902 & 0.803 & 1.173 \\
\hline 1995 & 0.758 & 4.057 & 5.068 & 2.837 & 2.738 & 2.029 & 2.499 & 2.791 & 2.535 & 3.592 & 2.473 & 1.656 \\
\hline 1996 & 1.563 & 2.097 & 1.220 & 2.080 & 2.418 & 4.287 & 2.841 & 2.001 & 2.503 & N/A & N/A & N/A \\
\hline 1997 & N/A & N/A & N/A & N/A & N/A & N/A & N/A & N/A & N/A & 0.000 & 0.000 & 0.480 \\
\hline 1998 & 3.238 & 4.969 & 3.147 & 6.169 & 4.235 & 1.423 & 2.731 & 4.162 & 3.653 & 4.963 & 1.495 & 1.891 \\
\hline 1999 & 2.821 & 0.995 & 1.324 & 1.382 & 1.897 & 0.953 & 3.310 & 2.336 & 2.915 & 1.835 & 1.420 & 1.421 \\
\hline 2000 & 2.757 & 0.941 & 0.000 & 0.982 & 2.706 & 0.469 & N/A & N/A & N/A & N/A & N/A & N/A \\
\hline UCL & 3.298 & 4.215 & 3.874 & 4.484 & 3.569 & 3.126 & 3.628 & 3.866 & 3.673 & 4.806 & 2.374 & 1.997 \\
\hline Mean & 2.308 & 2.456 & 1.928 & 2.308 & 2.587 & 1.659 & 2.438 & 2.491 & 2.557 & 2.458 & 1.238 & 1.324 \\
\hline LCL & 1.318 & 0.697 & -0.017 & 0.132 & 1.604 & 0.193 & 1.248 & 1.116 & 1.440 & 0.111 & 0.103 & 0.651 \\
\hline SD & 0.385 & 0.684 & 0.757 & 0.846 & 0.382 & 0.570 & 0.429 & 0.495 & 0.402 & 0.846 & 0.409 & 0.242 \\
\hline
\end{tabular}

$\underline{\text { Seasonal Analysis of Transitional Data - Primary Plant }}$

The seasonal index calculation was used to generate the Primary Plant monthly seasonal index figures that are presented in Figure 219. January, May, and December respectively were the three highest transitional incidence rates seasonal index figures for the Primary Plant. The second lowest seasonal index amount occurred in June. It was followed by a relatively stable period through October and then the lowest seasonal index amount was recorded for the month of November. 


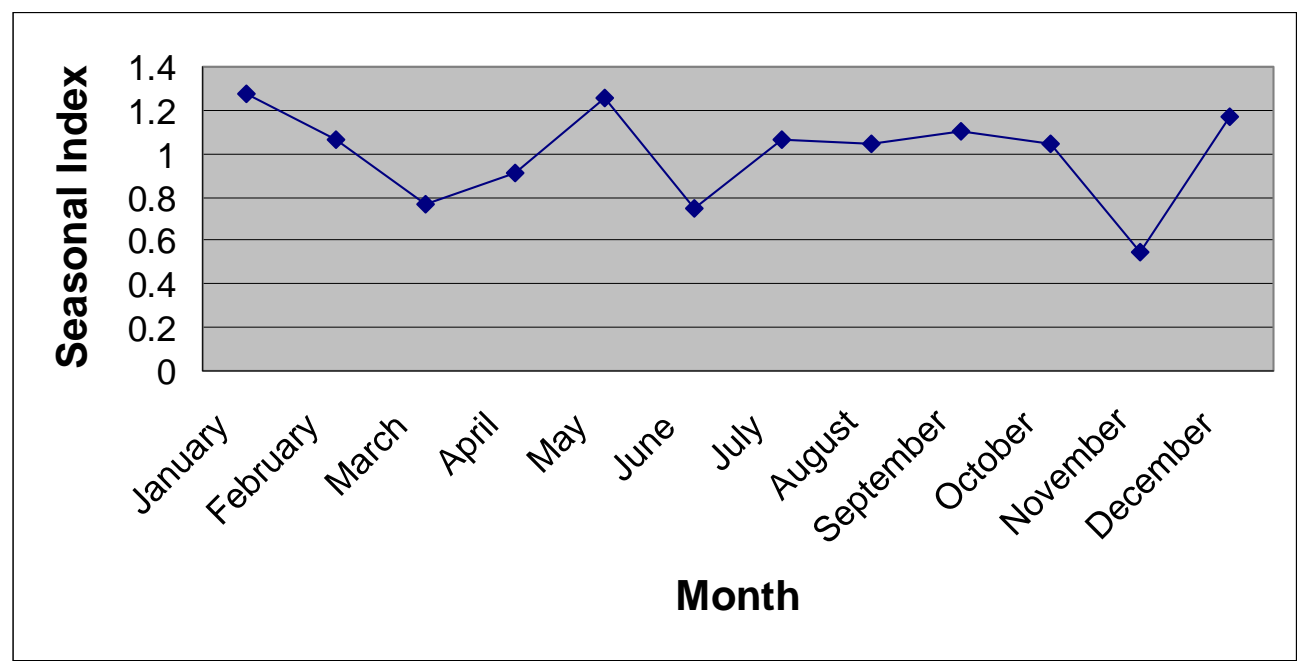

Figure 219. Monthly Seasonal Pattern of Transitional Incidence Rates Primary Plant

Testing the Statistical Relationship of Transitional Data - Primary Plant

\section{All 33 Months Prior to and Subsequent to the Work Stoppage}

For the entire 33 months prior to the work stoppage at the Primary Plant and the 33 post work stoppage months, the comparison t value was 0.589 . Because this calculated amount was less than the 1.96 critical $t$ value, a statistically significant increase in incidence rates did not occur between the periods.

\section{First 24 Months and Last 24 Months of the Research Period}

The same formula was applied to the Primary Plant transitional incidence rates for the first 24 months and the last 24 months of the period. These time periods excluded the nine months prior to and immediately following the work stoppage. Using the same 1.96 critical $t$ value, the 0.222 calculated amount indicated that there was not a statistically significant increase in incidence rates between the periods.

\section{Nine Month Intervals Prior to and Subsequent to the Work Stoppage}

Comparison of the Primary Plant transitional incidence rates for the nine months preceding the work stoppage and the nine months following the work stoppage was accomplished using the comparison formula. The result of this calculation 0.715, was less than the critical t value of 1.96. Therefore, at the .05 level of significance, there was 
not a statistically significant increase in incidence rates between the periods (See Table 39).

Table 39

Comparison of prior and post work stoppage periods - Primary Plant

\begin{tabular}{|c|c|c|c|c|}
\hline \multirow[b]{2}{*}{ Time Period } & \multicolumn{2}{|c|}{ Primary Plant Incidence Rates } & \multirow[b]{2}{*}{ Critical t Value } & \multirow[b]{2}{*}{$\begin{array}{l}\text { Calculated } \\
\text { Comparison Value }\end{array}$} \\
\hline & $\begin{array}{l}\text { Prior to } \\
\text { Work Stoppage }\end{array}$ & $\begin{array}{l}\text { Post } \\
\text { Work Stoppage }\end{array}$ & & \\
\hline 9 Months & 2.317 & 2.673 & 1.96 & 0.715 \\
\hline 24 Months & 2.006 & 2.066 & 1.96 & 0.222 \\
\hline 33 Months & 2.088 & 2.228 & 1.96 & 0.589 \\
\hline
\end{tabular}

* Indicates a statistically significant increase

** Indicates a statistically significant decrease

Finishing Plant \#1 Analysis

\section{Quarterly Analysis of Transitional Data - Finishing Plant \#1}

The first quarter transitional incidence rates for Finishing Plant \#1 are presented in Figure 220. The first two and the last first quarters did not experience any transitional incidents. The highest incidence rate, 2.266, occurred in 1998.

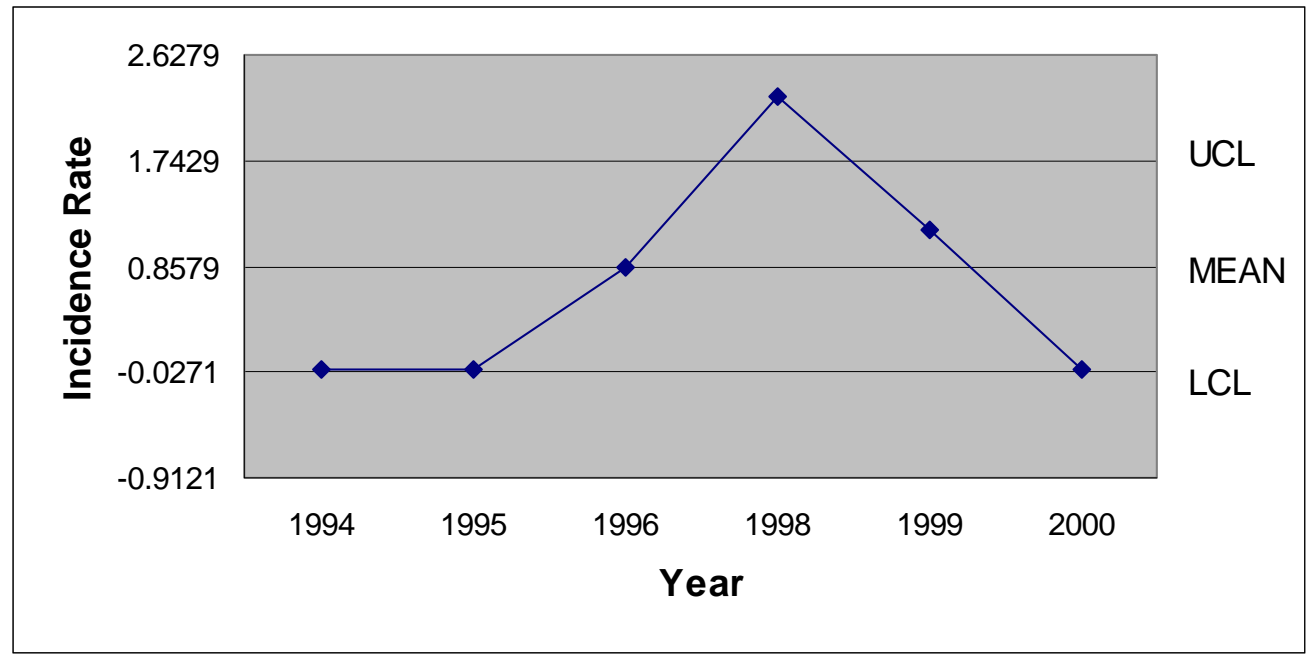

Note : No operations first quarter 1997

Figure 220. First Quarter 1994-2000 Transitional Incidence Rates - Finishing Plant \#1 
The 0.766 , incidence rates recorded in 1994 was the lowest nonzero second quarter incidence rates at Finishing Plant \#1. In 1995, the incidence rate was within a fraction of the UCL and in 1996 the incidence rates went above the UCL. The incidence rates decreased sharply in 1998 to a level just above the mean. The lowest incidence rates, 0.00, were recorded for the second quarters of 1999 and 2000 (See Figure 221).

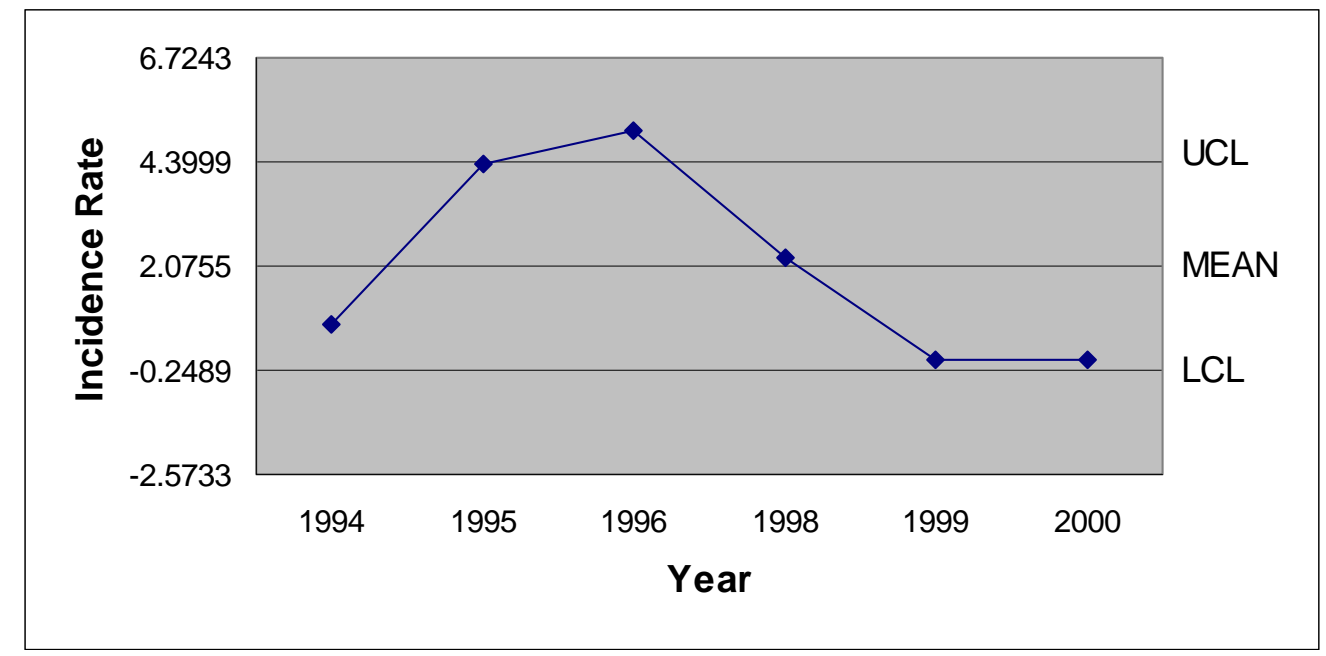

Note: No operations in second quarter 1997

Figure 221. Second Quarter 1994-2000 Transitional Incidence Rates - Finishing Plant \#1

As illustrated in Figure 222, the third quarter 1995 Finishing Plant \#1 incidence rate of 6.041 was much higher than the only other nonzero amount, 1.778, recorded in 1998. 


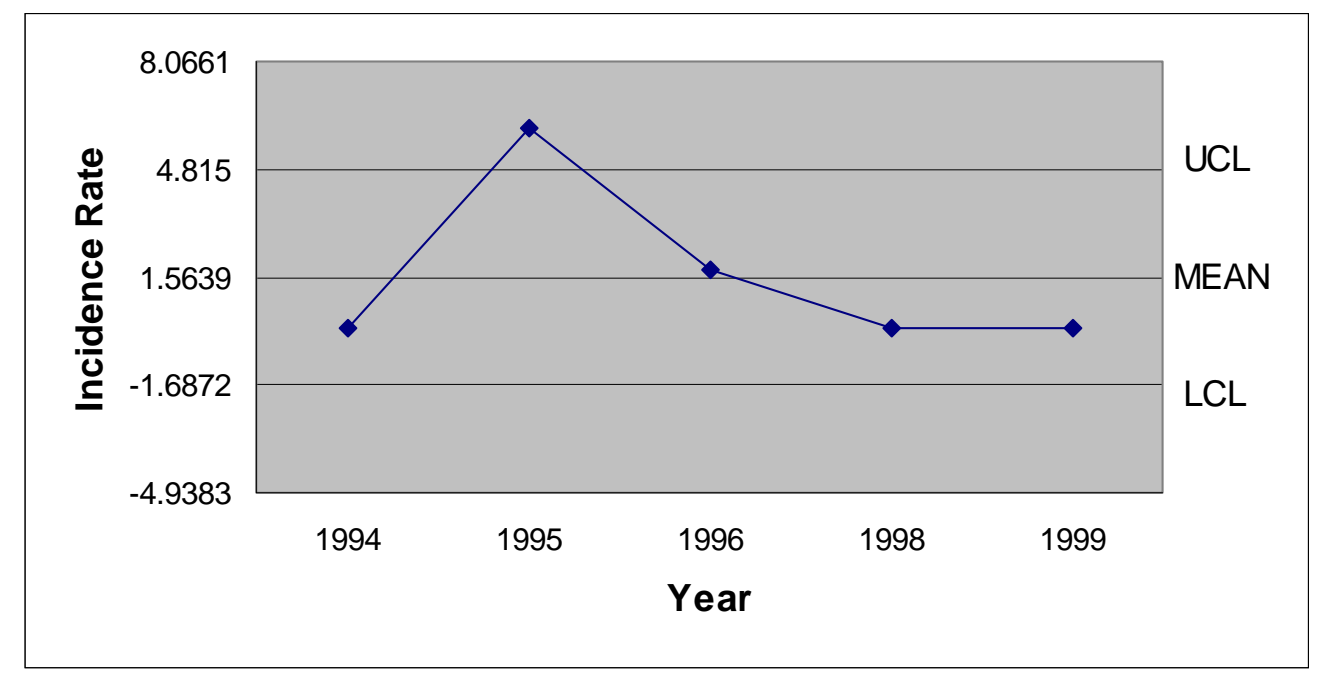

Note: No operations in third quarter 1997

Figure 222. Third Quarter 1994-1999 Transitional Incidence Rates - Finishing Plant \#1

All of the Finishing Plant \#1 fourth quarter incidence rates were within the control limits. The 1997 rate of 0.908 was above the mean as were the 1998 and 1999 incidence rates. The highest fourth quarter incidence rates, 1.202, was recorded in 1998 (See Figure 223).

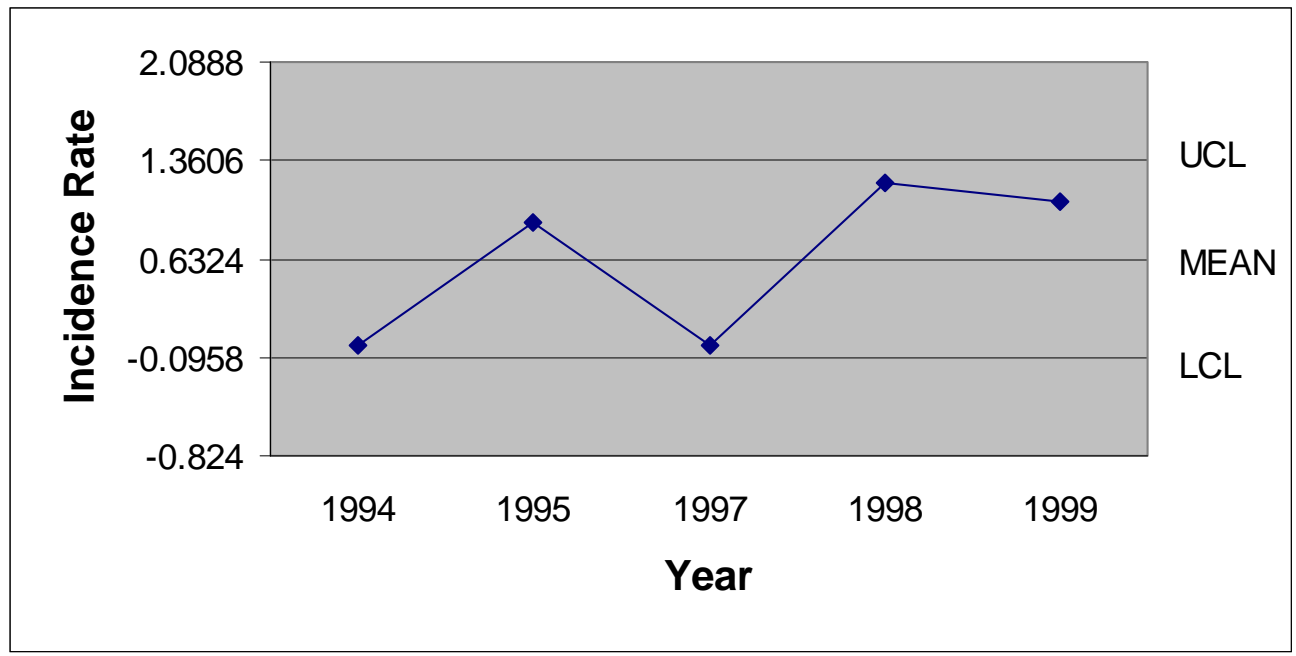

Note: No operations in fourth quarter 1996

Figure 223. Fourth Quarter 1994-1999 Transitional Incidence Rates - Finishing Plant \#1 
Table 40 presents the Finishing Plant \#1 quarterly incidence rates for each year of the study period, as well as the UCL, mean, LCL, and standard deviation. Nineteen ninety-six and 1997 are partial years because of the work stoppage and only the first six months of 2000 were included in the research.

Table 40

Summary of Quarterly Transitional Incidence Rates Data - Finishing Plant \#1

\begin{tabular}{|l|l|l|l|l|}
\hline & $1^{\text {st }}$ Quarter & $2^{\text {nd }}$ Quarter & $3^{\text {rd }}$ Quarter & $4^{\text {th }}$ Quarter \\
\hline 1994 & 0.000 & 0.766 & 0.000 & 0.000 \\
\hline 1995 & 0.000 & 4.345 & 6.041 & 0.908 \\
\hline 1996 & 0.846 & 5.076 & 1.778 & N/A \\
\hline 1997 & N/A & N/A & N/A & 0.000 \\
\hline 1998 & 2.274 & 2.267 & 0.000 & 1.202 \\
\hline 1999 & 1.169 & 0.000 & 0.000 & 1.053 \\
\hline 2000 & 0.000 & 0.000 & N/A & N/A \\
\hline UCL & 1.743 & 4.400 & 4.815 & 1.361 \\
\hline MEAN & 0.858 & 2.075 & 1.534 & 0.632 \\
\hline LCL & -0.027 & -0.249 & -1.687 & -0.096 \\
\hline SD & 0.344 & 0.904 & 1.171 & 0.262 \\
\hline
\end{tabular}

$\underline{\text { Seasonal Analysis of Transitional Data - Finishing Plant \#1 }}$

The quarterly seasonal index for transitional incidents at Finishing Plant \#1 is presented in Figure 224. The second quarter recorded the highest seasonal index, more than $50 \%$ greater than the any other quarter. The seasonal index numbers for the other three quarters were clustered closely together. 


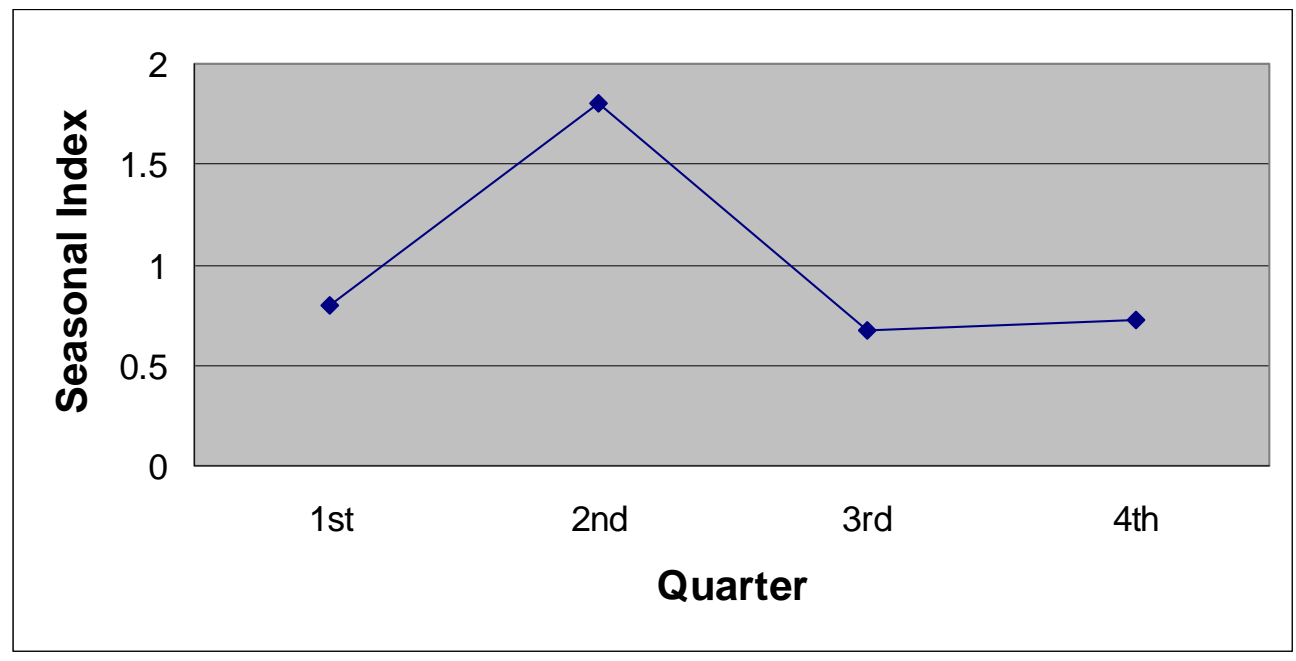

Figure 224. Quarterly Seasonal Index for Transitional Incidence Rates - Finishing Plant $\# 1$

\section{Monthly Analysis of Transitional Data - Finishing Plant \#1}

As illustrated in Figure 225, Finishing Plant \#1 did not experience any transitional incidents in the month of January during the study period. This created a situation where the UCL, mean, and LCL were all 0.000.

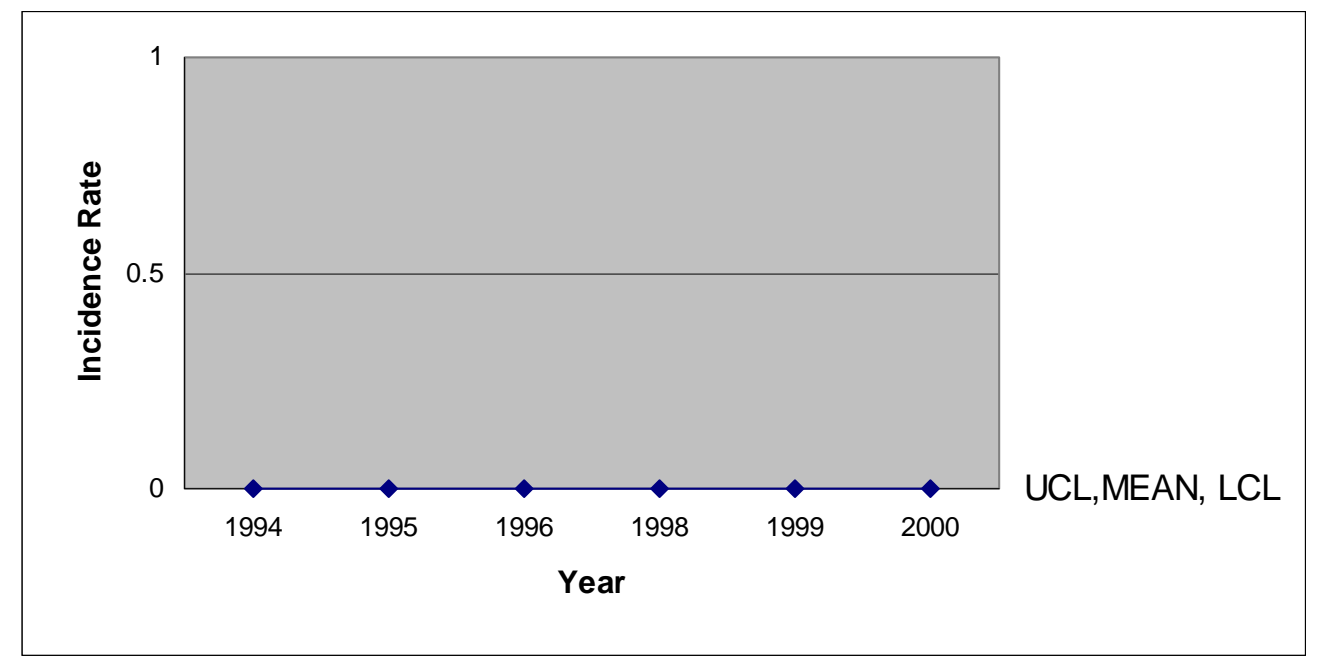

Note: No operations in January 1997

Figure 225. January 1994-2000 Transitional Incidence Rates - Finishing Plant \#1 
As illustrated in Figure 226, the only nonzero incidence rates for the month of February at Finishing Plant \#1 were recorded close to the UCL in 1996 and 1998. The 1998 incidence rates, 3.672, was greater than the UCL, while the 1996 incidence rates of 2.564 was just below the UCL.

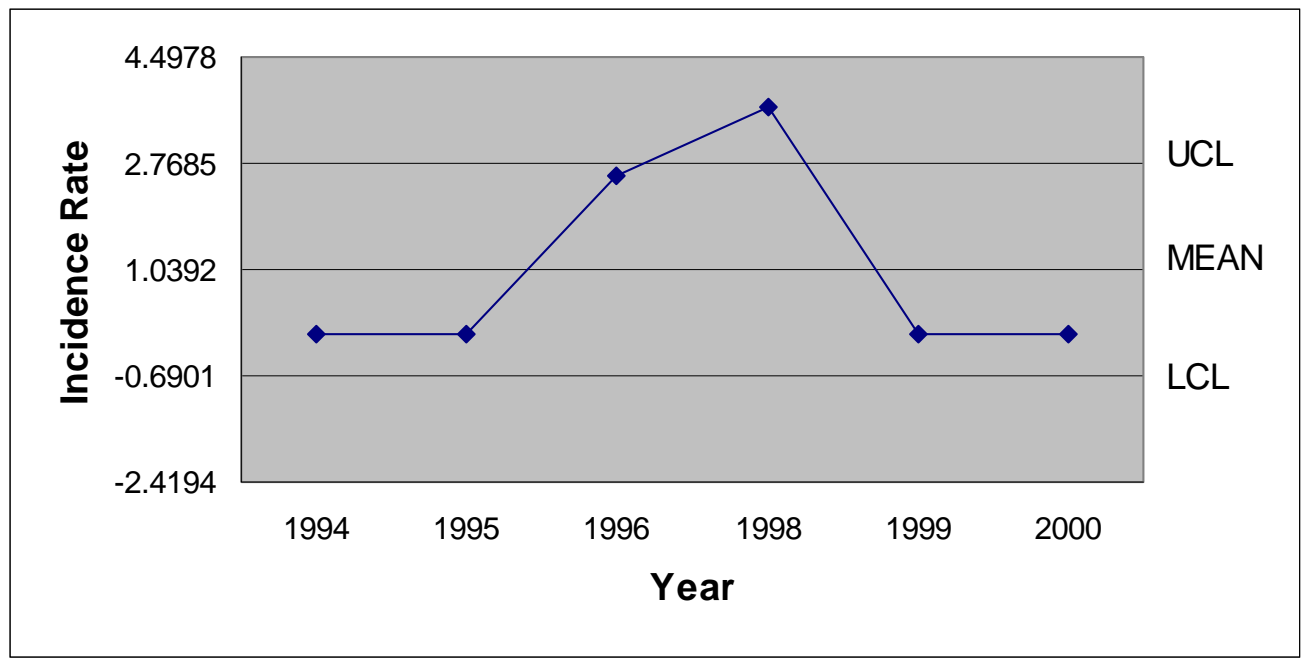

Note: No operations in February 1997

Figure 226. February 1994-2000 Transitional Incidence Rates - Finishing Plant \#1

For the month of March at Finishing Plant \#1, the first three and the last incidence rates of the research period were zeros. The March 1998 incidence rates of 3.272 was slightly higher than the March 1999 incidence rates of 3.222 (See Figure 227). 


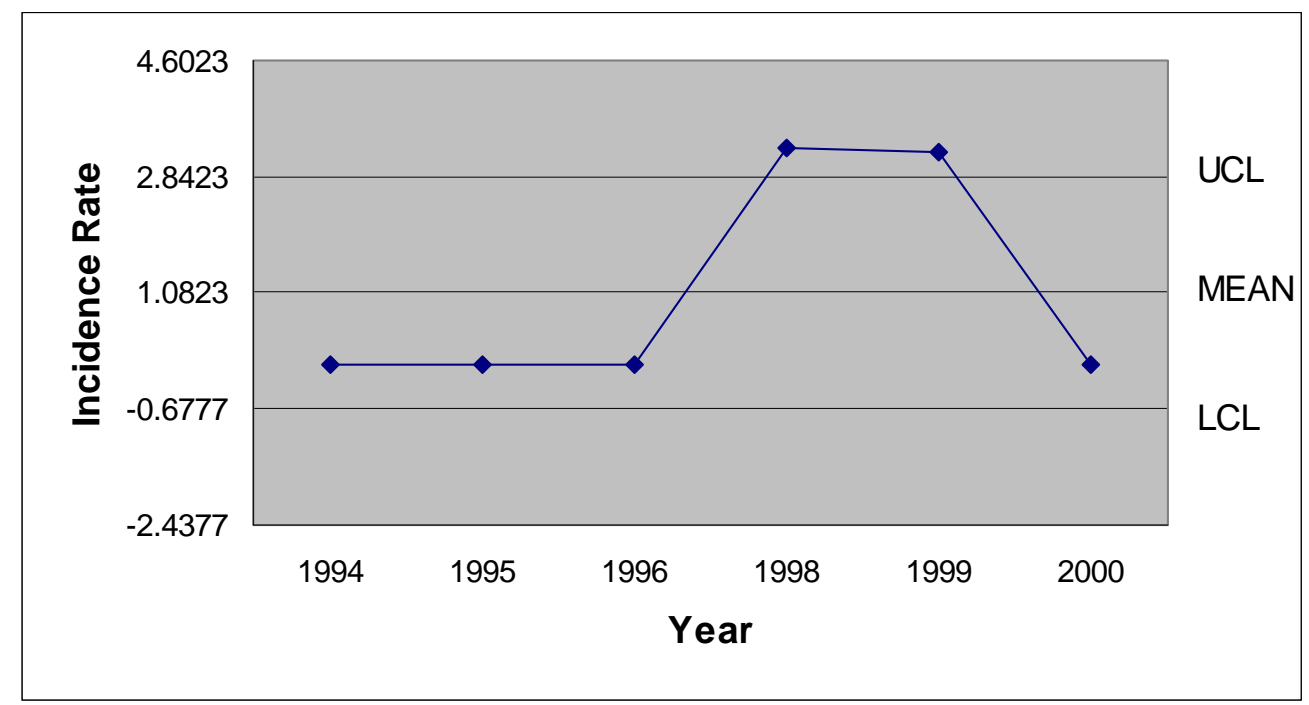

Note: No operations in March 1997

Figure 227. March 1994-2000 Transitional Incidence Rates - Finishing Plant \#1

April also experienced four of six periods with zero transitional incidents at Finishing Plant \#1. As illustrated in Figure 228, the high of 7.669 occurred in 1995. The only other nonzero April incidence rates, 3.448, was recorded in 1998.

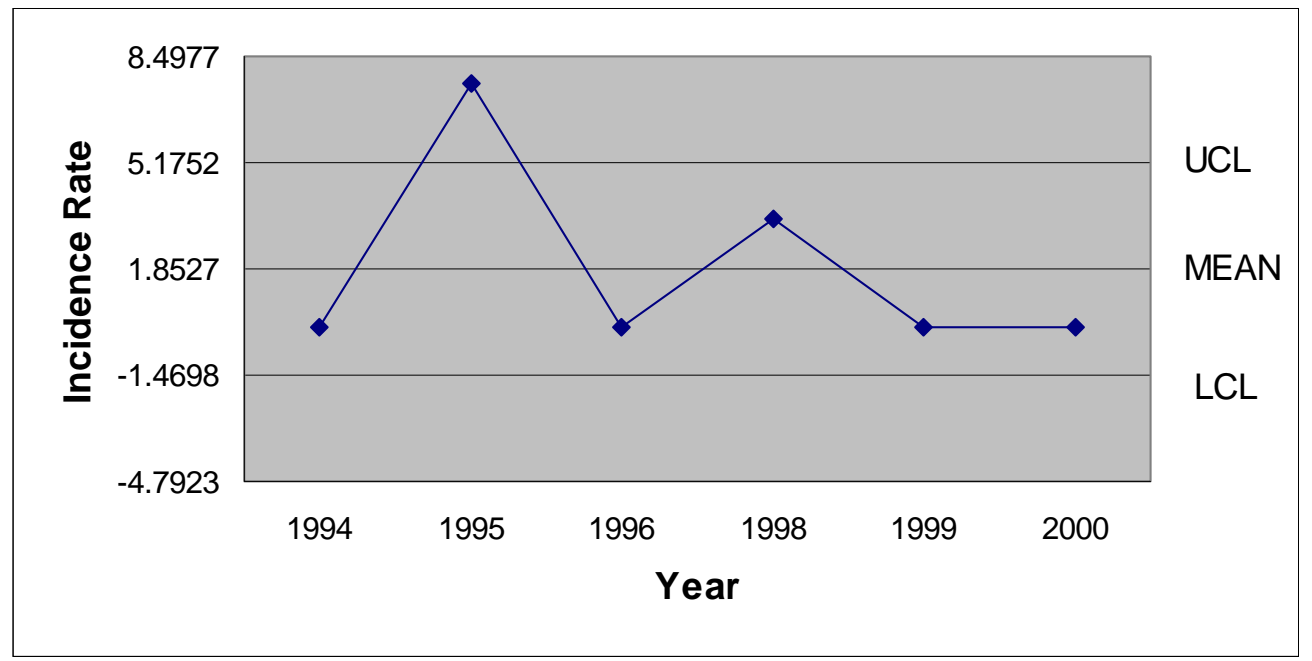

Note: No operations in April 1997

Figure 228. April 1994-2000 Transitional Incidence Rates - Finishing Plant \#1

The May 1996 transitional incidence rates of 7.401 was the only nonzero May incidence rates recorded for Finishing Plant \#1 during the study period (See Figure 229). 


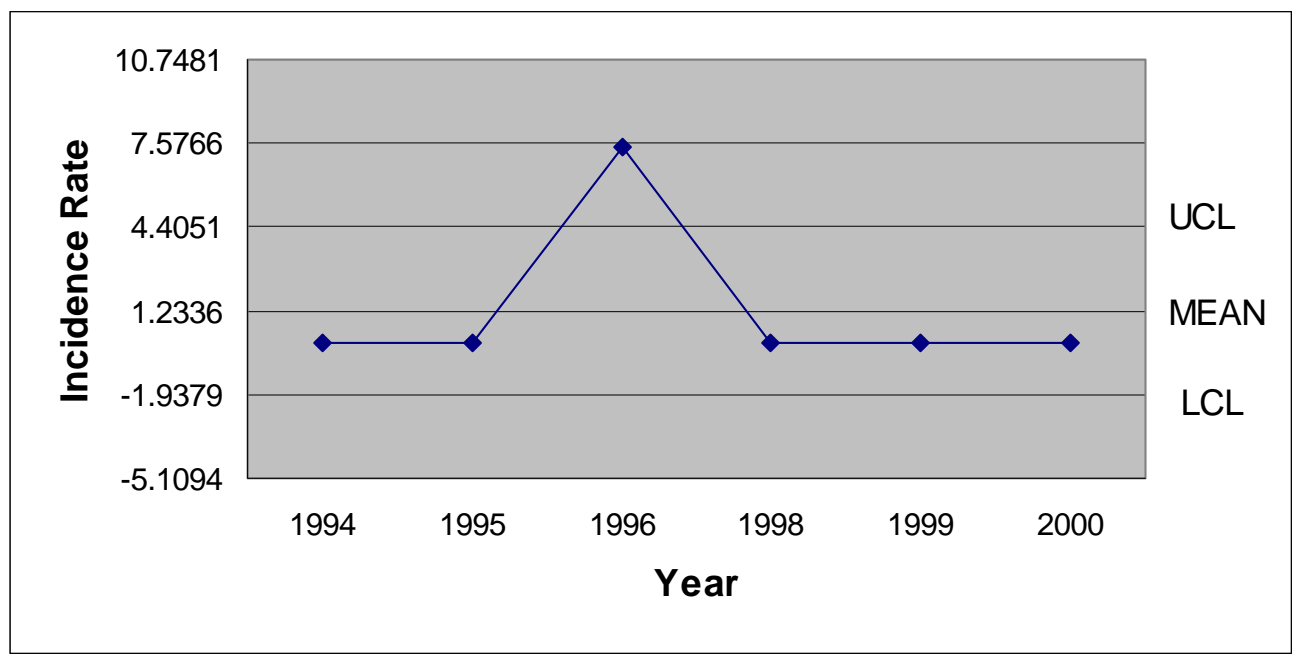

Note: No operations in May 1997

Figure 229. May 1994-2000 Transitional Incidence Rates - Finishing Plant \#1

The first three June periods at Finishing Plant \#1 rose steadily from a level below the mean to a level above the UCL. After peaking in 1996 the following period's incidence rate was just above the mean and the last two periods were 0.000 incidence rates (See Figure 230).

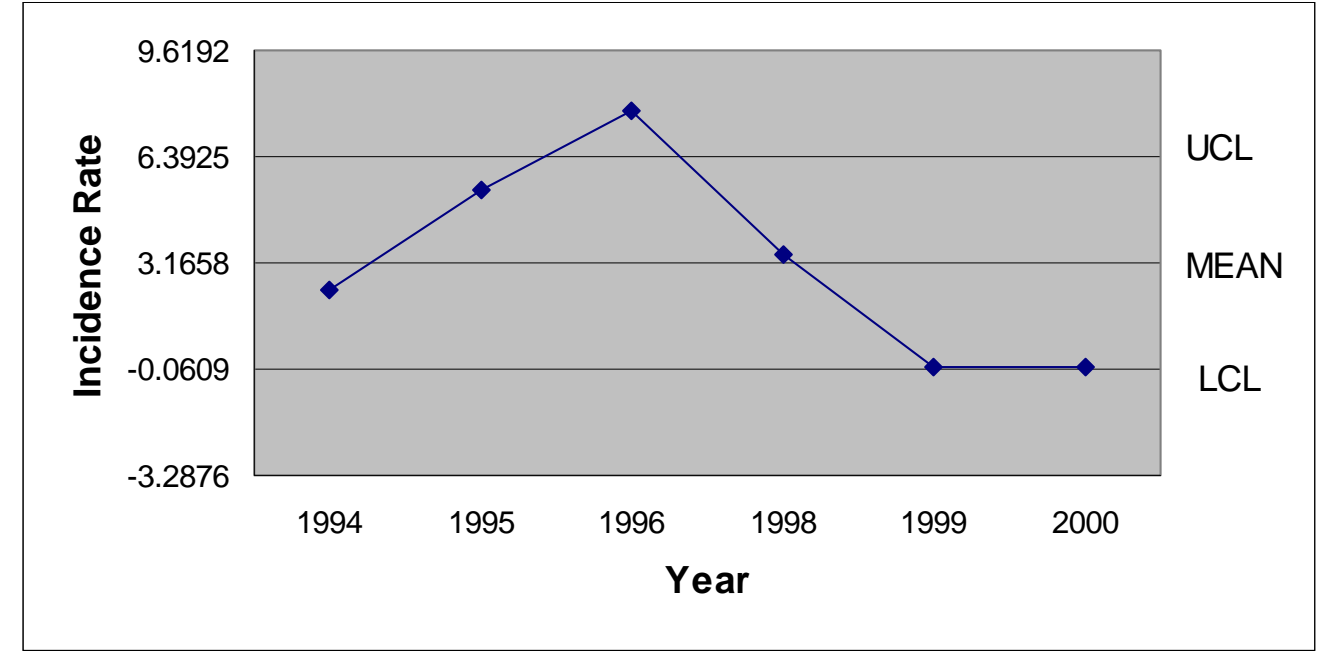

Note: No operations in June 1997

Figure 230. June 1994-2000 Transitional Incidence Rates - Finishing Plant \#1 
The 10.242 transitional incidence rate recorded in July 1995 at Finishing Plant \#1 was much greater than the 0.000 incidence rate posted in the remaining four July periods (See Figure 231).

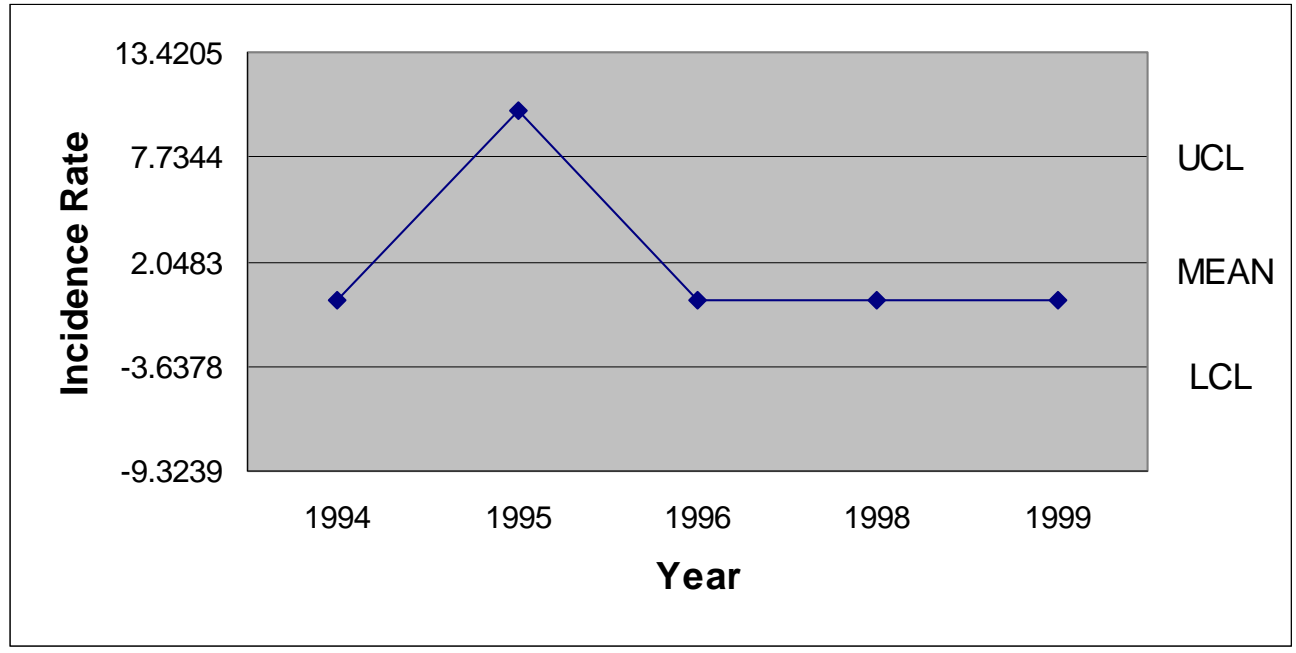

Note: No operations in July 1997

Figure 231. July 1994-1999 Transitional Incidence Rates - Finishing Plant \#1

The highest August incidence rate at Finishing Plant \#1 followed the highest July incidence rate in 1995. The August 1995 incidence rate of 7.567 was much higher than the 0.000 incidence rates recorded in the other August periods (See Figure 232).

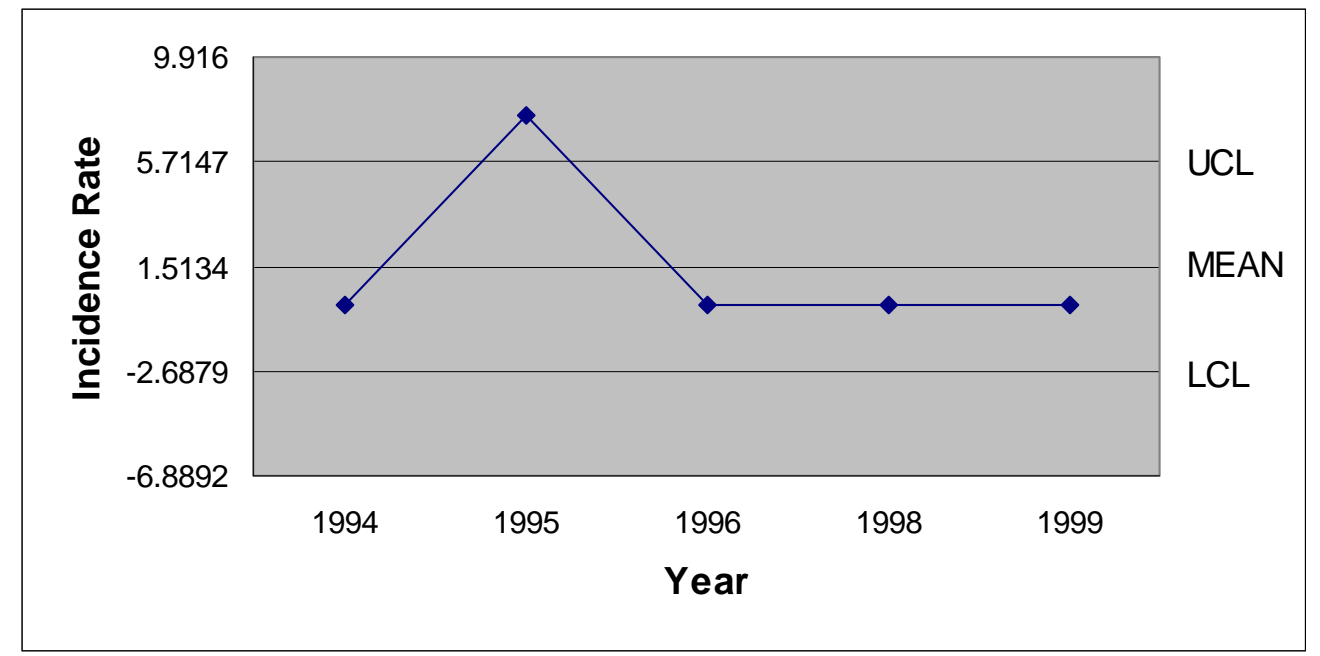

Note: No operations in August 1997

Figure 232. August 1994-1999 Transitional Incidence Rates - Finishing Plant \#1 
Finishing Plant \#1 also experienced only one nonzero incidence rate in September. This 6.195 incidence rate occurred in September 1996, the month preceding the work stoppage (See Figure 233).

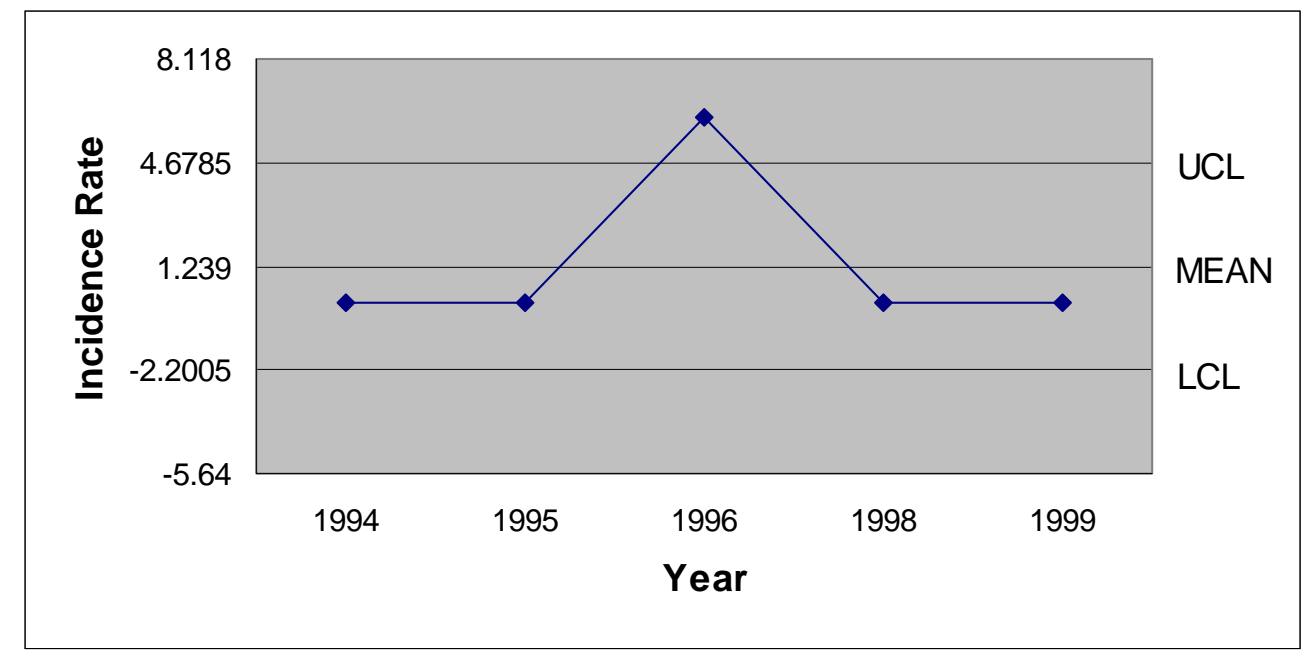

Note: No operations in September 1997

Figure 233. September 1994-1999 Transitional Incidence Rates - Finishing Plant \#1

Finishing Plant \#1 experienced the only nonzero October transitional incidence rate in 1999 (See Figure 234).

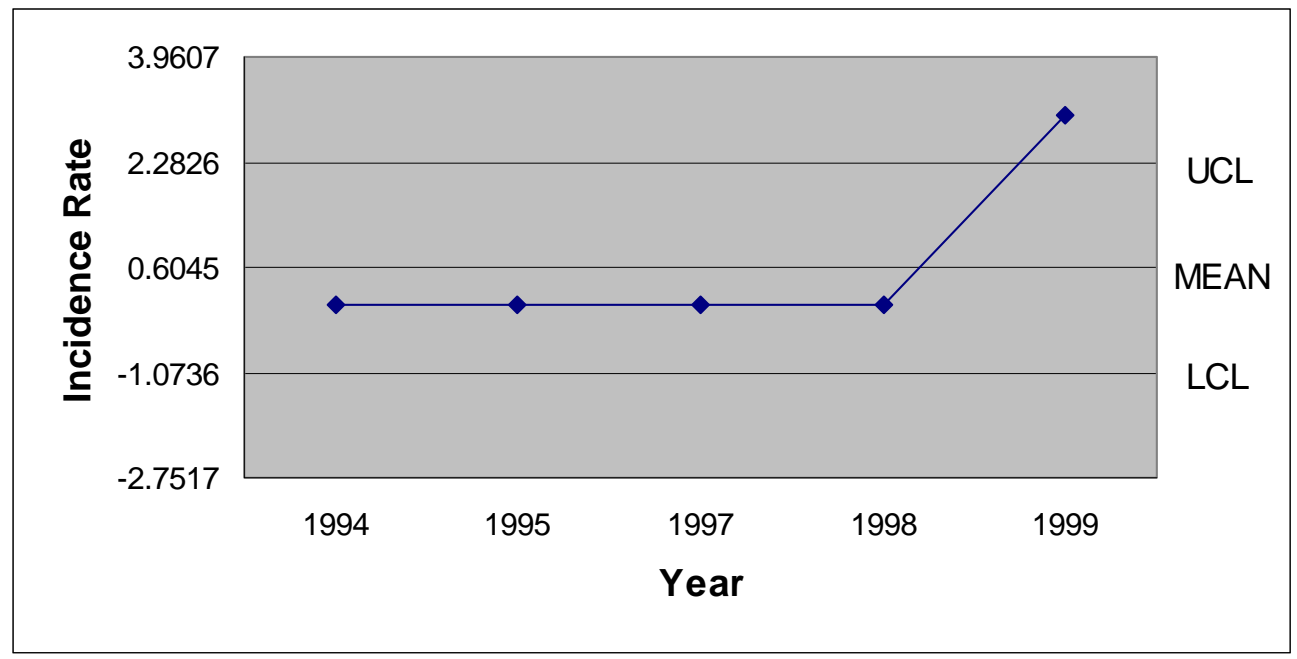

Note: No operations in October 1996

Figure 234. October 1994-1999 Transitional Incidence Rates - Finishing Plant \#1 
The only nonzero November incidence rate at Finishing Plant \#1 occurred in 1998, the second month of operations following the work stoppage (See Figure 235).

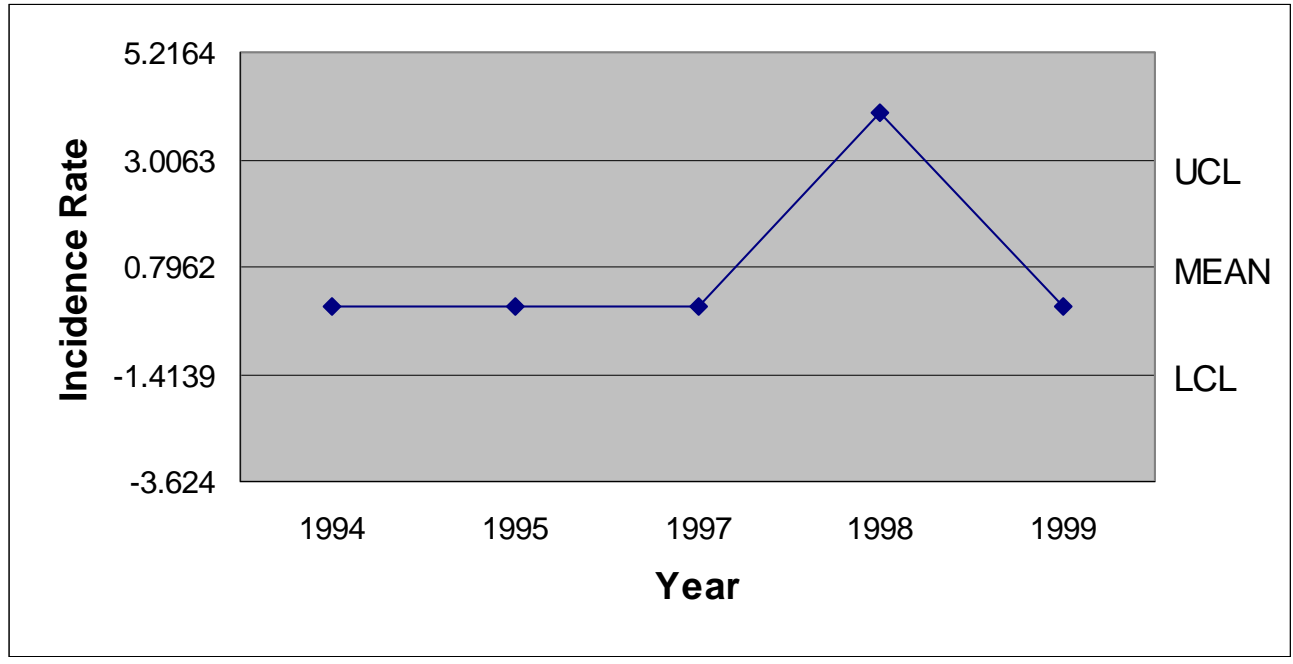

Note: No operations in November 1996

Figure 235. November 1994-1999 Transitional Incidence Rates - Finishing Plant \#1

The 2.676 incidence rate recorded in December 1995 was the only nonzero transitional incidence rate recorded for Finishing Plant \#1 during the research period (See Figure 236).

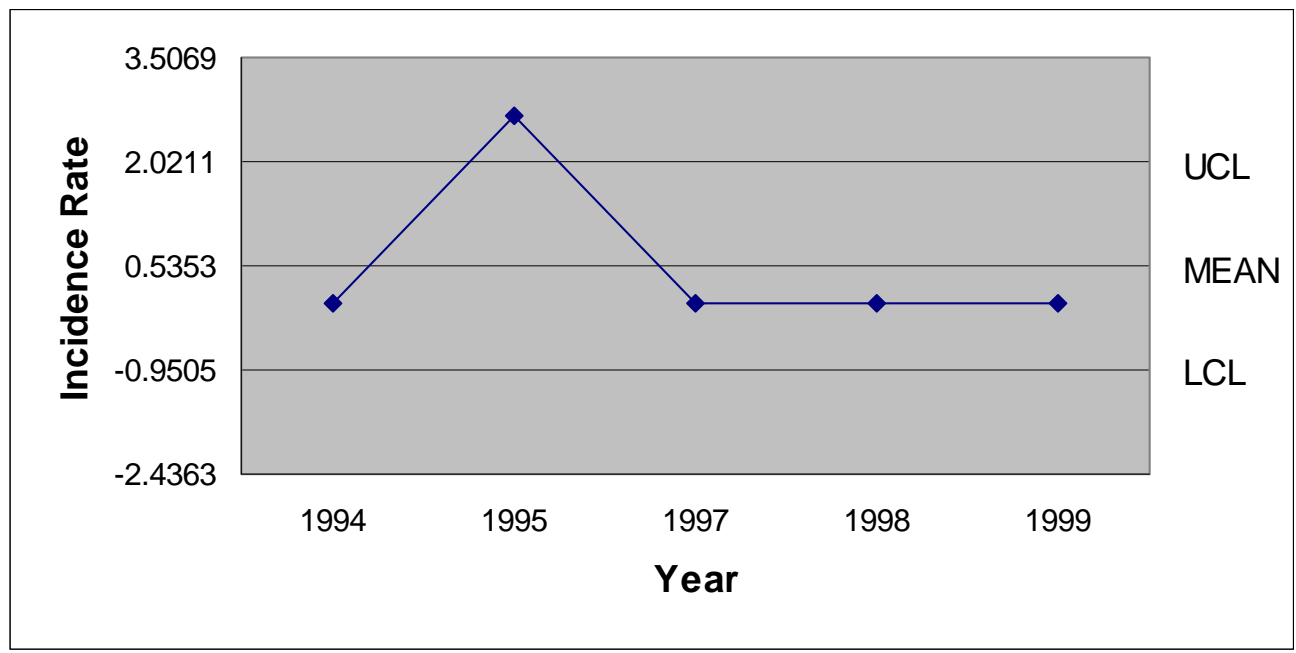

Note: No operations in December 1996

Figure 236. December 1994-1999 Transitional Incidence Rates - Finishing Plant \#1 
Table 41 presents the Finishing Plant \#1 monthly incidence rates for each year of the study period, as well as the UCL, mean, LCL, and standard deviation. Nineteen ninety-six and 1997 were partial years because of the work stoppage and only the first six months of 2000 were included in the research.

Table 41

$\underline{\text { Summary of Monthly Transitional Incidence Rates Data - Finishing Plant \#1 }}$

\begin{tabular}{|l|l|l|l|l|l|l|l|l|l|l|l|l|}
\hline & Jan. & Feb. & Mar. & Apr. & May & June & July & Aug. & Sept. & Oct. & Nov. & Dec. \\
\hline 1994 & 0.000 & 0.000 & 0.000 & 0.000 & 0.000 & 2.349 & 0.000 & 0.000 & 0.000 & 0.000 & 0.000 & 0.000 \\
\hline 1995 & 0.000 & 0.000 & 0.000 & 7.669 & 0.000 & 5.395 & 10.242 & 7.567 & 0.000 & 0.000 & 0.000 & 2.676 \\
\hline 1996 & 0.000 & 2.564 & 0.000 & 0.000 & 7.401 & 7.802 & 0.000 & 0.000 & 6.195 & N/A & N/A & N/A \\
\hline 1997 & N/A & N/A & N/A & N/A & N/A & N/A & N/A & N/A & N/A & 0.000 & 0.000 & 0.000 \\
\hline 1998 & 0.000 & 3.672 & 3.272 & 3.448 & 0.000 & 3.449 & 0.000 & 0.000 & 0.000 & 0.000 & 3.981 & 0.000 \\
\hline 1999 & 0.000 & 0.000 & 3.222 & 0.000 & 0.000 & 0.000 & 0.000 & 0.000 & 0.000 & 3.022 & 0.000 & 0.000 \\
\hline 2000 & 0.000 & 0.000 & 0.000 & 0.000 & 0.000 & 0.000 & N/A & N/A & N/A & N/A & N/A & N/A \\
\hline UCL & 0.000 & 2.769 & 2.842 & 5.175 & 4.405 & 6.392 & 7.734 & 5.715 & 4.678 & 2.283 & 3.006 & 2.021 \\
\hline Mean & 0.000 & 1.039 & 1.082 & 1.853 & 1.234 & 3.166 & 2.048 & 1.513 & 1.239 & 0.604 & 0.796 & 0.535 \\
\hline LCL & 0.000 & -0.690 & -0.678 & -1.470 & -1.938 & -0.061 & -3.638 & -2.688 & -2.200 & -1.074 & -1.414 & -0.951 \\
\hline SD & 0.000 & 0.673 & 0.685 & 1.292 & 1.234 & 1.255 & 2.048 & 1.513 & 1.239 & 0.604 & 0.796 & 0.535 \\
\hline
\end{tabular}

$\underline{\text { Seasonal Analysis of Monthly Transitional Data - Finishing Plant \#1 }}$

Figure 237 presents the figures generated from the seasonal index calculation at Finishing Plant \#1. June had the highest seasonal index, more than double the seasonal index recorded in any other month. The lowest seasonal index, 0.00 , was posted for the month of January, which did not experience any transitional incidents during the study period. 


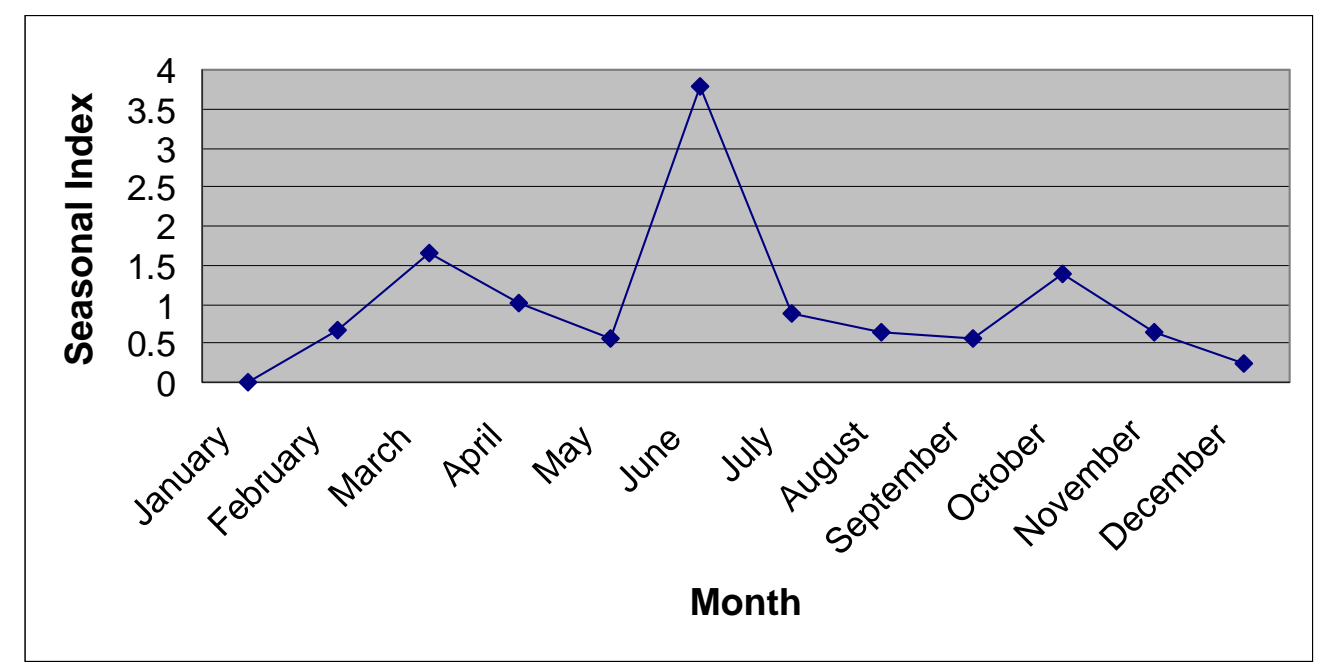

Figure 237. Monthly Seasonal Pattern of Transitional Incidence Rates - Finishing Plant $\# 1$

Testing the Statistical Relationship of Transitional Data - Finishing Plant \#1 All 33 Months Prior to and Subsequent to the Work Stoppage

Comparison of the transitional incidence rates for the 33 months preceding the work stoppage and the 33 months following the work stoppage at Finishing Plant \#1 was accomplished using the comparison formula. For the entire 33 months prior to the work stoppage and the 33 post work stoppage months at Finishing Plant \#1 the comparison $\mathrm{t}$ value was 0.47. Because this calculated amount was less than the critical $t$ value of 2.045, a statistically significant decrease in incidence rates did not occur between the two periods.

First 24 Months and Last 24 Months of the Research Period

The same formula was applied to the transitional incidence rates for the first 24 months and the last 24 months of the period at Finishing Plant \#1. These time periods excluded the nine months prior to and immediately following the work stoppage. Using a critical t value of 2.120 , the calculated amount, 2.061, indicated that the decrease in incidence rates between the periods was not quite statistically significant. 


\section{Nine Month Intervals Prior to and Subsequent to the Work Stoppage}

For the nine months prior to and subsequent to the work stoppage, the result of this calculation, 0.853 , was less than the 2.179 critical $t$ value for the .05 level of significance. Therefore it can be stated that at the .05 significance level, there is not a statistically significant decrease in transitional incidence rates between the two periods.

Table 42

Comparison of Prior and Post Work Stoppage Periods - Finishing Plant \#1

\begin{tabular}{|c|c|c|c|c|}
\hline \multirow[b]{2}{*}{ Time Period } & \multicolumn{2}{|c|}{ Finishing Plant \#1 Incidence Rates } & \multirow[b]{2}{*}{ Critical t Value } & \multirow[b]{2}{*}{$\begin{array}{l}\text { Calculated } \\
\text { Comparison Value }\end{array}$} \\
\hline & $\begin{array}{l}\text { Prior to } \\
\text { Work Stoppage }\end{array}$ & $\begin{array}{l}\text { Post } \\
\text { Work Stoppage }\end{array}$ & & \\
\hline 9 Months & 2.58 & 1.55 & 2.179 & 0.853 \\
\hline 24 Months & 1.43 & 0.42 & 2.120 & 2.061 \\
\hline 33 Months & 1.73 & 0.72 & 2.045 & 0.47 \\
\hline
\end{tabular}

* Indicates a statistically significant increase

** Indicates a statistically significant decrease

Finishing Plant \#2 Analysis

\section{Quarterly Analysis of Transitional Data - Finishing Plant \#2}

The first quarter transitional incidence rates for Finishing Plant \#2 reached a low of 0.000 in 1994 and a high of 2.547 the next year. The 1996 through 2000 incidence rates were close to the mean, with the 1996 incidence rate recorded below the mean (See Figure 238). 


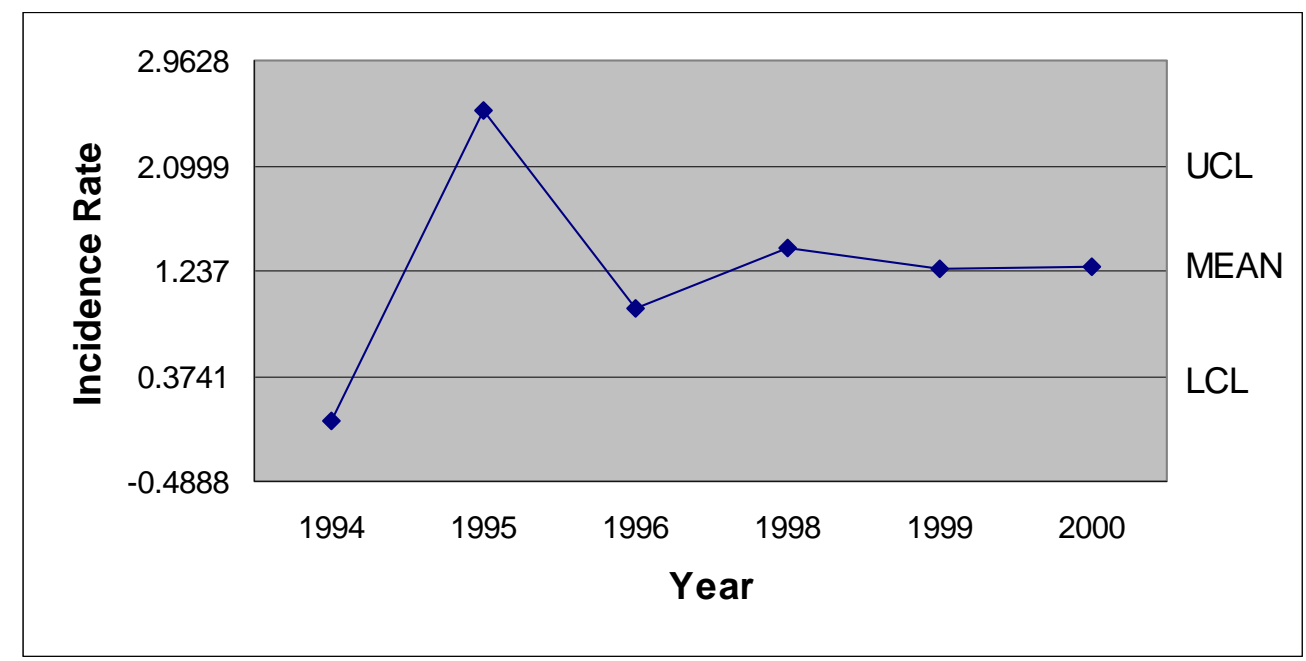

Note: No operations in first quarter 1997

Figure 238. First Quarter 1994-2000 Transitional Incidence Rates - Finishing Plant \#2

Second quarter 1994 and 1999 did not experience any transitional incidents. The highest second quarter transitional incidence rate for Finishing Plant \#2 was 5.246 recorded in 1998. The second highest incidence rate occurred in the second quarter of 2000 (See Figure 239).

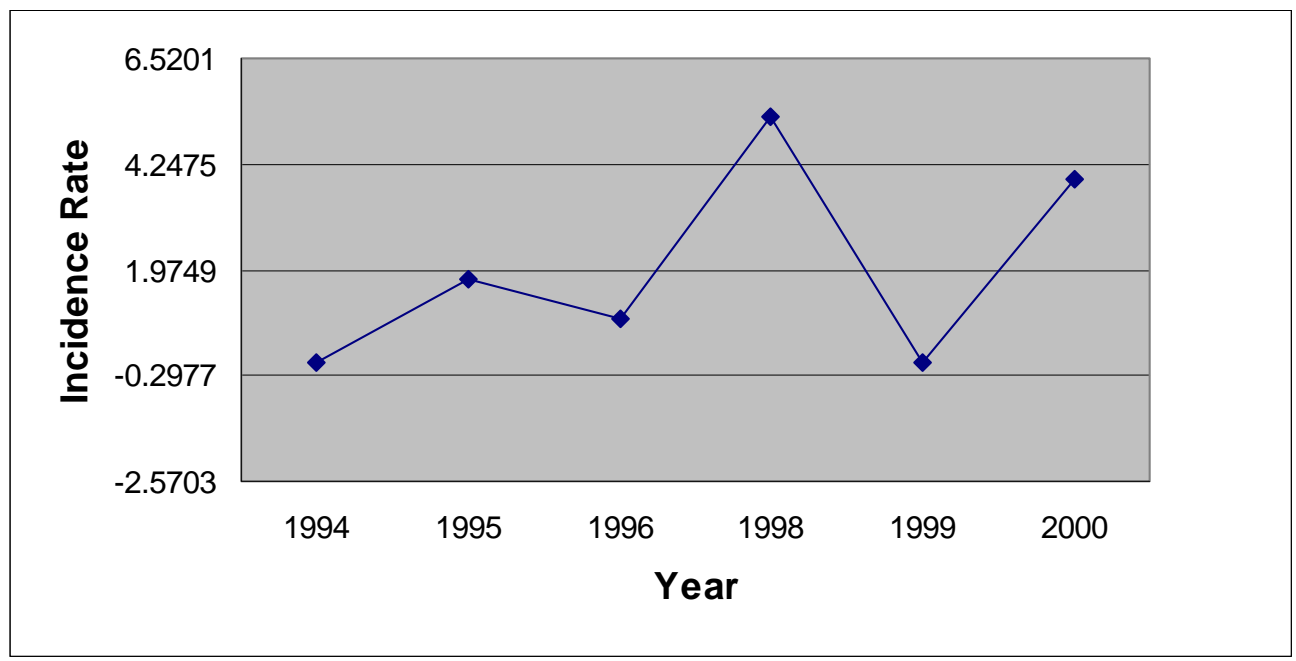

Note: No operations in second quarter 1997

Figure 239. Second Quarter 1994-2000 Transitional Incidence Rates - Finishing Plant \#2 
The third quarter incidence rate for 1994 at Finishing Plant \#2 was the highest during the research period. As illustrated in Figure 240, the 1994 incidence rate of 3.606 was the only third quarter rate outside the established control limits. The remaining periods were all between the mean and the LCL, except the 1998 incidence rate, which was above the mean.

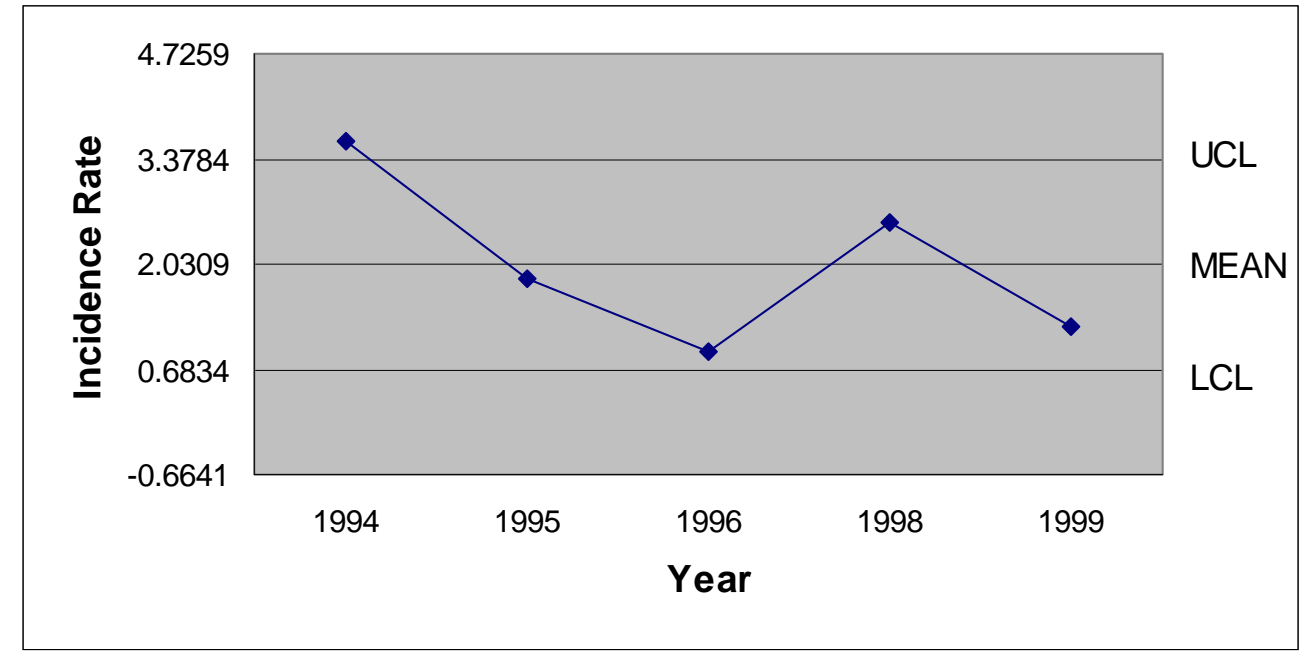

Note: No operations in third quarter 1997

Figure 240. Third Quarter 1994-1999 Transitional Incidence Rates - Finishing Plant \#2

Fourth quarter transitional incidence rates at Finishing Plant \#2 experienced a downward trend for the first three years of this study. After reaching the 0.00 level in 1997 the incidence rate was just below the mean in 1998 and above the UCL in 1999 (See Figure 241). 


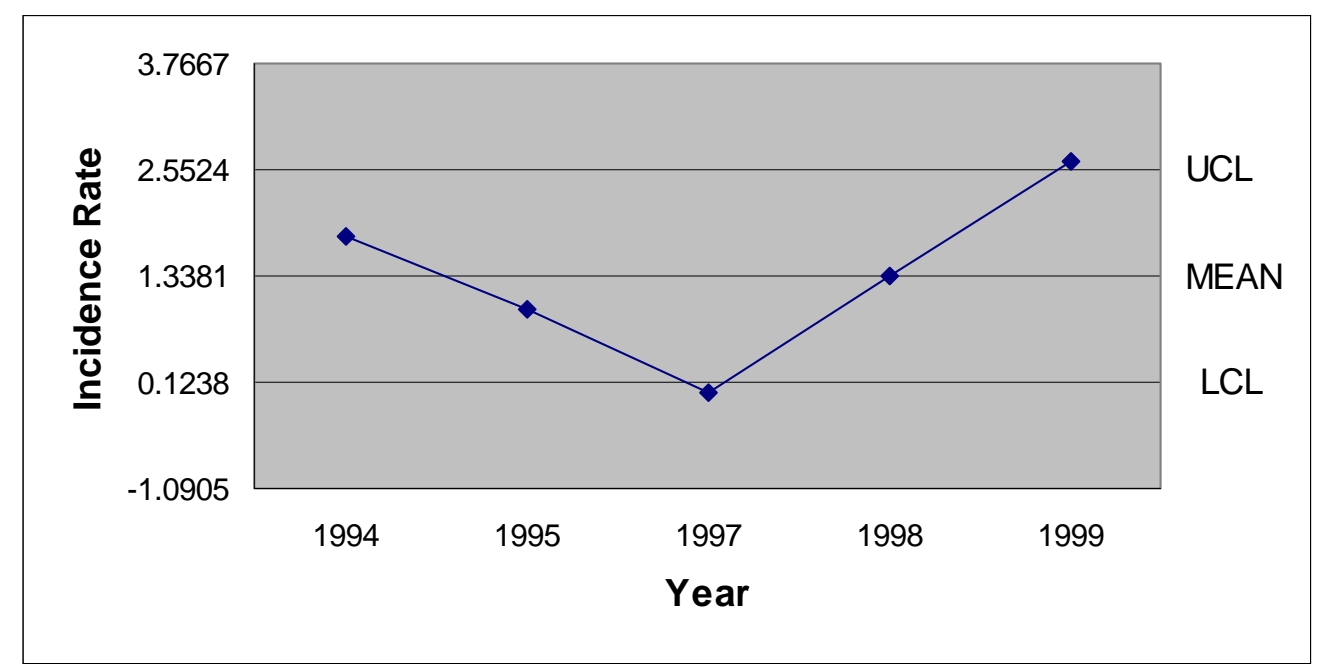

Note: No operations in fourth quarter 1996.

Figure 241. Fourth Quarter 1994-1999 Transitional Incidence Rates - Finishing Plant \#2

Table 43 presents the quarterly incidence rates at Finishing Plant \#2 for each year of the study period, as well as the UCL, mean, LCL, and standard deviation. Nineteen ninety-six and 1997 are partial years because of the work stoppage and only the first six months of 2000 were included in the research.

Table 43

Summary of Quarterly Transitional Incidence Rates Data - Finishing Plant \#2

\begin{tabular}{|l|l|l|l|l|}
\hline & $1^{\text {st }}$ Quarter & $2^{\text {nd }}$ Quarter & $3^{\text {rd }}$ Quarter & $4^{\text {th }}$ Quarter \\
\hline 1994 & 0.000 & 0.000 & 3.606 & 1.782 \\
\hline 1995 & 2.547 & 1.774 & 1.852 & 0.946 \\
\hline 1996 & 0.927 & 0.913 & 0.912 & N/A \\
\hline 1997 & N/A & N/A & N/A & 0.000 \\
\hline 1998 & 1.430 & 5.246 & 2.567 & 1.327 \\
\hline 1999 & 1.250 & 0.000 & 1.218 & 2.637 \\
\hline 2000 & 1.268 & 3.916 & N/A & N/A \\
\hline UCL & 2.100 & 4.248 & 3.378 & 2.553 \\
\hline MEAN & 1.237 & 1.975 & 2.031 & 1.338 \\
\hline LCL & 0.374 & -0.298 & 0.683 & 0.124 \\
\hline SD & 0.336 & 0.884 & 0.485 & 0.437 \\
\hline
\end{tabular}




\section{Seasonal Analysis of Transitional Data - Finishing Plant \#2}

The results of the Finishing Plant \#2 quarterly seasonal index calculations are presented in Figure 242. The incidence rates seasonal index indicated that the third quarter had the highest seasonal index and the first quarter the lowest. The second and fourth quarters were relatively close in magnitude.

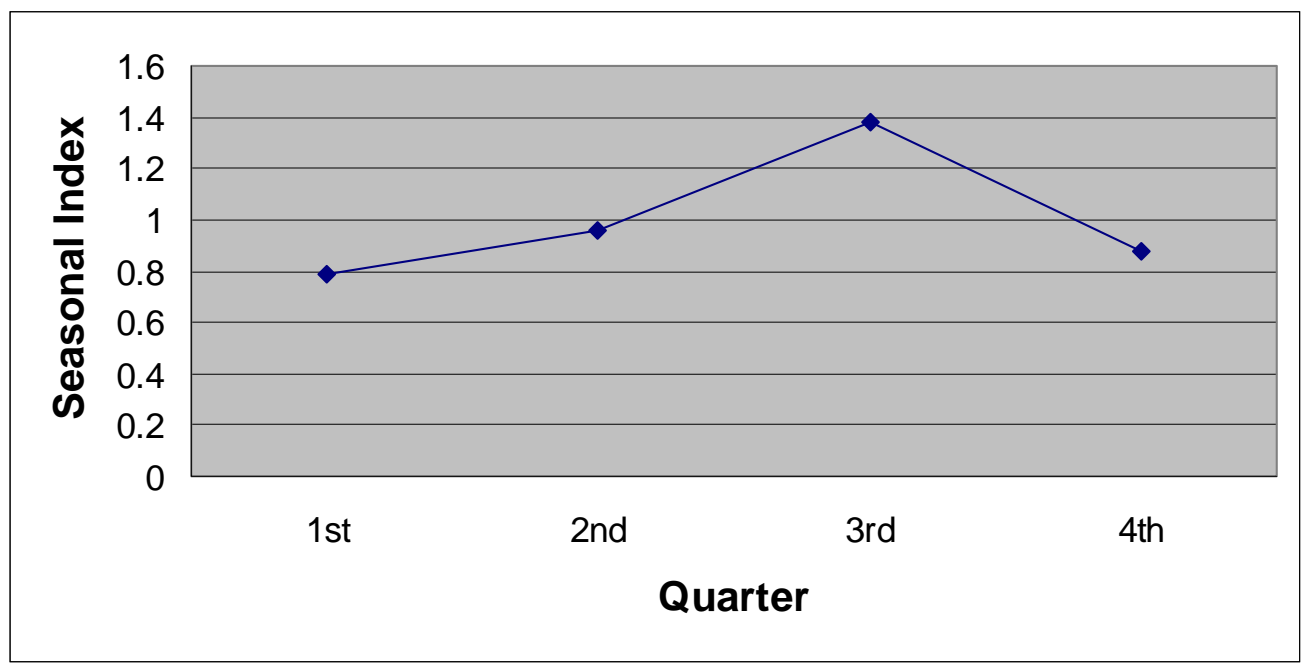

Figure 242. Quarterly Seasonal Index for Transitional Incidence Rates - Finishing Plant \#2

\section{Monthly Analysis of Transitional Data - Finishing Plant \#2}

As illustrated in Figure 243, the highest January incidence rate at Finishing Plant $\# 2,7.639$, was recorded in 1995 . The preceding and following years both had incidence rates of 0.000. In 1998 and 1999 the incidence rate was between the mean and the UCL. In 2000 the January incidence rate was 0.000 . 


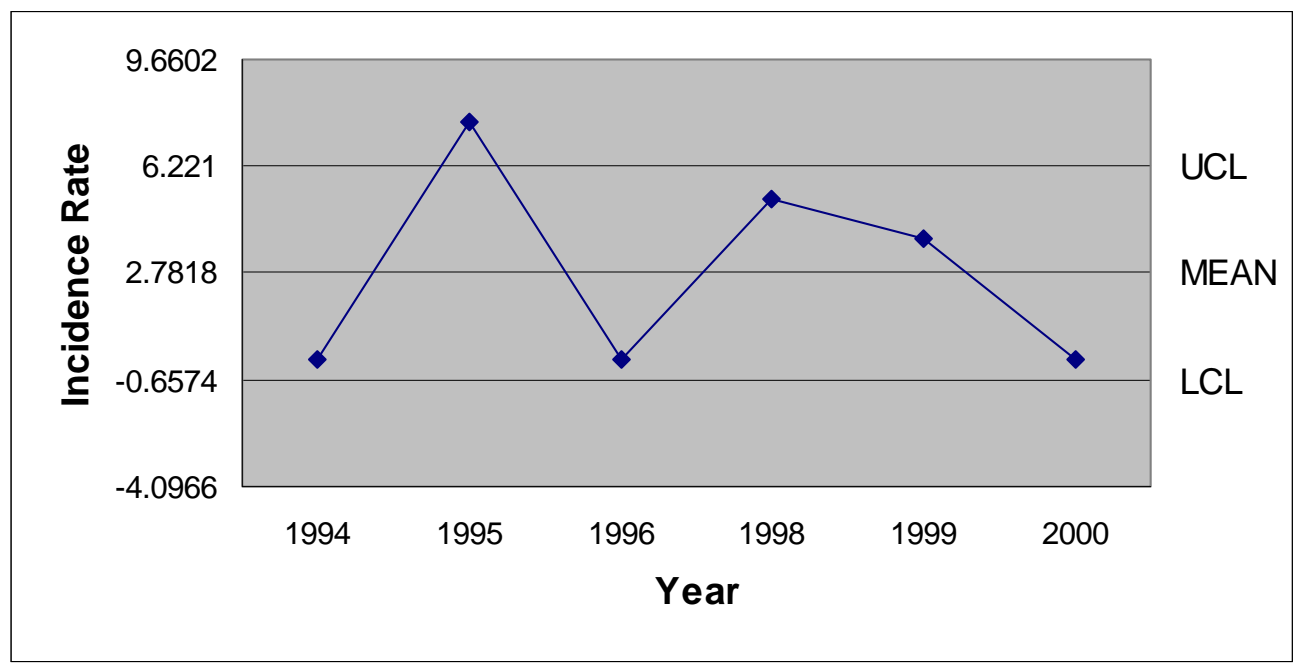

Note: No operations in January 1997

Figure 243. January 1994-2000 Transitional Incidence Rates - Finishing Plant \#2

The February incidence rate at Finishing Plant \#2were marked by four years that did not experience any transitional incidents. For the two nonzero years, the incidence rate was near the UCL (See Figure 244).

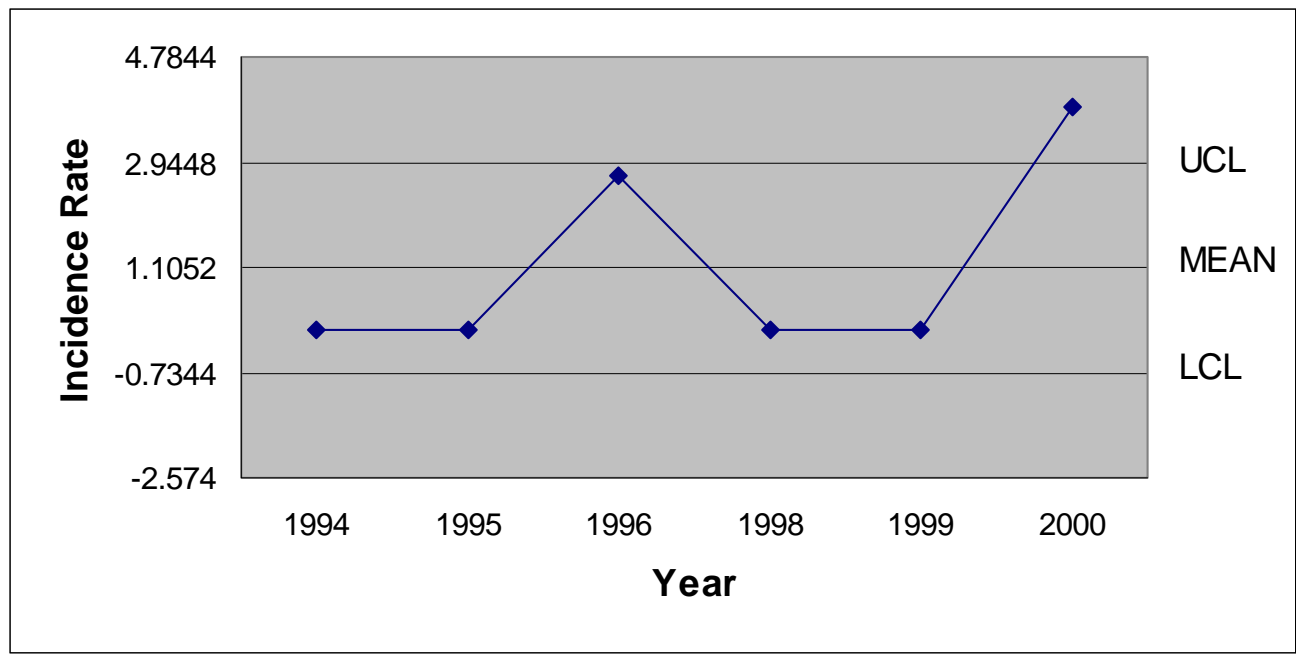

Note: No operations in February 1997

Figure 244. February 1994-2000 Transitional Incidence Rates - Finishing Plant \#2 
No transitional incidents were experienced at Finishing Plant $\# 2$ in the month of March during the study period. This created a situation where the UCL, mean, and LCL were all equal (See Figure 245).

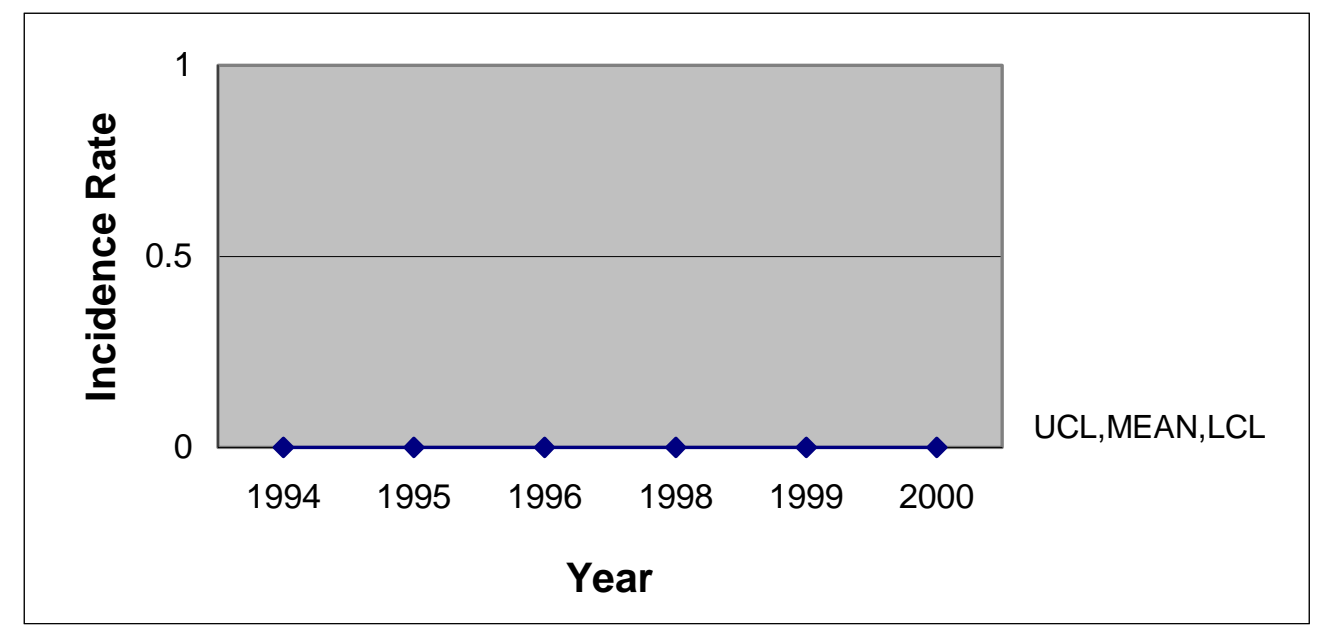

Note: No operations in March 1997

Figure 245. March 1994-2000 Transitional Incidence Rates - Finishing Plant \#2

During the research period at Finishing Plant \#2 April 2000 was the only nonzero month of April. The incidence rate in April 2000 was 4.198 (See Figure 246).

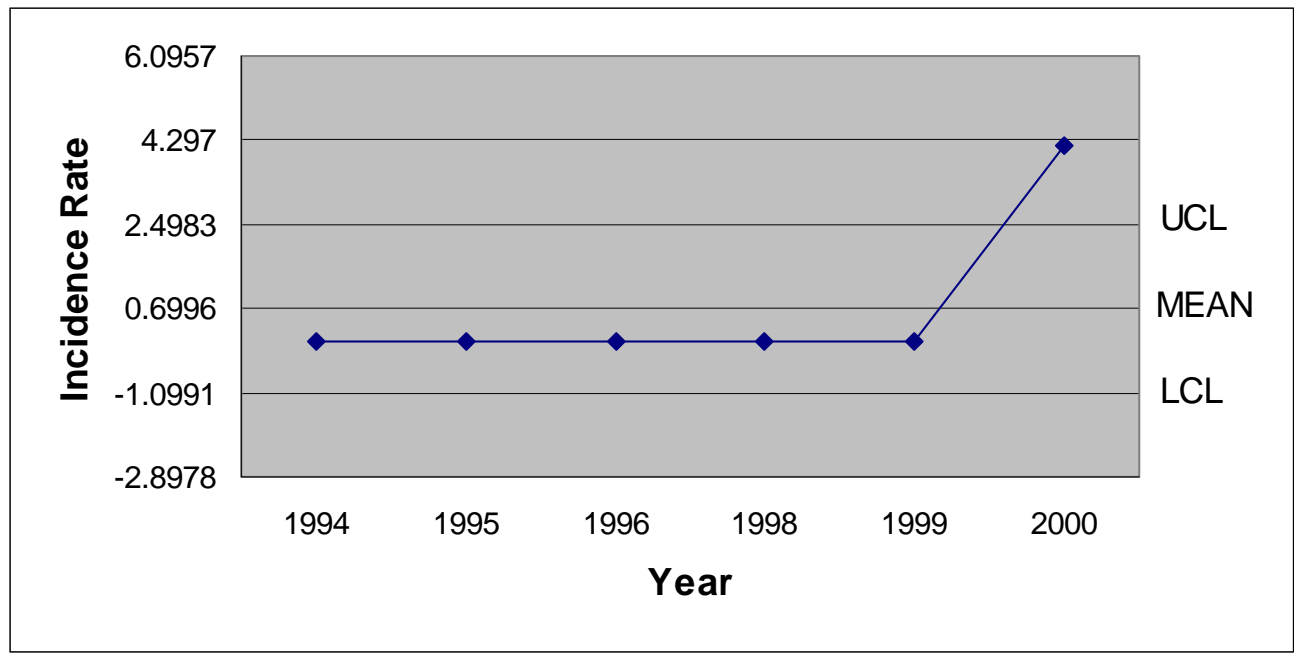

Note: No operations in April 1997

Figure 246. April 1994-2000 Transitional Incidence Rates - Finishing Plant \#2 
The highest transitional incidence rate, 7.776, during the month of May was recorded at Finishing Plant \#2 in 1998. Incidence rates of 0.000 were recorded in 1994, 1996, and 1999. The second highest rate occurred in May 2000 (See Figure 247).

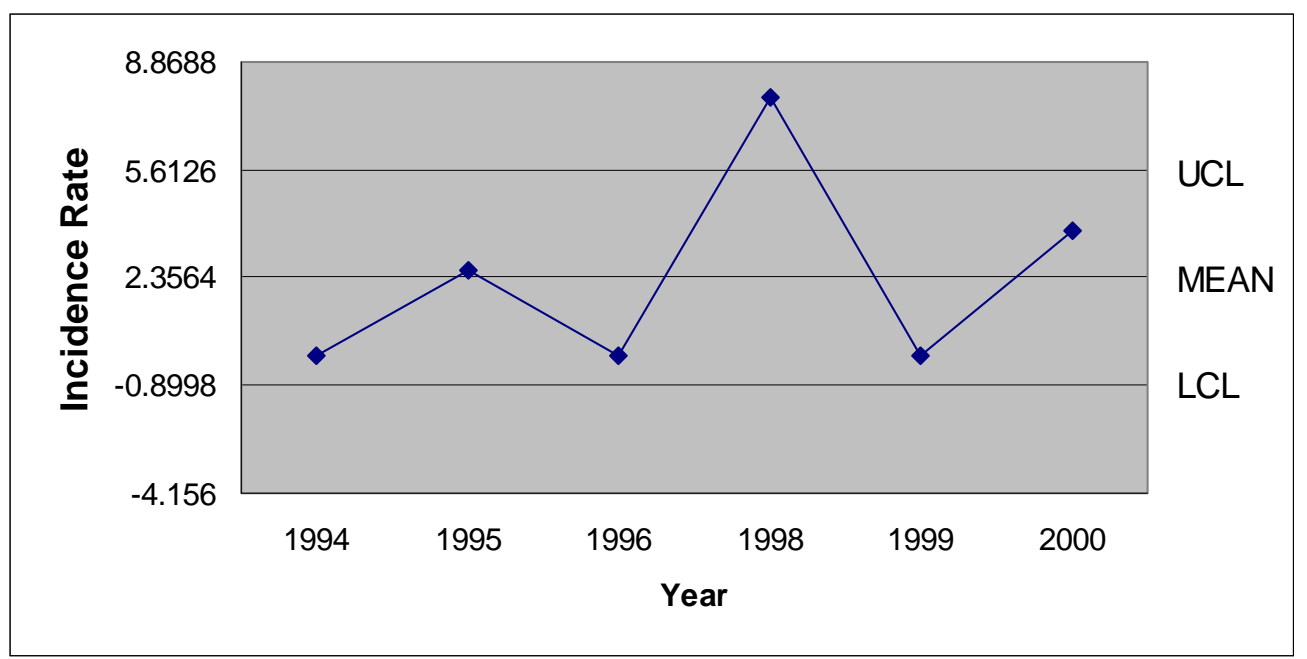

Note: No operations in May 1997

Figure 247. May 1994-2000 Transitional Incidence Rates - Finishing Plant \#2

The June 1994 and 1999 transitional incidence rates at Finishing Plant \#2 were 0.000. June 1995 and 1996 were almost equal to the mean. The highest incidence rate occurred in 1998, when a rate of 7.747 was recorded (See Figure 248).

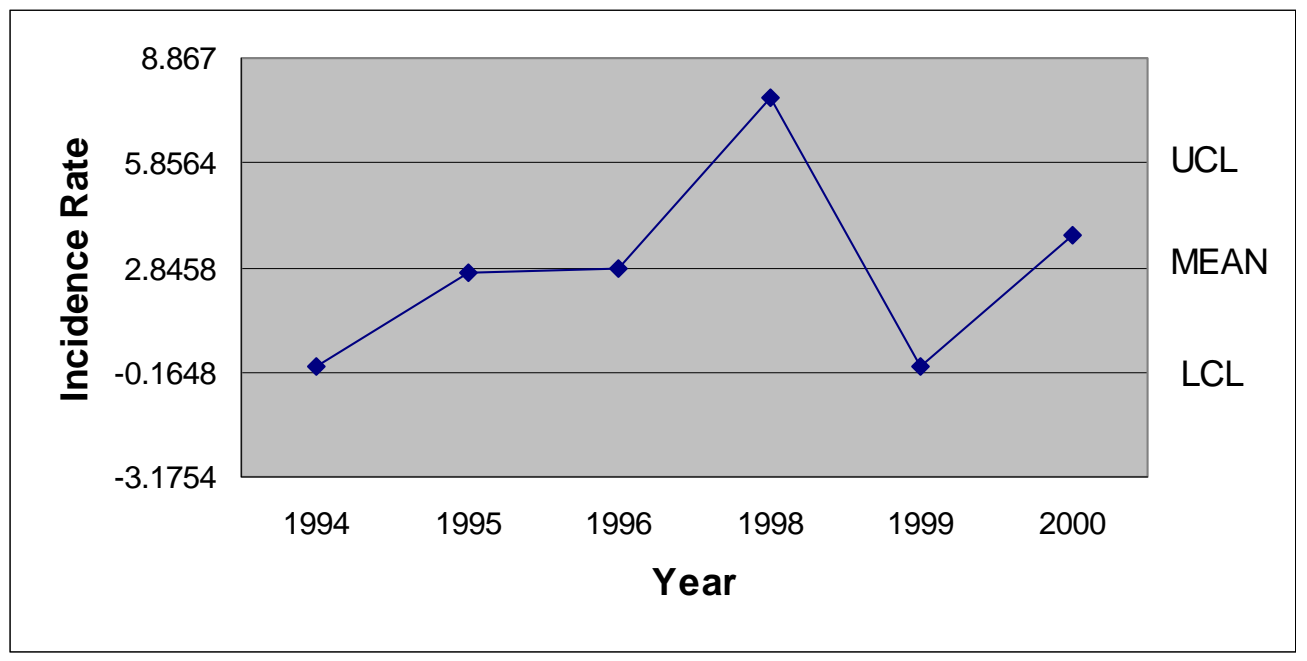

Note: No operations in June 1997

Figure 248. June 1994-2000 Transitional Incidence Rates - Finishing Plant \#2 
For the month of July at Finishing Plant \#2, the three nonzero incidence rates all appeared between the mean and the UCL. The zero incidence rates recorded in 1995 an 1996 were followed in 1998 with the highest incidence rate for the month of July (See Figure 249).

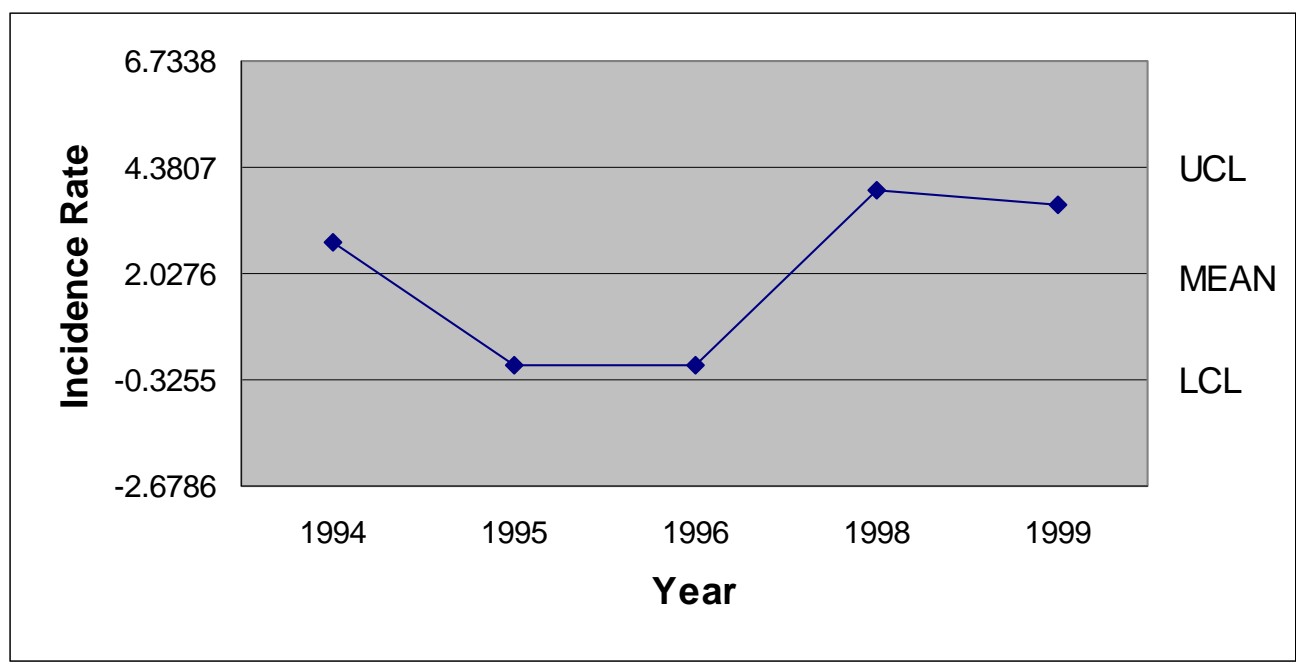

Note: No operations in July 1997

Figure 249. July 1994-1999 Transitional Incidence Rates - Finishing Plant \#2

The first August incidence rate recorded at Finishing Plant \#2 during the study period was above the UCL. In 1995 the incidence rate had decreased to a level just above the mean. Zero transitional incidents occurred during the next three years of operations in August (See Figure 250). 


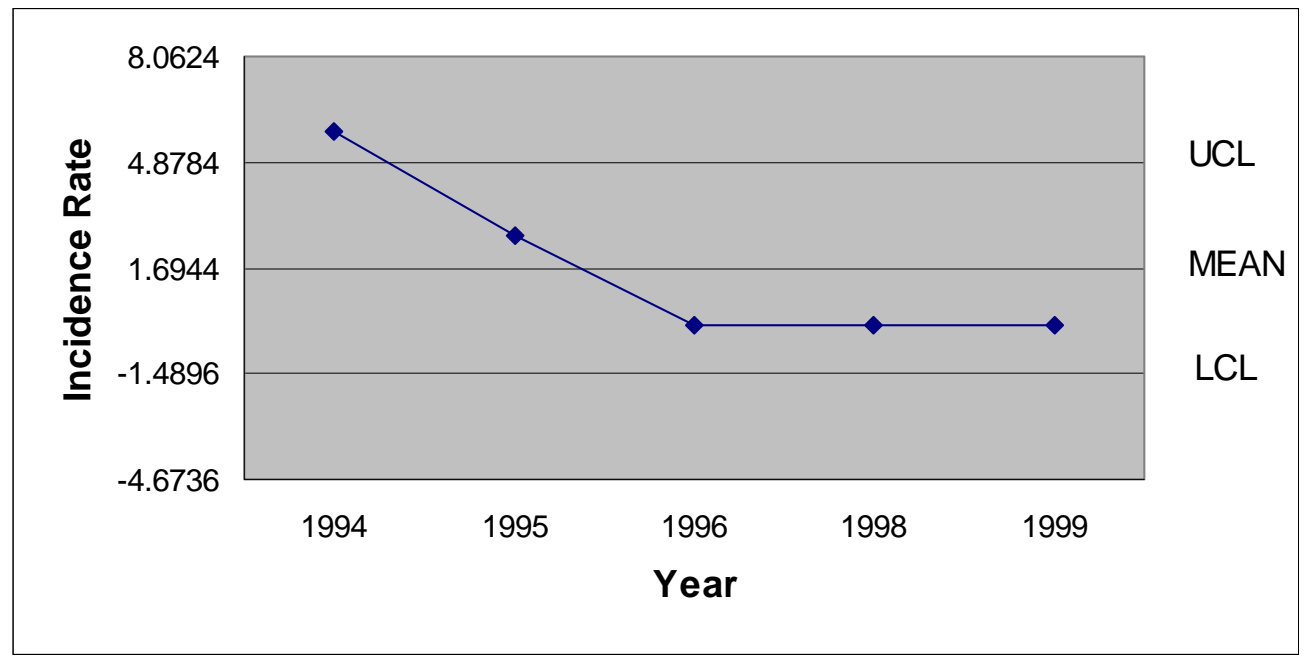

Note: No operations in August 1997

Figure 250. August 1994-1999 Transitional Incidence Rates - Finishing Plant \#2

September incidence rates at Finishing Plant \#2 began during the research period at 2.510 and steadily increased to the high of 3.884 in 1998 . September 1999 did not experience any transitional incidents (See Figure 251).

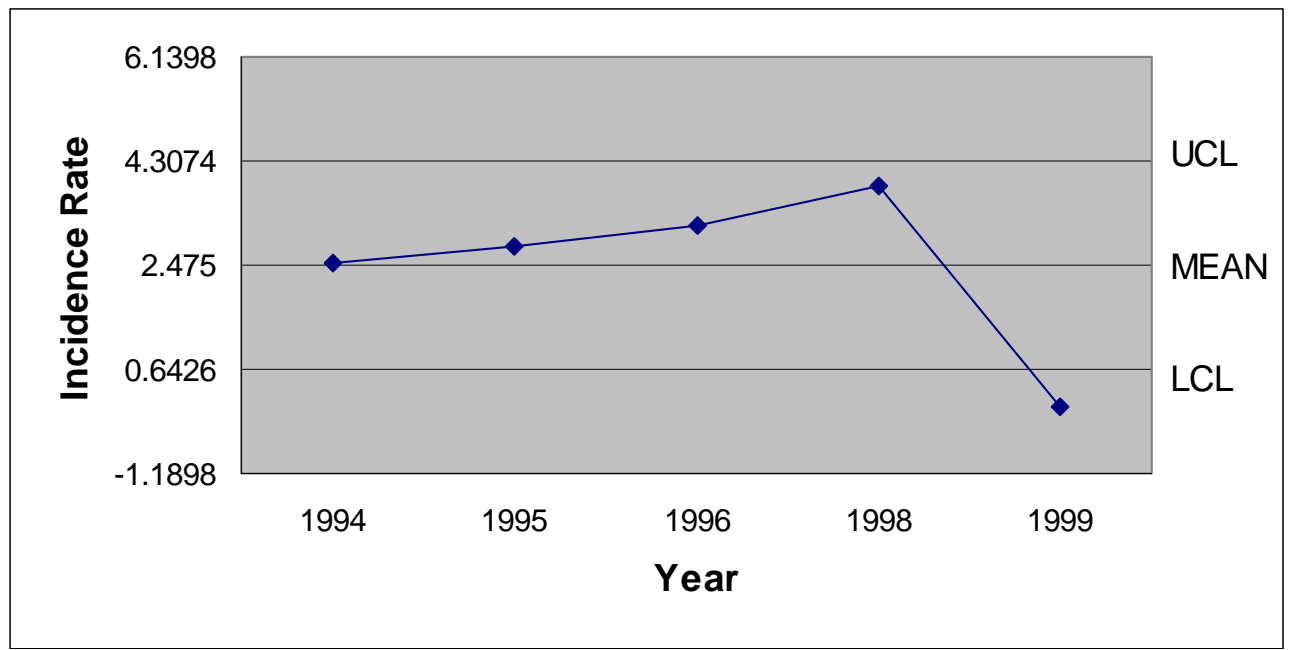

Note: No operations in September 1997

Figure 251. September 1994-1999 Transitional Incidence Rates - Finishing Plant \#2 
As illustrated in Figure 252, the October 1999 transitional incidence rate at Finishing Plant \#2 of 3.766 was the only nonzero October incidence rate during the study period.

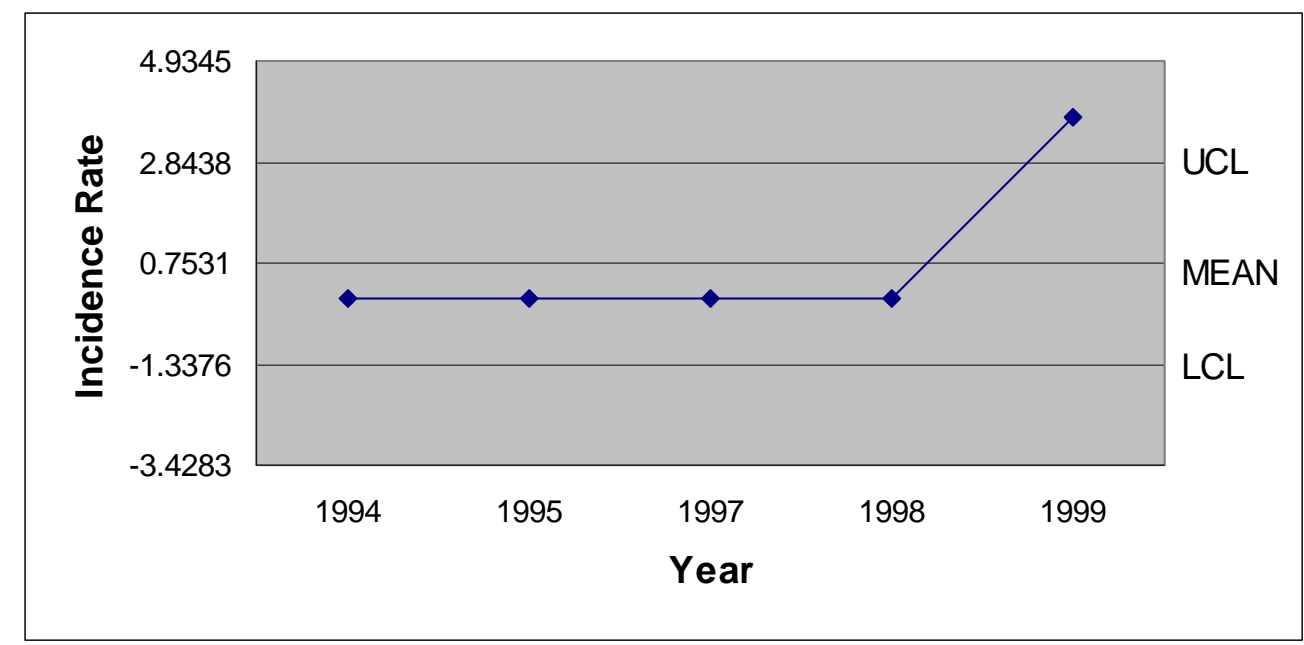

Note: No operations in October 1996

Figure 252. October 1994-1999 Transitional Incidence Rates - Finishing Plant \#2

In 1994 the November incidence rate at Finishing Plant \#2 was 2.765. The highest November rate occurred the next year at a level of 2.899. The remaining months of November all recorded incidence rates of 0.000 (See Figure 253).

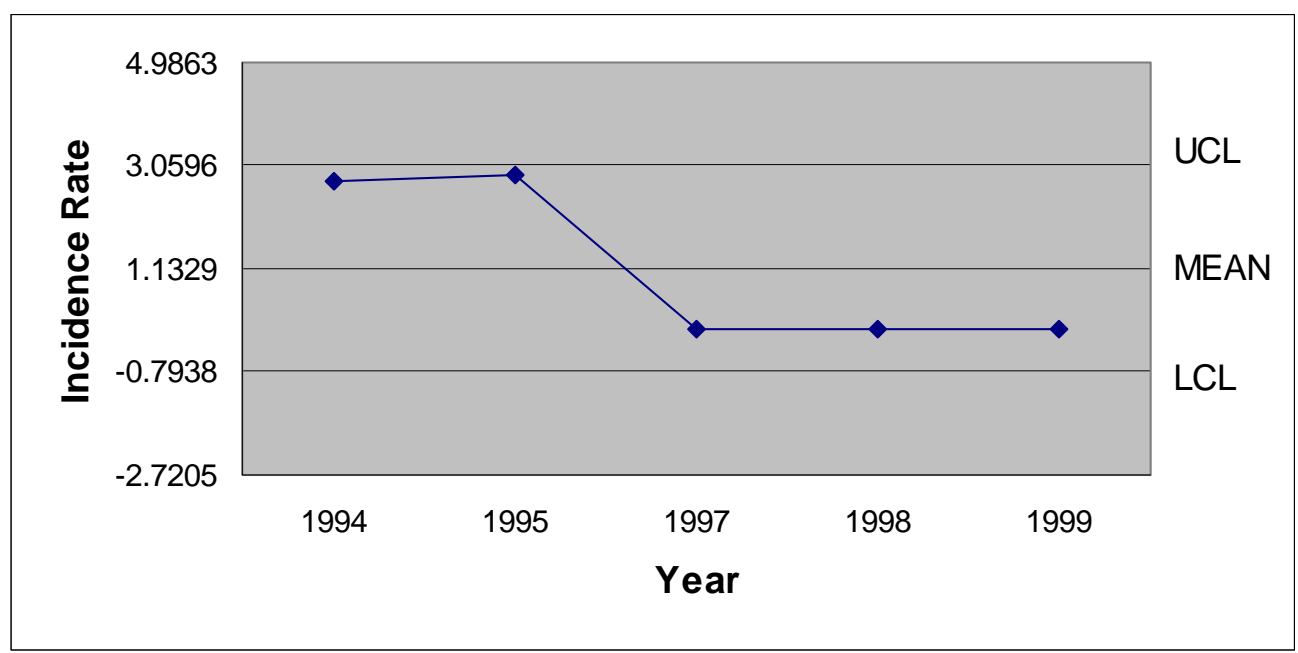

Note: No operations in November 1996

Figure 253. November 1994-1999 Transitional Incidence Rates - Finishing Plant \#2 
Finishing Plant \#2 experienced an incidence rate in December 1994 just above the mean. The next two periods, 1995 and 1997, recorded incidence rates of zero. In 1998 the second highest incidence rate of 3.801 was recorded. The highest incidence rate, 4.111, occurred in 1999 (See Figure 254).

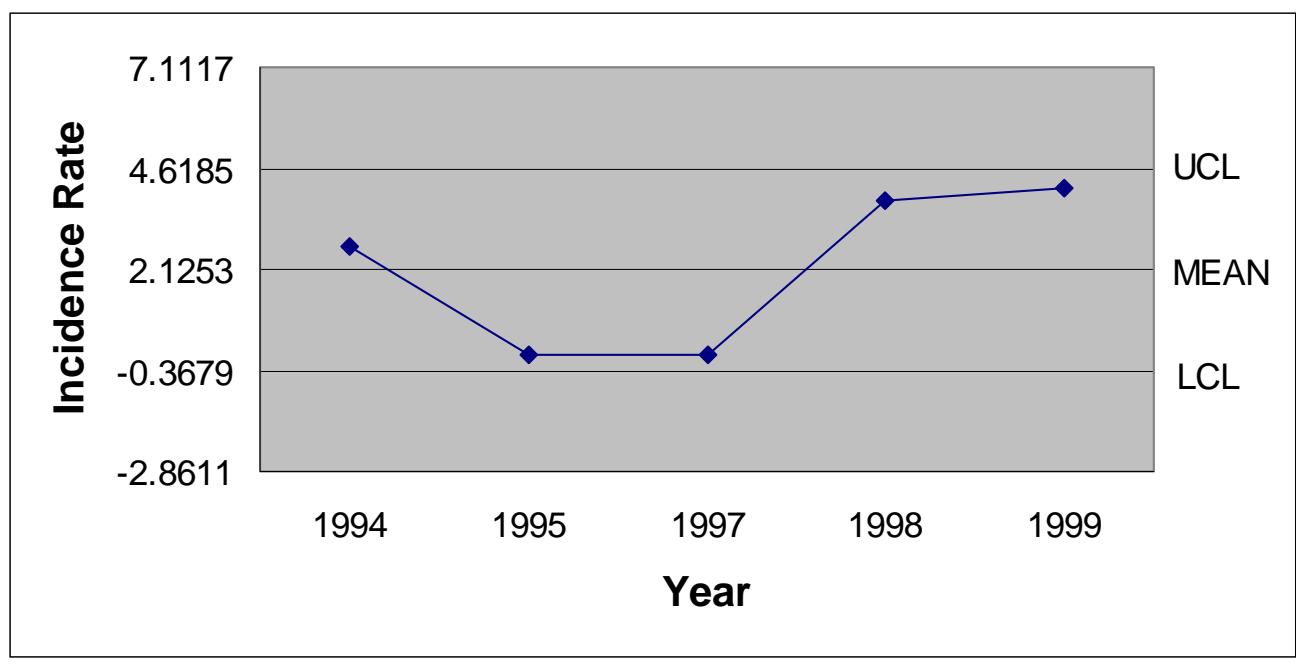

Note: No operations in December 1996

Figure 254. December 1994-1999 Transitional Incidence Rates - Finishing Plant \#2

Table 44 presents the monthly incidence rates for each year of the study period, as well as the UCL, mean, LCL, and standard deviation. Nineteen ninety-six and 1997 were partial years because of the work stoppage and only the first six months of 2000 were included in the research.

Table 44

$\underline{\text { Summary of Monthly Transitional Incidence Rates Data - Finishing Plant \#2 }}$

\begin{tabular}{|l|l|l|l|l|l|l|l|l|l|l|l|l|}
\hline & Jan. & Feb. & Mar. & Apr. & May & June & July & Aug. & Sept. & Oct. & Nov. & Dec. \\
\hline 1994 & 0.000 & 0.000 & 0.000 & 0.000 & 0.000 & 0.000 & 2.739 & 5.782 & 2.510 & 0.000 & 2.765 & 2.714 \\
\hline 1995 & 7.639 & 0.000 & 0.000 & 0.000 & 2.578 & 2.725 & 0.000 & 2.690 & 2.803 & 0.000 & 2.899 & 0.000 \\
\hline 1996 & 0.000 & 2.724 & 0.000 & 0.000 & 0.000 & 2.807 & 0.000 & 0.000 & 3.177 & N/A & N/A & N/A \\
\hline 1997 & N/A & N/A & N/A & N/A & N/A & N/A & N/A & N/A & N/A & 0.000 & 0.000 & 0.000 \\
\hline 1998 & 5.156 & 0.000 & 0.000 & 0.000 & 7.776 & 7.747 & 3.859 & 0.000 & 3.884 & 0.000 & 0.000 & 3.801 \\
\hline 1999 & 3.896 & 0.000 & 0.000 & 0.000 & 0.000 & 0.000 & 3.540 & 0.000 & 0.000 & 3.766 & 0.000 & 4.111 \\
\hline 2000 & 0.000 & 3.908 & 0.000 & 4.198 & 3.784 & 3.795 & N/A & N/A & N/A & N/A & N/A & N/A \\
\hline
\end{tabular}




\begin{tabular}{|l|l|l|l|l|l|l|l|l|l|l|l|l|}
\hline UCL & 6.221 & 2.945 & 0.000 & 2.498 & 5.613 & 5.856 & 4.381 & 4.878 & 4.307 & 2.844 & 3.060 & 4.618 \\
\hline Mean & 2.782 & 1.105 & 0.000 & 0.700 & 2.356 & 2.846 & 2.028 & 1.694 & 2.475 & 0.753 & 1.133 & 2.125 \\
\hline LCL & -0.657 & -0.734 & 0.000 & -1.099 & -0.900 & -0.165 & -0.325 & -1.490 & 0.643 & -1.338 & -0.794 & -0.368 \\
\hline SD & 1.338 & 0.716 & 0.000 & 0.700 & 1.266 & 1.171 & 0.848 & 1.147 & 0.660 & 0.753 & 0.694 & 0.898 \\
\hline
\end{tabular}

$\underline{\text { Seasonal Analysis of Transitional Data - Finishing Plant \#2 }}$

The seasonal index calculation was used to generate the monthly seasonal index figures that are presented in Figure 255. The lowest seasonal index was in March and the second lowest was April. The highest seasonal index was recorded in September and the second highest was in January.

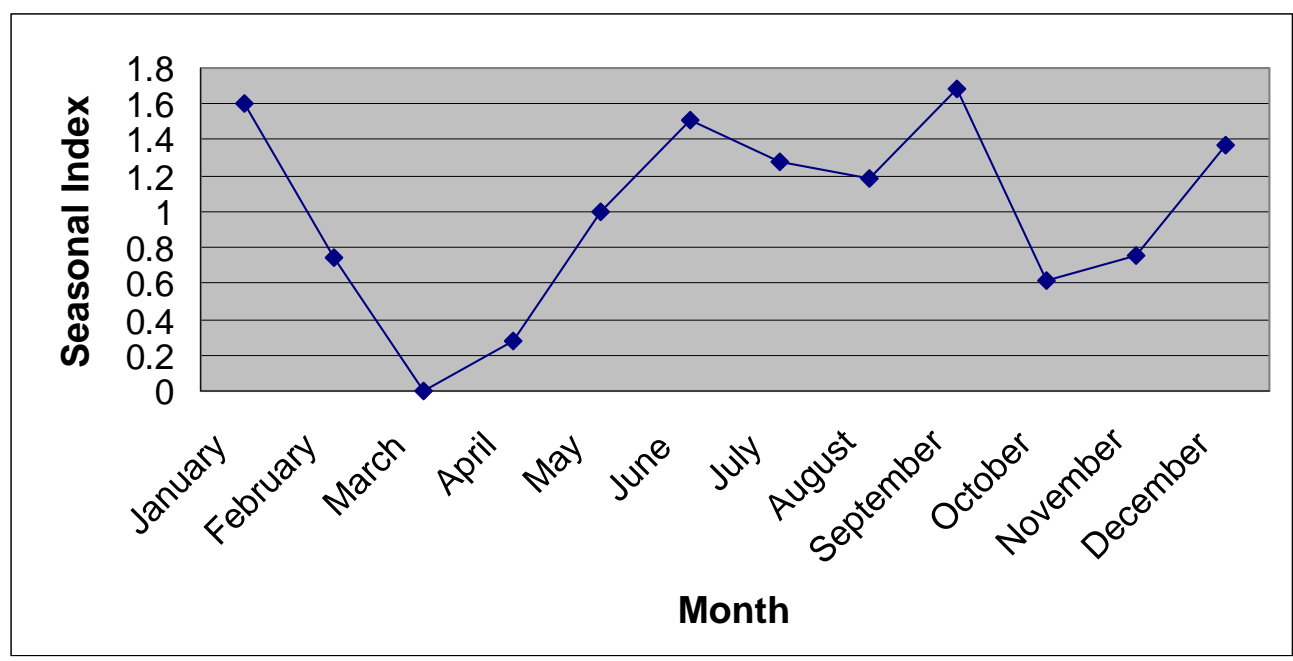

Figure 255. Seasonal Analysis of Monthly Transitional Data - Finishing Plant \#2

Testing the Statistical Relationship of Transitional Data - Finishing Plant \#2 All 33 Months Prior to and Subsequent to the Work Stoppage

At Finishing Plant \#2, for the entire 33 months prior to the work stoppage and the 33 post work stoppage months the calculated comparison $t$ value was 0.64 . Because this is lower than the 2.008 critical $t$ value, a statistically significant increase in the transitional incidence rates did not occur.

First 24 Months and Last 24 Months of the Research Period

The same formula was applied to the Finishing Plant \#2transitional incidence rates for the first 24 months and the last 24 months of the period. These time periods 
excluded the nine months prior to and immediately following the work stoppage. The calculated amount of 0.28 was considerably lower than the critical $t$ value of 2.060 . Thus at the .05 level of significance, a statistically significant increase in transitional incidence rates between the two periods was not found.

Nine Month Intervals Prior to and Subsequent to the Work Stoppage

Comparison of the transitional incidence rates for the nine months preceding the work stoppage at Finishing Plant \#2 and the nine months following the work stoppage was accomplished using the comparison formula. The result of this calculation, 1.36, was less than the critical $t$ value of 2.306. Therefore at the .05 level, a statistically significant increase in transitional incidence rates between the two periods was not found.

Table 45

Comparison of prior and post work stoppage periods - Finishing Plant \#2

\begin{tabular}{|c|c|c|c|c|}
\hline \multirow[b]{2}{*}{ Time Period } & \multicolumn{2}{|c|}{ Finishing Plant \#2 Incidence Rates } & \multirow[b]{2}{*}{ Critical t Value } & \multirow[b]{2}{*}{$\begin{array}{l}\text { Calculated } \\
\text { Comparison Value }\end{array}$} \\
\hline & $\begin{array}{l}\text { Prior to } \\
\text { Work Stoppage }\end{array}$ & $\begin{array}{l}\text { Post } \\
\text { Work Stoppage }\end{array}$ & & \\
\hline 9 Months & 0.92 & 2.39 & 2.306 & 1.36 \\
\hline 24 Months & 1.57 & 1.76 & 2.060 & 0.28 \\
\hline 33 Months & 1.39 & 1.91 & 2.008 & 0.64 \\
\hline
\end{tabular}

* Indicates a statistically significant increase

** Indicates a statistically significant decrease

\section{Finishing Plant \#3 Analysis}

Quarterly Analysis of Transitional Data - Finishing Plant \#3

The first quarter transitional incidence rates for Finishing Plant \#3 were marked by a low in 1994 that was followed in 1995 by a high almost five times greater in magnitude. In 1996 the first quarter incidence rate dropped below the mean. The incidence rates for 1998 and 1999 were above the mean, while the 2000 incidence rate was barely above the LCL (See Figure 256). 


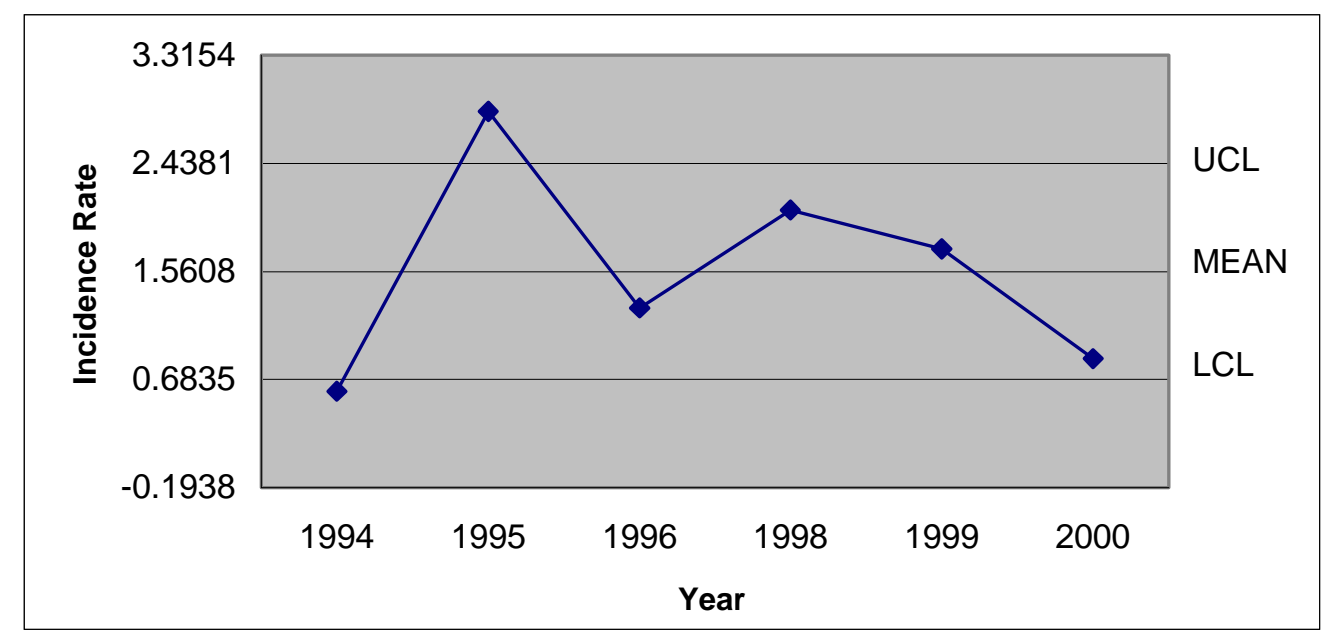

Note: No operations in first quarter 1997

Figure 256. First Quarter 1994-2000 Transitional Incidence Rates - Finishing Plant \#3

As illustrated in Figure 257, in 1994 the second quarter at Finishing Plant \#3 did not experience any transitional incidents. The next year had the second highest incidence rate, 3.616, just below the UCL. In 1996 the incidence rate was below the mean and in 1998 the highest incidence rate of 5.059 was recorded. The last two years of the study period were almost zero.

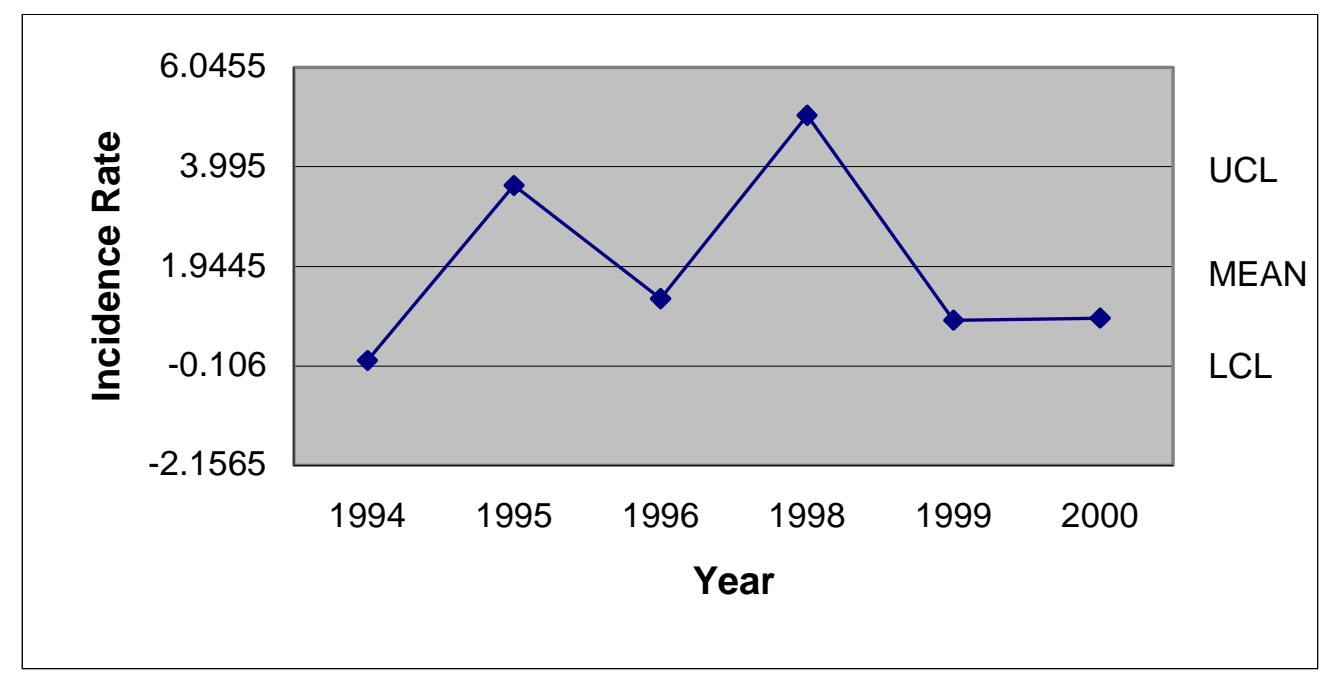

Note: No operations in second quarter 1997

Figure 257. Second Quarter 1994-2000 Transitional Incidence Rates - Finishing Plant \#3 
The lowest third quarter incidence rate at Finishing Plant \#3 occurred in 1994, which recorded an incidence rate of 0.000 . The highest third quarter rate occurred in 1996 with a rate of 4.543 . The remaining three periods were clustered around the mean (See Figure 258).

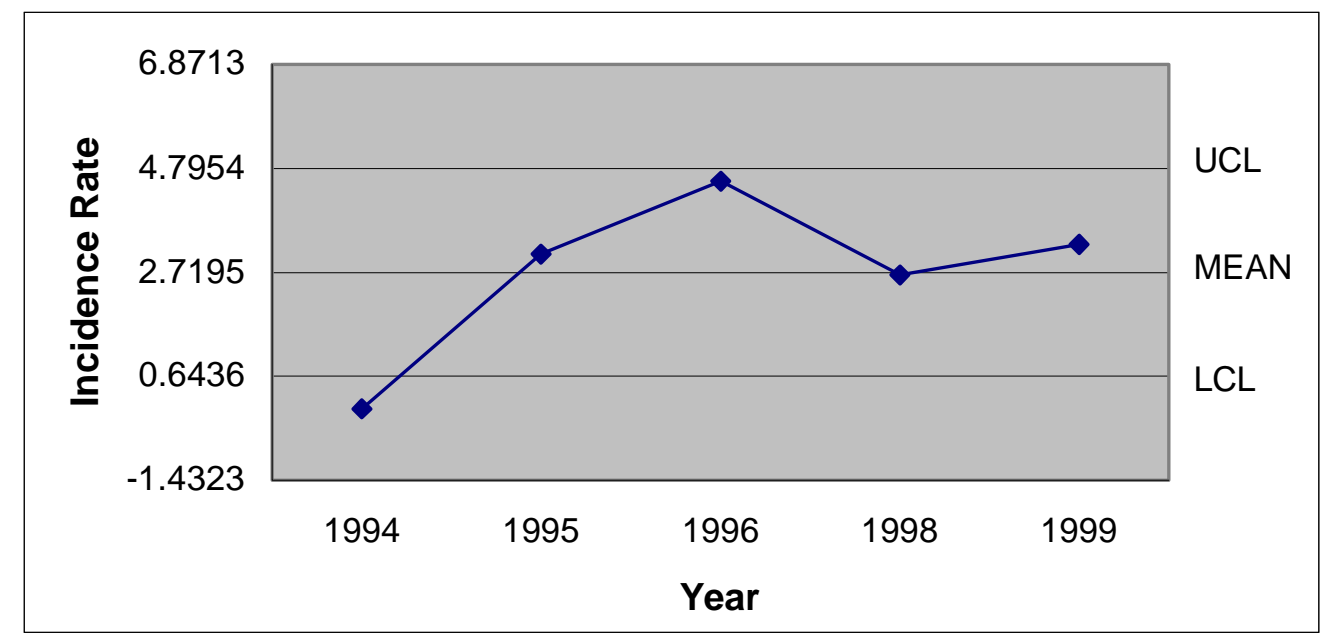

Note: No operations in third quarter 1997

Figure 258. Third Quarter 1994-1999 Transitional Incidence Rates - Finishing Plant \#3

Although, the fourth quarter of 1994 at Finishing Plant \#3 did not record a zero incidence rate, as was the case in the second and third quarters of 1994, it did experience the lowest fourth quarter incidence rate at a level of 0.575. In 1995 the fourth quarter incidence rate was slightly higher than the 1994 rate. The 1997 and 1998 fourth quarter incidence rates were above the mean, while the 1999 rate of 1.842 was above the UCL (See Figure 259). 


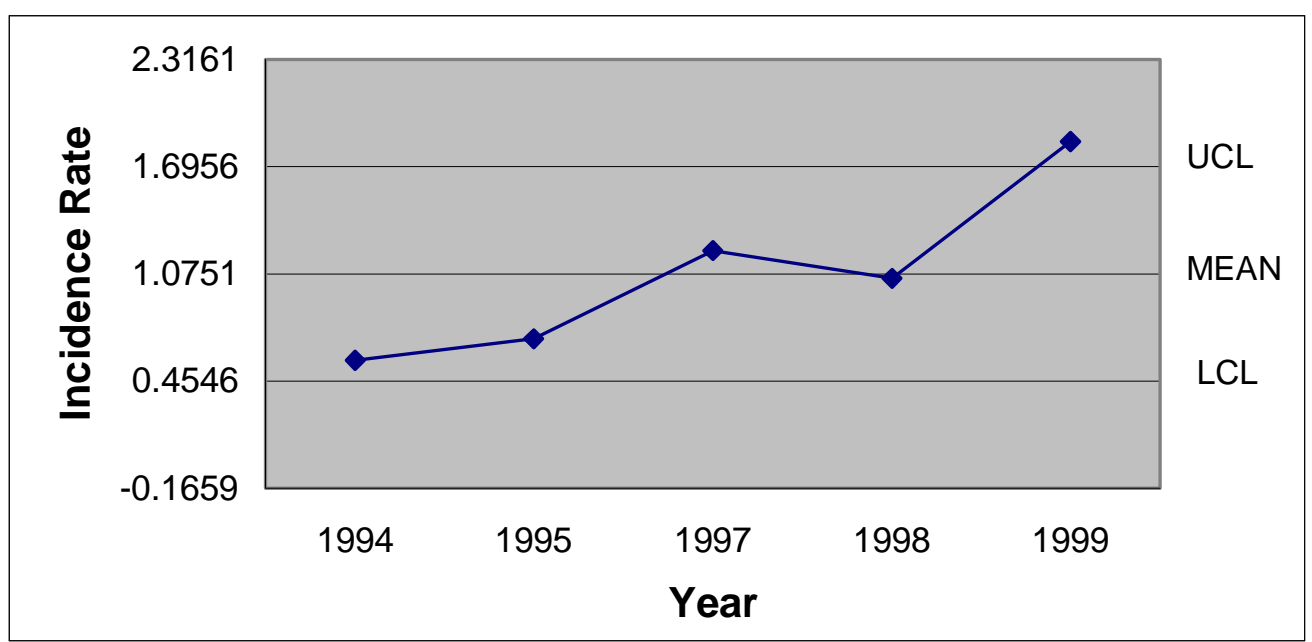

Note: No operations in fourth quarter 1996

Figure 259. Fourth Quarter 1994-1999 Transitional Incidence Rates - Finishing Plant \#3

Table 46 presents the quarterly incidence rates at Finishing Plant \#3 for each year of the study period, as well as the UCL, mean, LCL, and standard deviation. Nineteen ninety-six and 1997 are partial years because of the work stoppage and only the first six months of 2000 were included in the research.

Table 46

$\underline{\text { Summary of Quarterly Transitional Incidence Rates Data - Finishing Plant \#3 }}$

\begin{tabular}{|l|l|l|l|l|}
\hline & $1^{\text {st }}$ Quarter & $2^{\text {nd }}$ Quarter & $3^{\text {rd }}$ Quarter & $4^{\text {th }}$ Quarter \\
\hline 1994 & 0.588 & 0.000 & 0.000 & 0.575 \\
\hline 1995 & 2.856 & 3.616 & 3.094 & 0.699 \\
\hline 1996 & 1.265 & 1.277 & 4.543 & N/A \\
\hline 1997 & N/A & N/A & N/A & 1.210 \\
\hline 1998 & 2.057 & 5.059 & 2.674 & 1.049 \\
\hline 1999 & 1.745 & 0.837 & 3.288 & 1.842 \\
\hline 2000 & 0.853 & 0.879 & N/A & N/A \\
\hline UCL & 2.438 & 3.995 & 4.795 & 1.696 \\
\hline MEAN & 1.561 & 1.945 & 2.712 & 1.075 \\
\hline LCL & 0.684 & -0.106 & 0.644 & 0.455 \\
\hline SD & 0.341 & 0.798 & 0.748 & 0.224 \\
\hline
\end{tabular}




\section{$\underline{\text { Seasonal Analysis of Transitional Data - Finishing Plant \#3 }}$}

The highest seasonal index calculated for transitional incidence rates at Finishing Plant \#3 was in the third quarter. The first quarter had the second highest seasonal index, while the second and fourth quarters were almost identical as the lowest seasonal indexes (See Figure 260).

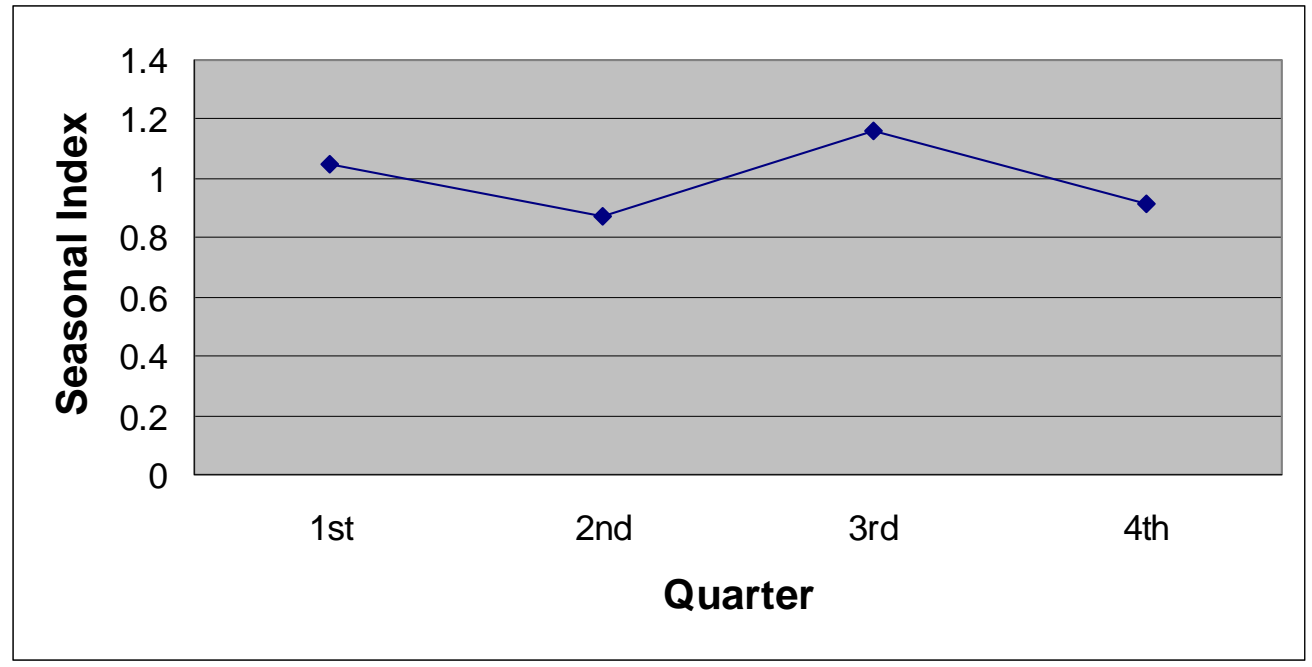

Figure 260. Quarterly Seasonal index for Transitional Incidence Rates - Finishing Plant \#3

\section{Monthly Analysis of Transitional Data - Finishing Plant \#3}

January 1995 recorded a transitional incidence rate of 8.417 at Finishing Plant \#3, a rate much greater than any other January rate recorded during the study period. In fact the only other nonzero January rate was 2.643, posted in January 2000 (See Figure 261). 


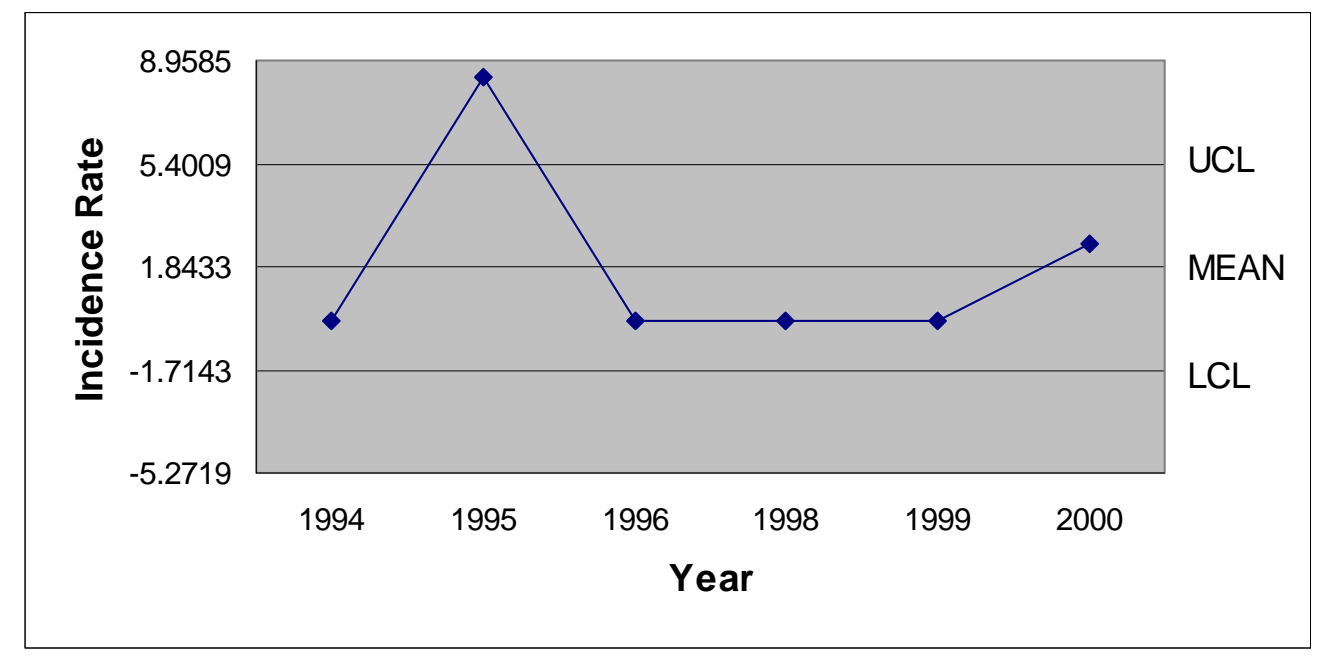

Note: No operations in January 1997

Figure 261. January 1994-2000 Transitional Incidence Rates - Finishing Plant \#3

The February 1999 incidence rate at Finishing Plant \#3 of 5.413 was the only nonzero transitional incidence rate recorded for the month of February (See Figure 262).

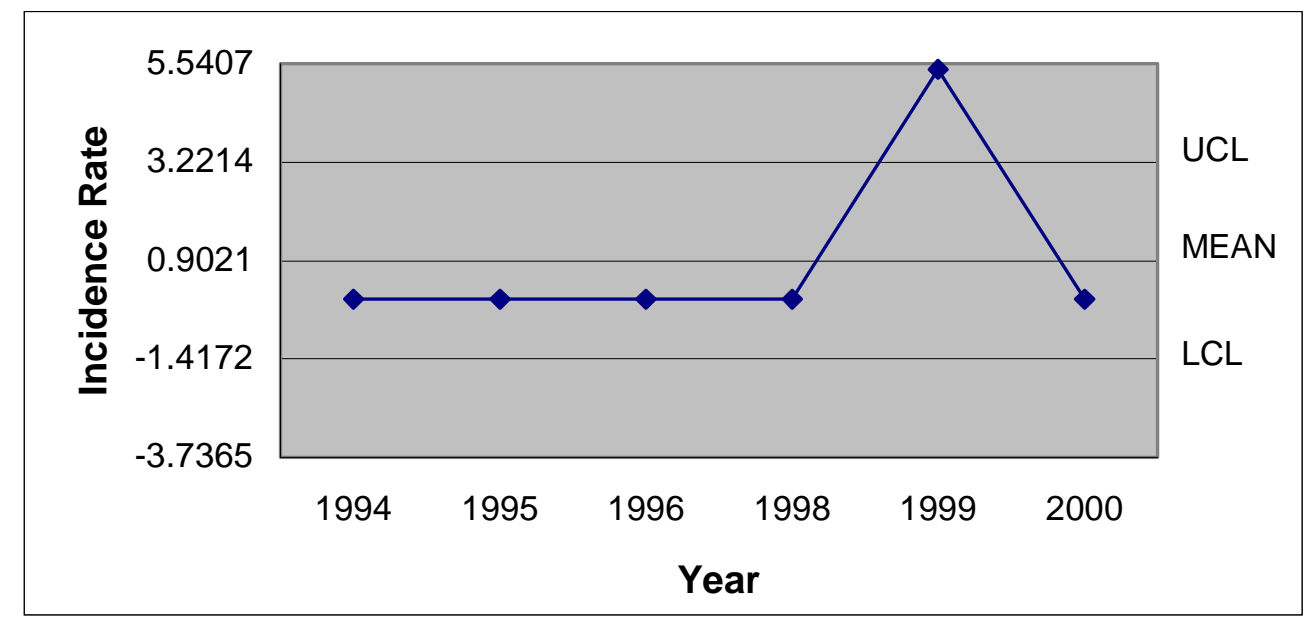

Note: No operations in February 1997

Figure 262. February 1994-2000 Transitional Incidence Rates - Finishing Plant \#3

March 1995, 1999, and 2000 all recorded 0.000 for incidence rates at Finishing Plant \#3. The highest transitional incidence rate for the month occurred in 1998. The high of 5.207 was nearly three times greater than the second lowest rate, which was recorded in 1994 (See Figure 263). 


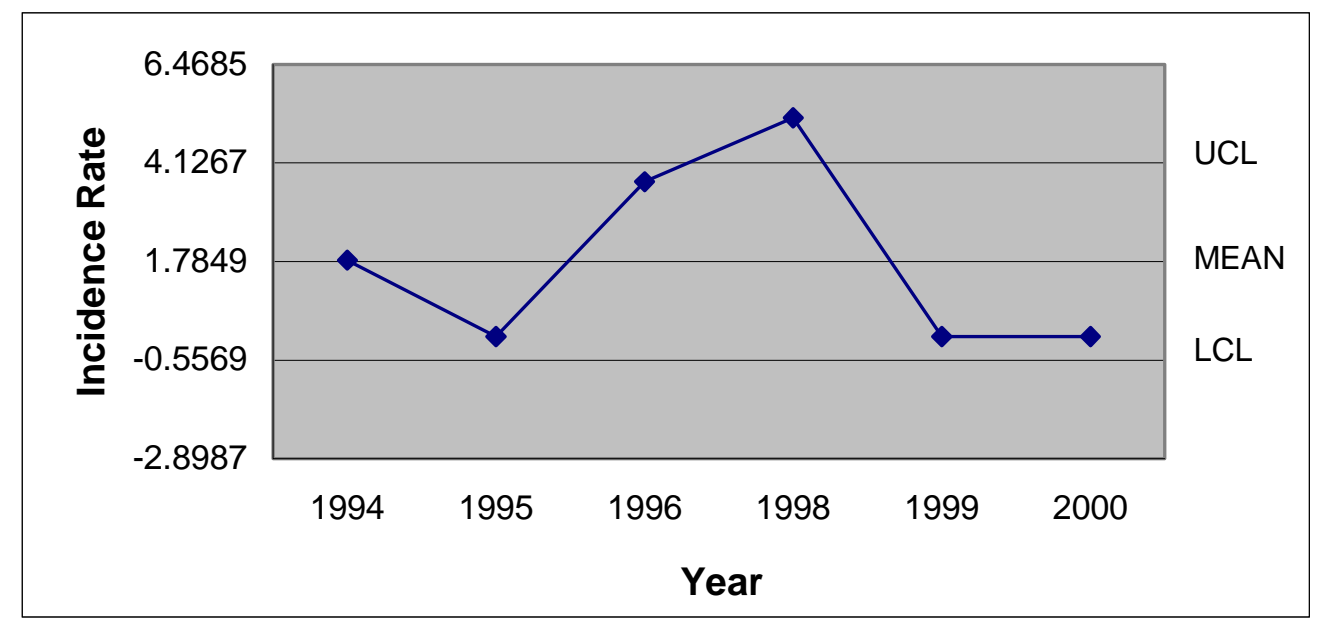

Note: No operations in March 1997

Figure 263. March 1994-2000 Transitional Incidence Rates - Finishing Plant \#3

Transitional incidence rates at Finishing Plant \#3 of 0.000 were recorded in April 1994, 1995, and 1998. April 1996 was above the mean, 1999 and 2000 were just above the UCL. The highest incidence rate occurred in 1999 (See Figure 264).

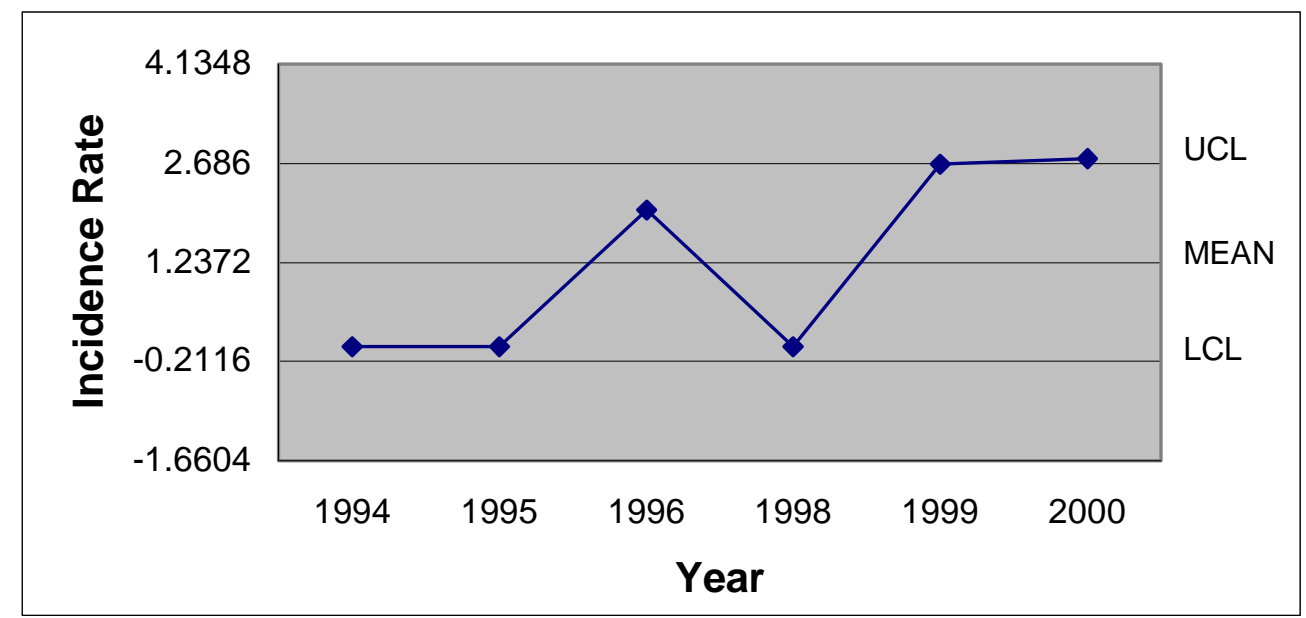

Note: No operations in April 1997

Figure 264. April 1994-2000 Transitional Incidence Rates - Finishing Plant \#3

As illustrated in Figure 265, the highest May incidence rate at Finishing Plant \#3 occurred in 1998 at a level of 12.393. The only other nonzero incidence rate for the month, 7.002, was recorded in 1995. 


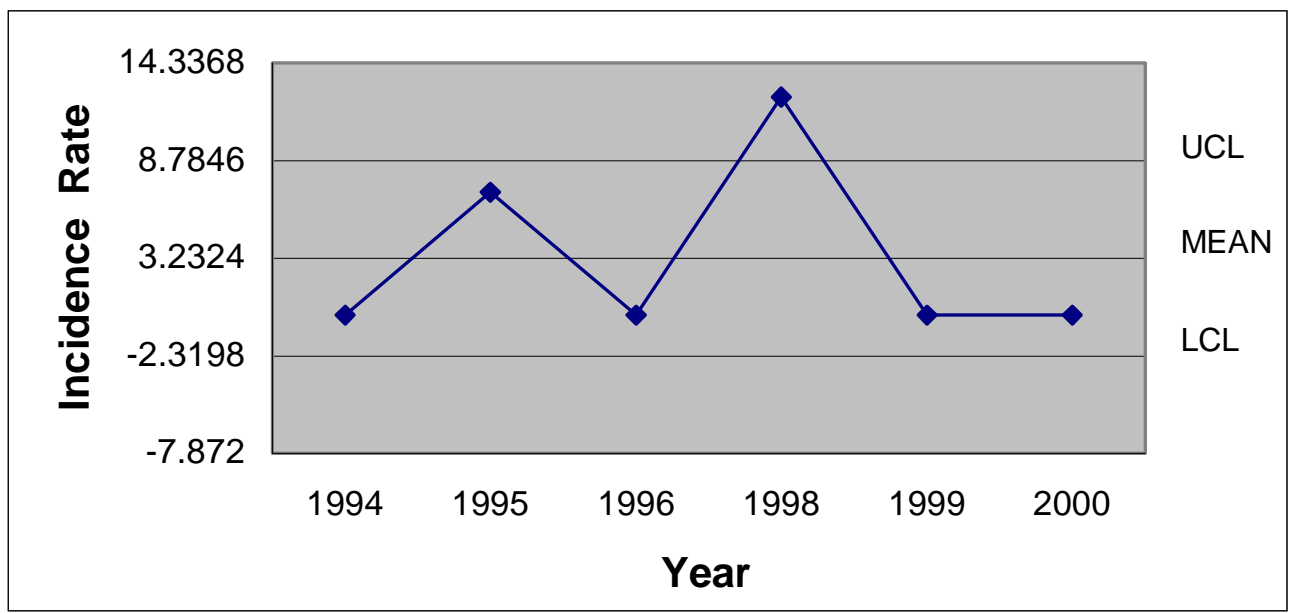

Note: No operations in May 1997

Figure 265. May 1994-2000 Transitional Incidence Rates - Finishing Plant \#3

After a zero incidence rate in June 1994 at Finishing Plant \#3, the highest June incidence rate, 3.803, was recorded in 1995. The next two years the incidence rates were between the mean and the UCL. The remaining two years recorded incidence rates of 0.000 (See Figure 266).

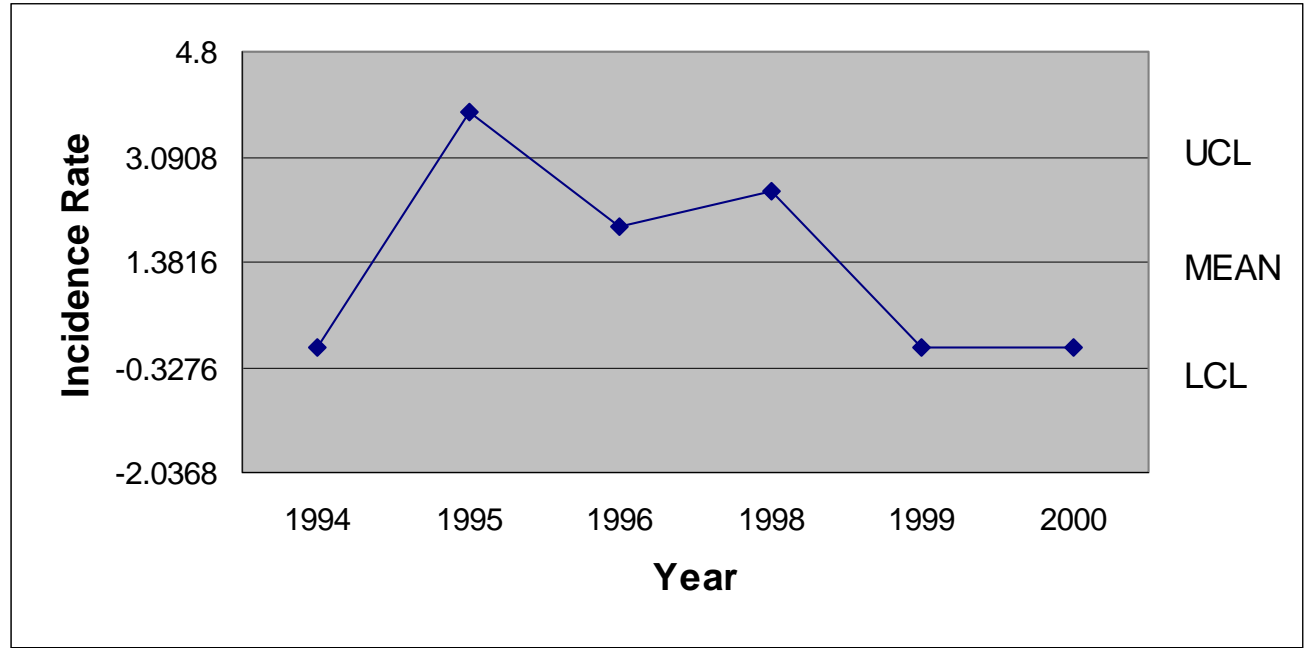

Note: No operations in June 1997

Figure 266. June 1994-2000 Transitional Incidence Rates - Finishing Plant \#3 
As illustrated in Figure 267, July incidence rates at Finishing Plant \#3 for 1994 and 1999 were 0.000. The 1995 and 1996 incidence rates, which were just above the mean, were followed in 1998 by the highest July incidence rate, 5.053.

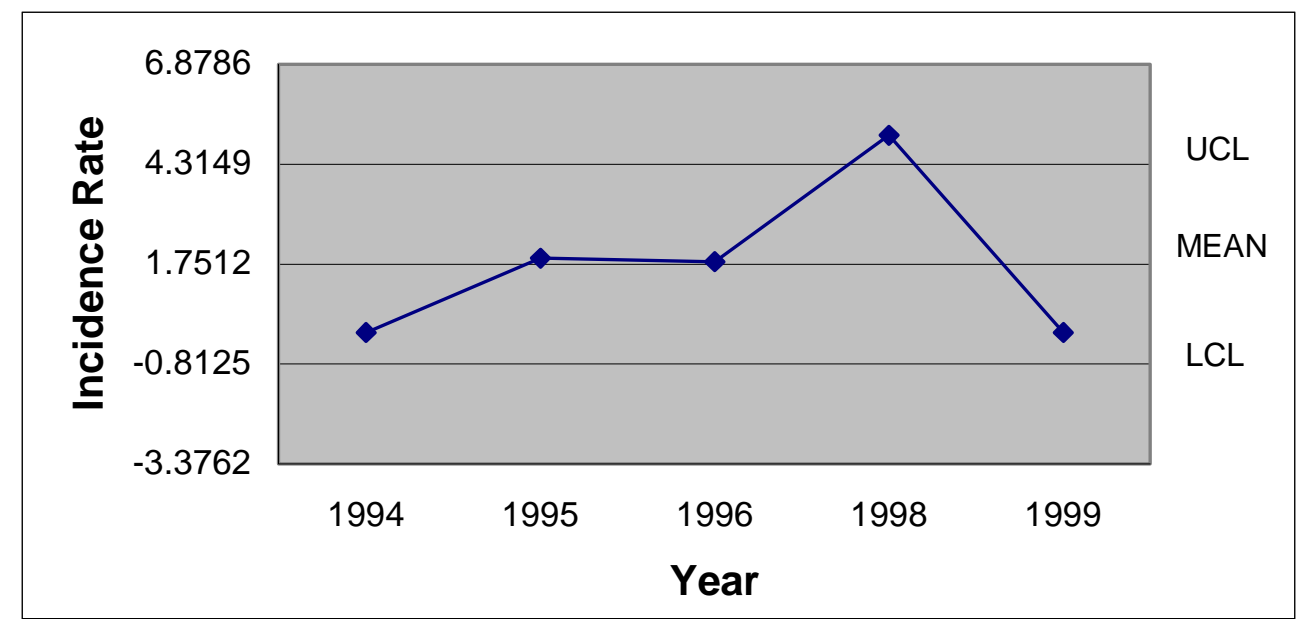

Note: No operations in July 1997

Figure 267. July 1994-1999 Transitional Incidence Rates - Finishing Plant \#3

August 1994 recorded the only zero incidence rate for the month at Finishing Plant \#3. In 1995 the incidence rate was just above the mean and in 1996, the highest August incidence rate of 7.343 was recorded. In 1998 the incidence rate was 2.661, which was below the mean. August 1999 recorded the second highest incidence rate, 7.178 (See Figure 268). 


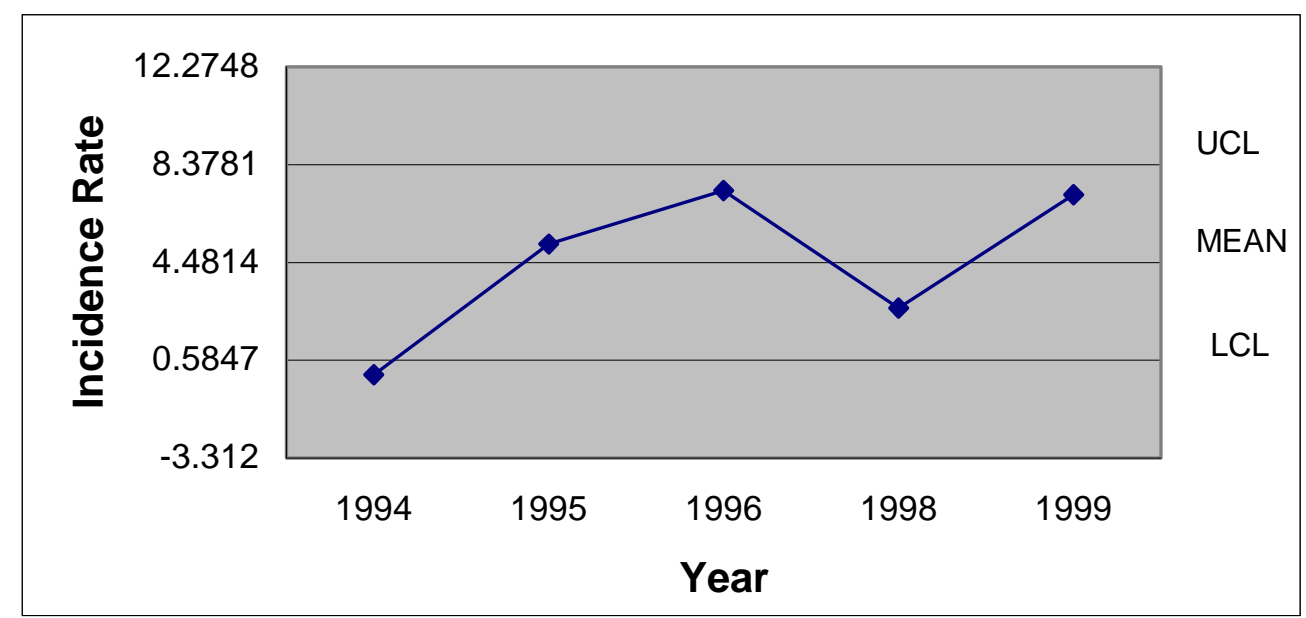

Note: No operations in August 1997

Figure 268. August 1994-1999 Transitional Incidence Rates - Finishing Plant \#3

The September transitional incidence rate at Finishing Plant \#3 steadily increased from the low of zero in 1994 to the high of 4.523 in 1996. The next year an incidence rate of 0.000 was recorded and in 1999 the incidence rate climbed back above the mean (See Figure 269).

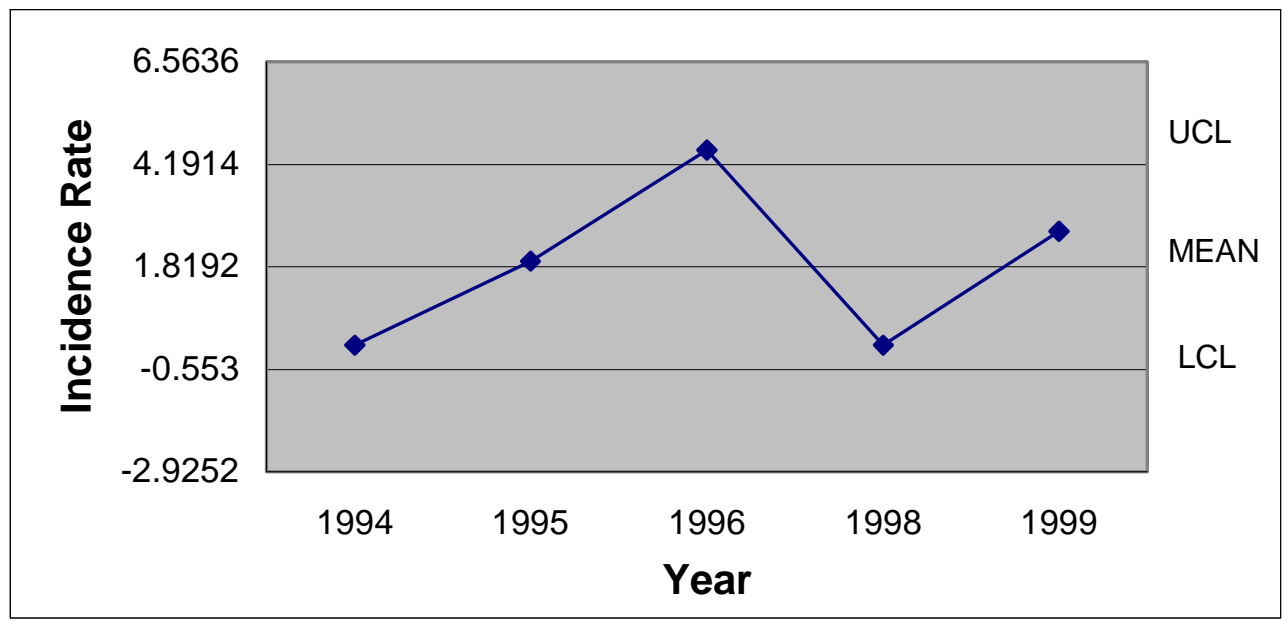

Note: No operations in September 1997

Figure 269. September 1994-1999 Transitional Incidence Rates - Finishing Plant \#3

The October 1999 incidence rate at Finishing Plant \#3 of 5.547 was more than three times greater than the only other nonzero incidence rate recorded for the month, which occurred in October 1994 (See Figure 270). 


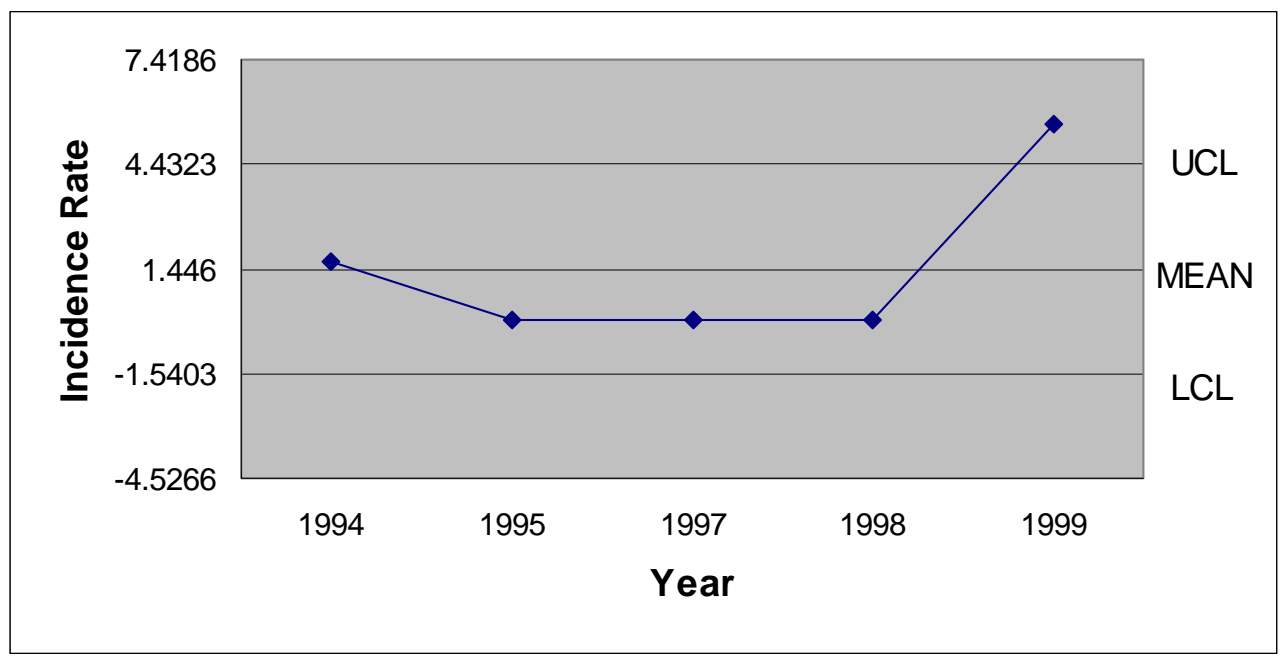

Note: No operations in October 1996

Figure 270. October 1994-1999 Transitional Incidence Rates - Finishing Plant \#3

As illustrated in Figure 271, incidence rates for the month of November at Finishing Plant \#3 were 0.000 across the entire study period. This created a situation where the UCL, mean, and LCL were all equal to 0.000 .

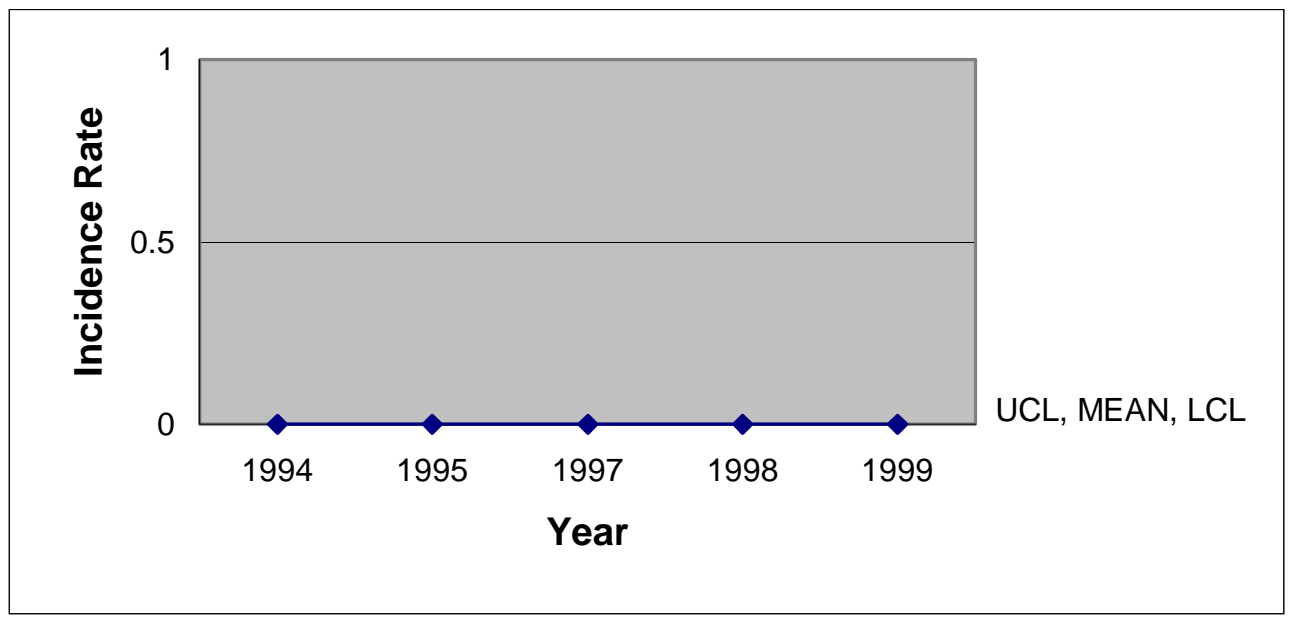

Note: No operations in November 1996

Figure 271. November 1994-1999 Transitional Incidence Rates - Finishing Plant \#3 
The December 1994 and 1999 incidence rates at Finishing Plant \#3 were 0.000, while the remaining three-year were all between the mean and the UCL. The highest December incidence rate occurred in 1997 at a level of 3.678 (See Figure 272).

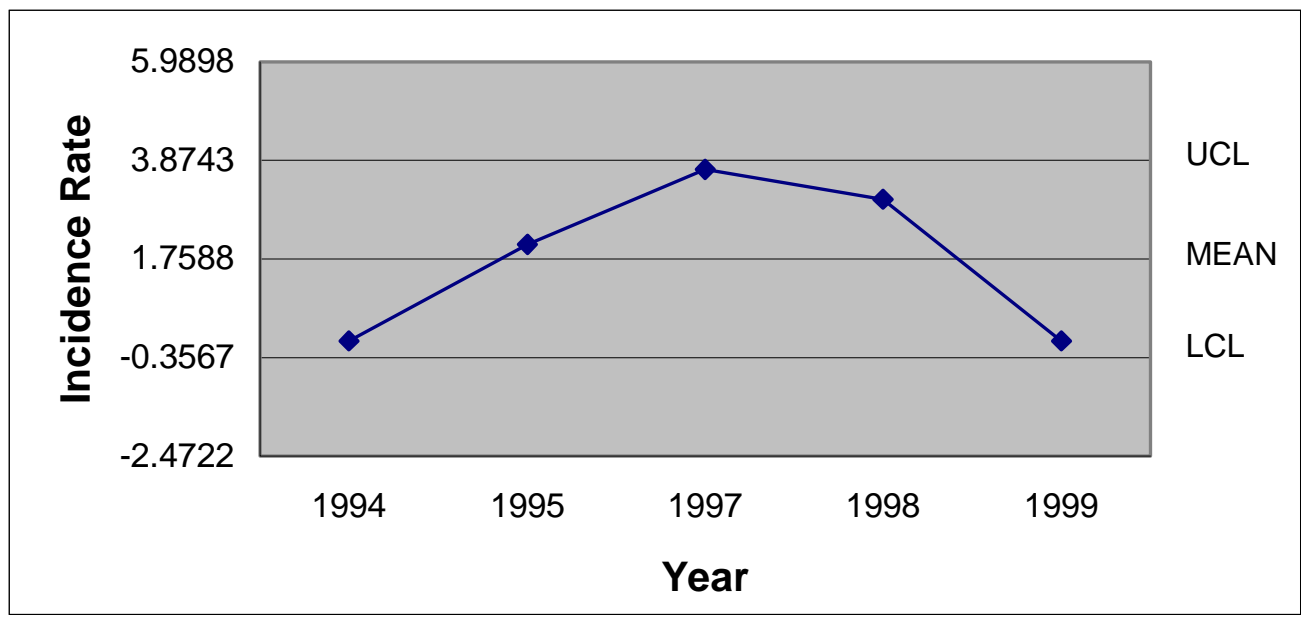

Note: No operations in December 1996

Figure 272. December 1994-1999 Transitional Incidence Rates - Finishing Plant \#3

Table 47 presents the monthly incidence rates at Finishing Plant \#3 for each year of the study period, as well as the UCL, mean, LCL, and standard deviation. Nineteen ninety-six and 1997 are partial years because of the work stoppage and only the first six months of 2000 were included in the research.

Table 47

Summary of Monthly Transitional Incidence Rates Data - Finishing Plant \#3

\begin{tabular}{|l|l|l|l|l|l|l|l|l|l|l|l|l|}
\hline & Jan. & Feb. & Mar. & Apr. & May & June & July & Aug. & Sept. & Oct. & Nov. & Dec. \\
\hline 1994 & 0.000 & 0.000 & 1.815 & 0.000 & 0.000 & 0.000 & 0.000 & 0.000 & 0.000 & 1.683 & 0.000 & 0.000 \\
\hline 1995 & 8.417 & 0.000 & 0.000 & 0.000 & 7.002 & 3.803 & 1.898 & 5.225 & 1.941 & 0.000 & 0.000 & 2.075 \\
\hline 1996 & 0.000 & 0.000 & 3.688 & 1.999 & 0.000 & 1.941 & 1.805 & 7.343 & 4.523 & N/A & N/A & N/A \\
\hline 1997 & N/A & N/A & N/A & N/A & N/A & N/A & N/A & N/A & N/A & 0.000 & 0.000 & 3.678 \\
\hline 1998 & 0.000 & 0.000 & 5.207 & 0.000 & 12.393 & 2.545 & 5.053 & 2.661 & 0.000 & 0.000 & 0.000 & 3.041 \\
\hline 1999 & 0.000 & 5.413 & 0.000 & 2.673 & 0.000 & 0.000 & 0.000 & 7.178 & 2.633 & 5.547 & 0.000 & 0.000 \\
\hline 2000 & 2.643 & 0.000 & 0.000 & 2.752 & 0.000 & 0.000 & N/A & N/A & N/A & N/A & N/A & N/A \\
\hline UCL & 5.401 & 3.221 & 4.127 & 2.686 & 8.785 & 3.091 & 4.315 & 8.378 & 4.191 & 4.432 & 1.000 & 3.874 \\
\hline MEAN & 1.843 & 0.902 & 1.785 & 1.237 & 3.232 & 1.382 & 1.751 & 4.481 & 1.819 & 1.446 & 0.500 & 1.759 \\
\hline LCL & -1.714 & -1.417 & -0.417 & -0.212 & -2.320 & -0.328 & -0.813 & 0.585 & -0.553 & -1.540 & 0.000 & -0.357 \\
\hline SD & 0.246 & 0.457 & 0.542 & 0.613 & 0.614 & 0.589 & 0.402 & 0.408 & 0.383 & 0.595 & 0.328 & 0.230 \\
\hline
\end{tabular}




\section{$\underline{\text { Seasonal Analysis of Transitional Data - Finishing Plant \#3 }}$}

The seasonal index calculation for Finishing Plant \#3 was used to generate the monthly seasonal index figures that are presented in Figure 273. October, the highest seasonal index, was closely followed in magnitude by April and August. The lowest seasonal index occurred in December. The lowest three-month period was May through July, with July being the lowest of the three.

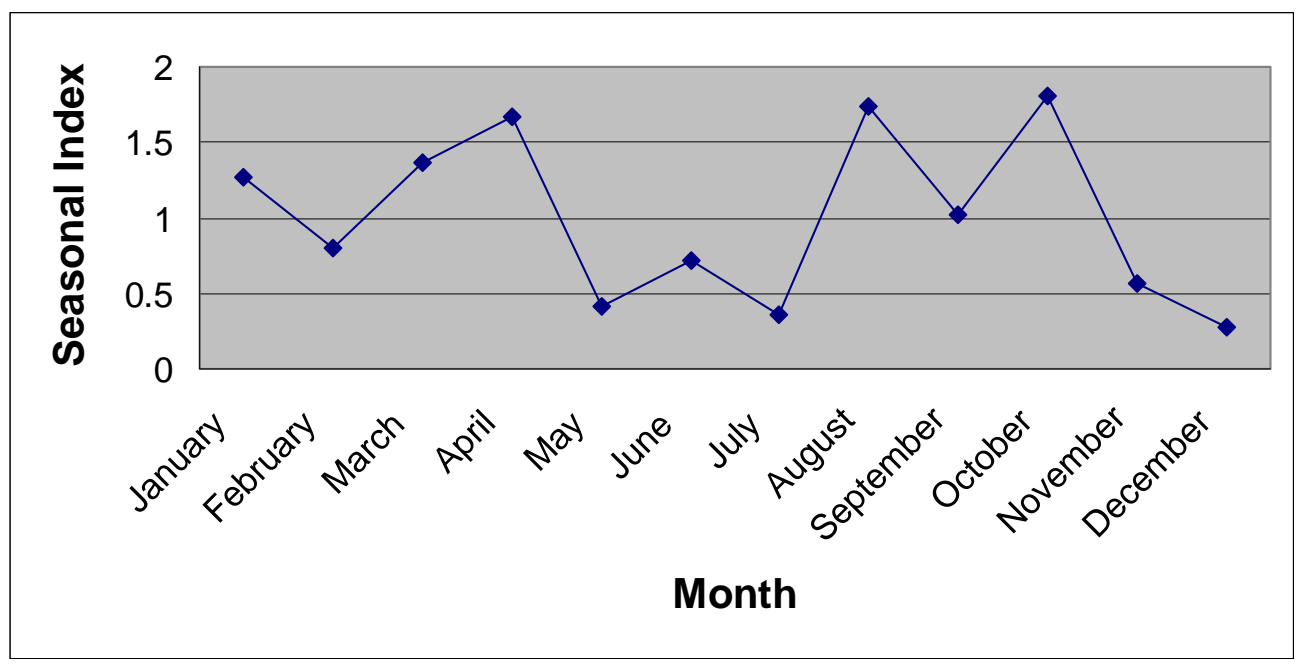

Figure 273. Monthly Seasonal Pattern of Transitional Incidence Rates - Finishing Plant \#3

Testing the Statistical Relationship of Transitional Data - Finishing Plant \#3

\section{All 33 Months Prior to and Subsequent to the Work Stoppage}

For the entire 33 months prior to the work stoppage and the 33 post work stoppage months at Finishing Plant \#3 the comparison t value was 0.691. Because this calculated amount was less than the critical t value of 2.006, a statistically significant increase in incidence rates did not occur between the two periods.

\section{First 24 Months and Last 24 Months of the Research Period}

The same formula was applied to Transitional Incidence Rates at Finishing Plant \#3 for the first 24 months and the last 24 months of the period. These time periods excluded the nine months prior to and the nine months immediately following the work stoppage. Using the 2.036 critical t value, the calculated amount of 0.471 was less than 
the critical $t$ value. Thus it can be stated that a statistically significant increase in incidence rates did not occur between the two periods.

\section{Nine Month Intervals Prior to and Subsequent to the Work Stoppage}

Comparison of the transitional incidence rates for the nine months preceding the work stoppage at Finishing Plant \#3 and the nine months following the work stoppage was accomplished using the comparison formula. The result of this calculation, 0.560, was less than the critical t value of 2.093 , for a .05 statistical significance level. Because the calculated amount was less than the significance level, no statistically significant increase in incidence rate was found between the periods.

Table 48

Comparison of prior and post work stoppage periods - Finishing Plant \#3

\begin{tabular}{|c|c|c|c|c|}
\hline \multirow[b]{2}{*}{ Time Period } & \multicolumn{2}{|c|}{ Finishing Plant \#3 Incidence Rates } & \multirow[b]{2}{*}{ Critical t Value } & \multirow[b]{2}{*}{$\begin{array}{l}\text { Calculated } \\
\text { Comparison Value }\end{array}$} \\
\hline & $\begin{array}{l}\text { Prior to } \\
\text { Work Stoppage }\end{array}$ & $\begin{array}{l}\text { Post } \\
\text { Work Stoppage }\end{array}$ & & \\
\hline 9 Months & 2.346 & 3.015 & 2.093 & 0.560 \\
\hline 24 Months & 1.412 & 1.661 & 2.036 & \begin{tabular}{|l|}
0.471 \\
\end{tabular} \\
\hline 33 Months & 1.654 & 1.998 & 2.006 & 0.691 \\
\hline
\end{tabular}

* Indicates a statistically significant increase

** Indicates a statistically significant decrease

\section{Corporate Analysis}

\section{Quarterly Analysis of Medical Treatment Data - Corporate}

Although the overall trend was decreasing for Corporate first quarter medical treatment incidence rates, there was a slight increase between 1996 and 1998. The incidence rate for the first quarter of 1994 was over $50 \%$ greater than the first quarter of 2000. The largest drop between periods was recorded between 1995 and 1996 when the incidence rate decreased by $25 \%$ (See Figure 274). 


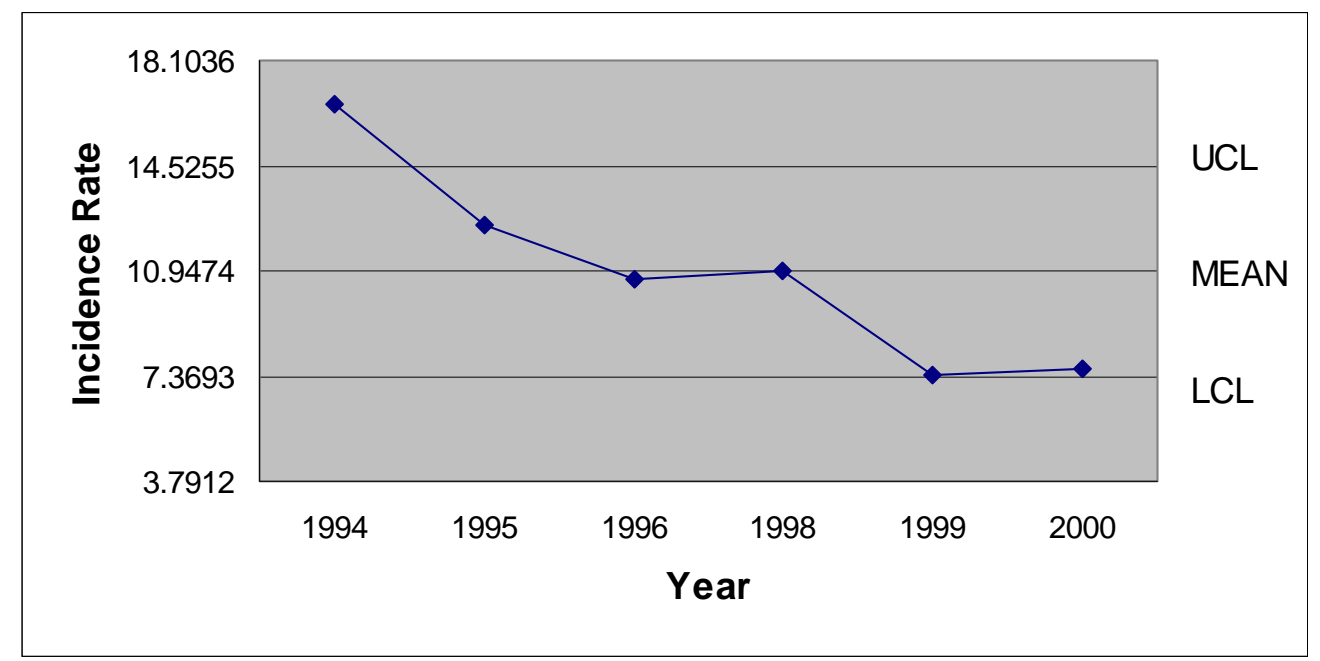

Note: No operations in first quarter 1997

Figure 274. First Quarter 1994-2000 Medical Treatment Incidence Rates Corporate

As illustrated in Figure 275, at the Corporate level, an overall second quarter decrease of more than 55\% was driven by a decrease of $40 \%$ between 1998 and 1999 . The highest incidence rate occurred in 1994, while the second highest occurred in 1998. The incidence rate fell from above the UCL in 1994 to below the mean in 1995. The next two years were between the mean and the UCL. The last two years recorded second quarter incidence rates close to the LCL.

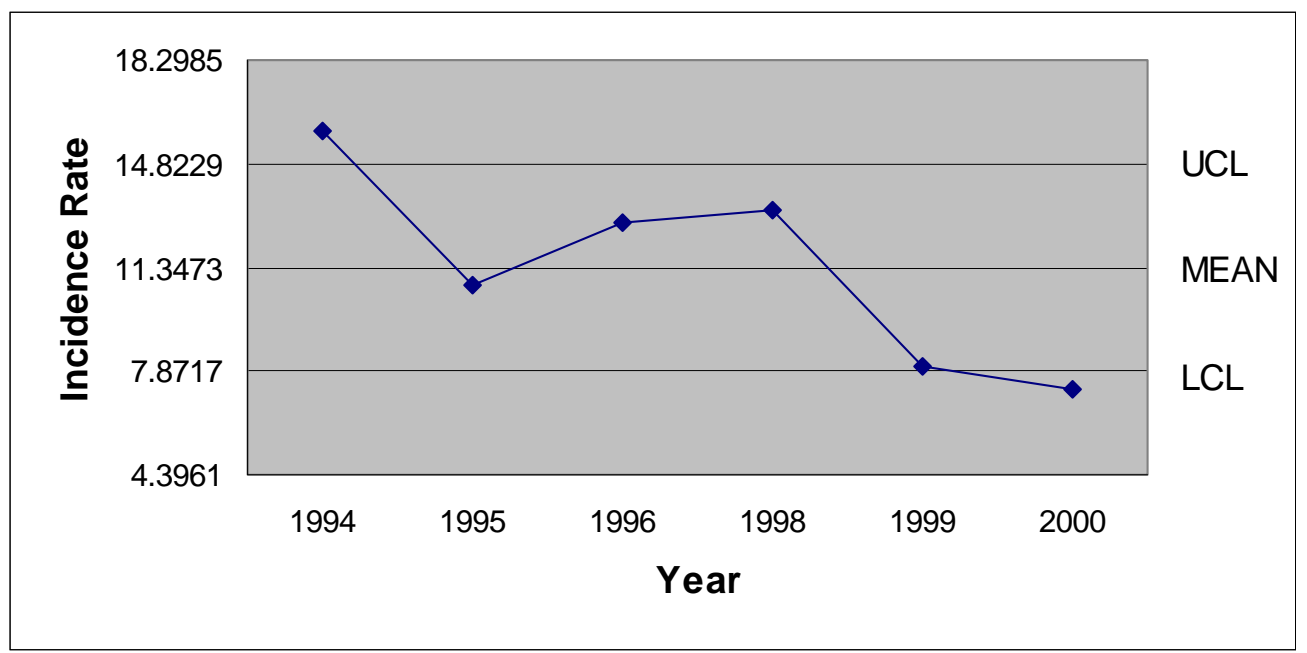

Note: No operations in second quarter 1997

Figure 275. Second Quarter 1994-2000 Medical Treatment Incidence Rates Corporate 
The third quarter Corporate medical treatment incidence rates experienced an almost straight-line decrease from the 1994 high of 18.391 to the 2000 low of 8.207. The only incidence rate for this quarter that was recorded outside the control limits was the 2000 incidence rate, which was below the LCL (See Figure 276).

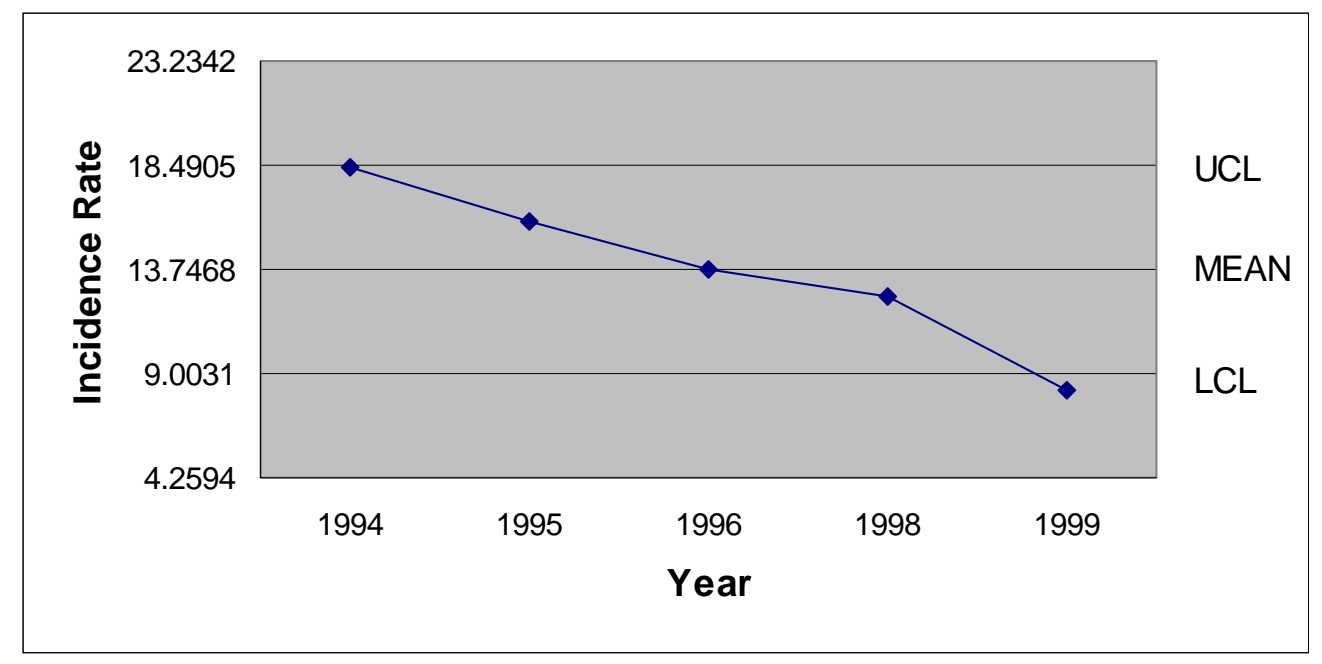

Note: No operations in third quarter 1997

Figure 276. Third Quarter 1994-1999 Medical Treatment Incidence Rates Corporate

As illustrated in Figure 277, the fourth quarter Corporate medical treatment incidence rates demonstrated an increasing pattern from 1994 to 1997. This pattern changed in 1998 when an incidence rate 25\% lower than the 1997 high was recorded. An additional decrease occurred between 1998 and 1999, when the incidence rate dropped below the LCL. 


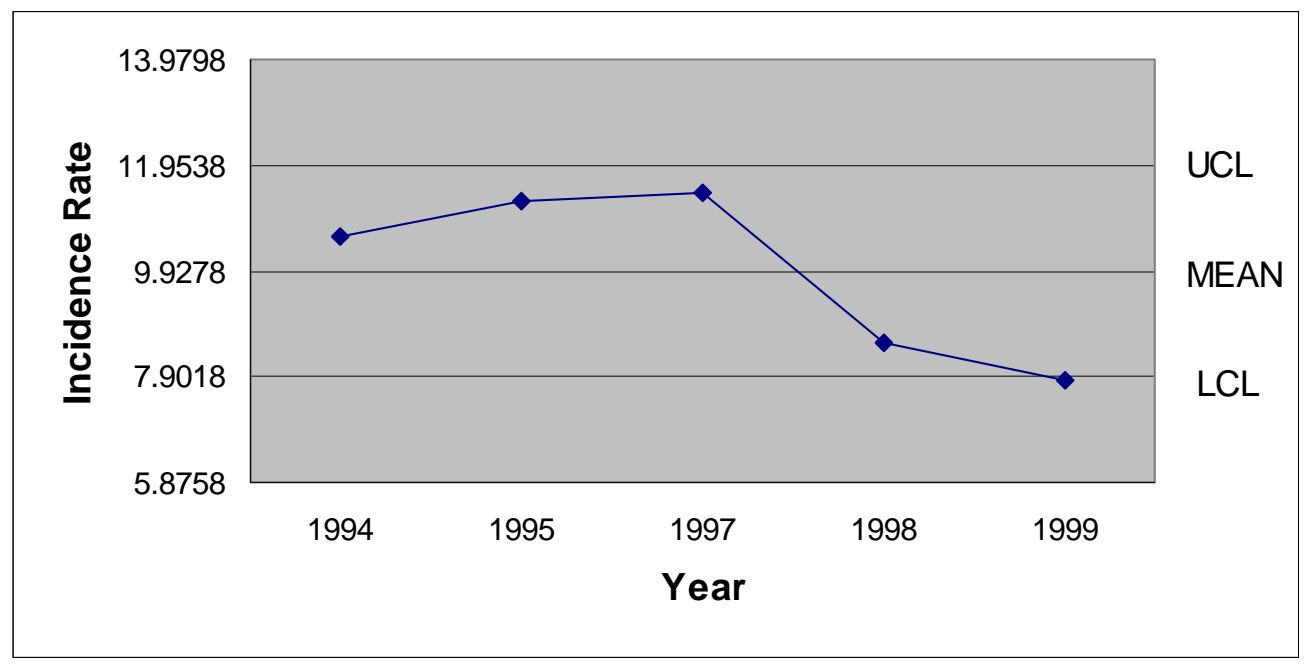

Note: No operations in fourth quarter 1996

Figure 277. Fourth Quarter 1994-1999 Medical Treatment Incidence Rates Corporate

Table 49 presents the Corporate quarterly incidence rates for each year of the study period, as well as the UCL, mean, LCL, and standard deviation. Nineteen ninetysix and 1997 are partial years because of the work stoppage and only the first six months of 2000 were included in the research.

Table 49

Summary of Quarterly Medical Treatment Incidence Rates Data - Corporate

\begin{tabular}{|l|l|l|l|l|}
\hline & $1^{\text {st }}$ Quarter & $2^{\text {nd }}$ Quarter & $3^{\text {rd }}$ Quarter & $4^{\text {th }}$ Quarter \\
\hline 1994 & 16.595 & 15.898 & 18.391 & 10.598 \\
\hline 1995 & 12.471 & 10.765 & 15.903 & 11.248 \\
\hline 1996 & 10.673 & 12.836 & 13.709 & N/A \\
\hline 1997 & N/A & N/A & N/A & 11.406 \\
\hline 1998 & 10.950 & 13.302 & 12.524 & 8.560 \\
\hline 1999 & 7.388 & 8.001 & 8.207 & 7.828 \\
\hline 2000 & 7.308 & 7.273 & N/A & N/A \\
\hline UCL & 14.526 & 14.823 & 18.491 & 11.954 \\
\hline MEAN & 10.947 & 11.347 & 13.747 & 9.928 \\
\hline LCL & 7.369 & 7.872 & 9.003 & 7.902 \\
\hline SD & 1.392 & 1.352 & 1.709 & 0.730 \\
\hline
\end{tabular}




\section{$\underline{\text { Seasonal Analysis of Medical Treatment Data - Corporate }}$}

The highest seasonal index of Corporate medical treatment incidence rates occurred in the third quarter, while the lowest occurred in the fourth quarter. The first and second quarters were close to the 1.0 level (See Figure 278).

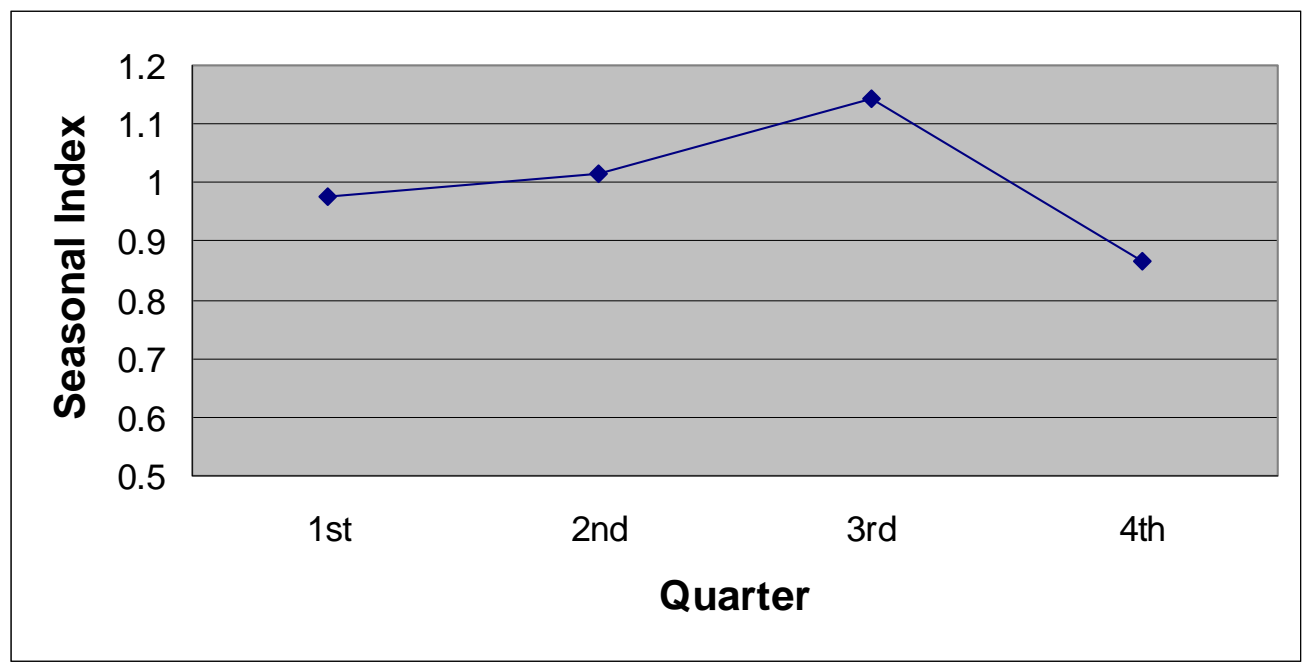

Figure 278. Quarterly Seasonal Index of Medical Treatment Incidents - Corporate

\section{Monthly Analysis of Medical Treatment Data - Corporate}

Over the entire study period, January medical treatment incidence rates at the Corporate level decreased by more than $60 \%$. The largest decrease of nearly $33 \%$ occurred between 1994 and 1995. The 1996 incidence rate was slightly higher than the 1995 incidence rate. The remaining three years demonstrated a steady decrease between 1996 and 2000 (See Figure 279). 


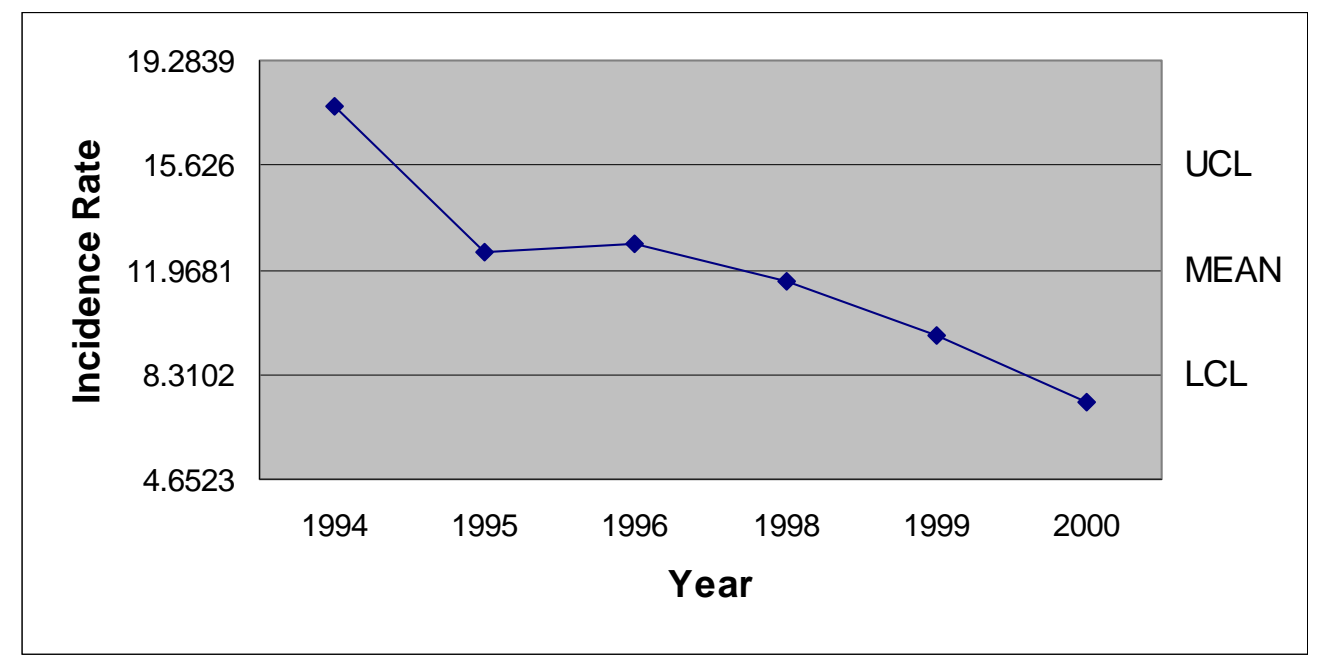

Note: No operations in January 1997.

Figure 279. January 1994-2000 Medical Treatment Incidence Rates - Corporate

A decrease of $70 \%$ in Corporate medical treatment rates occurred between the February 1994 high and the February 1999 low. The sharpest single year decrease, over 30\%, occurred between 1994 and 1995. The 1996 and 1998 incidence rates were close to the mean, while the 1999 and 2000 incidence rates were close to the LCL (See Figure 280).

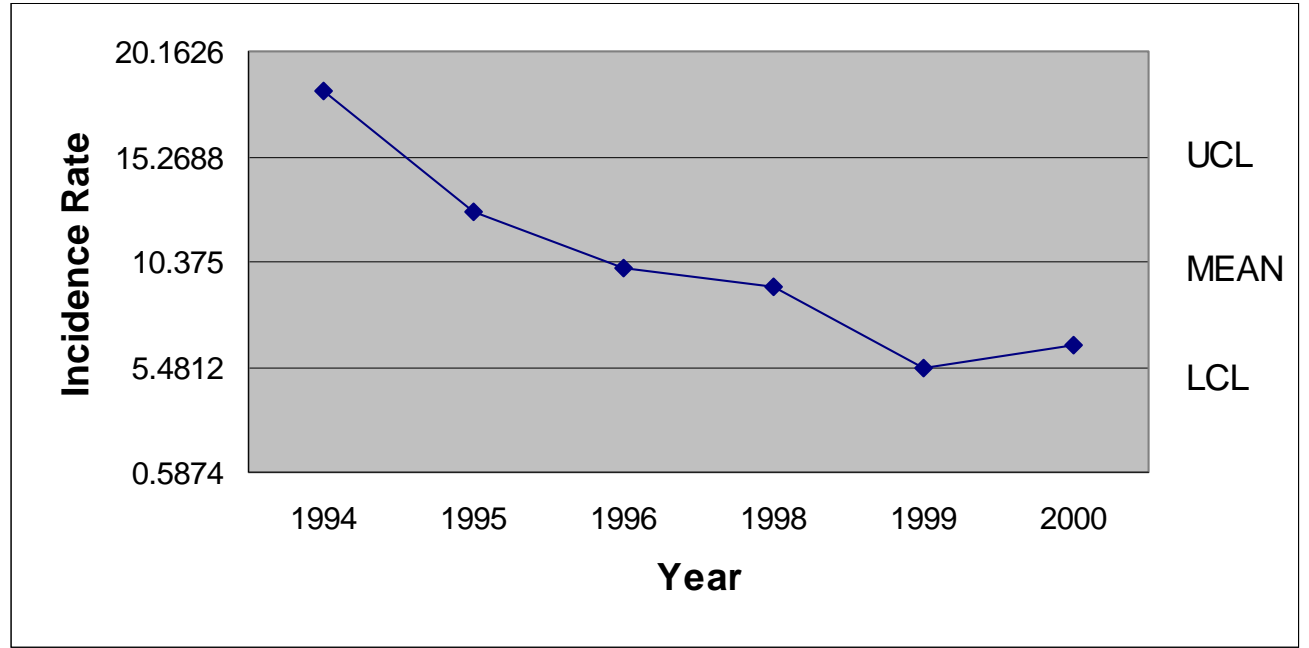

Note: No operations in February 1997

Figure 280. February 1994-2000 Medical Treatment Incidence Rates - Corporate 
The March 1994 high rate of 13.853 and the 1999 low rate of 7.012 were the only two values of Corporate medical treatment incidence rates outside of the control limits. The 1995 and 1998 incidence rates were between the mean and the UCL. The 1996 and 2000 incidence rates were between the mean and the UCL (See Figure 281).

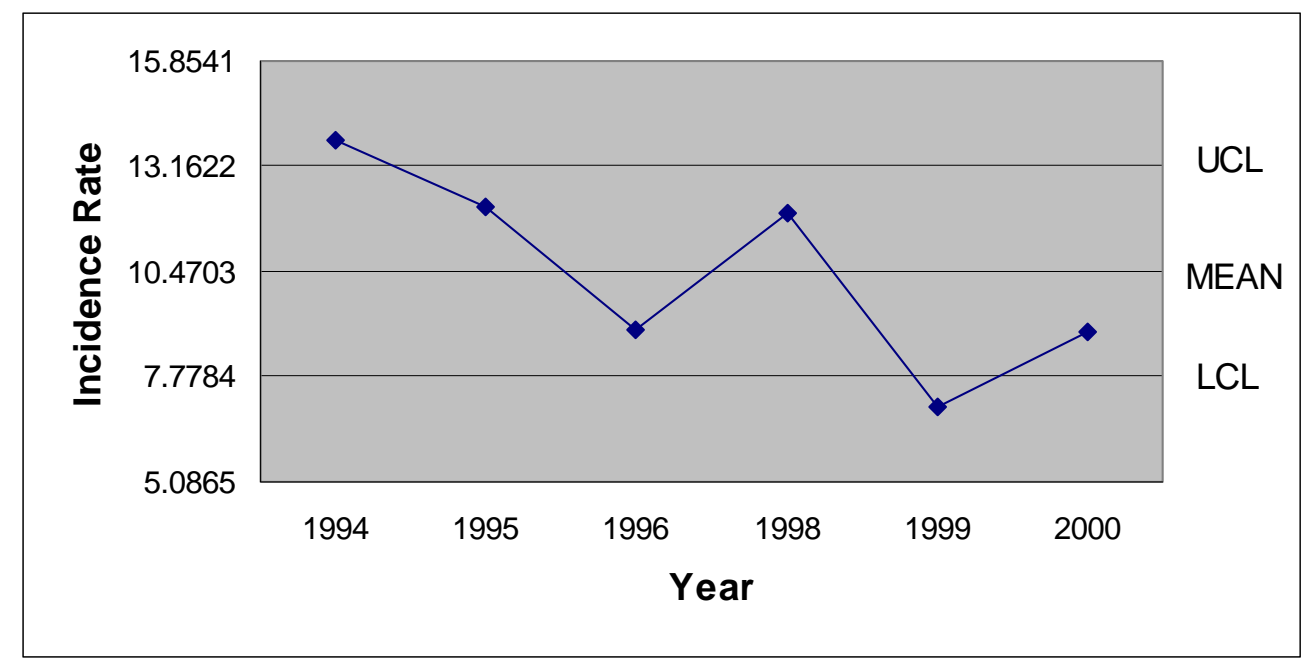

Note: No operations in March 1997

Figure 281. March 1994-2000 Medical Treatment Incidence Rates - Corporate

The first two years of Corporate April incidence rates were close to the mean. In 1996 the incidence rate increased to a level above the UCL. Over the next three years the incidence rates decreased gradually to the low in 2000, which was below the LCL (See Figure 282). 


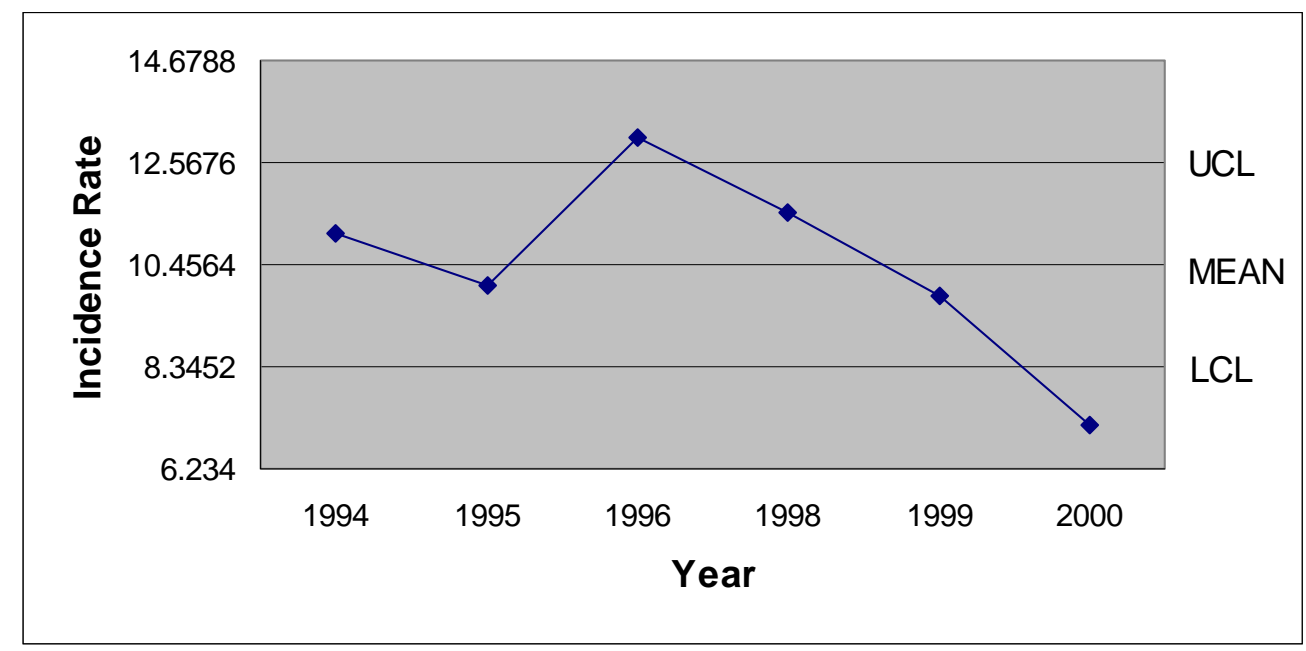

Note: No operations in April 1997

Figure 282. April 1994-2000 Medical Treatment Incidence Rates - Corporate

As illustrated in Figure 283, the 1994 Corporate May incidence rate of 16.380 was above the UCL. The next three years recorded incidence rates close to the mean. In 1999 the incidence rate was just above the LCL and in 2000 it was just below the LCL.

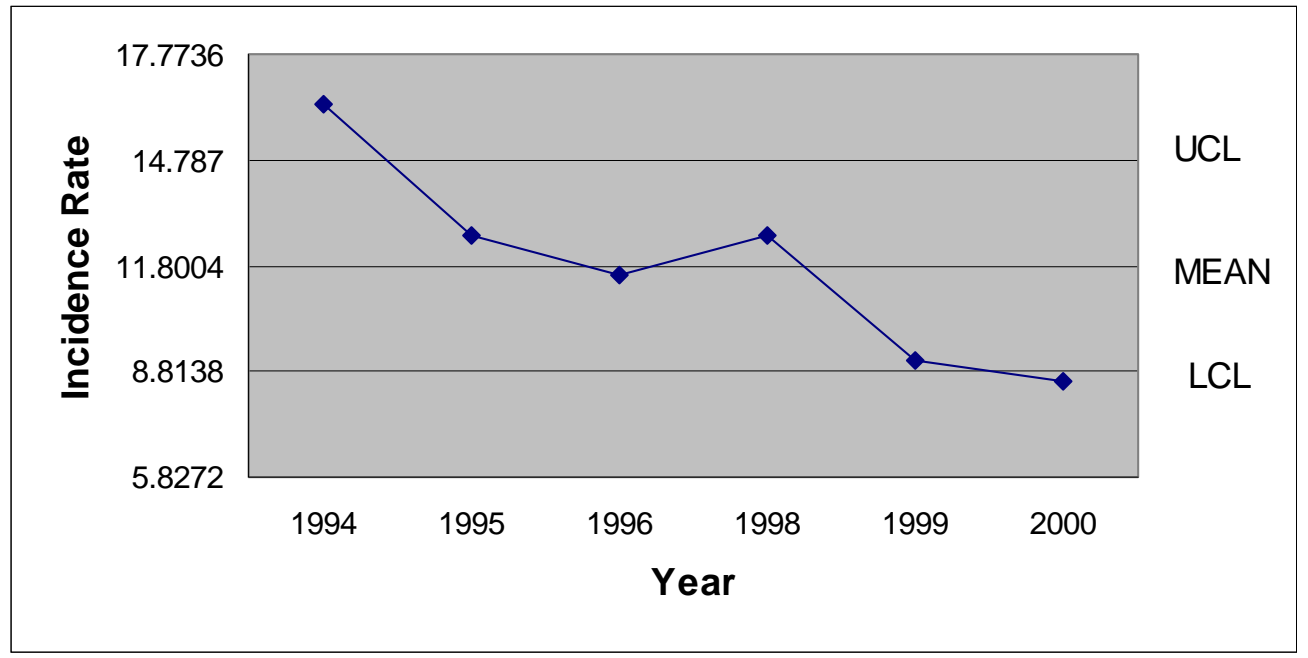

Note: No operations in May 1997

Figure 283. May 1994-2000 Medical Treatment Incidence Rates - Corporate

The June 1994 Corporate incidence rate, which was the highest for the month, was almost 75\% higher than the low recorded in June 1999. After the 1994 high, the incidence rate dropped to just above the mean in 1995. The next two years, 1996 and 
1998, edged toward the UCL. The last two years recorded incidence rates slightly below the LCL (See Figure 284).

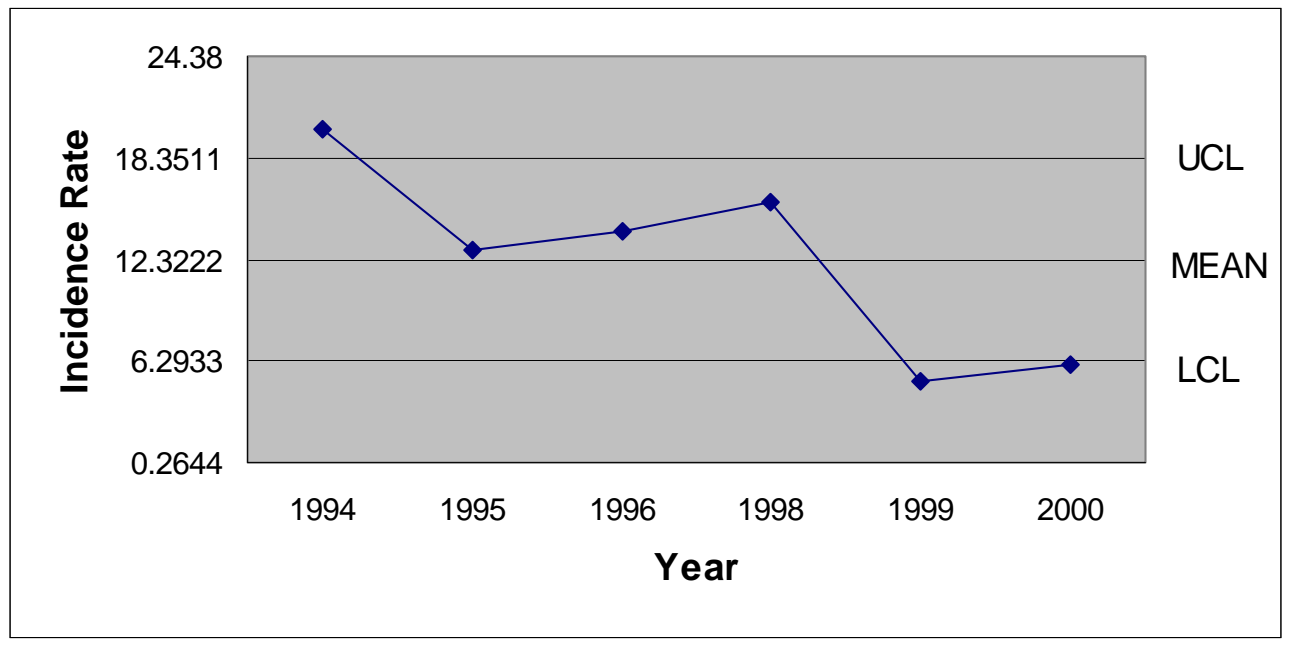

Note: No operations in June 1997

Figure 284. June 1994-2000 Medical Treatment Incidence Rates - Corporate

As illustrated in Figure 285, the July 1994 Corporate incidence rate of 23.252 was more than 4 times greater than the low of 4.817, which was recorded in July of 1999. The 1995 through 1998 period experienced incidence rates that were clustered around the mean.

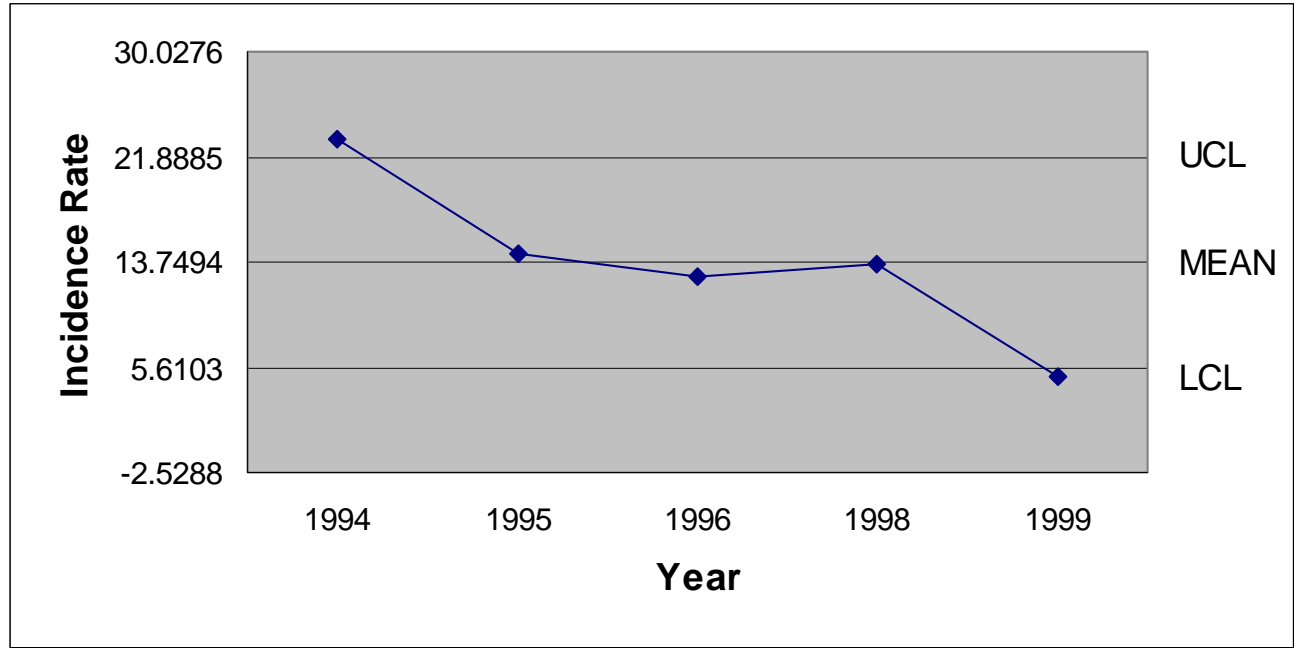

Note: No operations in July 1997.

Figure 285. July 1994-1999 Medical Treatment Incidence Rates - Corporate 
Although all of the August Corporate incidence rates were within the control limits during the study period, the 1994 and 1995 rates of 17.094 and 17.143 respectively were close to the UCL. A sharp decrease in incidence rate occurred between the high in 1995 and the 1996 incidence rates. After the large decrease, a gradual decrease occurred over the next two years to a level just above the LCL in 1999 (See Figure 286).

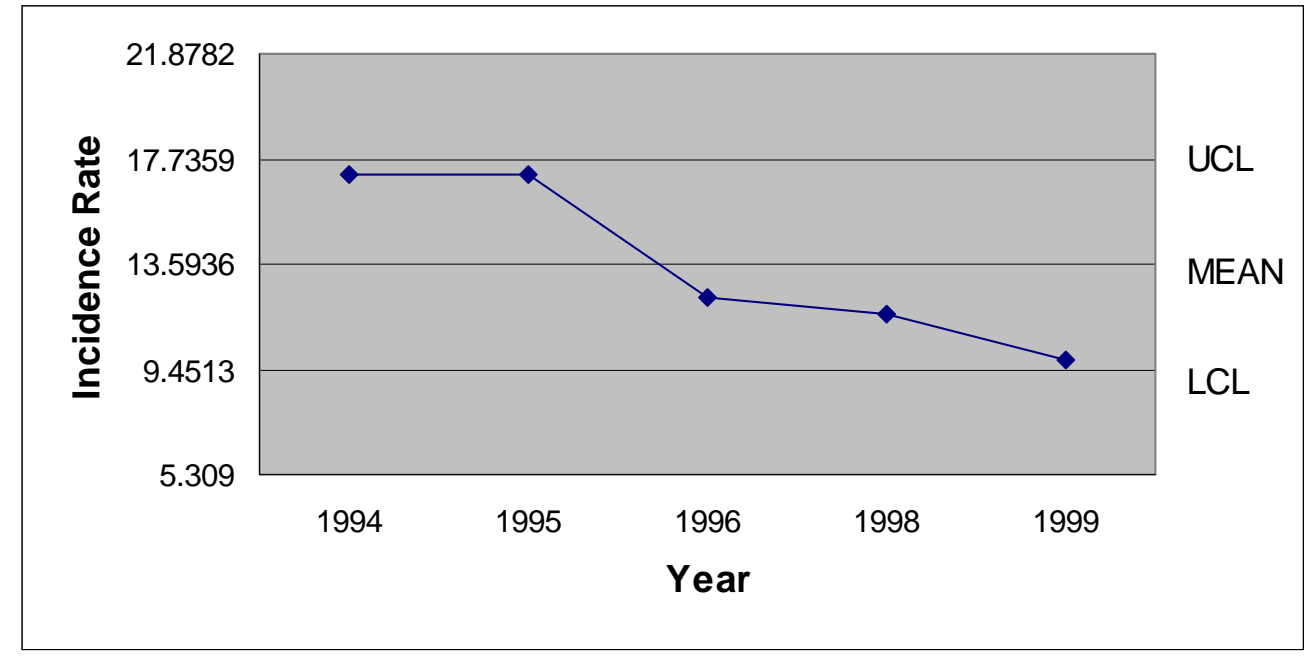

Note: No operations in August 1997

Figure 286. August 1994-1999 Medical Treatment Incidence Rates - Corporate

As illustrated in Figure 287, the Corporate September incidence rates were between the mean and the UCL for the first three years. A decrease from the 1996 high to a level below the LCL occurred over the next two years of operations. 


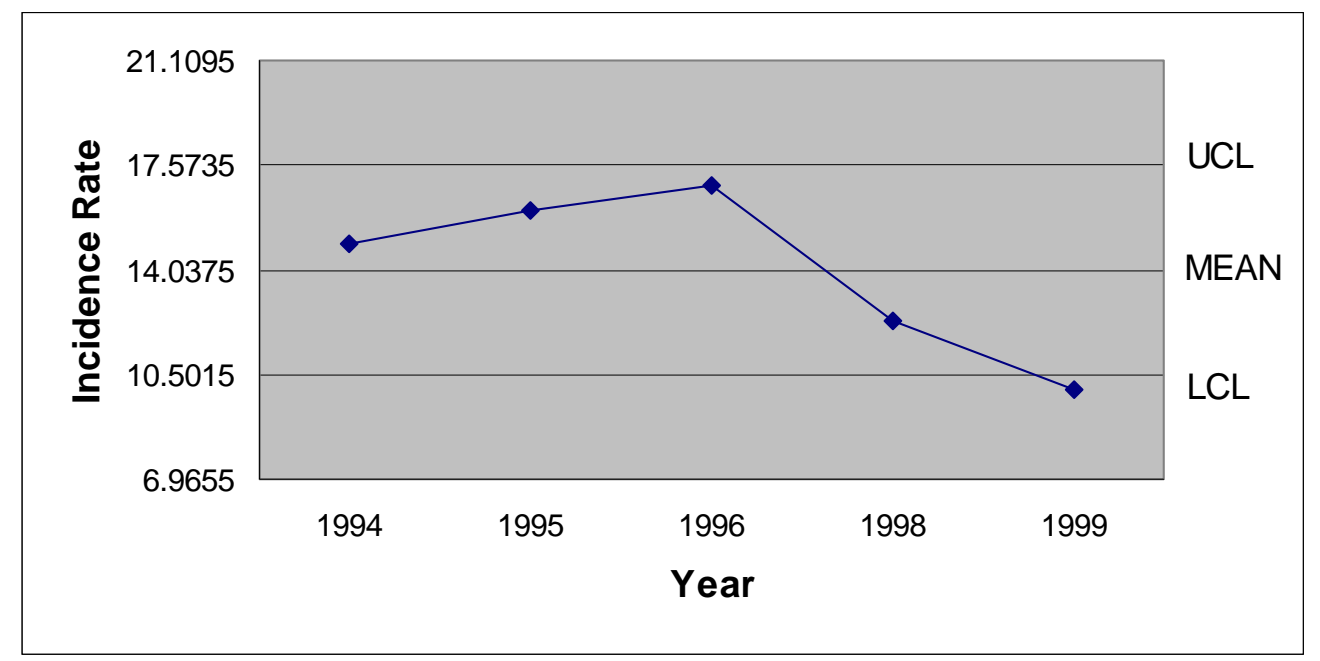

Note: No operations in September 1997

Figure 287. September 1994-1999 Medical Treatment Incidence Rates - Corporate

The 1994, 1998, and 1999 Corporate incidence rates for the month of October were below the mean. The 1995 incidence rate was between the mean and the UCL, while the 1997 incidence rate was barely above the UCL. The sharpest decrease in incidence rates occurred between 1997 and 1998, with a decrease of nearly 30\% (See Figure 288).

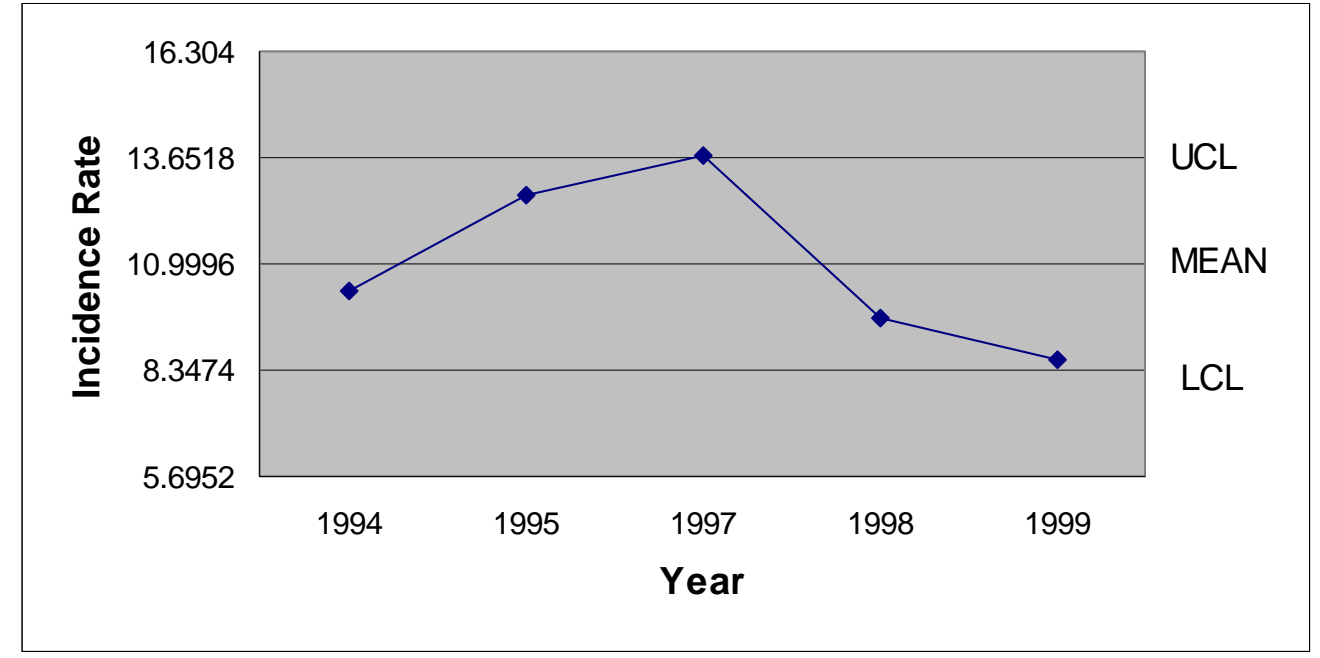

Note: No operations in October 1996

Figure 288. October 1994-1999 Medical Treatment Incidence Rates - Corporate 
A decreasing pattern of Corporate medical Treatment Incidence Rates occurred between November 1994 and 1998. The pattern that started above the UCL in 1994 and ended just above the LCL in 1998 was interrupted by an increase to a level just below the mean in 1999 (See Figure 289).

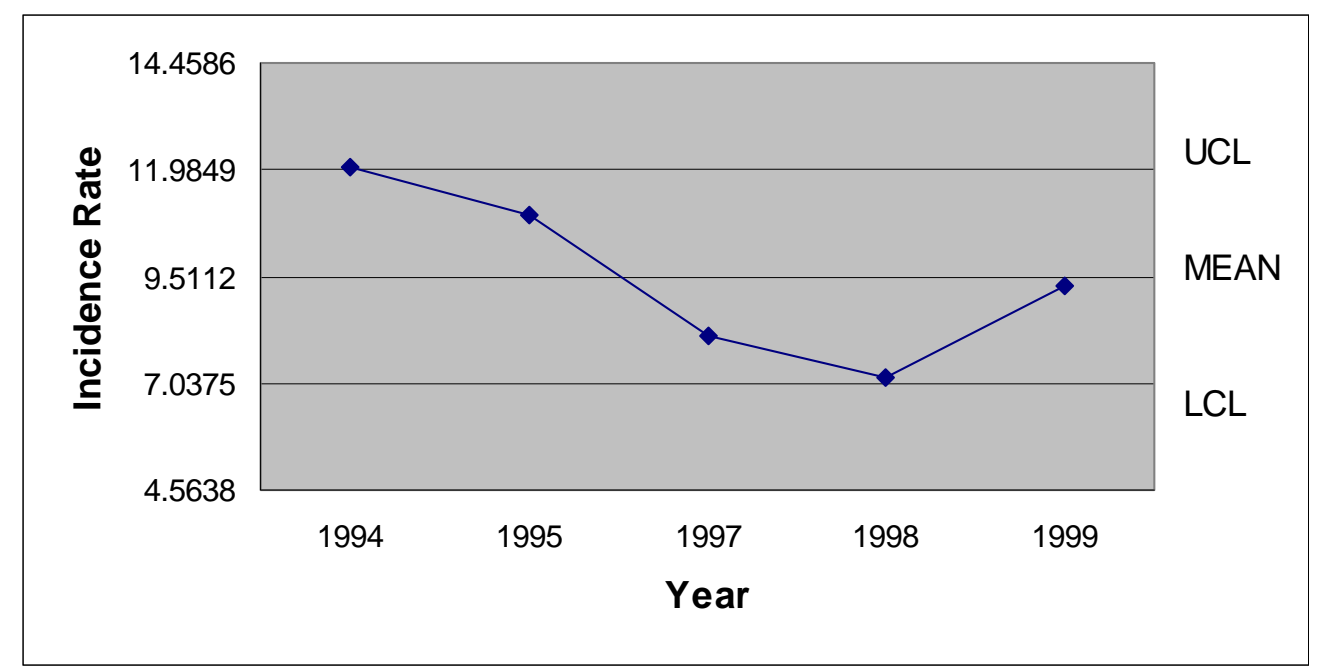

Note: No operations in November 1996

Figure 289. November 1994-1999 Medical Treatment Incidence Rates - Corporate

The 1994, 1995, and 1998 December Corporate medical treatment incidence rates were close to the mean. In 1997 the highest December incidence rate was recorded barely below the UCL. In the final December period the incidence rate was below the LCL (See Figure 290). 


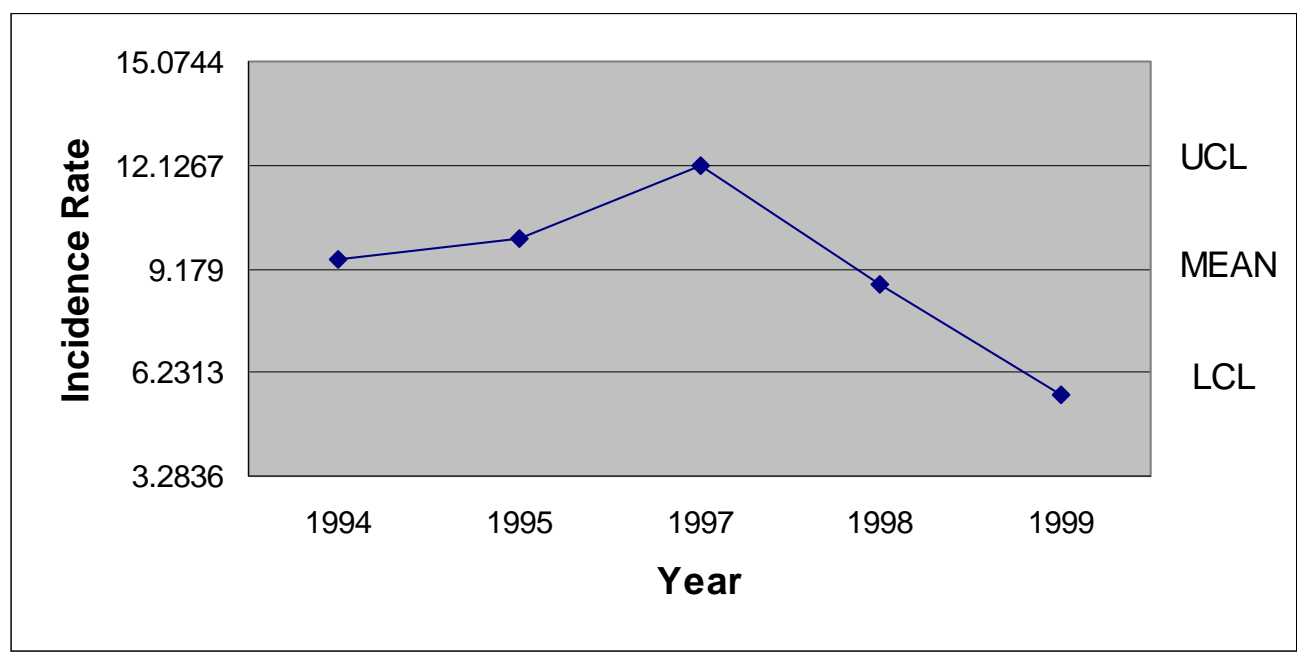

Note: No operations in December 1996

Figure 290. December 1994-1999 Medical Treatment Incidence Rates - Corporate

Table 50 presents the Corporate monthly incidence rates for each year of the study period, as well as the UCL, mean, LCL, and standard deviation. Nineteen ninetysix and 1997 are partial years because of the work stoppage and only the first six months of 2000 were included in the research.

Table 50

$\underline{\text { Summary of Monthly Medical Treatment Incidence Rates Data - Corporate }}$

\begin{tabular}{|l|l|l|l|l|l|l|l|l|l|l|l|l|}
\hline & Jan. & Feb. & Mar. & Apr. & May & June & July & Aug. & Sept. & Oct. & Nov. & Dec. \\
\hline 1994 & 17.705 & 18.288 & 13.853 & 11.121 & 16.380 & 20.103 & 23.252 & 17.094 & 14.935 & 10.336 & 12.054 & 9.450 \\
\hline 1995 & 12.619 & 12.706 & 12.117 & 10.177 & 9.476 & 12.876 & 14.444 & 17.143 & 16.062 & 12.731 & 10.924 & 10.013 \\
\hline 1996 & 12.860 & 10.119 & 9.004 & 13.105 & 11.545 & 13.933 & 12.581 & 12.240 & 16.898 & N/A & N/A & N/A \\
\hline 1997 & N/A & N/A & N/A & N/A & N/A & N/A & N/A & N/A & N/A & 13.688 & 8.115 & 12.122 \\
\hline 1998 & 11.589 & 9.179 & 11.936 & 11.535 & 12.629 & 15.744 & 13.653 & 11.605 & 12.296 & 9.636 & 7.183 & 8.724 \\
\hline 1999 & 9.665 & 5.474 & 7.012 & 9.822 & 9.113 & 5.140 & 4.817 & 9.855 & 9.997 & 8.606 & 9.281 & 5.586 \\
\hline 2000 & 7.370 & 6.485 & 8.900 & 7.138 & 8.507 & 7.138 & N/A & N/A & N/A & N/A & N/A & N/A \\
\hline UCL & 15.626 & 15.269 & 13.162 & 12.568 & 14.787 & 18.351 & 21.889 & 17.736 & 17.574 & 13.652 & 11.985 & 12.127 \\
\hline MEAN & 11.968 & 10.375 & 10.470 & 10.456 & 11.800 & 12.322 & 13.749 & 13.594 & 14.038 & 10.999 & 9.511 & 9.179 \\
\hline LCL & 8.310 & 5.481 & 7.778 & 8.345 & 8.814 & 6.293 & 5.610 & 9.451 & 10.502 & 8.347 & 7.038 & 6.231 \\
\hline SD & 1.423 & 1.903 & 1.047 & 0.821 & 1.162 & 2.345 & 2.932 & 1.492 & 1.274 & 0.955 & 0.891 & 1.062 \\
\hline
\end{tabular}




\section{$\underline{\text { Seasonal Analysis of Medical Treatment Data - Corporate }}$}

The Corporate seasonal index calculation was used to generate the monthly seasonal index figures that are presented in Figure 291. The period of May through September experienced the highest seasonal index figures, with July as the highest. December had the lowest seasonal index.

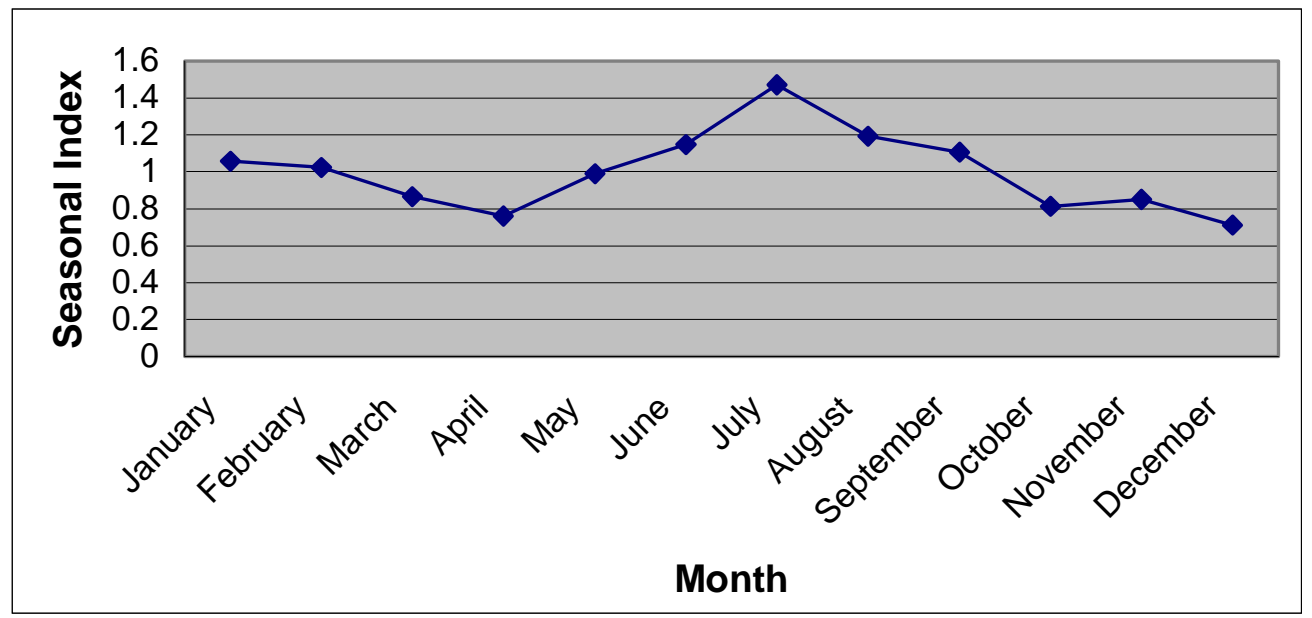

Figure 291. Monthly Seasonal Pattern of Medical Treatment Incidence Rates Corporate

Testing the Statistical Relationship of Medical Treatment Data - Corporate

\section{All 33 Months Prior to and Subsequent to the Work Stoppage}

At the Corporate level, for the entire 33 months prior to the work stoppage and the 33 post work stoppage months the calculated comparison t value was 9.217. Because this calculated amount exceeded the 1.96 critical $t$ value, a statistically significant decrease in incidence rate was found between the two periods.

\section{First 24 Months and Last 24 Months of the Research Period}

The same formula was applied to Corporate medical treatment incidence rates for the first 24 months and last 24 months of the research period. These time periods excluded the nine months prior to and immediately following the work stoppage. Using the same 1.96 critical t value, the calculated amount, 10.503, was greater than the critical 
$\mathrm{t}$ value. Therefore a statistically significant decrease in incidence rates was found between the two 24 month periods.

\section{Nine Month Intervals Prior to and Subsequent to the Work Stoppage}

Comparison of the Corporate medical treatment incidence rates for the nine months preceding the work stoppage and the nine months following the work stoppage was accomplished using The comparison formula. The result of this calculation, 0.519, was less than the critical $t$ value of 1.96 , for a .05 statistical significance level. Because the calculated amount is less than the critical $t$ value, a statistically significant decrease in incidence rates did not occur between the periods.

\section{Table 51}

Comparison of Prior and Post Work Stoppage Periods - Corporate

\begin{tabular}{|c|c|c|c|c|}
\hline \multirow[b]{2}{*}{ Time Period } & \multicolumn{2}{|c|}{ Corporate-wide Incidence Rates } & \multirow[b]{2}{*}{ Critical t Value } & \multirow[b]{2}{*}{$\begin{array}{l}\text { Calculated } \\
\text { Comparison Value }\end{array}$} \\
\hline & $\begin{array}{l}\text { Prior to } \\
\text { Work Stoppage }\end{array}$ & $\begin{array}{l}\text { Post } \\
\text { Work Stoppage }\end{array}$ & & \\
\hline 9 Months & 12.38 & 11.91 & 1.96 & 0.519 \\
\hline 24 Months & 13.99 & 8.43 & 1.96 & $10.503 * *$ \\
\hline 33 Months & 13.57 & 9.35 & 1.96 & $9.217 * *$ \\
\hline
\end{tabular}

* Indicates a statistically significant increase

** Indicates a statistically significant decrease

\section{$\underline{\text { Primary Plant Analysis }}$}

Quarterly Analysis of Medical Treatment Data - Primary Plant

As illustrated in Figure 292, the Primary Plant first quarter medical treatment incidence rate decreased from the 1994 high of 19.104 to the low in 1999 of 1.810 . In 2000 the incidence rate was $20 \%$ higher than the low recorded the preceding year. 


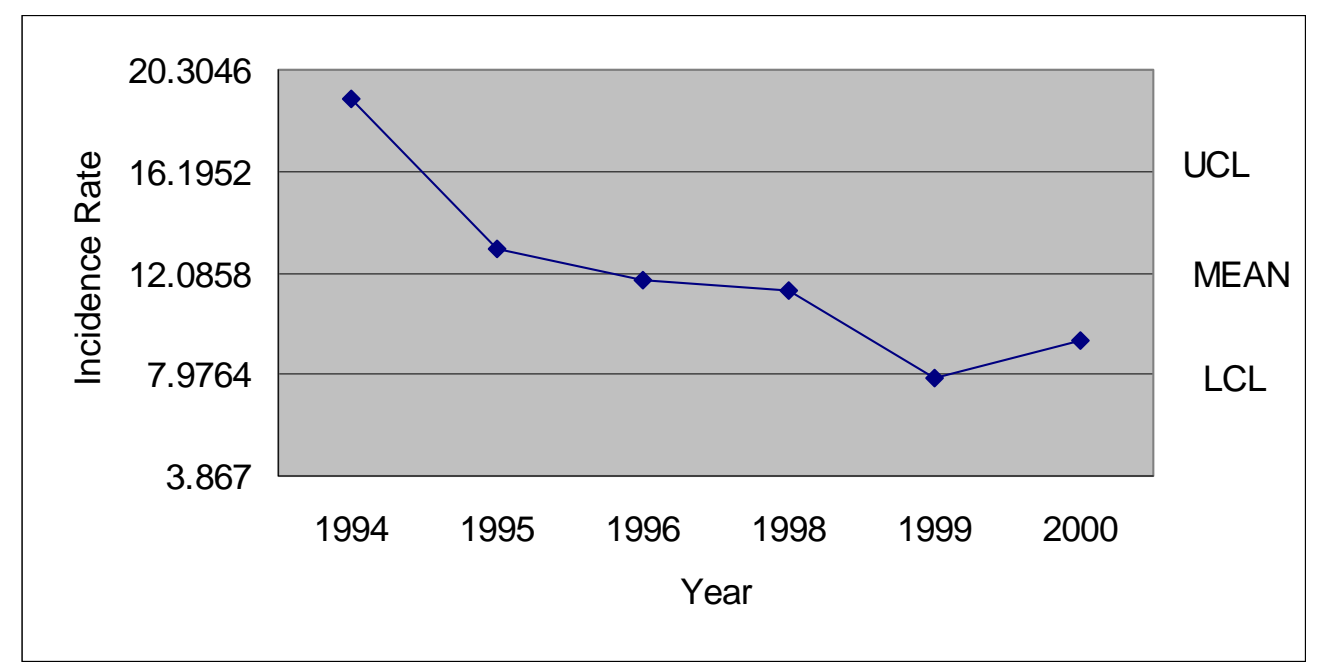

Note: No operations in first quarter 1997

Figure 292. First Quarter 1994-2000 Medical Treatment Incidence Rates - Primary Plant

The highest Primary Plant second quarter incidence rate occurred in 1994 and was followed by a decrease of over 30\% in 1995. In 1996 and 1998 the second quarter incidence rates were above the mean and approaching the UCL. The decrease in incidence rate between 1998 and 1999 almost paralleled the earlier decrease. In 2000 the incidence rate was below the LCL (See Figure 293).

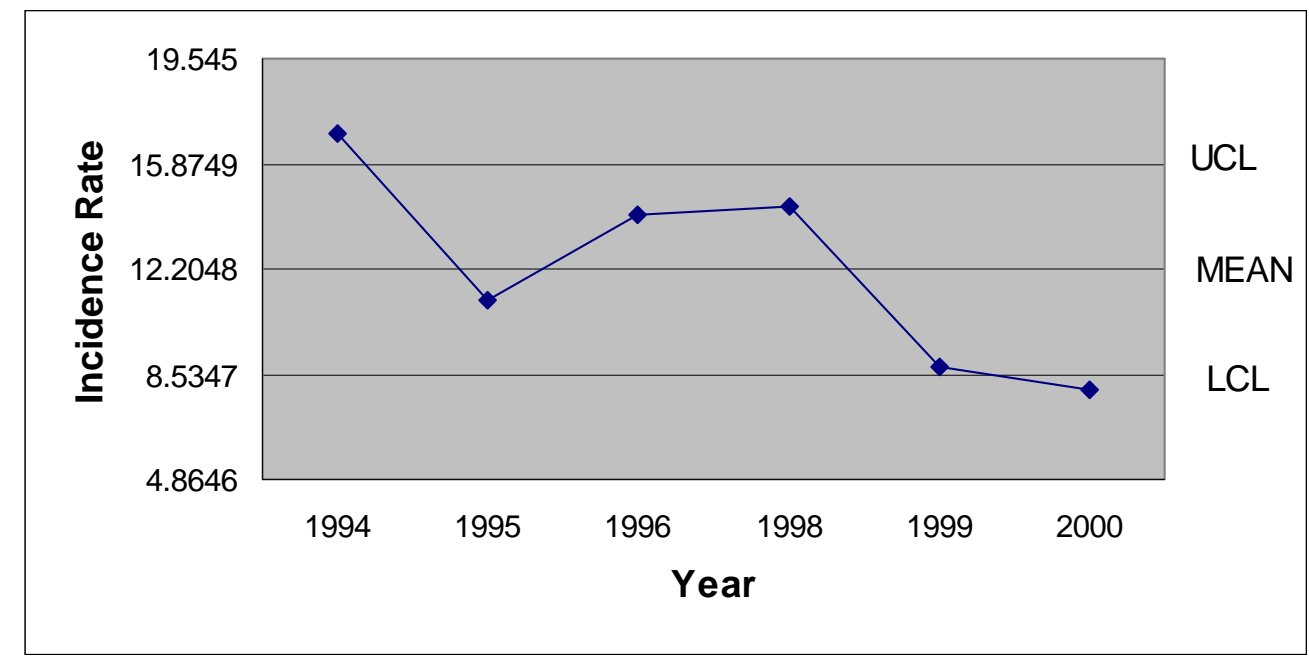

Note: No operations in second quarter 1997

Figure 293. Second Quarter 1994-2000 Medical Treatment Incidence Rates - Primary Plant 
The highest third quarter Primary Plant incidence rate, 22.235, was recorded in 1994. The next year the incidence rate was just above the mean and in 1996 a slight increase was recorded. The next year of third quarter operations, 1998, had an incidence rate between the mean and the LCL. In 1999 the medical treatment incidence rates was just below the LCL (See Figure 294).

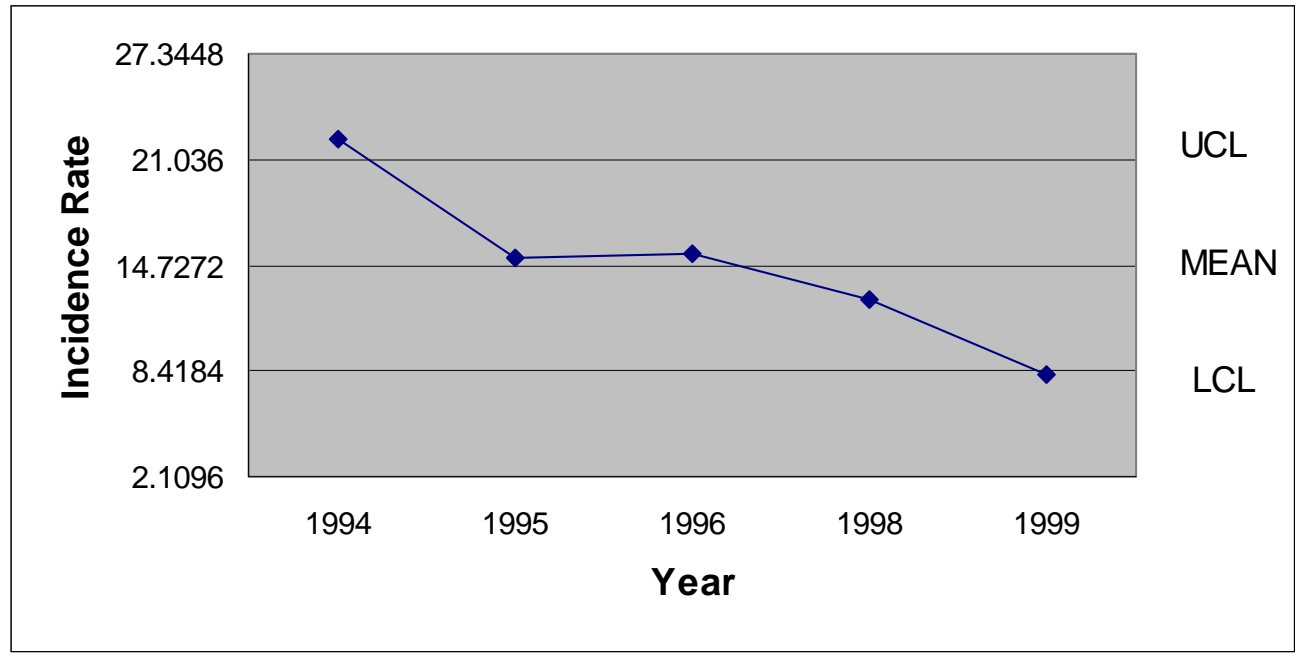

Note: No operations in third quarter 1997

Figure 294. Third Quarter 1994-1999 Medical Treatment Incidence Rates - Primary Plant

The first three Primary Plant fourth quarters of this research period were relatively stable, with 1997 recording the highest incidence rate, 11.728. The next year the incidence rate decreased to 8.046, the lowest fourth quarter recorded for the study period (See Figure 295). 


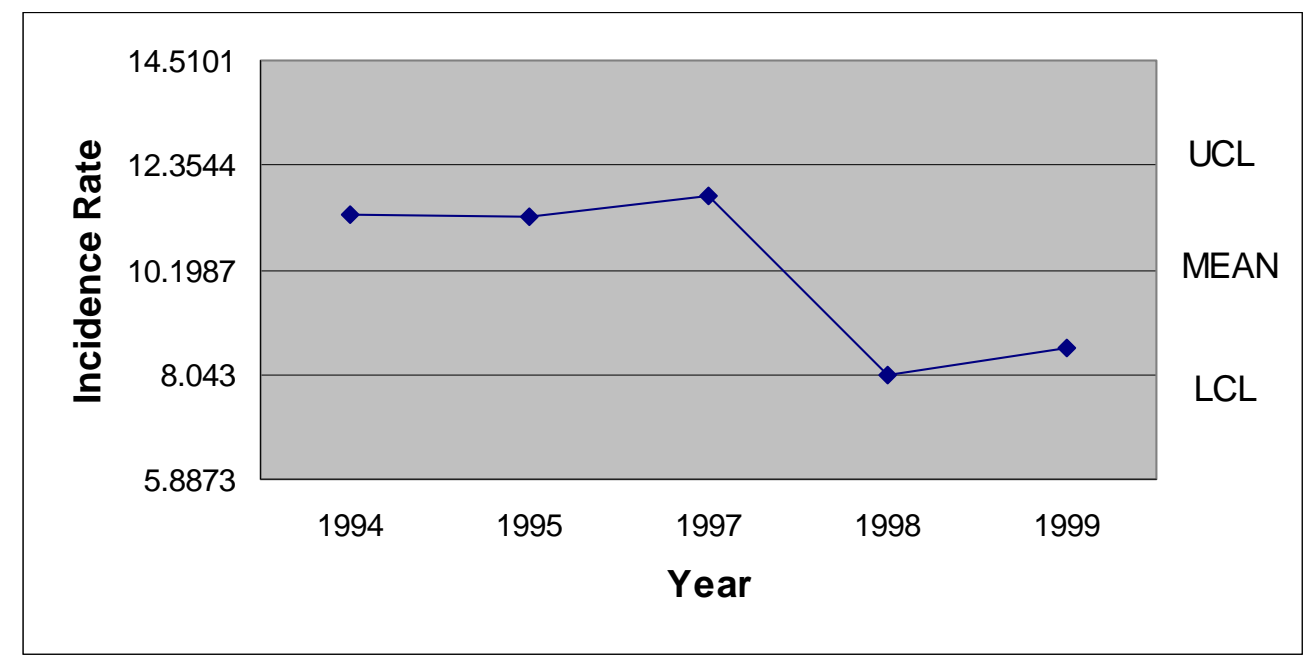

Note: No operations in fourth quarter 1996

Figure 295. Fourth Quarter 1994-1999 Medical Treatment Incidence Rates - Primary Plant

Table 52 presents the Primary Plant quarterly incidence rates for each year of the study period, as well as the UCL, mean, LCL, and standard deviation. Nineteen ninety six and 1997 are partial years because of the work stoppage and only the first six months of 2000 were included in the research.

Table 52

Summary of Quarterly Medical Treatment Incidence Rates Data - Primary Plant

\begin{tabular}{|l|l|l|l|l|}
\hline & $1^{\text {st }}$ Quarter & $2^{\text {nd }}$ Quarter & $3^{\text {rd }}$ Quarter & $4^{\text {th }}$ Quarter \\
\hline 1994 & 19.104 & 16.897 & 22.235 & 11.333 \\
\hline 1995 & 13.095 & 11.084 & 15.119 & 11.230 \\
\hline 1996 & 11.754 & 14.130 & 15.373 & N/A \\
\hline 1997 & N/A & N/A & N/A & 11.728 \\
\hline 1998 & 11.409 & 14.353 & 12.674 & 8.0458 \\
\hline 1999 & 7.810 & 8.780 & 8.236 & 8.589 \\
\hline 2000 & 9.344 & 7.984 & N/A & N/A \\
\hline UCL & 16.195 & 15.875 & 21.036 & 12.354 \\
\hline MEAN & 12.086 & 12.205 & 14.727 & 10.199 \\
\hline LCL & 7.976 & 8.535 & 8.418 & 8.043 \\
\hline SD & 1.598 & 1.427 & 2.273 & 0.777 \\
\hline
\end{tabular}




\section{$\underline{\text { Seasonal Analysis of Medical Treatment Data - Primary Plant }}$}

The results of the quarterly seasonal index calculations for the Primary Plant are presented in Figure 296. The incidence rates seasonal index indicates that the third quarter had the highest seasonal index and the fourth quarter had the lowest. The first and second quarters were both close to the 1.0 seasonal index figure.

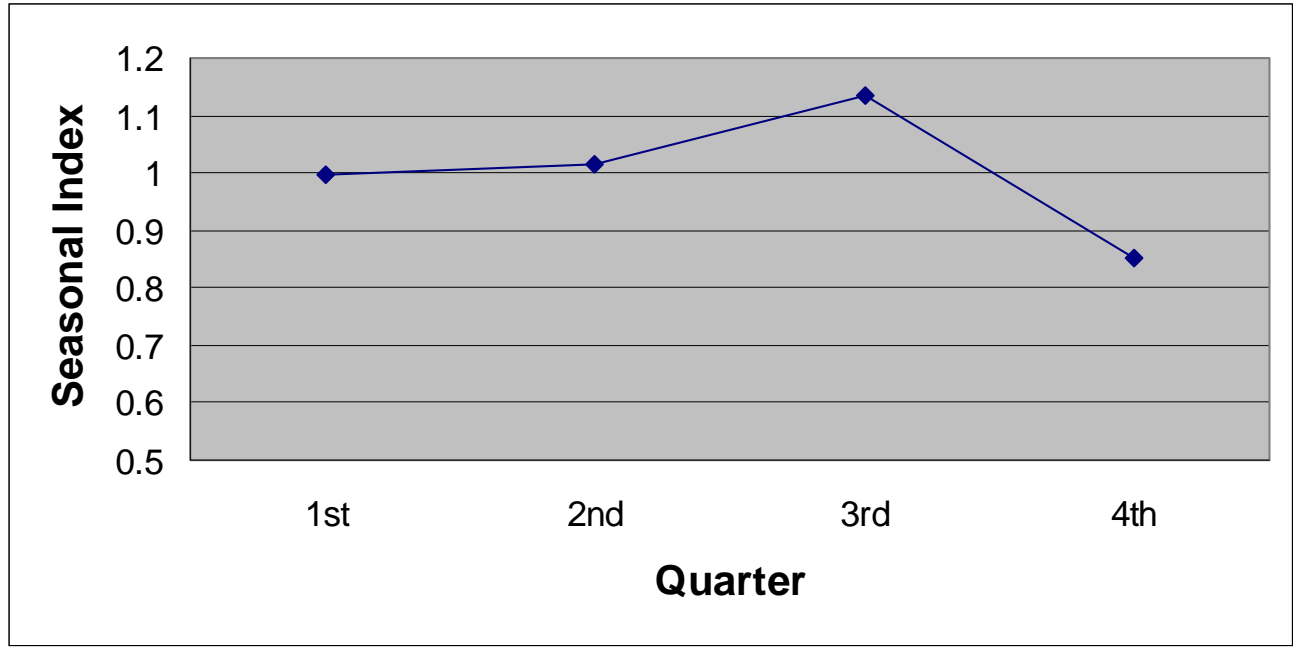

Figure 296. Quarterly Seasonal Index of Medical Treatment Incidence Rates Primary Plant

\section{Monthly Analysis of Medical Treatment Data - Primary Plant}

The highest medical treatment incidence rates for the month of January at the Primary Plant occurred above the UCL in 1994. The next three years had incidence rates clustered around the mean. In 1999 and 2000 the incidence rate was close to the LCL (See Figure 297). 


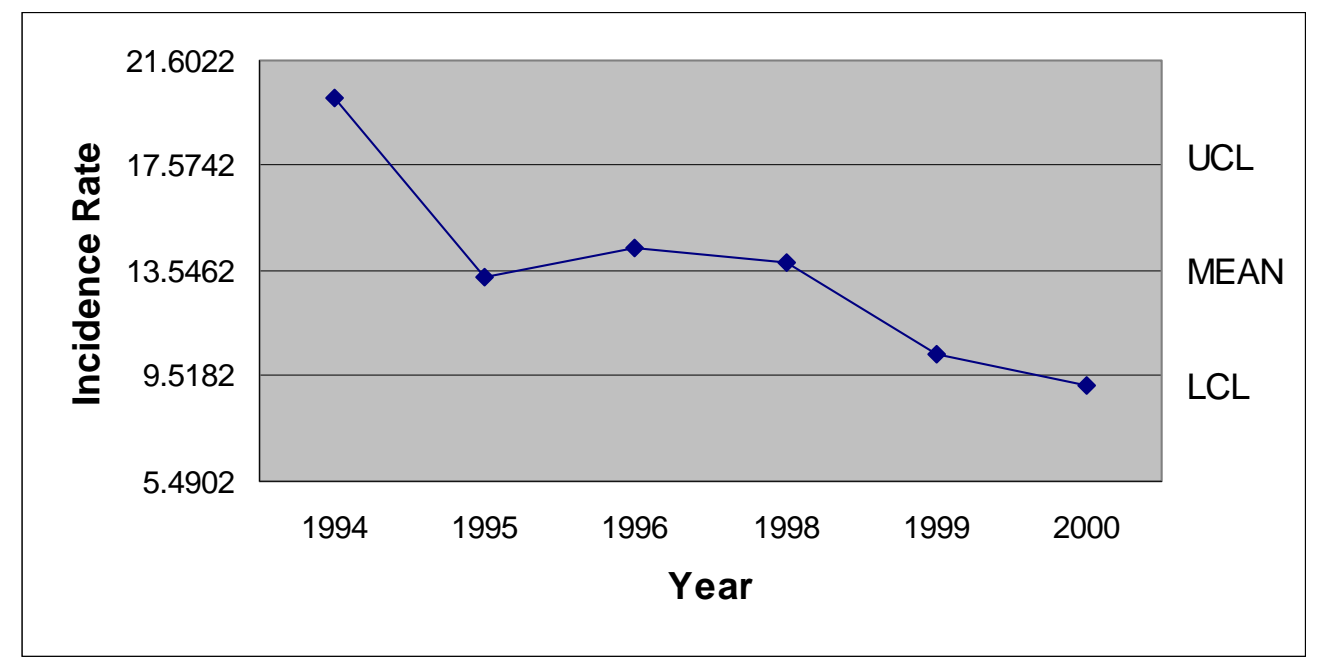

Note: No operations in January 1997

Figure 297. January 1994-2000 Medical Treatment Incidence Rates - Primary Plant

The steepest February decrease at the Primary Plant from the 1994 high occurred the next year when the incidence rate was $35 \%$ lower than the high. The next three years recorded consecutive decreases, until finally reaching a low in 1999. In February 2000 the incidence rate increased to a level between the LCL and the mean (See Figure 298).

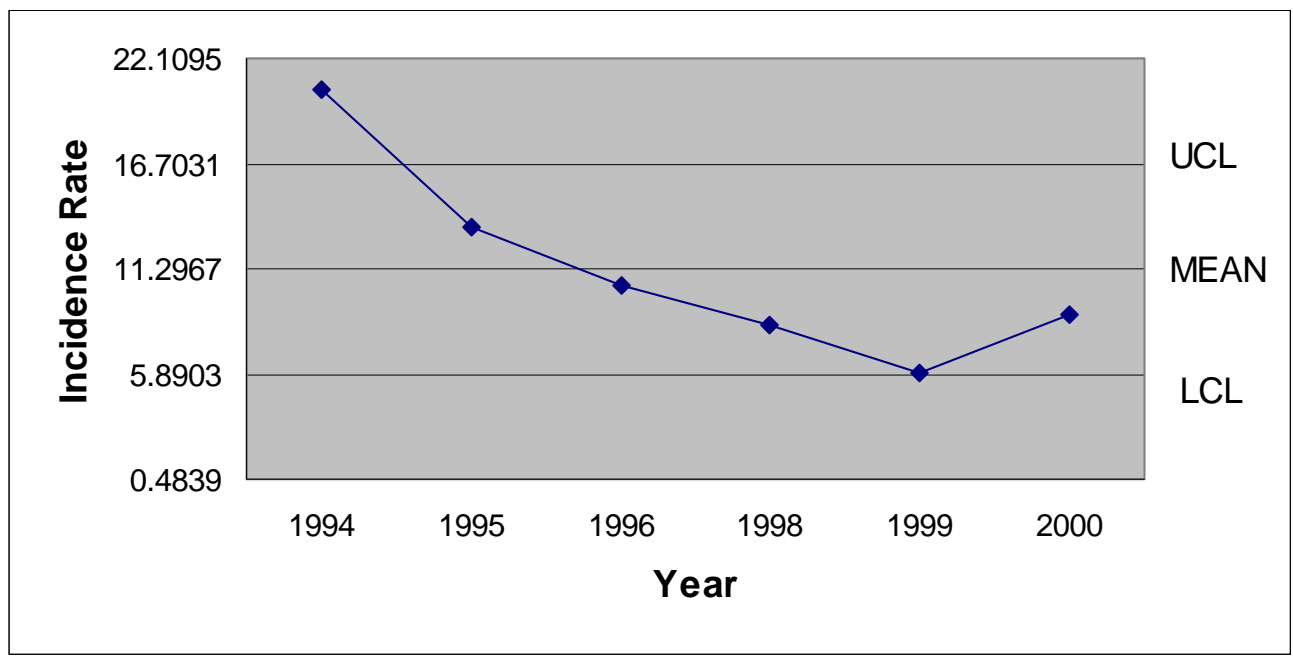

Note: No operations in February 1997

Figure 298. February 1994-2000 Medical Treatment Incidence Rates - Primary Plant 
The March Primary Plant incidence rates steadily decreased from the 1994 high to a level below the mean in 1996. This pattern was interrupted by an increase to a level above the mean in 1998. In 1999 the incidence rates dropped to a low of 7.060 (See Figure 299).

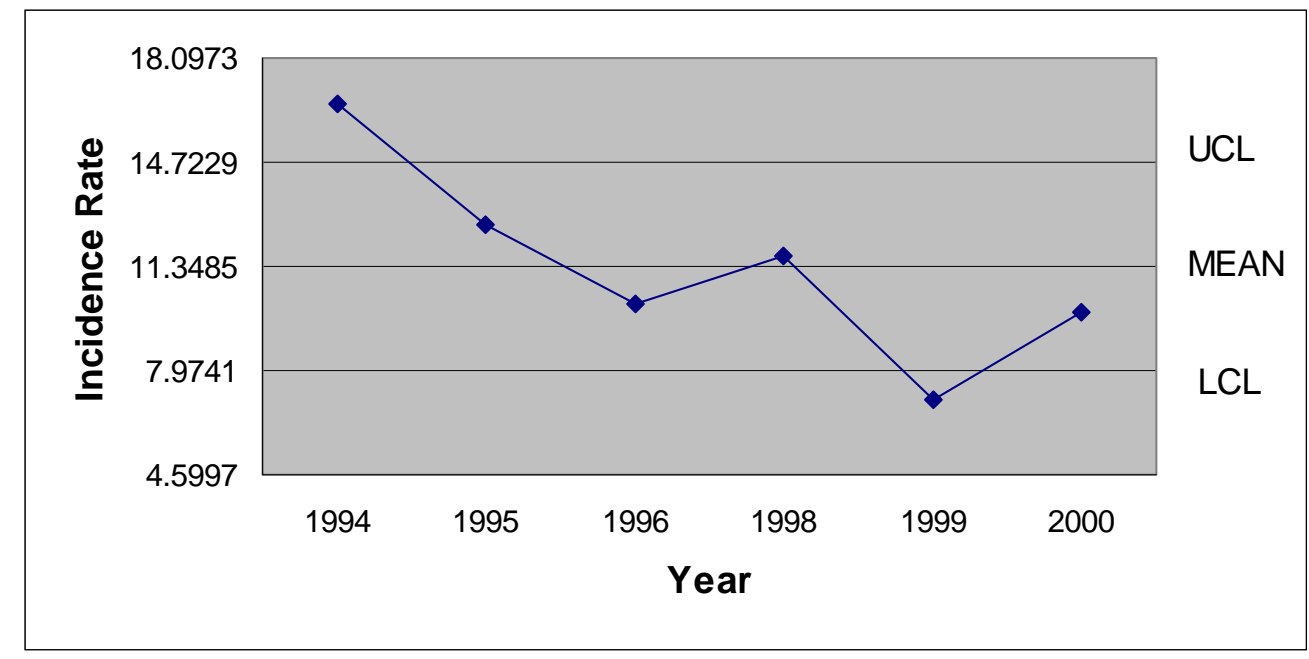

Note: No operations in March 1997

Figure 299. March 1994-2000 Medical Treatment Incidence Rates - Primary Plant

As illustrated in Figure 300, the April Primary Plant incidence rates were close to the mean in 1994 and 1995. In 1996 the incidence rate increased by 30\% to a level above the UCL. The incidence rates then leveled off in 1998 and 1999 at a level just above the mean. In 2000 the incidence rate reached 8.349, a low for the research period. 


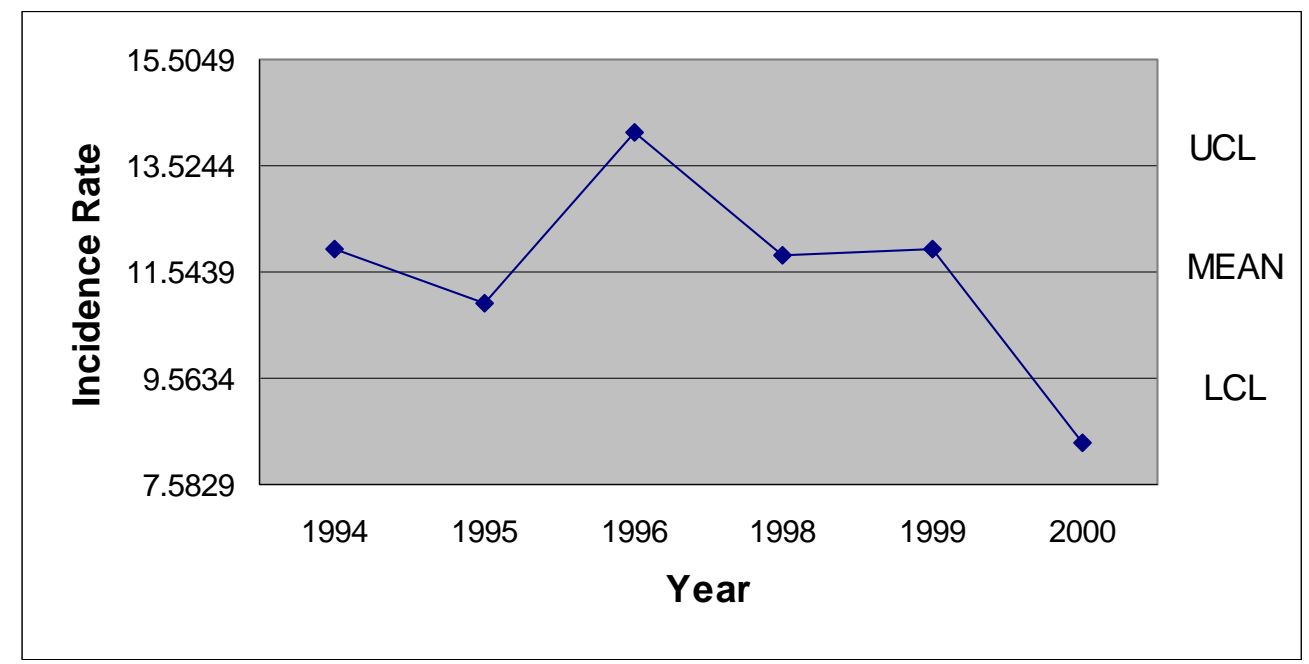

Note: No operations in April 1997

Figure 300. April 1994-2000 Medical Treatment Incidence Rates - Primary Plant

The decrease at the Primary Plant between the high in May 1994 and May 1995 was more than $45 \%$. The following two years recorded increasing incidence rates to a level between the mean and the UCL in 1998, the second highest incidence rate for the month. The incidence rate decreased over the next two years to the low in 2000 of 9.020 (See Figure 301).

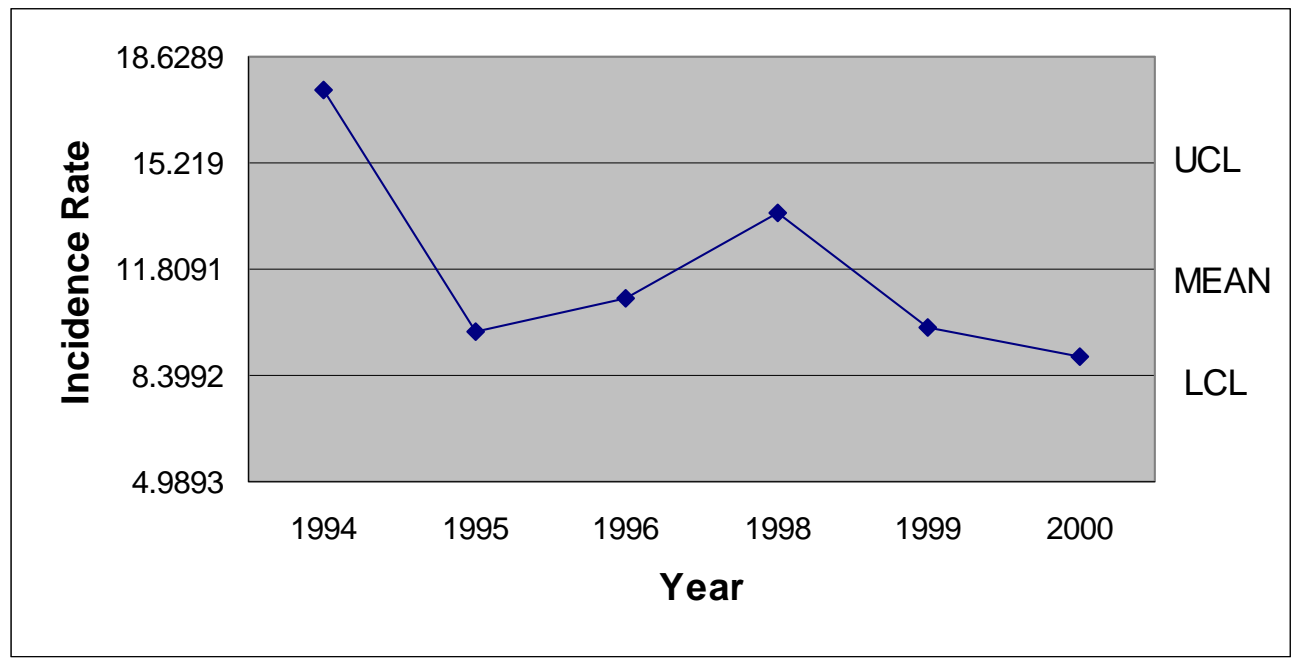

Note: No operations in May 1997

Figure 301. May 1994-2000 Medical Treatment Incidence Rates - Primary Plant 
The June 1994 high at the Primary Plant was almost five times greater in magnitude than the 1999 low. After an initial drop the first two years, the incidence rates increased and then leveled off close to 17.500. These two years were followed by a decrease of almost 75\%. As illustrated in Figure 302, following the 1999 low, the incidence rates increased to just above the LCL in 2000.

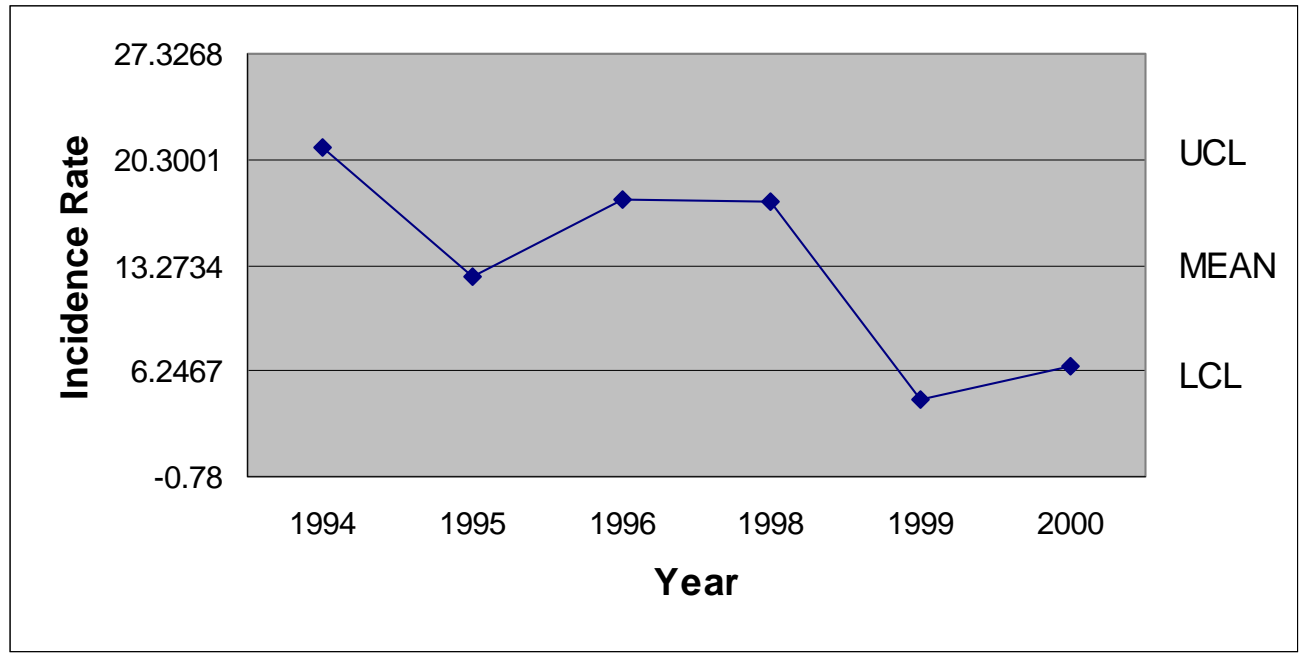

Note: No operations in June 1997

Figure 302. June 1994-2000 Medical Treatment Incidence Rates - Primary Plant

The lowest Primary Plant July incidence rate, recorded in 1999, was almost six times smaller in magnitude than the high of 27.426, which was recorded in 1994. The middle three years experienced incidence rates close to the mean (See Figure 303). 


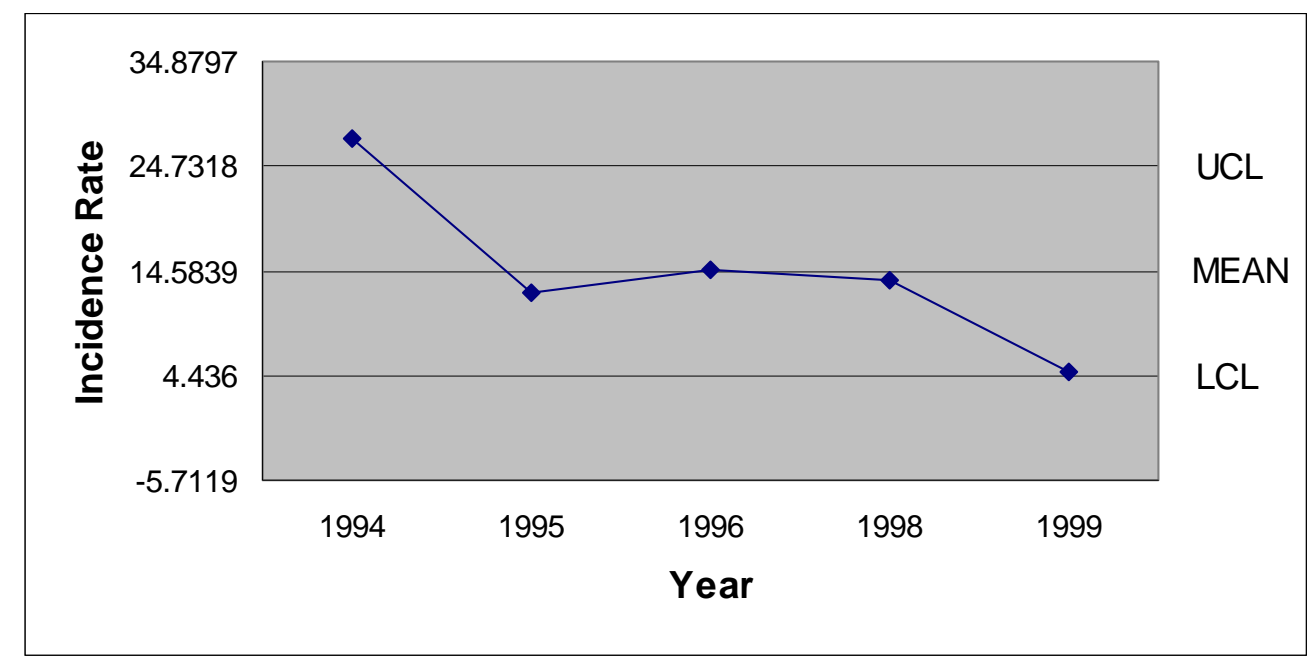

Note: No operations in July 1997

Figure 303. July 1994-1999 Medical Treatment Incidence Rates - Primary Plant

In 1994 the highest Primary Plant August incidence rate of 21.758 was recorded. The incidence rates decreased over the next several years to a level of 10.743 (See Figure 304).

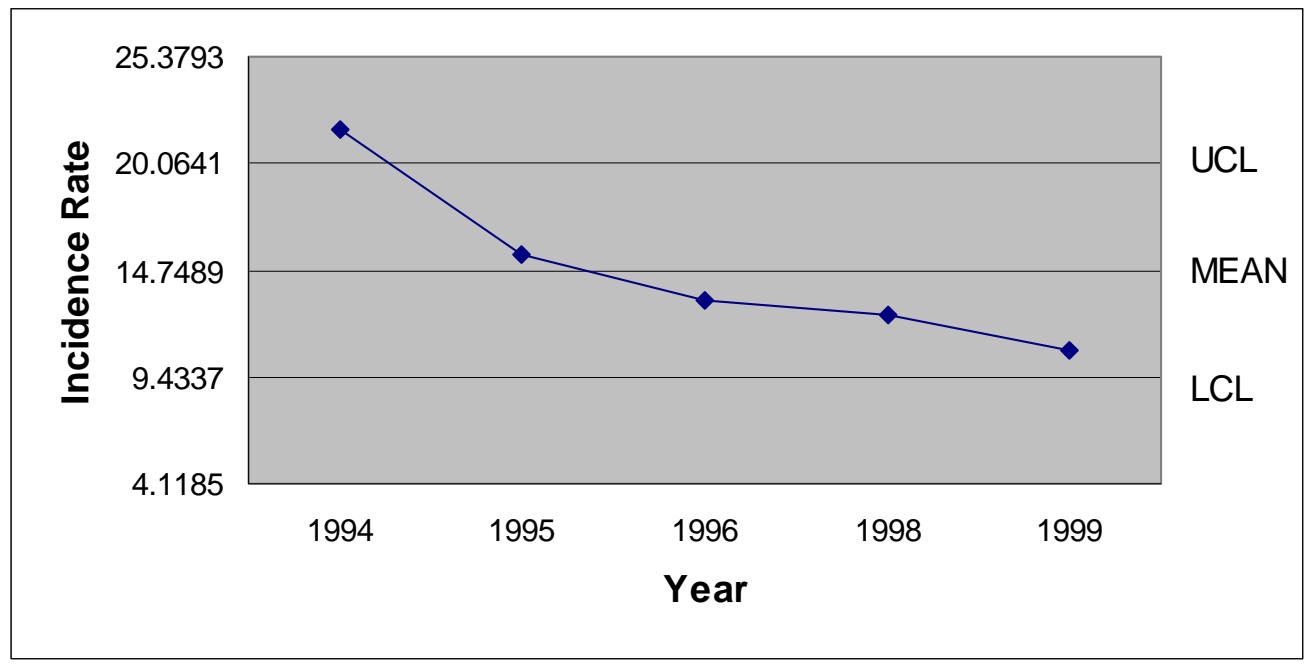

Note: No operations in August 1997

Figure 304. August 1994-1999 Medical Treatment Incidence Rates - Primary Plant

The first two Primary Plant September incidence rates were relatively stable. An increase of $10 \%$ occurred between 1995 and the high in 1996, the last month of 
operations preceding the work stoppage. The following year the incidence rate was $28 \%$ lower and the last year's incidence rate was below the LCL (See Figure 305).

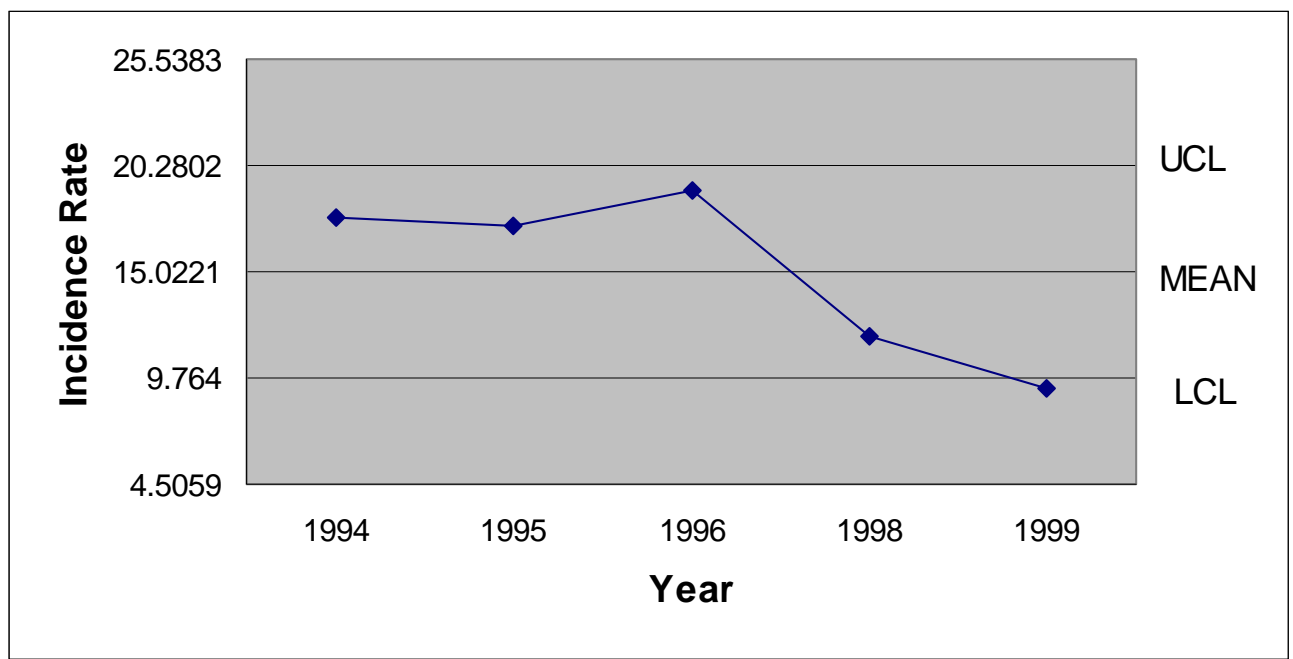

Note: No operations in September 1997

Figure 305. September 1994-1999 Medical Treatment Incidence Rates - Primary Plant

For the month of October, an almost straight-line decrease in Primary Plant incidence rates was interrupted in 1997 by the highest October incidence rate. October 1997 was the first month of operations following the work stoppage. Following the 1997 high, the incidence rates in 1998 and 1999 were close to the LCL (See Figure 306).

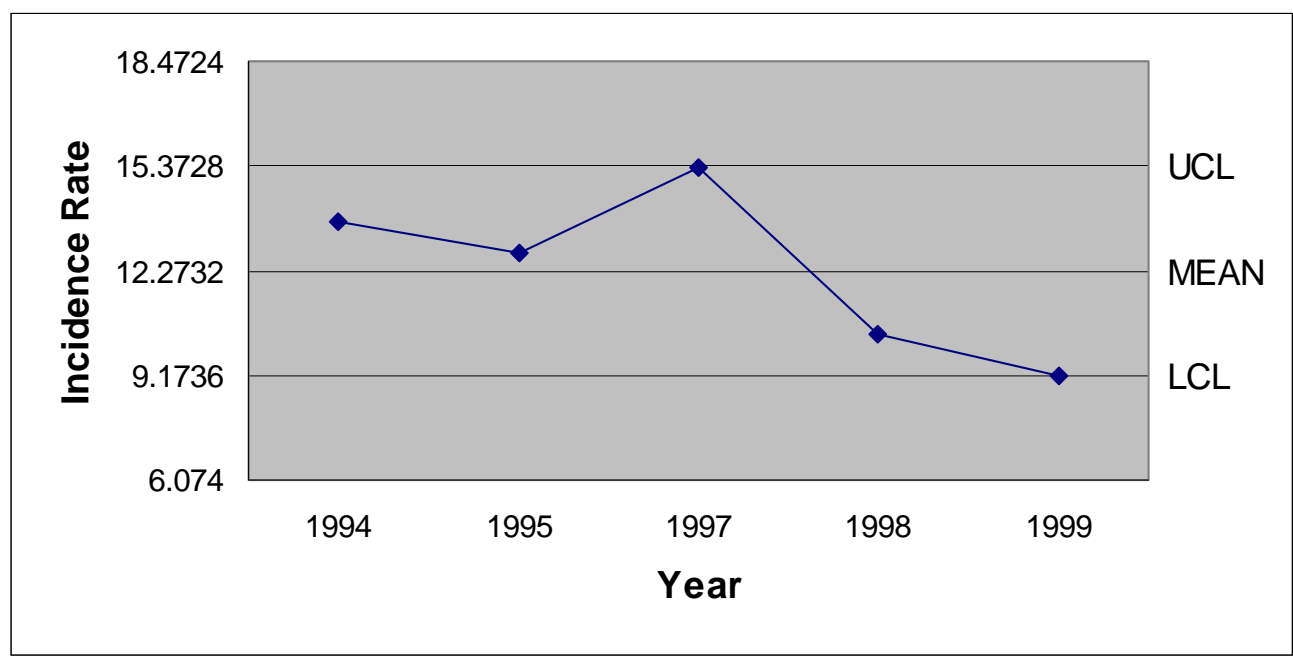

Note: No operations in October 1996

Figure 306. October 1994-1999 Medical Treatment Incidence Rates - Primary Plant 
The November Primary Plant incidence rates steadily decreased from the 1994 high to the low in 1998. After reaching the 1998 low, the incidence rate climbed to the second highest level in 1999 (See Figure 307).

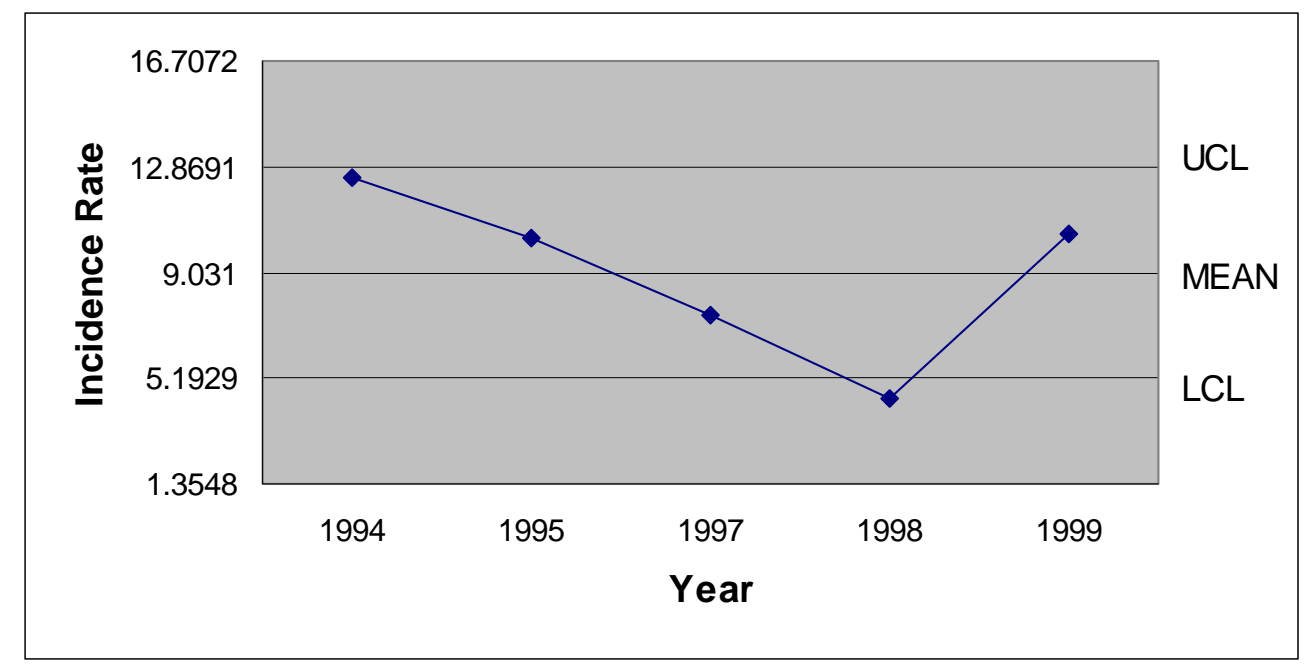

Note: No operations in November 1996

Figure 307. November 1994-1999 Medical Treatment Incidence Rates - Primary Plant

After the second lowest December Primary Plant incidence rate was recorded in 1994, the incidence rates nearly doubled in magnitude to a high of 12.004 in 1997. December 1997 was the third month of operations following the work stoppage. After the 1997 high, the incidence rate decreased in 1998 and reached a low of 6.159 in December 1999 (See Figure 308). 


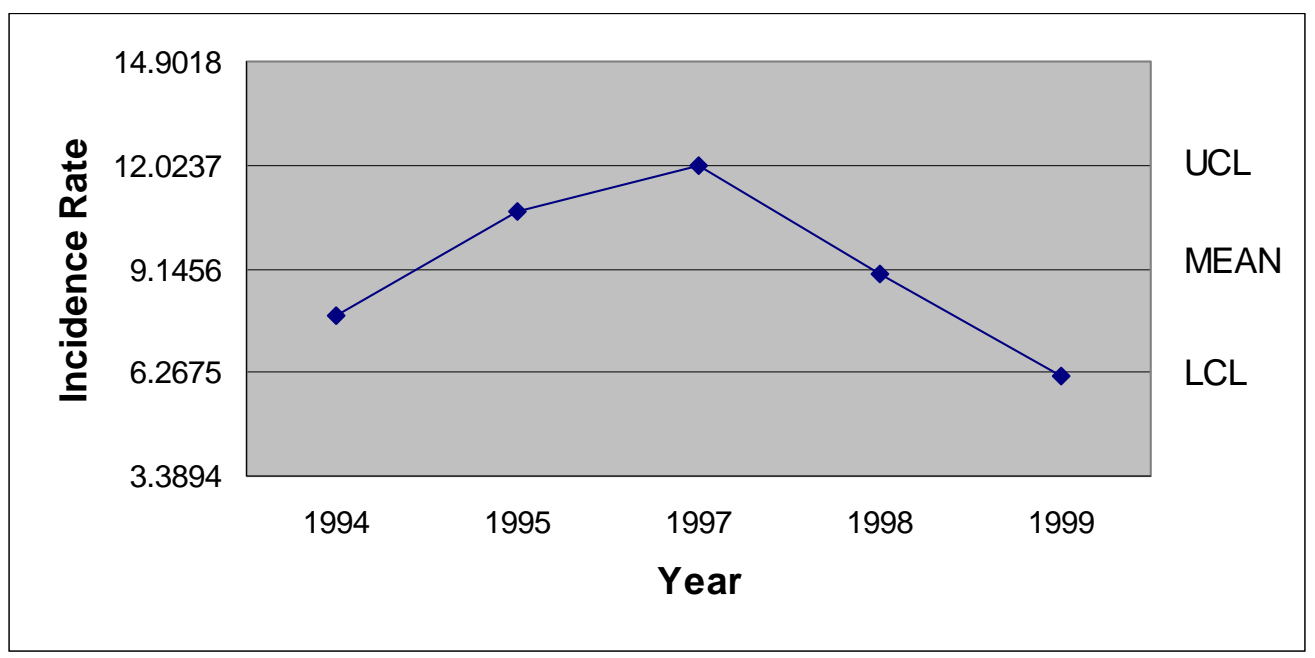

Note: No operations in December 1996

Figure 308. December 1994-1999 Medical Treatment Incidence Rates - Primary Plant

Table 53 presents the Primary Plant monthly medical treatment incidence rates for each year of the study period, as well as the UCL, mean, LCL, and standard deviation. Nineteen ninety six and 1997 are partial years because of the work stoppage and only the first six months of 2000 were included in the research.

Table 53

$\underline{\text { Summary of Monthly Medical Treatment Incidence Rates Data - Primary Plant }}$

\begin{tabular}{|l|l|l|l|l|l|l|l|l|l|l|l|l|}
\hline & Jan. & Feb. & Mar. & Apr. & May & June & July & Aug. & Sept. & Oct. & Nov. & Dec. \\
\hline 1994 & 20.134 & 20.549 & 16.627 & 11.988 & 17.571 & 21.082 & 27.426 & 21.758 & 17.665 & 13.694 & 12.449 & 7.820 \\
\hline 1995 & 13.269 & 13.387 & 12.670 & 10.943 & 9.779 & 12.580 & 12.496 & 15.552 & 17.320 & 12.772 & 10.306 & 10.764 \\
\hline 1996 & 14.461 & 10.486 & 10.165 & 14.141 & 10.879 & 17.576 & 14.610 & 13.205 & 19.024 & N/A & N/A & N/A \\
\hline 1997 & N/A & N/A & N/A & N/A & N/A & N/A & N/A & N/A & N/A & 15.349 & 7.501 & 12.004 \\
\hline 1998 & 13.878 & 8.447 & 11.688 & 11.863 & 13.647 & 17.554 & 13.657 & 12.486 & 11.873 & 10.378 & 4.485 & 8.981 \\
\hline 1999 & 10.345 & 5.972 & 7.060 & 11.979 & 9.958 & 4.288 & 4.729 & 10.743 & 9.229 & 9.173 & 10.414 & 6.159 \\
\hline 2000 & 9.191 & 8.939 & 9.880 & 8.349 & 9.020 & 6.561 & N/A & N/A & N/A & N/A & N/A & N/A \\
\hline UCL & 17.574 & 16.703 & 14.723 & 13.524 & 15.219 & 20.300 & 24.732 & 20.064 & 20.280 & 15.373 & 12.869 & 12.024 \\
\hline MEAN & 13.546 & 11.297 & 11.349 & 11.544 & 11.809 & 13.273 & 14.584 & 14.749 & 15.022 & 12.273 & 9.031 & 9.146 \\
\hline LCL & 9.518 & 5.890 & 7.974 & 9.563 & 8.399 & 6.247 & 4.436 & 9.434 & 9.764 & 9.174 & 5.193 & 6.268 \\
\hline SD & 1.567 & 2.103 & 1.312 & 0.770 & 1.326 & 2.733 & 3.656 & 1.915 & 1.894 & 1.117 & 1.383 & 1.037 \\
\hline
\end{tabular}




\section{$\underline{\text { Seasonal Analysis of Monthly Medical Treatment Incidence Rates - Primary Plant }}$}

January recorded the third highest seasonal index for medical incidence rates at the Primary Plant. The next four months recorded seasonal indexes of 1.0 or less. In June the seasonal index increased to above the 1.0 level and remained above the 1.0 level through October. The highest seasonal index occurred in September and was preceded in August by the second highest. In November the seasonal index decreased to a level below 0.8 and remained through December (See Figure 309).

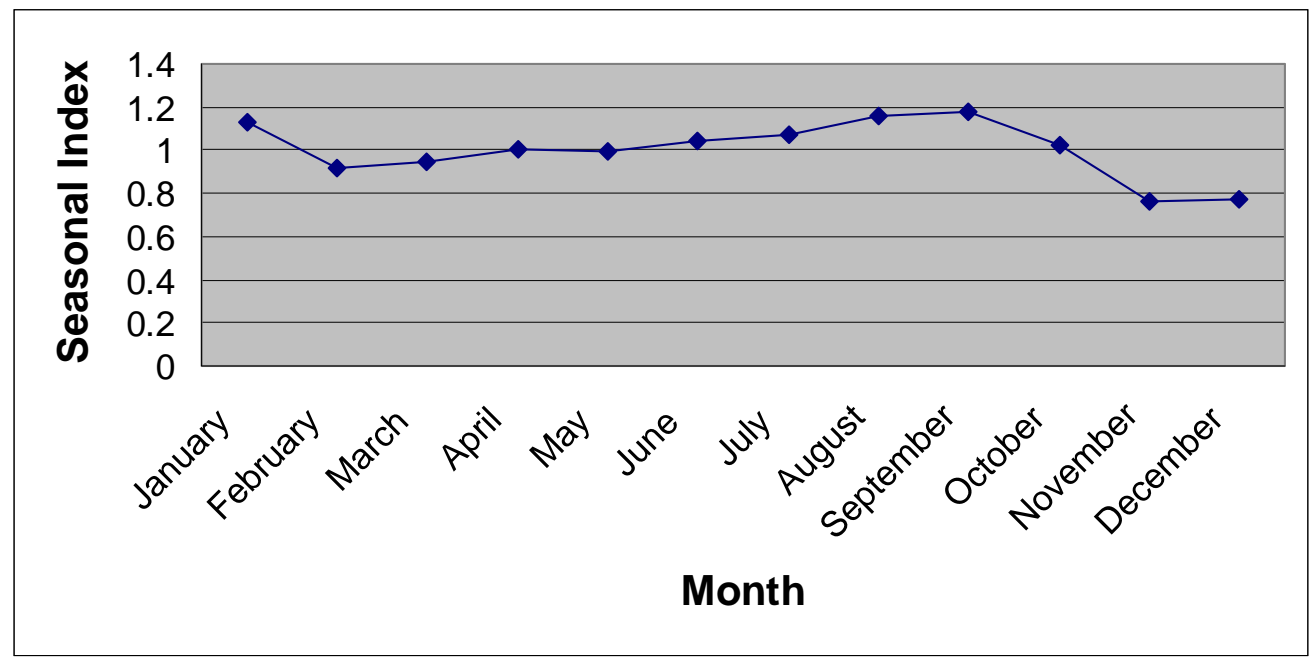

Figure 309. Monthly Seasonal Pattern of Medical Treatment Incidence Rates - Primary Plant

Testing the Statistical Relationship of Medical Treatment Data - Primary Plant

\section{All 33 Months Prior to and Subsequent to the Work Stoppage}

Comparison of the Primary Plant medical Treatment Incidence Rates for the 33 months preceding the work stoppage and the 33 months following the work stoppage was accomplished using the comparison formula. Because the calculated comparison $t$ value of 8.325 exceeded the 1.96 critical $t$ value, a statistically significant decrease in incidence rates occurred between the two periods. 
First 24 Months and Last 24 Months of the Research Period

The same formula was applied to Primary Plant medical treatment incidence rates for the first 24 months and the last 24 months of the research period. These time periods excluded the nine months prior to and immediately following the work stoppage. Using the same 1.96 critical t value, the calculated amount of 9.053 was greater than the critical $\mathrm{t}$ value at the .05 level of significance. Therefore, a statistically significant decrease in incidence rates occurred between the two periods.

Nine Month Intervals Prior to and Subsequent to the Work Stoppage

Comparison of the Primary Plant medical treatment incidence rates for the nine months preceding the work stoppage and the nine months following the work stoppage was accomplished using the comparison formula. The result of this calculation, 1.054, was less than the critical $t$ value of 1.96 , for a .05 statistical significance level. Because the calculated amount was less than the critical $t$ value, a significant decrease in incidence rates was not found between the two periods.

\section{Table 54}

Comparison prior and post work stoppage periods - Primary Plant

\begin{tabular}{|l|l|l|l|l|}
\hline \multirow{2}{*}{ Time Period } & \multicolumn{2}{|l|}{ Primary Plant Incidence Rates } & \multirow{2}{*}{ Critical t Value } & Calculated \\
\cline { 2 - 5 } & $\begin{array}{l}\text { Prior to } \\
\text { Work Stoppage }\end{array}$ & $\begin{array}{l}\text { Post } \\
\text { Work Stoppage }\end{array}$ & 1.96 & 1.054 \\
\hline 9 Months & 13.716 & 12.508 & 1.96 & $9.053^{* *}$ \\
\hline 24 Months & 15.020 & 8.947 & 1.96 & $8.325^{* *}$ \\
\hline
\end{tabular}

* Indicates a statistically significant increase

** Indicates a statistically significant decrease

Finishing Plant \#1 Analysis

\section{Quarterly Analysis of Medical Treatment Data - Finishing Plant \#1}

As illustrated in Figure 310, the highest first quarter incidence rate at Finishing Plant \#1 occurred in 1994. The high was eight and one-half times greater than the lowest 
rate, which was recorded in 1999. In 2000, the incidence rate occurred between the LCL and the mean.

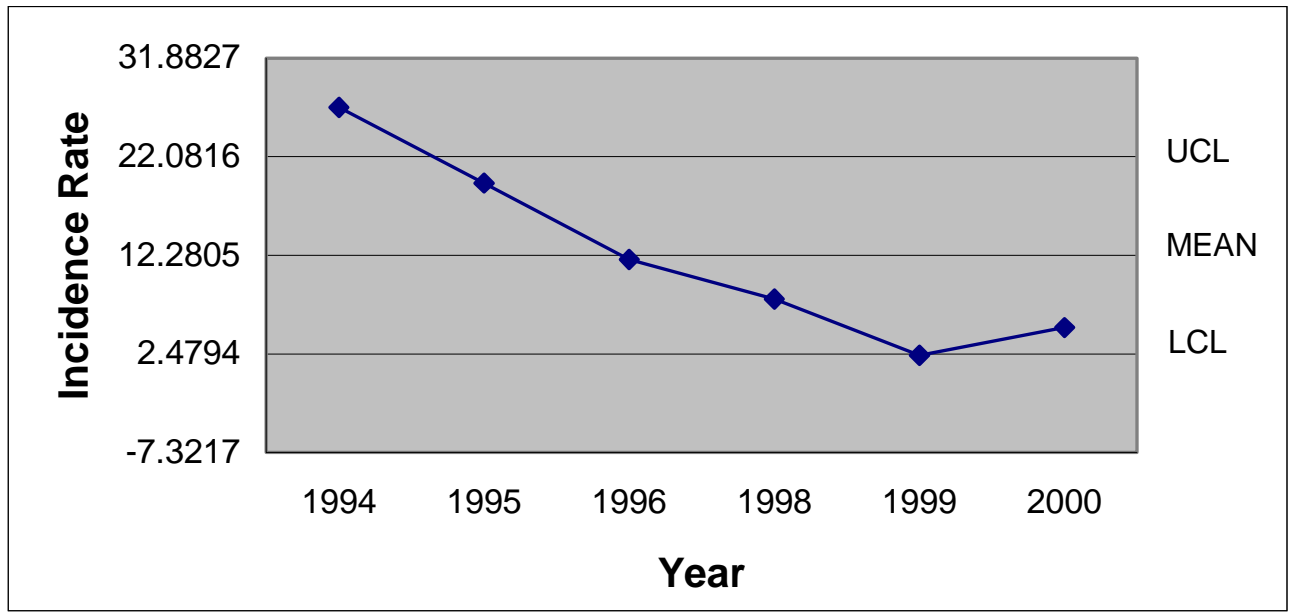

Note: No operations in first quarter 1997

Figure 310. First Quarter 1994-2000 Medical Treatment Incidence Rates - Finishing Plant \#1

The lowest second quarter incidence rate at Finishing Plant \#1, which was recorded in 2000, was almost five times smaller in magnitude than the 1994 high. The largest decrease in incidence rates, a drop of over 40\%, was recorded between 1994 and 1995 (See Figure 311).

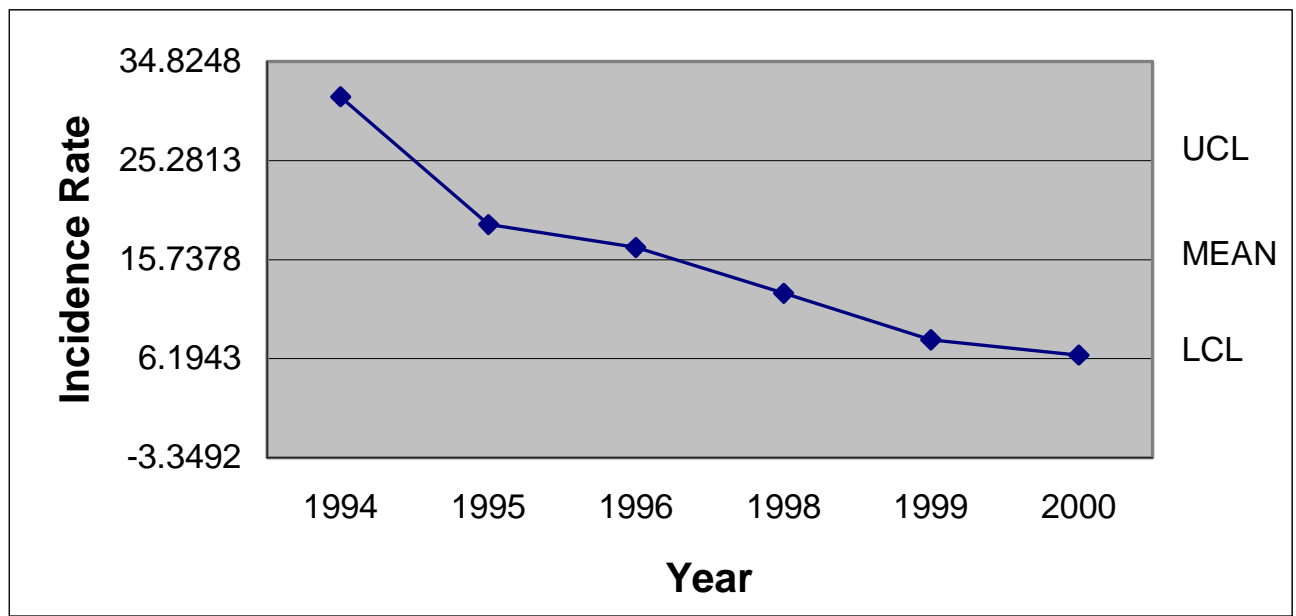

Note: No operations in second quarter 1997

Figure 311. Second Quarter 1994-2000 Medical Treatment Incidence Rates - Finishing Plant \#1 
In 1994, the Finishing Plant \#1 incidence rate was just above the mean. The highest incidence rate for the third quarter occurred in 1995. Following the 1995 high, the incidence rates were between the LCL and the mean for the next three years (See Figure 312).

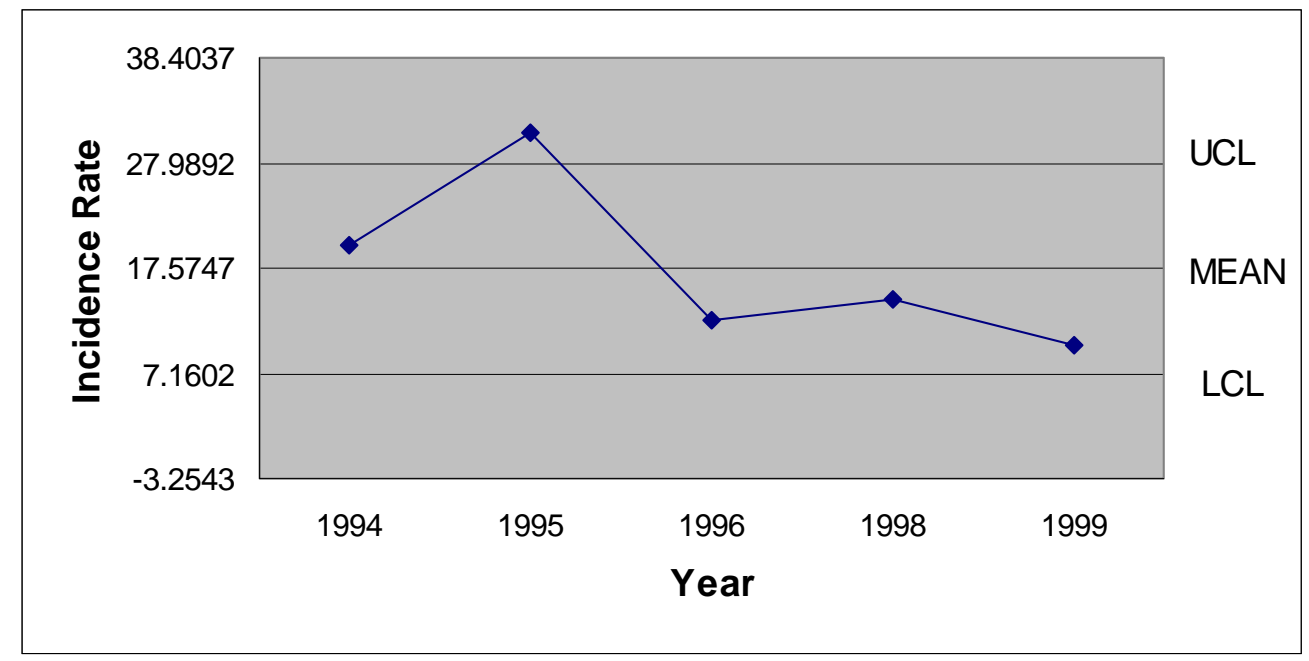

Note: No operations in third quarter 1997

Figure 312. Third Quarter 1994-1999 Medical Treatment Incidence Rates - Finishing Plant \#1

The highest fourth quarter incidence rate of Finishing Plant \#1 occurred above the UCL in 1995. Preceding the high, the 1994 incidence rate was just above the mean. After the 1995 high, the incidence rates trended downward to a low in 1999. The 1994 high was almost six times greater in magnitude than the 1999 low (See Figure 313). 


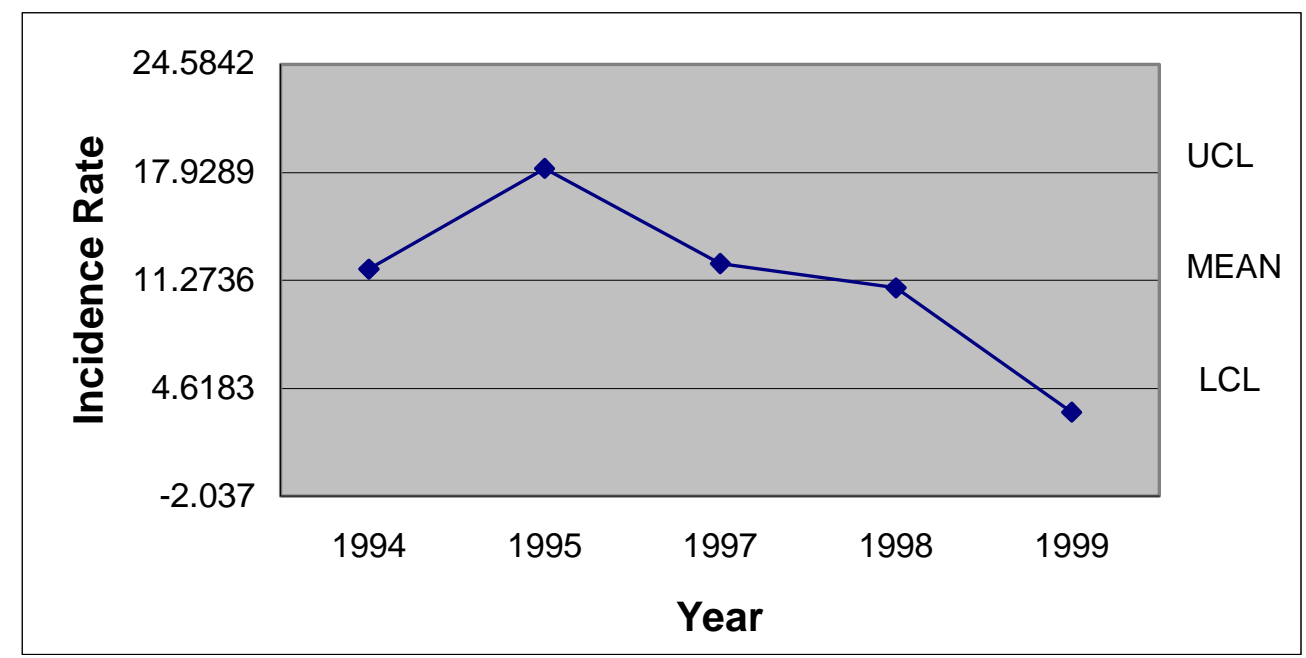

Note: No operations in fourth quarter 1996

Figure 313. Fourth Quarter 1994-1999 Medical Treatment Incidence Rates - Finishing Plant \#1

\section{Table 55}

$\underline{\text { Summary of Quarterly Medical Treatment Incidence Rates Data - Finishing Plant\#1 }}$

\begin{tabular}{|l|l|l|l|l|}
\hline & $1^{\text {st }}$ Quarter & $2^{\text {nd }}$ Quarter & $3^{\text {rd }}$ Quarter & $4^{\text {Quarter }}$ \\
\hline 1994 & 26.971 & 31.395 & 19.875 & 11.937 \\
\hline 1995 & 19.444 & 19.117 & 31.070 & 18.157 \\
\hline 1996 & 11.841 & 16.920 & 12.444 & N/A \\
\hline 1997 & N/A & N/A & N/A & 12.302 \\
\hline 1998 & 7.960 & 12.464 & 14.575 & 10.814 \\
\hline 1999 & 2.339 & 8.009 & 9.909 & 3.158 \\
\hline 2000 & 5.128 & 6.522 & N/A & N/A \\
\hline UCL & 22.082 & 25.281 & 27.989 & 17.929 \\
\hline MEAN & 12.281 & 15.738 & 17.575 & 11.274 \\
\hline LCL & 2.479 & 6.194 & 7.160 & 4.618 \\
\hline SD & 3.812 & 3.712 & 3.752 & 2.397 \\
\hline
\end{tabular}




\section{$\underline{\text { Seasonal Analysis of Medical Treatment Data - Finishing Plant \#1 }}$}

The highest medical treatment seasonal index figure at Finishing Plant \#1was calculated for the third quarter. The second highest was recorded in the second quarter, while the first and third quarters were almost identical (See Figure 314).

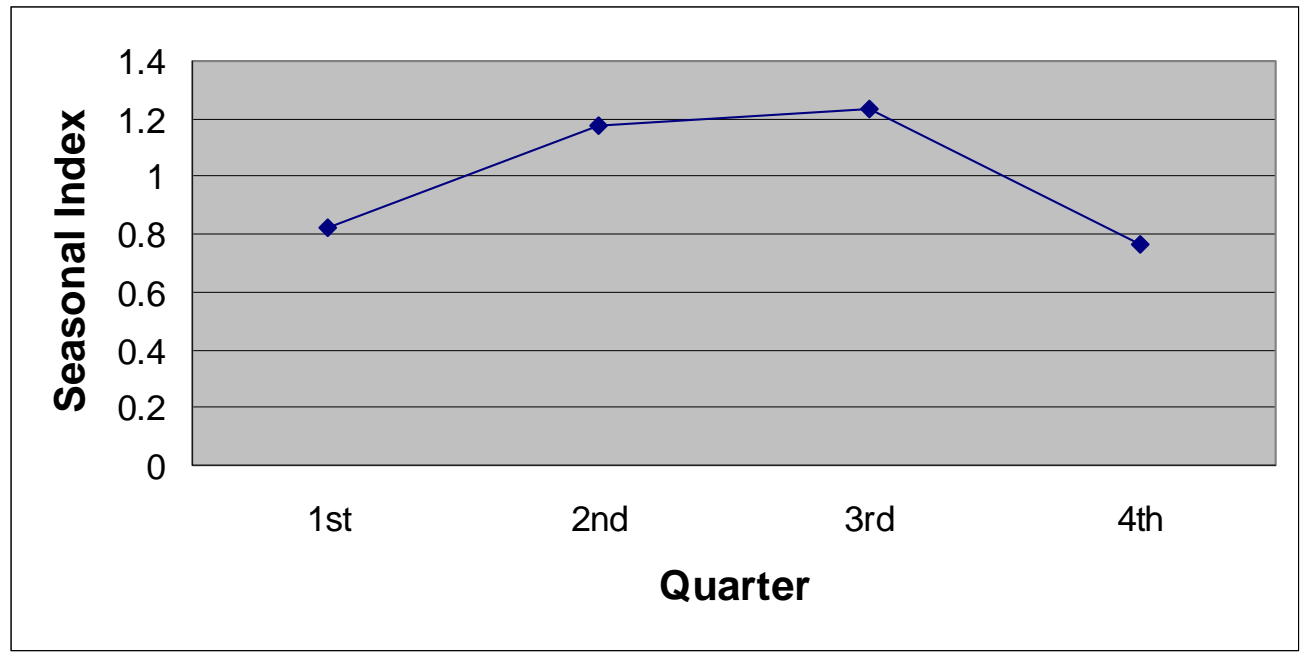

Figure 314. Quarterly Seasonal Index for Medical Treatment Incidence Rates Finishing Plant \#1

\section{Monthly Analysis of Medical Treatment Data - Finishing Plant \#1}

The highest January Finishing Plant \#1 medical treatment incidence rate occurred in 1994. A downward trend was evident through 1999, when the incidence rate reached a low of 3.897. The high was nearly seven and one-half times greater than the low. In 2000 the incidence rate remained between the LCL and the mean (See Figure 315). 


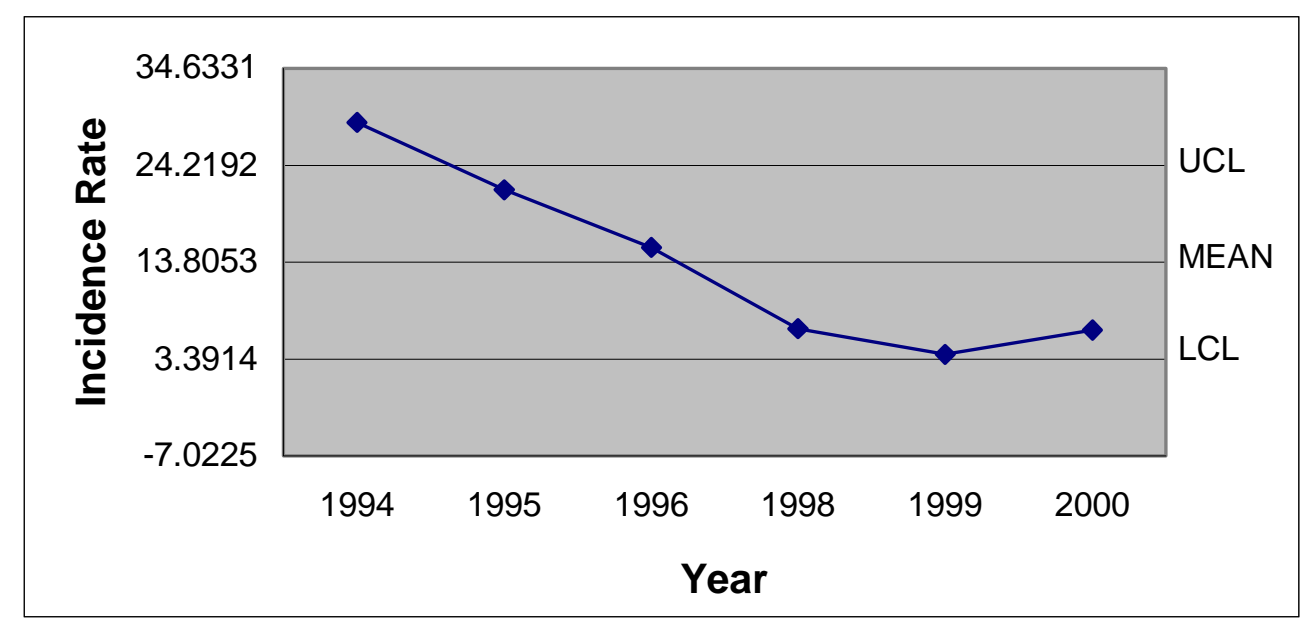

Note: No operations in January 1997

Figure 315. January 1994-2000 Medical Treatment Incidence Rates - Finishing Plant \#1

As illustrated in Figure 316, the Finishing Plant \#1 medical treatment incidence rates for February decreased steadily from the 1994 high to a level of 3.672 in 1998 . The next two years recorded slight decreases arriving at the low of 3.201 in February 2000. The lowest incidence rate for the month was nine times smaller in magnitude than the highest February incidence rate.

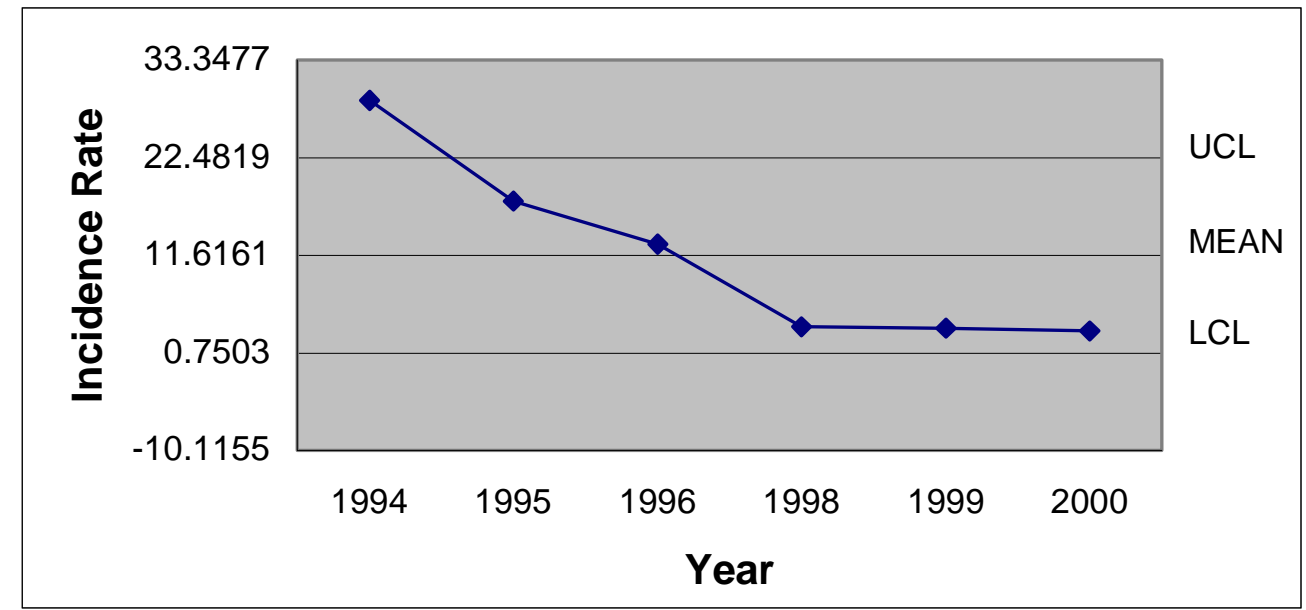

Note: No operations in February 1997

Figure 316. February 1994-2000 Medical Treatment Incidence Rates - Finishing Plant \#1

March Finishing Plant incidence rates were marked by a high of 23.196 in 1994 and a low of 0.000 in 1999. In 1995, the incidence rate was just below the UCL, and in 
1996 the incidence rate was below the mean. Another small peak occurred in 1998 when the incidence rate once again was above the mean (See Figure 317).

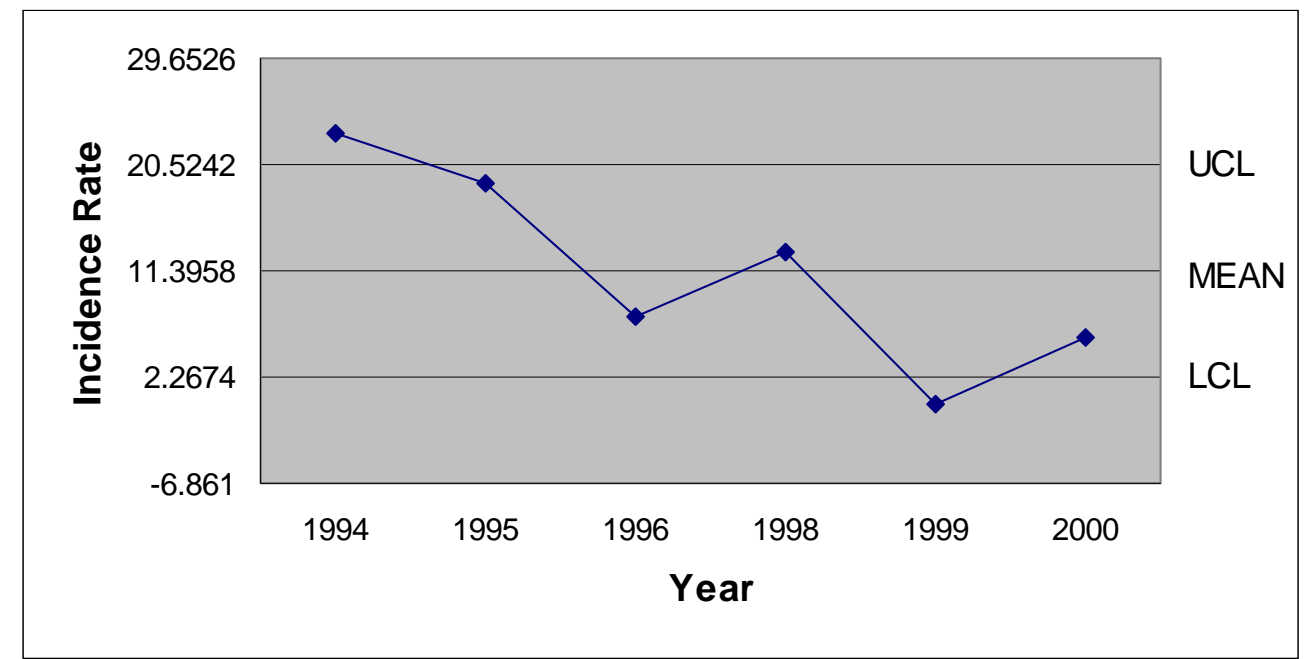

Note: No operations in March 1997

Figure 317. March 1994-2000 Medical Treatment Incidence Rates - Finishing Plant \#1

As illustrated in Figure 318, April incidence rates at Finishing Plant \#1 recorded values above the UCL in 1994 and 1996. In 1998 the incidence rate was just below the mean and just above the LCL for the last two years. The 1994 high was seven times greater than the low recorded in April 2000.

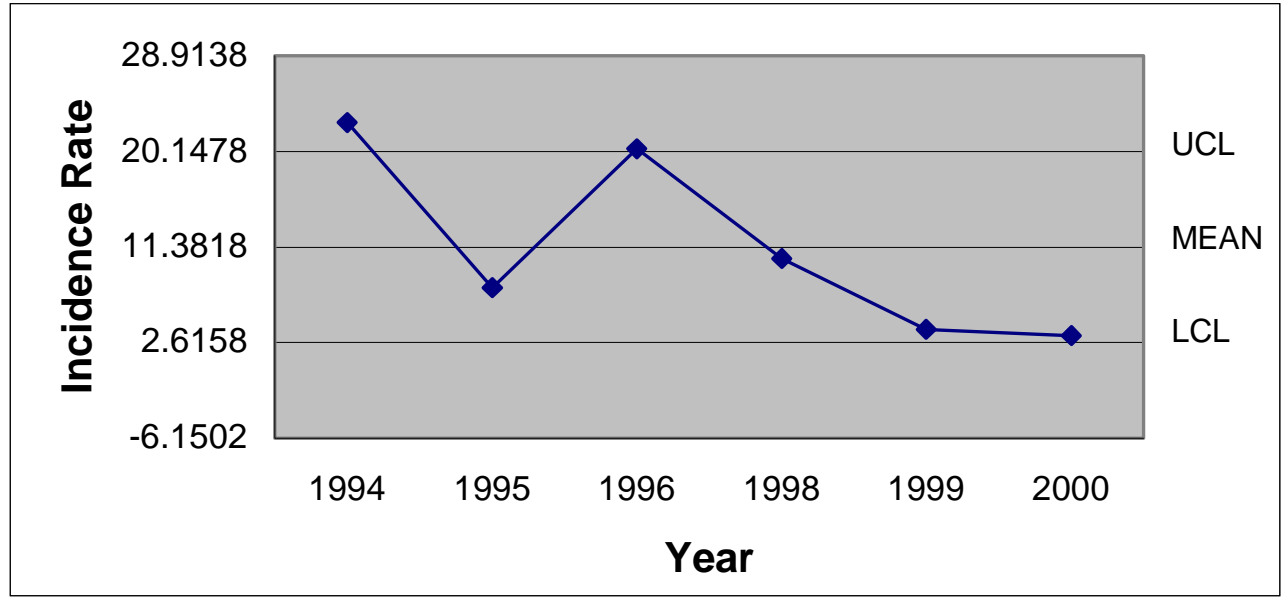

Note: No operations in April 1997

Figure 318. April 1994-2000 Medical Treatment Incidence Rates - Finishing Plant \#1 
The May incidence rate at Finishing Plant \#1 experienced a decrease of more than $45 \%$ between the 1994 high and 1995. In 1996, the incidence rate was up slightly from the previous year, but was followed by a sharp decrease in 1998. The 1998 low was followed by two periods between the LCL and the mean (See Figure 319).

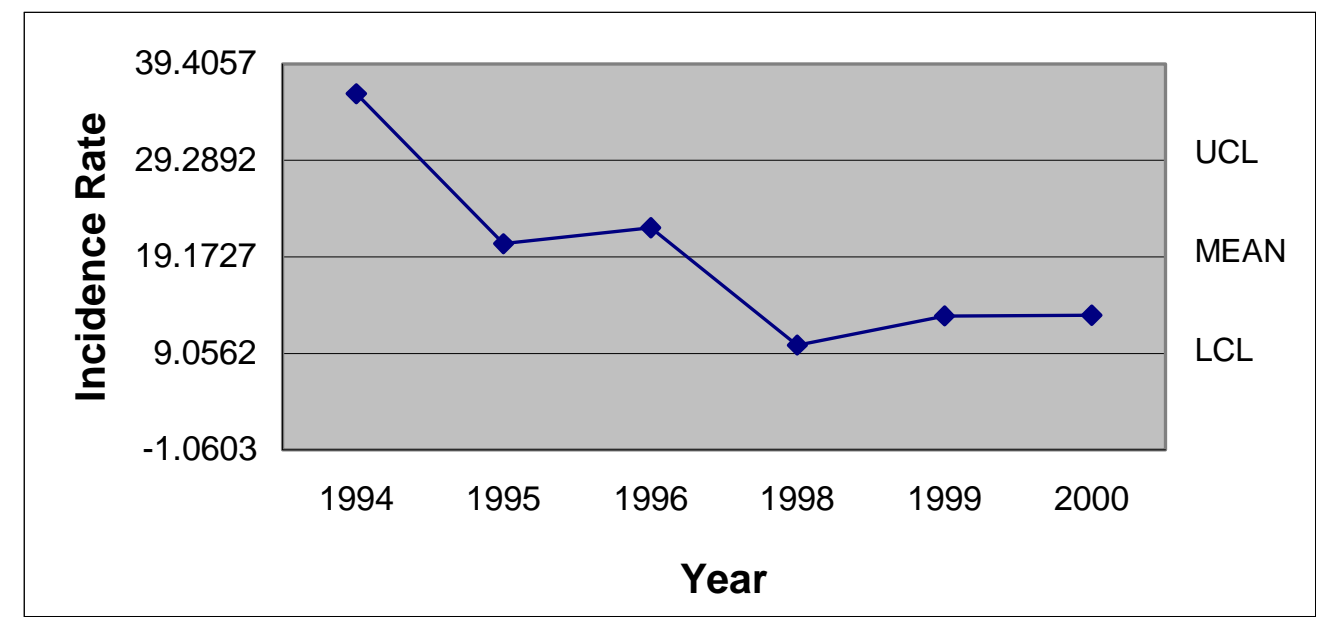

Note: No operations in May 1997

Figure 319. May 1994-2000 Medical Treatment Incidence Rates - Finishing Plant \#1

Medical treatment incidence rates for June at Finishing Plant \#1 were marked by a high in 1994 that was eleven times greater in magnitude than the low recorded in 2000. The sharpest decrease between years occurred between 1995 and 1996 (See Figure 320).

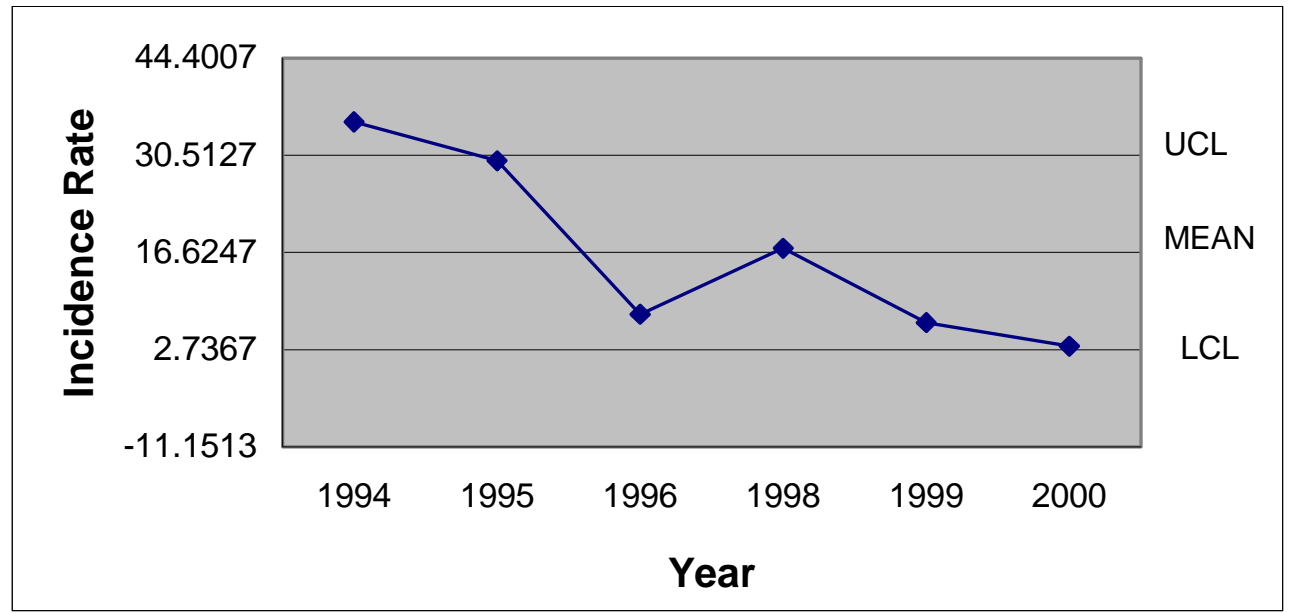

Note: No operations in June 1997

Figure 320. June 1994-2000 Medical Treatment Incidence Rates - Finishing Plant \#1 
The July 1995 Finishing Plant \#1 medical treatment incidence rate was the highest during the research period. The lowest incidence rate was recorded in 1999, the year after the high was recorded. The last two periods remained between the LCL and the mean (See Figure 321).

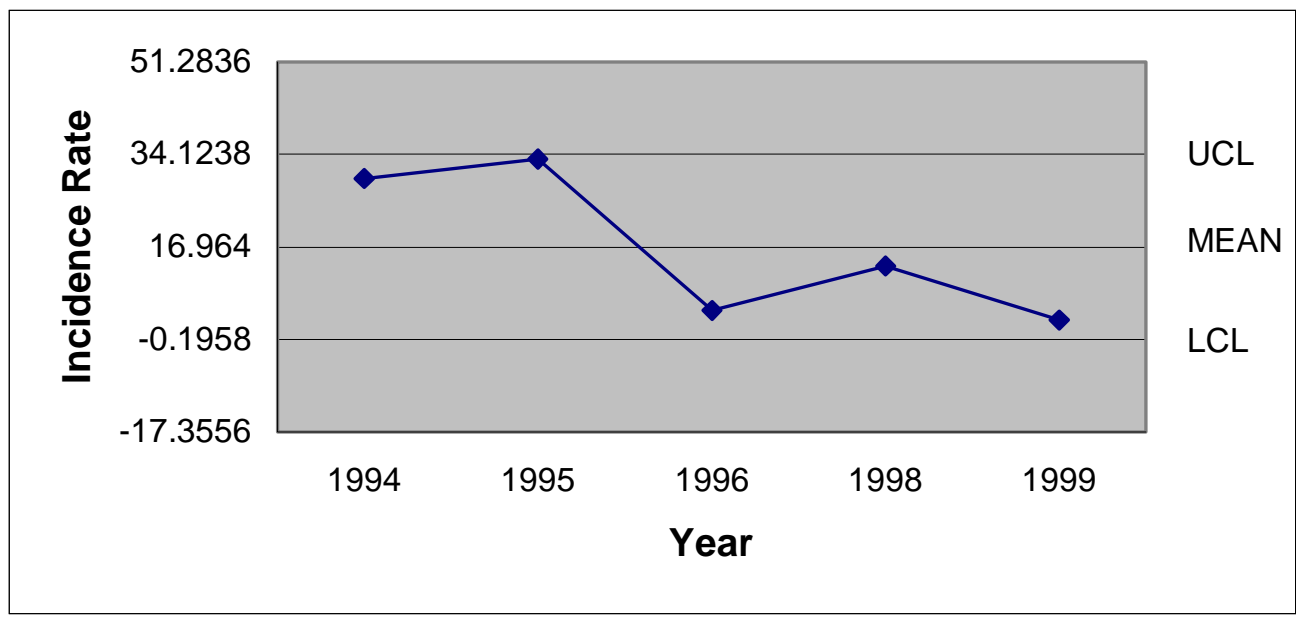

Note: No operations in July 1997

Figure 321. July 1994-1999 Medical Treatment Incidence Rates - Finishing Plant \#1

The Finishing Plant \#1 incidence rates for August 1994 was the second lowest incidence rate during the study period. The 1995 incidence rate, 40.358, was the highest recorded for August during the study period. Following the high in 1995, the incidence rate was between the LCL and the mean for the last three years (See Figure 322).

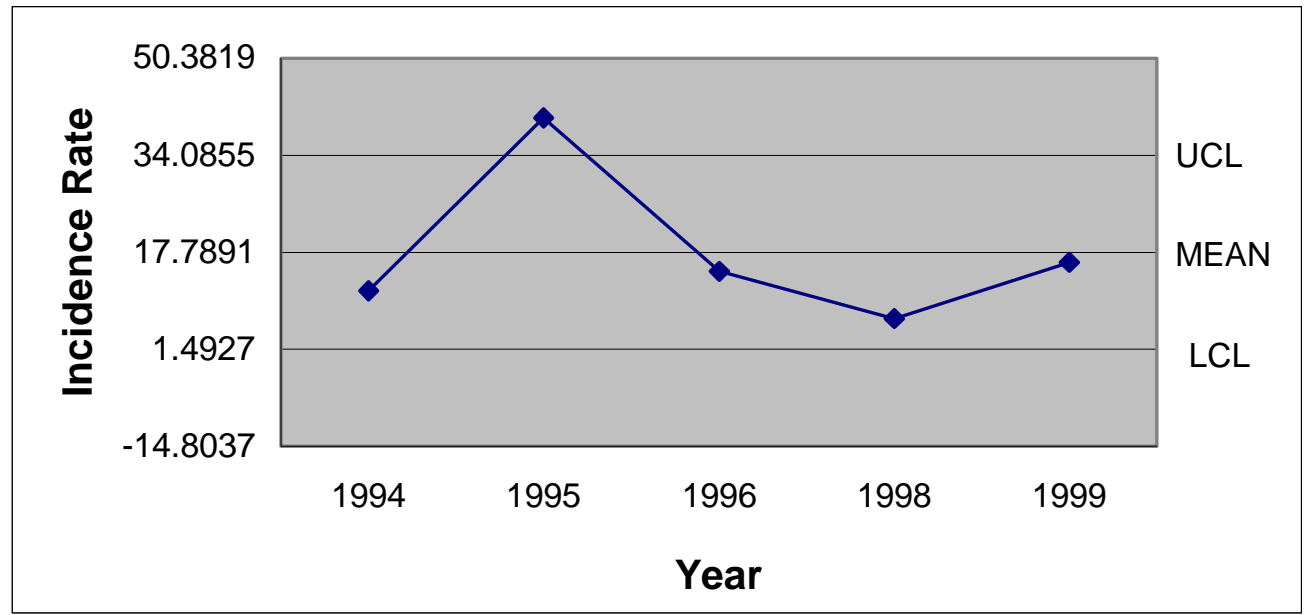

Note: No operations in August 1997

Figure 322. August 1994-1999 Medical Treatment Incidence Rates - Finishing Plant \#1 
The first three years of the study period recorded relatively consistent September Finishing Plant \#1 incidence rate at a level just above the mean. The next year, 1998, the incidence rate was just below the UCL. The 1998 high was followed by the low in 1999, which was less than half the magnitude of the high (See Figure 323).

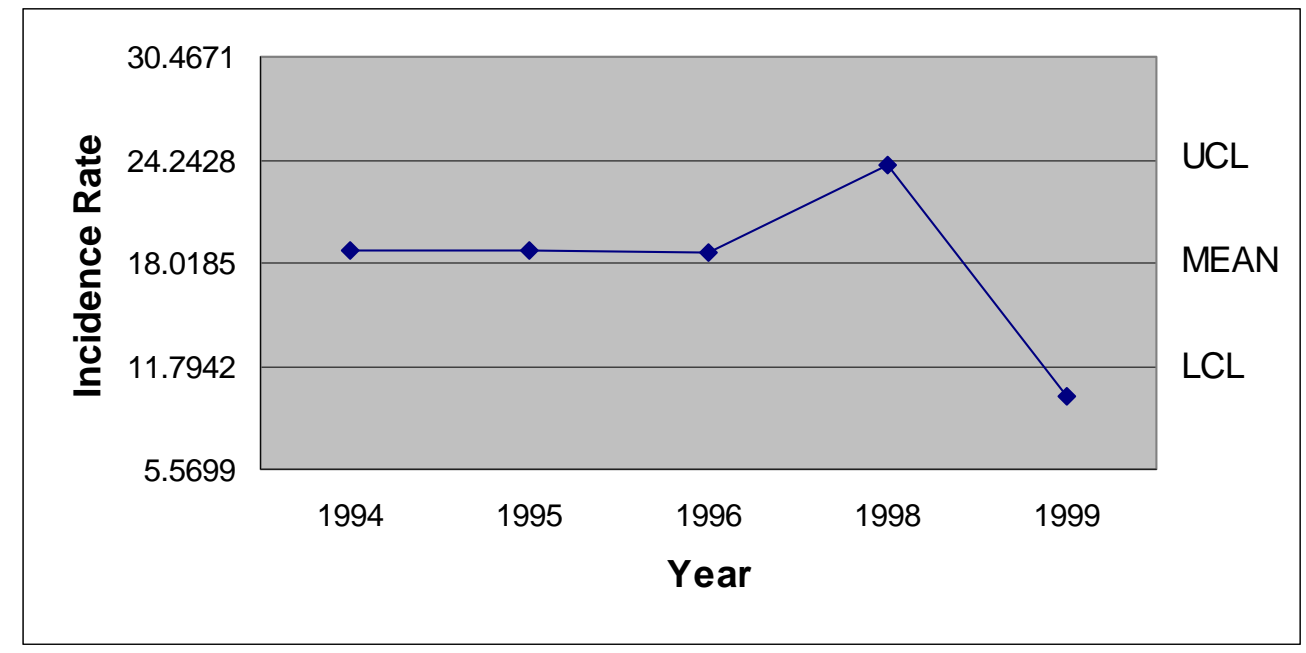

Note: No operations in September 1997

Figure 323. September 1994-1999 Medical Treatment Incidence Rates - Finishing Plant $\# 1$

As illustrated in Figure 324, the October Finishing Plant \#1 incidence rates reached a plateau close to the 13.0 level between 1995 and 1998. A sharp decrease of more than 75\% was recorded between 1998 and 1999. 


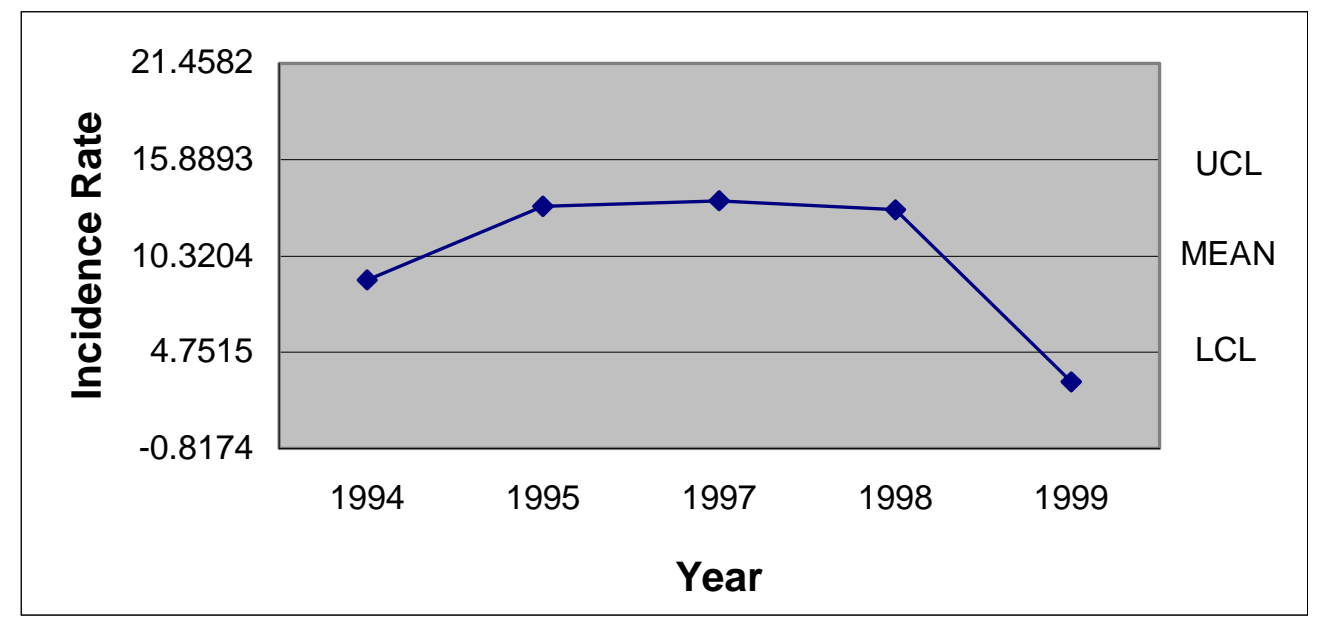

Note: No operations in October 1996

Figure 324. October 1994-1999 Medical Treatment Incidence Rates - Finishing Plant \#1

After recording an incidence rate at Finishing Plant \#1 below the mean in 1994, the November 1995 incidence rate increased to 22.968. The 1995 high was followed by a period of steadily decreasing incidence rates for the remainder of the research period. In 1999 the low of 3.335 was recorded (See Figure 325).

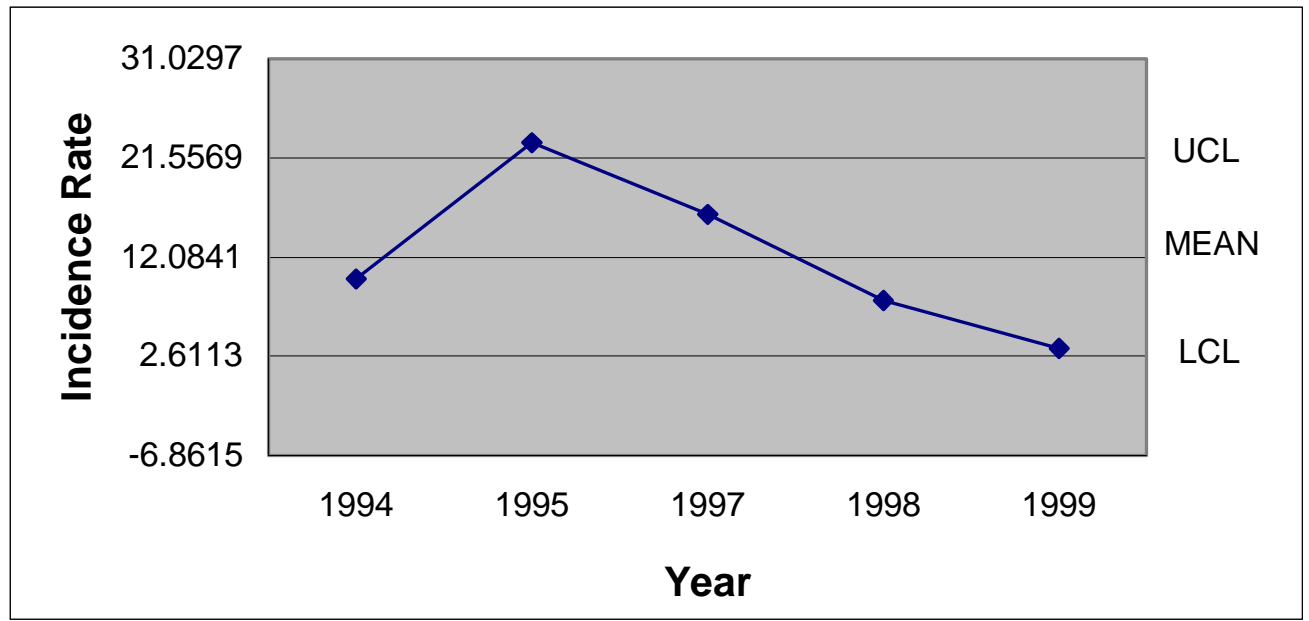

Note: No operations in November 1996

Figure 325. November 1994-1999 Medical Treatment Incidence Rates - Finishing Plant $\# 1$ 
The December 1994 and 1995 Finishing Plant \#1 incidence rates were close to the UCL, with 1995 being the highest incidence rate for the month. After the 1995 high, the incidence rate was between the LCL and the mean for the next two years. December 1999 recorded the lowest incidence rate, just below the LCL (See Figure 326).

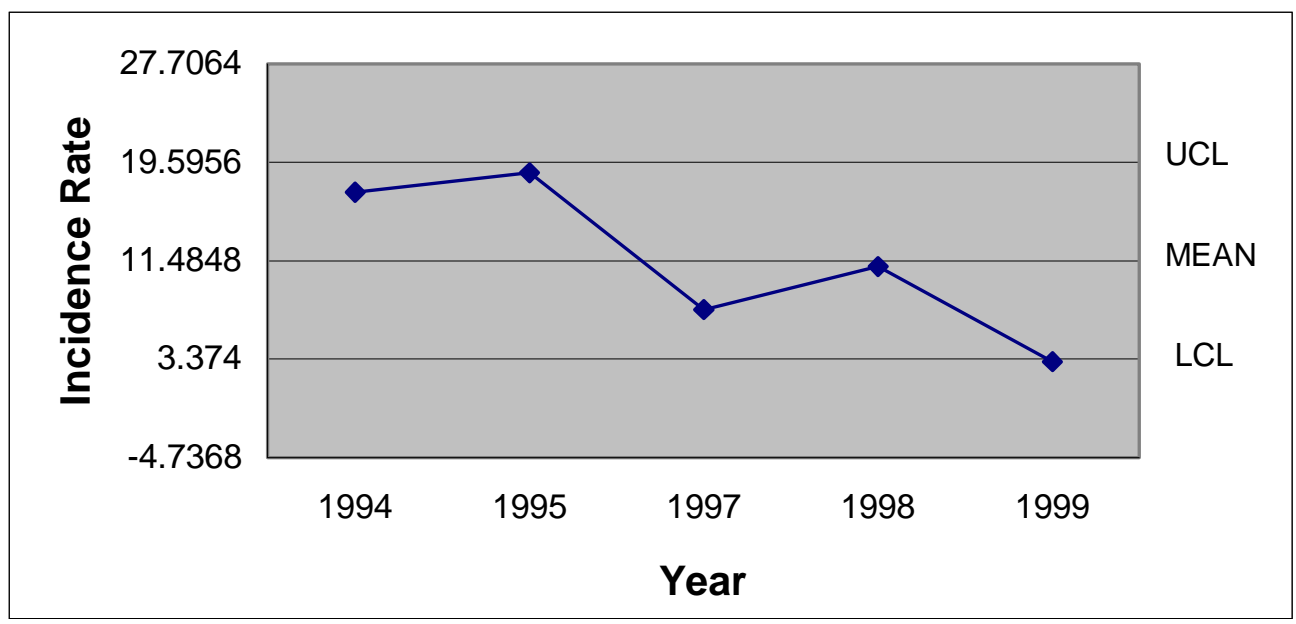

Note: No operations in December 1996

Figure 326. December 1994-1999 Medical Treatment Incidence Rates - Finishing Plant $\# 1$

Table 56 presents the monthly Finishing Plant \#1 incidence rates for each year of the study period, as well as the UCL, mean, LCL, and standard deviation. Nineteen ninety-six and 1997 are partial years because of the work stoppage and only the first six months of 2000 were included in the research.

Table 56

Summary of Monthly Medical Treatment Incidence Rates Data - Finishing Plant \#1

\begin{tabular}{|l|l|l|l|l|l|l|l|l|l|l|l|l|}
\hline & Jan. & Feb. & Mar. & Apr. & May & June & July & Aug. & Sept. & Oct. & Nov. & Dec. \\
\hline 1994 & 28.836 & 28.862 & 23.196 & 22.775 & 36.271 & 35.234 & 29.619 & 11.291 & 18.761 & 8.931 & 10.112 & 17.126 \\
\hline 1995 & 21.590 & 17.673 & 18.986 & 7.669 & 20.572 & 29.673 & 33.285 & 40.358 & 18.835 & 13.175 & 22.968 & 18.733 \\
\hline 1996 & 15.390 & 12.818 & 7.456 & 20.400 & 22.204 & 7.802 & 5.128 & 14.557 & 18.585 & N/A & N/A & N/A \\
\hline 1997 & N/A & N/A & N/A & N/A & N/A & N/A & N/A & N/A & N/A & 13.496 & 16.154 & 7.439 \\
\hline 1998 & 6.635 & 3.672 & 13.090 & 10.343 & 9.916 & 17.244 & 13.430 & 6.637 & 23.912 & 12.978 & 7.961 & 10.995 \\
\hline 1999 & 3.897 & 3.471 & 0.000 & 3.818 & 13.009 & 6.565 & 3.358 & 16.102 & 10.001 & 3.022 & 3.335 & 3.132 \\
\hline 2000 & 6.485 & 3.201 & 5.646 & 3.286 & 13.063 & 3.231 & N/A & N/A & N/A & N/A & N/A & N/A \\
\hline
\end{tabular}




\begin{tabular}{|l|l|l|l|l|l|l|l|l|l|l|l|l|}
\hline UCL & 24.219 & 22.482 & 20.524 & 20.148 & 29.289 & 30.513 & 34.124 & 34.086 & 24.243 & 15.889 & 21.557 & 19.596 \\
\hline MEAN & 13.805 & 11.616 & 11.396 & 11.382 & 19.173 & 16.625 & 16.964 & 17.789 & 18.019 & 10.320 & 12.084 & 11.485 \\
\hline LCL & 3.391 & 0.750 & 2.267 & 2.616 & 9.056 & 2.737 & -0.196 & 1.493 & 11.794 & 4.752 & 2.611 & 3.374 \\
\hline SD & 4.051 & 4.226 & 3.551 & 3.410 & 3.935 & 5.402 & 6.181 & 5.870 & 2.242 & 2.006 & 3.412 & 2.922 \\
\hline
\end{tabular}

$\underline{\text { Seasonal Analysis of Monthly Medical Treatment Incidence Rates - Finishing Plant \#1 }}$

The seasonal index calculation was used to generate the Finishing Plant

\#1monthly seasonal index figures that are presented in Figure 327. The January through April seasonal index figures were between 0.7 and 1.0. In May the seasonal index was the highest for Finishing Plant \#1. After the high in May, the seasonal indexes for June and July were between 1.0 and 1.2. In August and September the seasonal indexes peaked at a level close to 1.4. This was followed by a decrease in October to the 0.7 level, where it remained through December.

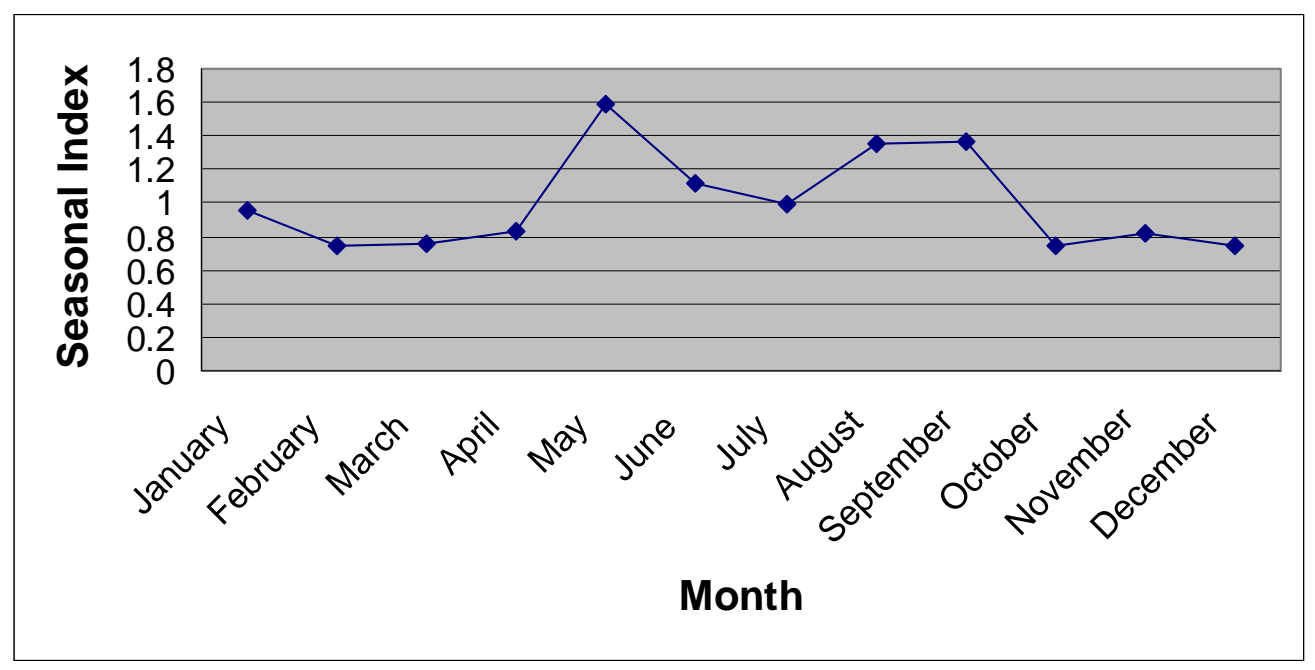

Figure 327. Monthly Seasonal Pattern of Medical Treatment Incidence Rates Finishing Plant \#1

Testing the Statistical Relationship of Medical Treatment Data - Finishing Plant \#1 All 33 Months Prior to and Subsequent to the Work Stoppage

Comparison of the Finishing Plant \#1 medical Treatment Incidence Rates for the 33 months preceding the work stoppage and the 33 months following the work stoppage was accomplished using the comparison formula. For the entire 33 months prior to the work stoppage and the 33 post work stoppage months the calculated 
comparison t value was 7.137. Because this calculated amount exceeded the 1.96 critical $\mathrm{t}$ value, a statistically significant decrease in occurred between incidence rates for these two periods.

First 24 Months and Last 24 Months of the Research Period

The same formula was applied to Finishing Plant \#1 medical Treatment Incidence Rates for the first 24 months and the last 24 months of the period. These time periods excluded the nine months prior to and immediately following the work stoppage. Using the 1.96 critical t value, the calculated amount, 7.546, was greater. Therefore a statistically significant decrease in incidence rates occurred between the two periods.

Nine Month Intervals Prior to and Subsequent to the Work Stoppage

For the nine month periods prior to and subsequent to the work stoppage, the result of this calculation, 0.972 was below the 1.998 critical t value. Thus there was not a significant decrease in incidence rates between the two periods.

\section{Table 57}

Comparison Prior and Post Work Stoppage Periods - Finishing Plant \#1

\begin{tabular}{|l|l|l|l|l|}
\hline \multirow{2}{*}{ Time Period } & \multicolumn{2}{|l|}{ Finishing Plant \#1 Incidence Rates } & \multirow{2}{*}{ Critical t Value } & Calculated \\
\cline { 2 - 5 } & $\begin{array}{l}\text { Prior to } \\
\text { Work Stoppage }\end{array}$ & $\begin{array}{l}\text { Post } \\
\text { Work Stoppage }\end{array}$ & 1.998 & 0.972 \\
\hline 9 Months & 13.76 & 10.87 & 1.960 & $7.546^{* *}$ \\
\hline 24 Months & 22.32 & 8.38 & 1.960 & $7.137^{* *}$ \\
\hline
\end{tabular}

* Indicates a statistically significant increase

** Indicates a statistically significant decrease

Finishing Plant \#2 Analysis

\section{Quarterly Analysis of Medical Treatment Data - Finishing Plant \#2}

As illustrated in Figure 328, the Finishing Plant \#2 incidence rate for 1994 was almost equal to the mean, and the 1995 incidence rate was almost equal to the UCL. The highest first quarter incidence rate occurred in 1996, with an incidence rate of 12.057. 
Following the high in 1996, the 1998 incidence rate was the lowest recorded during the first quarter. In 1999 and 2000 the incidence rates remained close to the LCL.

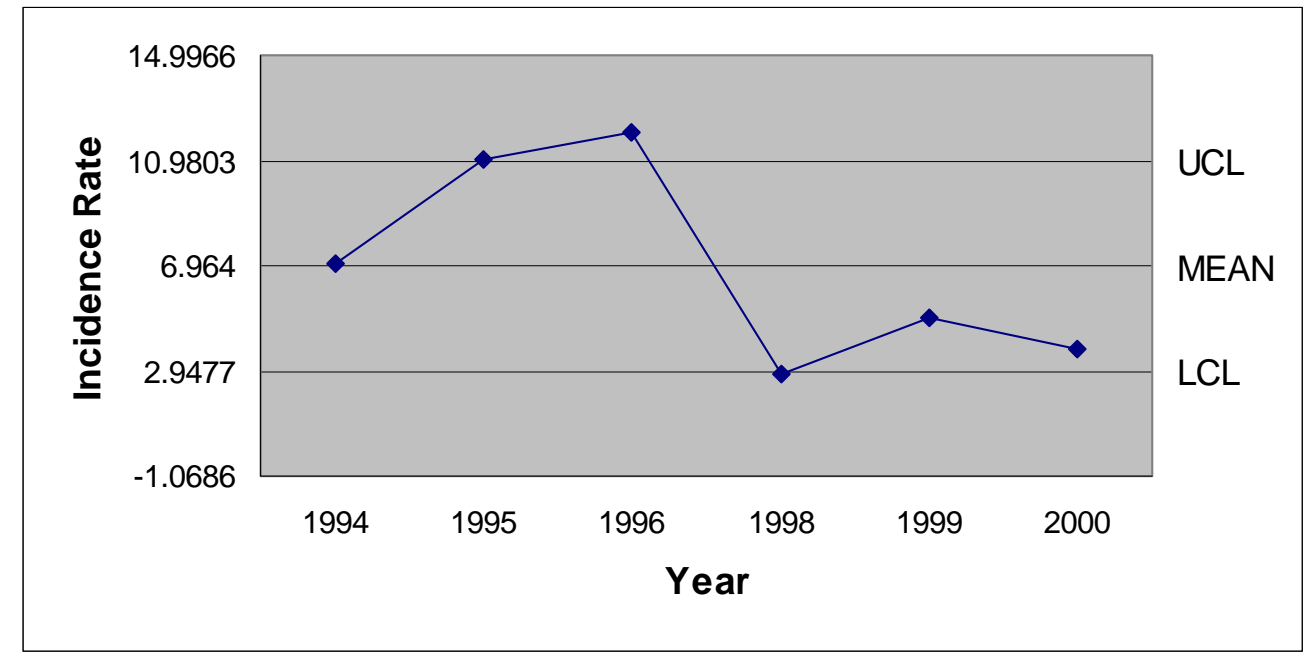

Note: No operations in first quarter 1997

Figure 328. First Quarter 1994-2000 Medical Treatment Incidence Rates - Finishing Plant \#2

The second quarter Finishing Plant \#2 incidence rate gradually grew from the 1994 level of 8.120 to the 1996 incidence rate of 9.128. Over the next three years of second quarter operations, the incidence rate steadily decreased to the low of 2.611, recorded in 2000 (See Figure 329).

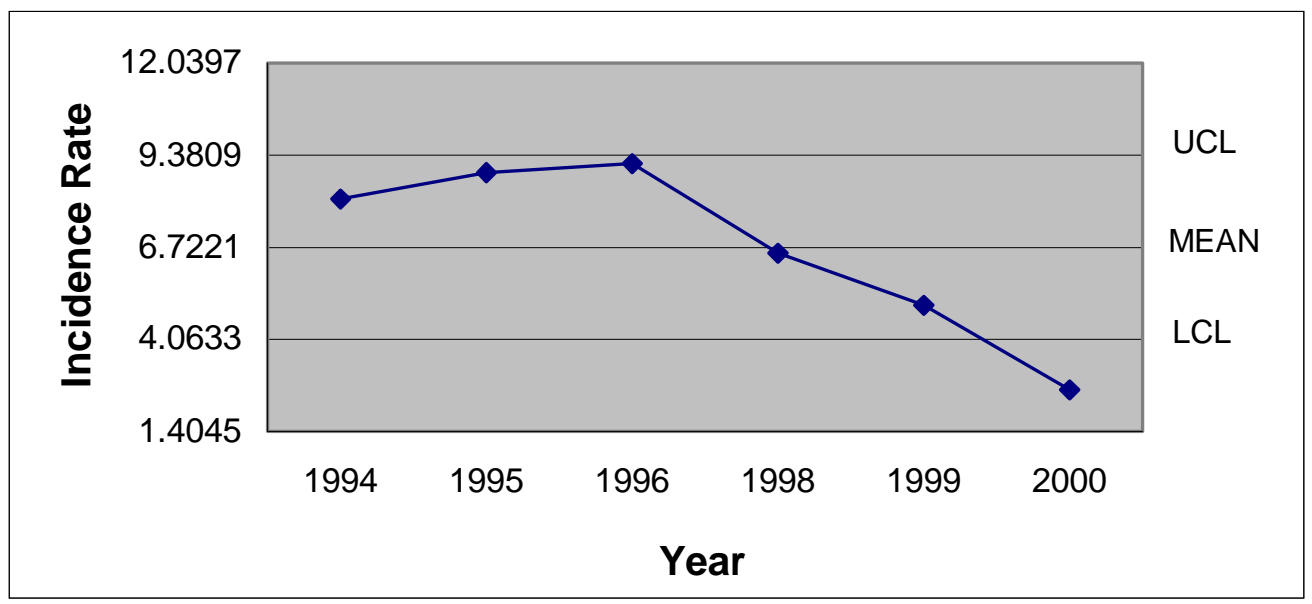

Note: No operations in second quarter 1997

Figure 329. Second Quarter 1994-2000 Medical Treatment Incidence Rates - Finishing Plant \#2 
The third quarter 1994 Finishing Plant \#2 incidence rate was nearly doubled by the 1995 incidence rate, which was the highest recorded for the third quarter. The 1996 incidence rate was the second highest incidence rate recorded for the third quarter. In 1998 the lowest incidence rate for the quarter was recorded at a level of 7.702 (See Figure 330).

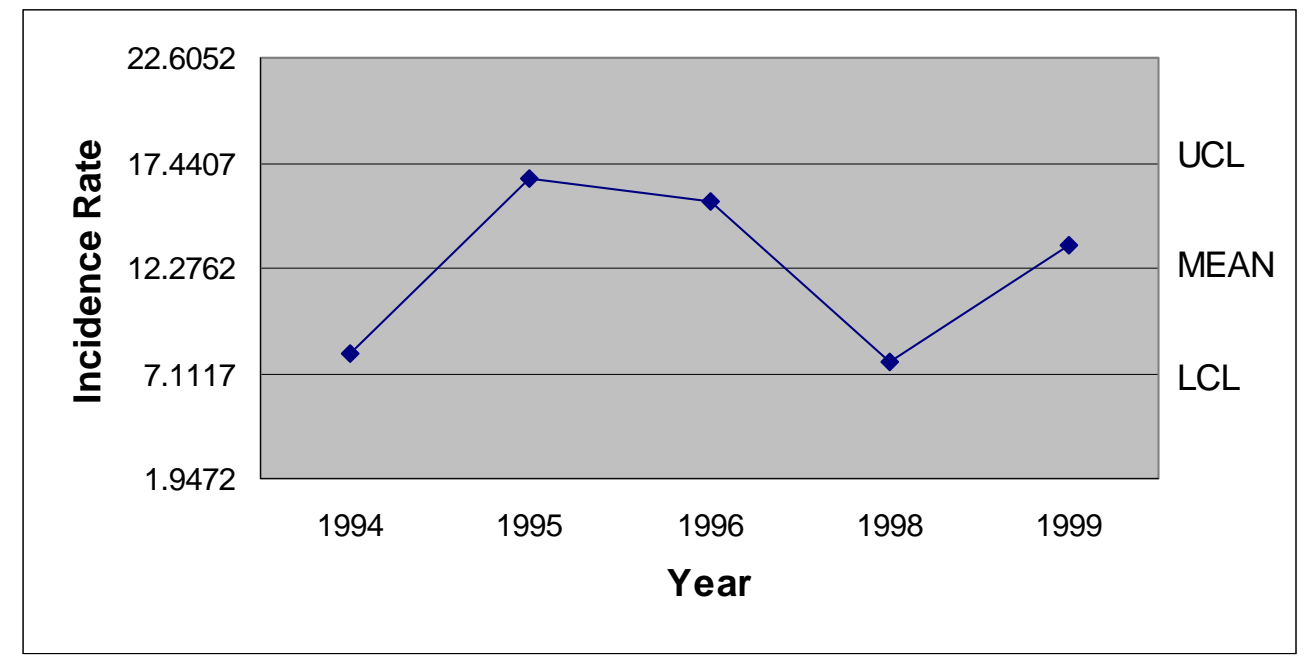

Note: No operations in third quarter 1997

Figure 330. Third Quarter 1994-1999 Medical Treatment Incidence Rates - Finishing Plant \#2

As illustrated in Figure 331, the highest Finishing Plant \#2 fourth quarter incidence rate was recorded in 1995. After the 1995 high, the incidence rates for the remainder of the research period were recorded between the LCL and the mean. 


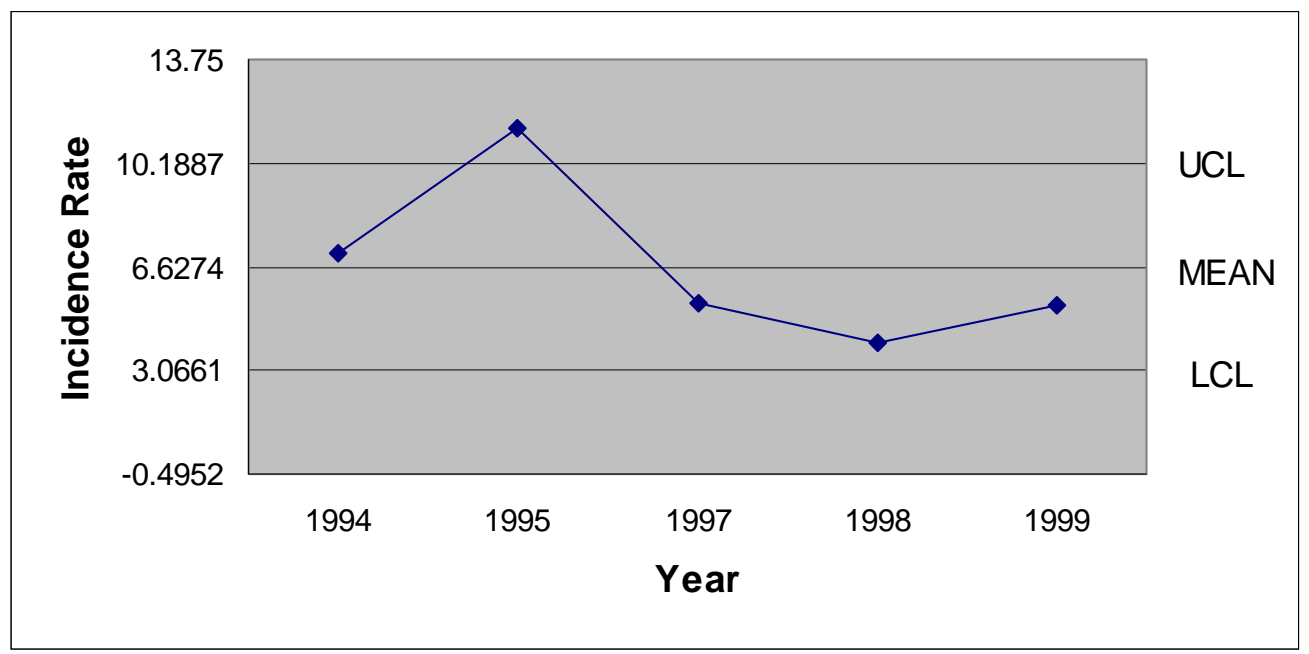

Note: No operations in fourth quarter 1996

Figure 331. Fourth Quarter 1994-1999 Medical Treatment Incidence Rates -

Finishing Plant \#2

Table 58

Summary of Quarterly Medical Treatment Incidence Rates Data - Finishing Plant\#2

\begin{tabular}{|l|l|l|l|l|}
\hline & $1^{\text {st }}$ Quarter & $2^{\text {nd }}$ Quarter & $3^{\text {rd }}$ Quarter & $4^{\text {th }}$ Quarter \\
\hline 1994 & 7.027 & 8.120 & 8.112 & 7.126 \\
\hline 1995 & 11.036 & 8.868 & 16.671 & 11.353 \\
\hline 1996 & 12.057 & 9.128 & 15.499 & N/A \\
\hline 1997 & N/A & N/A & N/A & 6.313 \\
\hline 1998 & 2.859 & 6.558 & 7.702 & 3.980 \\
\hline 1999 & 5.000 & 5.047 & 13.396 & 5.273 \\
\hline 2000 & 3.804 & 2.611 & N/A & N/A \\
\hline UCL & 10.980 & 9.381 & 17.441 & 10.285 \\
\hline MEAN & 6.964 & 6.722 & 12.276 & 6.809 \\
\hline LCL & 2.948 & 4.063 & 7.112 & 3.333 \\
\hline SD & 1.562 & 1.034 & 1.860 & 1.252 \\
\hline
\end{tabular}

$\underline{\text { Seasonal Analysis of Medical Treatment Data - Finishing Plant \#2 }}$

The results of the Finishing Plant \#2 quarterly seasonal index calculations are presented in Figure 332. The quarterly seasonal index indicated that the third quarter 
had the highest seasonal index. The first and second quarters experienced almost identical seasonal indexes and the fourth quarter was slightly lower.

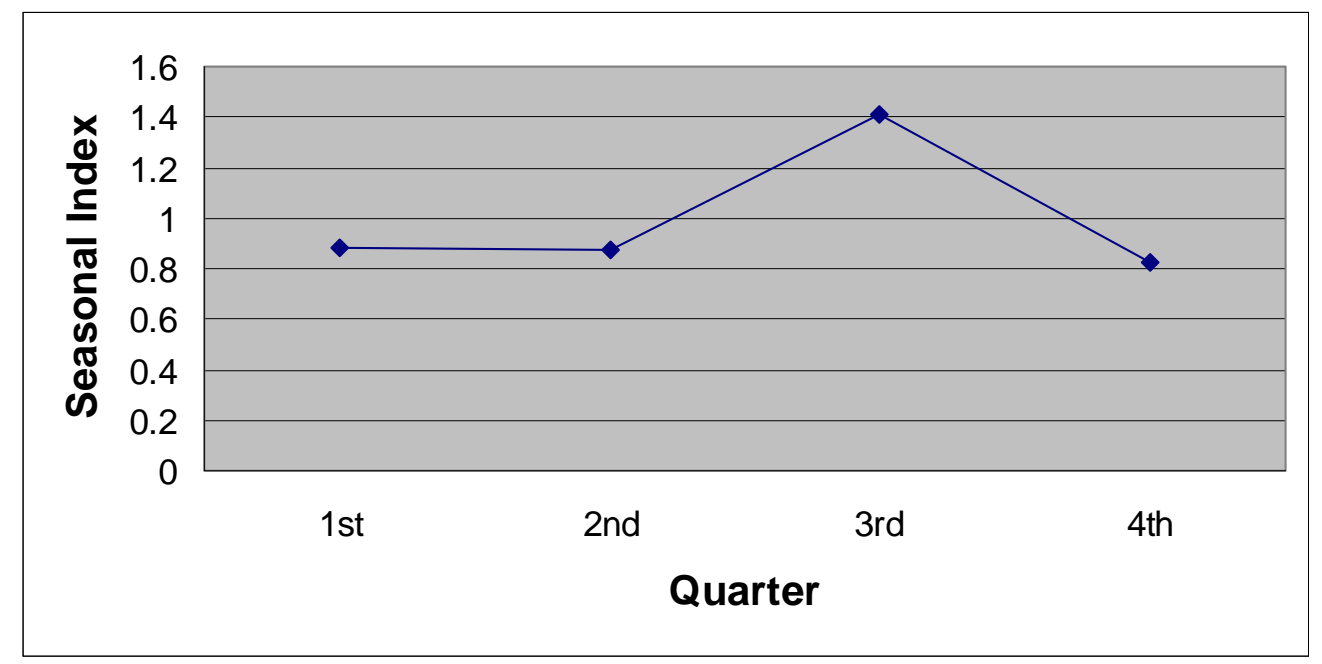

Figure 332. Quarterly Seasonal Index of Medical Treatment Incidence Rates Finishing Plant \#2

Monthly Analysis of Medical Treatment Data - Finishing Plant \#2

As illustrated in Figure 333, the January Finishing Plant \#2 incidence rates increased from a level close to the mean in 1995 to a level above the UCL in 1996. The 17.704 incidence rate recorded in January 1996 was the highest January rate and the 0.000 recorded in January 1999 was the lowest.

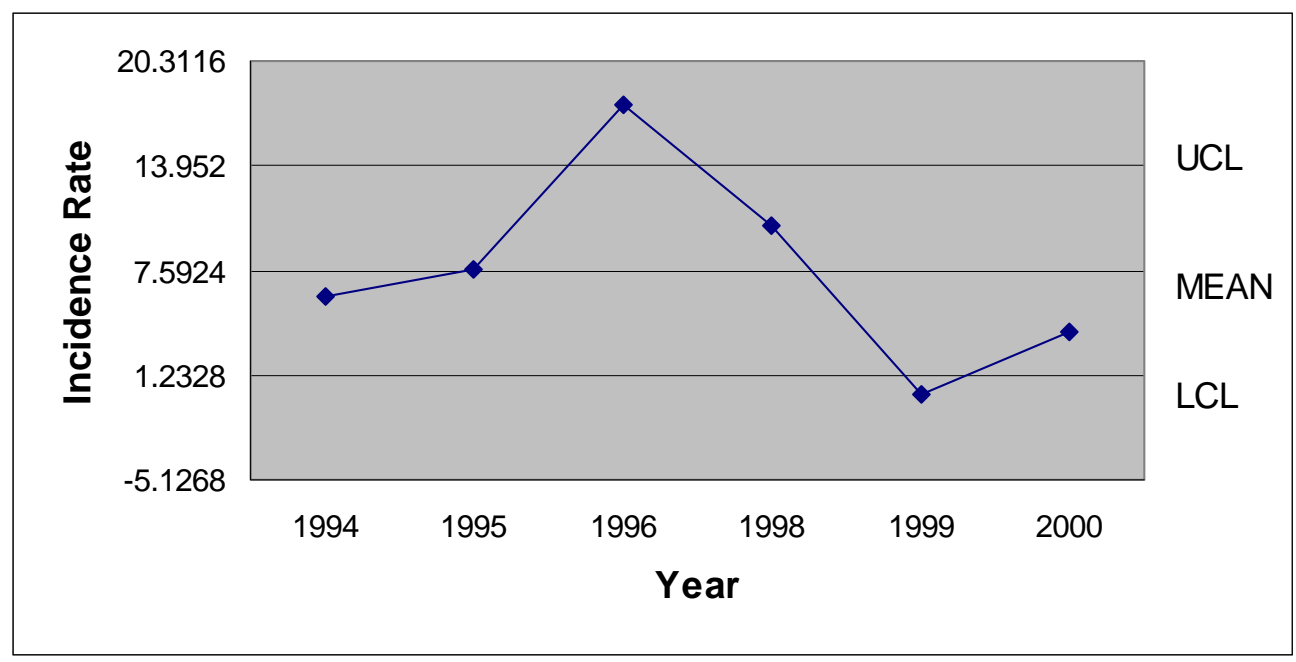

Note: No operations in January 1997

Figure 333. January 1994-2000 Medical Treatment Incidence Rates - Finishing Plant \#2 
The February 1994 Finishing Plant \#2 incidence rate of 14.028 was slightly higher than the 1996 incidence rate of 13.619. The largest decrease occurred between 1996 and 1998 when a 70\% decrease was experienced. February 2000 recorded an incidence rate of 0.000 (See Figure 334).

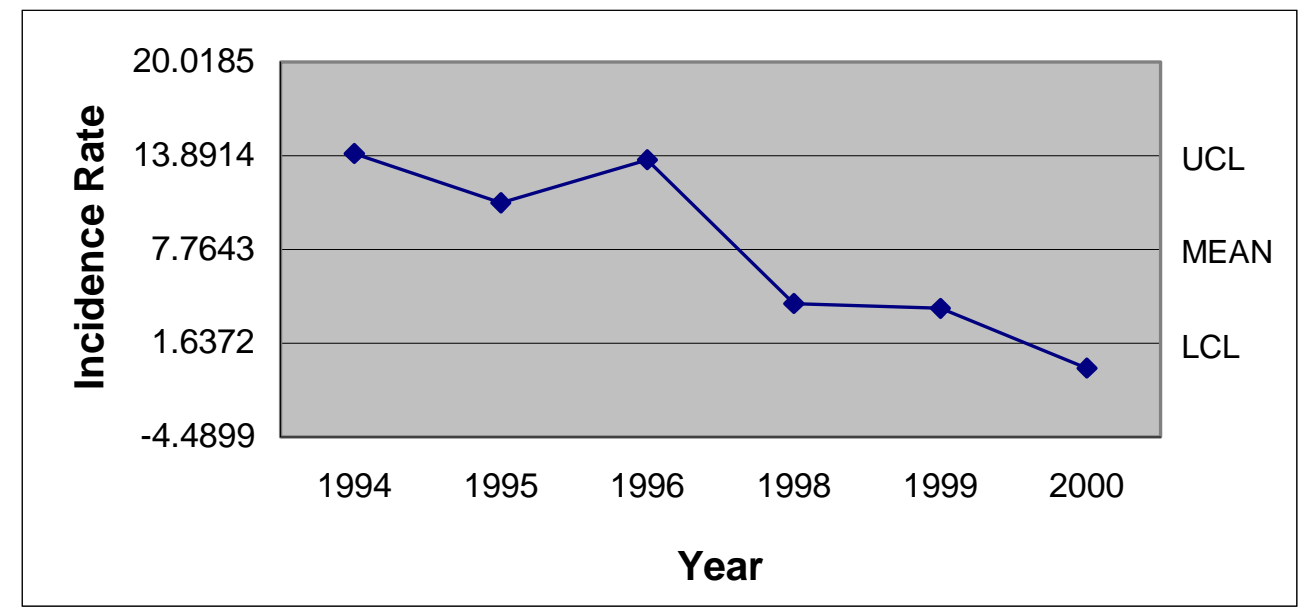

Note: No operations in February 1997

Figure 334. February 1994-2000 Medical Treatment Incidence Rates - Finishing Plant \#2

The lowest March incidence rate at Finishing Plant \#2 occurred in 1994, with a rate of 2.222. The low was followed in 1995 with the second highest incidence rate for the month. In 1996, the second lowest incidence rate was recorded just above the LCL. The next year of operations, 1998, recorded the highest incidence rate of 14.846. The next two years demonstrated a consistent decrease in incidence rates (See Figure X335). 


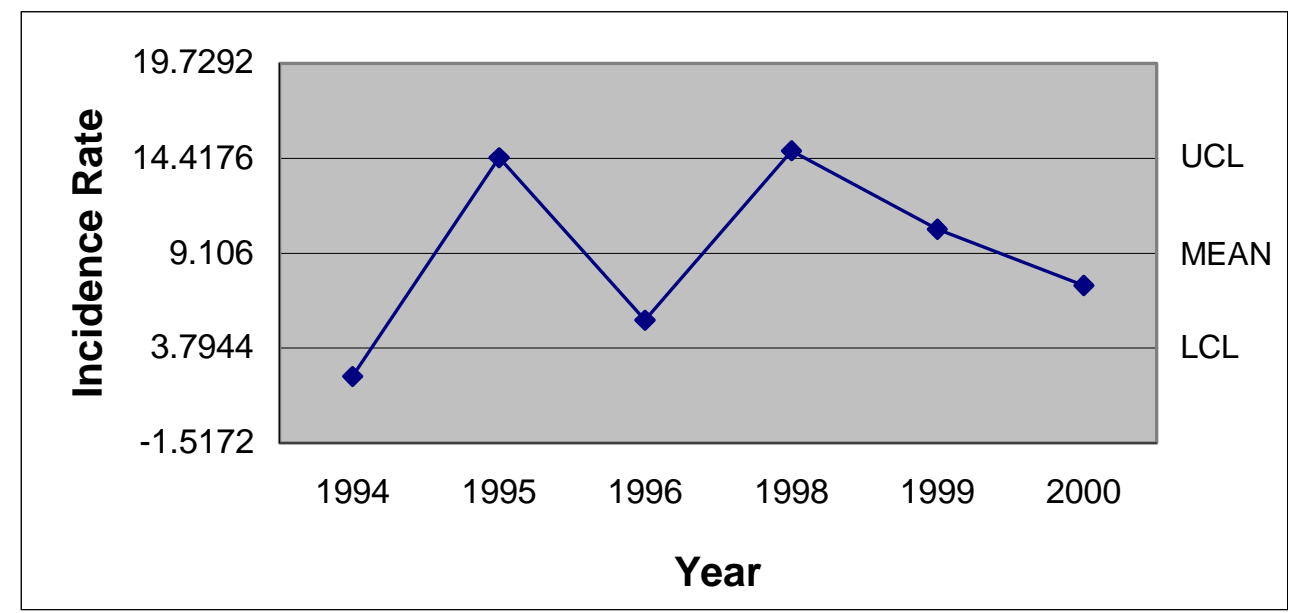

Note: No operations in March 1997

Figure 335. March 1994-2000 Medical Treatment Incidence Rates - Finishing Plant \#2

The lowest April Finishing Plant \#2 incidence rate, which occurred in 1994, was over four times smaller in magnitude than the highest, which was recorded in 1995 . The two years following the high remained just under the UCL. Incidence rates for 1999 and 2000 were close to the LCL (See Figure 336).

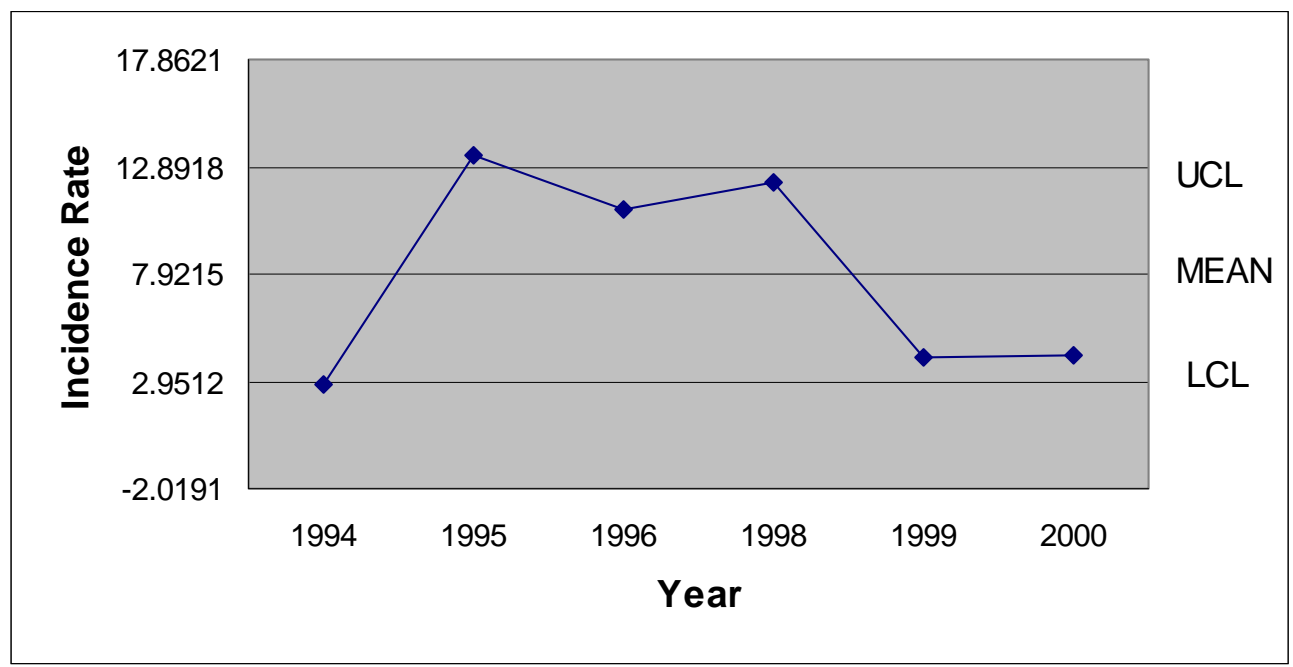

Note: No operations in April 1997

Figure 336. April 1994-2000 Medical Treatment Incidence Rates - Finishing Plant \#2 
The 1994 May incidence rate at Finishing Plant \#2 of 10.757 was almost as high as the 1998 incidence rate of 11.665. Following the high in 1998, May incidence rates for 1999 and 2000 were 0.000 (See Figure 337).

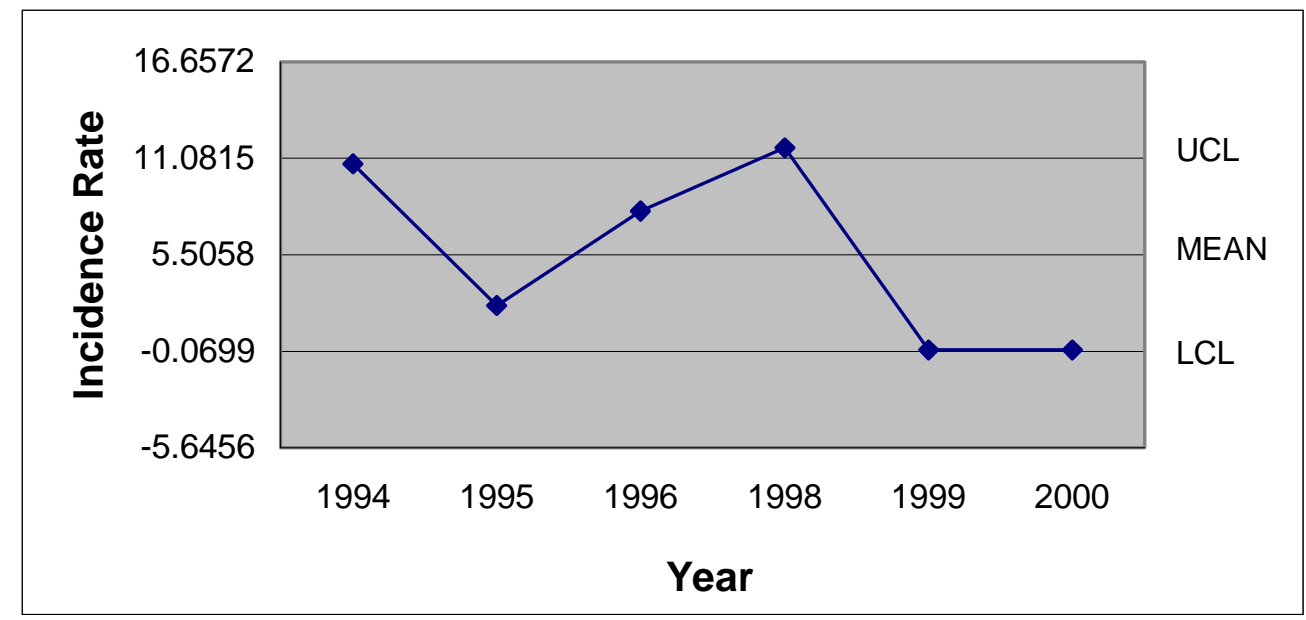

Note: No operations in May 1997

Figure 337. May 1994-2000 Medical Treatment Incidence Rates - Finishing Plant \#2

As illustrated in Figure 338, the Finishing Plant \#2 incidence rates for June 1994 through 1996 were clustered around the mean. In 1998 the incidence rate reached a high of 19.367. Following the 1998 high, the incidence rate decreased to just below the mean in 1999 and below the LCL in 2000.

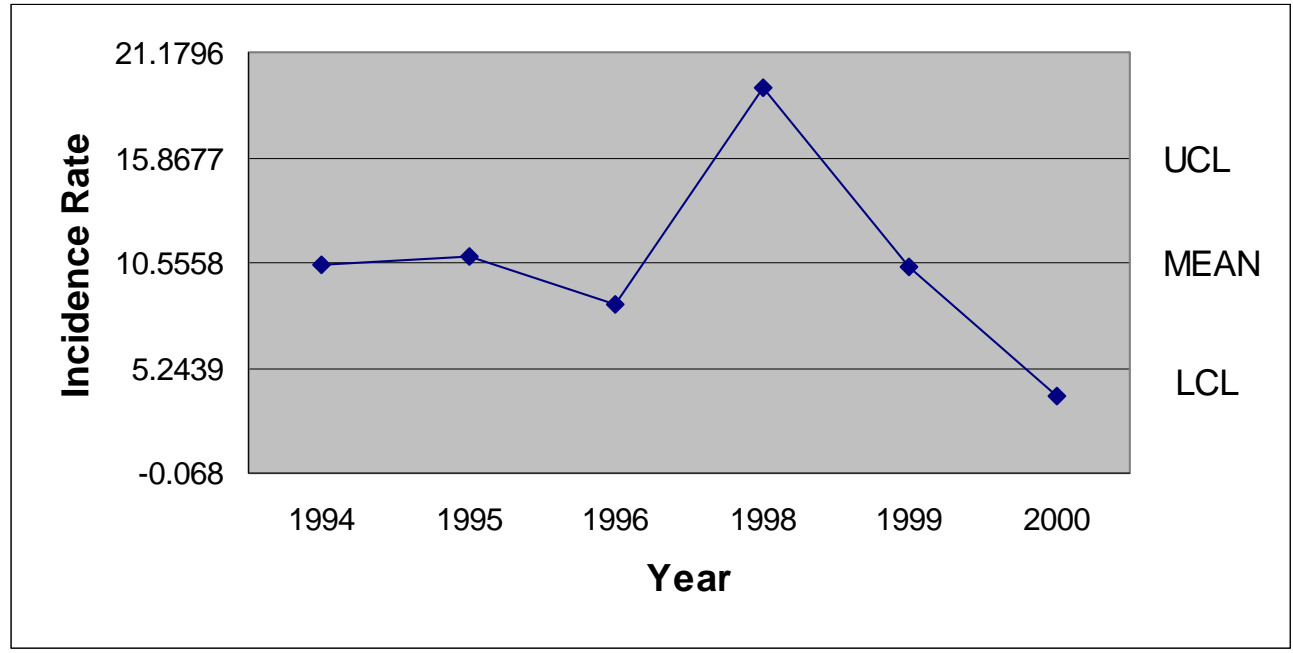

Note: No operations in June 1997

Figure 338. June 1994-2000 Medical Treatment Incidence Rates - Finishing Plant \#2 
The highest July incidence rate at Finishing Plant \#2, which was recorded in 1995, was nearly two and one-half times greater than the lowest rate, which was recorded in 1994. Following the 1995 high, the incidence rates decreased steadily over the next three years to the July 1999 level just above the LCL (See Figure 339).

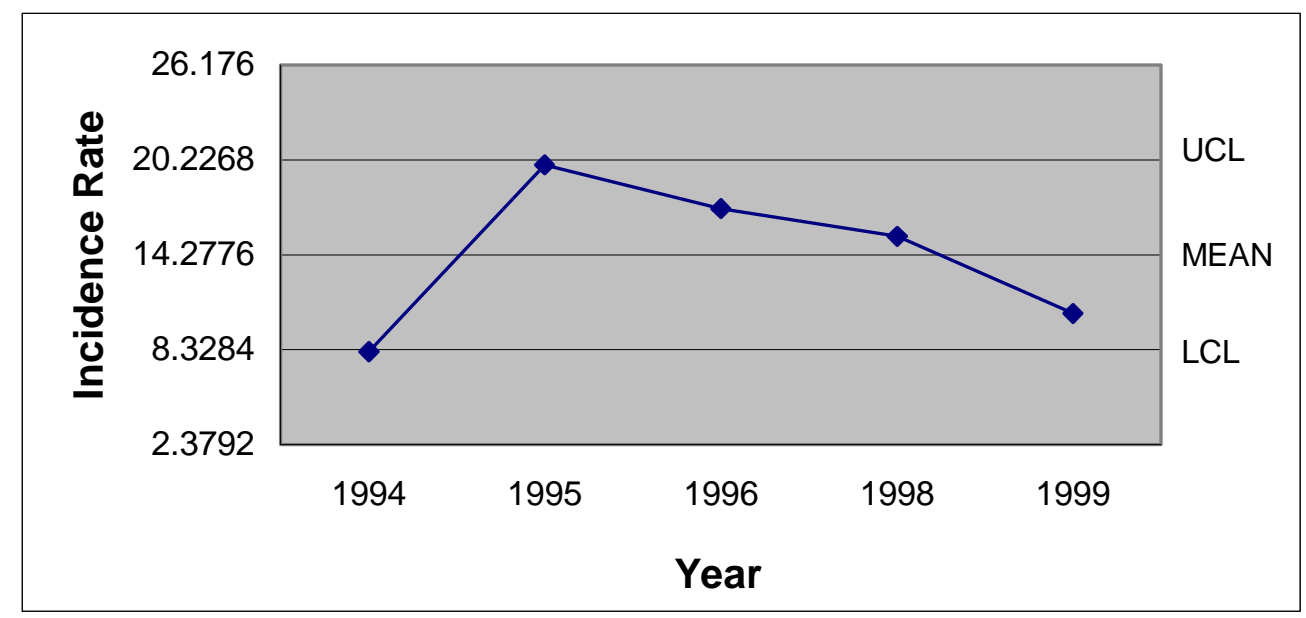

Note: No operations in July 1997

Figure 339. July 1994-1999 Medical Treatment Incidence Rates - Finishing Plant \#2

The finishing Plant \#2 August incidence rate recorded just above the mean in 1994 was followed by the high in 1995, which was slightly higher than the 1996 incidence rate. In 1998, the lowest August incidence rate was recorded at t level of 7.620. The incidence rate increased from the low in 1998 to a level just below the mean in 1999 (See Figure 340). 


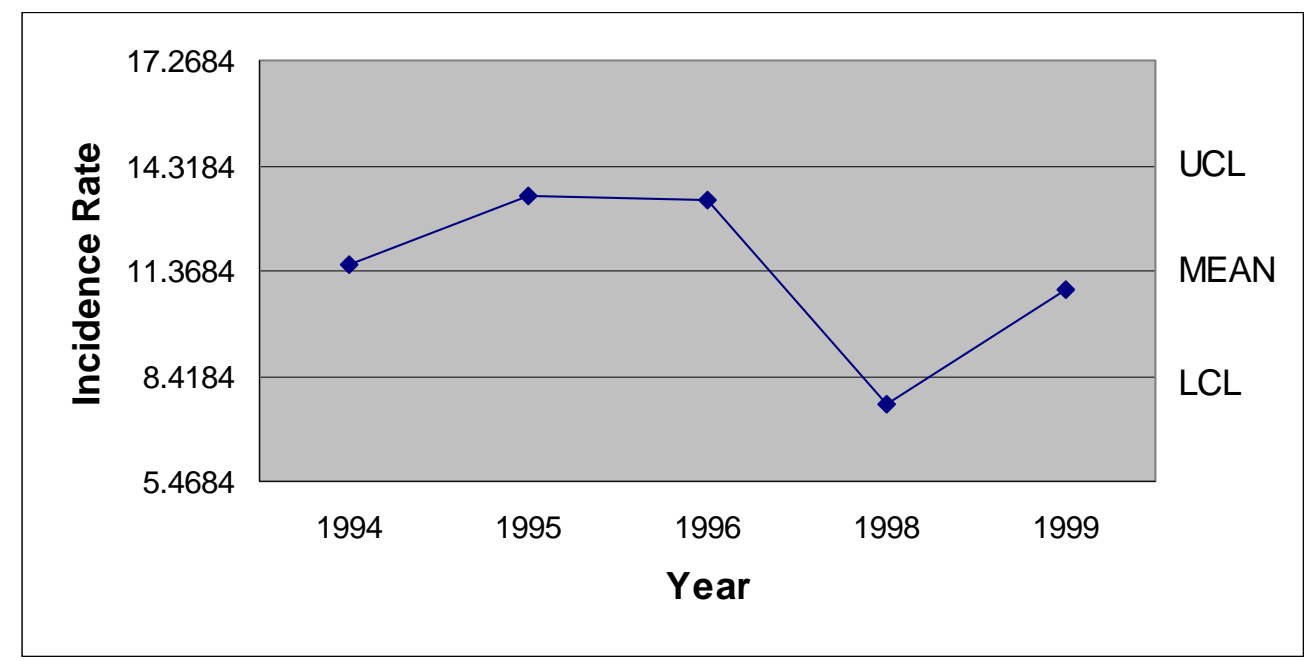

Note: No operations in August 1997

Figure 340. August 1994-1999 Medical Treatment Incidence Rates - Finishing Plant \#2

As illustrated in Figure 341, the lowest September incidence rate at Finishing Plant \#2 was recorded below the LCL in 1994. The lowest rate was more than tripled by both the 1995 and 1996 incidence rates. The highest rate, which was recorded in 1998, was almost one and one-half times greater than the 1996 incidence rate. In the last September of the research period the incidence rates decreased to a level just above the mean.

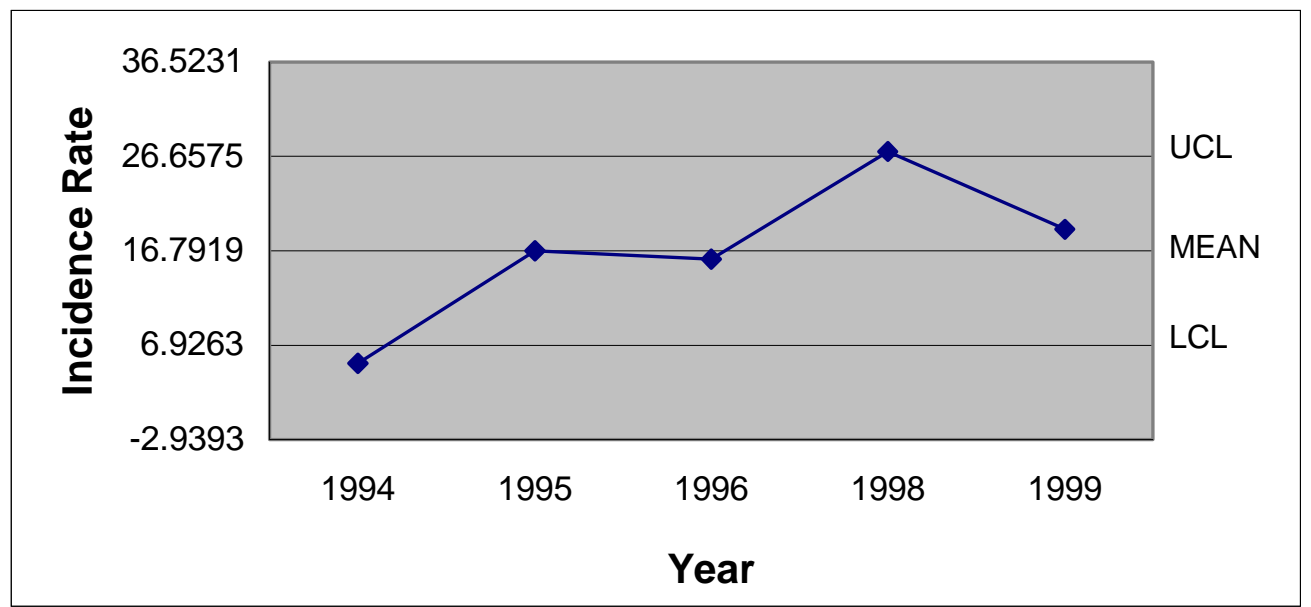

Note: No operations in September 1997

Figure 341. September 1994-1999 Medical Treatment Incidence Rates - Finishing Plant \#2 
October incidence rates at Finishing Plant \#2 experienced a zigzag pattern that started with the low in 1994 and ended just below the mean in 1999. The 1994 low was followed in 1995 with an incidence rate seven times greater in magnitude. The following year with October operations, 1997, recorded a decrease of almost the same magnitude as the previous increase. October 1998 recorded the second highest incidence rate for the research period (See Figure 342).

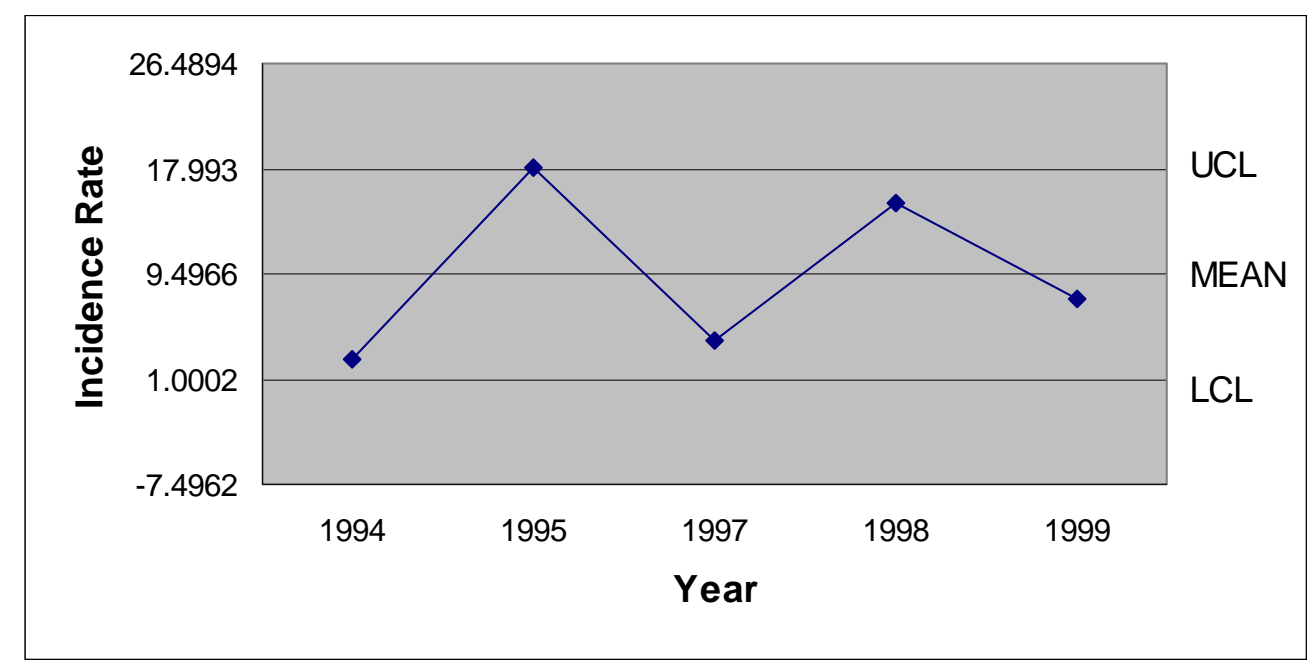

Note: No operations in October 1996

Figure 342. October 1994-1999 Medical Treatment Incidence Rates - Finishing Plant \#2

As illustrated in Figure 343, the November 1994 incidence rates of 11.062 at Finishing Plant \#2 was the highest November incidence rate for the study period. After a decrease in 1995 to a level below the mean, the incidence rate returned above the mean in 1997. The incidence rate decreased over the next two years to a level just above the LCL. 


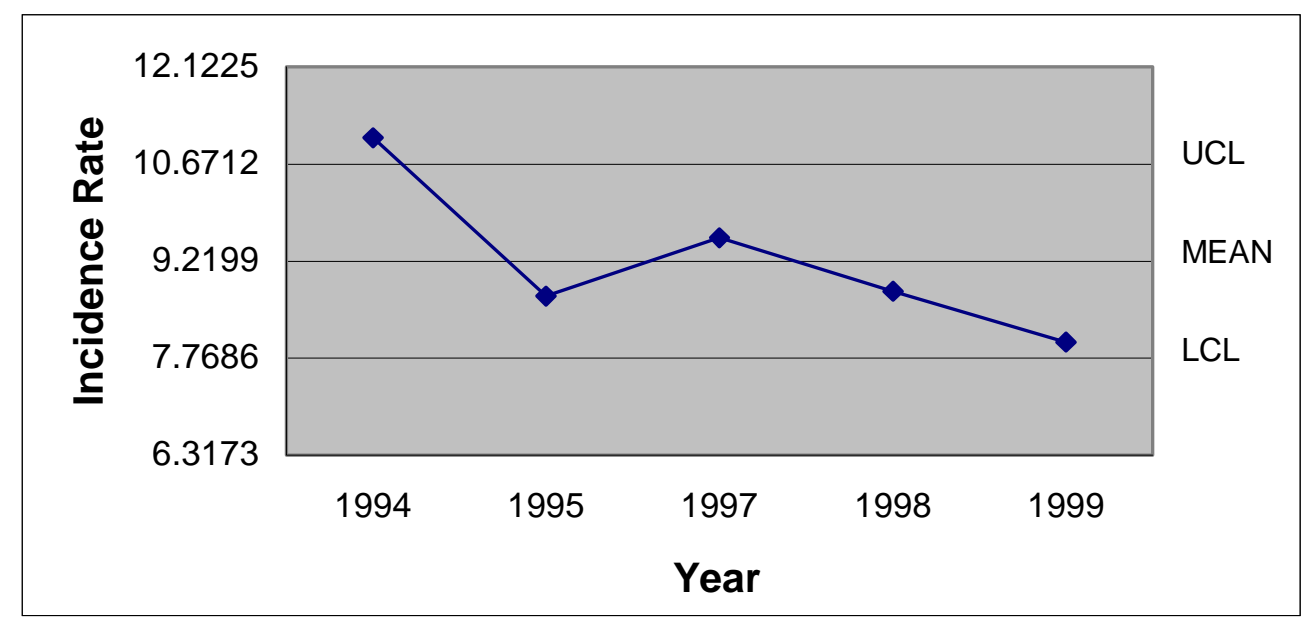

Note: No operations in November 1996

Figure 343. November 1994-1999 Medical Treatment Incidence Rates - Finishing Plant \#2

As illustrated in Figure 344, the December Finishing Plant \#2 incidence rates remained clustered around the mean for the first three years of the research. However, the 1998 incidence rate increased to a level just below the UCL. This increase was followed by a $37 \%$ decrease, the sharpest decrease recorded between two December incidence rates.

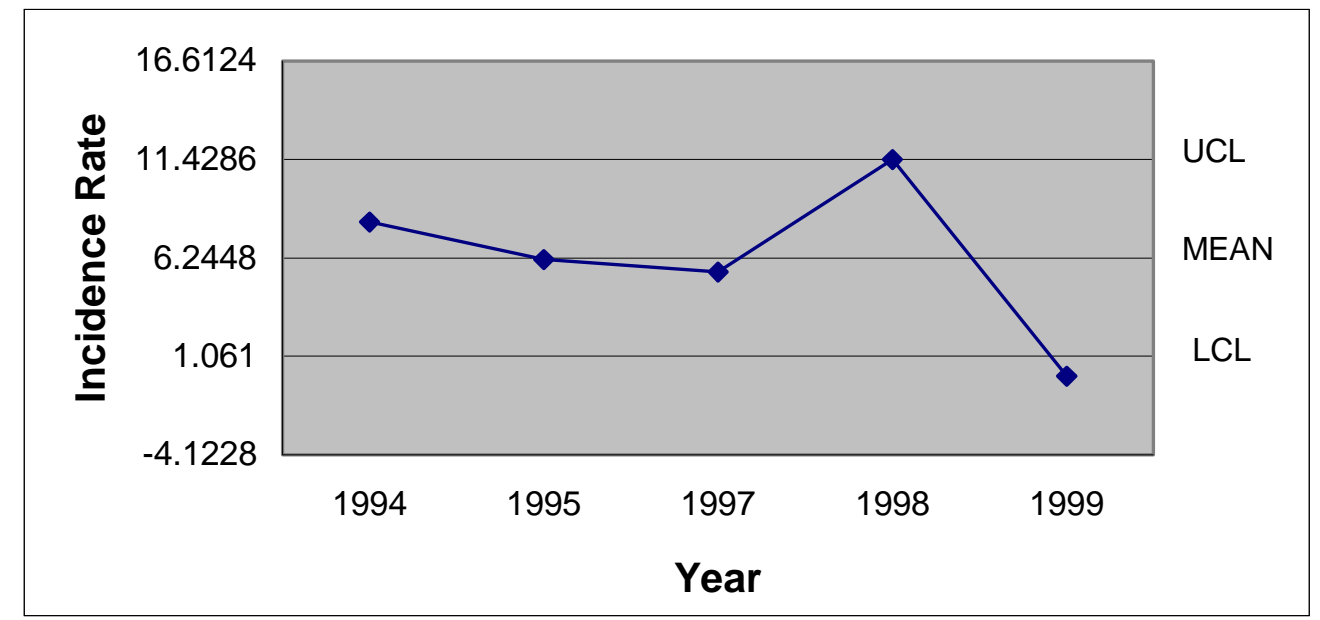

Note: No operations in December 1996

Figure 344. December 1994-1999 Medical Treatment Incidence Rates - Finishing Plant \#2 
Table 59 presents the Finishing Plant \#2 monthly incidence rates for each year of the study period, as well as the UCL, mean, LCL, and standard deviation. Nineteen ninety-six and 1997 are partial years because of the work stoppage and only the first six months of 2000 were included in the research.

Table 59

Summary of Monthly Medical Treatment Incidence Rates Data - Finishing Plant\#2

\begin{tabular}{|l|l|l|l|l|l|l|l|l|l|l|l|l|}
\hline & Jan. & Feb. & Mar. & Apr. & May & June & July & Aug. & Sept. & Oct. & Nov. & Dec. \\
\hline 1994 & 6.024 & 14.028 & 2.222 & 2.811 & 10.757 & 10.503 & 8.217 & 11.564 & 5.020 & 2.547 & 11.062 & 8.143 \\
\hline 1995 & 7.639 & 10.802 & 14.459 & 13.412 & 2.578 & 10.901 & 19.931 & 13.450 & 16.818 & 18.054 & 8.696 & 6.167 \\
\hline 1996 & 17.704 & 13.619 & 5.374 & 10.932 & 8.035 & 8.421 & 17.183 & 13.345 & 15.886 & N/A & N/A & N/A \\
\hline 1997 & N/A & N/A & N/A & N/A & N/A & N/A & N/A & N/A & N/A & 4.115 & 9.569 & 5.513 \\
\hline 1998 & 10.311 & 4.235 & 14.846 & 12.142 & 11.665 & 19.367 & 15.436 & 7.620 & 27.191 & 15.239 & 8.764 & 11.402 \\
\hline 1999 & 0.000 & 3.903 & 10.452 & 4.033 & 0.000 & 10.348 & 10.620 & 10.864 & 19.045 & 7.532 & 8.008 & 0.000 \\
\hline 2000 & 3.876 & 0.000 & 7.283 & 4.198 & 0.000 & 3.795 & N/A & N/A & N/A & N/A & N/A & N/A \\
\hline UCL & 13.952 & 13.891 & 14.418 & 12.892 & 11.082 & 15.868 & 20.227 & 14.318 & 26.658 & 17.993 & 10.671 & 11.429 \\
\hline MEAN & 7.592 & 7.764 & 9.106 & 7.922 & 5.506 & 10.556 & 14.278 & 11.368 & 16.792 & 9.497 & 9.220 & 6.245 \\
\hline LCL & 1.233 & 1.637 & 3.794 & 2.951 & -0.061 & 5.244 & 8.328 & 8.418 & 6.926 & 1.000 & 7.769 & 1.061 \\
\hline SD & 2.474 & 2.383 & 2.066 & 1.933 & 2.169 & 2.066 & 2.143 & 1.063 & 3.554 & 3.061 & 0.523 & 1.867 \\
\hline
\end{tabular}

$\underline{\text { Seasonal Analysis of Monthly Medical Treatment Incidence Rates - Finishing Plant \#2 }}$

The seasonal index calculation was used to generate the monthly seasonal index figures for Finishing Plant \#2 that are presented in Figure 345. The June through September period had the highest seasonal index amounts, with September having the highest by almost $15 \%$. February and November also exhibited relatively high seasonal index figures. The lowest seasonal index was May. 


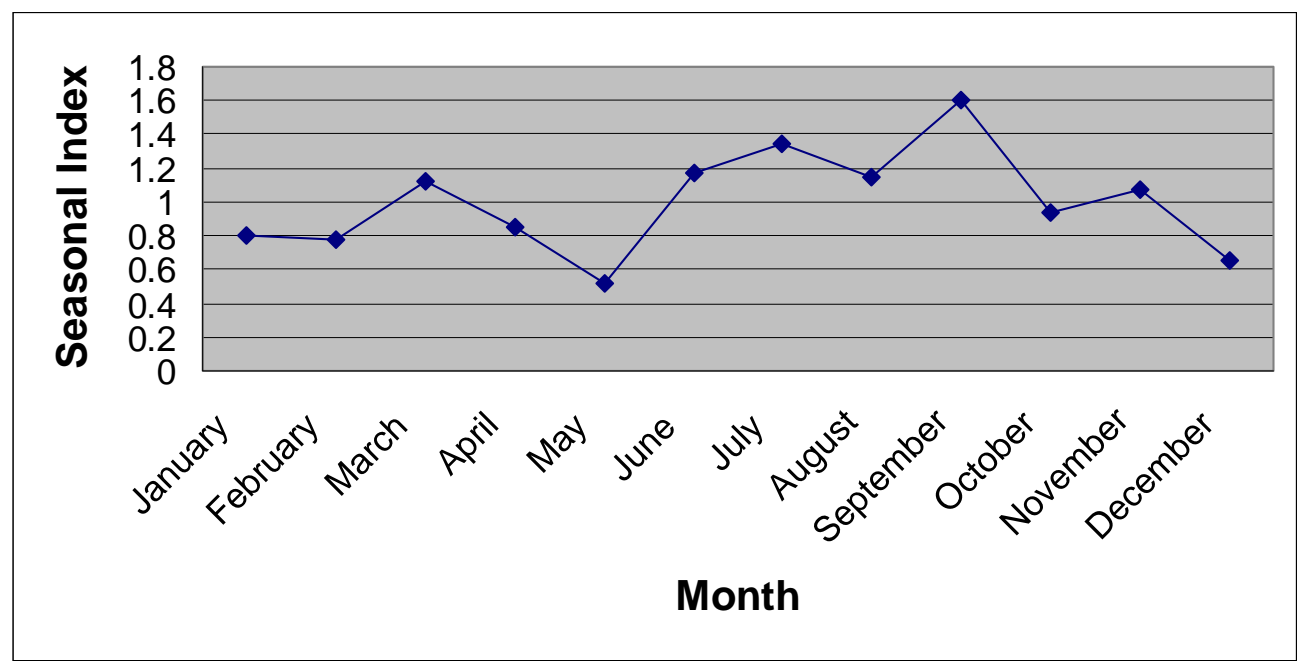

Figure 345. Monthly Seasonal Pattern of Medical Treatment Incidence Rates Finishing Plant \#2

Testing the Statistical Relationship of Medical Treatment Data - Finishing Plant \#2 All 33 Months Prior to and Subsequent to the Work Stoppage

For the entire 33 months prior to the work stoppage and the 33 post work stoppage months at Finishing Plant \#2 the calculated comparison t value was 3.563. Because the calculated amount exceeded the 1.96 critical $t$ value, a statistically significant decrease occurred between the incidence rates for these two periods.

First 24 Months and Last 24 Months of the Research Period

The same formula was applied to medical treatment incidence rates for the first 24 months and the last 24 months of the period at Finishing Plant \#2. These time periods excluded the nine months prior to and immediately following the work stoppage. Using the 1.96 critical $t$ value, the calculated amount of 2.578 , indicated a statistically significant decrease in medical treatment rates between the two periods.

Nine Month Intervals Prior to and Subsequent to the Work Stoppage

Comparison of the medical treatment incidence rates at Finishing Plant \#2 for the nine months preceding the work stoppage and the nine months following the work stoppage was accomplished using the comparison formula. The result of this calculation, 2.559 , was greater than the critical $t$ value of 2.007 , for a .05 statistical significance level. 
Because the calculated amount exceeds the significance level, a statistically significant decrease in incidence rates occurred between the two periods.

Table 60

Comparison Prior and Post Work Stoppage Periods - Finishing Plant \#2

\begin{tabular}{|c|c|c|c|c|}
\hline \multirow[b]{2}{*}{ Time Period } & \multicolumn{2}{|c|}{ Finishing Plant \#2 Incidence Rates } & \multirow[b]{2}{*}{ Critical t Value } & \multirow[b]{2}{*}{$\begin{array}{l}\text { Calculated } \\
\text { Comparison Value }\end{array}$} \\
\hline & $\begin{array}{l}\text { Prior to } \\
\text { Work Stoppage }\end{array}$ & $\begin{array}{l}\text { Post } \\
\text { Work Stoppage }\end{array}$ & & \\
\hline 9 Months & 12.23 & 5.25 & 2.007 & $2.559 * *$ \\
\hline 24 Months & 9.75 & 5.91 & 1.96 & $2.578^{* * *}$ \\
\hline 33 Months & 10.42 & 5.74 & 1.96 & $3.563 * *$ \\
\hline
\end{tabular}

* Indicates a statistically significant increase

** Indicates a statistically significant decrease

Finishing Plant \#3 Analysis

Quarterly Analysis of Medical Treatment Data - Finishing Plant \#3

As illustrated in Figure 346, the highest first quarter medical treatment incidence rate at Finishing Plant \#3 occurred in 1998. The three previous first quarters were between the LCL and the mean. The highest incidence rate was almost six and one-half times greater than the low, which occurred in 2000. 


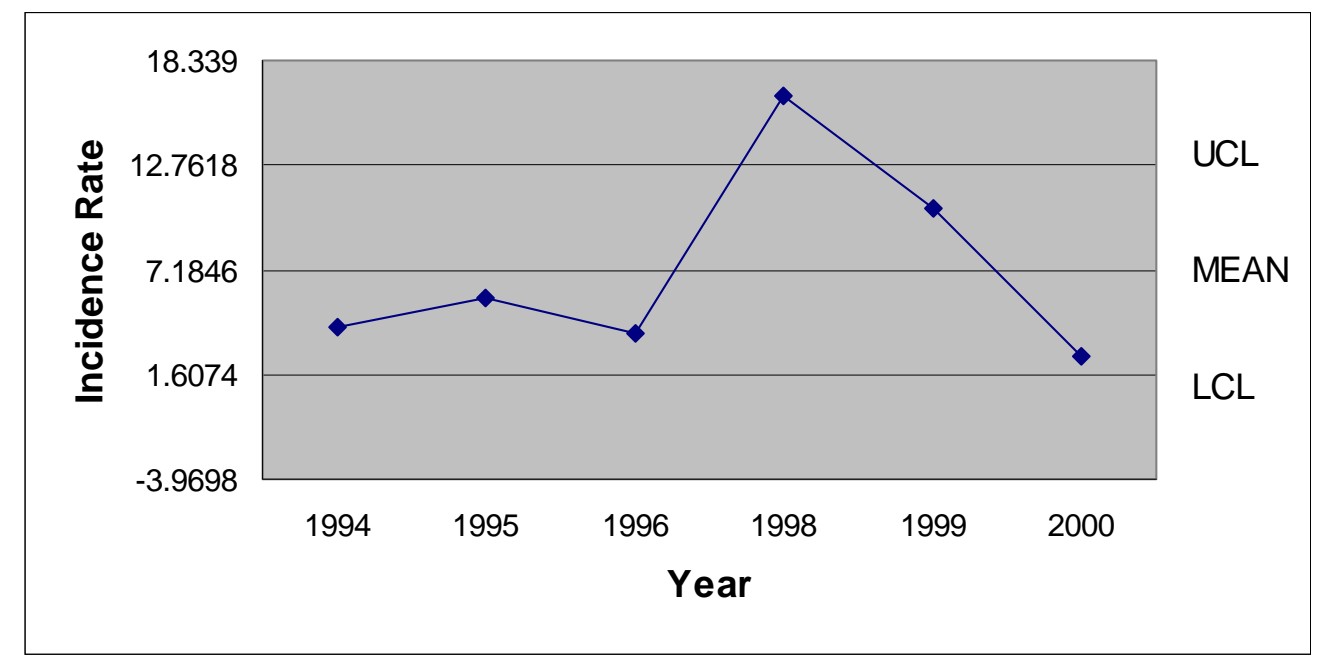

Note: No operations in first quarter 1997

Figure 346. First Quarter1994-2000 Medical Treatment Incidence Rates - Finishing Plant \#3

The second quarter medical treatment incidence rates at Finishing Plant \#3 were marked by a low in 1995 of 4.822 and a 1998 high of 12.647 . The incidence rates dropped over $50 \%$ between the 1998 and 1999. In 2000, the incidence rate was barely above the mean (See Figure 347).

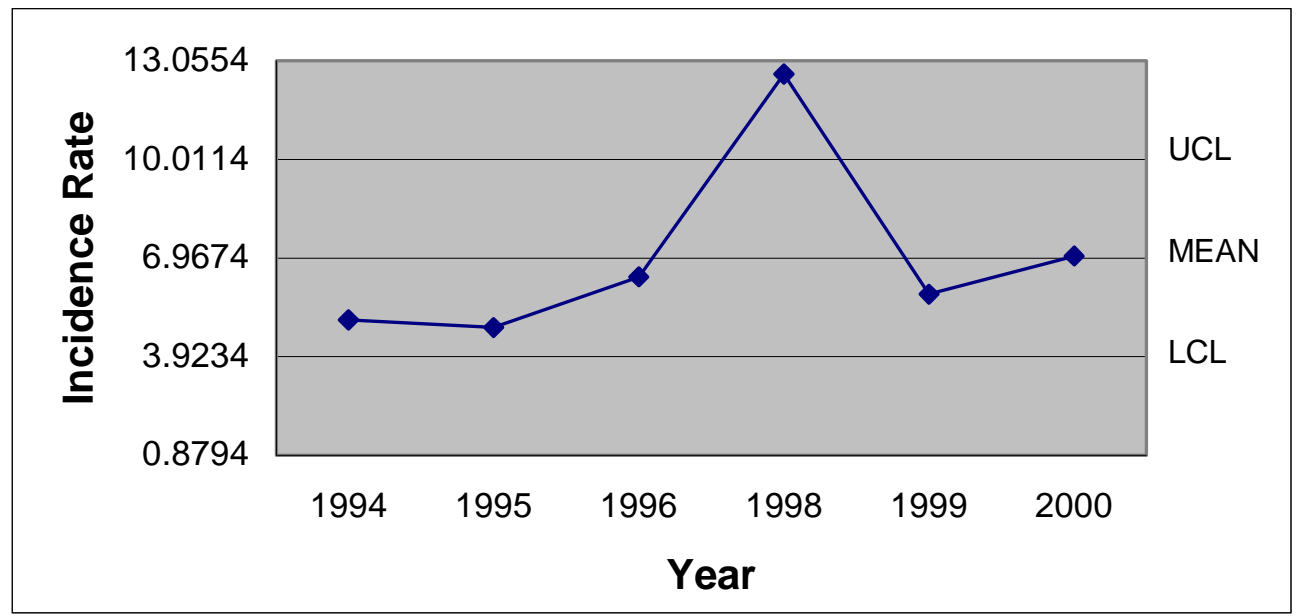

Note: No operations in second quarter 1997

Figure 347. Second Quarter1994-2000 Medical Treatment Incidence Rates - Finishing Plant \#3 
The first two third quarter periods at Finishing Plant \#3 were very close to the mean. In 1996, the incidence rate dropped below the mean and in 1998 the high of 13.369 was recorded above the UCL. The low of 3.288 occurred in 1999, the year following the high (See Figure 348).

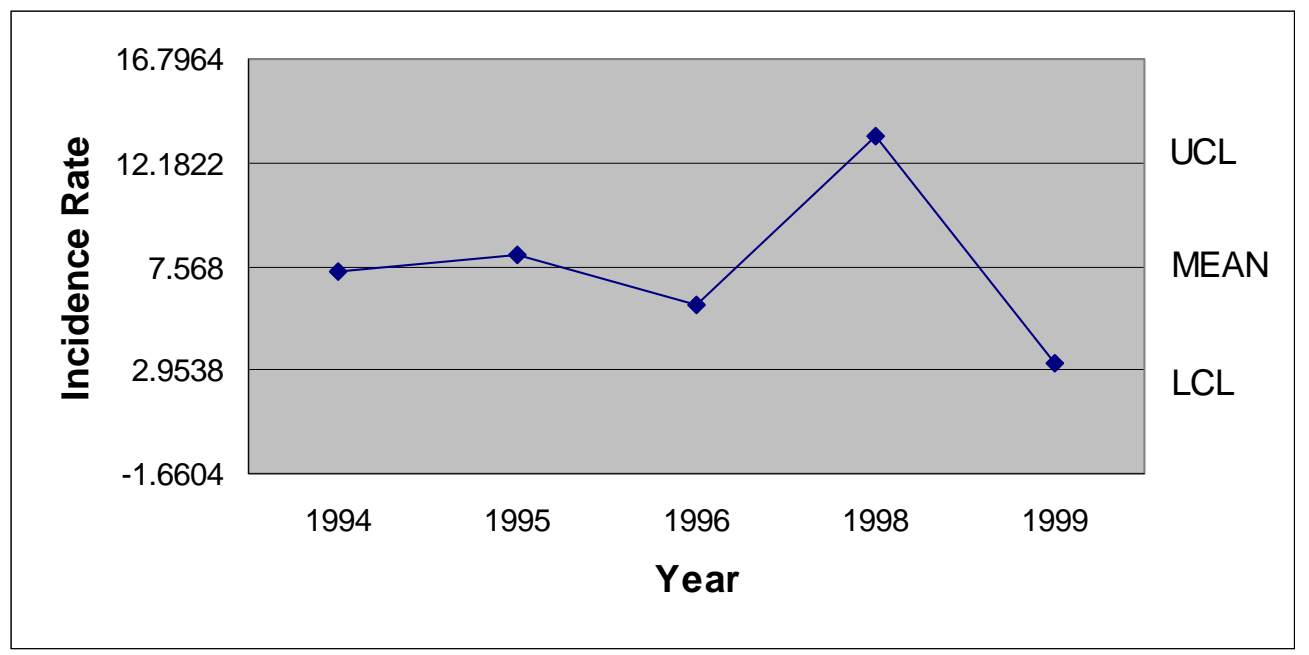

Note: No operations in third quarter 1997.

Figure 348. Third Quarter1994-1999 Medical Treatment Incidence Rates - Finishing Plant \#3

The lowest fourth quarter incidence rate at Finishing Plant \#3 was recorded below the LCL in 1995. In 1997 the incidence rate was between the mean and the UCL. The highest fourth quarter incidence rate of 13.637 occurred in 1998 (See Figure 349). 


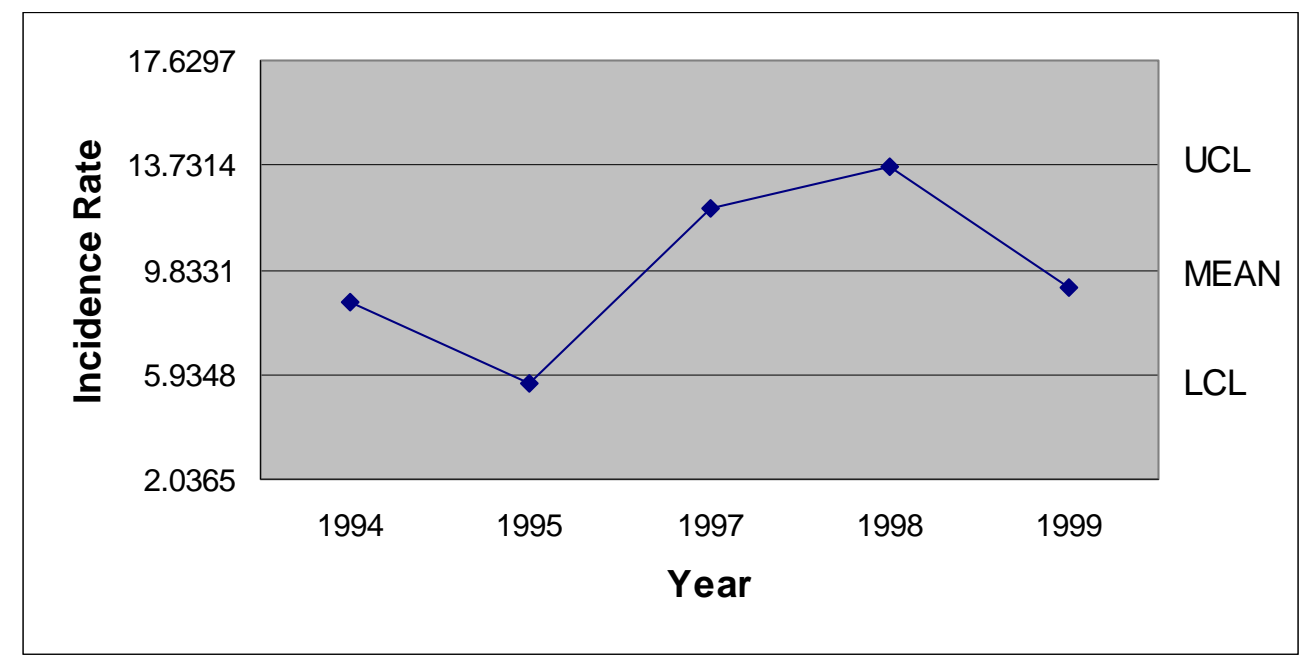

Note: No operations in fourth quarter 1996

Figure 349. Fourth Quarter1994-1999 Medical Treatment Incidence Rates - Finishing Plant \#3

Table 61.

$\underline{\text { Summary of Quarterly Medical Treatment Incidence Rates Data - Finishing Plant \#3 }}$

\begin{tabular}{|l|l|l|l|l|}
\hline & $1^{\text {st }}$ Quarter & $2^{\text {nd }}$ Quarter & $3^{\text {rd }}$ Quarter & $4^{\text {th }}$ Quarter \\
\hline 1994 & 4.116 & 5.065 & 7.300 & 8.625 \\
\hline 1995 & 5.713 & 4.822 & 8.044 & 5.592 \\
\hline 1996 & 3.796 & 6.385 & 5.841 & N/A \\
\hline 1997 & N/A & N/A & N/A & 12.100 \\
\hline 1998 & 16.455 & 12.645 & 13.369 & 13.637 \\
\hline 1999 & 10.467 & 5.857 & 3.288 & 9.212 \\
\hline 2000 & 2.560 & 7.029 & N/A & N/A \\
\hline UCL & 12.762 & 10.011 & 12.182 & 13.731 \\
\hline MEAN & 7.185 & 6.967 & 7.568 & 9.833 \\
\hline LCL & 1.607 & 3.923 & 2.954 & 5.935 \\
\hline SD & 2.169 & 1.184 & 1.662 & 1.404 \\
\hline
\end{tabular}




\section{Quarterly Seasonal Analysis of Medical Treatment Data - Finishing Plant \#3}

The results of the seasonal index calculations for Finishing Plant \#3 are presented in Figure 350. The incidence rates seasonal index indicates that the highest seasonal index occurred in the fourth quarter, while the lowest occurred in the first quarter. The second and third quarters were virtually identical.

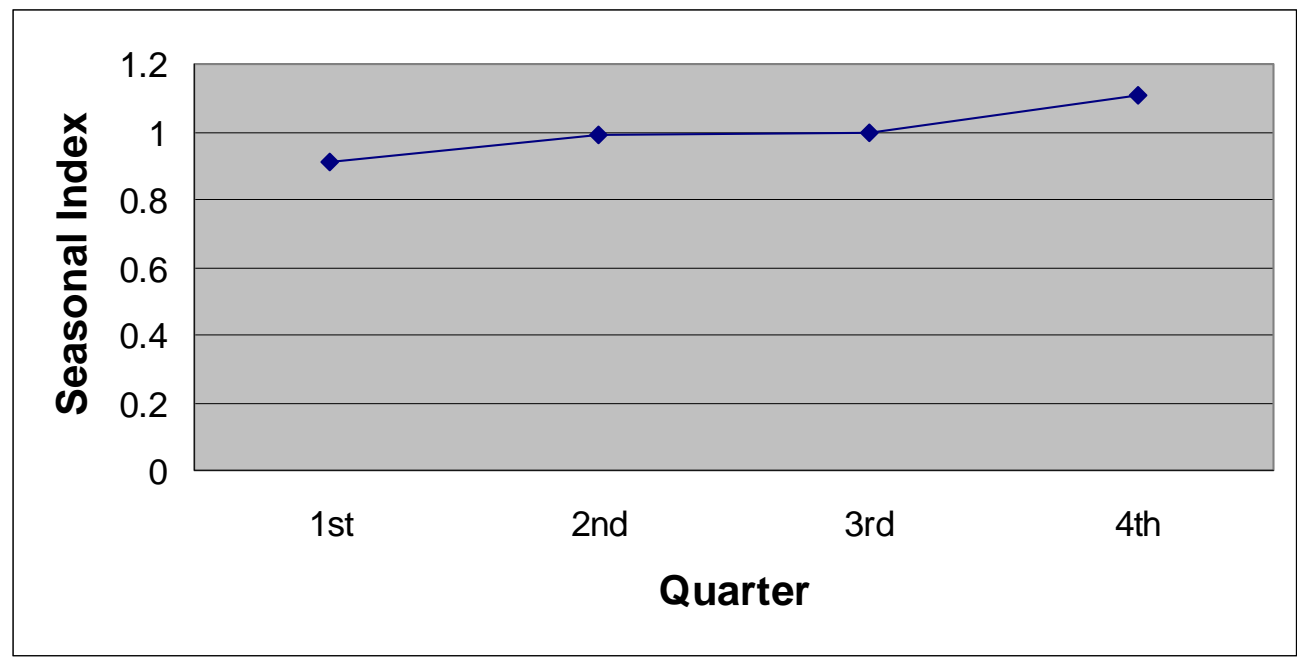

Figure 350. Quarterly Seasonal Index of Medical Treatment Incidence Rates - Finishing Plant \#3

\section{Monthly Analysis of Medical Treatment Data - Finishing Plant \#3}

Figure 351 illustrates the medical treatment incidence rates for 1994 through 2000 at Finishing Plant \#3. The first two January incidence rates occurred close to the mean. The lowest January incidence rates occurred in 1996 and 2000 when the incidence rates of 0.000 were recorded. The highest January incidence rate occurred in 1999 when the 16.643 rate was recorded above the UCL. 


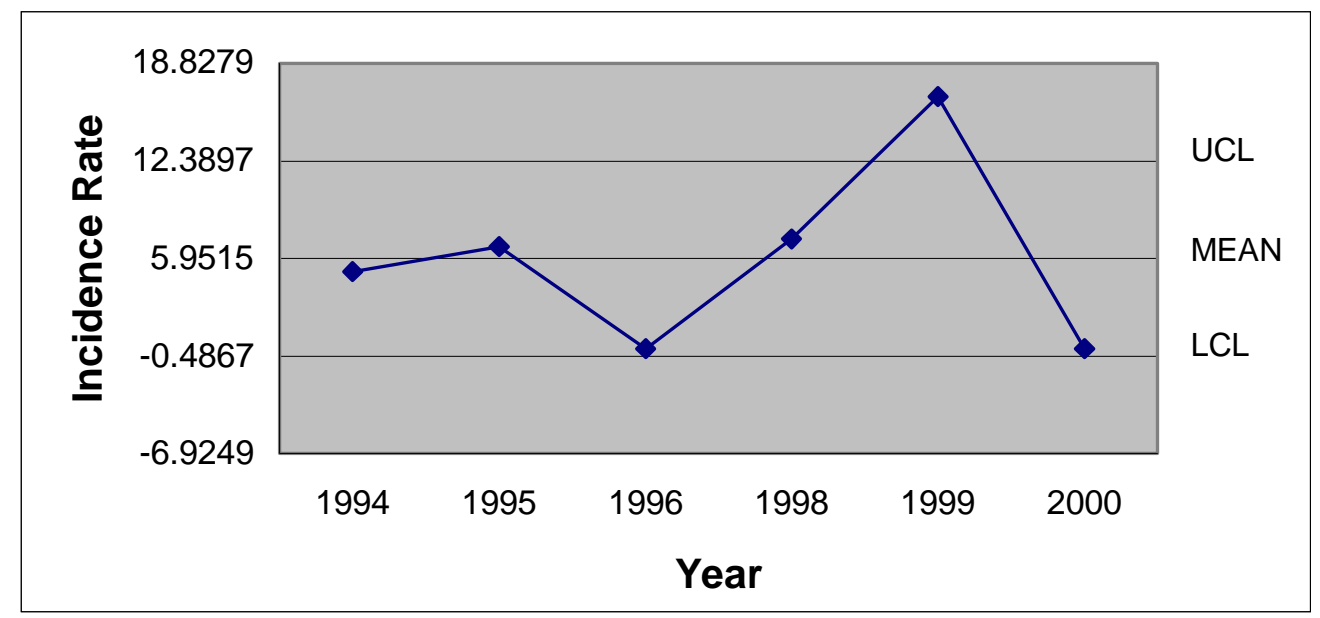

Note: No operations in January 1997

Figure 351. January 1994-2000 Medical Treatment Incidence Rates - Finishing Plant \#3

The February incidence rates at Finishing Plant \#3 remained close to the mean for the first three years of this research. However, in 1998 the incidence rate nearly tripled that of the previous periods. In 1999 the incidence rate returned to a level just below the mean and in 2000 the incidence rate was just above the LCL (See Figure 352).

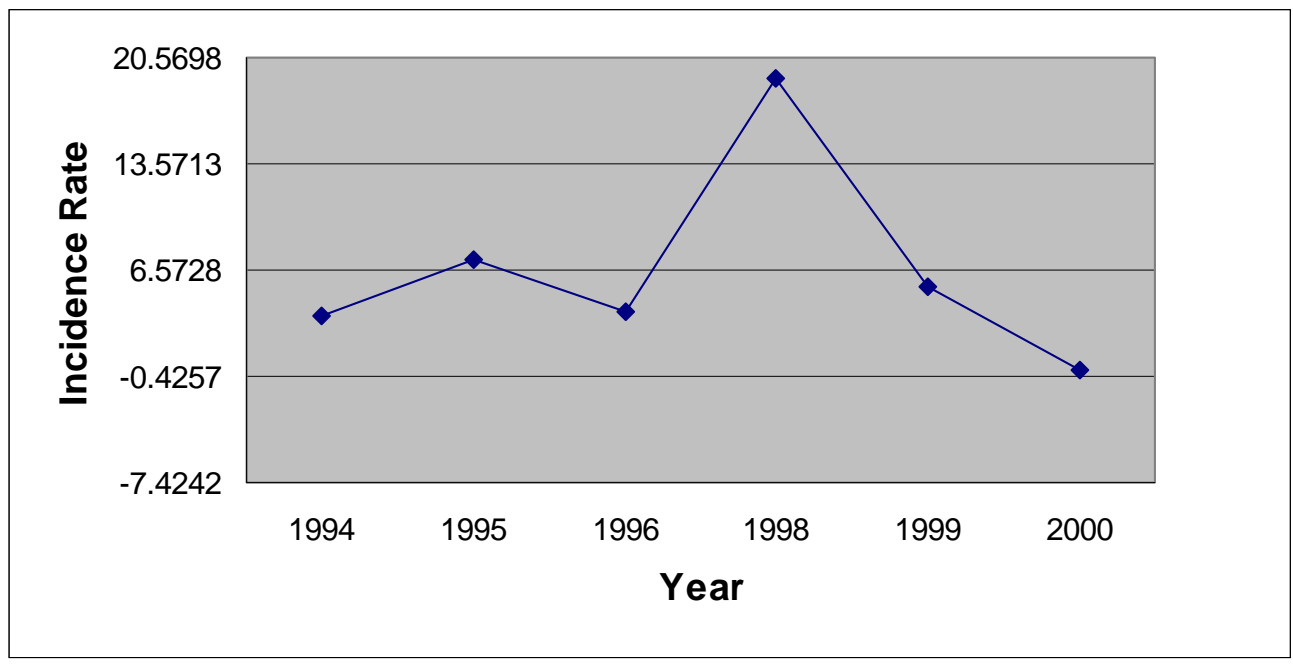

Note: No operations in February 1997.

Figure 352. February 1994-2000 Medical Treatment Incidence Rates - Finishing Plant \#3

As illustrated in Figure 353, the lowest March incidence rate at Finishing Plant $\# 3,3.278$, was recorded in 1995 . The low was followed by an increase to a level close to 
the mean in 1996. The highest March incidence rate, 20.827, was recorded in 1998. The last two years of the study recorded incidence rates close to the mean.

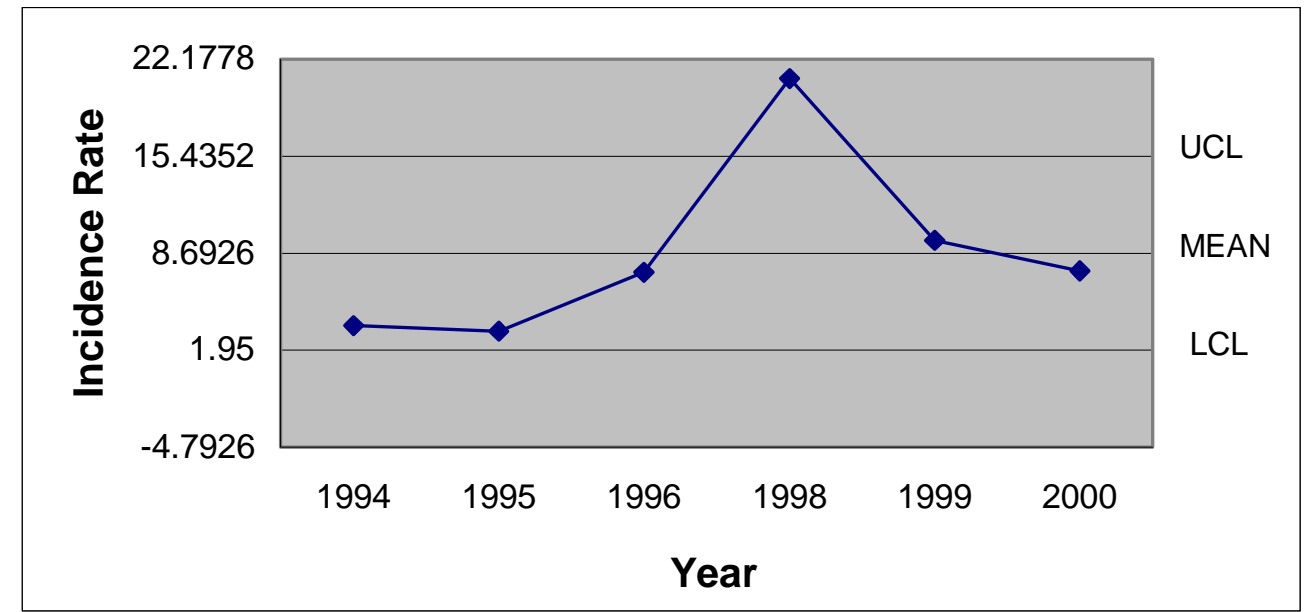

Note: No operations in March 1997

Figure 353. March 1994-2000 Medical Treatment Incidence Rates - Finishing Plant \#3

The 1994 through 1996 April incidence rates at Finishing Plant \#3 were all recorded between the LCL and the mean. As illustrated in Figure 354, the incidence rate was above the UCL in 1998. The 1998 high was followed by two consecutive incidence rates recorded below the mean.

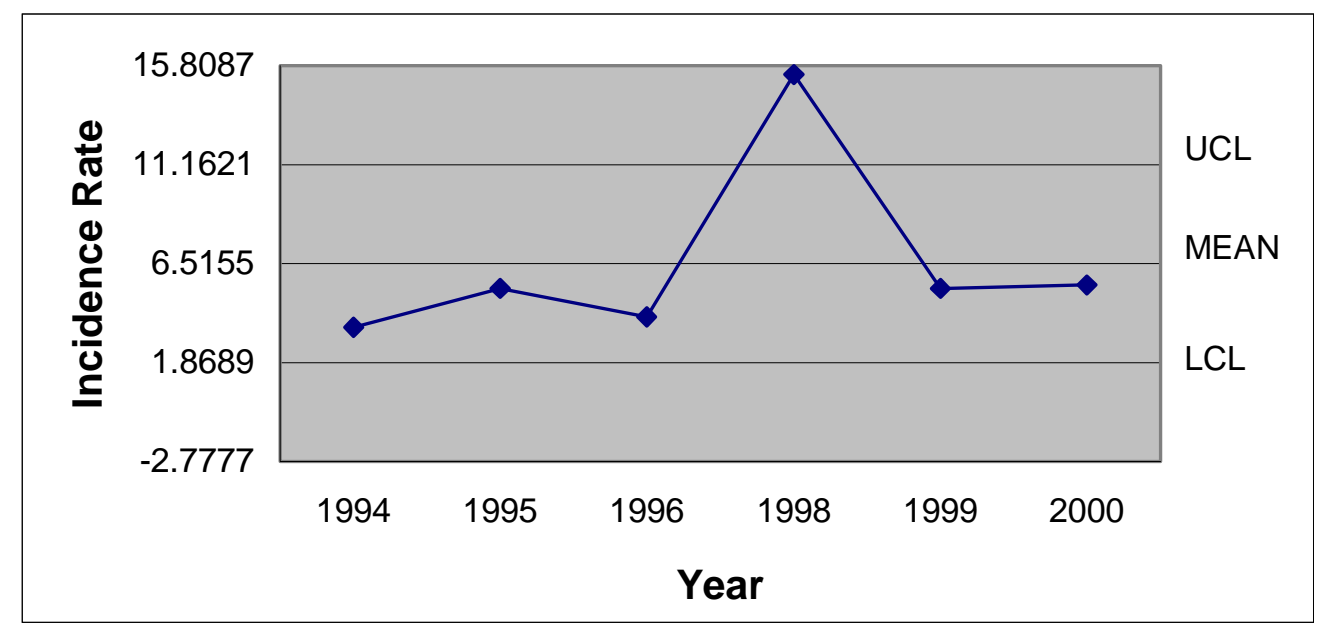

Note: No operations in April 1997

Figure 354. April 1994-2000 Medical Treatment Incidence Rates - Finishing Plant \#3 
Figure 355 illustrates the steadily increasing May incidence rates at Finishing Plant \#3. The 1994 incidence rate of 0.000 was the lowest for the research period. It was followed by three periods of increasing incidence rates, which reached a high of 12.393 in 1998. The next year the incidence rate decreased to a level just above the mean and remained at almost the same level for the last year of the study.

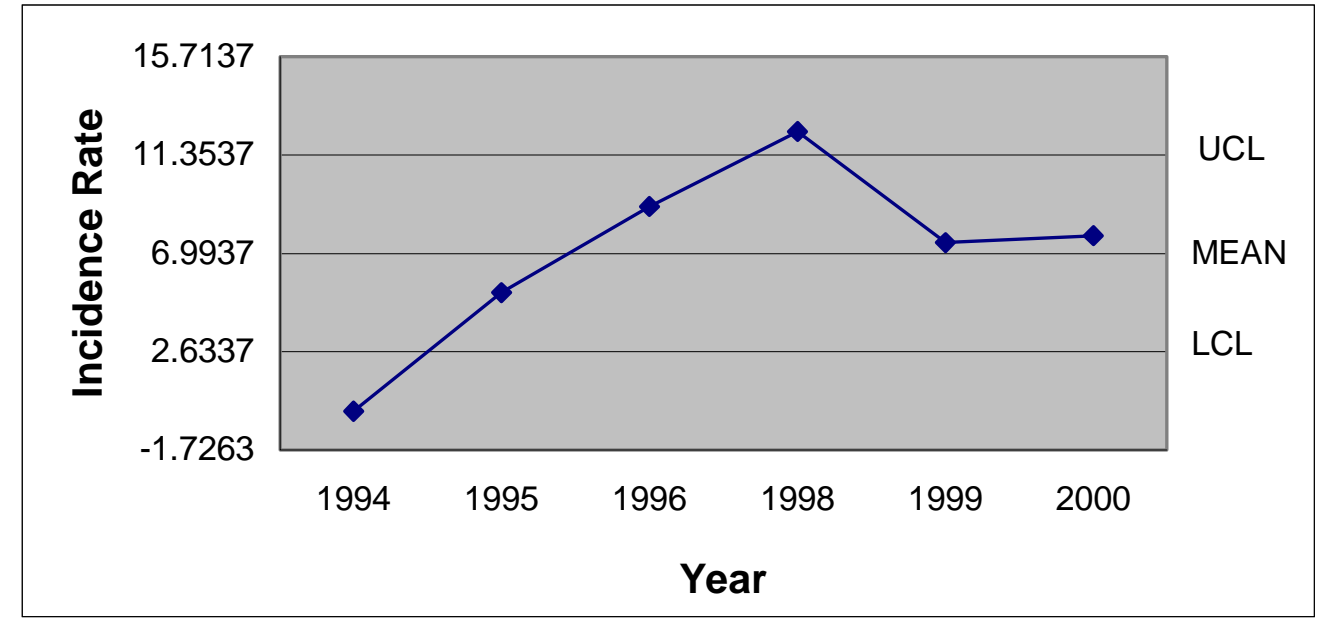

Note: No operations in May 1997.

Figure 355. May 1994-2000 Medical Treatment Incidence Rates - Finishing Plant \#3

The highest June incidence rate at Finishing Plant \#3, 11.489, occurred in 1994 and was followed in 1995 by the lowest June incidence rate, 3.803. The remaining four years of June incidence rates were recorded within the control limits with 1998 being just below the UCL (See Figure 356). 


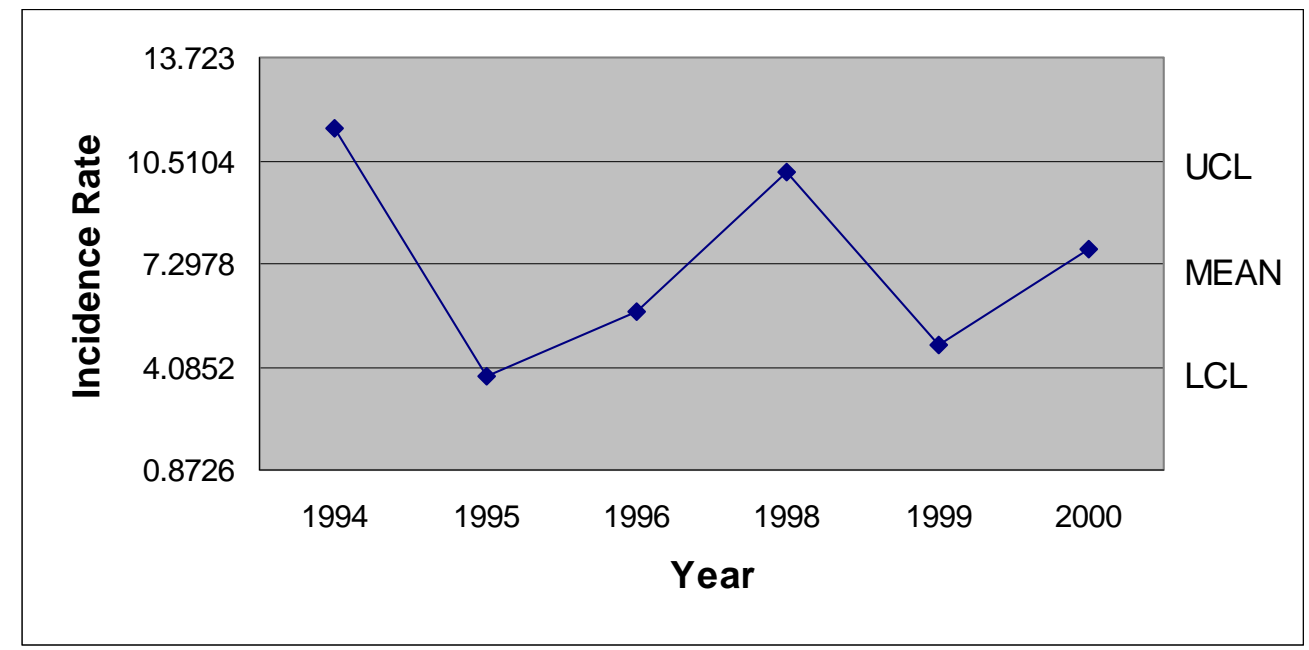

Note: No operations in June 1997

Figure 356. June 1994-2000 Medical Treatment Incidence Rates - Finishing Plant \#3

Medical treatment incidence rates for July at Finishing Plant \#3 were within the control limits for the first three years. However, the 1998 incidence rate of 12.632 was above the UCL. The following year the incidence rate decreased to a level just above the LCL (See Figure 357).

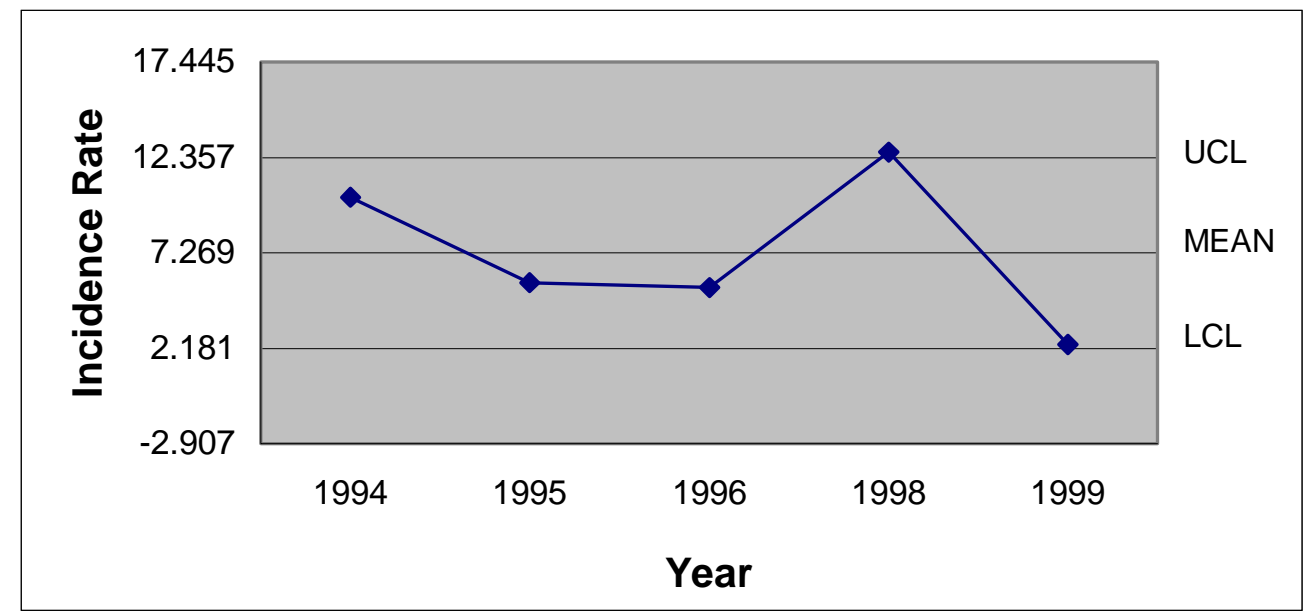

Note: No operations in July 1997

Figure 357. July 1994-1999 Medical Treatment Incidence Rates - Finishing Plant \#3 
After a period of three years of relatively stable incidence rates at Finishing Plant \#3, the month of August posted the highest incidence rate for the study period. The 1998 high of 15.966 was followed in 1999 with a 0.000 incidence rate (See Figure 358).

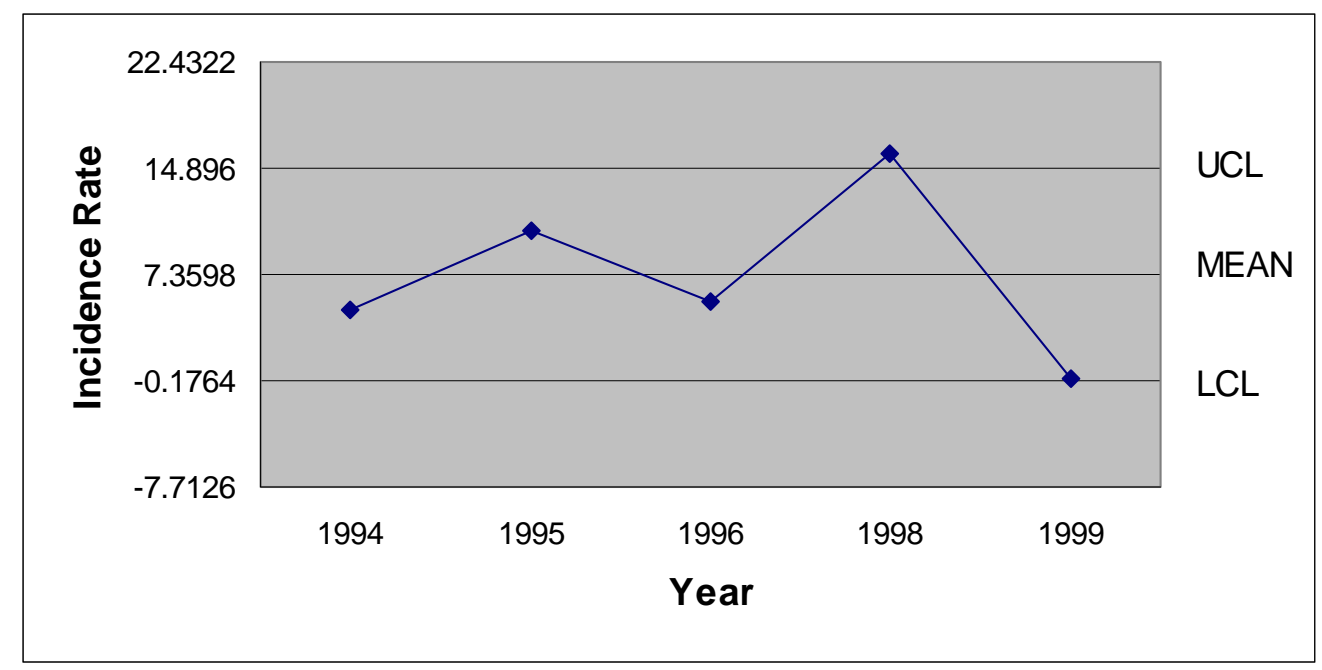

Note: No operations in August 1997

Figure 358. August 1994-1999 Medical Treatment Incidence Rates - Finishing Plant \#3

As illustrated in Figure 359, the 6.917 September 1994 medical treatment incidence rate at Finishing Plant \#3 was the second lowest incidence rate. The only incidence rate recorded below the 1994 rate, was the 1996 rate of 6.784. The low was followed in 1998 by a high of 11.417. The last September incidence rate recorded during this study period was just below the mean. 


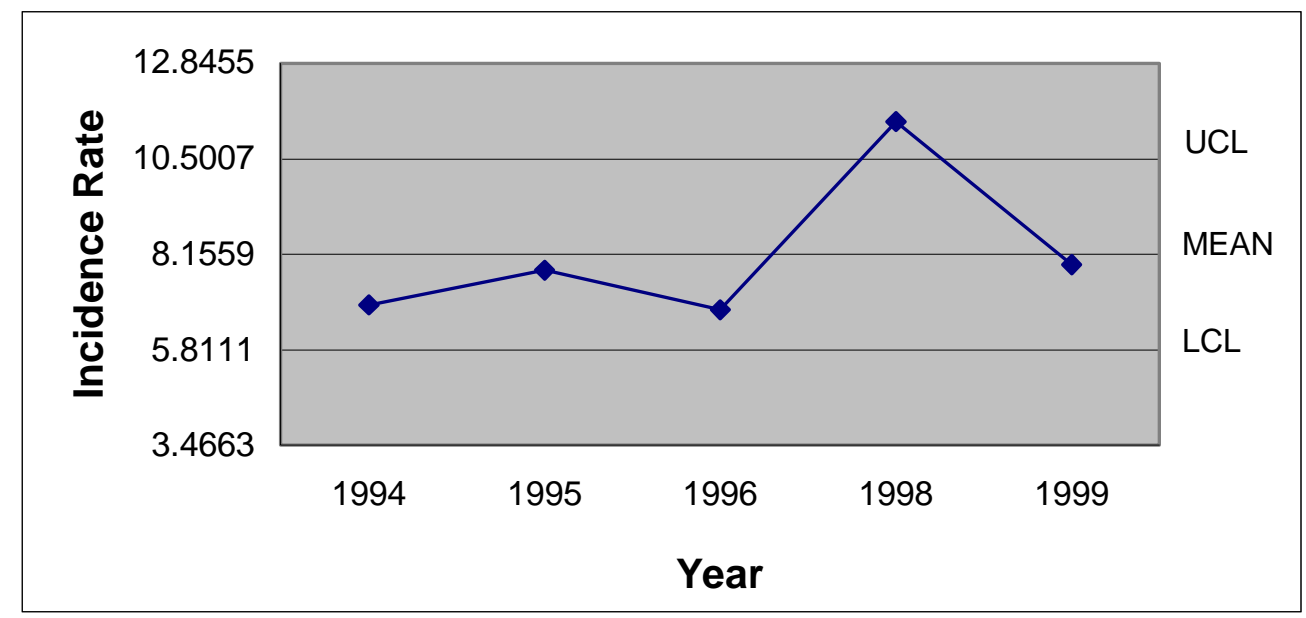

Note: No operations in September 1997

Figure 359. September 1994-1999 Medical Treatment Incidence Rates - Finishing Plant \#3

The October 1994 incidence rate of 1.683 at Finishing Plant \#3 was the lowest October rate recorded during the study period. In 1995 and 1997 the incidence rate was between the mean and the UCL. The rate fell to a level just above the mean in 1998, only to be followed the next year by the highest October rate (See Figure 360).

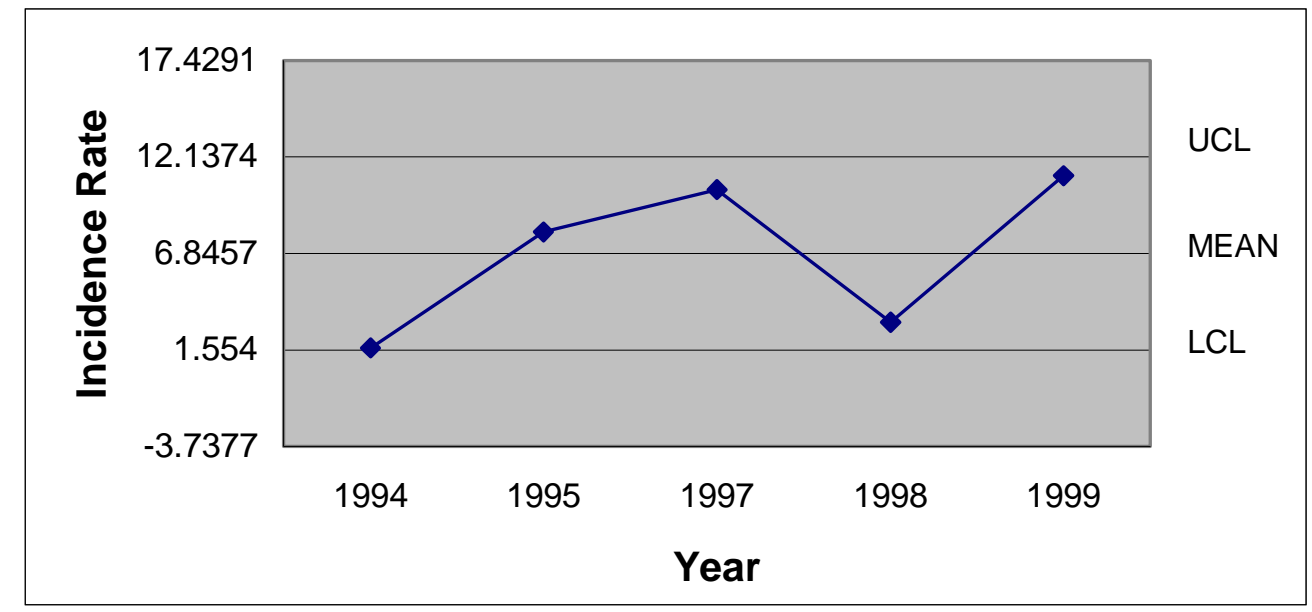

Note: No operations in October 1996

Figure 360. October 1994-1999 Medical Treatment Incidence Rates - Finishing Plant \#3

The November incidence rate at Finishing Plant \#3 trended downward from the 1994 rate of 12.398 to a rate of 3.779 in November 1997. Following the low recorded in 
1997, the November incidence rate increased seven times in magnitude to the high of 26.836 , recorded in 1998. A decrease of nearly $70 \%$ occurred the next year, when an incidence rate of 8.453 was recorded (See Figure 361).

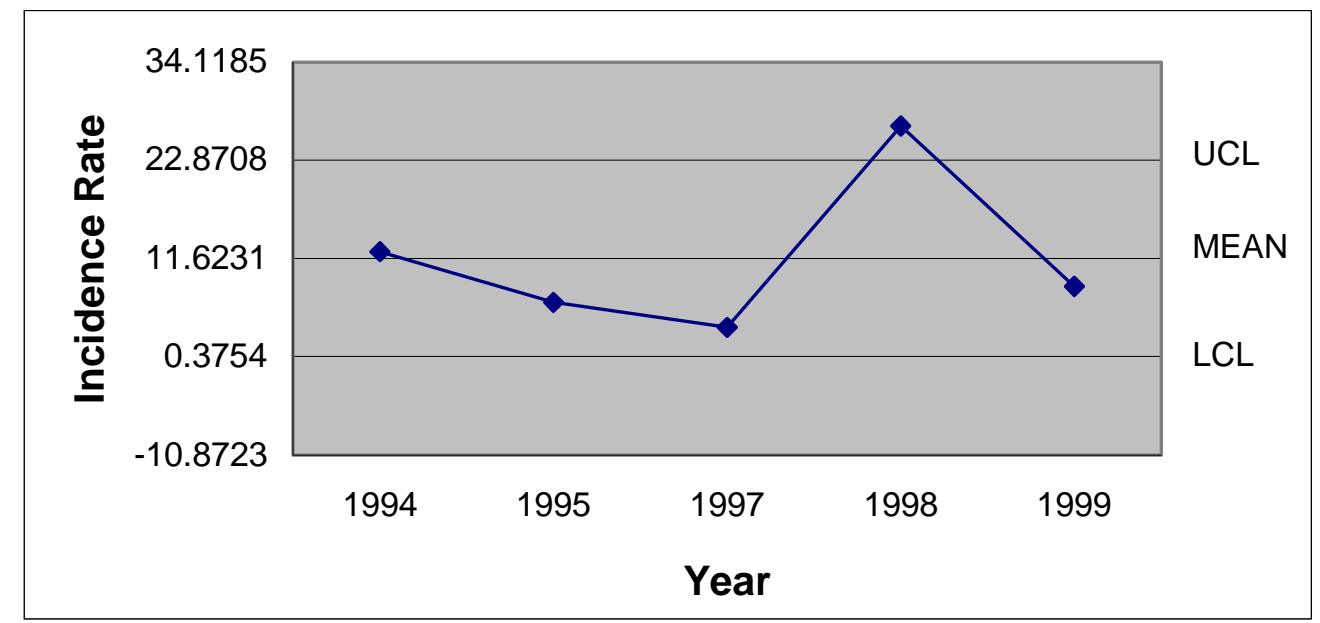

Note: No operations in November 1996

Figure 361. November 1994-1999 Medical Treatment Incidence Rates - Finishing Plant \#3

As illustrated in Figure 362, the lowest December medical treatment incidence rate at Finishing Plant \#3 was recorded in 1995. The highest incidence rate was recorded in December 1997. The high was more than ten times greater in magnitude than the lowest incidence rate.

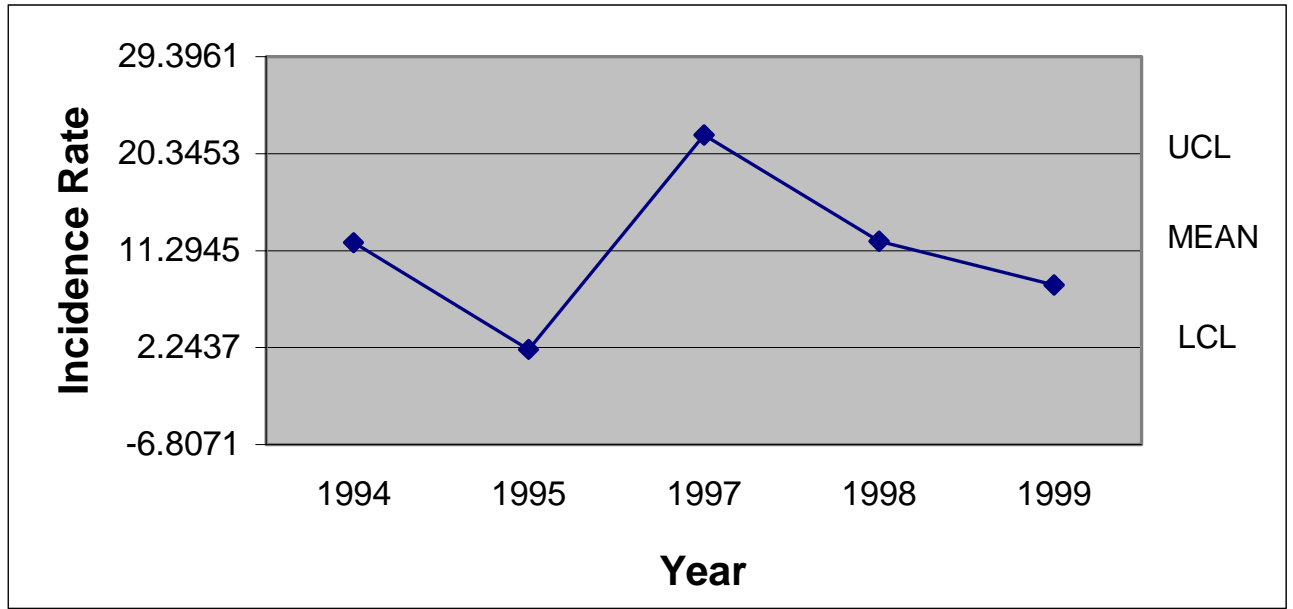

Note: No operations in December 1996

Figure 362. December 1994-1999 Medical Treatment Incidence Rates - Finishing Plant \#3 
Table 62 presents the monthly incidence rates at Finishing Plant \#3 for each year of the study period, as well as the UCL, mean, LCL, and standard deviation. Nineteen ninety-six and 1997 are partial years because of the work stoppage and only the first six months of 2000 were included in the research.

Table 62

Summary of Monthly Medical Treatment Incidence Rates Data - Finishing Plant \#3

\begin{tabular}{|l|l|l|l|l|l|l|l|l|l|l|l|l|}
\hline & Jan. & Feb. & Mar. & Apr. & May & June & July & Aug. & Sept. & Oct. & Nov. & Dec. \\
\hline 1994 & 5.102 & 3.561 & 3.629 & 3.513 & 0.000 & 11.489 & 10.215 & 4.875 & 6.917 & 1.683 & 12.398 & 12.058 \\
\hline 1995 & 6.733 & 7.325 & 3.278 & 5.338 & 5.251 & 3.803 & 5.695 & 10.451 & 7.763 & 8.041 & 6.650 & 2.075 \\
\hline 1996 & 0.000 & 3.882 & 7.376 & 3.998 & 9.080 & 5.823 & 5.415 & 5.507 & 6.784 & N/A & N/A & N/A \\
\hline 1997 & N/A & N/A & N/A & N/A & N/A & N/A & N/A & N/A & N/A & 10.346 & 3.779 & 22.069 \\
\hline 1998 & 7.230 & 19.256 & 20.827 & 15.395 & 12.393 & 10.181 & 12.632 & 15.966 & 11.417 & 3.065 & 26.836 & 12.164 \\
\hline 1999 & 16.643 & 5.413 & 9.606 & 5.345 & 7.471 & 4.769 & 2.387 & 0.000 & 7.898 & 11.093 & 8.453 & 8.107 \\
\hline 2000 & 0.000 & 0.000 & 7.441 & 5.504 & 7.767 & 7.722 & N/A & N/A & N/A & N/A & N/A & N/A \\
\hline UCL & 12.390 & 13.571 & 15.435 & 11.162 & 11.354 & 10.510 & 12.357 & 14.896 & 10.501 & 12.137 & 22.871 & 20.345 \\
\hline MEAN & 5.952 & 6.573 & 8.693 & 6.516 & 6.994 & 7.298 & 7.269 & 7.360 & 8.156 & 6.846 & 11.623 & 11.295 \\
\hline LCL & -0.487 & -0.426 & 1.950 & 1.869 & 2.634 & 4.085 & 2.181 & -0.176 & 5.81 & 1.554 & 0.375 & 2.244 \\
\hline SD & 2.504 & 2.722 & 2.623 & 1.807 & 1.696 & 1.250 & 1.833 & 2.715 & 0.845 & 1.906 & 4.052 & 3.260 \\
\hline
\end{tabular}

$\underline{\text { Seasonal Analysis of Monthly Medical Treatment Incidence Rates - Finishing Plant \#3 }}$

The seasonal index calculation was used to generate the monthly seasonal index figures that are presented in Figure 363. The highest seasonal index figures at Finishing Plant \#3 were recorded in November and December, while the lowest were in January and February. The May through August period remained clustered around the 1.0 level. 


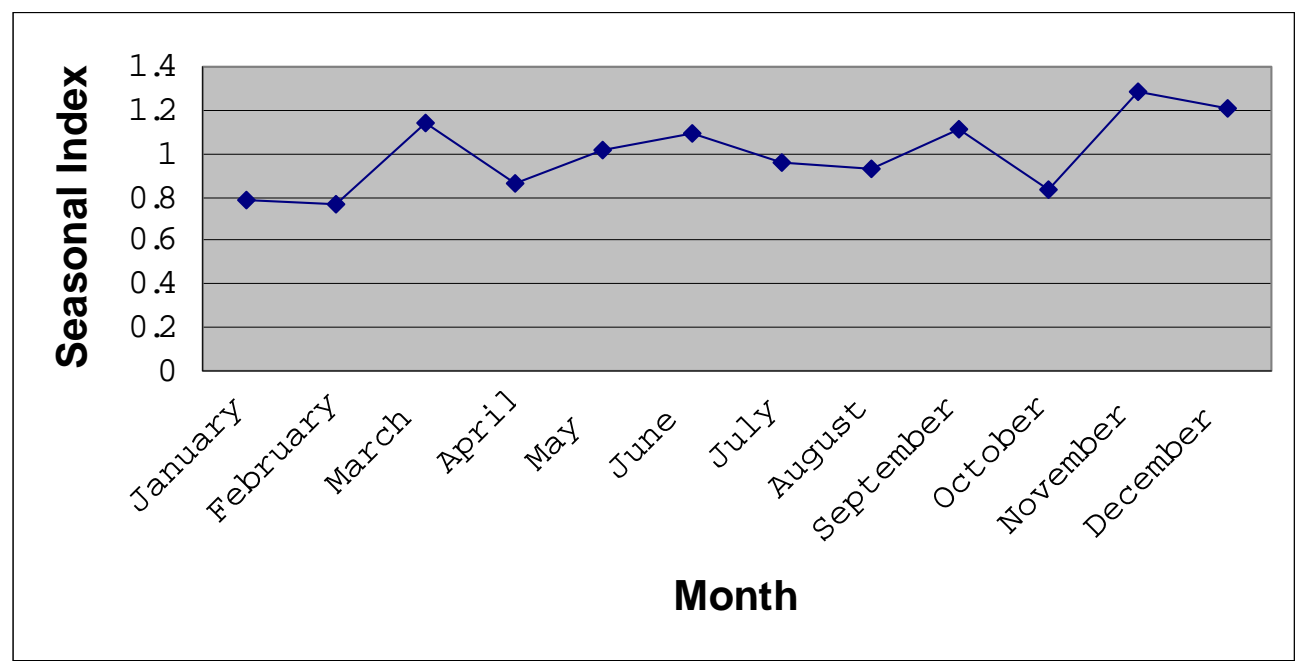

Figure 363. Monthly Seasonal Pattern of Medical Treatment Incidence Rates Finishing Plant \#3

$\underline{\text { Testing the Statistical Relationship of Medical Treatment Data - Finishing Plant \#3 }}$

\section{All 33 Months Prior to and Subsequent the Work Stoppage}

Comparison of the Finishing Plant \#3 medical treatment incidence rates for the 33 months preceding the work stoppage and the 33 months following the work stoppage was accomplished using the comparison formula.. Because the calculated comparison $t$ value of 3.428 exceeded the 1.96 critical t value, a statistically significant increase in incidence rate occurred between the two periods.

\section{First 24 Months and Last 24 Months of the Research Period}

The same formula was applied Finishing Plant \#3 to medical treatment incidence rates for the first 24 months and the last 24 months of the period. These time periods excluded the nine months prior to and immediately following the work stoppage. Using a critical t value of 1.96 , the calculated amount, 1.599, indicated that a statistically significant increase in incidence rates did not occur between the two periods.

\section{Nine Month Intervals Prior to and Subsequent to the Work Stoppage}

Comparison of the Finishing Plant \#3 medical treatment incidence rates for the nine months preceding the work stoppage and the nine months following the work 
stoppage was accomplished using the comparison formula. The result of this calculation, 9.390, was greater than the 2.014 critical t value for a .05 statistical significance level.

Because the calculated amount exceeds the significance level, a statistically significant increase in incidence rates occurred between the two periods.

Table 63

Comparison Prior and Post Work Stoppage Periods - Finishing Plant \#3

\begin{tabular}{|c|c|c|c|c|}
\hline \multirow[b]{2}{*}{ Time Period } & \multicolumn{2}{|c|}{ Finishing Plant \#3 Incidence Rates } & \multirow[b]{2}{*}{ Critical t Value } & \multirow[b]{2}{*}{$\begin{array}{l}\text { Calculated } \\
\text { Comparison Value }\end{array}$} \\
\hline & $\begin{array}{l}\text { Prior to } \\
\text { Work Stoppage }\end{array}$ & $\begin{array}{l}\text { Post } \\
\text { Work Stoppage }\end{array}$ & & \\
\hline 9 Months & 5.333 & 7.036 & 2.014 & $9.390 *$ \\
\hline 24 Months & 6.169 & 7.974 & 1.96 & 1.599 \\
\hline 33 Months & 5.953 & 9.406 & 1.96 & $3.428^{*}$ \\
\hline
\end{tabular}

* Indicates a statistically significant increase

** Indicates a statistically significant decrease 


\section{CHAPTER V}

Findings, Conclusions, and Recommendations

The problem of this research was to determine the effect of work stoppages on production levels and the frequency of safety related issues such as safety training, safety meetings, audits, inspections, and OSHA recordable injury/illness at a selected steel manufacturer located in Ohio, Pennsylvania and West Virginia.

\section{Research Hypotheses}

Research hypothesis I for this research, that at the .05 significance level, production would remain constant during the study period, was rejected. The determined value for $\chi^{2}$ of 23.48 was greater than the .05 Chi Square value of 3.84. Thus the assumption that production before and after the work stoppage would remain constant was not correct. It was concluded with at least a $95 \%$ level of confidence that production after the work stoppage was significantly greater than production before the work stoppage.

Research hypothesis II for this research, that at the .05 significance level, there would be no difference between frequency of safety training, audits, inspections, and OSHA recordable injury/illness for monthly intervals during the period covering two and one half years prior to and two and one half years immediately following the work stoppage was not correct for all variables. The safety training, audits, and inspections were not examined for the reasons of confidentiality and requests from management not to pursue this line of analysis. The OSHA recordable injuries and illnesses exhibited significant differences under various classifications of analysis.

\section{Production Levels}

\section{Findings and Conclusions}

It was determined that analyzing the raw production figures would be very misleading, due to partial years of operations and variations in the number of employees. Therefore, Index 4, which was calculated using the ratio of current year output per worker hour to base year output per worker hour, as described in Table 1, Chapter IV, page 29, was used for this analysis. The result was a comparative statistic for each year of the study. 
Findings from the use of Index 4 indicate that the peak production per worker hour occurred in the fourth quarter of 1997, which was the first quarter of operations following the work stoppage. The production per worker hour experienced in this quarter was more than $19 \%$ greater than the second highest period, which occurred in the first six months of 2000. It should be noted that 1998, the first full year of operations following the work stoppage, recorded a rate of production per worker hour that was just 0.003 less than the second highest per worker hour rate. Thus two of the top three production periods occurred immediately following the work stoppage. These production figures may have resulted from a combination of reasons such as: (a) a push by management to regain market share, (b) rapid finishing of raw steel produced by management during the work stoppage, (c) distribution of finished product that was warehoused prior to the work stoppage, and (d) a workforce that was highly motivated to return to work after such an extended period of unemployment. Therefore a firm conclusion for the high level of production following the work stoppage cannot be made.

The nine months immediately preceding the work stoppage was the third lowest production period during the period of this research. Originally it was thought that this would be one of the higher production periods, based on personal observation and discussions with management and employees.

\section{Number of OSHA Recordable Incidents and Number of Employees}

The method described in Chapter IV, page 33, of summing the corresponding quarters for the previous year and subsequent year and dividing by two, created an average that was used to annualize the incident data. The annualized data demonstrated a continuous decrease in numbers of OSHA recordable incidents for each year of the research. It was found that the rates of change from the first year to the second year and the second year to the third year, were decreases of $11 \%$ and $13 \%$ respectively (See Table 64). Rates of change for the years involved in the work stoppage also decreased, but at a much slower rate. The decrease between 1996 and 1997 was 3\%, while the decrease between 1997 and 1998 was 4\%. The largest rate of decrease occurred between 1998 and 1999, with a decline of $32 \%$, more than double the decrease between any other two years. The last rate of decrease, between 1999 and 2000, was 15\%. 
Table 64

$\underline{\text { Rates of Change in OSHA Recordable Incidents and Employee Numbers }}$

\begin{tabular}{|l|r|r|}
\hline Years & $\begin{array}{l}\text { Rate of Change - OSHA } \\
\text { Recordable Incidents }\end{array}$ & $\begin{array}{l}\text { Rate of Change - Number of } \\
\text { Employees }\end{array}$ \\
\hline $1994-95$ & $11 \%$ Decrease & $1 \%$ Decrease \\
\hline $1995-96$ & $13 \%$ Decrease & $33 \%$ Decrease \\
\hline $1996-97$ & $3 \%$ Decrease & $13 \%$ Increase \\
\hline $1997-98$ & $4 \%$ Decrease & $4 \%$ Increase \\
\hline $1998-99$ & $32 \%$ Decrease & $1 \%$ Decrease \\
\hline $1999-2000$ & $15 \%$ Decrease & \\
\hline
\end{tabular}

Further findings from this analysis indicated that the rate of change for the number of employees did not mirror the rate of change for the number of OSHA recordable incidents. The 1994-95, 1995-96, and 1999-2000 periods each recorded decreases in employee numbers of just over 1\%, probably due to attrition. Between 1996 and 1997 the rate of decrease in employee number was 33\%, due to the number of employees opting to retire after the work stoppage. The following period, 1997 to 1998 experienced an increase of $13 \%$ in the number of employees. The only other increase occurred between 1998 and 1999, an increase of 4\%.

As was the case with examining the raw production figures, the number of OSHA recordable incidents can also be misleading. Analysis of this data by incidents alone would be inaccurate, because of the variation in number of employees and number of worker hours. The preferred method of analysis is based on incidence rates.

\section{OSHA Recordable Incidence Rates}

Because a control group was not available for comparison purposes, the Corporate incidence rates were compared to Bureau of Labor Statistics (BLS) steel industry incidence rates. As indicated in Table 3 in Chapter IV, page 35, the Corporate incidence rates were higher than the BLS industry incidence rates for the first five years of this 
research. It was found that the first full year of operations following the work stoppage, 1998, recorded an incidence rates $21.4 \%$ higher than the BLS industry incidence rates. Thus it was concluded that this rate was influenced by the large number of workers that were returned to the steel mill environment after an absence of over 300 days. The period of re-acclimatization and work hardening that occurred over the first year returning to the steel mills was undoubtedly responsible for the large increase in incidence rates.

It was found that in 1999, the Corporate incidence rates was $12.6 \%$, lower than the steel industry incidence rates of 12.9. Personal experience and discussions with the Corporate manager of safety support the conclusion that efforts by the safety managers and joint safety committees to accommodate the transformation and reentry of the workforce during 1998 were most likely responsible for the reduced incidence rates experienced in 1999. Further discussion with Corporate safety indicated that the corporation's $9.9 \%$ incidence rate that was calculated for the year 2000 would likely be lower than the BLS steel industry incidence rates, if it were currently available. The Corporate manager of safety felt that the addition of risk management to the focus of the already established and functioning safety program served a large part in the reduction of incidence rates during 2000.

The effects of the work stoppage at the corporation were apparent when compared to the incidence rates for the steel industry. To more specifically determine the effect of the work stoppage on the incidence rates at the corporation, it was necessary to analyze each OSHA recordable injury classification by plant location. Furthermore, several time periods were used to provide an overall view and to isolate the effects of the work stoppage. The 66-month period that spanned January 1994 through June 2000, was the focus of this research. The 33 months prior to and the 33 months subsequent to the work stoppage were examined to determine if significant changes occurred in the pre and post work stoppage incidence rates. The nine months preceding the work stoppage were compared to the nine months subsequent to the work stoppage. The first and last 24month periods of the research timeframe, which excluded the nine months prior to and subsequent to the work stoppage, were also analyzed to determine changes in incidence rates. 


\section{Quarterly OSHA Recordable Incidence Rates}

Examining the overall quarterly data for a period of one year prior to the work stoppage and one year after the work stoppage, indicated that $60 \%$ of the research period's highest OSHA recordable incidence rates occurred within one year of the work stoppage. Furthermore, $75 \%$ of these occurred within one year after the work stoppage (See Table 65). Fifty-five percent of the highest lost work day incidence rates occurred within one year after the work stoppage. None of the highest lost work day incidence rates were recorded within one year prior to the work stoppage. The highest transitional incidence rates occurred $65 \%$ of the time within one year of the work stoppage. The majority, $(85 \%)$ of the highest transitional incidence rates for this two year period were recorded within one year after the work stoppage. In contrast, only $40 \%$ of the highest incidence rates for medical treatment incidents were recorded within one year of the work stoppage. Of these, $63 \%$ occurred after the work stoppage.

Table 65

Quarterly Summary of Highest Incidence Rates within One Year of the Work Stoppage

\begin{tabular}{|l|l|l|l|l|l|l|l|l|}
\hline & $\begin{array}{l}1^{\text {st }} \\
\text { Quarter }\end{array}$ & $\begin{array}{l}2^{\text {nd }} \\
\text { Quarter }\end{array}$ & $\begin{array}{l}3^{\text {rd }} \\
\text { Quarter }\end{array}$ & $\begin{array}{l}4^{\text {th }} \\
\text { Quarter }\end{array}$ & Total & $\begin{array}{l}\text { Total } \\
\text { Percent }\end{array}$ & $\begin{array}{l}\text { Percent } \\
\text { Before }\end{array}$ & $\begin{array}{l}\text { Percent } \\
\text { After }\end{array}$ \\
\hline OSHA Recordable & 2 & 4 & 1 & 5 & 20 & 60 & 25 & 75 \\
\hline Lost Work Day & 3 & 3 & 2 & 3 & 11 & 55 & 0 & 100 \\
\hline Transitional & 3 & 5 & 3 & 2 & 13 & 65 & 15 & 85 \\
\hline Medical Treatment & 2 & 2 & 1 & 3 & 8 & 40 & 38 & 63 \\
\hline
\end{tabular}

The lost work day and transitional injuries are considered to be the more severe injury classifications. These injuries require time away from work or modification of the employees work or job. Medical treatment injuries do not require any lost time or modified work. The majority of the more severe injuries occurred within one year prior to or one year after the work stoppage. The conclusion drawn from this analysis was that the work stoppage did have an effect on the severity of the injuries during this two year timeframe. One explanation for this would be that the added pressure at work and at home of preparing for the shut down or start up related to the work stoppage, affected the 
concentration of the employees. Another explanation could be that the employees performed non-routine tasks during the time surrounding the work stoppage.

\section{Monthly OSHA Recordable Incidence Rates}

As indicated in Table 66, almost $50 \%$ of the highest OSHA recordable and lost work day incidence rates occurred within one year of the work stoppage. Additionally, over $50 \%$ of the highest transitional incidence occurred within one year of the work stoppage, and over $40 \%$ of the highest medical treatment incidence rates were recorded during this period.

It was found that of the highest OSHA recordable incidence rates that occurred within one year of the work stoppage, $71 \%$ occurred after the work stoppage. Similarly, of the highest lost work day incidence rates that occurred within one year of the work stoppage, $93 \%$ were recorded after the work stoppage. A total of $59 \%$ and $69 \%$ of the highest incidence rates for transitional and medical treatment injuries, respectively, were recorded within one year of the work stoppage.

Table 66

Monthly Summary of Highest Incidence Rates within One Year of the Work Stoppage

\begin{tabular}{|l|c|c|c|c|}
\hline & $\begin{array}{c}\text { OSHA } \\
\text { Recordable }\end{array}$ & Lost Work Day & Transitional & $\begin{array}{c}\text { Medical } \\
\text { Treatment }\end{array}$ \\
\hline January & 1 & 2 & 2 & 1 \\
\hline February & 2 & 3 & 2 & 1 \\
\hline March & 2 & 3 & 2 & 2 \\
\hline April & 3 & 3 & 5 & 1 \\
\hline May & 4 & 3 & 1 & 1 \\
\hline June & 1 & 0 & 2 & 5 \\
\hline July & 1 & 4 & 5 & 4 \\
\hline August & 5 & 3 & 0 & 1 \\
\hline September & 2 & 1 & 3 & 2 \\
\hline October & 1 & 1 & 3 & 2 \\
\hline
\end{tabular}




\begin{tabular}{|l|c|c|c|c|}
\hline November & 1 & 3 & 4 & 1 \\
\hline December & 5 & 3 & 2 & 4 \\
\hline Total & 28 & 29 & 32 & 26 \\
\hline Total Percent & 47 & 48 & 53 & 43 \\
\hline Percent Before & 29 & 7 & 41 & 31 \\
\hline Percent After & 71 & 93 & 59 & 69 \\
\hline
\end{tabular}

OSHA Recordable Incidence Rates for Nine Months Prior and Subsequent to the Work

\section{Stoppage}

As indicated in Table 67, the overall Corporation, the Primary Plant, and

Finishing Plant \#3 had increased OSHA recordable incidence rates for the nine month time period following the work stoppage, when compared with the nine months prior to the work stoppage. Of these three increases, the only one not significant at the .05 level was the increase in incidence rates for the Primary Plant. Finishing Plants \#1 and \#2 both experienced decreases in OSHA recordable incidence rates. Neither of these decreases was significant at the .05 level.

Table 67

OSHA Recordable Incidence Rates for Nine Months Prior and Subsequent to the Work $\underline{\text { Stoppage }}$

\begin{tabular}{|l|c|c|l|c|c|l|}
\hline \multicolumn{1}{|c|}{ Plant } & $\begin{array}{c}\text { Prior Nine } \\
\text { Months }\end{array}$ & $\begin{array}{c}\text { Post Nine } \\
\text { Months }\end{array}$ & $\begin{array}{c}\text { Increase or } \\
\text { Decrease }\end{array}$ & $\begin{array}{c}\text { Critical _. } \\
\text { Value }\end{array}$ & $\begin{array}{l}\text { Calculated } \\
\text { Value }\end{array}$ & Significant \\
\hline Corporation & 15.59 & 17.79 & Increase & 1.96 & 2.07 & Yes \\
\hline Primary Plant & 16.96 & 18.98 & Increase & 1.96 & 1.51 & No \\
\hline Finishing Plant \#1 & 18.63 & 14.37 & Decrease & 1.96 & 1.26 & No \\
\hline Finishing Plant \#2 & 14.68 & 10.50 & Decrease & 1.96 & 1.31 & No \\
\hline Finishing Plant \#3 & 7.68 & 18.43 & Increase & 1.96 & 4.21 & Yes \\
\hline
\end{tabular}

Apparent conclusions from initial analysis of only the incident numbers, created the illusion that safety was only minimally effected by the work stoppage, because the number of OSHA recordable incidents continued to decrease. Further analysis of the 
OSHA recordable incidents by incidence rates revealed the overall negative effect on safety that resulted from the work stoppage. This negative effect was evidenced by the two statistically significant increases, combined with a third increase. The two decreases in incidence rates were found to be statistically insignificant.

Findings related to lost work day incidents that involve an injury severe enough to require the employee to miss work in order to recuperate from the injury are indicated in Table 68. Incidence rates for the overall Corporation, Primary Plant, and Finishing Plant \#3 experienced significant increases in incidence rates when the nine month period prior to the work stoppage was compared to the nine month period following the work stoppage. Finishing Plant \#2 also had an increase in incidence rates, but it was not a statistically significant increase. Although statistically insignificant, Finishing Plant \#1 experienced a decrease in lost work day incidence rates.

Table 68

Lost Work Day Incidence Rates for Nine Months Prior and Subsequent to the Work Stoppage

\begin{tabular}{|l|c|c|l|c|l|l|}
\hline \multicolumn{1}{|c|}{ Plant } & $\begin{array}{c}\text { Prior Nine } \\
\text { Months }\end{array}$ & $\begin{array}{c}\text { Post Nine } \\
\text { Months }\end{array}$ & $\begin{array}{c}\text { Increase or } \\
\text { Decrease }\end{array}$ & $\begin{array}{c}\text { Critical _ } \\
\text { Value }\end{array}$ & $\begin{array}{c}\text { Calculated } \\
\text { Value }\end{array}$ & Significant \\
\hline Corporation & 0.999 & 3.300 & Increase & 1.960 & 6.209 & Yes \\
\hline Primary Plant & 0.927 & 3.795 & Increase & 1.987 & 6.041 & Yes \\
\hline Finishing Plant \#1 & 2.292 & 1.942 & Decrease & 2.160 & 0.292 & No \\
\hline Finishing Plant \#2 & 1.529 & 2.863 & Increase & 2.228 & 1.053 & No \\
\hline Finishing Plant \#3 & 0.000 & 1.675 & Increase & 2.776 & 8.872 & Yes \\
\hline
\end{tabular}

As evidenced by the incidence rates, in general, injuries that were more severe in nature occurred at a higher rate immediately following the work stoppage. One conclusion supported by these findings was that workers who returned to their jobs after an extended period of unemployment were not conditioned mentally or physically to perform their normal tasks.

Transitional injuries do not require time away from work, but they are severe enough to involve modification of the employee's job or transfer to another job. The 
findings presented in Table 69 indicated four increases and one decrease in incidence rates for transitional injuries. For the nine months prior to and the nine months following the work stoppage none of the increases or decreases were statistically significant. The conclusion drawn from the transitional injury data was that although not statistically significant, the increases in transitional incidence rates should be of concern to the corporation. These injuries are only a step away from being a more severe lost work day case.

Table 69

$\underline{\text { Transitional Incidence Rates for Nine Months Prior and Subsequent to the Work }}$

Stoppage

\begin{tabular}{|l|c|c|l|c|c|l|}
\hline \multicolumn{1}{|c|}{ Plant } & $\begin{array}{c}\text { Prior Nine } \\
\text { Months }\end{array}$ & $\begin{array}{c}\text { Post Nine } \\
\text { Months }\end{array}$ & $\begin{array}{c}\text { Increase or } \\
\text { Decrease }\end{array}$ & $\begin{array}{c}\text { Critical } \\
\text { Value }\end{array}$ & $\begin{array}{c}\text { Calculated } \\
\text { Value }\end{array}$ & Significant \\
\hline Corporation & 2.210 & 2.579 & Increase & 1.960 & 0.919 & No \\
\hline Primary Plant & 2.317 & 2.673 & Increase & 1.960 & 0.715 & No \\
\hline Finishing Plant \#1 & 2.579 & 1.554 & Decrease & 1.960 & 0.853 & No \\
\hline Finishing Plant \#2 & 0.917 & 2.386 & Increase & 2.306 & 1.360 & No \\
\hline Finishing Plant \#3 & 2.346 & 3.105 & Increase & 2.093 & 0.560 & No \\
\hline
\end{tabular}

Findings for the nine month intervals indicated that four decreases in medical treatment incidence rates were recorded (See Table 70). Finishing Plant \#3 posted a statistically significant increase in its incidence rates. Medical treatment incidents have long been regarded as indications of potential for transitional or lost work day injuries. This leads to the conclusion that Finishing Plant \#3 would have experienced statistically significant increases in transitional and lost work day injuries. The actual findings from the data indicate that a statistically significant increase in lost work day incidence rates did occur, but the increase in transitional incidence rates was not statistically significant. Furthermore, the statistically significant decrease in medical treatment incidence rates for Finishing Plant \#3 was not an indicator of the increase in lost work day and transitional incidence rates at the same plant. A conclusion drawn from these findings was that the 
incidence rates for medical treatment injuries is not a good indicator of lost work day or transitional injuries.

Table 70

Medical Treatment Incidence Rates for Nine Months Prior and Subsequent to the Work Stoppage

\begin{tabular}{|l|c|c|l|c|c|l|}
\hline \multicolumn{1}{|c|}{ Plant } & $\begin{array}{c}\text { Prior Nine } \\
\text { Months }\end{array}$ & $\begin{array}{c}\text { Post Nine } \\
\text { Months }\end{array}$ & $\begin{array}{l}\text { Increase or } \\
\text { Decrease }\end{array}$ & $\begin{array}{c}\text { Critical } \\
\text { Value }\end{array}$ & $\begin{array}{c}\text { Calculated } \\
\text { Value }\end{array}$ & Significant \\
\hline Corporation & 12.383 & 11.911 & Decrease & 1.960 & 0.519 & No \\
\hline Primary Plant & 13.716 & 12.508 & Decrease & 1.960 & 1.054 & No \\
\hline Finishing Plant \#1 & 13.756 & 10.875 & Decrease & 1.992 & 0.972 & No \\
\hline Finishing Plant \#2 & 12.231 & 5.249 & Decrease & 2.007 & 2.559 & Yes \\
\hline Finishing Plant \#3 & 5.333 & 7.036 & Increase & 2.014 & 9.390 & Yes \\
\hline
\end{tabular}

OSHA Recordable Incidence Rates for the First 24 Months and Last 24 Months of the $\underline{\text { Research }}$

It was found that three of the four decreases in OSHA recordable incidence rates reported in Table 71 were statistically significant. Finishing Plant \#2 recorded the only non-significant decrease, while Finishing Plant \#3, the corporation, the Primary Plant, and Finishing Plant \#1 all recorded a statistically significant decrease. These findings support the conclusion that OSHA recordable incidence rates decreased between the two 24 month periods.

Table 71

OSHA Recordable Incidence Rates for the First 24 Months and Last 24 Months of the $\underline{\text { Research }}$

\begin{tabular}{|l|c|c|c|c|c|l|}
\hline \multicolumn{1}{|c|}{ Plant } & $\begin{array}{c}\text { First 24 } \\
\text { Months }\end{array}$ & $\begin{array}{c}\text { Last 24 } \\
\text { Months }\end{array}$ & $\begin{array}{c}\text { Increase or } \\
\text { Decrease }\end{array}$ & $\begin{array}{c}\text { Critical } \\
\text { Value }\end{array}$ & $\begin{array}{c}\text { Calculated } \\
\text { Value }\end{array}$ & Significant \\
\hline Corporation & 17.40 & 12.26 & Decrease & 1.96 & 8.46 & Yes \\
\hline Primary Plant & 18.12 & 13.18 & Decrease & 1.96 & 6.54 & Yes \\
\hline
\end{tabular}




\begin{tabular}{|l|c|c|l|c|c|l|}
\hline Finishing Plant \#1 & 28.84 & 9.99 & Decrease & 1.96 & 8.41 & Yes \\
\hline Finishing Plant \#2 & 11.88 & 8.95 & Decrease & 1.96 & 1.72 & No \\
\hline Finishing Plant \#3 & 9.51 & 11.19 & Increase & 1.96 & 3.26 & Yes \\
\hline
\end{tabular}

The lost work day incidence rates findings presented in Table 72, indicated statistically significant increases in incidence rates for the Corporation and Primary Plant, while Finishing Plant \#2 experienced an increase that was not statistically significant. Finishing Plant \#1 experienced a statistically significant decrease and Finishing Plant \#3 posted an insignificant decrease. From this analysis, the observation was made that the lost work day incidence rates for the Corporation and the Primary Plant increased significantly in both the nine months and 24 months periods. This led to the conclusion that although incidence rates at these plants were likely effected by the work stoppage during the short-term, something else continued to effect them over the long-term.

Table 72

Lost Work Day Incidence Rates for the First 24 Months and Last 24 Months of the $\underline{\text { Research }}$

\begin{tabular}{|l|c|c|l|c|c|l|}
\hline \multicolumn{1}{|c|}{ Plant } & $\begin{array}{c}\text { First 24 } \\
\text { Months }\end{array}$ & $\begin{array}{c}\text { Last 24 } \\
\text { Months }\end{array}$ & $\begin{array}{c}\text { Increase or } \\
\text { Decrease }\end{array}$ & $\begin{array}{c}\text { Critical _ } \\
\text { Value }\end{array}$ & $\begin{array}{c}\text { Calculated } \\
\text { Value }\end{array}$ & Significant \\
\hline Corporation & 1.59 & 2.01 & Increase & 1.96 & 2.003 & Yes \\
\hline Primary Plant & 1.09 & 2.164 & Increase & 1.96 & 4.476 & Yes \\
\hline Finishing Plant \#1 & 5.09 & 2.08 & Decrease & 1.997 & 3.144 & Yes \\
\hline Finishing Plant \#2 & 0.56 & 1.28 & Increase & 2.179 & 1.140 & No \\
\hline Finishing Plant \#3 & 1.93 & 1.55 & Decrease & 2.023 & 0.666 & No \\
\hline
\end{tabular}

None of the transitional incidence rates changes between 24 month periods were found to be significant (See Table 73). However, the corporation as a whole, Primary Plant, and Finishing Plant \#3 demonstrated increased incidence rates. The transitional incidence rates for the 24 month periods support the conclusion that a statistically significant change in incidence rates did not occur between the first and last 24 months of the research. 
Table 73

Transitional Incidence Rates for the First 24 Months and Last 24 Months of the Research

\begin{tabular}{|l|c|c|l|c|c|l|}
\hline \multicolumn{1}{|c|}{ Plant } & $\begin{array}{c}\text { First 24 } \\
\text { Months }\end{array}$ & $\begin{array}{c}\text { Last 24 } \\
\text { Months }\end{array}$ & $\begin{array}{c}\text { Increase or } \\
\text { Decrease }\end{array}$ & $\begin{array}{c}\text { Critical } \\
\text { Value }\end{array}$ & $\begin{array}{c}\text { Calculated } \\
\text { Value }\end{array}$ & Significant \\
\hline Corporation & 1.816 & 1.829 & Increase & 1.96 & 0.635 & No \\
\hline Primary Plant & 2.006 & 2.066 & Increase & 1.96 & 0.222 & No \\
\hline Finishing Plant \#1 & 1.427 & 0.416 & Decrease & 2.179 & 0.853 & No \\
\hline Finishing Plant \#2 & 1.569 & 1.757 & Decrease & 2.060 & 0.281 & No \\
\hline Finishing Plant \#3 & 1.412 & 1.661 & Increase & 2.036 & 0.471 & No \\
\hline
\end{tabular}

All five medical treatment incidence rates recorded statistically significant levels of change from the first 24 months of the research to the last 24 months (See Table 74). Finishing Plant \#3 experienced the only increase in incidence rates over the two comparison periods and it was not statistically significant. From this finding it was concluded that in general, medical treatment incidence rates decreased between the first and last 24 months of this research.

Table 74

Medical Treatment Incidence Rates for the First 24 Months and Last 24 Months of the $\underline{\text { Research }}$

\begin{tabular}{|l|c|c|l|c|c|l|}
\hline \multicolumn{1}{|c|}{ Plant } & $\begin{array}{c}\text { First 24 } \\
\text { Months }\end{array}$ & $\begin{array}{c}\text { Last 24 } \\
\text { Months }\end{array}$ & $\begin{array}{l}\text { Increase or } \\
\text { Decrease }\end{array}$ & $\begin{array}{c}\text { Critical } \\
\text { Value }\end{array}$ & $\begin{array}{c}\text { Calculated } \\
\text { Value }\end{array}$ & Significant \\
\hline Corporation & 13.999 & 8.429 & Decrease & 1.96 & 10.503 & Yes \\
\hline Primary Plant & 15.020 & 8.947 & Decrease & 1.96 & 9.053 & Yes \\
\hline Finishing Plant \#1 & 22.315 & 7.493 & Decrease & 1.96 & 7.546 & Yes \\
\hline Finishing Plant \#2 & 9.752 & 5.911 & Decrease & 1.96 & 2.578 & Yes \\
\hline Finishing Plant \#3 & 5.953 & 9.406 & Increase & 1.96 & 1.599 & No \\
\hline
\end{tabular}


OSHA Recordable Incidence Rates for the Entire 33 Months Prior and Subsequent to the

\section{Work Stoppage}

Analysis of OSHA recordable incidence rates for the entire 33 month period before the work stoppage and the 33 month period following the work stoppage revealed that Finishing Plant \#3 experienced a statistically significant increase, while the other four incidence rates were statistically significant decreases (See Table 75). This leads to the following conclusions:

1. The significant increase experienced by the overall Corporation during the nine month periods was offset by a greater decrease that occurred during the 24 month periods.

2. The non-significant increase posted by the Primary Plant during the nine month periods was offset by a greater decrease that occurred during the 24 month periods.

3. The non-significant decrease experienced by Finishing Plant \#1 during the nine month periods combined with the significant decrease during the 24 month periods yielded a significant decrease for the entire 33 month comparison.

4. Although Finishing Plant \#2 posted non-significant decreases for the two smaller time periods, it experienced a significant decrease over the entire 33 month period.

5. Finishing Plant \#3 consistently experienced significant increases in incidence rates for each of the three periods of time.

Table 75

OSHA Recordable Incidence Rates for 33 Months Prior and Subsequent to Work Stoppage

\begin{tabular}{|l|c|c|c|c|c|l|}
\hline \multicolumn{1}{|c|}{ Plant } & $\begin{array}{c}\text { Prior 33 } \\
\text { Months }\end{array}$ & $\begin{array}{c}\text { Post 33 } \\
\text { Months }\end{array}$ & $\begin{array}{c}\text { Increase or } \\
\text { Decrease }\end{array}$ & $\begin{array}{c}\text { Critical } \rightarrow \\
\text { Value }\end{array}$ & $\begin{array}{c}\text { Calculated } \\
\text { Value }\end{array}$ & \begin{tabular}{l} 
Significant \\
\hline Corporation
\end{tabular} \\
\hline Primary Plant & 16.93 & 13.72 & Decrease & 1.96 & 2.07 & Yes \\
\hline
\end{tabular}




\begin{tabular}{|l|c|c|l|c|c|l|}
\hline inishing Plant \#1 & 26.16 & 11.14 & Decrease & 1.96 & 8.01 & Yes \\
\hline Finishing Plant \#2 & 12.63 & 9.34 & Decrease & 1.96 & 2.18 & Yes \\
\hline Finishing Plant \#3 & 9.040 & 12.985 & Increase & 1.96 & 3.26 & Yes \\
\hline
\end{tabular}

Findings from this research indicated that the 33 month lost work day figures for the Corporation, Primary Plant, and Finishing Plant \#2 all demonstrated the same pattern as they did in the two smaller time periods (See Table 76). Although Finishing Plant \#1 had decreases in all periods, the decrease for the nine month period was insignificant, while the other two periods were significant. Finishing Plant \#3 experienced a significant increase for the nine month comparison but coupled with a decrease for the 24 month comparison, the 33 month figure was an increase that was not statistically significant. It was concluded from this analysis that the magnitude by which the level of significance was exceeded for the comparison of the nine month periods was much greater than the level of the 24 month and the 33 month periods.

Table 76

Lost Work Day Incidence Rates for 33 Months Prior and Subsequent to Work Stoppage

\begin{tabular}{|l|c|c|l|c|c|l|}
\hline \multicolumn{1}{|c|}{ Plant } & $\begin{array}{c}\text { Prior 33 } \\
\text { Months }\end{array}$ & $\begin{array}{c}\text { Post 33 } \\
\text { Months }\end{array}$ & $\begin{array}{c}\text { Increase or } \\
\text { Decrease }\end{array}$ & $\begin{array}{c}\text { Critical } \\
\text { Value }\end{array}$ & $\begin{array}{c}\text { Calculated } \\
\text { Value }\end{array}$ & Significant \\
\hline Corporation & 1.43 & 2.35 & Increase & 1.960 & 5.015 & Yes \\
\hline Primary Plant & 1.05 & 2.60 & Increase & 1.960 & 7.18 & Yes \\
\hline Finishing Plant \#1 & 4.36 & 2.04 & Decrease & 1.991 & 2.991 & Yes \\
\hline Finishing Plant \#2 & 0.82 & 1.68 & Increase & 2.069 & 1.761 & No \\
\hline Finishing Plant \#3 & 1.433 & 1.582 & Increase & 2.020 & 0.327 & No \\
\hline
\end{tabular}

It was found that transitional incidence rates had no statistically significant changes during the two smaller periods, but the overall corporation figure and the Finishing Plant \#3 figure both demonstrated statistically significant values for the 33 month comparison (See Table 77). The corporation transitional incidence rates comparison yielded a decrease and the Finishing Plant \#3 comparison yielded an increase. 
Table 77

Transitional Incidence Rates for 33 Months Prior and Subsequent to Work Stoppage

\begin{tabular}{|l|c|c|l|c|c|l|}
\hline \multicolumn{1}{|c|}{ Plant } & $\begin{array}{c}\text { Prior 33 } \\
\text { Months }\end{array}$ & $\begin{array}{c}\text { Post 33 } \\
\text { Months }\end{array}$ & $\begin{array}{l}\text { Increase or } \\
\text { Decrease }\end{array}$ & $\begin{array}{c}\text { Critical } \\
\text { Value }\end{array}$ & $\begin{array}{c}\text { Calculated } \\
\text { Value }\end{array}$ & Significant \\
\hline Corporation & 2.406 & 1.617 & Decrease & 1.960 & 4.194 & Yes \\
\hline Primary Plant & 2.088 & 2.228 & Increase & 1.960 & 0.589 & No \\
\hline Finishing Plant \#1 & 1.729 & 0.716 & Decrease & 2.045 & 0.470 & No \\
\hline Finishing Plant \#2 & 1.394 & 1.915 & Increase & 2.008 & 0.640 & No \\
\hline Finishing Plant \#3 & 5.953 & 9.406 & Increase & 1.96 & 3.428 & Yes \\
\hline
\end{tabular}

Findings from this research indicated that medical treatment incidence rates demonstrated a consistent pattern of increases and decreases during the three time periods (See Table 78). The magnitude of these changes during the nine month comparison period was not significant for the Corporation, Primary Plant, and Finishing Plant \#1 decreases. The 24 month period for these same plants, recorded much greater statistically significant comparison values. From this analysis it was concluded that the decrease for these plants was slowed during the nine months immediately following the work stoppage.

Table 78

Medical Treatment Incidence Rates for 33 Months Prior and Subsequent to Work Stoppage

\begin{tabular}{|l|c|c|l|c|c|l|}
\hline \multicolumn{1}{|c|}{ Plant } & $\begin{array}{c}\text { Prior 33 } \\
\text { Months }\end{array}$ & $\begin{array}{c}\text { Post 33 } \\
\text { Months }\end{array}$ & $\begin{array}{l}\text { Increase or } \\
\text { Decrease }\end{array}$ & $\begin{array}{c}\text { Critical } \\
\text { Value }\end{array}$ & $\begin{array}{c}\text { Calculated } \\
\text { Value }\end{array}$ & \multicolumn{1}{|l|}{ Significant } \\
\hline Corporation & 13.574 & 9.345 & Decrease & 1.96 & 9.217 & Yes \\
\hline Primary Plant & 14.676 & 9.899 & Decrease & 1.96 & 8.325 & Yes \\
\hline Finishing Plant \#1 & 20.071 & 8.383 & Decrease & 1.96 & 7.137 & Yes \\
\hline Finishing Plant \#2 & 10.417 & 5.745 & Decrease & 1.96 & 3.563 & Yes \\
\hline Finishing Plant \#3 & 5.953 & 9.406 & Increase & 1.96 & 3.428 & Yes \\
\hline
\end{tabular}




\section{$\underline{\text { Summary }}$}

The desire of the corporation to improve worker safety served as the driving force behind this research. A second aspect was management's desire to investigate several phenomena associated with the time periods leading up to the work stoppage and those following it. The intent was to use the information gained from this study to assist in safeguarding the workers during any future work stoppages.

Upon completion of this research it was found that a relationship between OSHA recordable incidence rates and work stoppages does indeed exist. The true extent of this relationship can not be generalized from one case study, because of the number of confounding factors involved in analysis of data, which was not collected under controlled circumstances.

This research examined the OSHA recorable incidence rates from both an injury classification and a plant perspective. Information that was brought to light by this study included that incidence rates for more severe classifications of injuries, i.e. lost work day and transitional cases, were higher immediately after the work stoppage than they were immediately preceding the work stoppage. Just as each injury classification must be analyzed individually, so must each plant be treated as an individual entity for prevention and intervention efforts. The nature of the work, the age of the workforce, the experience of the workforce, and the working environment are some of the additional factors that make each plant a unique operation.

\section{$\underline{\text { Recommendations for Further Research }}$}

An important concern for future research involves obtaining information about the various complications that are associated with a major work stoppage. Detailed information about the retraining of the workforce prior to reentry into the workplace is important. Information concerning the working environment prior to and following the work stoppage could provide insight into effective prevention efforts. The worker's perceptions of safety prior to and following the work stoppage could assist in analysis of changes that occurred surrounding the work stoppage.

Finally, methods of incorporating the safety function into every system within the organization should be studied. For instance, this research indicated that the addition of 
risk assessment to the safety function coincided with a large decrease in injury numbers. It needs to be determined whether this was a coincidence or a direct result of the new program. Preliminary analysis indicates that it was a direct result, but more in-depth analysis is needed concerning this issue. 


\section{BIBLIOGRAPHY}

Anonymous (1974). How they look at job health and safety in big steel. Health and Safety, 43 (5), 38-39.

Barbash, R.J., Lampman, S.A. \& Levitan, S.A. (1983). The work ethic A critical analysis.Bloomington, IL: Industrial Relations Research Association.

Becker, G. Making mills safer. (1995). New Steel, 11, 76.

Bennett, J.D. \& Passmore, D.L. (1984) Correlates of coal mine accidents and injuries: A literature review. Accident Analysis \& Prevention, 16, (1), 37-45.

Blomberg, R., Levy, E., \& Anderson, A. (1988). Assessing the value of employee training. Health Care Management Review, 13, 63-70.

Blosser, F. (1992). Primer on occupational safety and health. Washington, DC: The Bureau of National Affairs, Inc.

Brauer, R.L. (1994). Safety and health for engineers. New York: Van Nostrand Reinhold.

Brown, M. P., \& Nguyen-Scott, N. (1992). Evaluating a training-for-action job health and safety program. American Journal of Industrial Medicine, 22, 739-749.

Bureau of Labor Statistics (1997). Occupational injuries and illnesses: Counts, rates, and characteristics, 1994. Bulletin 2485, U.S. Department of Labor, Washington, DC.

Bureau of National Affairs, Inc. (1971). The job safety and health act of 1970. Washington, DC: The Bureau of National Affairs, Inc.

Crites, T. R. (1995). Reconsidering the costs and benefits of a formal safety program. Professional Safety. 28-32.

Culvenor, J., \& Else, D. (1997). Finding occupational injury solutions: The impact of training in creative thinking. Safety Science, 25 1-3, 187-205.

DeReamer, R. (1980). Modern safety and health technology. New York: John Wiley \& Sons.

Flaherty, S. (1987). Strike activity, worker militancy, and productivity change in manufacturing, 1961-1981. Industrial and Labor Relations Review, Vol. 40. No. 4.

Forman, J. (1975, September). 1920-1929: The jazz age - America s joyride ends with a crash. Occupational Hazards. $70-73$. 
Freeman, N. T. (1969). Training for safety. Personnel, 2 (4), 17-19.

Gun, R. T. (1993). The role of regulations in the prevention of occupational injury. Safety Science, 16 (1), 47-66.

Holley, W.H. \& Jennings, K.M. (1991). The labor relations process. Chicago: Dryden Press.

Johnston, J. J., Cattledge, G. T., \& Collins, J. W. (1994). The efficacy of training for occupational injury control. Occupational Medicine, 9 (2), 147-58.

Kalis, D. B. (1975, September). 1776 - 1850: The post revolutionary period The first stirrings of industrialism in America. Occupational Hazards. 53-56.

Keller, J. J. (Ed.). (1993). OSHA compliance manual: 29 CFR 1910 plant safety. Neenah, WI: J. J. Keller \& Associates, Inc.

Kennan, J. (1986). The economics of strikes. In Ashenfelter and R. Layard (Ed.). The handbook of labor economics, Volume II. (Pp. 1091 - 1137). BV: Elsevier Science Publishers.

Livesay, H.C. (1978). Samuel Gompers and organized labor in America. Boston: Little, Brown and Company.

Marcum, C. E. (1978). Modern safety management practice. Morgantown, WV: Worldwide Safety Institute.

McMurdy, D. (1998, September). Labor s resurgence. Maclean s, 111 (36), 37.

Miernyk, W.H. (1973). The economics of labor and collective bargaining. Lexington: D.C. Heath and Company.

Mussachio, C. (1975, September). 1850-1900: The industrial revolution What price progress? Occupational Hazards. 57-63.

Oberman, G. (1996). An approach for measuring safety training effectiveness. Occupational Health \& Safety, 65 48+.

O'Brien, D. P. (1998, August). Business metrics for safety: A quantitative measurement approach to safety performance. Professional Safety. 41-44.

Petersen, D. (1989). Techniques of safety management. Goshen, NY: Aloray, Inc.

Petersen, D. (1998). What measures should we use, and why? Measuring safety system effectiveness. Professional Safety 37-40. 
Robbins, T. G., Hugentobler, M. K., Kaminski, M., \& Klitzman, S. (1994). A joint labor-management hazard communication training program: A case study in worker health and safety training. Occupational Medicine, 9 (2), 135-145.

Sandler, H. M. (1997). Does your occupational health program need a checkup? Occupational Hazards, 19-20.

Shannon, H. S., Mayr, J. \& Haines, T. (1997). Overview of the relationship between organizational and workplace factors and injury rates. Safety Science, 26 (3), 201-217.

Shannon, H.S., Walters, V., Lewchuk, W., Richardson, J., Moran, L.A., Haines, T.\& Verma, D. (1996). Workplace organizational correlates of lost-time accident rates in manufacturing. American Journal of Industrial Medicine, 29, 258-268.

Sheridan, P.J. (1975, September). 1900-1916: The progressive period: reform charges the American air. 65-69.

Sorrell, L. W. (1998). Safety and statistical process control: One practitioner's perspective. Professional Safety 37-38.

U.S. Department of Health and Human Services (DHHS) (1997). NIOSH strategic plan 1997-2002. Publication No. 98-137.

U.S. Department of Labor, Bureau of Labor Statistics (1997). BLS handbook of methods. [On-line], Available: http://stats.bls.gov/hom/homhome.htm

U.S. Department of Labor.(1993). OSHA voluntary compliance outreach program: instructor reference materials (OSHA Office of Training and Education). Des Plaines, IL

U.S. Department of Labor (1997) Occupational safety and health administration revised strategic plan FY 1997 - FY 2002. [On-line], Available: http://www.osha.gov/oshinfo/strategic/toc.html

Vojtecky, M.A. (1988). Education for job safety and health. Health Education Quarterly, 15 (3), 289-298.

Vojtecky, M. A. \& Schmitz, M. F. (1986). Program evaluation and health and safety training. Journal of Safety Research, 17, 57-63.

Zahlis, D. F. (1995). Caution: Beware of OSHA statistics. Professional Safety 41-43.

Zieger, R.H. (1994). American workers, American unions. Baltimore: The Johns Hopkins University Press. 
Zwerling, C., Daltroy, L. H., Fine, L. J., Johnston, J. J., Melius, J., \& Silverstein, B. A. (1997). Design and conduct of occupational injury intervention studies: A review of evaluation strategies. American Journal of Industrial medicine, 32 (2), 164-179. 